\title{
ARCHAEOLOGY, HERITAGE AND ETHICS IN THE WESTERN WALL PLAZA, JERUSALEM
}

DARKNESS AT THE END OF THE TUNNEL

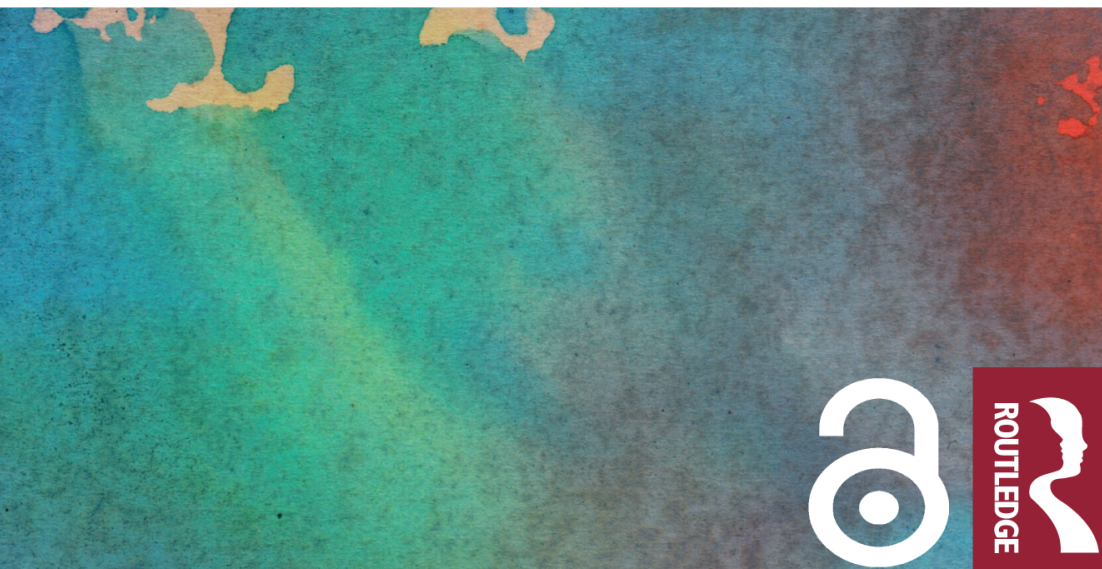




\section{Archaeology, Heritage and Ethics in the Western Wall Plaza, Jerusalem}

This volume is a critical study of recent archaeology in the Western Wall Plaza area, Jerusalem. Considered one of the holiest places on Earth for Jews and Muslims, it is also a place of controversy, where the State marks 'our' remains for preservation and adoration and 'theirs' for silencing.

Based on thousands of documents from the Israel Antiquities Authority and other sources, such as protocols of planning committees, readers can explore for the first time this archaeological 'heart of darkness' in East Jerusalem. The book follows a series of unique discoveries, reviewing the approval and execution of development plans and excavations, and the use of the sites once excavation has finished. Who decides what and how to excavate, what to preserve - or 'remove'? Who pays for the archaeology, for what aims? The professional, scientific archaeology of the past happens now: it modifies the present and is modified by it. This book 'excavates' the archaeology of East Jerusalem to reveal its social and political contexts, power structures and ethics.

Readers interested in the history, archaeology and politics of the IsraeliPalestinian conflict will find this book useful, as well as scholars and students of the history and ethics of archaeology, Jerusalem, conservation, nationalism and heritage.

Raz Kletter completed his $\mathrm{PhD}$ in 1995 at Tel Aviv University, Israel, on material culture and borders of Iron Age Judah. Following a post-doctoral year at the University of Oxford, UK, he worked in the Israel Antiquities Authority as Deputy of Finds Department, Senior Archaeologist and Head of the Scientific Processing Unit. Dr. Kletter participated, directed and published excavations from varied periods and sites in Israel/Palestine. Since 2008 he is Docent for Near-Eastern Archaeology at the University of Helsinki, Finland, and member of the Centres of Excellence 'Changes in Sacred texts and Traditions' (CSTT) and 'Ancient Near Eastern Empires' (ANEE). Dr. Kletter's main fields of study are Near-Eastern Archaeology (Bronze and Iron Ages), religion and cult, ancient economy, archaeological theory and history of archaeology in Israel/Palestine. He has published extensively in these fields. 


\section{Copenhagen International Seminar}

General Editors: Ingrid Hjelm, University of Copenhagen, Denmark, and Emanuel Pfoh, National Research Council, Argentina

\section{Myths of Exile}

History and Metaphor in the Hebrew Bible

Edited by Anne Katrine De Hemmer Gudme and Ingrid Hjelm

Rewriting Peter as An Intertextual Character in The Canonical Gospels Finn Damgaard

Japheth Ben Ali's Book of Jeremiah

A Critical Edition and Linguistic Analysis of the Judaeo-Islamic Translation Joshua A. Sabih

Origin Myths and Holy Places in The Old Testament

A Study of Aetiological Narratives

Lukasz Niesiolowski-Spanò

The Emergence of Israel In Ancient Palestine Historical and Anthropological Perspectives Emanuel Pfoh

Syria-Palestine in the Late Bronze Age An Anthropology of Politics and Power Emanuel Pfoh

Plato and the Creation of the Hebrew Bible Russell E. Gmirkin

Archaeology, Heritage and Ethics in the Western Wall Plaza, Jerusalem Darkness at the End of the Tunnel Raz Kletter Jeremiah in History and Tradition Edited by Jim West and Niels Peter Lemche 


\section{Archaeology, Heritage and Ethics in the Western Wall Plaza, Jerusalem}

Darkness at the End of the Tunnel

\section{Raz Kletter}


First published 2020

by Routledge

2 Park Square, Milton Park, Abingdon, Oxon OX14 4RN

and by Routledge

52 Vanderbilt Avenue, New York, NY 10017

Routledge is an imprint of the Taylor \& Francis Group, an informa business

(C) 2020 Raz Kletter

The right of Raz Kletter to be identified as author of this work has been asserted by him in accordance with sections 77 and 78 of the Copyright, Designs and Patents Act 1988.

The Open Access version of this book, available at www.taylorfrancis.com, has been made available under a Creative Commons Attribution-Non Commercial-No Derivatives 4.0 license.

Trademark notice: Product or corporate names may be trademarks or registered trademarks, and are used only for identification and explanation without intent to infringe.

British Library Cataloguing-in-Publication Data

A catalogue record for this book is available from the British Library

Library of Congress Cataloging-in-Publication Data

Names: Kletter, Raz, author.

Title: Archaeology, heritage and ethics in the Western Wall Plaza,

Jerusalem : darkness at the end of the tunnel / Raz Kletter.

Description: First edition. | New York : Routledge, [2019] |

Series: Copenhagen international seminar |

Includes bibliographical references and index.

Identifiers: LCCN 2019016898 (print) | LCCN 2019017777 (ebook) |

ISBN 9780429031311 (ebook) | ISBN 9780429633461 (web pdf) |

ISBN 9780429630484 (mobi/kindle) | ISBN 9780429631979 (epub) |

ISBN 9780367143350 (hardback : alk. paper)

Subjects: LCSH: Excavations (Archaeology)-West Bank. |

Excavations (Archaeology)-Jerusalem.

Classification: LCC DS110.W47 (ebook)|

LCC DS110.W47 K64 2019 (print) | DDC 956.94/42-dc23

LC record available at https://lccn.loc.gov/2019016898

ISBN: 978-0-367-14335-0 (hbk)

ISBN: 978-0-429-03131-1 (ebk)

Typeset in Times New Roman

by Newgen Publishing UK 


\section{Contents}

1 Journey to East Jerusalem - an introduction 1

2 Antiquities in the toilets - the Strauss Building 27

3 Wild Western Wall Tunnels - The Davidson Centre and the Archaeological Park 49

4 A museum for Jewish prayer in a Mamluk bathhouse - the Ohel Yitzhak Synagogue 65

5 An archaeological site with depth - the Ha-Liba Building 97

6 The comprehensive plan for the Western Wall Plaza $\quad 120$

7 Lingua Orientalis Hierosolimitanae 149

8 Pilegesh at Givati - Little Tel Aviv in East Jerusalem $\quad 160$

9 The ethics of East Jerusalem 166

10 Conclusions 181

Appendix: the documents $\quad 187$

Bibliography 331

Index $\quad 342$ 


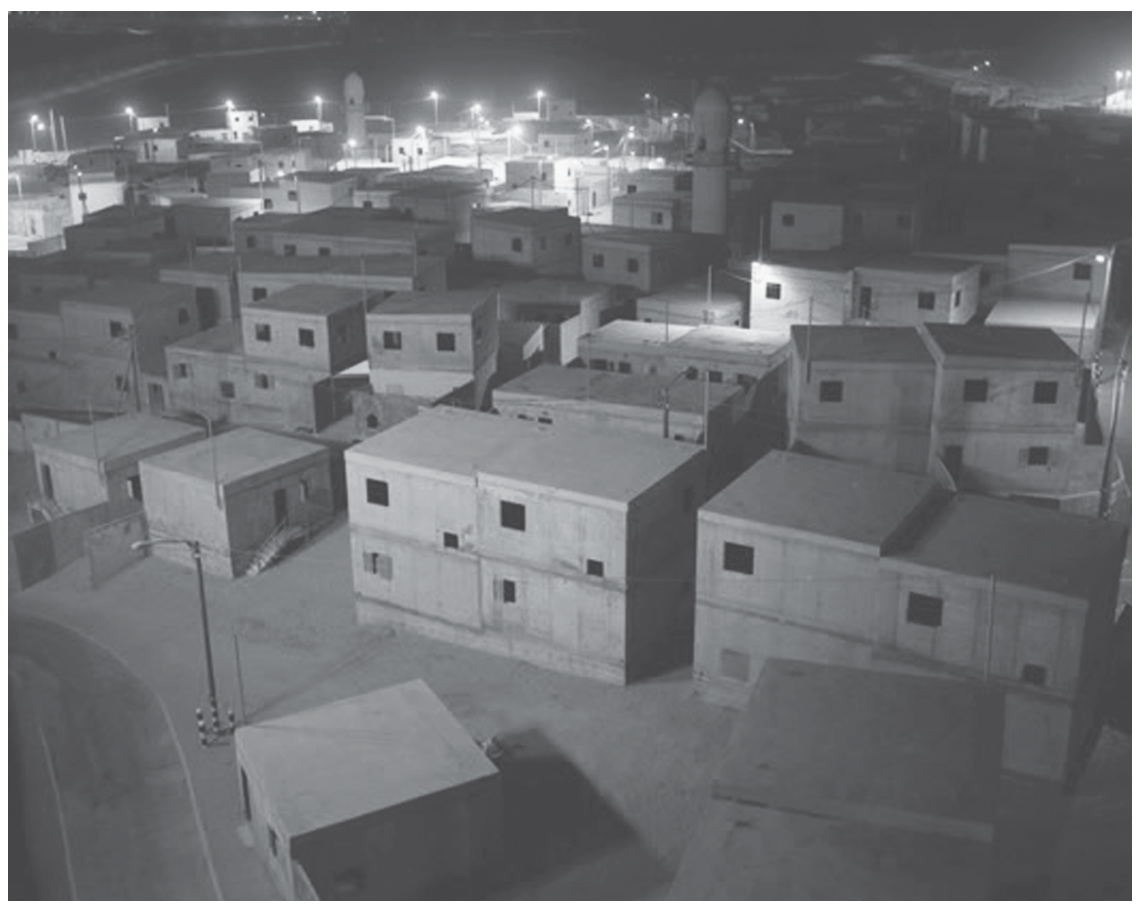

Detroit training city at night (video and prints, work by Amir Yatziv, 2009). Photo Amir Yatziv 


\section{Journey to East Jerusalem - an introduction}

In February 2016, a friend and I visited the City of David. Like most tourists we came to see exciting archaeological attractions. Unlike most tourists, we did not look just for King David, and walked a little farther into Silwan than the El-Ad visitor centre. Without a guide from El-Ad, the extreme settler organization that controls the City of David site, we did not have someone to tell us what to see: a present not less mysterious than the past. Archaeologists offer the past in scientific reports, popular articles, exhibitions - wrapped and detached from the present by 'clean' photos and professionally drawn plans. But archaeology does not happen in a void; we need to see it without cutting the surroundings out.

Currently, the Givati parking site (Fig. 1.1) is a yawning hole in the ground. Dominating the view are the massive cement supports along its edges. Eventually, some of 'our' remains will be exhibited here, buried under a towering visitor-cum-entertainment-centre. The latest technologies will animate the show, but will they show the life of all the inhabitants of Silwan? The archaeology of El-Ad is limited to one people and two periods: First Temple, Second Temple. More than Iron Age archaeology, it is an archaeology of Iron. Its fossiles directeurs are strewn all around: metal fences, heavy iron-beam constructions, mesh wire, long rods bearing cameras and flags. Later levels, read Islamic levels, are removed, that is, destroyed, to reach 'our' remains, which are preserved. Imagine living in a house beside the hole, years of noise and dust, even before construction starts. Silwan is one of the poorest neighbourhoods in East Jerusalem: barely 20 metres down from the pompous entrance to the El-Ad site the garbage 'frog' overflows (Fig. 1.2).

Like all digs in East Jerusalem, the Givati site is surrounded by a metal fence. Outside, the fence is covered by colourful pop-art (probably rendered from pictures), presenting a futuristic vision. This vision is fast becoming past, crumbling, peeling off the metal; it has already been replaced more than once (see Beer 2009). ${ }^{1}$ El-Ad is an extreme right-wing, religious organization; but the vision on the fence is addressed to 'common' Israelis and tourists, and is therefore secular. Theodor Herzl, the spiritual father of Israel, would have been pleased with such a Western paradise. The images show no orthodox rabbis and dancing bearded youth on the barren hills of Judea 


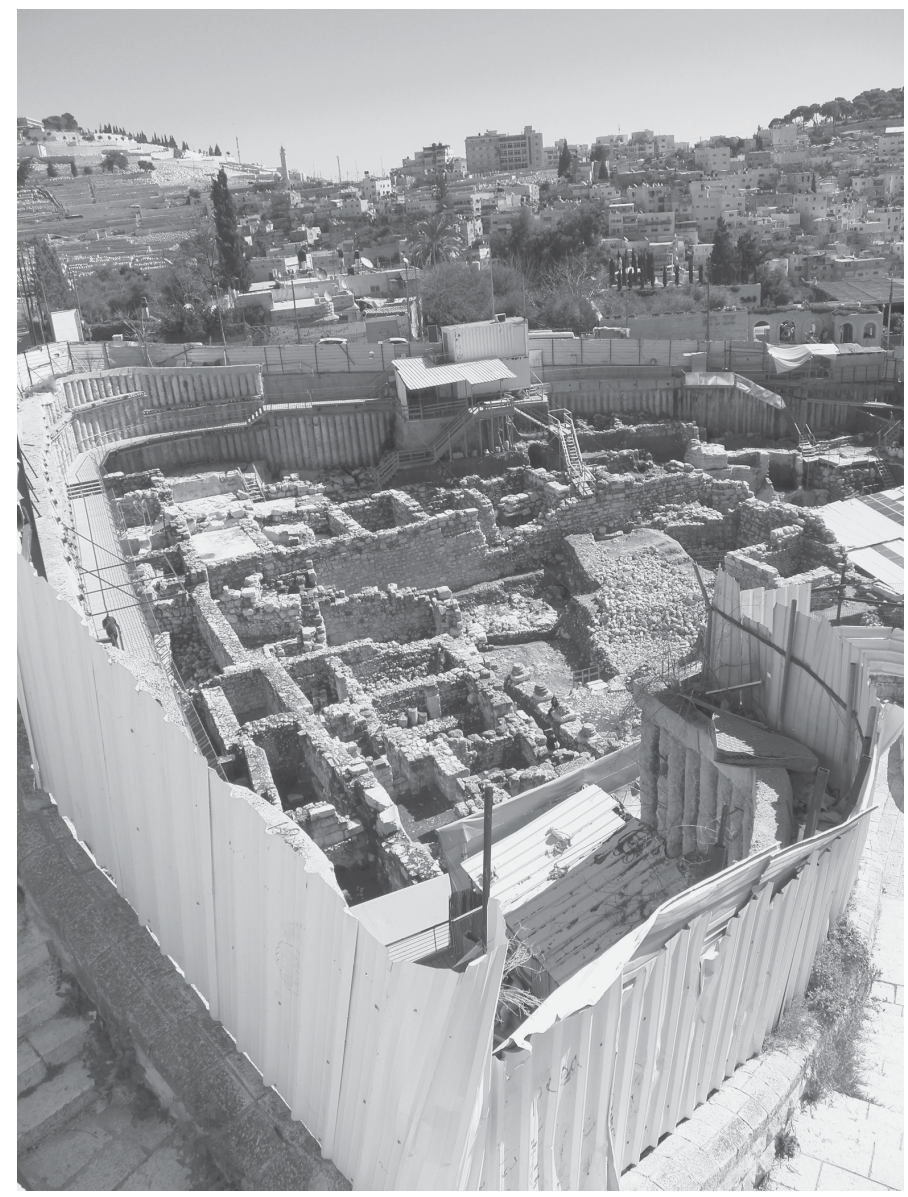

Figure 1.1 The Givati parking site, Silwan/City of David, 2016, view east. Photo R. Kletter

and Samaria - only one man wears a small kippah. Behold the good life in a modern, clean city. Many people are fair-skinned, blue-eyed and light-haired (Figs. 1.3-9). They joyfully excavate without fear of finding human bones; or walk with kids, smiling, wearing jeans and T-shirts. Happy tourists brandish cameras (Fig. 1.4), just like the model tourist that happens to pass them by (Fig. 1.5). The Superman rides a Segway (Fig. 1.6).

A former version of the fence showed also two Arabs next to two dogs (Beer 2009). The present fence is an improved version: there are no Arabs or Palestinians. Still, reality creeps in. It adds slogans and moustaches, and erases faces with scratches or paint. A small Palestinian flag is glued on a child's nose (Fig. 1.8), and 'Allah' inscribed on an excavation bucket (Fig. 1.9). 


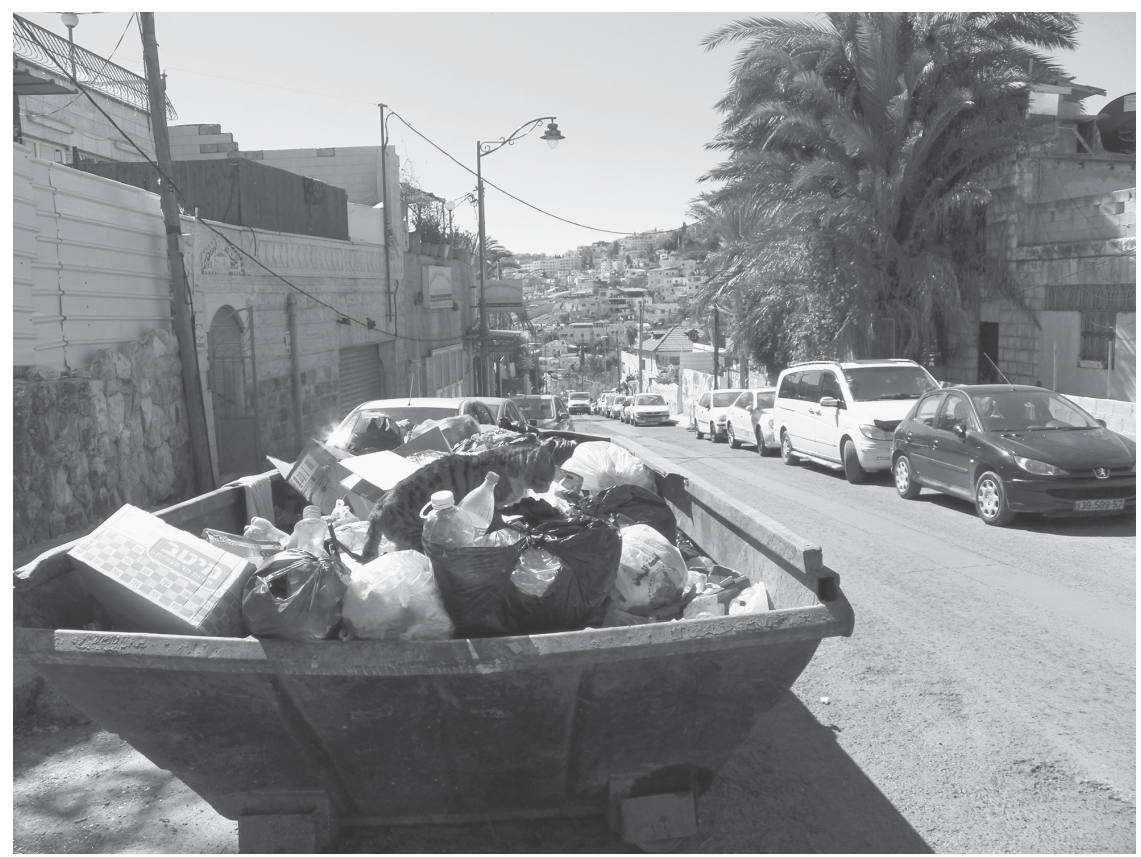

Figure 1.2 The Main Street of Silwan, $20 \mathrm{~m}$ past the El-Ad site entrance. Photo R. Kletter

On the eastern side of the fence, which is perhaps more accessible to Silwan's kids, the paintings are more eroded. The pictures are the same, but the action is less coherent (Fig. 1.7). The secular heroes are fading away. Suddenly, there is an opening in the fence, a sort of gate with open doors (Fig. 1.10), leading nowhere. In the United-Lands of Jerusalem open doors lead nowhere. Only gates that are closed are important.

Farther down into Silwan, we notice new flags above houses occupied by settlers since our last visit, and tons of steel around the excavation fields, old and rusting or new and glittering. The site of the Siloam Pool and the famous drainage tunnel is crowned by a large, rusted construction (Fig.1.11) - an archaeological relic - that nobody cares to dismantle, because in East Jerusalem the temporary is eternal. The brutal aesthetics of exposed cement and iron go all the way down to the water source (Fig. 1.12).

In the beginning there was sewage, and in the end too: the excavations here started, in part, in order to improve the old sewage system. Perhaps the ugly, temporal, black sewage pipe is an improvement (Fig. 1.13), but we were greeted by leakage. Instead of stepping into the treasure halls of Solomon, we tumble into a third-world toilet facility. The sign that tells you that water was taken 

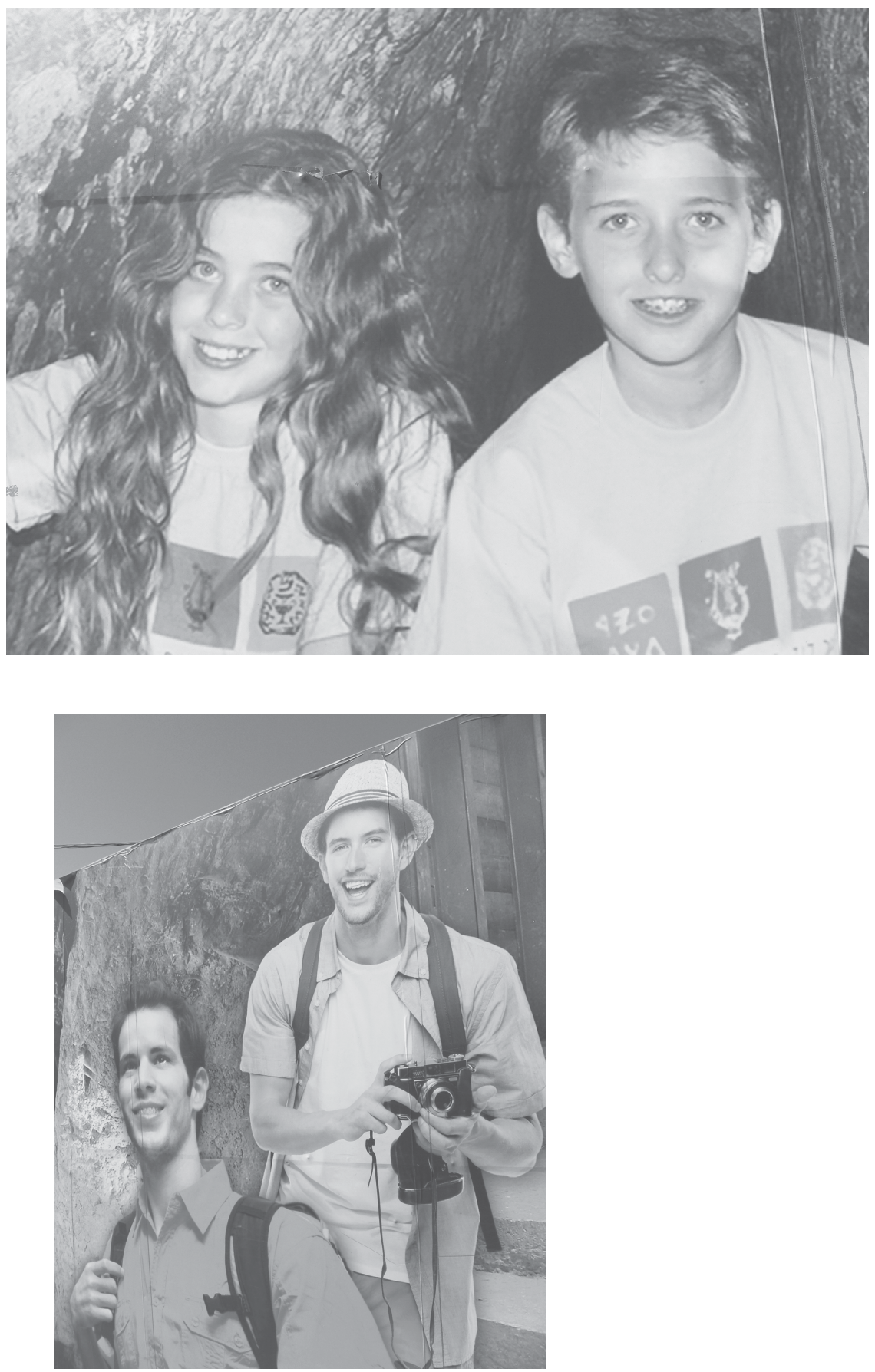

Figures 1.3-1.4 El-Ad Vision on the Givati Fence: 1.3 (top): Children; 1.4 (bottom): Tourists.

Photos R. Kletter 


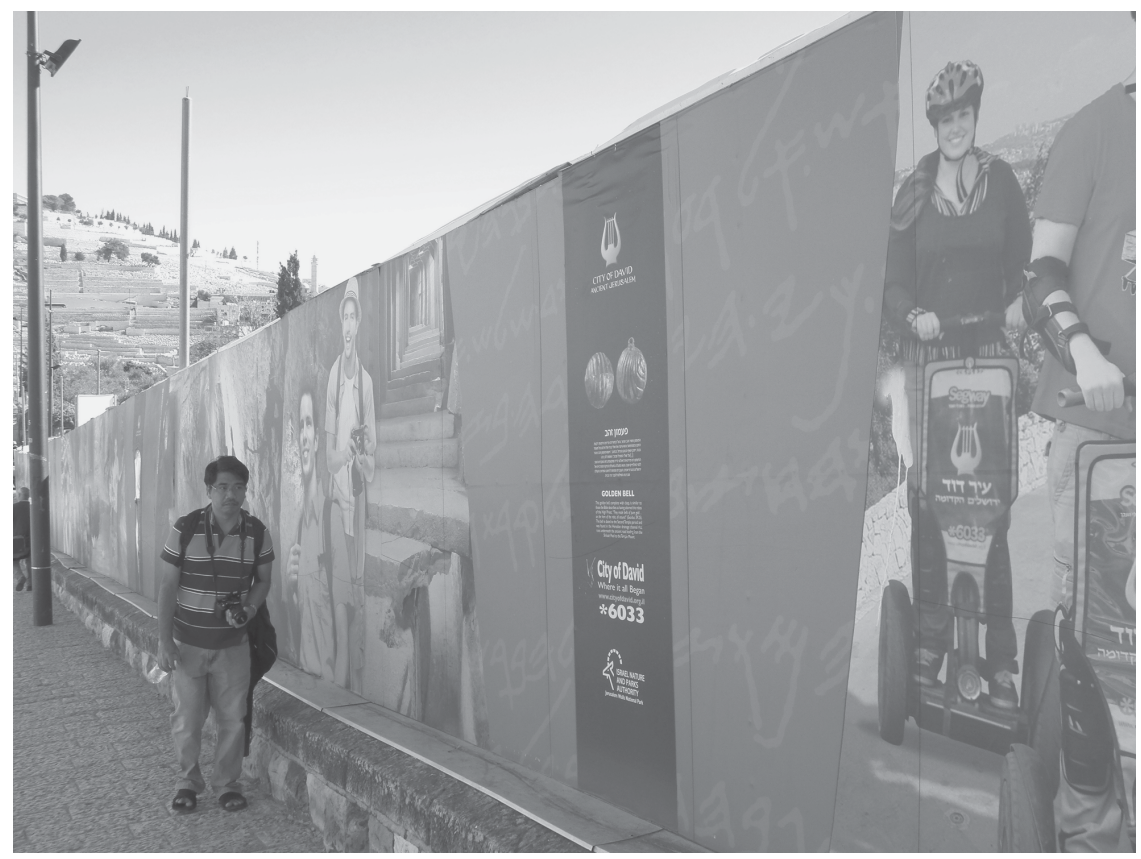

Figure 1.5 Model tourist.

from this pool to the Temple Mount does not whet the appetite. The excavators imagine in addition ritual bathing: they should try it themselves first.

An elderly group from Brazil struggles in front of us in the tunnel. Yes, they enjoy Jerusalem, and after the tunnel will go to their hotel to rest. How pretentious we, archaeologists, are. For us any tunnel is a marvel; but for them it is too long, too narrow and too dirty. They worry about the cabeça and in reaching, finally, the exit, exclaim in relief: Hallelujah!

In the dark maze of corrugated iron one hears the excavators working, sideways, breaking new ground, under some Palestinian homes. Is it for the oil, or for a much-needed Metro line?

At the entrance to the tunnel El-Ad offers another vision (Fig. 1.14): the glorious past of Jewish Jerusalem. It is the complete opposite of the secular Givati fence art. Gone are the blue eyes and fair hair: we are back in the Middle East. The gadgets (camera, Segway) are replaced by a sheep - taken for slaughter to the Mount, by a boy that points the way, commanding the visitors to go up, immediately, now (Fig. 1.15).

The modern T-shirts and jeans are replaced by long toga-like dresses and biblical sandals. The men are all bearded and wear keffiyehs; the women chaste, hiding their hair under burqa-like veils (Fig. 1.16). Men and women do not cross each other's paths. Men do not look at women; women do not disturb 

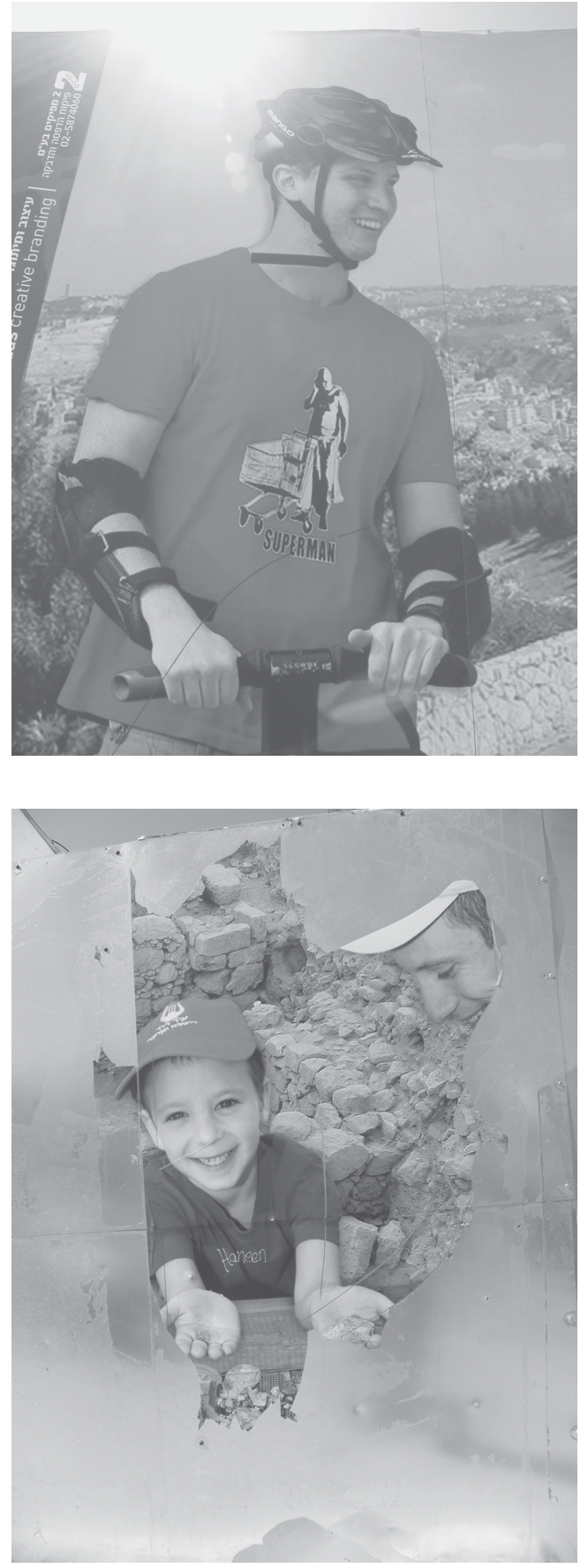

Figures 1.6-1.7 The good life on the El-Ad fence: 1.6 (top): Superman; 1.7 (bottom): Boy showing finds.

Photos R. Kletter 

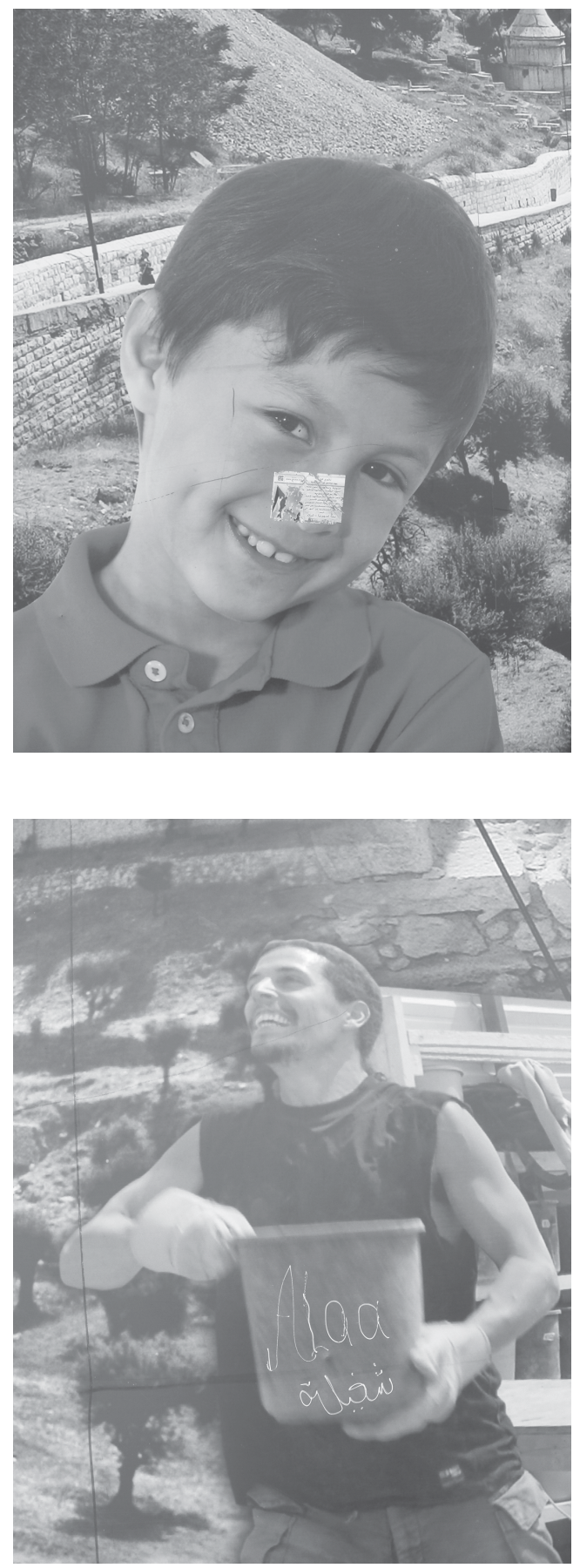

Figures 1.8-1.9 The good life on the El-Ad fence (cont.): 1.8 (top): Boy; 1.9 (bottom): Excavator. 


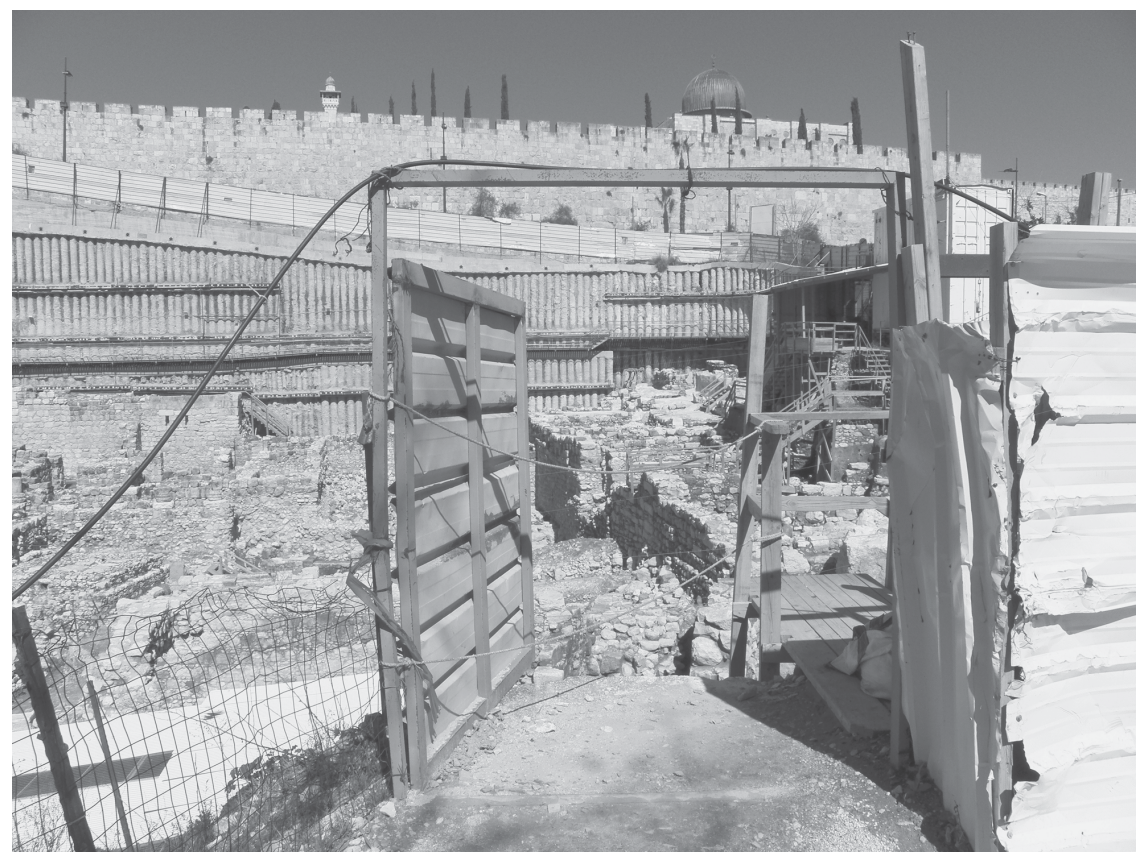

Figure 1.10 Givati parking site with the Old City wall in the background. Photo R. Kletter

men with idle talk. A boy holds his father's hand, two boys play together, and a baby boy sits on his father's shoulders. Little girls do not play in the streets of this Sparta. One biblical man vaguely resembles Yasser Arafat, but is obviously someone else (Fig. 1.17), and his un-heroic proportions deviate from the idyllic landscape.

The picture-based realism of the Givati fence gives way to the Siloam Pool naïve art. Unintentionally, El-Ad has portrayed the changing fate of the State of Israel. Moving from the Givati fence to the Siloam Pool art, one moves away from a modern democracy to a fundamentalist state.

In this book the focus is not Silwan/City of David, but the just as sensitive, but less known area in terms of its recent archaeology: the Western Wall Plaza, the most holy site to Jews in Jerusalem (Fig. 1.18).

The Western Wall Plaza was created in June 1967, during the Six Days War (Segev 2008). The two Gods of Archaeology - creation and destruction - worked hand in hand: the Plaza was created by the destruction of the old Mughrabi ('western') Quarter. This neighbourhood was established in $1192 \mathrm{CE}$ and populated by pilgrims that originated from the Maghreb area of North Africa (hence the name). The orders for destruction were not written down and it is unclear who exactly gave them, but the destruction 


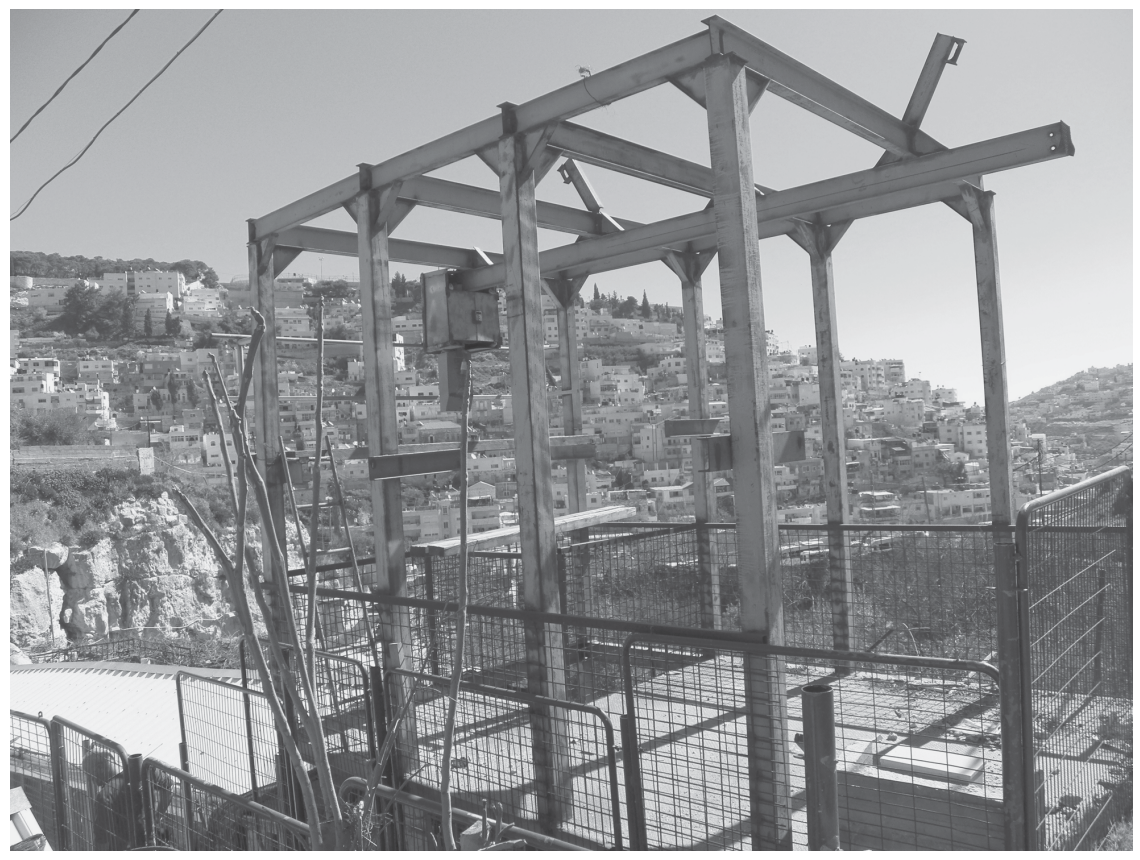

Figure 1.11 Iron Archaeology - above the Siloam Tunnel.

Photo R. Kletter

was swiftly executed starting on the night of June 10, 1967. A few houses that survived were demolished two years later. The Western Wall, which formerly was experienced intimately, towering above a narrow alley, was suddenly opened to a wide Plaza. To stress the Western Wall, the upper metre or two was scrapped off the entire Plaza soon after its creation (Benziman 1973:38-44; Weigert 1990; Bahat 2016; Yaniv 2007; Segev 2008:333-334; Bar and Cohen-Hattab 2017:3; Hasson 2017c:58-60; Nitzan-Shiftan 2017:231234). These acts were not accompanied by archaeological inspection and the houses were not documented before the demolition. They included an ancient madrasa (school) and mosque, the remains of which would resurface later in our story.

The Mughrabi Bridge leads to the Temple Mount and serves the Israeli police and non-Muslim visitors. It is based (since 1970) on an earthen ramp laid atop some of the former Mughrabi neighbourhood houses. The section of the Western Wall north of the bridge became a prayer area under the auspices of the Ministry of Religion, while the area south of the bridge became an archaeological excavation site, in a sort of competition between archaeology and religion (Benziman 1973; Hasson 2007; Cohen-Hattab 2010; Shragai 2011; Bar and Cohen-Hattab 2017; Cohen-Hattab and Bar 2018) (Fig. 1.19). 


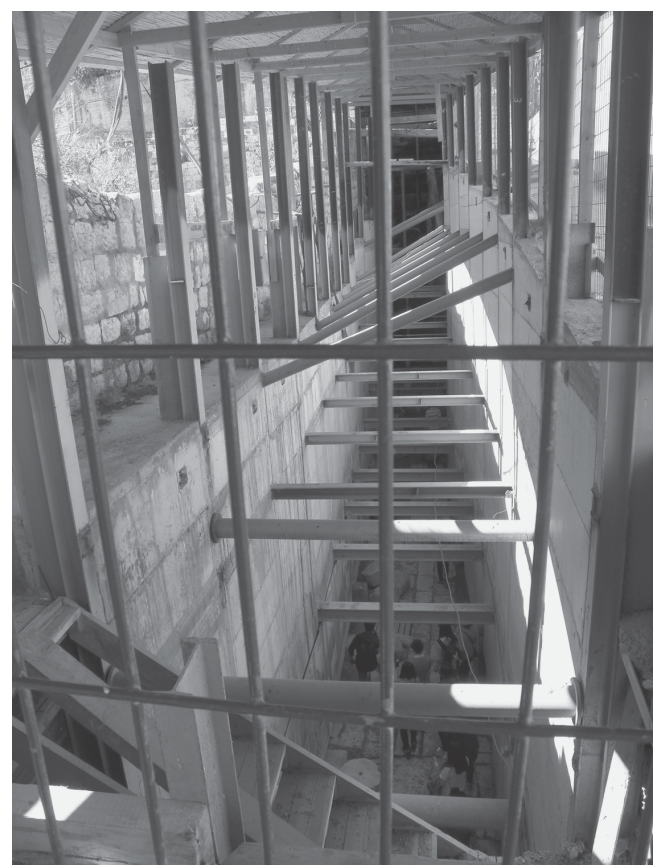

Figure 1.12 Iron Archaeology.

Photo R. Kletter

Starting in 1968, Binyamin Mazar of the Hebrew University carried out large-scale excavations near the southwestern corner of the Temple Mount/ Haram al-Sharif, and subsequent excavations followed suit (for reports see Mazar and Mazar 1989; Mazar and Ariel 2003; Mazar 2011; for criticisms Abu el-Haj 2001:130-164; Sulimany 2013; Greenberg 2018:369). In the 1990s, the Israel Antiquities Authority (henceforward, IAA) developed this area as an open archaeological park, which included a newly established archaeological museum - the Davidson Centre. Due to the excavations, much of this area became lower than the prayer area north of the Mughrabi Bridge. Visitors to the Archaeological Park and the Davidson Museum pay entrance fees, while entry to the prayer Plaza to the north is free.

The Plaza is located in the ancient Tyropoeon Valley ('Valley of the Cheese Makers'), between the Temple Mount and Mt. Zion. This valley became partially filled during the centuries with up to ca. 20 metres accumulation of archaeological remains. Large-scale buildings were constructed in this area during several periods, one on top of the other, leaving a maze of underground walls and cavities under the present-day Plaza. In 1968 the Ministry of Religion began digging into the cavities, which became known later as the Western Wall Tunnels. For nearly 20 years the workers of the Ministry dug 


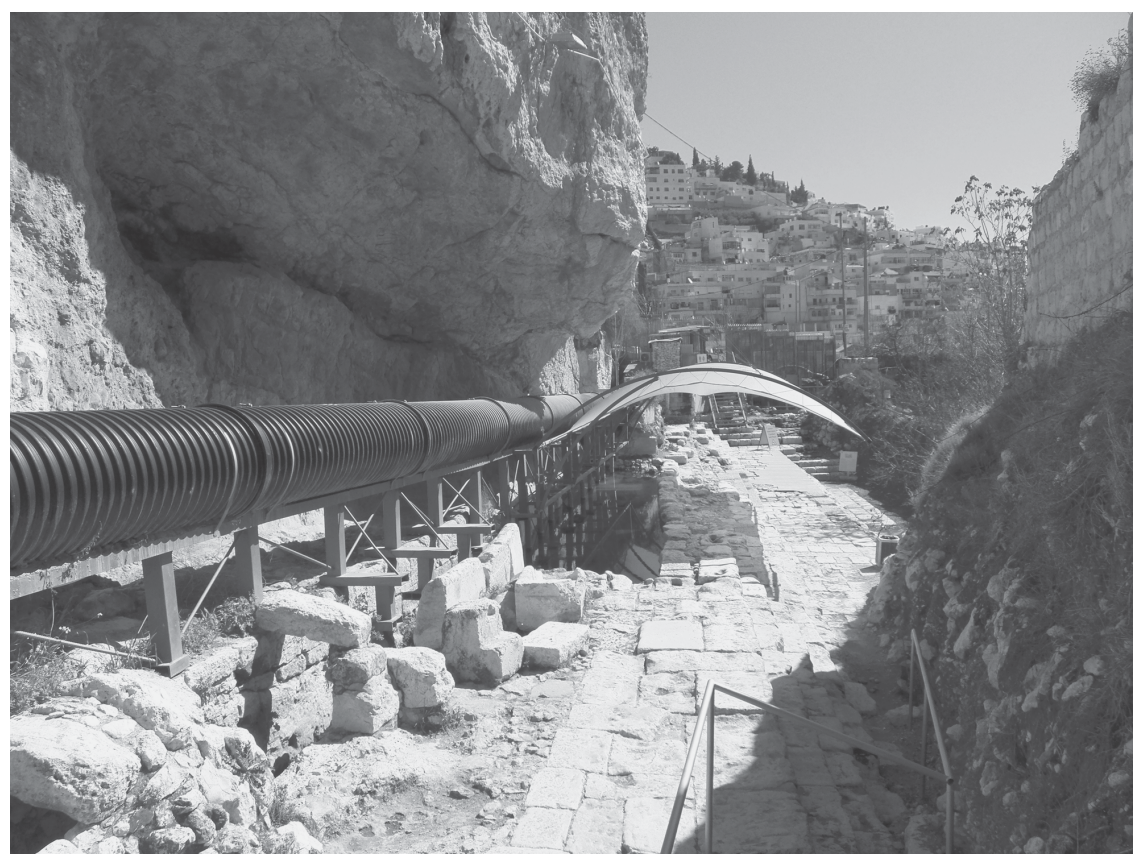

Figure 1.13 Sewage pipe at the Siloam Pool.

Photo R. Kletter

without any involvement of professional archaeologists or supervision by the governmental body responsible over antiquities - at the time, the Israel Department of Antiquities and Museums (Avni and Seligman 2006:275). Only years later were archaeologists Dan Bahat and Meir Ben-Dov added as inspectors (Ben-Dov 1981; 1982; Avni and Seligman 2006). The crowning glory of these diggings was the penetration of rabbi Getz (the rabbi presiding over the Western Wall for many years) in 1982 into the area under the Temple Mount. Getz was searching for the Temple artefacts under the pretence of placing an ark for a Bible book as service to worshippers (Raz 2003:265-319; Getz 2014).

To date, Israel has not approved a master plan for Jerusalem (there are various unofficial plans, for example, Jerusalem 2000). Receiving a building permit (conditioned on proving ownership of the land) became an impossible mission for the (mostly Arab) residents of East Jerusalem, and they resort to building without a permit, which is a criminal offense. Not only private residents, but also all the municipal and governmental agencies that act in the Old City do so without an approved master plan. ${ }^{2}$

At first the Western Wall Plaza was just a flattened dirt surface created by the bulldozers that levelled the Mughrabi Quarter. Several plans were 


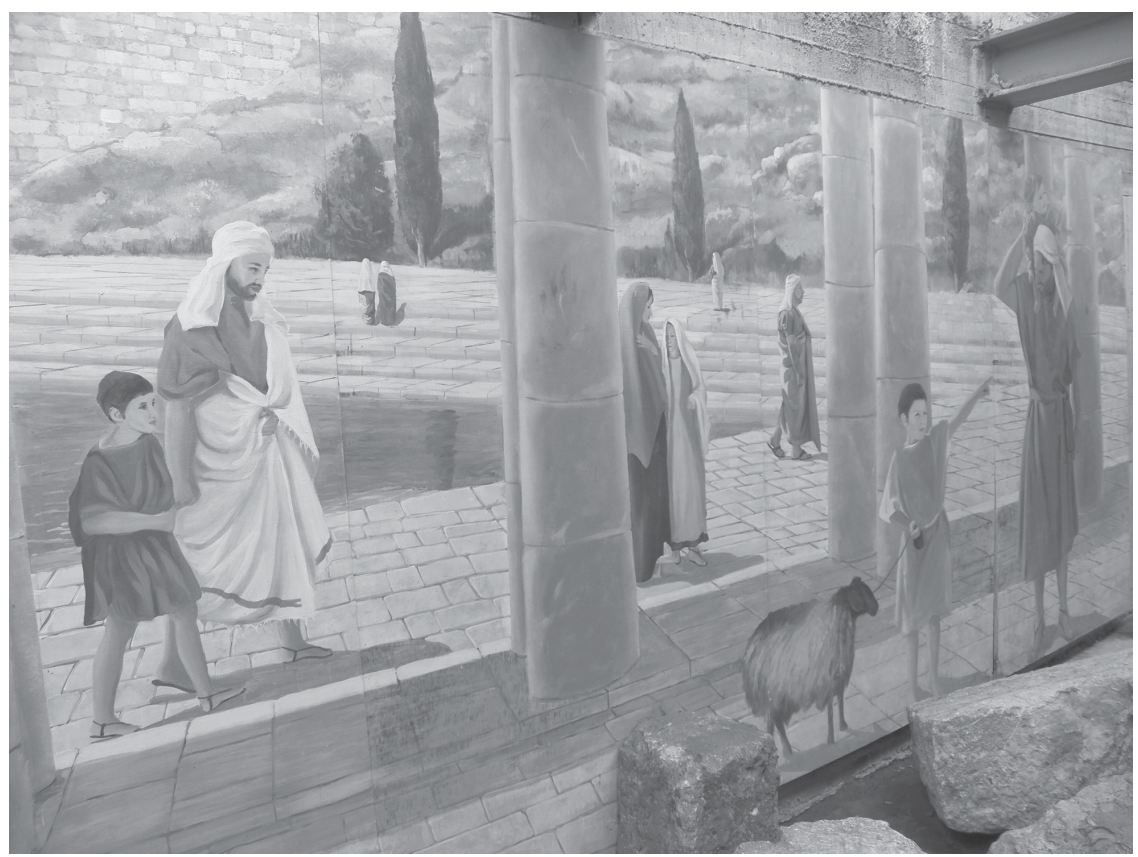

Figure 1.14 Naïve El-Ad art, entrance to the drainage tunnel.

Photo R. Kletter

proposed for its development over the years. The most famous of them was named after the architect responsible - 'the Safdie Plan.' For various reasons, none of the plans was realized (Zandberg 2007; Cohen-Hattab 2010; Jacobson 2011; Nitzan-Shiftan 2011; Rosenblum 2013; Slae et al. 2013; Nitzan-Shiftan 2017:231-277). Throughout the years, the Plaza was gradually improved in a piecemeal way by the Ministry of Religion: the surface was covered by a stone pavement and various facilities for visitors were added.

In 2004 the Mughrabi Bridge collapsed and was replaced by a temporary structure. The plans to restore the bridge opened the way for a wave of development projects in the Plaza. Because of international pressures, a new permanent bridge was not (yet) built, but in a petition on the matter the Supreme Court determined that a comprehensive plan was necessary for the entire Plaza before new buildings (or the bridge) can be built. Meanwhile, however, a number of specific plans were already taking shape, initiated by the Western Wall Heritage Foundation. This body, which now operates under the auspices of the Prime Minister's Office, was established in 1988 as part of the Ministry of Religion and vested with the responsibility of managing the Western Wall (Rapoport 2008). It is a religious body identified with Orthodox Judaism (the movement that dominates Jewish religious life in Israel). The projects that the 


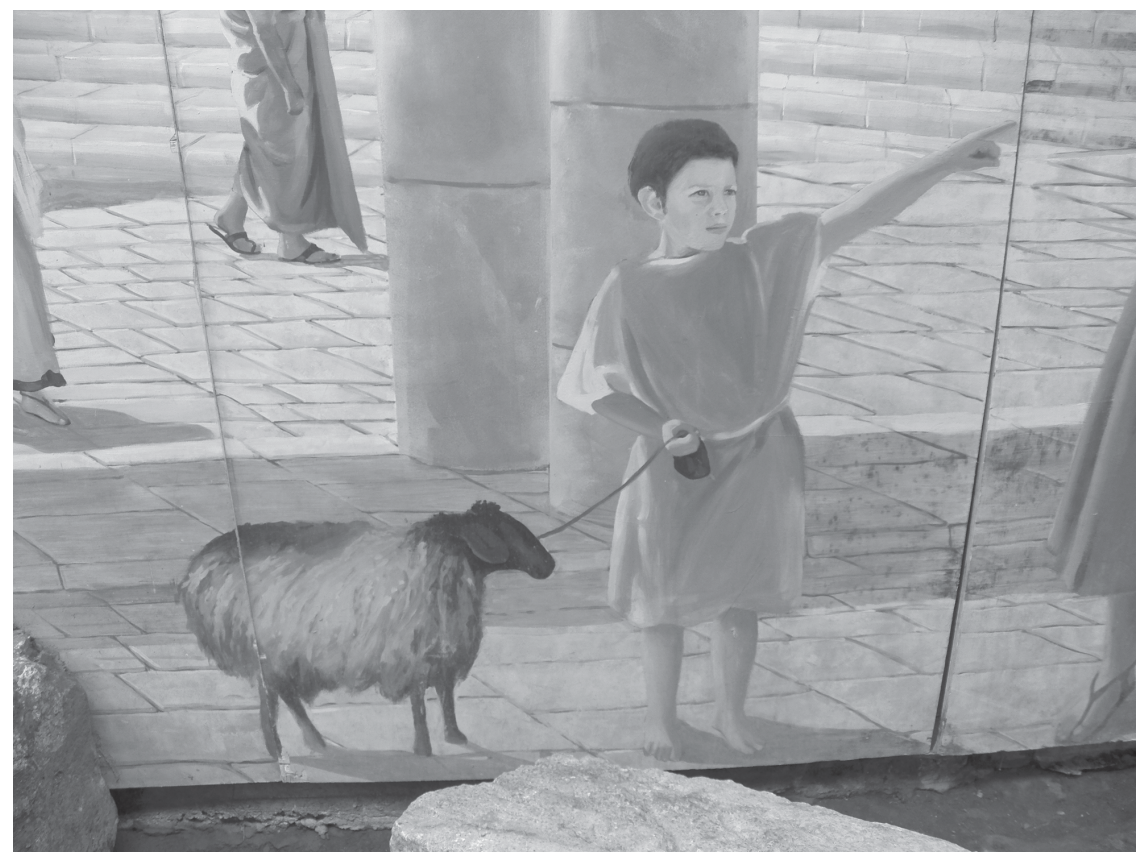

Figure 1.15 Naïve El-Ad Art, detail - boy and sheep for sacrifice.

Photo R. Kletter

foundation advanced since 2004, in addition to the on-going expansion of the Western Wall Tunnels, included the following:

1. Expansion of an old building (the Strauss Building) at the northern side of the Plaza;

2. Construction of a new building (the Ha-Liba Building) at the western side of the Plaza;

3. Continuation of excavations (often more than one at the same time) in the Western Wall Tunnels;

4. Connecting the Plaza by tunnels with the Archaeological Park and the El-Ad site in Silwan;

5. Connecting the Plaza by tunnels under the Muslim Quarter with the Ohel Yitzhaq Synagogue.

The rise in the scope of development is related to political changes in Israel. The days of Oslo are over. The right-wing government in power is 'pumping' for years now hundreds of millions of Shekels to projects in East Jerusalem, including archaeological projects by El-Ad and the Western Wall Heritage Foundation (see, for example, Portugali 2016; Borschel-Dan 2018). Private 

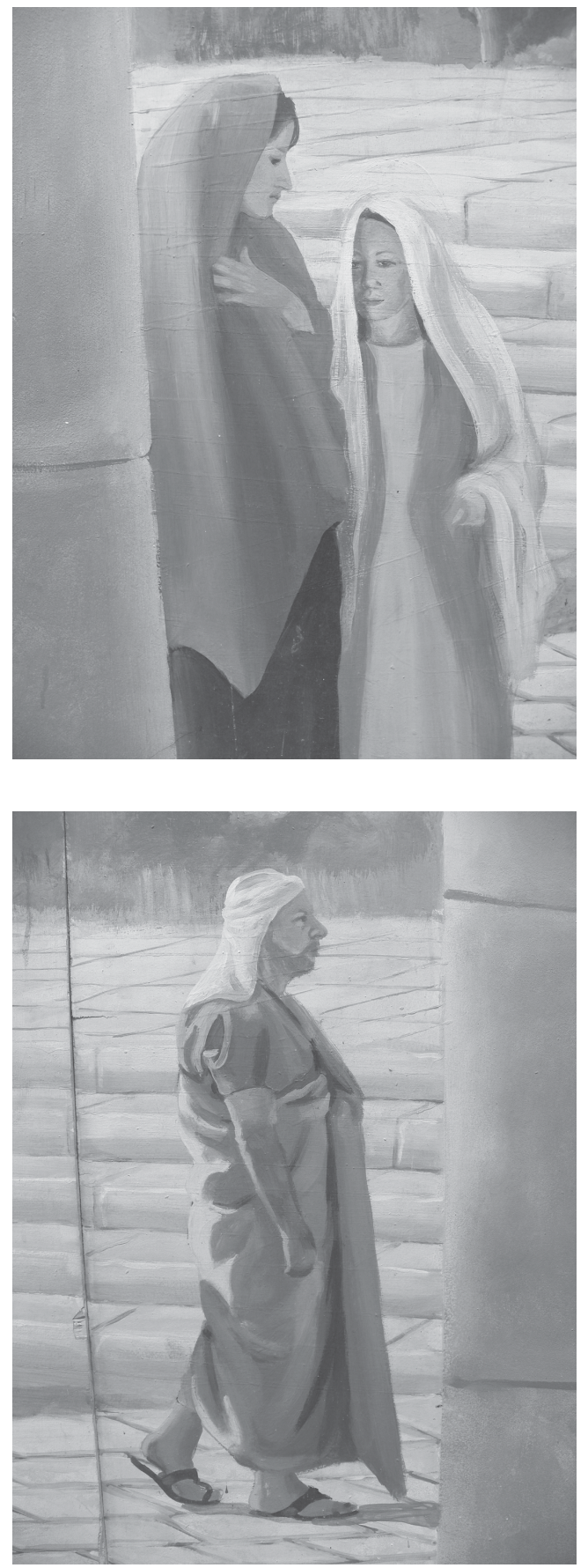

Figures 1.16-1.17 Naïve El-Ad art, details - woman and girl (top); biblical man (bottom). Photo R. Kletter 


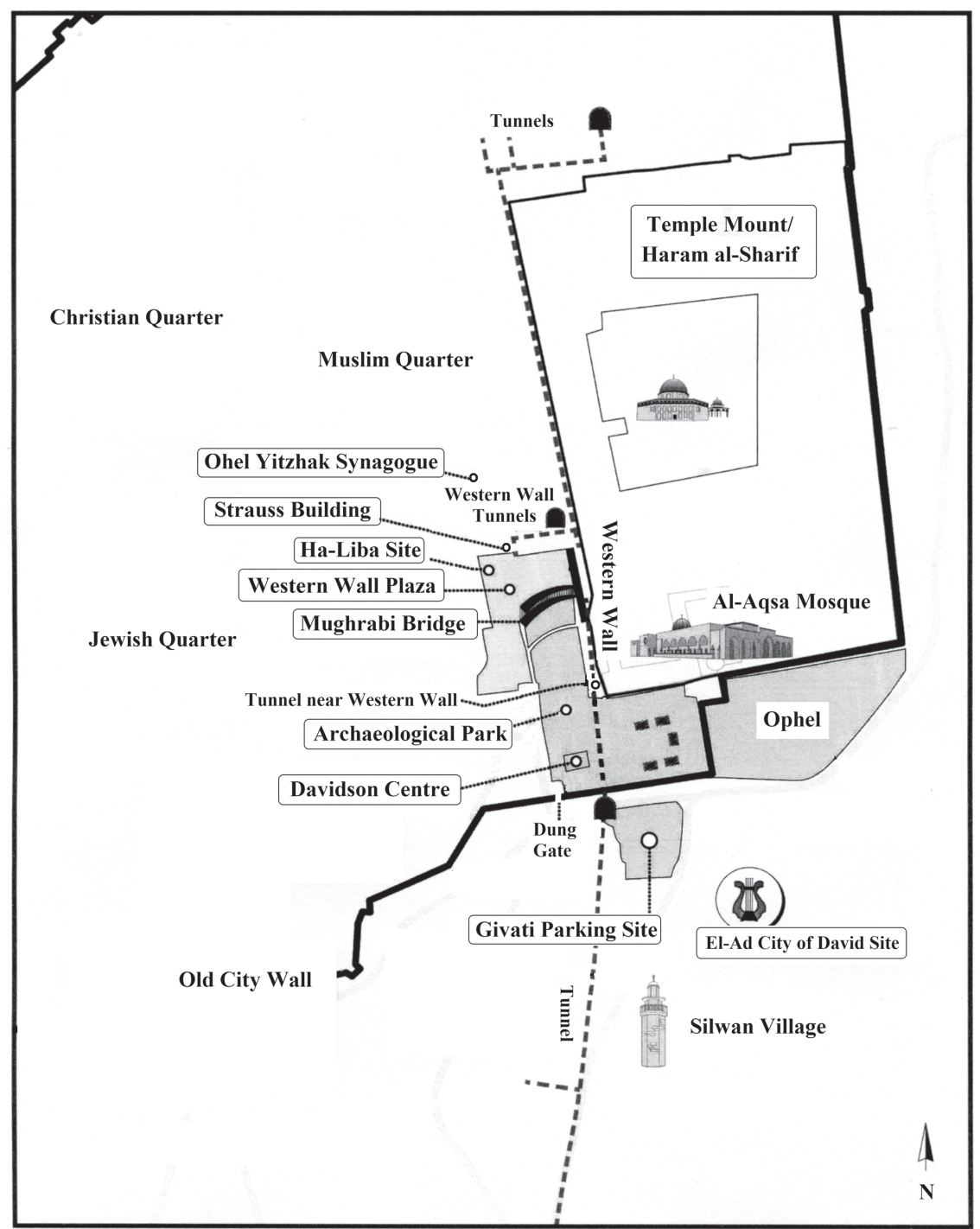

Figure 1.18 General location map.

After Lior Cohen, Emek Shaveh

settler organizations like El-Ad, which were marginal in the past, enjoy complete cooperation with and support of municipal and state authorities today. Their members and supporters dominate public boards and committees that make fateful decisions about Jerusalem.

South of the Western Wall Plaza, most of the activity is sponsored by the El-Ad organization. This religious organization, supported by powerful 


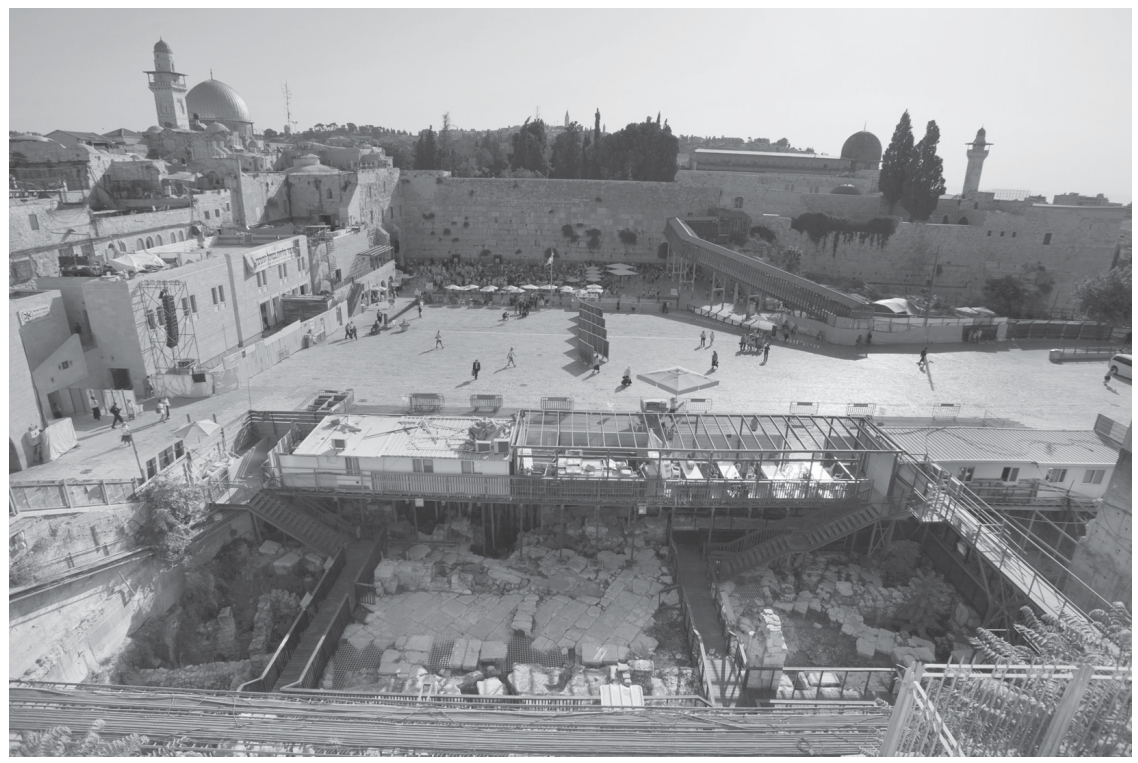

Figure 1.19 The Western Wall Plaza (general view, looking east). The Mughrabi Bridge (at centre) separates the prayer area (left) from the Archaeological Park. Notice the enlarged Strauss Building (far left) and the Ha-Liba excavation area (at bottom).

Photo R. Kletter

politicians and rich donors, aims at settling Jews in Silwan, one of the densest and poorest Palestinian neighbourhoods in East Jerusalem. In this neighbourhood many roads are still unpaved; there is no orderly evacuation of refuse; some schools are not yet connected to a sewage system; there is no community centre and not even one public garden. For the settlers the aim justifies all the means, including shady deals in property: threats, faked documents, 'signing' testimonials by people no longer alive, supplying 'girls' to help seal transactions, etc. (Hasson 2018a). Between 1967 and 2009 only some 20 Palestinian residents in Silwan received building permits, mostly for minor additions. Having no other choice, they build illegally and live under constant threat of demolition (hundreds of houses have been demolished since 1967). Meanwhile, the settlers have built a seven-storeys' tall building in an area where two are the legal limit (Cheshin et al. 1999:16, 211-224; Marom 2004; Rapoport 2009; Greenberg 2009b; 2014; Margalit 2010; Feige 2015; Hasson 2018a; Greenberg 2018).

North of the Western Wall Plaza much of the activity is carried out by Ateret Cohanim and the Moskowitz Foundation, which strive for Jewish settlement in the Muslim Quarter. These private organizations operate without transparency and documents on their activities are rare; the Moskowitz funds 
come from a bingo hall business in California (see Johnson 1992; McGreal 2009; Margalit 2010; Hasson 2018a; 2018b; Hever 2013).

The Western Wall is considered by many the most holy site for Jews (Benvenisti 1996: Chap. 3; Bahat 2007; Aderet 2013 cf. Bar 2014). After the hiatus of Jordanian control (1948-1967), the area north of the Mughrabi Bridge became again an active holy site. There are no criteria that define 'holy sites' in Israel, but in a Law from 1981 the Western Wall and 15 other places were declared holy sites for Jews (Mack 2016; no Muslim holy sites have been declared so far in Israel). British Mandate Regulations and the following Israeli legislation limit the power of the Department of Antiquities (later the IAA) concerning active holy places. The Law of Antiquities (Antiquities Law 1978: \#29, 32b) puts limits on confiscation of land and excavations in holy sites, although they can be declared as antiquities sites (practically the entire Old City of Jerusalem is a declared antiquities site). According to the Law, three Ministers (of Education, Religion and Justice) can convene to allow archaeological excavations in an active holy site; but to the best of my knowledge this procedure has never been employed.

As the Western Wall Plaza (and the tunnels underneath it) are defined as an active holy site, the Ministry of Religion could prevent, for many years, the involvement of the Department of Antiquities in the digging of the Western Wall Tunnels. However, in the last two decades the IAA became a key player - a sort of contractor - for the bodies that develop East Jerusalem, and especially for the Western Wall Plaza Foundation. One reason for this change relates to finances. In the past, the Department of Antiquities worked on the basis of governmental budgets. Although entrepreneurs usually paid for salvage excavations, this was neither grounded in legislation nor a source of income for the Department (it could not keep to itself 'gains' from excavations: Kletter 2006:303-304; Kersel and Kletter 2006:323). At that time and also in the first years of the IAA (in the 1990s) there was a clear archaeological policy that central, major tells should be protected as much as possible from development and kept for 'research' or 'academic' excavations. This was true for Jerusalem too, and the IAA strongly opposed in the 1990s the plans of El-Ad to build a visitor's centre at Silwan/City of David, since this central site should be left open for future scientific research (Greenberg 2014).

During the 1990s, salvage excavations in Israel became a (limited) 'market.' The IAA takes the lion's share, and the rest is performed by several companies affiliated to universities in Israel. ${ }^{3}$ The companies work for profits, which are channelled to the host universities. ${ }^{4}$ Salvage excavations became a crucial source of income for the IAA too (in 2013 the annual IAA budget was ca. 195 million Shekels, of which 143 million Shekels derived from projects, mostly from salvage excavations and restoration following excavation). The IAA developed a keen interest in performing more salvage excavations and restoration projects, in order to maintain - and increase - the flow of income. This process has accelerated since 2000, when IAA Director Shuka Dorfman (1950-2014) (Dahari 2014) replaced the former Director, Amir 
Drori (1937-2005) (Tsafrir 2005). The differences between the two directors could not be greater, though both came from a Military background. Drori was a born leader and a modest person. He loved archaeology and held an archaeological degree, and the IAA was for him a vocation. For Dorfman the IAA was a career; he was an arrogant 'manager' with little esteem for archaeology. Under him the IAA became a sort of contractor that supports many development plans, even at the expense of archaeology (see the example of the Mamilla cemetery in Jerusalem, Sulimany and Kletter 2017).

The official vision of the IAA, a short text composed under Dorfman in 2000 , states that the IAA 'will maintain a balance between development needs and antiquities preservation' (IAA 2000). In our opinion this should not be part of the goals of the IAA (cf. Greenberg 2008). There are adequate bodies for development in the State of Israel, and they are very powerful. They include, first and foremost, the Ministry for Construction and Housing (regular annual budget ca. 270 million Shekels). Four other ministers hold direct responsibilities for development: the Minister for National Infrastructure, Energy and Water; the Minister for Agriculture and Rural Development; the Minister of Transportation; and the Minister for Development of the Negev and the Galilee (who is also the Minister of the Interior). Extra-governmental bodies dealing with development include the Jewish National Fund, which holds ca. $13 \%$ of the land in Israel (annual budget ca. 511 million Shekels). There are thousands of contractors and construction companies, some of them very large. Development also enjoys significant private donations (Hever 2013) and special governmental budgets.

In East Jerusalem alone, active bodies (except private NGOs and companies) include the Jerusalem Municipality, the Company for Development of East Jerusalem (PAMI), and the company for the Reconstruction and Development of the Jewish Quarter (on its restoration - rather rebuilding see Ricca 2007). There is a special Minister for Jerusalem in the Government; in just one decade (2005-2015) the Government approved eight plans for the development of Jerusalem with a total budget of ca. 3 billion Shekels (more than 700 million US Dollars). Four of these plans were for development of East Jerusalem (State Comptroller 2018:14). The special Government allocation just to the development of the Western Wall Plaza for 2016-2021 amounts to 271 million Shekels (State Comptroller 2018:15).

In comparison to these behemoths there is only one (not large) authority responsible for archaeology, the IAA. It should act for the interests of archaeology and antiquities, defending them from development. The IAA goals should be similar to those of the Ministry for Environmental Protection: to protect the environment, not to find 'balance' between protection and development. ${ }^{5}$

The major reason for the change in the IAA involvement in East Jerusalem is political (rather than financial or archaeological). The IAA is a (semi) governmental authority, and its policies necessarily reflect those of the State. If in the past bodies like El-Ad were marginal, today they are part and parcel of 
the establishment. ${ }^{6}$ In promoting and executing excavations for such bodies the IAA indirectly supports their ideology, by granting them governmental authority and legitimacy. In addition, years of close cooperation with bodies like El-Ad and Ateret Cohanim created a routine, in which the IAA is exposed to the ideologies of these bodies on a daily basis. We have by now reached a situation in which the IAA is not always forced to excavate due to development plans, but it itself initiates and 'pushes' the developers to finance more excavations in East Jerusalem.

The IAA presents the important discoveries in East Jerusalem as justification for carrying the excavations there. However, important finds will be exposed in any broad-scale excavation in this antiquities-rich area (on which see Grabar and Kedar 2009). Excavations are essential before development; but the IAA's decision whether to support a building plan or not should be independent, not governed by non-archaeological considerations (such as considerations of finances or political pressures).

\subsection{Inspectors, entrepreneurs and archaeologists: the 'status meetings'}

To introduce readers to some leading figures in the archaeology of East Jerusalem and to the structure of power within the IAA, we review here a little-known institution created by Shuka Dorfman, the IAA Director in the years 2000-2014: the 'status meetings.'

A major division within the IAA, inherited from the earlier times of the Archaeological Department, runs between inspection and excavation. Inspection is considered statutory, as it is fully financed by governmental budgets; while most excavations (and surveys) are financed from external sources (mainly by developers). Inspectors sit in four geographical regions, each responsible for several smaller districts: northern region (Galilee); central region (the central Coastal Plain); southern region (Negev); and Jerusalem region (the central Highlands). ${ }^{7}$ The four heads of regions are members of the IAA management. Excavating archaeologists belong to the Department of Excavations and Surveys, but since the 1990s some sit in this department (in Jerusalem), while others are permanently 'loaned' to the inspection regions and work in close cooperation with them. The head of the Excavations and Surveys Department (in the years under study Dr. Gideon Avni) is a member of the IAA management. Traditionally, the IAA Director had a senior archaeologist as Deputy Director (in the years under study Dr. Uzi Dahari). Shuka Dorfman reformed this role as 'Head of Archaeological Administration.' Apart of the Excavations and Surveys Department, this Administration includes the Departments of Publications, State Treasures, and Artifacts' Treatment; but their heads do not sit in the IAA management. Dorfman also created a Conservation Administration (in the years under study headed by Raanan Kislev).

Until the 1990s, the separation between inspection and excavation was less categorical, in that the heads of the inspection districts were senior 
archaeologists with considerable experience in excavating and publishing the results. The 'pool' of candidates for heads of regions and districts was the Department of Excavations and Surveys. Since then, for various reasons, the division deepened, and most heads of inspection regions today come from inspection districts. In other words, inspection is becoming a separate professional career within the IAA. ${ }^{8}$ In the IAA management, the 'archaeologists' (those with many years' experience in excavations, surveys, work on finds and publications) form a small minority now.

When the number of excavations in (East) Jerusalem expanded, the IAA Director, Shuka Dorfman, organized what he called 'status meetings' in order to manage them. The meetings were usually held once a month; their aim was to allow Dorfman to personally monitor all the projects of importance in Jerusalem (he also wanted to promote projects and maintain a large and steady 'volume of work,' see Document 6.16 in the Appendix):

Jerusalem is the only city in which I am personally involved in each and every detail ... I am involved in general in projects that happen in the Galilee, Accho, Jaffa; but in Jerusalem we really took it much more particularly, because of the importance of Jerusalem and the heart of the matter, which is the Western Wall Plaza and all this area, the City of David.

(Dorfman, in Planning Committee 2010 [Transcript]:24)

The status meetings reflected the IAA hierarchy (Table 1.1). Regular participants included (except Dorfman) two 'inspection people': the Jerusalem Region Archaeologist (Jon Seligman, later Yuval Baruch) and the Jerusalem District Archaeologist (Yuval Baruch, later Amit Reem). The Conservation Department was represented by two to four people, including the head of the department (Raanan Kislev) and the Architect of the Old City of Jerusalem (Shachar Poni). Entrepreneurs and people working on their behalf (architects, contractors) were invited very often, some of them becoming almost permanent participants. This is different from other projects elsewhere, where the frequency of meetings with entrepreneurs is lower and they usually work against regional and district inspectors.

While the 'inspectors,' the 'conservators' and the entrepreneurs were well represented in the status meetings, the 'archaeologists' were not. Uzi Dahari, Head of the Archaeology Administration, was present in only about half. Gideon Avni (Head of the Excavations and Survey Department) did not participate at all, while his deputy and Scientific Advisor of the Jerusalem Region, David Amit (who passed away in 2013), participated only once. The IAA management never invited experts on the archaeology of Jerusalem to the 'status meetings,' whether from universities, or people that work within the IAA.

Excavating archaeologists were seldom invited, and then usually only to a specific part of the meeting relating to their excavations. ${ }^{9}$ On several occasions 
Table 1.1 Status meeting-participants (IAA)

\begin{tabular}{|c|c|c|c|c|c|c|c|c|c|c|c|c|c|c|c|c|}
\hline $\begin{array}{l}\text { Date and document } \\
\text { number } \rightarrow \text { Name }\end{array}$ & $\begin{array}{l}11.3 . \\
132.25\end{array}$ & $\begin{array}{l}23.9 . \\
123.2\end{array}$ & $\begin{array}{l}12.2 . \\
123.5\end{array}$ & $\begin{array}{l}17.12 . \\
094.28\end{array}$ & $\begin{array}{l}7.3 .10 \\
5.5\end{array}$ & $\begin{array}{l}8.7 .10 \\
5.6\end{array}$ & $\begin{array}{l}30.8 . \\
095.22\end{array}$ & $\begin{array}{l}21.6 . \\
096.3\end{array}$ & $\begin{array}{l}27.4 \\
086.4\end{array}$ & $\begin{array}{l}1.6 .08 \\
6.5\end{array}$ & $\begin{array}{l}5.10 \\
086.7\end{array}$ & $\begin{array}{l}9.11 \\
086.8\end{array}$ & $\begin{array}{l}14.12 . \\
096.9\end{array}$ & $\begin{array}{l}18.1 . \\
096.10\end{array}$ & $\begin{array}{l}30.11 . \\
096.14\end{array}$ & $\begin{array}{l}14.4 .10 \\
6.16\end{array}$ \\
\hline $\begin{array}{l}\text { David Gabay } \\
\text { (finances) }\end{array}$ & & + & & & & & $\mathrm{p}$ & + & & & + & & + & + & + & \\
\hline Uzi Dahari & & + & & & + & & & & + & $\mathrm{p}$ & + & + & + & + & + & \\
\hline David Amit & & & & & & & & & & + & & & & & & \\
\hline Jon Seligman & & & & + & + & + & + & & + & + & + & + & + & + & + & + \\
\hline Yuval Baruch & + & + & + & + & + & & + & + & + & & + & + & + & + & + & + \\
\hline Amit Reem & + & + & & & & & & & & & & & & & & \\
\hline *Raanan Kislev & + & + & + & + & + & + & + & & + & + & + & + & + & + & + & + \\
\hline *Shachar Poni & + & & + & + & + & + & & + & + & + & + & & + & + & + & + \\
\hline *Eran Chemo & & + & + & & + & + & & + & & + & + & + & + & + & + & \\
\hline *Jonny Ivanowsky & & + & & & + & + & + & + & + & + & + & + & + & + & + & + \\
\hline *Amos Goldstein & & + & & & + & + & + & + & + & + & + & + & + & + & + & \\
\hline Alexander Onn & & & & + & + & & & + & + & + & & + & + & + & + & \\
\hline S. Weksler-Bdolah & & & & & $\mathrm{p}$ & $\mathrm{p}$ & & & & & & & & & & \\
\hline Hayim Barbé & & & & & & + & & & + & $\mathrm{p}$ & & $\mathrm{p}$ & + & & & \\
\hline Soli Eliav (WWHF) & + & + & & & + & + & + & + & + & + & + & + & + & + & + & \\
\hline Chen Canari (WWHF) & + & + & & & + & + & + & + & + & + & + & + & + & + & + & \\
\hline Ofer Cohen (WWHF) & & + & + & + & + & + & + & + & & $\mathrm{p}$ & + & $\mathrm{p}$ & $\mathrm{p}$ & + & + & \\
\hline Rafi Kutschmer & & + & & + & + & + & + & + & + & + & + & + & + & + & + & \\
\hline Eli Elan & & & & & + & + & + & + & & + & + & + & + & & + & \\
\hline Dan Rahat & & & & & & & & & + & + & & & & & & \\
\hline Ada Karmi-Melamede & + & & & & & & & & & & & & & & & \\
\hline Amir Gilead & & + & & & + & + & + & + & + & + & + & & & + & & \\
\hline Avner Gilead & & & & & + & & & & & & & + & + & & + & \\
\hline Gobi Kertesz & & & & & & & & & & + & & & & & & \\
\hline Gai Teomi & + & & & & & & & & & & & & & & & \\
\hline Eitan Kimmel & & & & + & & & & & & & & & & & + & \\
\hline Dan Bahat & & & & & & & + & & & & & & & & & \\
\hline
\end{tabular}

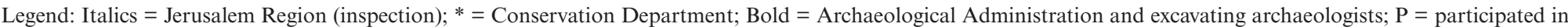

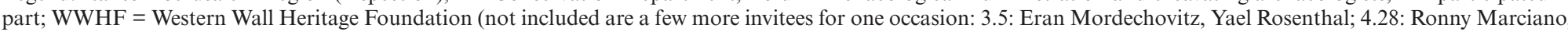
Eitan Stekel; 5.5: Yoram Saad; 6.5: Eli Rothberg; and 6.14: Shemuel Rabin, Udi Armoni). 
Weksler-Bdolah was invited just because of the lack of funding for sieving. It was necessary to ask for additional monies from the entrepreneur, and convenient to let Weksler-Bdolah do the asking.

The 'status meetings' reflect Dorfman's close ties with the rich and influential entrepreneurs in Jerusalem, as well as with the 'conservation' people of the IAA. Dorfman enlarged the Conservation Department into an Administration, so this close tie is expected. The limited participation of 'the archaeologists' reflects Dorfman's lack of mutual language with them, and their deteriorating status within the IAA.

As a result of this hierarchy, the fate of archaeological projects in Jerusalem was decided by a very narrow circle (mainly Dorfman, with the advice of three-four officials from the Jerusalem Region and Conservation Administration). The decisions were made without the participation and professional advice of the best archaeological experts that the IAA has. Even when representatives of the Archaeology Administration participated, their views were not given weight. Additionally, Dorfman had the custom of 'concluding' each meeting, and nobody dared object to his conclusions. He had to say the last word, sometimes ignoring what others said earlier in the meeting.

Subordinated managers learned not to criticize, but to accept the Director's opinions. Instead of expressing independent views or working according to procedures, they tried to understand what he wanted and fulfilled his wishes. We will see an example of this in the case of the Strauss Building: when Dorfman uttered unclear conclusions, his subordinates tried to interpret them, instead of acting according to procedures (Documents 2.3; 5.13). It was difficult to oppose Dorfman, because the Law (Antiquities Law 1978) gave absolute power to the IAA Director. At the time the Law was made, nobody imagined that someone who is not a professional archaeologist, and has little respect for archaeology, will become the IAA Director.

Decisions about Jerusalem became a one-man show. They were motivated mainly by financial (securing income to the IAA), entrepreneurial (Dorfman idealized development) and political considerations. ${ }^{10}$ One should add that while Dorfman intimidated his subordinates, he was accommodating to those equal or more powerful than him. The waiving of a full-scale excavation at the Strauss Building (see Chapter 2 in this volume) was not an exception. Dorfman approved the building of the El-Ad centre at Silwan in the same way; and gave up the proper excavation of hundreds of tombs at Mamilla because of pressures of influential politicians and rich entrepreneurs (Sulimany and Kletter 2017).

The status of the IAA excavating archaeologists deteriorated under Dorfman. It is true that this process had started earlier, but it escalated during his days. An example concerns the positioning of the foundation pillars at the Ha-Liba Building. For several months, discussions were held between the architect, Karmi-Melamede, and the IAA Conservation Department, without alerting the excavating archaeologist. When Weksler-Bdolah learned of it, she complained: 
I am certain that there were many pressures, and I am certain that the Conservation Department including Shachar and Raanan did their best. Yet I find it hard to understand how no one spoke to me regarding the matter, even once, since there was a clear directive from Shuka [Dorfman] on the matter.

(Document 5.9)

What pressures prevented making a phone call to inform the excavator? One did not bother, because it was a 'pure matter of conservation.' Dorfman's directive was lip service.

Under Dorfman, senior managers come mostly from the ranks of 'conservation' and 'inspection.' Excavating archaeologists are no longer the natural reservoir of future IAA senior managers. Professional advance (such as acquiring a $\mathrm{PhD}$ in Archaeology, publications in prestigious journals, excavation reports) may give some financial benefits, but is no longer considered vital for top management positions.

Excavating is a highly specialized and complex task, which involves many factors and issues; even more so with salvage excavations. At present, excavating archaeologists have little authority. They do not decide about the start and the end of their excavations, and hence, their pace. They have little say about the budget. The excavations are called 'projects,' but are not processed as such. Post-excavation work is highly centralized. The budget is not kept separately per project. Instead of answering the needs of each 'project,' the projects wait in long ques for photography, drawing, pottery restoration, etc. The result is a host of unpublished projects.

This book is based on thousands of documents from the IAA, obtained by the NGO Emek Shaveh under the 'Freedom of Information' Law and partially published by the present author in Hebrew (Kletter 2015). The text has been significantly revised and three new chapters added (Chapters 7-9). Additional documents were obtained from the Western Wall Heritage Foundation in 2017 and incorporated in the book. All these documents are open to the public and are presented in English translation at the end of the text (arranged by chapter and running number: 2.1,3.2, etc.). Although we were not given full access, the available documents allow a unique view of the scope and nature of the archaeological activities in the heart of Jerusalem's 'Holy Basin,' and form an important addition to the study of politics of heritage and archaeology. Scientific products written by archaeologists (preliminary articles, final reports) and interviews that they give rarely discuss the circumstances behind their work, and least of all relations of power. ${ }^{11}$ We focus in the present book on four sites: the Strauss Building, the Archaeological Park (which includes the Davidson Centre), Ohel Yitzhak Synagogue, and Ha-Liba Building (Chapters 2-5). Another chapter deals with the plan for excavating the entire Western Wall Plaza in the future (Chapter 6). We excluded from discussion the Mughrabi Bridge, because the plans for the new bridge are shelved, and relatively few documents are available on the excavations related to it. We also do not discuss the Western Wall 
Tunnels - a maze of spaces and passages, excavated for decades, with few, partial publications. Their discussion would require a separate monograph.

Translation of Hebrew place and personal names is notoriously difficult. We did our best to verify spellings, and any mistakes that might remain are unintentional. We tried to give as accurate as possible translations to the original documents, correcting only typos, without changing meanings (for example, in one place the Roman name of Jerusalem - Aelia Capitolina - was given as 'Aina Batolina'). Our comments appear in square brackets.

In this book we do not focus on the role of excavating archaeologists, including excavation techniques, work on finds and writing excavation reports. We appreciate the work of the IAA's archaeologists and believe that it is and must be - similar to that of university-affiliated scholars. There are welltrained, professional excavating archaeologists in the IAA; some of them have more experience in the field than many university professors. However, as we will show (later), excavating archaeologists have little influence on the IAA policy. Our study concerns policies and decisions that affect their professional work, but are not decided by them.

Naturally, there have been changes in personal positions and organization structure in the IAA during the years under discussion. This book is not a 'who's who' for archaeology in Israel and therefore, we mention only some more relevant changes. ${ }^{12}$

Not only the general public, but even many archaeologists in Israel have heard little about the stories presented here. The decision-makers and officials that appear in the documents may seem elsewhere, in work or social contexts (visiting a site, asking for an excavation license, meeting in an international conference), to be likeable professionals, who just do their job. The documents expose a different, less likeable side. Those responsible for archaeology in East Jerusalem would like to nourish an image of 'pure' men of science, which has nothing to do with politics, let alone 'dirty' politics. They claim that they excavate only because it is necessary; their work is always objective and scientific, without involvement with politics. The present documents remove such illusions. The issue is not their political beliefs and convictions, but their professional acts, based on thousands of 'new' documents. A scholar's duty is to publish such documents, not hide them. ${ }^{13}$ Similarly, what matters when reading this book is not the author's political opinions, but his craftsmanship: are the translations accurate, the interpretation reasonable? Criticism should not be ad hominem, but in relation to the documents. If my aims as author are relevant at all, they are to contribute to archaeology as a humanistic field of study, and to the ideal of democracy.

Many people were involved in the creation of this book. I wish to thank first the Emek Shaveh Organization (www.alt-arch.org) for giving me access to the documents and photos published here and for financing my work for the 2015 report. This book, however, presents my own views. I thank all those who contributed to my work, especially Maayan Ben Hagai, Talya Ezrahi, Yoni Mizrahi, Gideon Sulimany, Dalia Tessler and Ana Veeder, as well as 
Lior Cohen and Slava Pirski (for preparing the maps and plans). I am grateful to Amir Yatziv for the permission to use the 'Detroit' photo (www.amiryatziv. com/detroit.html). Parts of two chapters were translated into English by Samuel Thrope and Jessica Bonn, a process that involved long and fruitful discussions. I am deeply indebted to Jodi Magness of the University of North Carolina at Chapel Hill for her valuable comments as a peer reviewer of the book proposal, as well as to Jim West and Johannes Bach for their advice. Special thanks go also to the readers of Routledge, to Emily Boyd and Kelly Winter of Newgen Publishing UK, and to the editors of the Copenhagen International Seminar series, Ingrid Hjelm of the Universiy of Copenhagen and Emanuel Pfoh of the National University of La Plata and the National Research Council (CONICET) of Argentina for their dedicated work on this book.

I have not received grants or salary for writing this book, and to the best of my knowledge have no conflicts of interest. ${ }^{14}$ The present book was written thousands of kilometres from Jerusalem, but is based on intimate knowledge of archaeology in Israel in general and the IAA in particular. One could not write this book from within, but also not as a foreigner. It requires a sort of a present-absentee for an author.

\section{Notes}

1 For graffiti and politics on the separation wall in Jerusalem see Hanauer 2011.

2 On Israeli politics of inequality in East Jerusalem see Dumper 1997; Cheshin et al. 1999; Kedar 2003; Amirav 2007; Cohen 2007; Hasson 2017c.

3 Salvage excavations (aimed at documenting/saving remains before development) do not differ in methodology or scientific merit from 'research' or 'academic' archaeological excavations. Every archaeological excavation in Israel requires a license issued by the IAA. The procedures differ: salvage excavations receive internal permits, marked by the letters A (for IAA excavations) or B (for excavations by companies affiliated to universities). Excavations of research institutes (almost always universities) that are not salvage excavations receive licenses (marked by the letter G), after discussion in the Archaeological Council. This is an advisory council to the IAA, which includes representatives of universities, the IAA, the government, and the public (cf. Section 4.2). According to International Law, only necessary salvage excavations are permitted in occupied territories (see Section 9.1).

4 The companies are considered private, and do not publish data about their profits.

5 It does not mean an anti-development stance. The Ministry for Environmental Protection supports 'sustainable development', and a similar formulation can also fit the IAA.

6 Expressions of this are many. To cite only two examples: David Beeri, head of El-Ad, received the prestigious 'Israel Prize' in 2017. Yisrael Hasson, former Parliament member of right-wing parties and supporter of El-Ad, was nominated as the new IAA Director in 2014.

7 So, for example, in the Jerusalem region, which encompasses the central highlands, there are two districts: the Jerusalem District (for the municipal area of Jerusalem) and the Judah District. 
8 Of course, the division is not absolute, and inspectors are also archaeologists with academic degrees. We present a general trend, in which there are exceptions. The change was related to a change in the nature of the role of IAA Director. Until 1990 the IAA Director was a professional archaeologist with at least an MA in Archaeology. But since then the politicians that choose the IAA Director prefer candidates with a military rather than archaeological career.

9 An exception is the late Alexander Onn, partly because work in the Western Wall Tunnels went on and on, sometimes in several locations at the same time. Onn continued working after retirement, to complete a pension. He barely spoke in the meetings and had little impact on decisions.

10 However, the political aspects (strengthening Israel's hold in East Jerusalem, developing 'our' heritage, etc.) were so obvious that they were never discussed. They were not considered a matter for discussion, but an immutable, unquestionable natural foundation.

11 To quote Said (1978:5): 'ideas, cultures, and histories cannot seriously be understood or studied without their force, or more precisely their configurations of power, also being studied.'

12 IAA Director Shuka Dorfman passed away in 2014 and was replaced by Yisrael Hasson. Uzi Dahari (Head of Archaeological Administration) retired and was replaced by Gideon Avni. Yoram Tsafrir and David Amit passed away (respectively, in 2015 and 2013). Jon Seligman (Jerusalem Region Archaeologist) replaced Gideon Avni as head of the Excavations and Surveys Department. Yuval Baruch took over the Jerusalem Region, while Amit Reem replaced Baruch as the Jerusalem District Archaeologist.

13 I hasten to stress that none of these documents hold state secrets. None is stamped 'secret' or 'top secret'; they all deal with archaeological, not military or securityrelated, issues.

14 I have worked on figurines from the Ha-Liba Building excavation of WekslerBdolah, but finished this work and submitted it in 2009, years before reading (or even being aware of) the documents discussed in this book. 


\section{Antiquities in the toilets - the Strauss Building}

\subsection{Introduction}

The Strauss Building is an old structure at the northern edge of the Western Wall Plaza, named after a philanthropist who purchased it during the British Mandate period. The building served as a soup kitchen and, for some time, as a synagogue. In August 2008 the Western Wall Heritage Foundation, the body responsible for the Western Wall, its Plaza and underground tunnels, presented a building plan (number 12996) to expand the Strauss Building. The main purpose of the plan was to add a level and expand the building southwards; this would entail taking over 360 square metres of the open plaza. The additions were intended to provide space for various needs, such as toilets (160 square metres), a lobby, a police station (125 square metres), offices, and a 'hall of the pilgrims to Jerusalem' (125 square metres; though not explained in detail, its aim seems to be an exhibition about Jewish pilgrimage to Jerusalem) (Figs. 2.1-2.2).

It is not the business of the IAA to decide whether the Western Wall Heritage Foundation needs all these spaces, and whether the correct solution is to enlarge the Strauss Building. The IAA is responsible only for antiquities that may be found in the area designed for development, and should act only in the interests of archaeology.

\subsection{The Israel Antiquities Authority does not want to excavate}

Two months before the plan for the Strauss Building was brought to the Jerusalem Planning Committee (August 2008), the IAA management met with the representatives of the entrepreneur. The title of the protocol already signals the position of the IAA: 'Advancing the Strauss Building' (Document 2.1). Soli Eliav, Director General of the Western Wall Heritage Foundation, presented the plans and asked for approval for making 'several drills' for the foundations of the new construction. In fact, not fewer than 30 drills were required (as mentioned later in the same document). Jon Seligman, then the IAA Jerusalem Regional Archaeologist, expressed his opinion about the new building with brutal honesty: 


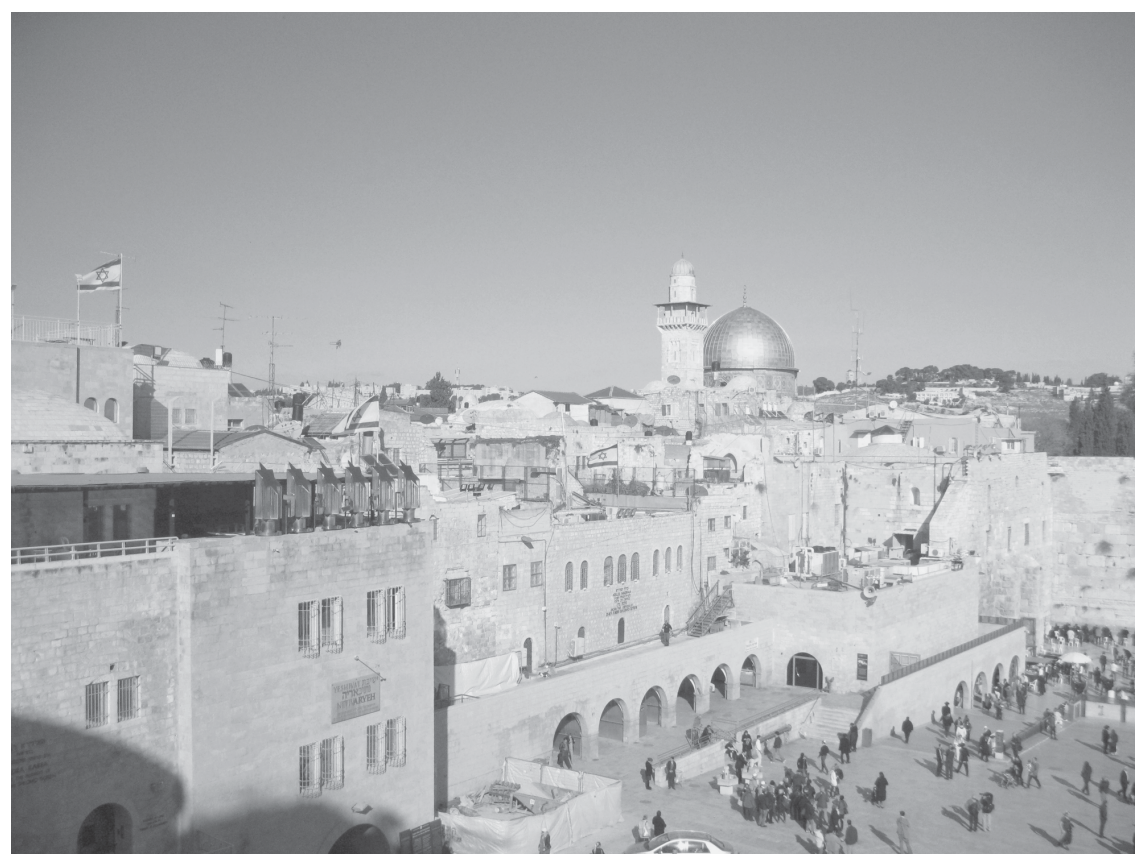

Figure 2.1 The Strauss Building (at centre) before the enlargement; the Western Wall on the right.

Photo Emek Shaveh

Jon Seligman: Ada Karmi-Melamede [the architect] did not analyze the surroundings. The planning is detached from the existing surroundings. There is no reference to the Old City. There is no division of the fifth façade of the Old City ['fifth façade' means the roof area, especially of flat modern roofs; the expression was coined by Le Corbusier].

(Document 2.1, July 6, 2008)

Shachar Poni, the architect for the Old City at the IAA Conservation Department, emptied Seligman's criticism by saying that the façade is something to be discussed elsewhere, while the volume of the building and its height 'are correct.' Fine; but the architecture should not be the IAA's main concern. Yuval Baruch (then the Jerusalem District Archaeologist, working under Seligman) led the discussion back to archaeology, telling the entrepreneur what many entrepreneurs heard from the IAA before: 'Yuval Baruch: One should condition the building on a salvage excavation, as a condition for approving the plan and for executing it later. One must present an accurate foundation plan' (Document 2.1).

Shuka Dorfman (then the IAA Director), summarized the discussion, as he customarily did. Often, his summaries disregarded what the other 


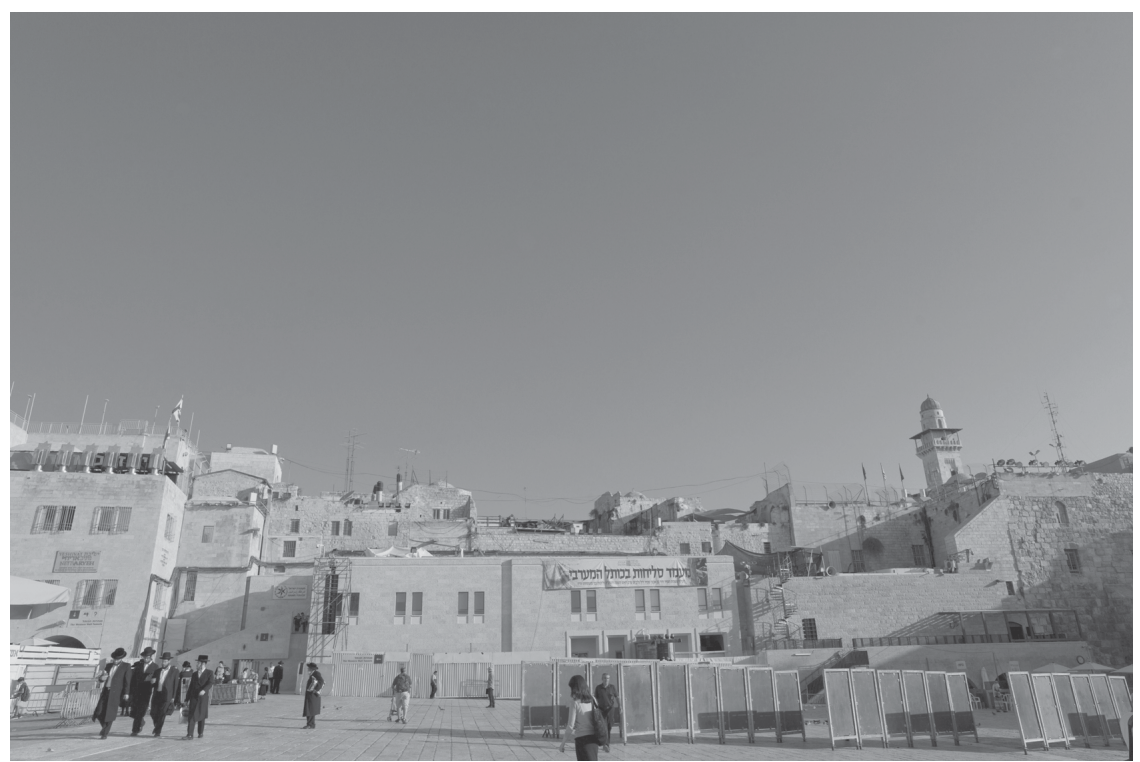

Figure 2.2 The Strauss Building after enlargement, view north from the Western Wall Plaza.

Photo Emek Shaveh

participants said. In this case too, he sharply contradicted Seligman and Baruch, expressing admiration for the new building:

Shuka Dorfman summarized the discussion:

a) Indeed, Ada Karmi-Melamede referred to the entire Western Wall Plaza.

b) The Old City was created without anyone planning it, and here lies its beauty.

c) The [new] building is not protruding and is being built with up to date technologies.

d) The project will be approved after a detailed plan with a minimum number of drills is presented.

(Document 2.1)

The Old City was perhaps created without a general city plan, though houses, public buildings, the walls, etc., were certainly planned in advance. To the core of the matter, though, what about the archaeology? Dorfman announced that the building 'will be approved,' but said nothing about a salvage excavation.

As the plan progressed, Jon Seligman sent the entrepreneur a preliminary letter (Document 2.2). It was the usual, formulaic letter that the IAA 
issues to entrepreneurs in such cases. The letter stressed that the IAA has not yet finished examining the plans. Then followed the standard IAA clauses (Document 2.2: first list, items 4-5) and conditions or 'instructions' (Document 2.2: second list of nine items) about the plan. They included the standard demands, namely, full salvage excavations and preservation of finds:

Scientific archaeological excavations must be conducted in the entire area under discussion. Only after the completion of the excavations, and depending on their results, will the IAA determine the conditions and requirements for approving construction [...] [Page 2]

3. Prior to submitting an application for a [building] permit, the entrepreneur will conduct full archaeological excavations, at his own expense, according to the conditions of the [IAA] Director by the instructions of the Antiquities Law, 1978.

4. The antiquities exposed in the area will be preserved in situ [=in their original place of finding], according to the conditions that will be set by the Director during and immediately after the excavation.

5. Should there be found in the area, as mentioned above, antiquities which require on site preservation, all the acts for preserving the antiquities shall be made and also the entrepreneur will act over the years to maintain and to guard the antiquities in place.

(Document 2.2)

However, this was not Mr. Dorfman's intention. From the start, he decided not only to support the plan, but also to dispense with a full salvage excavation. None of the documents that we have read contain details as to what considerations went into this decision or how it was reached. It was a grave decision. In Israel, it is highly irregular to begin construction in an archaeological site without first undertaking rescue excavations. Especially in such a central site as the Old City of Jerusalem, where the presence of antiquities is not in doubt.

Just two days before the hearing in the Planning Committee, Shachar Poni approached Jon Seligman in order to coordinate the IAA's position. Poni explained that his words were 'based on my understanding of the conclusions reached in the meetings with Shuka [Dorfman].' Instead of working by procedures, the IAA's position is determined according to the whims of Dorfman, which the employees must guess from his vague conclusions (in Document 2.1). Poni offered an 'initial suggestion':

We analyzed the plan according to a detailed documentation file that had been prepared [...] and based on a study of the proposal according to the criteria established in plan 10276 (in process) [the Jerusalem city master plan], and on a thorough examination of the proposal's compatibility with existing topography, current construction styles, issues of visibility and effect on the cityscape. 
This may sound impressive, but it is irrelevant. Next Poni outlined four subjects 'which require consideration':

A) Functional-pragmatic considerations. B) The impact of the proposed volumes [of the new construction], from an overall perspective. C) The compatibility of the proposed exterior and building elements with, and their overall impact on, the design of the Western Wall Plaza. D) The potential damage to valuable [archaeological] remains. The first three issues mentioned above necessitate a more comprehensive perspective, beyond an examination of the building itself. In consideration of this requirement, the preparation of a comprehensive plan for the Western Wall Plaza has begun.

(Document 2.3)

The first three subjects concern architecture, and, as Poni says, require a comprehensive perspective, that is, not only an examination of the new plan, but also considering whether it is compatible with its surroundings. Hence, it relates to the issue of a comprehensive plan for the entire Plaza (for which see Chapter 6). The fourth subject concerns archaeology - 'damage to valuable archaeological remains' - but no comprehensive perspective is mentioned in this case. In any event, the IAA supports the plan and does not see any reason to condition its approval on the completion of a comprehensive plan for the Plaza: 'This is because it is recognized that the majority of the proposed functions [of the building] indeed address real needs. The proposed scale of construction [...] is also appropriate and reasonable' (Document 2.3).

Since when does the IAA determine the needs of a developer? Who gave it the authority to judge if the entrepreneur planned too many or too few toilet booths, or if the 'hall of pilgrims to Jerusalem' is too small or too large? Why is the IAA concerned with such things, instead of giving an archaeological point of view? No excavation has yet been undertaken, so no one knows what lies underground (aside from vaults which are partly visible, close to the surface). Regardless, Shachar Poni proposed to tell the Jerusalem District Planning Committee that there was no need to:

condition the approval of the plan [for the Strauss Building] on the statutory approval of the comprehensive plan [for the Western Wall Plaza], (as we also think is true for requests concerning small additions to private homes in the Old City: one should consider them by strict criteria, but not condition the additions on [approval of] new general plans.

(Document 2.3)

Is the case of a small addition to a private house in an Old City alley comparable to the large expansion of a public structure in the Western Wall Plaza?

The IAA discussed some details with the planners, particularly the topic of an elevator shaft. It deliberated whether to allow the destruction of an 
old vault for this purpose (Document 2.4). Yuval Baruch admitted that 'we do not know when the structure was built,' but assumed that the vault was late and therefore could be destroyed without causing pangs of conscience. After all, much more substantial remains were damaged at Ohel Yitzhak (see Chapter 4) because of an elevator. The IAA Director (Dorfman) wasn't sure. This was a marginal issue, however. The IAA had conceded hundreds of square metres of excavation to a depth of 14-21 metres (verified later from drills). The deliberations on the elevator shaft concern maybe 20 square metres to a limited depth (the IAA would finally approve the shaft in 2012).

The Jerusalem District Planning Committee concluded on March 24, 2009, as follows:

Concerning changes to the interior areas [meaning within the existing building] - the IAA opposes any planned destruction of remains from the Middle Age, and asks the committee to demand alternative solutions for the elevator and the stairwell. Mr. Poni was asked if excavations have been conducted or if they will be conducted in the future in the area under planning, and he answered that, with the start of work they will perform an inspection, following the normal procedures; excavations will be undertaken only as needed, if [the need] will arise during the inspection of the [construction] work.

(Planning Committee 2009a: 9, \#5, emphases added)

Mr. Poni did not raise the subject of excavations until the committee asked. The committee expected the IAA to request a full salvage excavation, as is the norm in cases of construction in registered antiquities' sites. The request never came. In his response, Poni said that excavations would be undertaken if needed, as if it was unknown whether or not there were antiquities at this site - the heart of the Old City of Jerusalem. The committee decided to deposit the plan subject to certain conditions, including:

B) Coordination with the IAA regarding the proposed construction, including the issue of the location of the elevator and the staircase on the site of the vaults; and the possibility of future excavation and documentation in relation to the proposed construction.

(Planning Committee 2009a: 9)

Following this decision, the process of clarifying the IAA conditions for approving the construction began.

\subsection{The IAA pretends to request an excavation}

On March 31, 2009, Jon Seligman (Jerusalem Region Archaeologist) wrote to Dalit Zilber, then the Planner of the Jerusalem District Planning Committee: 
Subject: The IAA's Position Regarding the Plan for the 'Strauss Building': On March 24, 2009, during a hearing about the plan for the 'Strauss Building', the IAA's position was presented in a detailed manner.

I wish to highlight two subjects that were, perhaps, not adequately stressed in the hearing itself:

1) Regarding the changes to ancient walls that appear in the plan - the IAA [...] opposes any destruction of medieval remains included in the plan.

2) Insofar as the structure rests on foundation piles, in accordance with an agreed engineering plan, the IAA will not condition the implementation of the project on an archaeological excavation in the designated construction area, but solely on close archaeological inspection.

(Document 2.5)

Section (1) concerns visible remains on or near the surface. The meaning of section (2) is that the IAA waives the condition of an archaeological excavation at the outset, and that it is taking pains to stress this to the committee.

Archaeological inspection is a preliminary tool that precedes an excavation, not replaces it. Inspection is employed in sites where it is suspected that antiquities may be found. If antiquities are discovered, the site can only be released for construction once the antiquities have been exposed by salvage excavations. In the case of the Strauss Building, the IAA established a dangerous precedent which undermines its own status. Many structures can be built on foundation piles. If the IAA's stance concerning the Strauss Building is acceptable, then there is apparently no need for the hundreds of salvage excavations that the IAA performs throughout Israel every year. Inspection and construction on piles would be sufficient.

However, it is impossible to excavate an area after it has been built over. If excavation is not carried out prior to construction, there will be no documentation, preservation, study or exhibition of the remains that could have been discovered there. No civilized country forfeits its past in this way; all conduct salvage excavations prior to development in places where there are antiquities.

Notice the phrase 'close archaeological inspection' (Document 2.5, section 2). It suggests a superior, upgraded form of inspection. What kind of inspection isn't close? The very meaning of archaeological inspection is that an inspector is present at the site and oversees the work. An inspector is never permitted to leave the area while work is underway.

In preparation for the hearing on the plan, the IAA formulated its conditions for approval. The standard procedure is that the IAA requests a full salvage excavation, as indeed has been requested earlier by Jon Seligman (see Document 2.2). Now Jon Seligman presented Dorfman with a draft of the conditions (Document 2.6). It began with the usual wording, adding that this specific site is of 'exceptional importance,' followed by the standard formula: 'Scientific archaeological excavations must be conducted in the 
entire area under discussion. Only after the completion of the excavations, and depending on their results, will the IAA determine the conditions and requirements for approving construction' (Document 2.6, \#2).

However, in the same section, though many sentences later, this very condition was voided: 'Insofar as the structure rests on foundation piles, in accordance with an agreed engineering plan, the IAA will not condition the implementation of the project on an archaeological excavation' (Document 2.6).

The same pattern is repeated in the list of conditions on the second page of Document 2.6. Item 2 contained the standard demand for a salvage excavation. However, item 8 voided this demand by stating that the IAA will not require an excavation if the entrepreneur uses foundation piles according to an acceptable plan.

The draft managed to confuse the IAA Director. When Dorfman read the standard requirement for an excavation on the first page, he marked a large question mark in the margin and wrote: 'Okay - but as far as I can recall there is no excavation?' (Document 2.6). Mr. Dorfman decided that there would be no excavation, and this standard wording about an excavation was for him an unwelcome surprise.

Seligman was forced to re-edit the document, although the change was only cosmetic (Document 2.7). Now the waiver of the excavation immediately followed the 'fake requirement,' both appearing on the first page. In the list of conditions on the second page a few words were added to item 2 ('and all this is dependent upon that written in item 8, below'), subordinating the 'fake requirement of excavation' to the item that waived it.

We were not provided with the complete document, since another letter (Document 2.8) mentioned an item no. 10 in the list of conditions (while what we received from Document 2.7 reached only item 8). Item 10 was also based on a standard formula, but Seligman added to it now, after the words 'only at the end of the excavation', the clarification: 'should it be carried out'...

\subsection{Overcoming objections to the plan}

When archaeologists heard of the proposed plan they harshly criticized it. Professor Amos Kloner of Bar-Ilan University wrote an objection letter to the chairman of Jerusalem's Planning and Construction Committee. Kloner emphasized the importance and uniqueness of the Western Wall Plaza, stating:

The proposed construction on the northern edge of the plaza in plan number 12996 threatens to damage the delicate and complex fabric [of the Plaza] presented here [i.e., in the letter]. Though the façade of the proposed building would protrude 'only' a few metres south of existing structures currently in use, it represents a danger of eroding the entire delicate and fragile framework [...] The proposed construction is a 
significant blow to the archaeological environment. Archaeology deals in general with underground structures and finds; but there is, nonetheless, an archaeological environment, a combination of ancient treasures and their preservation in their present condition [...] The proposed construction plan threatens to cause significant damage to the archaeological environment.

(Document 2.9)

The committee rejected Kloner's arguments, which mentioned, but did not emphasize, the waiving of the excavation. The committee believed the IAA when it said that it was involved in coordinating the construction, and that 'the antiquities located under the Western Wall Plaza will not be damaged' (Planning Committee 2009b:12).

Professor Kloner also raised the plan for discussion at the Archaeological Council, Israel's highest body on archaeological matters which serves as an advisory council to the IAA. The present council exists since 1962 and is also the body that decides the fate of applications for excavation licenses (Kletter 2006:214-249). The material that reached us is partial, mainly a draft, ${ }^{1}$ but later documents obtained from the Western Wall Heritage Foundation filled some gaps. The Archaeological Council discussed the plan on December 16, 2009. Only a few members participated, while Dorfman brought with him a large team from the IAA in support. Professor Kloner complained that the IAA approved the construction without an excavation: 'The IAA director approved the construction of the Strauss Building with no archaeological excavation, on the basis of [the builders] using foundation piles' (Document 2.10).

In response, Dorfman made various claims: that the building will not damage the Plaza or the archaeology; that approving construction on the basis of foundation piles without a full excavation is a common IAA procedure (not true); and even that the drilling is necessary 'to stabilize the building.' $\mathrm{He}$ presented the waiving of the excavation as a compromise done because the entire Plaza would be excavated soon. Professor Joseph Patrich (the Hebrew University, Jerusalem) criticized Dorfman sharply:

Joseph Patrich: Concerning the 'Strauss Building', [...] the question is what the IAA policy on the matter is. As a Council member, in my view this is a wrong (pasul) thing and might become a legal precedent; so in other places you [the IAA] will be unable to stop entrepreneurs from building structures based on foundation piles above an archaeological site. It is a damage to archaeology. It damages the foundation of the Antiquities Law itself, therefore it is a wrong thing. [...] In my view the IAA should not allow someone to build such a building, unless it 'floats'; if not, one should excavate deeply anywhere where they [the builders] penetrate the ground.

(Document 2.10) 
Professor Yoram Tsafrir of the Hebrew University, Jerusalem, stressed that he is not opposed to excavations in the Plaza, but that 'if one excavates, the excavation should be [made as] an archaeological excavation as we have been taught, and not by inserting foundation piles' (Document 2.10). Tsafrir added sharp criticism about this 'wrong act':

It pains me to say that the IAA has taken sides here, supporting the construction from the beginning, even before the digging had started ... How can one take Ada Karmi [the Architect of both Ha-Liba and Strauss Buildings] to design a building before a principal, ethical discussion is held on the subject [whether to build]?

(Document 2.10).

Dorfman said that this was not so, referring to the Ha-Liba Building (for which see Chapter 5); he claimed that his position was objective, but did not answer the point. Returning to the Strauss Building, the IAA representatives and supporters claimed that the decision to waive the excavation was connected to the fact that the entire Plaza would soon be excavated. ${ }^{2}$ However, remains lost at one place are not 'compensated' by remains found elsewhere, even if nearby. There can be unique buildings and artefacts under the Strauss Building, and their fate should not depend upon plans for other areas. Such a view might lead to the conclusion that we do not need to excavate anything more in the Plaza, because very large areas have already been excavated by Binyamin Mazar south of the Mughrabi Bridge. Joseph Aviram, for many years the secretary of the Israel Exploration Society, said:

If one builds this structure, then the IAA should have said that they will excavate and only then [let them] build this structure, and not waive the excavation because they are planning to undertake a larger excavation [elsewhere in the Western Wall Plaza].

(Document 2.10, page 3)

Professor Ephraim Stern, then chairman of the Archaeological Council, concluded the discussion by saying that the goal of the meeting was to clarify the issues and that they had been clarified. However, what was the Council's recommendation? No recommendation: the Council dispersed without expressing an opinion, leaving the IAA free to continue as it pleased.

In March 2010 the Planning Committee rejected more objections to plan 12996 (this time unrelated to archaeology) (District Committee 2010). The plan was formally approved by the Minister of the Interior in June 2011.

Prior to the construction, a request was submitted for a second discussion in the Archaeological Council (apparently by Professor Kloner). The copy that has reached us is blurred and difficult to read. We reconstructed it to the best of our ability: 
Dear members of the Archaeological Council,

In approximately one month construction will begin on the addition to the Strauss Building [...] The construction has been approved without an excavation at the site, one of the most important in Jerusalem. It is planned that only a very minor trial excavation will be undertaken at the site [...] The construction itself will take place in the midst of the accumulated remains expected to be found in the Tyropoeon Valley [the Tyropoeon or 'Valley of the Cheesemakers' separates Mount Zion to the West and the Temple Mount to the East. Today it is partially filled] [...]. It seems that the considerations that led to the waiver of the excavation here go against the [logic?] and best interest of archaeology; this is the reason for my request [for another discussion].

(Document 2.11)

We do not have further documentation concerning this request, and it seems that a second discussion never took place.

\subsection{Construction under 'close' inspection}

In 2011 the engineers explained to the IAA how the structure's foundation would be constructed, in the 'up down' method:

The intention was to base the deep foundation on the bedrock and inside it [that is, by drilling]; then to dig down two metres where necessary for placing the beams; [then] to install the beams and the floor, and to proceed with the construction upward.

(Document 2.12).

Placing the beams would cause extensive damage, so probably the entire upper two metres had to be excavated by the IAA. Of course, the foundation piles will not 'float' above the antiquities, but in the mind of the IAA this damage was acceptable.

In April 2013 the drilling for foundations began. At that time the Movement for Quality Government in Israel (an NGO) complained that the work includes 'the use of heavy machinery, raising concerns that antiquities located there may be damaged' (Document 2.13) (Fig. 2.3). Shachar Poni reported to Yuval Baruch, who in turn reported to Shuka Dorfman about the general area (387.2 square metres), number of boreholes (16), etc. (Document 2.14). Yuval Baruch proposed responding to the Movement for Quality Government in Israel as follows:

The construction plans for the Strauss Building were thoroughly examined by the IAA, which even prepared a comprehensive conservation file for it.

Due to the importance of the project, it has been discussed several times within the IAA in different forums, and a discussion was even devoted to 
the topic by the IAA Council [an inner board that meets once a year and is 'toothless'] [...]

The planned excavations at the site will be performed after the site is prepared from an engineering perspective. Up until that point all work at the site will be done under close archaeological inspection. In addition, conservation work is being performed at the site by IAA experts, with constant engineering supervision.

(Document 2.15; see also Eli 2013)

Making a 'conservation file' is a standard procedure before conservation. However, the conservation file in this case concerned only the old building, that is, remains that could be examined without excavation. Note the language: 'close inspection,' 'conservation works' and 'engineering supervision.' All these were intended to conceal the lack of a real archaeological excavation. The letter mentions 'several' discussions 'in various forums,' but we have not been given documentation supporting this claim. It seems that Shuka Dorfman had decided to waive the excavation without any discussion.

An internal document bears witness to the brutality of the drilling:

Dear Yuval [Baruch],

Shachar [Poni] asked me to send you a report on the drilling today and yesterday. Yesterday we drilled one borehole [...] to a depth of ca. 16 metres. Into this borehole we inserted a camera [...] with the camera I saw the following:

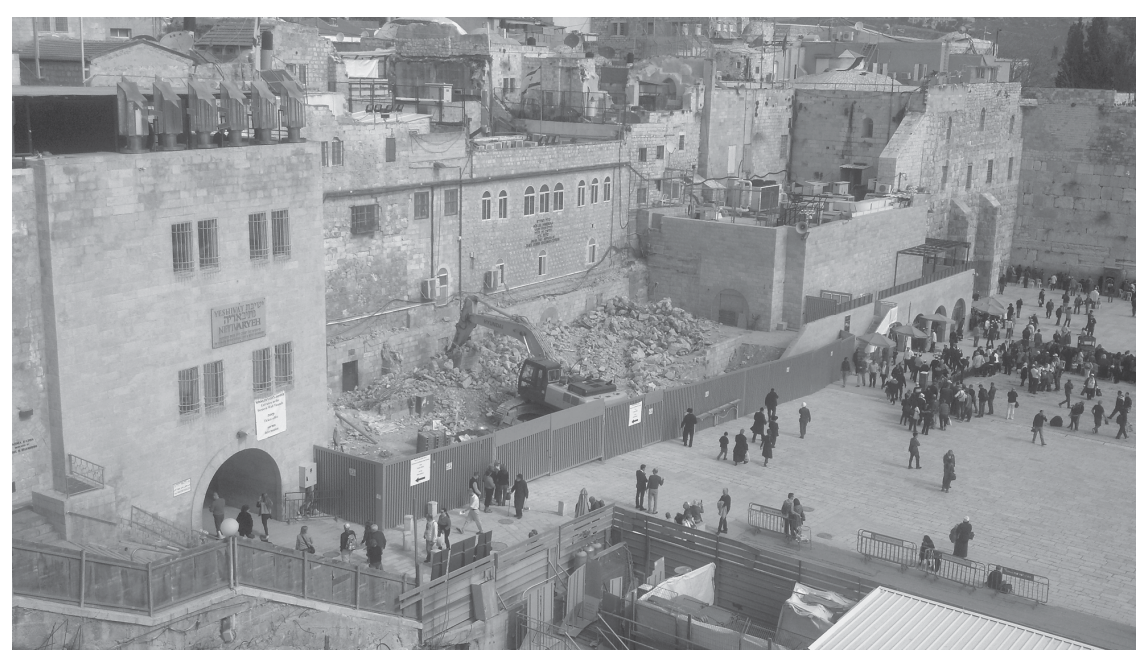

Figure 2.3 Demolition of part of the old building before the limited excavations. Photo Emek Shaveh 
After one metre there is something that looks like fallen stones.

8 [metres deep], the remains of a wall.

9.8 [metres deep], a wall.

10.4 [metres deep], a wall.

12.8 [metres deep], a wall.

16 [metres deep], the bottom of the borehole.

They poured 16 cubic metres of CLSM [a type of concrete] into this hole, and 4 metres still remain to the top of the borehole. According to the calculations, 8 cubic metres should have been enough to fill the entire hole.

In the second borehole (number 1) they drilled to a depth of 14 metres and then reached bedrock. When they tried to drill into the bedrock, the sidewalls started to collapse.

In the third borehole (number 9) they drilled to a depth of 5 metres, but the earth was very wet and this caused a massive collapse of the walls of the shaft, and for this reason they stopped drilling.

(Document 2.16)

Clearly not only the direct area of the boreholes was damaged, but also their surroundings. Tons of concrete spilled over one hole, apparently because it bore through some constructed cavity. In the past, when Ultra-Orthodox Jews wanted to prevent an archaeological excavation in a burial cave, they poured concrete inside. How can one claim that the drilling has not damaged antiquities?

Complaints reached the Israel State Comptroller (Document 2.17), who asked the IAA for clarification. The complaints were not free of interests (coming from residents of the Jewish Quarter, who opposed the new building due to alleged effects on their houses, see Planning Committee 2014:40); but seem honest enough. Document 2.17 mentions that many archaeologists were afraid to speak against Shuka Dorfman, fearing revenge. It also mentions correctly the ignorance of the legal procedures necessary for excavating an active holy place (but this could hardly stop the project, because the religious body operating the Plaza and the governmental authorities all favoured the plan). An untitled document is apparently a draft reply to the State Comptroller:

As part of preparing the plans for the building known as the 'Strauss Building,' located at the entrance to the Western Wall Tunnels, the IAA compiled a documentation file

With the approval of the plan by the relevant planning authorities, the IAA granted the building permit for the structure subject to certain conditions $[\ldots]$

These conditions included, among others, rescue excavations in the entire area underneath the building floor.

The first stage of these rescue excavations began a week ago [...] 
In order to implement the plan, the developers were forced to base the new part of the structure on a system of piles [...] the IAA approved the drilling for the piles (16 in total), even if this directly causes damage to antiquities. In the IAA's view, this damage will be proportional when compared with the area that will be excavated (some $3 \%$ of the construction area) $[\ldots]$

Among other considerations that led the IAA to permit building the structure using foundation piles is the fact that the excavation underneath the new part of the Strauss Building is part of a larger assemblage of archaeological excavations that have been, until recently, conducted in the Western Wall Plaza, and which are meant to continue in the future as part of an excavation of the entire plaza. All these considerations are derived from an overall planning vision for the Western Wall Plaza [...]

Conducting archaeological excavations in such a complex site, in which the archaeological remains extend from the surface deep down (14-20 metres), requires complicated engineering solutions, including, among others, the construction of engineering supports and retaining walls that will allow it to be implemented.

(Document 2.18, emphases added)

This is a long and convoluted letter; hardly any sentence can be taken at face value. The IAA approved the construction without a full salvage excavation, violating common procedures. Allegedly, the approval was given after 'documentation and study,' but the documentation file was written prior to excavation and included mostly documentation of the existing structure. The limited excavation at the site by Dr. Peter Gendelman began only in July 2013, so the documentation file could not refer to it, or to deeper remains that were not going to be excavated. The statement concerning 'proportional' damage takes into account only the drilling area, but the drilling destroyed a larger area due to collapses in the boreholes and spilled concrete. The IAA did not give up the area of the boreholes, but rather, the entire area (deeper than 2 metres from the surface).

Allegedly (Document 2.18) the IAA demanded a full excavation 'in the entire area,' but as we have seen, the condition about the excavation was meaningless, since it was voided by another paragraph. The claim that the entrepreneurs 'were forced' to use piles in order to enable an archaeological excavation is far from accurate. As the documents prove, the foundation piles served to circumvent the archaeological excavation, not to allow it. Deep archaeological excavations usually necessitate supports, but their nature and position are different from construction piles. In an archaeological excavation the sides of the area are supported, while for construction the supports are scattered throughout the area, in accordance with the construction plan (Document 2.19).

So far no reports have not been published about the limited excavation at the Strauss Building, and we were not even given a preliminary 'report to the 
entrepreneur.' ${ }^{3}$ However, a presentation delivered by the Jerusalem Region on preparations for this excavation is instructive (Documents 2.20-2.22). There are three stages. The very short 'Stage A' (Document 2.20) is preparatory: it includes a few days of work, mainly for trial trenches and removal of surface dirt. 'Examination sections' (=trial trenches) are often made by tractors before excavating - mainly in areas where antiquities are suspected. 'Stage C' (Document 2.21) is a post-excavation stage, performed by the team of archaeologists to shut-down the excavation, with only 20 labourers allocated for one last day. The 'Stage B' page - the main excavation - was not given to us. However, data is included on another page from the presentation (Document 2.22). More data appears in the summary of a meeting with two engineering companies in preparation of this excavation:

\section{The Excavation:}

Over the course of next week, permission will be granted to begin excavation at the work site - the beginning of the work will be coordinated between Peter [Gendelman, the excavating archaeologist] and Amichai [Lev, the project coordinator on behalf of Shoham Engineering Co.] [...]

For the excavation work it is necessary to 'arrange' [make available] a $\mathrm{JCB}$ [tractor] and trucks/containers for excavating and removal of material [dirt]. In addition, one should be prepared for manual excavations by c. forty workers, of which ten will be workers from the [Israel Antiquities] Authority.

The work stages will be determined by Peter [Gendelman] after the trial excavations.

During stage A the excavation will reach the basement level.

(Document 2.23)

Let's attempt to provide some sense of order: the documents (2.20-2.21) show that the entire area for development encompassed ca. 600 square metres. However, the estimation for the excavation was 15 days with about 30 workers, hence 450 workdays in total (ten more workers would be the professional IAA team). The depth of 2 metres is the general goal of the excavation. Archaeologically, it is impossible to properly excavate 600 square metres (24 squares) to such a depth with so few workers and in such a short time. Compare, for example, the 148 workdays spent over 19 days for excavating barely 30 square metres to a similar depth at $\mathrm{Ha}-$ Liba Building (see Document 5.19). There, despite the help of additional volunteers, not all the area was cleared. Apparently, most of the Strauss Building area was cleared with a bulldozer, a procedure that the IAA usually refers to as exposure (hisuf). Exposure is done under inspection when antiquities are buried under layers that do not contain remains, such as sand dunes or modern fills. For some unknown reason, the IAA calls this procedure here 'exploratory excavations' (hafirot gishush). Was there so much worthless debris here? We cannot say. The entire Plaza was brutally 
lowered by ca. 1.5 metres in late 1967, using tractors, in order to stress the Western Wall. Hopefully, the IAA did not remove remains close to the surface only because they belonged to the 'late' Mughrabi Quarter.

The limited archaeological excavation began in July 2013, and with the help of the exposure probably reached the goal of 2 metres' depth (that is, the start line for the second stage, the 'basement excavation level'). During the second stage, in November 2013, the excavation was taken deeper, though only in a limited area intended for some necessary infrastructure.

The total estimation (for both stages) - 45 days with a few dozen workers is next to nothing for a site 'of exceptional significance' in the heart of Jerusalem's Old City, with some 20 metres of archaeological accumulation. Compare again the excavation at Ha-Liba Building, which was made in haste, but still lasted five years, reaching the depth of 'only' 6-7 metres (see Chapter 5). The IAA hardly scratched the surface in the Strauss Building. An additional season was carried by the IAA in 2015 to a somewhat greater depth. This, because (rather strangely) the electrical facility under the building required a much larger area than what was conceived in the original planning. Also, in order to preserve some remains, the IAA asked to move some infrastructure (water, sewage) outside the original plan, so now a new area was excavated. It was no real compensation for the waiving of a full excavation.

Concluding this section, we draw attention to one sentence:

The estimate [of the excavation budget of this stage - 299,731 NIS, based on other documents that we did not translate] has been prepared in such a way that allows the excavators to implement a large part of the sorting and initial processing of materials in the field.

(Document 2.22)

The initial sorting of finds from an excavation is usually done in the field. This concerns, essentially, potsherds. If the excavators reach a conclusion that certain baskets of pottery cannot be restored into vessels, they keep relatively few sherds for research and discard the rest. This has no relation to the work on the finds later, in order to preserve and document them, and issue a scientific report. What does the present author wish to say? Perhaps he has a special patent on how to save on expenses by throwing more staff in the field. More likely, he fears that his superiors will jump down his throat for allowing five days for shutting down the excavation ('Stage C', Document 2.21), as if this is a special favour to the excavators. We are not sure, because the language is barely legible. Part of the legacy of Shuka Dorfman is the corruption of the Hebrew language into a bureaucratic jargon (see Chapter 7).

We believe that the excavator, Peter Gendelman, is an able and professional archaeologist, and that he has performed this excavation in the best possible way. The issue is not his work, but the decisions of the management of the IAA and their unfortunate results. 


\subsection{The Antiquities are in the toilets}

In the absence of large-scale excavations, there are few remains that can be preserved in the Strauss Building. Some vaults were observed underneath the old building, but they have not been excavated. A report of a visit shows what potential finds the IAA abandoned: a hall built of Ashlar (Document 2.24; ashlar is a term for well-dressed stones that have smooth surfaces). According to this report this hall is so special that nothing like it 'has been found in Jerusalem.' The IAA established, as one of the conditions to the entrepreneur, that the antiquities in the Strauss Building would be open to the public (Documents 2.6-2.7; 1.8, section 6); but these vaults are inaccessible. In order for visitors to reach them, they would have to be dropped down through a narrow entrance with the aid of a 'frame, harness, and pulley' (Document 2.24).

All that remains, except these vaults, are higher and later walls that were part of the old building. These walls form part of the planned toilets. The IAA is preserving the toilets' walls:

\section{Subject: The Presentation of the Plan for the Strauss Building [...] The main points follow:}

Shachar Poni presented the subject.

Gai Teomi presented the specifications.

(Document 2.25)

The IAA minutes often leave something to be desired. Somebody 'presented the subject,' but the minutes do not state what was presented, despite the fact that this was the basis for the entire discussion.

The architect, Ada Karmi-Melamede, proposes using glass. She understands that the IAA wished to preserve and display the walls. No one asks what the value of preserving walls inside a toilet might be, or what educational message it gives to the public. Perhaps a mechanism of psychological compensation was at work here, rationalizing that since so much had been compromised by not excavating, something should be preserved - anything at all - never mind what. Or maybe what matters is not the cultural value of the remains, but the economic value of doing preservation work.

The idea of using glass raised concerns within the IAA about maintenance and vandalism:

Shuka Dorfman: How do we prevent vandalism? We have to take into account that the lighting causes green scum [...]

Ada Karmi-Melamede: Everywhere in the world they place a guard [...]

Chen Canari: We chose the appropriate and most durable solution against vandalism. In essence, we compromised about beauty in favour of [protection against] vandalism.

(sic, Document 2.25, emphasis added) 
The glass is not the problem. Guards will stand inside the toilets, as it is written, 'I have posted watchmen on your toilets, O Jerusalem' (Isaiah 62:6). Poni leads the discussion back to the toilets:

Shachar Poni: the idea is correct and this is the function [?]. I would have added a system that shows the exposed arches. We should contemplate how they can be shown and accessed.

Shuka Dorfman: the idea will cause us to lose [meaning: a reduction in the number of] toilet booths.

(Document 2.25)

Dorfman worries not for the antiquities, but for the toilets. When it becomes clear that the number of toilets cannot be reduced, the participants move to discuss the toilets' walls: 'Raanan Kislev: [...] the overall idea is right but it is important that the visitor understands the space. Putting the toilets here is problematic, but the direction [probably meaning the solution of using glass] is a good one' (Document 2.25).

The solution of Karmi-Melamede was not for the 'problematic' location of the toilets in relation to the old walls, but only to the preservation of the walls inside the toilets. According to Kislev, 'visitors' to the toilets need 'to understand the space.' Indeed, people in toilets must understand which stalls are free, whether paper and soap is available, where the hand dryers are (Figs. 2.4-2.5). What kind of person goes to a public toilet to look at the walls?

Amit Reem (the Jerusalem District Archaeologist, subordinate to Yuval Baruch) tried to propose an archaeological excavation, even a small one, since underneath the toilets were important antiquities, and research questions could only be answered by excavations:

Amit Reem: The plan is acceptable [...] a minor archaeological examination is important in order to reach the vaults that relate to the dating of the 'secret passage' [in the Western Wall Tunnels] [...] We need to consider that visitors will ask questions and, therefore, there needs to be an explanation based on knowledge.

(Document 2.25)

No one took this proposal seriously. They knew that Dorfman did not wish to excavate. The 'visitors' to the toilets will not ask anything about the vaults below the toilets, because they will not see them. In fact, it is not even known when the walls destined for preservation were built. The IAA assumes that these walls belong to a 'late stage' of the Mughrabi neighbourhood (see Document 2.2). If the walls are so late, why are they considered antiquities? The legal definition of 'antiquities' in Israel (Antiquities Law 1978) does not include objects later than 1700 CE (Avni 2000; Kletter and Sulimany 2016:192-193). Based on what knowledge did the IAA request a budget for conserving these walls? 

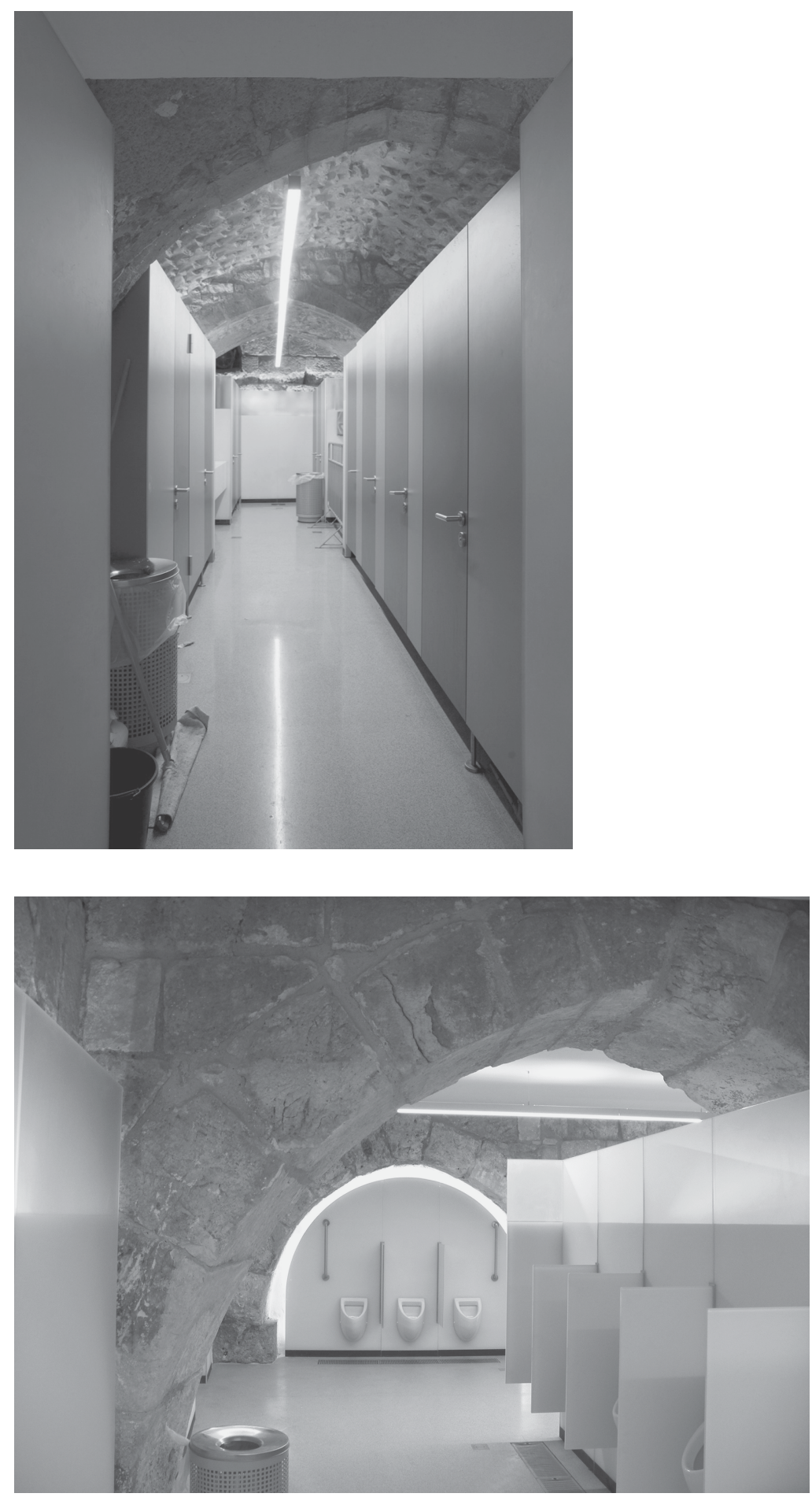

Figures 2.4-2.5 The Strauss Building toilets, 2015. Photos R. Kletter 
After all the work that the architects invested in planning the preservation of the walls in the toilets, Yuval Baruch proposed to simply plaster them over: 'Yuval Baruch: [...] I'm not ruling out the option of plastering over part of the walls, despite the fact that in the past they were not plastered. This helps with the maintenance of the area' (Document 2.25).

Is Dr. Baruch responsible for maintenance of toilets? Do not his words reveal that these walls are so unimportant to the IAA that it does not matter if they are plastered over and concealed? The IAA is trapped in 'conservation,' masking its abandonment of the essence - full salvage excavation and documentation of antiquities covered forever by construction. The meeting nearly ends, the participants discuss the timetable, it is important to the entrepreneur to put the toilets 'into use' by a certain date, so the architect proposes completing the work in one room first, as an example:

Yuval Baruch: That means a lot of conservation work.

Chen Canari: The conservation work will be completed soon.

Soli Eliav: We gave you the green light, and I'm asking that you proceed with the work as quickly as possible.

(Document 2.25)

Whether or not much work remained, the previous discussion remained inconclusive. Perhaps the conclusions are missing - we have often received partial documents. It was not Mr. Dorfman's custom to leave a discussion without concluding it. Perhaps it is fitting that this cacophony remained without conclusion.

\subsection{Summary}

In March of 2015 two Emek Shaveh researchers visited the Strauss Building (male) toilets (Fig. 2.6). In their opinion the toilets are designed in good taste and are clean. It could be that in the women's toilets there are lengthy inscriptions written on glass, but in the men's toilets one finds only the usual features of men's toilets. The researchers spent longer in the toilets than usual, during which time some 20 people 'visited' the site. They all used the toilets in a manner one would expect. No one asked questions about antiquities.

Professor Joseph Patrich (the Hebrew University, Jerusalem) labelled the waiving of the excavation in the Strauss Building a 'tragedy for generations to come.' He emphasized that very important remains could have been found there: 'This is an extremely sensitive area, and when I say sensitive, I mean that there is a high probability of finding important remains from our history,' (Patrich 2013; compare his words in Document 2.10).

Perhaps there were important finds for history in general, not only ours. But let us imagine what would have happened if a large-scale salvage excavation had taken place, and a find important to us had been discovered, say a Herodian structure. Would that, too, have been preserved in the toilets, and 


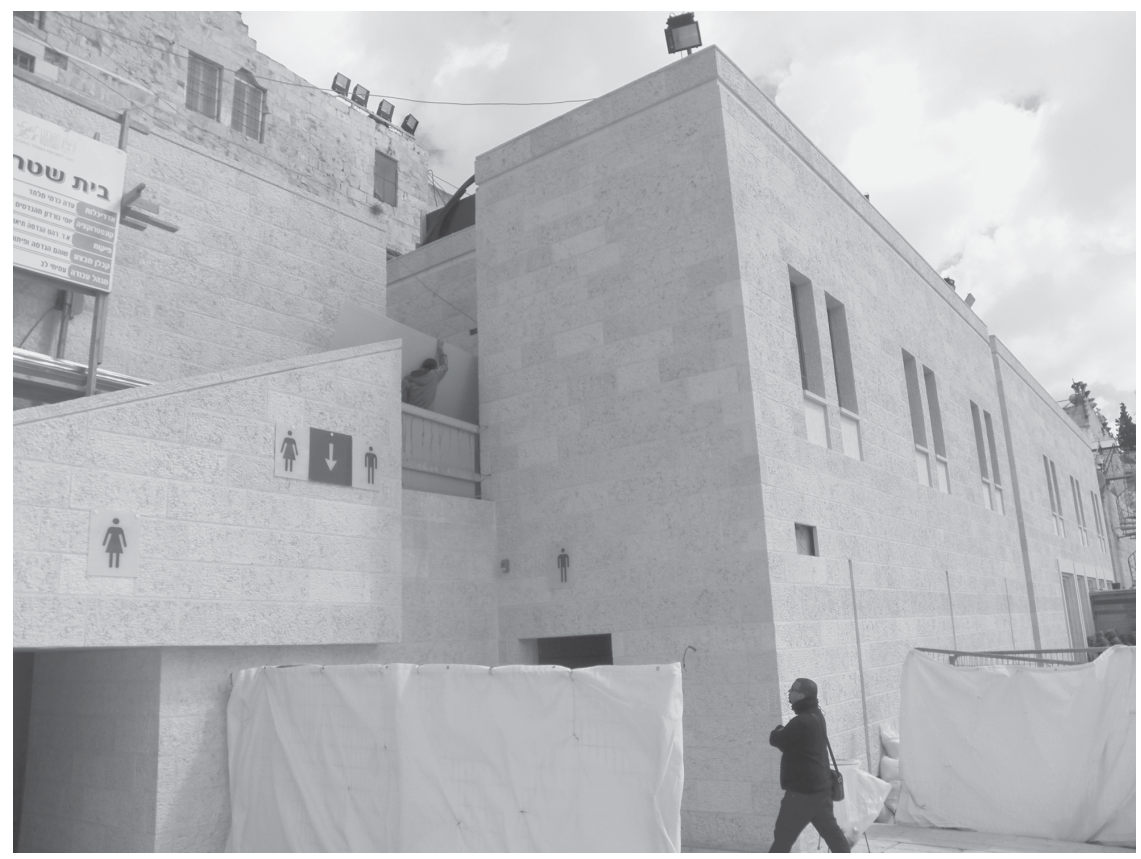

Figure 2.6 The Strauss Building after the extension (2015). Photo R. Kletter

would visitors have been expected to marvel at it as they flushed? Or would a more dignified solution have been found? The unpleasant odours emanating from the story of the Strauss Building project cannot be concealed by long glass walls.

We are not questioning whether there was a need to expand the Strauss Building or whether the architectural plan was acceptable. Nor do we question whether it was appropriate to establish toilets in this place. A site with millions of visitors per year must offer proper services, although other solutions were perhaps possible. From an archaeological perspective, the principal question is not why the IAA approved the building plan, but why it waived a comprehensive salvage excavation. This was a personal decision of the IAA Director, Shuka Dorfman. Its motives can only be guessed.

As far as we are aware, the Strauss Building is the only site in the world where following archaeological excavations and conservation, the antiquities are located inside active toilet facilities. They are preserved for 'visitors' who come to use the toilets, not to see antiquities. They are 'exhibited' without any explanatory signs or labels. Well, one cannot expect that the Western Wall Heritage Foundation and the IAA will tell the visitors something about the history of the Mughrabi Quarter. 
Dorfman and those supporting him have managed to create a unique archaeological site, the only one of its kind in the world. The Strauss Building toilets are their legacy.

\section{Notes}

1 The meetings of the Council generally take place in the IAA offices, and the IAA prepares the minutes. This explains why draft pages are included among IAA documents. However, a final protocol should exist too.

2 See the words of Oded Wiener, one of the architects of the Ha-Liba House, in Document 2.10. Wiener also tried to present the waived excavation as insignificant - ' 6 metres' - when in fact it concerned hundreds of metres.

3 Preliminary reports appear in 'Excavations and Surveys in Israel,' a bilingual internet journal of the IAA (www.hadashot-esi.org.il/about_eng.aspx). A first article on this excavation appeared in Hebrew elsewhere, Gendelman and Chalaf 2016.] 


\section{Wild Western Wall Tunnels - The Davidson Centre and the Archaeological Park}

\subsection{Introduction}

In the former pages (Chapter 2) we discussed a site at the northern edge of the Western Wall Plaza, the Strauss Building, and excavations - or rather waiving of excavations - before new construction. In this chapter we discuss the southern area of the Western Wall Plaza: the Archaeological Park and the Davidson Museum. The recent excavations in this area are called 'salvage excavations,' though there are no plans for any construction, except that required by the excavations themselves. Here we also meet for the first time in this book a typical sort of archaeological activity in East Jerusalem: digging tunnels from the side.

Following the destruction of the Mughrabi Quarter in 1967, the area south of the Mughrabi Bridge and between the southern wall of the Temple Mount and the City Wall became an archaeological excavation site (Benziman 1973). For about a decade, the area was excavated by Benjamin Mazar, and other scholars followed. Remains of structures were discovered from the early Islamic period (the 7th and 8th centuries CE) and from the Roman and Byzantine periods ( 7 th-1st century CE). Some remains were also found from earlier periods (see, among others, Yadin 1975; Mazar and Mazar 1989; Mazar and Ariel 2003; Mazar 2011; for criticisms see Abu el-Haj 2001:130 164; Sulimany 2013).

By the 1980s the wave of excavations has subsided, and the IAA, together with the 'East Jerusalem Development Company' (known by its initials as 'PAMI') ${ }^{1}$ started to develop this area for tourism. They created an open-air archaeological park and a museum - the Davidson Centre, established in 2001 (Figs. 3.1-3.2). It is a cleverly designed modern building, situated inside one of the administrative buildings of the Umayyad (7th century CE) period exposed by Benjamin Mazar. Most of the building is underground, so it does not hide the landscape. Such modesty does not seem to be the norm in more recent projects in the Plaza.

The Davidson Centre displays finds from the excavations at the site, highlighting the Second Temple period (particularly the 1st century CE) a street, shops, traces of the destruction of the city by the Romans - and 


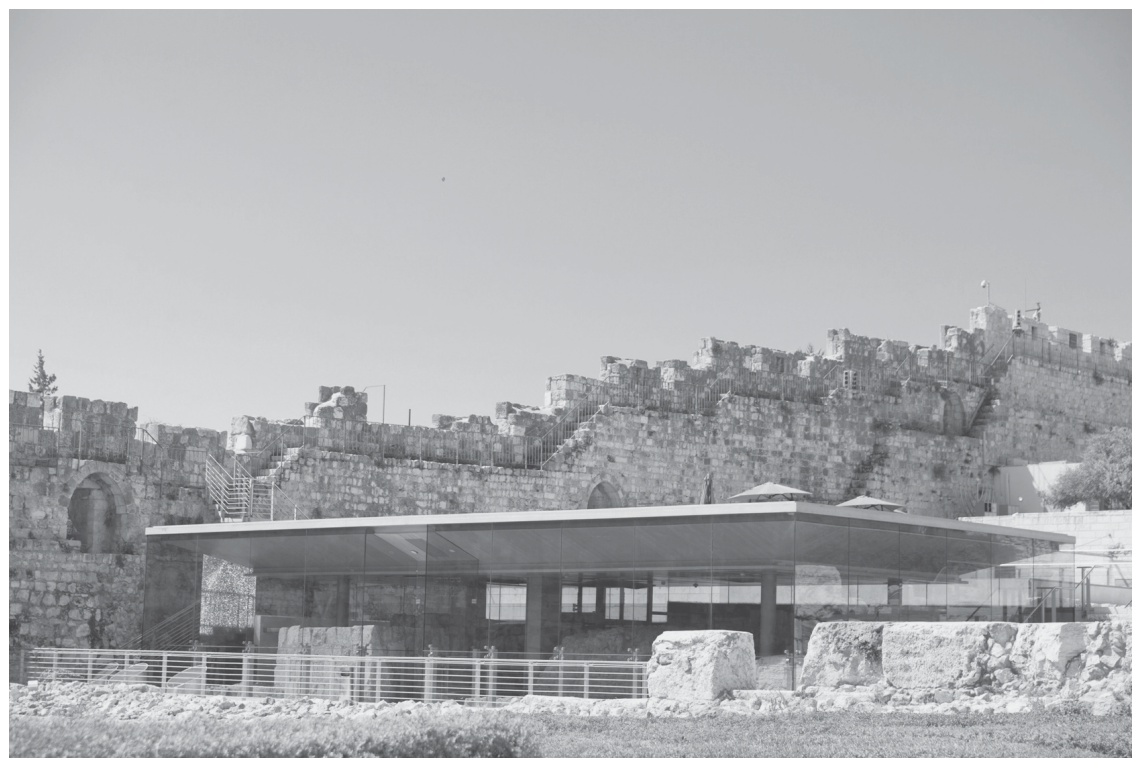

Figure 3.1 The Davidson Centre with the Old City Wall behind.

Photo Emek Shaveh

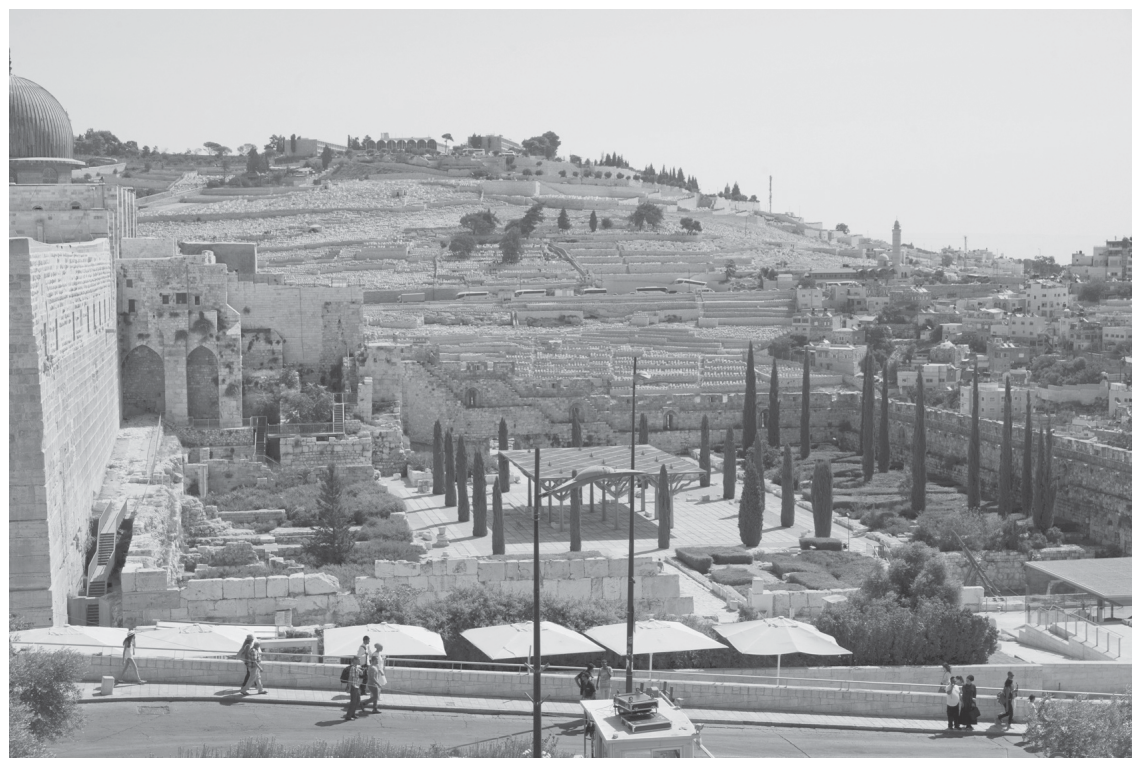

Figure 3.2 The SW Corner of the Temple Mount (left) and the edge of the Davidson Centre (right). The area in between is part of the Archaeological Park.

Photo Emek Shaveh 
the Umayyad period - a system of four administrative buildings. Visitors to the centre can watch a film that simulates the experience of a Jewish pilgrim who ascends the Temple Mount, buying a sheep for sacrifice. A computerized model offers the visitor an opportunity to walk through the Temple Mount during the Second Temple period. The Umayyad period is also represented by a computerized model. ${ }^{2}$

\subsection{The legal status of the Davidson Centre}

The Davidson Centre was built by the East Jerusalem Development Company (PAMI) and the IAA together. The IAA participated in the planning and secured funding for the centre; for several years it also participated in managing it. In a discussion of the Jerusalem District Planning Committee on July 2009, Deputy Director General of PAMI, Eli Shmuelian, noted that the Davidson Centre was the 'child' of the IAA: 'Mr. Davidson, who donated the [money for the] first Davidson Centre, he donated $\$ 5$ million to the previous centre, and prior to his death donated an additional $\$ 2.5$ million that are held by the IAA' (Planning Committee 2009c:84; Shmuelian confusingly speaks about the existing building as 'the first' or 'former' centre).

Incredibly, the Davidson Centre was built without a building permit. The IAA and PAMI 'assumed that these [construction] works are included within the definition of "archaeological excavations", a claim which is completely baseless" - thus wrote the Jerusalem Municipality Comptroller, Shlomit Rubin, after the Centre was already completed (Rubin 2005:1013).

The Government of Israel leased the area to another company, the 'Company for the Reconstruction and Development of the Jewish Quarter' (henceforward, JQDC), which, in turn, leased it to PAMI. However, a conflict ensued between these two government-owned companies regarding the operation of the Davidson Centre. According to PAMI, it did all the work of development, while the JQDC wanted to enjoy the fruits: 'only once development was in full swing and the centre was built did it [JQDC] try to assume control over the site without having to assume any financial burden' (Rubin 2005:1021).

PAMI and the IAA wanted to 'legalize' the centre by submitting a city building plan (no. 10294); but the original plan was lost and the process was delayed. In addition, for years, the Director General of the JQDC refused to sign the plan and in so doing prevented its approval. In late 2012 the plan was updated. Beyond legitimizing the centre, the entrepreneurs (IAA and PAMI) wished to expand it by 400 square metres into another Umayyad period building. They also asked for approval to demolish the entrance structure to the centre, in case this would be warranted by the comprehensive plan for the Western Wall Plaza (on this plan see Chapter 6).

Throughout this period, the dispute between the two governmental companies continued and finally came to court. In December 2013 the court decided that the PAMI Company must vacate the property and transfer ownership to the JQDC. At the same time, the JQDC sued the PAMI Company for 
rent arrears. The companies reached an agreement outside court, whereby the far right settler organization, El-Ad, would pay the debt of rent to the JQDC, in return for operating the Davidson Centre. An agreement from October 28, 2013, between El-Ad and the JQDC stated that the Davidson Centre is a 'continuation' of the El-Ad held Silwan/City of David site, and that El-Ad will run the Davidson Centre (and the Archaeological Park - the entrance is shared for both sites), collect entrance fees and develop the centre in cooperation with the IAA (State of Israel v. JQDC 2014). At the time the agreement was signed, the PAMI Company was headed by Naftali Bennett (then Education Minister and formerly Minister of the Economy and the Minister for Jerusalem and the Diaspora), and the JQDC was directed by Uri Ariel (then Minister of Agriculture and Rural Development, formerly Minister of Housing, and also chairman of the 'lobby for archaeology' in the Knesset [Parliament]). Both belonged to the same right-wing 'Jewish Home' faction (Hasson 2014a).

Once the agreement was publicized, criticism was voiced of the intention to place such a sensitive public site in the hands of a private organization. The Reform and Conservative Movements, as well as the 'Women of the Wall' movement, ${ }^{3}$ protested to the government that the agreement might jeopardize their ability to run suitable prayer sites. The State also appealed against the agreement and the court invalided it. The fundamental reasons for this were as follows:

A. The court decided that the El-Ad Organization does not hold any property rights at the Davidson Centre and the Archaeological Park.

B. The court learned that this is not a standard management agreement, such as the running of a food stand and cleaning services, but a deal that hands over control to El-Ad over marketing of the site, guiding visitors, managing development and excavation projects, using the El-Ad logo in reference to the site, etc.

C. The court ruled that: 'sites which carry unique archaeological and historic qualities, as well as cultural and religious significance must remain in the hands of a public authority, as a trustee of the public. The running of the site by a non-profit organization cannot guarantee the principle according to which a sensitive and important place such at the one in question will retain "all-Israeli and all-Jewish features and not allow sectorial activities of any kind""

(State of Israel v. JQDC 2014)

The Davidson Centre and the Archaeological Park together form an important antiquities site, which had been created to a large degree by the IAA. The IAA has, on more than one occasion, proudly taken credit for building the Davidson Centre and the Archaeological Park:

The Archaeological Park in Jerusalem was the IAA's flagship project during the first decade of its existence ... The IAA invested substantial sums of 
money in developing this impressive site to open it to the public and exhibit finds from the excavations. Also, the IAA built the Davidson Centre.

(Dvar Avar 15, 2010:17)

Such a site should remain public and the IAA should object to giving it to a private, right-wing settler organization.

\subsection{The IAA protects the Davidson Centre}

When the 'Women of the Wall' campaigned to be given a place for prayer, the IAA objected at first to allowing them to pray within the Archaeological Park. Jon Seligman, then Jerusalem Regional Archaeologist, wrote to the 'Women of the Wall' in June 2010:

\section{Subject: Conference on the subject of the Western Wall plaza}

I would like only to note that the Israel Antiquities Authority set up the archaeological park in Jerusalem in order to balance the presentation of the Western Wall legacy for the public, in a place where the subjects of Jerusalem and the Western Wall are explained by various religious organizations. The purpose of founding the park was to offer a secular, research-based perspective on the history of Jerusalem, and the Western Wall in particular, to the people of Israel in general and also to tourists from abroad. Unfortunately, the Supreme Court has obliged us to agree to prayer in the area of the park when in fact we felt, and still feel, that this may become a slippery slope whereby religious groups will take over the park piece by piece. This has been manifested today in the discussion when a representative on behalf of the Conservative Movement stated that in order to expand prayer in the park he is requesting to extend prayer times, to enable free access to the park for the purposes of prayer, and to set up permanent facilities for religious purposes. This undermines the Archaeological Park as a place where anyone can come to learn about the Western Wall, without being subject to religious coercion or religious features. Unfortunately, I foresee that these demands by the Conservative Movement will only increase in the next few years.

In my opinion, safeguarding the archaeological park as the only secular site in the vicinity of the Western Wall is also part of your responsibility as a lobbying group for pluralism [...]

Sincerely,

Jon Seligman

Jerusalem Region Archaeologist

(Document 3.1). ${ }^{4}$

Does the IAA safeguard the 'secular' nature of this area? It seems that in recent years the IAA protects the Davidson Centre and the Archaeological Park primarily from one type of religious group: moderate ones (the Reform 
and Conservative Movements and the 'Women of the Wall'). Following a Supreme Court ruling, a temporary 'floating' prayer podium (called Ezrat Yisrael) was installed in 2013 for the 'Women of the Wall' above part of the Archaeological Park. The 'Women of the Wall' supported the position that it is wrong to damage the Archaeological Park. They did not want to be separated from the Plaza, in what they called mockingly 'a sunbathing balcony' (Bender 2013; Shragai 2013; Lis and Etinger 2013). At some point, the Chairman of the Jewish Agency, Natan Sharansky, suggested expanding this podium. The IAA expressed strong objections; senior IAA representatives and other archaeologists protested against this initiative. The Jerusalem Regional Archaeologist, Dr. Yuval Baruch, said in an interview:

'We are dooming the most important site in the state,' he said. The Sharansky plan refers to 81 [square] metres at the expense of the archaeological site. This is the only place from which we can view the stone courses of the Western Wall [...] and the Herodian Street, and from where it is possible to experience the events of the destruction. The IAA objects to the plan, and designating such an extensive area [for prayer] will attract criticism from the entire archaeological community.

(Quoted in Bender 2013)

It seems that only the Western Wall, the Herodian Street and the "events of the destruction' should be safeguarded, while a variety of other periods and finds are not mentioned. There was no intention of 'dooming' the entire Archaeological Park, but only extending the prayer podium by 81 square metres. How could the IAA object to this plan, when it promoted the construction of a much larger roof (the Ha-Liba Building) for the Western Wall Heritage Foundation above the Roman Cardo (Chapter 5)? The IAA gave up ca. 360 square metres for the Western Wall Heritage Foundation at the Strauss Building (Chapter 2), so why can't it allow 81 square metres here?

In our view, 'burying' antiquities in a basement level disconnects them from their surroundings and detracts from their value. It should only be done when there is no other choice. At the Ha-Liba and Strauss buildings the IAA supported the entrepreneur, the Western Wall Heritage Foundation, a mainstream Jewish Orthodox body. The issue at stake is not religious. Rather, the Western Wall Heritage Foundation is endowed with generous budgets and political power, and the IAA has benefitted by serving as their contractor.

After the Government stepped in, the IAA removed the objections, and is now supporting the enlargement of the prayer podium (Levinson 2018).

\subsection{The IAA introduces El-Ad to the Davidson Centre through a sewage tunnel}

The El-Ad organization channelled many millions to the IAA for excavations in Silwan (Greenberg 2014). Then El-Ad expanded its activities to the Archaeological Park - with the encouragement of the IAA. 
For several years now, the IAA has been excavating an ancient underground drainage channel in the Archaeological Park with funding from ElAd. The main goal of the excavations is not archaeological, but touristic and political: to create a subterranean connection between Silwan and the Western Wall area (Hasson 2011; Mizrahi 2012:19, 23). The Western Wall attracts millions of visitors a year. Even if only some were to arrive there through this tunnel, at an extra cost, it would fill the coffers of El-Ad. More important is the political goal: to link these sites together in the public mind in order to blur any distinction between Israeli and Palestinian Jerusalem. Most Israelis do not think of a visit to East Jerusalem as an attraction. The Western Wall is an exception, because it is strongly identified as a sacred and national Jewish/Israeli site. It can be reached without crossing densely populated Arab neighbourhoods (either through the Jewish Quarter, or by a bus that stops at the nearby Dung Gate). Were people to pass in subterranean tunnels, visiting only fenced-off sites empty of Palestinians (like the Silwan/City of David site held by El-Ad), they could avoid experiencing Jerusalem's divided reality.

The official website of the IAA includes several reports about conservation of sites, which were excavated for El-Ad. A page discussing conservation in the City of David conducted for El-Ad in 2010-2011 contains the following text:

\section{Determining the Significance of the Site}

[...] Here the Bible was sealed, the cultural-religious Book of Books of the Jewish People. Following 1967, with the development of archaeological research and the discovery of tangible finds which substantiate the scriptures, the 'City of David' became an important component in [building] the sense of a link between the present-day Israeli experience and the distant Biblical past.

The finds from excavations in 'area $G$ ' at the centre of the site offer tangible evidence that the Babylonians destroyed the city in the year 586 BCE. This destruction and the destruction of the Second Temple were events that were deeply imprinted in the collective memory of diaspora Jewry and were foundational events in the shaping of the nation in Israel. Signet rings were discovered in 'area G' and in the area of the 'visitors' centre' $[. .$.$] these finds link the present-day Israeli experience to the time$ of the Bible, and the Jewish people to Jerusalem.

\section{The religious perspective}

1. Judaism - the site is associated with King David who unified the tribes of Israel, declared his seat in Jerusalem and crowned it the capital of the kingdom. The figure of King David has followed the people of Israel throughout history. He represents 'repentance' [for his sin with Bath Sheba, 2 Samuel 12], the writing of the Book of Psalms and the purchasing of the 'Arunah Threshing Floor', the Temple Mount, on top of which the Temple was built. 
2. Christianity - The Christians call the Bible the 'Old Testament'. They consider it scripture, and therefore any tangible connection to the 'Old Testament' carries [for them] deep religious significance. According to the 'New Testament', Jesus was a descendant of the House of David'

(www.iaa-conservation.org.i1/Projects_Item_heb. asp?subject_id=10\&site_id=3\&id=127).

In this description, there is no mention of Islam; no reference is made to periods such as the Islamic or Byzantine, and to their treasures, and the entire site is attributed to King David and the people of Israel (cf. Mizrahi and Veeder 2013). The Jewish religious perspective is emphasized and the Christians are mentioned favourably. In Islam, too, the Old Testament is important, as is the figure of King David (prophet, king, judge and more). Yet, Islam and Islamic remains are not mentioned in this text.

The IAA Conservation Department has taken a text written by the ElAd organization, or based on El-Ad's ideology, ignoring the fact that this is propaganda and not a scientific text. By presenting a text like this on the official website, the IAA blurs the boundaries between a private organization and a government agency, propaganda and science.

Ostensibly the excavations in the sewage tunnel have been completed by January 2011; yet excavations continued northwards. In 2012 the Director of IAA, Shuka Dorfman, spoke about transferring the responsibility for these excavations:

\section{The Sewage Tunnel}

Yuval Baruch: The issue is attended to by the Western Wall Rabbi.

Soli Eliav [Director General of the Western Wall Heritage Foundation]: We will excavate there.

Shuka Dorfman: The 'stick must be transferred' to the Western Wall Heritage Foundation.

Decision: It is the responsibility of the Western Wall Heritage Foundation to initiate a meeting with David Be'eri [Director General of El-Ad] and Yuval Baruch.

(Document 3.2).

El-Ad had already succeeded in creating a link with the Archaeological Park; the rest of the route, underneath the Mughrabi Bridge towards the Western Wall Tunnels, would be funded by the Western Wall Heritage Foundation:

Yuval Baruch: We completed the excavation in the area of the El-Ad Foundation. The question is what to do now.

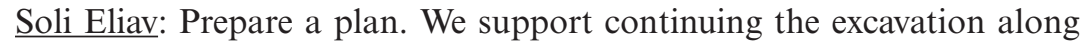
the current route. It is important to us that it will link up with the Western Wall Tunnels. 
Yuval Baruch: We are removing the soil [from the sewage tunnel] out at the Givati Parking Lot. Everything is in place [...] It is possible to continue excavating in a south-north direction. [...]

Soli Eliav: We are interested in a physical connection to the [Western Wall] Tunnels.

(Document 3.3, emphases added)

The 'area' of El-Ad, according to the IAA, reaches the Archaeological Park (Fig. 3.3). With excavation completed, it was time to begin conservation and El-Ad was paying for this. But the documents suggest that in addition El-Ad continued to make substantial payments to the IAA for excavating the sewage tunnel in May 2013. For this particular section the sum of 335,468 NIS was mentioned (Document 3.4). The documents show that the IAA is on very familiar terms with El-Ad:

Yuval Baruch: The El-Ad Foundation signed an agreement with Arie Rahamimoff, to hire him as the architect of the sewage tunnel project stretching from Hezekiah's Pool to the Mughrabi Bridge [...]

Raanan Kislev [Head of conservation, IAA]: [...] as of today, architectural planning should be discussed with the El-Ad Foundation [...] and it is necessary to take an operative decision on how to begin the work. Now we must complete the planning for the whole length of the tunnel [...]

Shuka Dorfman summed up the discussion:

2. The IAA is not replacing El-Ad in managing [the site], but it bears a responsibility as the organization that excavated the site.

(Document 3.5)

According to Dorfman, the landlord is El-Ad and the IAA is just a subcontractor, although the funding for the Davidson Centre was secured by the IAA. Dorfman's position is shared by Uzi Dahari, Deputy Director of the IAA:

To tell you that I like the fact that the El-Ad Foundation is funding the project [at Silwan/Givati Parking Lot]? No, I do not. But El-Ad is like any other entrepreneur, it is the landlord and the excavation is a scientific excavation [...] we do not involve ourselves in politics.

(Quoted in Hasson 2011)

Since when does El-Ad own the Archaeological Park and the Davidson Centre? The IAA documents hardly discuss a larger idea, a 'vision' that would give direction to the IAA's activities in the Western Wall area. There are no discussions in the IAA about the educational, scientific or ideological content that would be offered at the sites once the excavation and conservation works are completed. In a meeting from April 2012, only representatives of El-Ad mention content: 
Rafi Ben-Basat [formerly operations officer for the West Bank 'Yesha' Council and Deputy Chairman of the Binyamin Area Council]: We chose an architect who will plan the tunnel and its environs [...] Arie Rahamimoff [...].

Yehuda Mali [one of the heads of El-Ad]: Now we must think about adding content and what would be the experience of the visitor in the tunnel.

(Document 3.6)

The entrepreneur is interested in content that would serve its ideology. It is easy to guess what the content and the visitor's experience in the sewage tunnel would look like. The IAA website had a link to a publicity film about the El-Ad tunnels, starring an archaeologist who worked for the IAA at that time, Eli Shukron:

'I am now ascending the first step on my way to the Temple,' says Shukron (who directed the excavations together with Ronny Reich) in the film. 'From here they began to ascend to the Temple, very slowly. One doesn't run to the Temple, one walks very slowly. I feel a great deal of excitement because this is the first time I can actually touch the destruction.

(Quoted in Hasson 2011)

No one walked to the Temple inside a sewage tunnel, but the significance is clear: this is where the ascension to the Temple Mount begins, in the present tense. Perhaps at present these are only a few voices within the IAA, but they appeal to a growing messianic, national-religious public.

\subsection{The IAA and El-Ad in a tunnel along the Western Wall}

The sewage tunnel was not the end. In a much more crude alliance the IAA and El-Ad are excavating together a new tunnel alongside the southern part of the Western Wall. The aims of this excavation, begun in early 2011, are not clear. The intention, as far as we can understand, is to excavate alongside the Wall - that is, to simply expose the bottom layers of the Western Wall. The IAA has handed us almost no documentation regarding this excavation. In the first published report on this project, the excavators 'forgot' to mention the entrepreneur (Shukron and Reich 2012; in such IAA reports the entrepreneur is always mentioned). It is, of course, El-Ad. The excavation lasted from December 2013 to March 2014 (excavation permits A6971, A7016; see Hagbi and Uziel 2015).

Though defined as 'salvage excavations,' these were not salvage excavations, as there was no intention of constructing anything in this area. No urgent reason existed for excavating this area, it did not face danger of any kind. These were planned excavations of a very particular kind. The initiation came not from El-Ad, but from the IAA: 
Shuka [Dorfman] hello,

The following is my opinion regarding your request to complete the excavations along the base of the Western Wall as far as its southwestern corner:

1. The excavations are possible from an engineering point of view, and carry considerable scientific interest. [...] It is also an opportunity to consider an excavation alongside some part of the [Temple Mount] southern wall, but this is a matter for a more serious conversation. $[\ldots]$ Yuval [Baruch].

(Document 3.7, emphases added)

El-Ad did not impose the excavations of a new tunnel along the Western Wall upon the IAA. The IAA itself initiated these excavations (and even contemplates starting new ones south of the Temple Mount. Excavating along walls is the opposite of modern, proper archaeological methods). ElAd is happy to pay, since these excavations promote its political aims. After the excavation is completed, El-Ad would decide the contents, and guides of El-Ad will lead visitors from the Silwan/City of David site to the Western Wall. On the way, visitors will hear only what El-Ad wants them to hear.

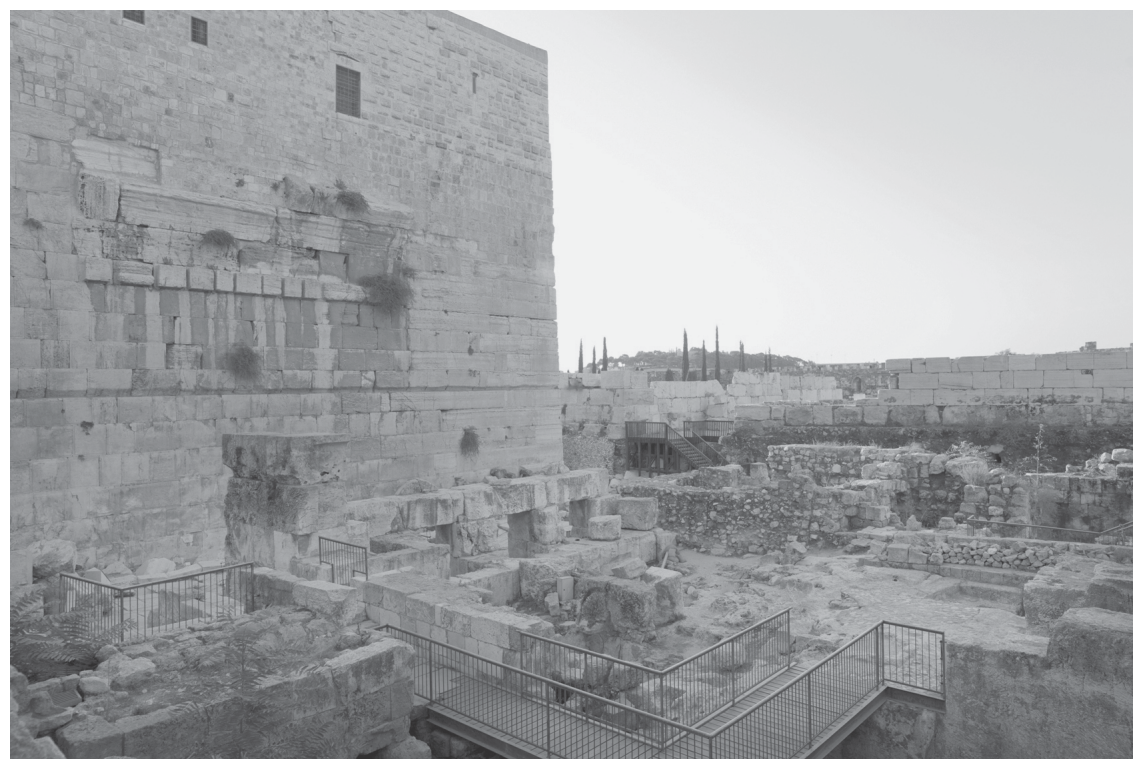

Figure 3.3 The Archaeological Park at the foot of the Western Wall, with the remains of Wilson's Arch.

Photo Emek Shaveh 


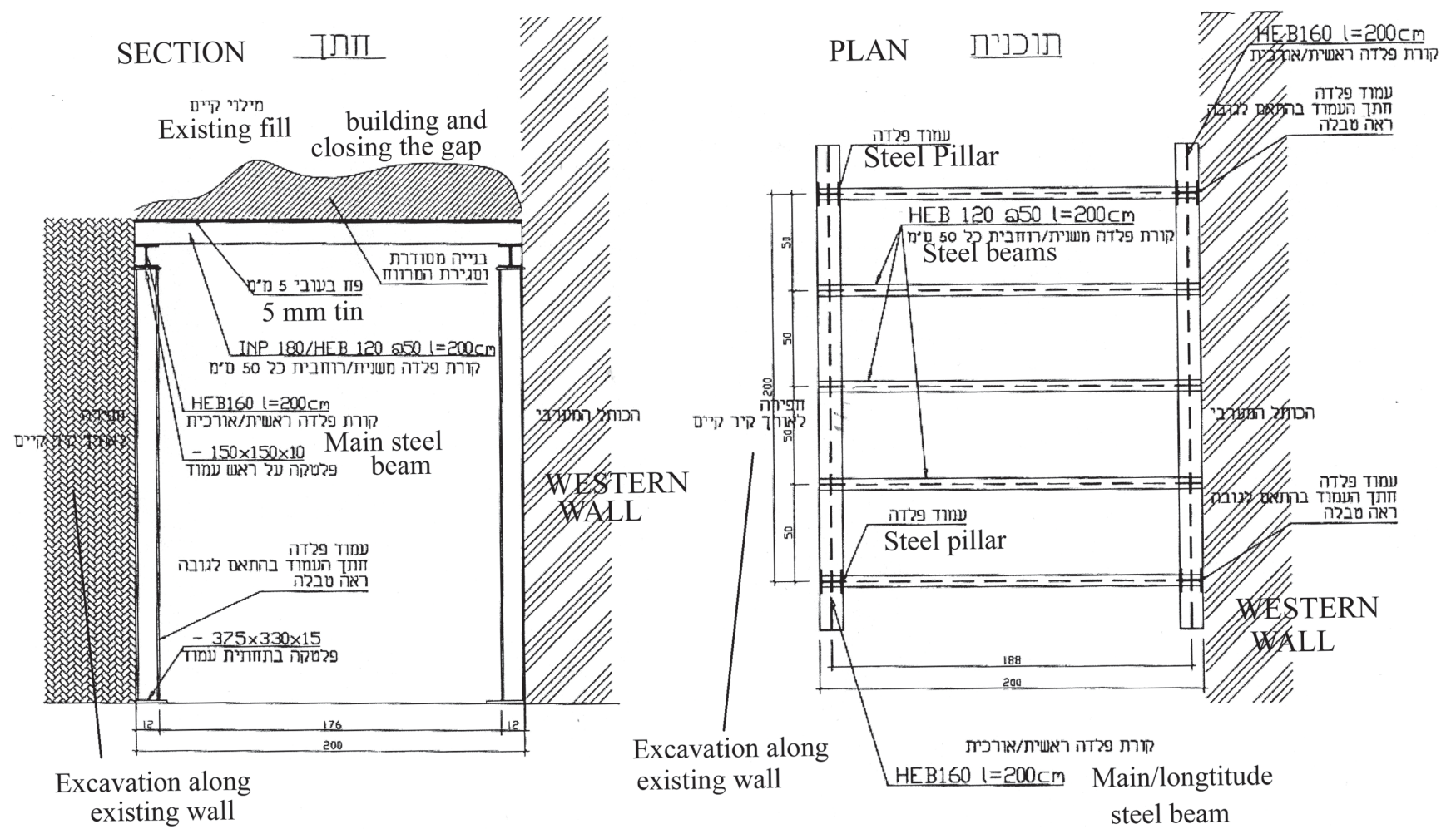

Figure 3.4 Plan of the supports for the tunnel along the Western Wall.

After IAA Document 3.8 


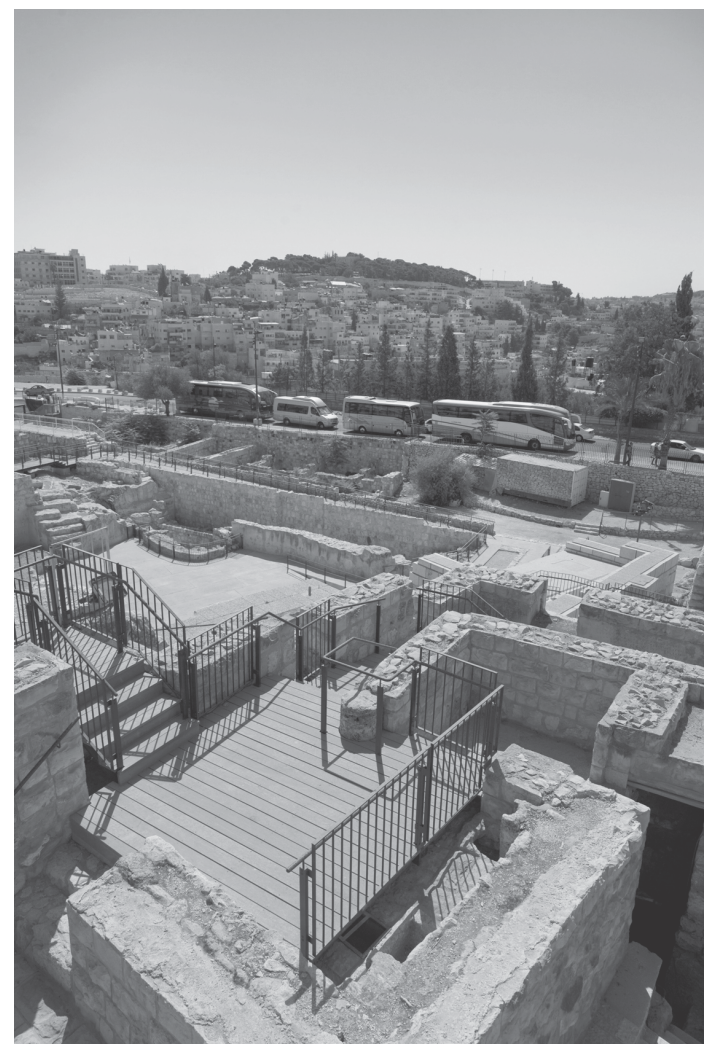

Figure 3.5 The 'Ritual Baths Route' near the southern wall of the Temple Mount. Photo Emek Shaveh

Apparently, in the opinion of the IAA, neither they nor the Government of Israel own the antiquities, but El-Ad, even if the antiquities in this case include the Western Wall.

The 'salvage excavations' of the IAA/El-Ad along the Western Wall involve digging in tunnels from the side - despite the fact that no one has forced the IAA to use this inappropriate technique here. Since it is agreed by everyone that this is an archaeological site of great importance, it ought to be excavated by leading researchers in the field with a proven record of publishing final excavation reports. They should work in a scientific way, that is, from top to bottom, distinguishing the stratigraphy (separating the various layers) slowly and meticulously. There are technologies today that allow researchers to document and dismantle remains, and to reconstruct them after the completion of the excavation. Therefore, there is no justification for digging tunnels at the foot of the Western Wall. 
Yet the IAA breached a new tunnel, an unscientific and destructive act. Safety guidelines for this project were laid out by a conservation engineer, Ofer Cohen. This is not so much an archaeological dig as it is a work of construction (Fig. 3.4). It includes breaching, digging horizontally and building a massive support system: steel pillars, steel sheets, welding, filling with construction, pouring grout (a liquid type of cement). Although the excavation is taking place alongside the Western Wall, the conservation engineer writes on the plans 'City of David.' We do not know why this is the case. Perhaps he is updating plans for tunnels breached previously for El-Ad in Silwan; or, from his point of view, Silwan and the Western Wall are one and the same (Document 3.8). Need we mention that the IAA and El-Ad have no building permit for this work? Apparently, the Western Wall is El-Ad's private property, so they can do as they please there.

In response to claims that they are digging the sewage tunnel in an unscientific and destructive manner, the IAA answers that it merely clears soil and rockslide from the tunnel, without cutting new archaeological layers on the way. However, the fill inside the tunnel is also an archaeological layer - perhaps more than one layer. Possibly remains from later periods were deposited inside the tunnel, or even built into it when it was no longer in use. Working from the side cuts, and destroys, such remains (whereas a top-down excavation would document them properly).

There is no sewage tunnel along the Western Wall. The IAA breached towards the Western Wall in two old tunnels that had been previously excavated by Charles Warren in the 19th Century (Wilson 1865:75; Warren and Conder 1884:178), but then turned sideways and breached a new tunnel alongside the Western Wall: 'Our excavation linked up these two tunnels alongside the Western Wall - and created in fact a new tunnel 2 metres wide and 3.5 metres high' (Shukron and Reich 2012:222).

This is not an acceptable archaeological excavation, but a harmful dig that destroys the layers of soil, structures and finds along the way. First, a massive steel construction is forced in, fracturing and destroying antiquities. Then, when excavating from the side, the fill is extracted leaving no possibility for examining and properly documenting the layers. This is not archaeology, but the destruction of archaeology.

\subsection{Additional projects: all the remains are 'ours'}

The IAA/El-Ad tunnelling in the sewage tunnel and along the Western Wall are not the only projects conducted in and around the Archaeological Park in recent years.

In 2011-2012 conservation works were conducted along the so-called 'Trail of Ritual Baths' south of the Temple Mount, in the Ophel area (Fig. 3.5). This trail emphasizes only the remains associated with 'Jewish periods,' despite the fact that the area contains many remains from other periods, such as 
the Byzantine (buildings and a wall), Umayyad (administration buildings, one of them a palace according to Benjamin Mazar) and Fatimid (a wall above the Byzantine wall) periods. There is also a massive medieval tower blocking most of the Hulda Gates. To the east, the 'Site of the Ophel Walls' was opened to the public recently, displaying remains from the First Temple period (Iron Age), ignoring remains from other periods. In addition, excavations and conservation works have begun near the Bab a-Rahma cemetery (on the east side of the Temple Mount), and there too the aim is most probably to uncover and emphasize Jewish remains (Mizrahi 2012:17-21). In September 2012 the IAA made a statement regarding the discovery of a cistern from the period of the Kingdom of Judah in the Ophel, although it cannot be dated with certainty (Mizrahi 2013:15).

\subsection{Summary}

In the 'wild west' tunnel-archaeology of East Jerusalem, double standards are the norm. What is considered an excellent solution for preserving and saving antiquities (covering them by the Ha-Liba Building, Chapter 5) is considered to be devastation by religious bodies in the case of the Archaeological Park. The El-Ad organization is the landowner of the underground tunnels in the Archaeological Park and along the Western Wall, but the residents of the Muslim Quarter do not own the ground underneath their own homes (Chapter 4).

When the agreement about transferring the control over the Archaeological Park and the Davidson Centre to El-Ad was discussed in court, the IAA's voice was not heard. The silence has aided El-Ad's cause. Statements about objectivity and scientific excavations are meaningless when the activities concern grant legitimacy to extremist settlers' organizations like El-Ad and promote an Apartheid-like narrative.

The Davidson Centre and the Archaeological Park, like all other archaeological sites in Jerusalem, should exhibit the remains that are discovered from all the periods and from all the cultures of the city's long history. They belong to the public and not to 'entrepreneurs.'

This story is not over, for despite the court's ruling, allegedly the Government has recently reached a 'compromise agreement' with El-Ad. It will allow El-Ad to operate the Davidson Centre in the near future (Hasson 2017a).

\section{Notes}

1 See www.pami.co.il/he/ (Hebrew). The company was established in 1966 with the aim of developing two border neighbourhoods in (West) Jerusalem. Since the 1970s it became active also in East Jerusalem (Mizrahi 2008).

2 http://archpark.org.il. Strich (2013:153, 155-157) probably visited the Park before the Umayyad model was installed; he notes the selectivity in that the Second Temple period is stressed while Islamic periods are downplayed. 


\section{Wild Western Wall Tunnels}

3 The 'Women of the Wall' is a feminist movement established in 1988. Their wish is to be allowed to pray freely in the Plaza, not according to the Orthodox rules (e.g., to put a Talith and read the Bible aloud, acts which only the men perform in Orthodox communities) (Chesler and Haut 2003; Jobani and Perez 2017).

4 As far as we know, no other document states that the Davidson Centre and the Archaeological Park have a secular purpose as a sort of balance to the Western Wall Tunnels. 


\section{A museum for Jewish prayer in a Mamluk bathhouse - the Ohel Yitzhak Synagogue}

\subsection{Ohel Yitzhak Synagogue and building plan 5480}

Ohel Yitzhak is a synagogue in the Muslim Quarter, on Ha-Gai ('the valley') Street, north of the Western Wall Plaza. The synagogue was established at the beginning of the 20th century, on land purchased from an Arab family. During the Arab revolt of 1936 is was deserted, and after 1948 destroyed by the Jordanians. Between 1993 and 2008 it was owned by the Moskowitz family. Irwin Moskowitz (1928-2016), an American legal-gambling magnate, funded much of the settlement activity in East Jerusalem and the Old City (Blumenthal 2012; McCoy 2013). During the 1990s, the building was used by the Ateret Cohanim Yeshiva (an extremist body of religious settlers, see Shragai 1995:191-213; Rapoport 2005a). In 2001, a Municipal building plan (No. 5840) for the restoration of the synagogue was approved; it was issued to the Everest Foundation (owned by the Moskowitz family), on an area of 417 square metres along Ha-Gai Street. The IAA conducted archaeological excavations there in 2004-2005, under the direction of Haim Barbé and Tawfiq Da'adli, in two areas. The main find was a large Mamluk period (14th century CE) bathhouse (Barbé and Da'adli 2007; 2011).

\subsection{Area $\mathrm{C}$ and the archaeological museum}

The small-scale IAA excavations of 2004-2005 also documented a large (10.3 x $27.8 \mathrm{~m}$ ) underground vaulted hall, of which only a small part was exposed. According to the report (Avner and De'adle 2009), the hall is found beneath Ohel Yitzhak, but this is inaccurate: it is located in the area east of the synagogue, which is neither owned by the synagogue nor situated in the bounds of Municipal building plan 5480 (Figs. 4.1-4.2). This is 'Area C' - ostensibly a direct continuation of the synagogue excavations (Areas A-B); but in fact, a separate area. The designation 'Area C' was given to it long after the 2004 2005 excavations.

Until 2008, the Ohel Yitzhak archaeological project was managed by Buki Boaz on Moskowitz's behalf, in conjunction with Ateret Cohanim. The IAA helped Ateret Cohanim find a donor to finance the development of the site: 
Re: Ohel Yitzhak - Donor File

1. Following the request of the Ateret Cohanim organization, the Conservation Department has started preparing a 'donor file' on the matter of Ohel Yitzhak.

(Document 4.1, emphasis added)

At the end of 2006, a plan was submitted for the continuation of the excavations:

A. Area A will be excavated everywhere possible to the [layer of the] Second Temple Period [layer].

B. Area B will be excavated to the floor of the Cardo [the street dated to the Roman Period]

C. Area $\mathrm{C}$ will be excavated at certain points that need to be completed, according to the considerations of the excavating archaeologist.

(Document 4.2, submitted by the entrepreneur after consultation with the excavating archaeologist)

The plan sets as a goal the Cardo Street and 'our' Second Temple layer, so the intention is to cut deep through all the later layers at the site. In a following meeting the entrepreneur (Everest Foundation of the Moskowitz Family) declared the intention of establishing a museum:

3. The entrepreneur intends to establish a museum for the history of Jerusalem and its archaeology beneath the synagogue. [...]

5. The entrepreneur intends to preserve the ancient layers beneath a transparent floor; its level will be determined after the excavation work has been completed.

(Document 4.3)

Before the ink on this document had time to dry, the entrepreneur decided 'to change some of the agreements that had been made,' but not his commitment to the museum:

1. The intention of the entrepreneur to change some of the agreements reached on 25/12/06 was presented. [...]

3. The entrepreneur has again repeated his view [sic, should be: his wish] to develop the structure as an open museum.

4. The IAA will give the entrepreneur an estimate for the archaeological excavations, including the cost of the workers. [With salvage excavations the developers may ask the IAA to bring workers, or hire workers independently. This does not refer, of course, to professional excavation staff, but to manual labourers]. 

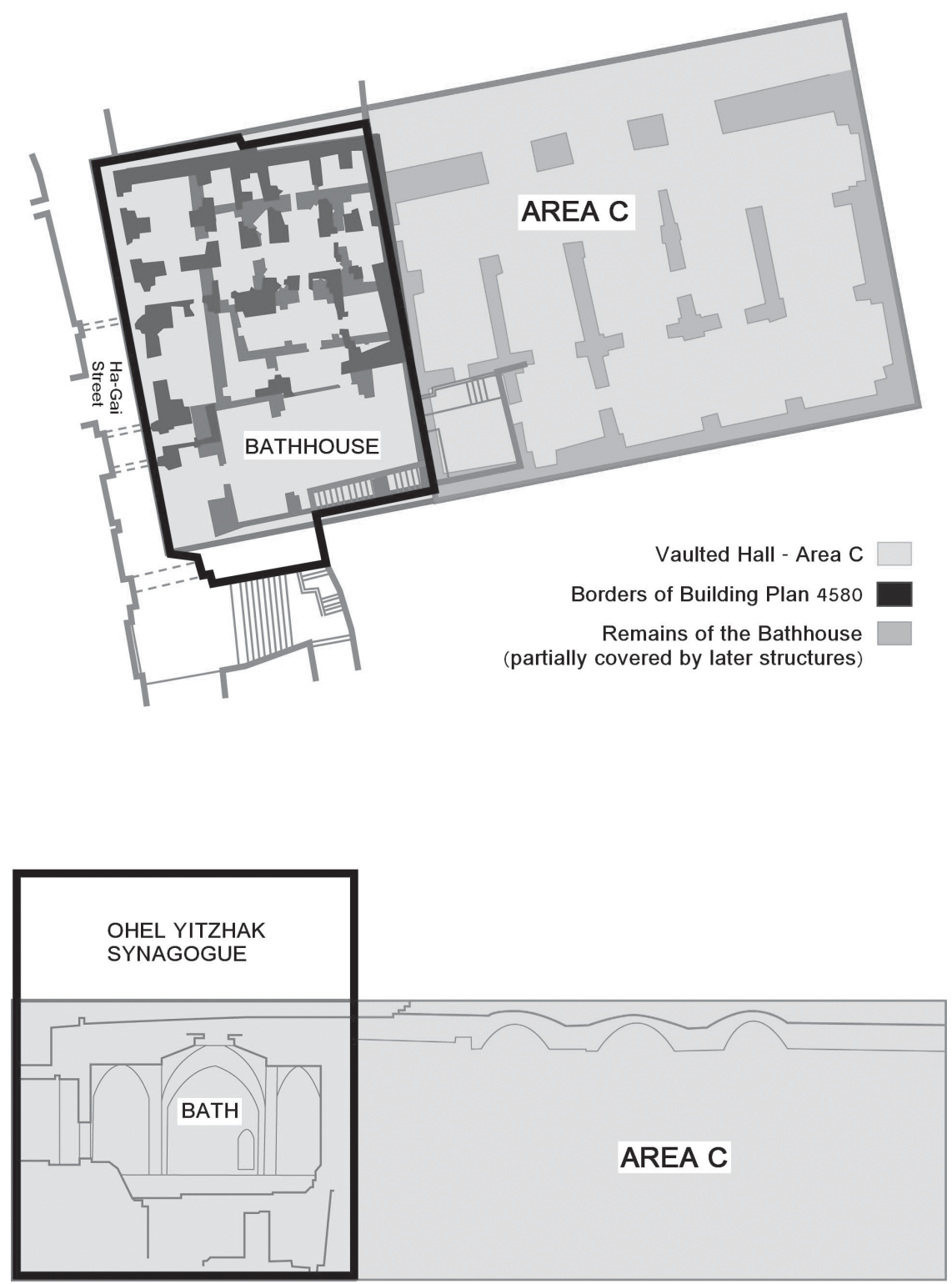

Figure 4.1 Map (top) and schematic section (bottom) of the Ohel Yitzhak Synagogue, Mamluk bathhouse and the vaulted hall (Area C). Border of building plan 5480 shown in thick black line.

Prepared by Slava Pirski for Emek Shaveh, based on the IAA documents 


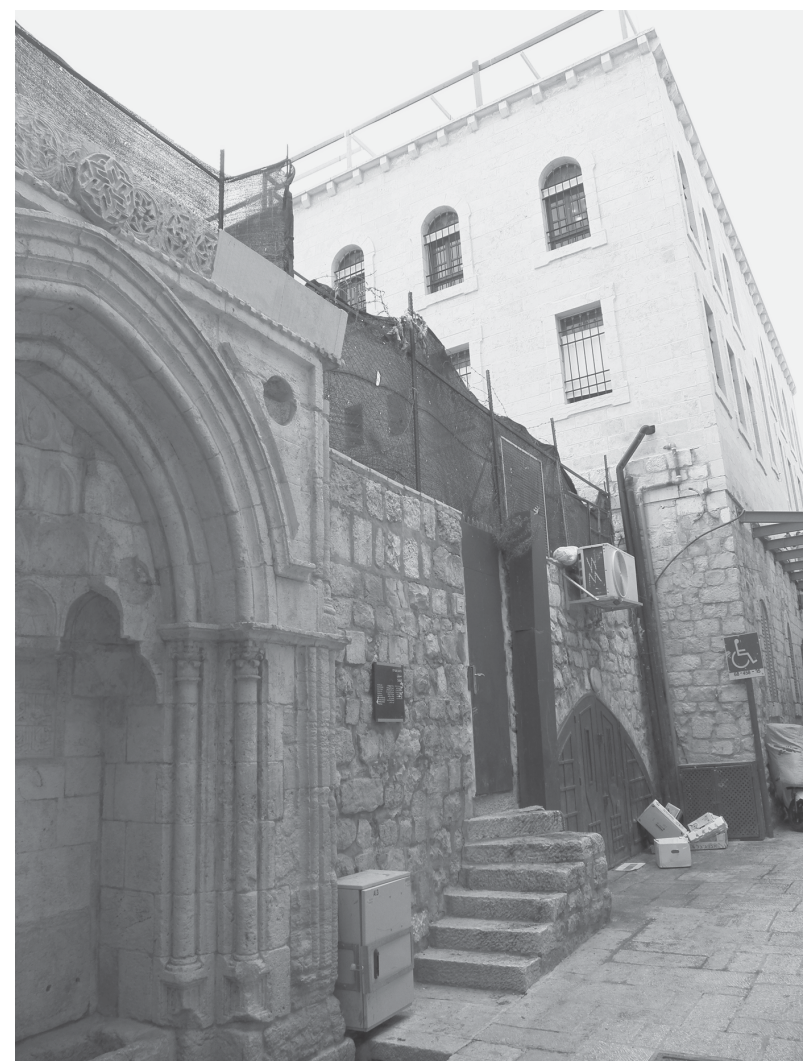

Figure 4.2 Ohel Yitzhak Synagogue after rebuilding (the tall white building,). To the left, private homes in the Muslim Quarter.

Photo R. Kletter

5. The estimate and the area for excavations was [read 'were'] determined in keeping with the intention of the developer to present remains from various periods there and [these] are not rescue excavations. [...]

8. The IAA would like to begin preparing a preliminary program for the preservation and development of the site.

(Document 4.4, emphasis added)

Building plan 5480 was approved solely for rebuilding the synagogue; it made no allowance for development and use of the underground areas. The IAA itself determined (Document 4.4) that the continuation of the excavation was not a salvage excavation. Why was the proper procedure not implemented? Salvage excavations are performed before development, and the excavator receives an excavation permit, issued by the IAA after an internal 
procedure. An excavation by research institutes (sometimes called 'initiated excavation,' Hebrew hafirot yezumot) is conducted for research, and the excavators receive an excavation license from the IAA, after recommendation by the Archaeological Council (the advisory council to the IAA, composed of respected representatives of the IAA, the universities, the Government and the public). Licensed excavators are free to determine the scale, duration and depth of their excavation. Perhaps the universities in Israel would have refused to work with such an entrepreneur; but they were never asked about it. By treating this excavation as a salvage operation, the IAA has kept it to itself. Dorfman (see Document 4.5) said that the Hebrew University was not interested, but he did not speak with other universities. Cunningly, he presented the project to the Hebrew University as a salvage excavation (at that time the Hebrew University was not interested in performing salvage excavations). The temptation for the IAA was high, because entrepreneurs usually develop an area for their own needs - whether housing, industry, transportation and so on. Here the entrepreneur was ready to finance a deep - hence, an expensive excavation, and also establish a museum for archaeology and history! Such an opportunity the IAA could not relinquish. Never mind that there was no necessity to excavate (it was not 'salvage' work) and that the building permit did not allow the creation of additional, underground spaces. It remains to be seen who led whom by the nose: the IAA or the entrepreneur?

The IAA issued an assessment for a preliminary programme for 'development and display' of the Ohel Yitzhak compound in early January 2007. In March 2007, the project director on behalf of the entrepreneur, Buki Boaz, met with IAA Director Shuka Dorfman. Mr. Boaz confirmed that the entrepreneur plans to establish a museum:

There is no connection between Ohel Yitzhak and Ateret Cohanim. Matti Dan [head of Ateret Cohanim] has various different interests than those of the Moskowitz family, which owns the land. We want to continue the excavations in the portion beneath the synagogue [...,] to plan a glass floor, and to establish a museum open to the general public. In the long term, we would want to excavate the eastern [vaults] and then establish an active museum for the general public. The Moskowitz family will finance all the excavations.

(Document 4.5)

Yuval Baruch, at that time the Jerusalem District Archaeologist, supported the request, and explained the division between the synagogue and the archaeological level: 'Archaeological requirements were defined for the excavation. The excavation was estimated to be medium to small, not including the excavation in the eastern spaces. Jon Seligman approved the excavation in the eastern spaces' (Document 4.5, emphasis added).

The words are perplexing: at this stage, no permit had been issued for the new excavations. Baruch's words refer to the past: the soundings of 2004-2005. 
Apparently, something was amiss, and Baruch explains that he was not responsible. Though the document is partial (a second page is missing), we can deduce the problem. The area east of the synagogue did not belong to the entrepreneur. Approving an excavation there was a mistake: an unnecessary, not to say illegal, act.

As early as 2005 the media reported that Ateret Cohanim had excavated 20 metres east of the synagogue, and was planning to link these excavations with the Western Wall Tunnels. Jon Seligman, interviewed at that time, waived it off as unfounded rumours, but admitted that the IAA works for Ateret Cohanim as a 'contractor.' He knew exactly what their goal was:

Their declared goal, says Seligman, is clear: To reach the mother rock, the rock on which Jerusalem was first built 3,000 years ago. 'The rock of our existence' ${ }^{1}$ as then Prime Minister Benjamin Netanyahu called it. [... 'They are enthusiastic about the First or Second Tempe periods' he explains. 'They have an agenda. But I don't have to dance according to their agenda... I won't allow them to destroy antiquities [like] the Cardo or the [Mamluk] bathhouse.'

(Quoted in Rapoport 2005b)

Jerusalem was founded much earlier, but people like the Canaanites are not counted by Ateret Cohanim. Who dances according to whose agenda? We shall find out later. Meantime, Ateret Cohanim was pleased with the work of the IAA:

'They're expensive, but convenient to us', says someone who was involved in the dig at the site. 'It's not correct to talk about dialogue between Ateret Cohanim and the IAA', he adds. 'It's more correct to talk about a monologue: Ateret Cohanim says, and the IAA does.'

(Quoted in Rapoport 2005b)

\subsection{A museum is not enough: we also need tunnels}

In April 2007 the entrepreneur (Mr. Boaz) met with Architect Faina Milstein of the IAA Conservation Department, responsible for preparing a programme for the project. It is hard to know what the plan for the museum was, because there was no discussion of that, but only of technical aspects. The sides agree:

To check-in with the Director of the IAA about the possibility of connecting the Ohel Yitzhak compound with the Western Wall Tunnels. The reason for this comprises three professional aspects: the aspect of safety at archaeological sites in Jerusalem, the archaeological aspect, and the architectural-touristic aspect.

[...] 
- The proximity between [these] two important sites in Jerusalem gives an opportunity to create a circular complex with emergency exits/ entrances.

- Identity and continuity in periods: the historical, archaeological and architectural [identity/continuity] naturally calls for connecting the two sites, [a connection that will] offer the visitor a broad and more varied view that includes the Museum [for the] Archaeology and History of Jerusalem.

(Document 4.6)

A private entrepreneur and a government authority (IAA) cooperate for establishing a museum in Jerusalem. They would build this museum by transgressing the approved building plan, excavating in property that the entrepreneur does not own, and tunnelling through such property without a construction permit. Regarding 'safety at archaeological sites,' it is unclear why passing through a narrow tunnel is safer than entering and exiting the same building (perhaps through different doors). The 'archaeological' and 'architectural-touristic' aspects are not explained. What relationship is there between a Mamluk bathhouse at Ohel Yitzhak and the Western Wall?

It is difficult to escape the conclusion that the excavation of tunnels in the Old City of Jerusalem, beneath private Palestinian homes, is accepted by the IAA without thorough investigation. In archaeological terms, tunnelling means destruction of antiquities (compare the tunnel along the Western Wall, Chapter 3).

\subsection{Principles for the museum - not for the entrepreneur's knowledge}

In May 2007, the IAA prepared a document titled 'Principles for a Program' for the future museum. It was addressed to Raanan Kislev, head of the Conservation Department, probably written by Faina Milstein. The word 'program' can mean in Hebrew any sort of plan. Allegedly, due to 'the size and volume of the archaeological excavations, two separate projects started to be performed' at Ohel Yitzhak:

1. The historical layer: The Ohel Yitzhak Synagogue, which begins at the level of Ha-Gai Street and ascends (henceforward: 'the Synagogue').

2. The archaeological layer: a museum for the archaeology and history of Jerusalem. This layer includes two parts: the western part and the eastern part $[\ldots]$

The - excavated - western part extends over the area of the former 'Kollel Shomrei HaChomot' (the Ohel Yitzhak Synagogue), located at a level of some eight metres beneath Shaar Ha-Gai Street. 
The eastern part - 'The eastern halls' - is only partially excavated and is found today at a level of three metres above Ha-Gai Street.

(Document 4.7)

How were two projects created for the same entrepreneur by the same Antiquities Authority? One project is on land belonging to the entrepreneur, though deviating from the municipal building plan. The second is in Area $\mathrm{C}$, without a building permit and on land that is not owned by the entrepreneur. Notice the strange description: the eastern part is not yet completely excavated, but the western part (the synagogue) is. Is this a conservation plan, an excavation plan or a plan for a museum? The author pays no attention to such trifles, but writes that at this stage they will 'implement the program' only for the western part.

The three principles for the museum are a work of art:

1. To exhibit 'the building of the museum itself' (but there is, and never will be, a 'museum building' here; only the synagogue and earlier archaeological remains);

2. To exhibit 'archaeological and architectural finds' (this means the same as items 1 and 3 !);

3. To exhibit small finds 'in a museal way' (can finds be exhibited in a museum not in a museal way?).

Apparently, every new museum needs a building and some exhibits, but can one call such things 'principles' of museums? The author adds: 'the cultural aspect is the main aspect of the museum.' Is there an archaeological museum not about culture?

When Jon Seligman and Yuval Baruch received this letter, they had no questions whatsoever about the future museum. They corresponded in the margins about an issue that is more pressing to them: who will present the 'principles' to the IAA Director, 'we, or the entrepreneur' (Document 4.7)? This is an empty formality, since the author of the 'principles' is the IAA. Meantime, the pull eastward continues:

After completing the program for the western part, and conducting the necessary excavations, a plan will be prepared for the western part [mistake for 'eastern' part, or a conservation plan for the western part?] in keeping with the program, and immediately after, it will be possible to implement the plan.

(Document 4.7)

'In keeping with the program' - what program? 'The plan' - what plan? The temporary 'western' plan, the 'eastern' plan, or a plan of both 'parts'? The language is vague, but the term 'part' already connects the areas together. The summary states that the plan for the eastern part, which is ostensibly being postponed at the moment, must still be carried out in parallel' to the western part, that is, without delay: 'In parallel to the planning of 
the western part, one must make a general plan that encompasses the entire compound' (Document 4.7).

We seem to move in circles. ... Likely the author of the 'principles' was used to writing conservation plans, and the task of establishing a museum under such vague circumstances (excavations still in planning, an entrepreneur who does not define his wishes) proved a daunting task. But the project rolled on: in June 2007 Seligman presented the 'letter of agreement' (Document 4.6) to Shuka Dorfman (IAA Director), saying:

The entrepreneur presented his wishes and now we must examine the archaeological requirements and analyze what finds to present and exhibit in the structure that will be established. The document [the 'principles', Document 4.7] is complex and we must determine whether to approve the project. There will be no excavations beyond the boundaries of the structure, and the existing area will not be expanded. It is not easy to acknowledge the fact that we are again excavating in the Old City without [general?] planning. The eastern area, which is not owned by them, must be considered. The fundamental problem is that the entrepreneur does not define the content of this museum. I propose not sharing the document with the entrepreneur.

(Document 4.8)

What a strange presentation. Did the entrepreneur express his wishes in the 'agreement' document, or was it the IAA's own wishes? Later Raanan Kislev said: 'Faina Milstein met with Buki Boaz, corrected the [agreement] document, and defined the principles "of the IAA"' (Document 4.8, emphasis added). The document that is called by Seligman 'complex' is not the agreement letter (Document 4.6), which the entrepreneur already received, but the 'principles' (Document 4.7). ${ }^{2}$ Seligman's opening (in Document 4.8) is also complex: there will be no excavation outside the boundaries of Ohel Yitzhak, but they intend to excavate the eastern 'part,' which is outside these boundaries. It is 'not easy' to work, again, without general planning; but who is forcing the IAA to do so, since the planned excavation is not necessary for the rebuilding of the synagogue (it is not a salvage excavation)? Since Area $\mathrm{C}$ is not owned by the entrepreneur, what is there to 'consider' about it? Can an entrepreneur develop land that is not his/hers? Seligman's only operative suggestion is not to show the 'principles' (Document 4.7) to the entrepreneur.

If the tunnelling at the face of the Western Wall (Chapter 3) resembles a Wild West film, here we follow the lines of a soap opera. An entrepreneur and the IAA are going to create together a museum for archaeology, but the entrepreneur should not receive from the IAA the document that defines the principles of this museum.

The pull eastward - to the promised land - is also expressed by Raanan Kislev:

Raanan Kislev: [...] The document [of the 'principles'] is divided into the historical layer and the archaeological layer, and it is necessary to examine how to connect them and what will be done in the western part. I suggest 
carrying out Stage 1 [synagogue, historical level] so that we will be able to carry out Stage 2 [beneath the synagogue, archaeological level] and only then check the feasibility of Stage 3 [the eastern part], which at present can still not be implemented. We ordered that a designer be appointed. Progress can [meanwhile] be made in the western part, according to the conditions of the document [of the principles].

Yuval Baruch continued:

Yuval Baruch: [...] In order to begin planning, the excavation must be completed. The extent of the area is the Ohel Yitzhak building in the lower portions [...] The [conservation?] program will define what is to be conserved $[\ldots]$ The entrepreneur has understood that conservation is the leading element.

(Document 4.8)

Apparently, the entrepreneur understands that he will finance the conservation, without which the museum cannot be established. Indeed, conservation is important, but archaeology less: the Archaeological Administration of the IAA is not part of the planning and has no say in it. Mr. Dorfman concludes the meeting, asserting that the document of the 'principles' must not reach the entrepreneur, adding: 'The IAA will not be a partner in the planning, but will retain the ability of monitoring' (Document 4.8 ).

The IAA is not merely a partner to the planning, it is the planner. What 'monitoring' will it retain? The IAA can determine whether and how to preserve archaeological remains. It does not determine how the entrepreneur uses the property, as long as he/she does not damage the remains. The question is different: what is the legal status of a governmental authority, which works for an entrepreneur in an area that is not the property of the entrepreneur?

\subsection{The museum programme}

Stage 1 begins: drills are carried out beneath the synagogue to find the bedrock; the archaeological excavations are resumed, and preparatory work on the museum programme is underway. One additional detail: David Beeri ('Davidleh'), Director of El-Ad, is attending meetings as the representative of the entrepreneur (Document 4.9).

Upon resumption of work, Yuval Baruch declares that there are 'three separate focuses' in the compound: the historical synagogue (the existing building); the archaeological level (under the synagogue), and 'a series of vaults from the Middle Ages east of the Ohel Yitzhak compound' (Document 4.10). So the vaults are east of the compound, but the compound is said to have three parts, one of which is the vaults.... The drilling indicates that the rock is very low, 
so it seems that the entrepreneur's dream to reach it cannot be easily fulfilled (Document 4.10, Section D). However, deep excavations were carried out, at this stage beneath the synagogue, for approximately four months.

In September 2007, Faina Milstein submitted a draft programme for the project. It was edited by Yuval Baruch, and a (partial) copy with his comments was given to us. The synagogue and its location are defined: 'The area is made up of impressive archaeological and architectural sites associated with various cultures, which exhibit the history of settlement in ancient Jerusalem from the First Temple Period to our days' (Document 4.11, p.3).

Baruch marked this section for deletion, claiming that it was superfluous. Apparently there is no place for 'various cultures' in this project. Milstein continues:

In 2007, the IAA decided together with the commissioning client to carry out an additional season of excavations as a continuation of the previous excavation season, in order to deepen the areas as far as possible to the level of the Second Temple Period.

(Document 4.11, emphasis added; cf.

Document 4.2, Section A)

The explicit goal of the continued excavation is to reach Second Temple remains. Yuval Baruch 'politically corrects':

In 2007, according to the demands of the commissioning client, it was decided to complete the archaeological excavation at the site. Prior to the excavation, drilling of the ground was done to check the depth of the layers and the bedrock level.

(Document 4.11)

Milstein continues with the two 'parts,' and Baruch comments that the eastern area 'is not part of the project' (Document 4.11, p.4). On a plan Baruch marks erasure lines on the eastern area (Document 4.11, p.5). The author reiterates on the following page that the museum 'comprises two parts' - and Baruch again remarks about the eastern area: 'not part of the project.' The author writes: 'at this stage of the project, the program will be executed for the western part only,' and Baruch writes: 'superfluous - it's obvious' (Document 4.11, p.6).

Baruch does not notice that the continuation requires similar erasures, because again Milstein reiterates and reemphasizes how much the eastern 'part' is inseparable from the 'part' owned by Ohel Yitzhak:

After completion of the program for the western part, and conducting the necessary excavations, the plan for the western part will be devised [copied from Document 4.7] [...] At the same time as 'Ohel Yitzhak' is planned, an overall plan should be undertaken for the entire compound.

(Document 4.11, p.6) 
A graph on page 7 of Document 4.11 (see Fig. 4.3) shows all the stages, leading to the execution of the 'combined plan.' The fuss about 'planning' (see Chapter 7) cannot hide the lack of archaeological principles for the entire project. Of course, it has political principles: connecting Ohel Yitzhak to the Western Wall Tunnels by excavating under the Muslim Quarter.

While the entrepreneur wants the Second Temple period and the 'rock of our existence,' Document 4.11 shows that most of the remains found are later (e.g., p.13). Milstein emphasizes (for example on pp. 13 and 25) that the visitor must feel the Mamluk bathhouse in various parts of the museum.

\subsection{Sensitive tunnelling}

In late 2007 the Ohel Yitzhak project was transferred from the Moskowitz family to the Western Wall Heritage Foundation (e.g., Document 4.12). The entire plot, synagogue included, was transferred as a gift (no taxes involved). The sides signed a contract in October 2007, stipulating that 'the entire premises shall be used always and only as a Museum for Archaeology and/or of Judaica open to the public.' Why is the Western Wall Heritage Foundation active in an area outside the Plaza? The documents offer no explanation.

In November 2007 the plan of connecting Ohel Yitzhak to the Western Wall Tunnels was leaked to the media (Shragai 2007). We are puzzled as to where documents can be obtained regarding planning the connections, determining the routes, selecting the contractor, etc. Was all of this determined orally?

In early 2008 the IAA breached tunnels connecting to different rooms/ spaces in the Western Wall Tunnels (Fig. 4.4). The documents are so partial that the details are unclear.

We have not found an excavation permit or license for the tunnelling. It was carried out by a contractor (Avner Gilead Ltd.) with 'an accompanying conservator' from the IAA (Document 4.13). While the contractor's safety file mentions 'manual horizontal archaeological excavation to clear the passageway' and 'excavation in an archaeological fill,' this is only whitewashing. In effect the tunnelling is made horizontally, not like an excavation, tearing apart 'walls and parts of structures' (Document 4.14). The contractor defined the work as follows:

Carrying out archaeological excavation for deepening the levels to the First Temple Period; exposure of existing spaces and making a connection between the Western Wall Tunnels and nearby areas. The work comprises a number of aspects. Supreme sensitivity to the historical heart of the Jewish people [...] the scope of the work is some 12,000,000 ILS. Period of execution 2006-2010.

Commissioned by: The Western Wall Heritage Foundation and the Antiquities Authority.

(www.avnergilad.co.il/projects/Jerusalem,

'Western Wall Tunnels.' The sums perhaps relate also to additional projects in the Plaza) 

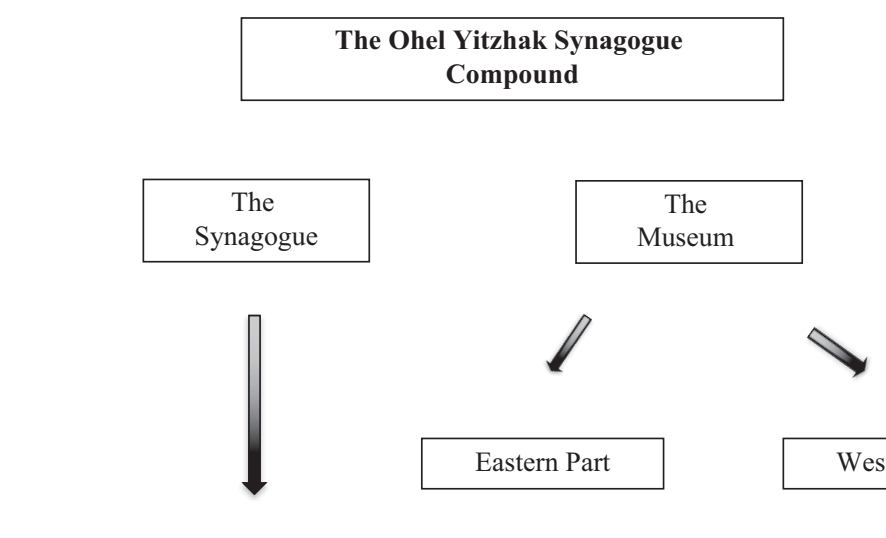

Phase A
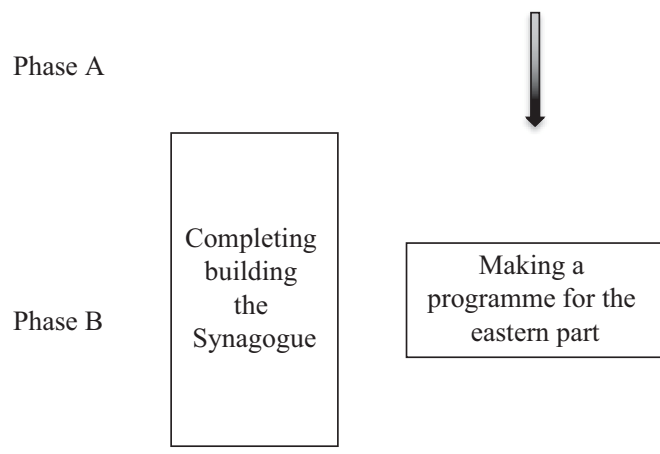

Making a programme for the western part

Phase C

\begin{tabular}{|c|}
\hline $\begin{array}{c}\text { Making a } \\
\text { programme for the } \\
\text { eastern part }\end{array}$ \\
\hline
\end{tabular}

Completion of Excavations

Making a detailed plan for the western part according to the programme Phase D $\begin{gathered}\text { Making a detailed plan for joining the western part, the eastern part } \\ \text { and the Synagogue }\end{gathered}$
and

\begin{tabular}{|c|c|}
\hline $\begin{array}{c}\text { Executing the western } \\
\text { part }\end{array}$ & $\begin{array}{l}\text { Executing the } \\
\text { combined plan }\end{array}$ \\
\hline
\end{tabular}

Figure 4.3 Graph of the order of Planning and Executing Works at the Ohel Yitzhak Compound, from Document 4.11. 
$\downarrow$

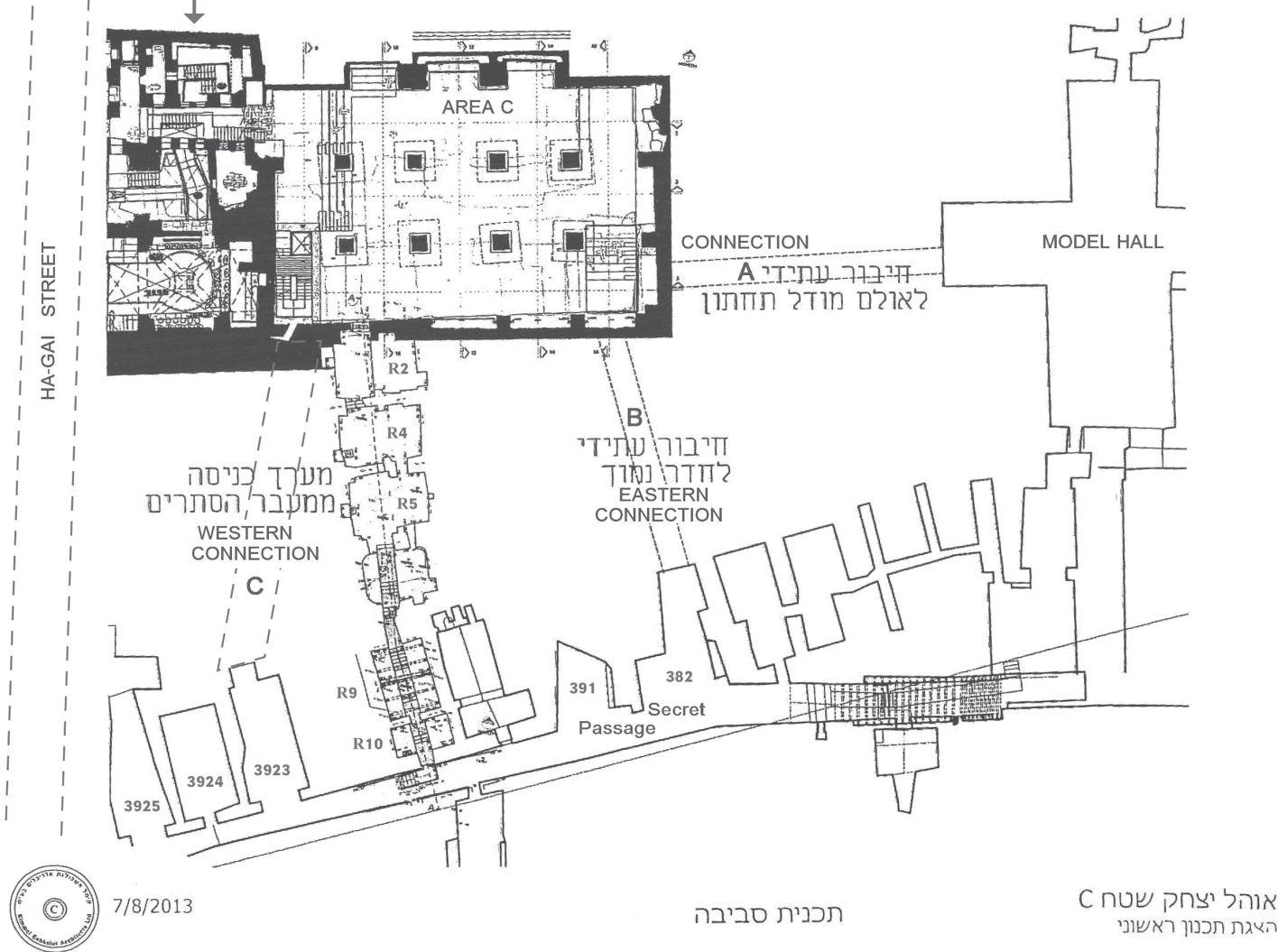

Figure 4.4 Map of the tunnels connecting Ohel Yitzhak and the Western Wall Tunnels. Tunnels A-B marked as future connections. Prepared by Slava Pirski for Emek Shaveh, based on the IAA Documents 
The contractor understood the aim well - it fits the wishes of the entrepreneur: exposing 'our' remains. The word 'archaeological' is out of place, because this contractor is not allowed to make, and has no expertise in making, archaeological excavations. In parallel, a large excavation commenced in the 'eastern part' (Document 4.15) (Fig. 4.5). To this day, there is no publication about this alleged 'excavation.'

\subsection{Second Temple or Early Roman?}

On January 8, 2008, Attorney Shaul Seidemann, acting on behalf of the NGO 'Ir Amim' (City of Peoples), wrote to the Attorney General (Meni Mazuz) a complaint about an 'illegal project' at Ohel Yitzhak. His long letter (Document 4.16) listed several issues, foremost among them:

1. The IAA calls the project a salvage excavation, but it is not, since it does not serve the construction of the synagogue. The IAA did not ask for construction permit, which is necessary for building tunnels.

2. The 'eastern' area and the tunnels are not on land of Ohel Yitzhak or the Western Wall Heritage Foundation, but under houses in the Muslim Quarter. Permission of the house owners for the work was not obtained.

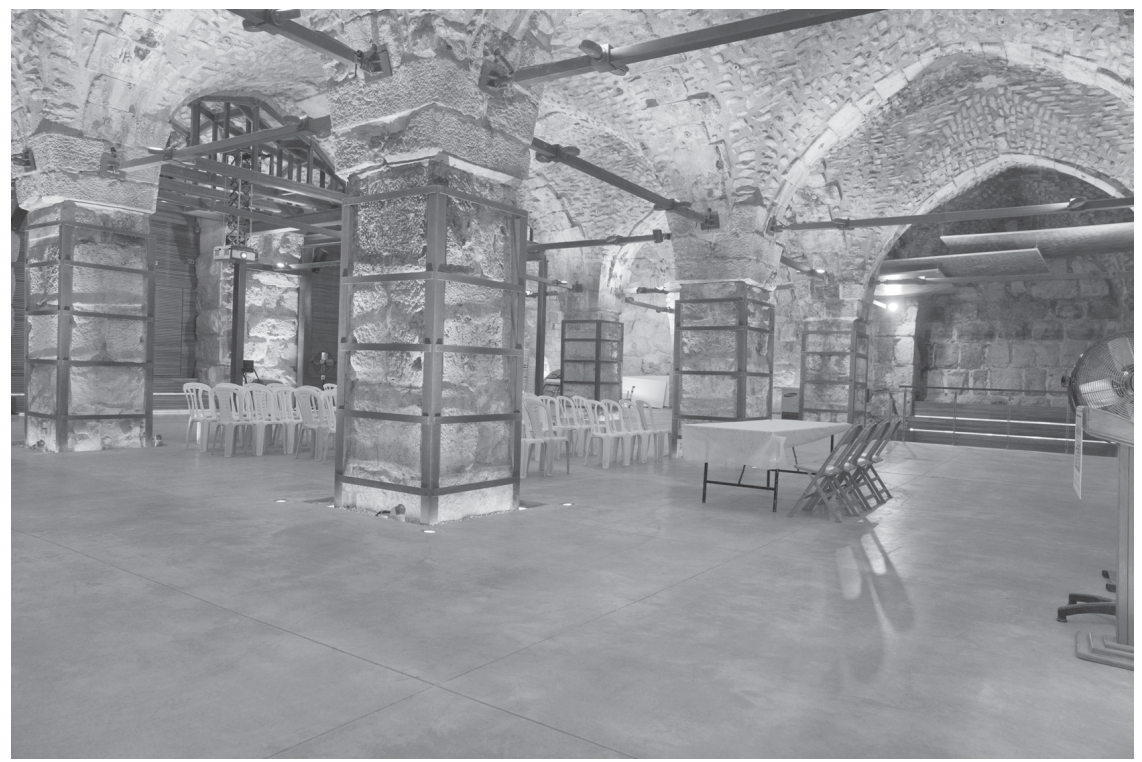

Figure 4.5 The Vaulted Hall (Area C) after restoration (2015). Photo Emek Shaveh 


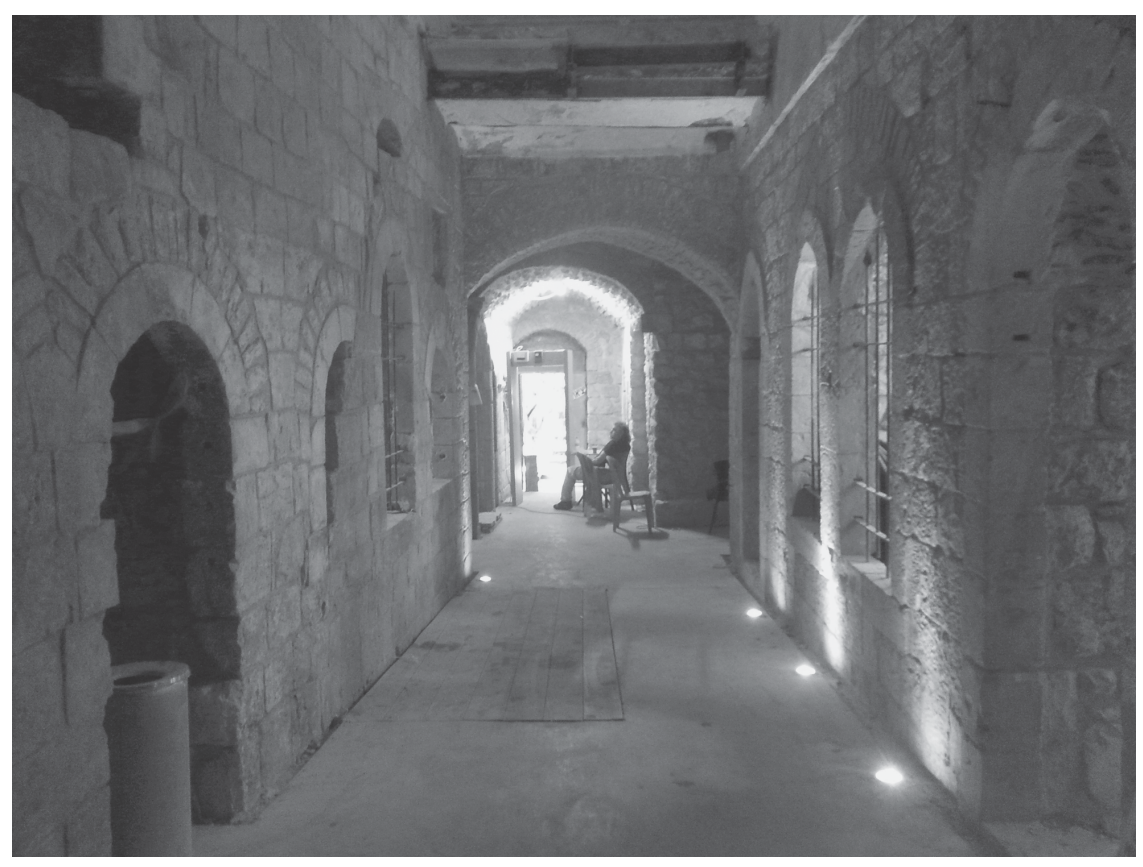

Figure 4.6 The exit from Area C to the Ha-Gai Street (late 2015). The Mamluk bathhouse is located on both sides of this passage, not yet open to the public. Photo Emek Shaveh

Seidemann asked:

How did it transpire that all the archaeological excavations (over ten) carried out in the Old City [some words unreadable, perhaps: are done for] the settlers in East Jerusalem and their direct supporters and with their financing? Is this consistent with the official, scientific and independent character of the IAA [...] Does this not constitute illegal politicization of a governmental authority and of the discipline of archaeology that takes place under its aegis?

(Document 4.16, p.3)

The Attorney General contacted the IAA, which began drafting a response. Jon Seligman submitted information to the legal advisor of the IAA (Document 4.17). Following is a summary, with our comments in italics:

1. The Ohel Yitzhak excavations are made in an area that has an approved building plan. - Not in Area $C$ and the tunnels, they are outside the scope of building plan 5480 . 
2. The excavation is being carried out legally under authorization. - Why is it carried out as a salvage excavation, which it is not?

3. Archaeological excavations do not require a construction permit. Construction of tunnels is not 'archaeological excavations.'

4. Archaeological excavations are sometimes carried out prior to construction and without building permits in order to 'collect the necessary information' for future planning. -What data was collected from the Ohel Yitzhak tunnels, how is this (phantom) data related to 'future planning'?

5-8. The IAA casts responsibility for several issues on the Western Wall Heritage Foundation. - There is no mention that this foundation is acting outside the area of its authority.

9. Rejection of the claim of politicization; IAA excavations are excellent and published without any influence on the part of the entrepreneur. Hard to tell, for there has been no publication yet on the 'excavations' of the tunnels. The politicization happens not so much in scientific publications, as in popular publications and in the fate of the sites after the excavations.

Seligman writes:

The identity of those who commissioned [this project] and their political agenda might have led us towards an improper search of 'Jewish layers.' Surprisingly [said with irony], the Antiquities Authority excavated an Ayyubid-Mamluk bathhouse at Ohel Yitzhak and presented precisely this fact.

(Document 4.17)

As we have seen, the excavations were made with the explicit aim of reaching 'our' remains. True, the IAA archaeologists will publish them properly in scientific publications. Not many people read these publications, though. Many more read popular media - such as the occasional IAA press release about new discoveries in Jerusalem. To the best of our knowledge, the bathhouse was not stressed in such publications, in contrast to 'our' remains from East Jerusalem: Herodian road, ritual baths, seal featuring a Hebrew name, water cistern, etc. Such remains are also preserved and exhibited, whereas 'late' remains are often removed, making them invisible. Seligman concludes:

10. The excavations in the Western Wall Tunnels do not violate anyone's property. While they are being conducted beneath the Old City, there is nothing in this that violates the rights of a person to his home or his property. It should be recalled that antiquities in Israel are the property of the nation. Since the Authority acts in the realms of the archaeological layer, it is operating within the realm of its authority.

(Document 4.17) 
Does the IAA have the authority to act in land that does not belong to the entrepreneur and to construct tunnels without a building permit? Not according to the precedent of the Davidson Centre (Chapter 2). In the case of the Mughrabi Bridge too, the Jerusalem comptroller Shlomit Rubin sent a harsh letter of reprimand against the attempt to legalize building without a permit through archaeological excavations:

Over the past year, we have become aware from various sources that the IAA intends to soon begin excavating foundations for the pillars of the said bridge, backed, allegedly, by a construction permit, which is based solely on an excavation license from the IAA and a letter from the Ministry of Public Security [...] I would like to draw your attention to [the fact] that according to the Building and Planning Law and its regulations, any entity, including the IAA, the police or a government office, is prohibited from starting laying foundations for pillars of the bridge beneath the Mughrabi Bridge prior to the approval of the municipal building plan (Detailed Plan No. 10294) [...] and receipt of a legally valid construction permit. In the past, attempts have been made by the legal advisor of the IAA to approve construction work through an excavation license of the IAA, on the claim that it is an excavation in the broad sense of the word [...] Neither the law nor the jurisprudence can be interpreted as permitting a private, municipal or government entity to carry out construction work under these circumstances without a construction permit.

(Rubin 2007:153-154)

An excavation license granted by the IAA for carrying out archaeological excavations $[\ldots]$ cannot render superfluous a construction permit, with all of the implications concerned.

(Rubin 2007:136)

After the construction of the new bridge was halted, the comptroller hoped that the situation had improved:

In a report of the Parliament Centre for Research and Information on 'Work at the Mughrabi Ascent' (www.knesset.gov.il) the policy of the IAA concerning the granting of permits to integrate rescue excavations with building initiatives is described as follows:

'The IAA carries out excavations at a site (according to permission from the Director of the IAA) after the developer presents it with a construction permit that is meant to testify to a proper planning and building process.'

If the above description indeed reflects the policy of the IAA today, this is a turnaround from prior positions, and the comptroller lauds the decision of the Authority to adhere to the law in all that pertains to the 
advancement of building initiatives on the basis of a legal construction permit.

(Rubin 2007:138, emphasis added)

It seems that the IAA continues to ignore adhering to the Law. In another document Seligman added more details:

A hall with large vaults was discovered east of the bathhouse, connected to the inn established for [=near] the Cotton Market. Work is underway to remove the fill from these vaults, as well in as the vaults located in the space between the large bridge, over which Ha-Shalshelet Street passes, and the this hall of vaults.

(Document 4.18)

Here we see the combined plan materializing. It is not clear whether the 'work' in the vaults is being performed as scientific excavations, or just under 'inspection.'

In internal documents and discussions with the entrepreneurs there is open talk about remains of the First and Second Temple periods. These are the heart's desire, 'our' treasures. Yet, in the response to Seidemann, neutral terminology suddenly appears: 'Early Roman Period' (Document 4.18). The IAA fits the words to the occasion. Outwardly, it is downplaying the political implications of its excavations.

The legal advisor of the IAA responded to Seidemann on March 11, 2008 (Document 4.19), claiming that the project is perfectly legal:

The beginning of the excavation is a rescue excavation, since it [permission] was given based on a condition [of the IAA] following a plan or permit [5480]; but due to the scientific and historic importance of the area and because this is a one-time opportunity to conduct an archaeological excavation in the Old City to the greatest depth possible, this excavation is not only considered a rescue excavation but [also] a real scientific excavation.

(Document 4.19)

A rescue excavation is a scientific excavation too. We are in favour of excavating, but not without proper building plans and excavation permits/licenses. Unfortunately, the excavation extended to land not owned by the entrepreneur, or, in the words of the IAA legal advisor:

... In the area of the 'Ohel Yitzhak' building, spaces, rooms, vaulted structures, and arches were discovered that spill outwards from the area of the [synagogue] structure and continue southwards towards the vaults of the ancient bridge structure [above the Ha-Shalshelet St.] [...] The excavation taking place [now] is in effect the removal of waste [psolet] from the existing spaces, rooms, and vaulted structures. 
[...] All the spaces known as the Western Wall Tunnels are joined together. So are the rooms and the arches that were exposed by the excavations in the Ohel Yitzhak synagogue compound, they are all joined together. Removal of the rubbish [sic, ashpah], which is performed by way of an archaeological excavation, reveals these spaces, vaulted structures, and rooms. Ultimately, they connect with the spaces in the Western Wall Tunnels [...]

(Document 4.19)

Since when do rooms, spaces and vaults 'spill' to another place? It is not they that did, but the IAA spilled out of the area owned by the entrepreneur, and not just to the south, where the work is done now (see Fig. 4.4, either connection $\mathrm{C}$ or spaces R2-5), but also to the east (Area C). On the one hand the legal advisor presents the work as an archaeological excavation; but on the other hand as 'removal of rubbish.' He concludes:

It should be said here that there is no property ownership arrangement in the Old City compound. Therefore, perhaps there is no dispute over the right of the claim-holders [Hebrew ba'aley hezkah] who live or are located above these spaces. However, they have no right of ownership on the ancient spaces.

(Document 4.19, p.3; cf. Document 4.17: item 10)

In simpler language, the Palestinians living in the Old City of Jerusalem are temporary residents at best. Should they claim ownership of the land under their feet, they might discover that they have no rights to their own homes. To the best of our knowledge, the Law does not divide land in Israel by layers. For example, the Law stipulates that oil reserves belong to the State. This does not contradict private property rights. If oil is discovered under a private house, the State cannot tunnel in and extract it without notifying the owners and reaching an agreement with them.

When someone else excavates an underground space in the Old City, without a license from the IAA, it is a breach of the Law:

The fact that it is impossible to receive a construction permit in the Old City or advance it [the permit process] (not even for the smallest modification), has not changed, and is one of the factors that propels illegal building in the city [...] There has been a rise in the number of excavations carried out without a permit by public institutions, mainly Christian institutions. Among the organizations that have carried out excavations without a permit are: The Custodia Terræ Sanctæ: excavations in the floors of residential spaces in order to expose and renovate underground spaces [...] The Syrian Church: excavation of an underground passage... 
The IAA carries out similar activities on a larger scale, in land not owned by the entrepreneur on whose behalf it is acting. It performs some of these activities as an inspection, without issuing excavation permits/licenses. Does the IAA stand above the Law?

\subsection{A museum for no-matter-what}

In March 2008, Nadav Shragai reported in Haaretz:

Along the underground connection, a pedestrian passageway will be prepared that is approximately twenty metres long. Its goal - to serve the visitors to the Western Wall Tunnels on their way to the educational centre on prayer and a museum for bar-mitzvah children that will be established in the Ohel Yitzhak Compound [...] Connection work was carried out within a number of days, barely requiring excavation, but rather, for the most part, raking and emptying waste and fills of earth in already extant spaces beneath a series of vaults. The Rabbi of the Western Wall, Rabbi Shmuel Rabinowitz, told Haaretz that the goal of the connection is to enable children and visitors to the Western Wall Tunnels to complete the tour of the Western Wall Tunnels and to exit them in the area near the Western Wall, bordering on the Jewish Quarter, and not as is the case today - in the heart of the Muslim Quarter, through an opening at the Via Dolorosa. 'That is safer and less threatening, and will surely bring more visitors, mainly children, to the Western Wall Tunnels, where they will learn about their past and their heritage. A visit to the plaza only is a partial visit,' said Rabbi Rabinowitz.

(Shragai 2008, emphases added)

Apparently, the intention to establish a museum for the archaeology and history of Jerusalem has been dropped. However, children are not mentioned in any other document concerning Ohel Yitzhak. The unfortunate assertion that a visit to the Western Wall is incomplete without visiting the tunnels suggests that the essence is not the Western Wall, but the tunnels. The claim that safety considerations force the new tunnelling is hypocritical. Were this true, why target the Muslim Quarter, instead of making a safer exit inside the Jewish Quarter or the Archaeological Park? Tunnelling under Jewish neighbourhoods is not on the agenda, because there is no nationalistic glory in it, and because it is a risky venture (the complaints of the inhabitants cannot be ignored, as if they are Arabs).

In March 2008 the first steering meeting of the future museum was convened. The minutes are brief:

A discussion was held regarding the essence of the content, and it was agreed that the content message intended for the place [is] 'We all pray.' 
This idea will make a connection, as far as possible, between the archaeological content of the site and the intended museum content $[\ldots]$ The essence is an archaeological tour in the layers of time that Jerusalem offers, while being exposed to the topic of prayer. There is agreement with the IAA regarding the details of the planning [...] The planning team will present a script of ideas that will include the description of the experience [of the visitors] and its contents [...] The connection from [Area] $\mathrm{C}$ will be considered in the future $[\ldots]$

(Document 4.20)

Though never said explicitly, the planning is not about a universal museum, showing that also Pagans and Christians pray. It is a museum for 'our' prayers only. The essential archaeological find in Area A is a Mamluk period bathhouse. It could be a wonderful place for an exhibition 'we all bathe.' The steering team pushes the language to the limits in trying to coordinate 'prayer' and archaeology, while ignoring the (Islamic) archaeology of the site. They reach some original combinations. For example, descending into the layers of Jerusalem 'in order to deliver the message' of prayer; or that the essence is 'an archaeological tour' while 'being exposed to the topic of prayer.' Maybe they are building a horror tunnel, with praying figures jumping from the walls? The IAA representatives (Shachar Poni and Yuval Baruch) participated in this farcical meeting without making any objections. Maybe they just prayed for the meeting to end.

After the IAA learns about the cancelling of the archaeological museum, Shuka Dorfman (IAA Director) concludes a 'status' meeting (the beginning is missing) thus:

4. Establishment of the exhibition must be made in coordination with the Department of the Treasures of the State in the Antiquities Authority.

5. The idea of prayer is acceptable, but it is important to ensure that the archaeological part is being expressed and is properly expressed.

6. Much information in a short time span will create a problem in showing and in understanding. It is important to think about something catchy that operates on the senses, which will attract the attention of the visitor.

7. In the past, an initiative that [later] failed was launched, to create unified coordination and management of all of the projects in the Western Wall Plaza. Today, every initiative operates as it pleases and we have no control over it. [...]

10. To the extent that area A is crowded, it is possible to use Area C.

11. The IAA will provide instruction on archaeological matters and will advise about matters of content.

(Document 4.21) 
No matter what the entrepreneur will exhibit, Dorfman wants him to use the good services of the IAA's Department of the Treasures of the State. To the best of our knowledge this department holds few Judaica objects related to prayer. The laconic discussion of the Museum's steering committee (Document 4.20) seems to Dorfman overbearing. In his view museums should serve the senses rather than the intellect. Indeed, the 'exhibition' that he established in the Strauss Building toilets (Chapter 2) follows this principle most faithfully.

\subsection{The entrepreneur tries 'to make the bathhouse disappear'}

By this time, it should have been clear to the IAA that it must protect the Mamluk bathhouse from the entrepreneur. Yet, in a long process the entrepreneur changed the plans more than once and the bathhouse was damaged - by agreement with the IAA. It is difficult to understand the details: documents are incomplete, and plans are missing. The damage begins with 'a partial breakthrough' in walls in order to make a route for potential donors (Documents $4.22,4.23)$. Seligman tries to stop the damage by arguing that a conservation plan must be drawn up first; Dorfman agrees for a while, but the entrepreneur demands more changes 'due to discovered finds' ('our' finds from the Roman period) and 'the progress of work' (Document 4.24). On September 24, 2009, Seligman opposes changes, calling the work done 'improper' (bilti re'uyah). However, Yuval Baruch supports the entrepreneur, saying that the IAA only 'adjusts' the excavation 'to the needs of the planning and the entrepreneur' (Document 4.25). Seligman finally says openly: 'He feels uncomfortable that the entrepreneur is trying to make the bathhouse disappear' (Document 4.25).

However, his IAA colleagues do not support him - on the contrary:

Shachar Poni: The situation at the moment concerning the passage from the foyer of the dressing room to the paving of the Cardo [is], [that] the engineer changed his mind, and that, although the planning was based on his earlier guidelines. Indeed there is an aesthetic dilemma and the solution is not simple.

Jon Seligman: It is not right to approve the passage through the corner of the bathhouse.

Yuval Baruch: Eitan Kimmel [the architect on behalf of the entrepreneur] is planning the route, the content is being examined in another channel, by a steering committee that makes progress in its work [...] The archaeology is located only in the background, there is content that is supposed to be exhibited, which is not related to the site.

(Document 4.25, emphases added)

The steering committee is a farce, as Baruch knows, because he sits on it (Document 4.20). Baruch tells the IAA now that 'the archaeology is only in the 
background' and that the content 'is not related to the site' (Document 4.25). An entrepreneur may decide the contents, but cannot be allowed to damage the archaeology. The IAA was not facing 'an aesthetic dilemma,' but an ethical and professional one: to allow the damage or not? Dorfman postponed the decision, asking to re-examine the plans with architect Kimmel; but Kimmel 'remained persistent about his plans' (Document 4.26). When archaeology is merely background scenery, it can easily be dismantled:

Following are the decisions of the Director:

1. The two elevator piers in the north-western part of the structure - are approved [...]

2. The corner of the Mamluk bathhouse - the director adopts the suggestion of architect Eitan Kimmel, the significance [being] passage through the corner of the Mamluk bathhouse. [...]

3. The pillar in the area of the warm room of the bathhouse - is subject to the decision of the planners. It can be moved and it can be left.

4. The Roman wall in the north-eastern part of the structure-breaking through the wall to the north is not approved

(Document 4.26)

It seems that the IAA protects well only 'our' remains. An elevator was planned from one of the central rooms of the bathhouse. The IAA tried to find another solution (Document 4.26, par. 5). The planners submitted an alternative without this elevator (Document 4.27), but with two elevators that descend lower into the bathhouse. Even Yuval Baruch was upset:

\section{Elevator 1:}

Eitan Kimmel: The new plan is to descend an additional level.

Shachar Poni: The elevator descends to a place that hasn't yet been excavated.

Yuval Baruch: I don't understand the insistence on taking the public down to the area of the ovens and the hexagonal [room]?

Eitan Kimmel: That's how we solve the problem of the disabled and this route is also related to content that we wanted to present.

(Document 4.28)

Kimmel is 'bluffing': there is no clear content. Since the architecture is unrelated to 'prayers,' the 'content' does not force any specific route. The famous ability to monitor evaporates and Dorfman approves the elevator. Likewise the second elevator:

Eitan Kimmel: The new plan is to descend an additional level.

Alexander Onn [excavating archaeologist]: There are insignificant water pools beneath the elevator, but we do not know what lies beneath them. 
Decisions:

1. Alexander Onn will supervise the work. If an important find is discovered, it will be necessary to stop and reconsider the continuation. Approval of the planning will be carried out by the [Jerusalem] District and the Conservation Department, and presented to the Director's approval only if necessary [...]

Removal of two stones from the Roman wall

Eitan Kimmel: The plan is to dismantle two stones from the upper course in the wall, in order to complete the stairs in a more convenient manner.

Decision: Removing the stones is not approved. One should plan the stairs so that they do not damage the stones.

(Document 4.28)

Yuval Baruch once said that this 'is the most complete Mamluk structure that has been found in Jerusalem' (in Shragai 2007). It appears that two stones from a Roman period wall are more valuable than this most complete Mamluk period structure.

\subsection{Archaeology as background scenery}

The excavators of the site were not asked for an opinion, or informed in advance about the damage to the bathhouse. When they found out they wrote:

\section{Subject: Violation of Agreements for Ohel Yitzhak Excavations}

In 2004 we were responsible for the archaeological excavation project carried out as part of the restoration and conservation of the Ohel Yitzhak Synagogue. As early as the first season, it appeared that the Ottoman building was based on impressive remains of a Mamluk bathhouse, which, according to the sources, was called Hammam Darj al-'Ein.

This public bath, which has the same layout as the adjacent Hammam al-'Ein, was built in the Mamluk Period, during the renovation of the Cotton Market Quarter.

In many work meetings we emphasized the importance of preserving vast portions of the remains of the bathhouse, in order to exhibit them to the general public. Our view was supported by various IAA officials, even though it was contrary to the position of the capitalizers [literally 'those who finance']. We also maintained our position in our meetings with the architect of the future museum.

Unfortunately, a few days ago Haim Barbé visited the site, and was shocked to discover the destruction of part of the façade of the building next to the monumental entrance, as well as the destruction of one of the 
heating pools, in order to install an elevator and access route to the site. We must state that the facts on the ground indicate that the wish of the donors supersedes the wish to preserve past heritage. We decry this situation and regret that we have become partners to activities to which we are opposed.

Sincerely,

Haim Barbé and Tawfiq Da'adli'

(Document 4.29)

Jon Seligman, backing Mr. Dorfman, gallantly responded, although he had tried to warn against the entrepreneur's plans. Discussions were held, compromises were made, but finally:

At the end of the development process, the main elements of the bathhouse will be presented to the public, including the building's façade, the foyer, the octagonal room and the ovens' room, together with additional elements from other periods [...] We must be sufficiently flexible to find the best compromises between our wishes as researchers and the legitimate wishes of the entrepreneur.

(Document 4.30)

However, the topic is not the academic wishes of the excavators, but the duty of the IAA to protect important antiquities from the wishes of entrepreneurs.

In August 2010, in a dispute concerning who should direct the excavations at Ohel Yitzhak, Haim Barbé wrote:

I saw that a support arch from the Ottoman Period was dismantled during the 'conservation' work [quotation marks in original], apparently, without documentation. Two support arches of the same style, which are still standing complete in the field, will also be dismantled.

(Document 4.31)

The rest of the letter was not given to us. In a meeting of February 7 , 2011, the danger of collapse in the Old City projects was discussed, following consultation with the Geological Survey of Israel (Document 4.32). The decisions were panicked, so the potential for disaster was likely substantial. Yuval Baruch notes:

Yuval Baruch: The Machkama - the Border Police building ${ }^{3}$, is falling apart, apparently due to works in the tunnel; there is damage and falling of stones there. In the tunnels there are presently four excavations, but if we open another area, it will become a mess.

(Document 4.32) 
When Silwan residents complained of damage due to the excavations beneath their homes, their claims were rejected outright. The blame was put on their illegal building methods (Rapoport 2009:19; Behrman 2010:59). The Ohel Yitzhak project was discussed again at the end of 2012:

Raanan Kislev: According to the Western Wall Heritage Foundation, this is one of the large projects that they want us to do [...] Eitan Kimmel's plan and the plan to turn the compound into a museum have been cancelled at this stage.

(Document 4.33)

Apparently the cancellation was due to financial considerations of the entrepreneur (see Document 4.34). The implication is that despite all the former breakthroughs and damages, nothing is clear about the use of the bathhouse (the last documents at our disposal mention the utilization of Area $\mathrm{C}$ as a classroom). Dorfman summarized the discussion:

1. It is the responsibility of the office of the [IAA] Director to schedule a meeting on the topic [...]

2. It is the responsibility of the Western Wall Heritage Foundation to present a plan and priorities, which will explain the entire operation of all the excavations and projects, with an overall view of the entire Western Wall compound (Area A, Area C, secret tunnel, emergency exit, etc.)

3. It is important to understand the implications of the museum's cancellation. How will they operate Area A and would it be opened to the general public [?].

4. At the time, the plan for a museum of prayer had a steering committee of which Yuval Baruch was a member. One must consider how to continue after the cancellation of the plan.

5. Regarding exhibition and signs, the IAA must be involved in all of the stages.

6. Regarding management of the project and coordination of the work, someone must take responsibility for this. The matter must be properly addressed.

(Document 4.33)

Typically, everyone is responsible except Dorfman, but his decisions played a crucial role in creating the present situation. In a clarifying meeting with the entrepreneur an exhibition is still discussed, but it is not clear of what:

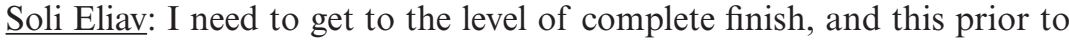
the display. The work on the display will only begin some eight months from now. 
Raanan Kislev: There are many engineering problems, and Ofer Cohen needs to enter the planning, which has not begun yet, and which will have an influence on the conservation work.

Soli Eliav: You start the conservation work, and meanwhile, we will finish the engineering planning as well as the development planning, including railings. We'll complete the topic of the display in about three weeks. Before conservation enters [the picture], we will have finished the planning by Ofer Cohen, which is marginal relative to what there is at the moment.

Yuval Baruch: The display can change the entire concept.

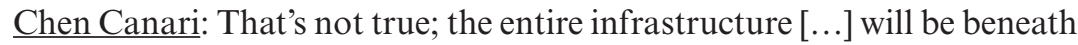
the wooden deck.

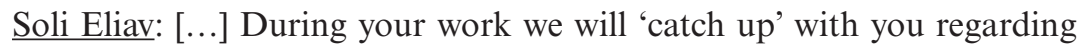
the final planning of the stabilization and also the planning of the walkways, which already exists. Afterwards we'll recruit a donor for the exhibition. The visitors' route has not changed. The steering committee for the content made a decision a year ago [probably about the museum], but it cannot be implemented in terms of budget. Within a month we will be able to reach new understandings.

Yuval Baruch: I participated in the steering committee about four years ago, and I understood that the issues are not related to archaeology and that it [the bathhouse?] will be only the background setting for the archaeology.

(Document 4.34)

The Museum for the Archaeology and History of Jerusalem, the Museum for Bar-Mitzvah Children, and the Prayer Museum have not materialized so far. Inside the synagogue there is still an inscription stating that the Western Wall Heritage Foundation will establish a museum here. Committed by the contract with Moskowitz, they may eventually establish some sort of museum here. Maybe a museum for lost causes?

\subsection{The 'inspection mode' of excavating}

In a seemingly marginal email, Yuval Baruch asked Shuka Dorfman to approve a small excavation between Ohel Yitzhak and the Western Wall Tunnels, before installing support for a vault:

$[\ldots]$ 2. This year we did not issue a permit for an excavation, and I think that there is no need to issue a new permit for such a limited excavation.

3. I ask your approval for performing the excavation in the framework of inspection.

(Document 4.35; request granted February 13, 2012)

This is a new invention: performing salvage excavations without issuing excavation permits, as if they are merely inspection works. In this case, the 
excavation is small; but it is not the only case. Compare another, handwritten and hard to read document:

\section{[To] Amit,}

Enclosed please find a request [not included in the material given to us] of the [Western Wall Heritage] Foundation for settling the passageways between the Western Wall Tunnels and Ohel Yitzhak [Area] C.

I checked the requests + [with] Raanan [Kislev], and it can be done by a condition of inspection (within the existing framework in the [Western Wall] Tunnels) and preliminary documentation. Under the responsibility of Haim Barbé + Avi Solomon.

Urgent [unclear signature].

[Note added below:] 26/8/2013. A field tour was carried out with Chen, and [it] was dealt with under the inspection of Avi Solomon.

(Document 4.36)

Inspection is usually done to ensure that no harm is caused to antiquities during development. Here, however, it is a new mode of inspection, which replaces an archaeological excavation. In another document Hayim Barbé receives an excavation permit for Ohel Yitzhak, but it means only 'conservational inspection'; he cannot be present at the site, so 'the inspection will have to be done by an inspector of the [Jerusalem] District' (Document 4.37).

As a result, even the IAA employees are not always sure what 'inspection' means. Is it a full excavation getting underway without a permit, or merely an inspection? In one case, a request for 66 days of inspection in the Western Wall Tunnels is issued - a very long period. This confuses an IAA employee from the finance department, who asks: 'What does all this mean? Is there a request [for inspection by the entrepreneur]? Is there a commitment [for payment by the entrepreneur]?' (Document 4.38). Yuval Baruch responds:

\section{Ronen,}

To remind you that the work of $\mathrm{Al}[$ expander] [Onn] [the name is crossed over, replaced by:] Avi [Solomon] in the [Western Wall] Tunnels was carried out in the framework of inspection.

(Document 4.38)

According to the Antiquities Law (1978), any archaeological excavation in Israel must be conducted under license. It turns out that parts of the Western Wall Tunnels are 'excavated' by inspection. An inspector, in contrast to an archaeologist working under license, is not obliged to use scientific methods, document the remains and publish anything about the 'inspection.'

If the Western Wall Tunnels are not merely the 'bedrock of our existence' and a sacred site, but also an archaeological site, the IAA should excavate there in a suitable manner, and not by an illegal mode of 'inspection.' 


\subsection{The sensory experience of perfect unity}

In January 2013 the Western Wall Heritage Foundation presented to the IAA a 'detailed plan' for the use of Area A (the bathhouse). The entrepreneur tried to present some sort of content:

Subject: Presentation of the detailed plan for the content of Ohel Yitzhak Area A to the IAA

[...] The content-wise use of the various spaces and the division of the content [sic] was explained in detail. The central story is based on the exegesis (midrash): 'When the Temple was destroyed the Holy One Blessed be He dispersed the stones all over the world, and in every place where a stone fell - a synagogue was one day built there.'

(Document 4.39)

No prayers here, but how is a Mamluk Bathroom related to Synagogues? The document describes the display:

\section{Entrance Displays:}

The passage to the central room and the opening [display?][.] In the central room, prior to the display [there?], they will tell the history of the site, the structure of the site and the significance of the archaeology discovered in the place.

\section{First part - The Central Hall:}

Jerusalem in its glory with the Temple standing. The Temple is destroyed and splits into dozens of sparks of light that are dispersed throughout the world. Each such spark is a prayer of yearning, a fragment of the great perfection.

Second part - The Walking route:

Prayers of yearning - parts of the whole, which in every exile take on a different melody [.] Exhibits that become visible as reliefs of synagogues when viewed from close.

\section{Last part - The Steps to the Second Temple:}

The first return of the harmony, to the sensory experience of perfect unity... This is still not the complete perfection, but the process begins and nothing can stop it. The synagogues turn into beams of light that gradually multiply, creating a gate of light. At the end of the road, the lights that guided us join into a single body [-] 'an imperfect geometry' of the original body.

(Document 4.39)

There is no connection between the terminology of the entrepreneur and the archaeology of the site. Seemingly the entrepreneur does not wish to use 
terms that describe the bathhouse (dressing room, warm room, etc.). We try to place the display (in italics) in the actual spaces:

1. Foyer - at the entrance/edge of the dressing room: an introduction, perhaps with a sign about the excavation of the site by the IAA.

2. Central hall-octagonal dressing room of the bathhouse: the Temple in its glory, its destruction, and its sparks dispersed throughout the world.

3. Walking route - through the warm room and ovens' room: exhibition of reliefs of synagogues from around the world.

4. Climax - at the Roman Period stairs: the return to harmony. Visitors lift their eyes to the ideal future.

Regarding the technical aides, an 'archaeological narrator' will explain the archaeological components of the site; but the key actor will be a messianic soundtrack:

\section{The musical Soundtrack:}

The main actor! It leads us to the heights of emotion, yearning, and to the chance of hearing again the music that we yearn for. The great music splits into the prayers of yearning of the people in the synagogues dispersed all over the world ... and begins to be rebuilt with our return here ...

The script of the Narration:

A delicate addition of narration (mostly verses [of Halacha, Bible, etc.]) that strengthens the soundtrack and gives it emphases.

(Document 4.39)

At the time of writing the Mamluk bathhouse had not yet been opened to the public (Fig. 4.6). The vaulted hall (Area C) received a Jewish name based on Songs of Songs 2:9 - 'beyond our wall' (achar kotlenu). ${ }^{4}$ Apparently, it is used for entertaining VIPs and is rented out for private events for a 'donation' of 36,000 US Dollars (Heller 2014; Hasson 2016; Chen 2017). It was revealed that the Ukrainian oligarch Zvi (Gennady) Bogolyubov funded the Ohel Yitzhak project (after 2008), with approximately 20 million US Dollars (cf. Hawkes 2018). An unnamed IAA official said: 'Although the majority of the finds are undoubtedly from the Mamluk period, identified with Muslim rule in Jerusalem, the educational visitors' center will address the genealogy of the Jewish nation and its connection to Jerusalem' (quoted in Eisenbud 2014).

The journalist was given (or produced) the following bogus story:

To dig below the Old City's Muslim Quarter, IAA officials first had to receive permission from the Palestinian residents living above the sites, as the excavations must be conducted vertically. 'The professional reason for abstaining from horizontal tunnel excavations is that archeological 
excavation must be done vertically, starting from the surface [...]' the IAA [official] noted.

(Eisenbud 2014)

The Western Wall Heritage Foundation is implementing, with the generous help of the IAA, a dangerous plan. In the dim underground the impressive Mamluk and Ottoman architectural remains are used as a background for delivering a messianic message. Intoxicating water is produced from the rock of our existence - the few early remains that are 'ours.' An ideal future is expressed not as a far-away dream in private, but in immediate, unquestionable terms; supported by a loud soundtrack and ecstatically experienced together in groups, so close to the Temple Mount. How many visitors understand the message not in terms of a distant longing that only God can fulfil, but an immediate call for action, here and now?

\section{Notes}

1 A term coined by Netanyahu in 1996, after allowing to breach an opening from the Western Wall Tunnels to Via Dolorosa in the Muslim Quarter, the work funded by Moskowitz. This led to riots in which about a hundred Palestinians and 17 Israelis were killed. After the riots Israel agreed (unofficially) to the digging of the Wakf in the Temple Mount (cf. Greenberg 2009b:274).

2 Seligman cannot be referring to the protocol of the meeting (Document 4.8), because such protocols are not distributed to entrepreneurs. Also, who would think that a protocol of a meeting is a 'complex' document? Notice that when the 'principles' were written (Document 4.7), the author hesitated who should send it to the entrepreneur - so it was not yet sent at the time, and now Seligman proposes not to send it at all.

3 The Machkama building near the Western Wall was established in 1329 AD as a madrassa (school). For hundreds of years it served as a courthouse and in the Jordanian period as a school. It was confiscated in 1969 and currently serves the Israel border police; but a small synagogue was also established inside it in 1977.

4 According to one interpretation the 'one standing ready behind our wall' is the Messiah, so he will come soon (e.g., www.chabad.org.il/Magazines/Article.asp?Art icleID $=4813 \&$ CategoryID $=1146$ ). In the context of the Western Wall, these words assume a double meaning. 


\section{An archaeological site with depth - the Ha-Liba Building}

\subsection{Introduction}

Ha-Liba ('the core') Building is a large structure currently being built for the Western Wall Heritage Foundation in the northwestern part of the Western Wall Plaza (Fig. 5.1), according to Municipal building plan 11053 (Mizrahi 2013:17; Hasson 2014b). The plan was submitted by one of the landowners, the Company for the Reconstruction and Development of the Jewish Quarter. It is not clear if the Western Wall Heritage Foundation received, leased or purchased this land.

The structure is meant to serve various purposes (classrooms, exhibition hall, offices, etc.). Salvage excavations began in 2005. The IAA documents at our disposal start in 2008 and are partial. For example, out of at least nine 'reports to the entrepreneur' on various stages of the excavations, we have received parts of four. Sometimes, only even or odd number pages were handed over. ${ }^{1}$

The excavations at the site, directed by Shlomit Weksler-Bdolah, lasted about five years (2005-2009) and exposed important remains. Large vaulted structures, a Sheikh's tomb, a bakery, stores and other finds were uncovered from the Ottoman, Mamluk and Early Islamic periods. From the Late Roman and the Byzantine periods the city's eastern Cardo ${ }^{2}$ was found. West of it, at the rock escarpment marking the edge of the Jewish Quarter, there was a row of shops which survived until 1967 (Fig. 5.2). East of the Cardo a monumental structure was discovered. An Iron Age structure was found under the Cardo (Weksler-Bdolah et al. 2009; Weksler-Bdolah 2014). Weksler-Bdolah called these excavations the 'Western Wall Plaza excavations'; but soon other excavations followed suit. One should not confuse her excavations with the similarly titled 'comprehensive' project of excavating the entire Plaza (Chapter 6).

\subsection{Advance assurance of construction}

According to proper procedures, when a developer seeks to build at a declared archaeological site, and submits a building plan to the Planning authorities, 


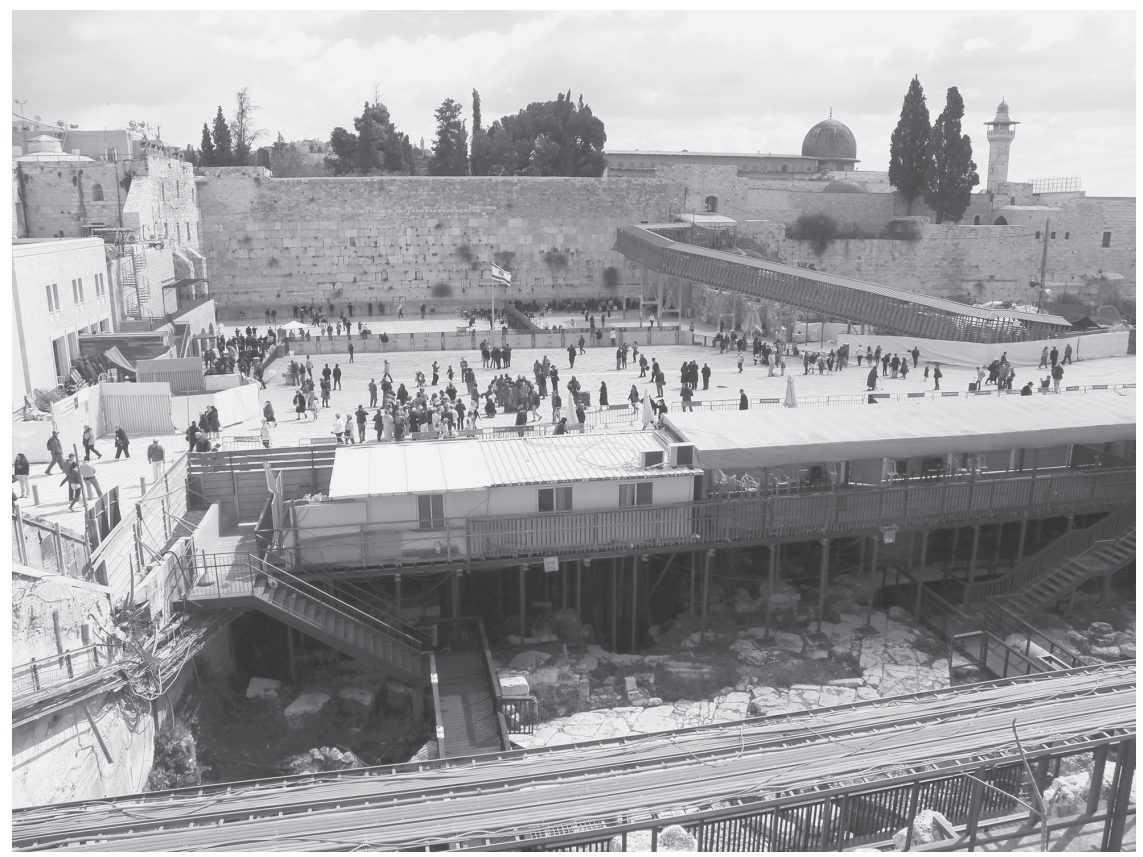

Figure 5.1 The Ha-Liba Building excavation (bottom); the Western Wall and the temporary Mughrabi Bridge (top).

Photo Raz Kletter

the IAA conditions the approval of the plan on making a salvage excavation in the entire area first. Only after the excavation does one know whether there are important remains, which may require alterations or (in rare cases) cancellation of the entire building plan. However, here the IAA promised to the entrepreneur in advance that it will be possible to build. The same happened (later) at the Givati site in Silwan (Greenberg 2014).

Professor Amos Kloner, an archaeologist from Bar-Ilan University, mentioned this in the Jerusalem Planning Committee:

Prof. Amos Kloner:

I would like just to comment that the Antiquities Authority has given its approval to the building in advance. Indeed, they [may be] sitting here saying that...

Uzi Dahari [Head of Archaeological Administration, IAA]:

Not true.

Prof. Amos Kloner:

I have a protocol, with meetings (unclear). ${ }^{3}$ Indeed, formally they say that they demanded performing an excavation, and [only] afterwards 


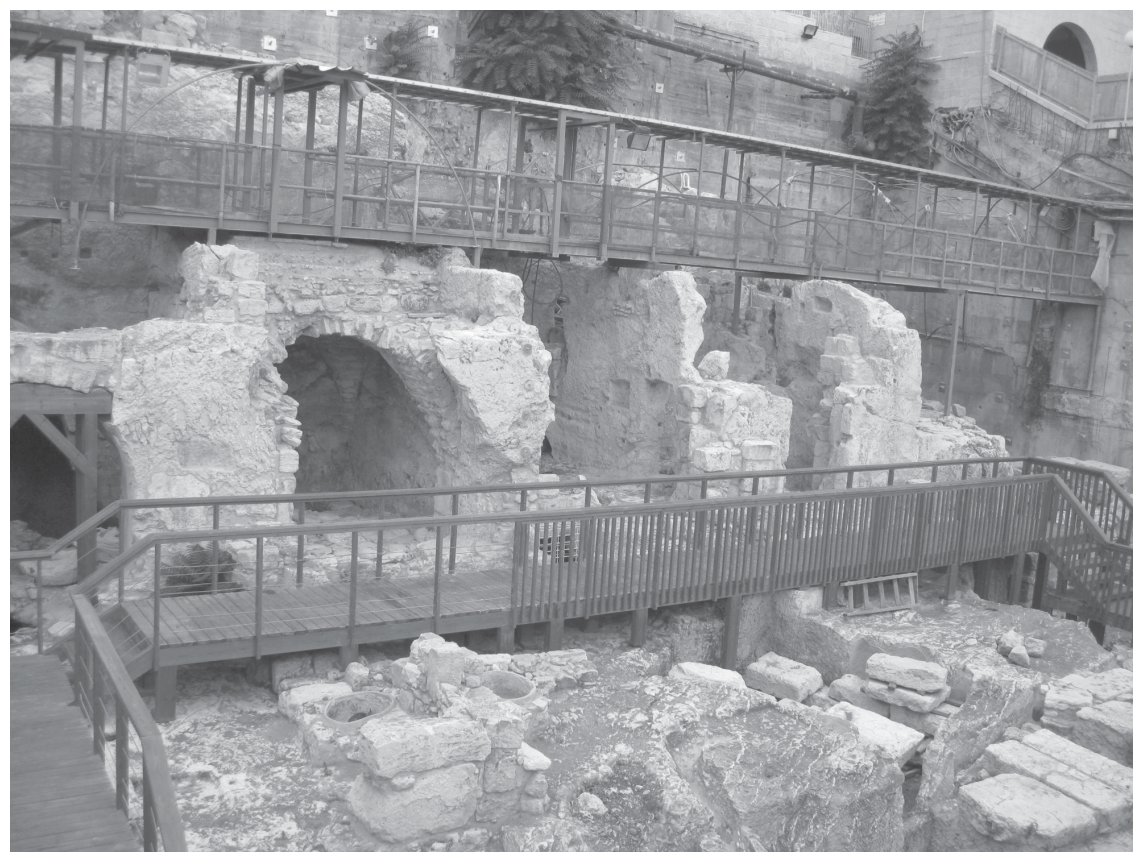

Figure 5.2 Ha-Liba excavation area, parts of stores serving until 1967. Many other Islamic remains had been removed.

Photo Emek Shaveh

construction was approved. The Western Wall Heritage Foundation financed this excavation, and other excavations [too], and the IAA (unclear [apparently: paid]) back in the same coin it has received.

(Planning Committee 2012:71-72)

Words said in 2010 by Shuka Dorfman (IAA Director) prove this:

We sat with [architect] Ada Karmi before she began drawing [the plans], before we began excavating, and our principal demand was - how did we define it - that the building will float above the archaeology [...] That was the first time in the history of the IAA that we agreed to start working before there was an approved plan, with all the conditions in the plan or in the agreement that we signed, with those with whom we should sign. Incidentally, it happened there [Ha-Liba] and it's happening now in the Givati Parking Lot in the City of David [Silwan]. Usually we don't work like that, in order to verify that really all the archaeological values $[s i c]$ are integrated in the building [plan].

(Planning Committee 2010:50) 
True, the IAA's standard conditions, demanding salvage excavations, appear in the directives of the Ha-Liba plan. However, the IAA promised its approval in advance. Professor Yoram Tsafrir (of the Hebrew University) said regarding this approval:

They tell us that the responsible [body, the] IAA agreed and took part in the planning. I also understand that Shuka Dorfman presented these matters with pride. This is the first time that the IAA says [so], since I've known it - and I know it and love it and respect it. [It is] the first time that I have heard the [IAA] Director saying: Our policy is to give a hand to the planners, out of clear knowledge that at the end we shall have to, if we find something - we shall have to reach a compromise with them. It's unacceptable, this policy, but it has been employed here. Well, it happens that authorities forget their purpose. I'll mention just one example. The Nature and Parks Authority joined forces with all kinds of developers on the Gilboa [Mountains,] in the area [where] irises [grow], in order to build there an ecological community [...] Only the public opposed and turned the Nature and Parks Authority back to its proper course. This is what we want to do with the IAA, to return it back to its proper course.

(Planning Committee 2010:89)

\subsection{The fate of 'late' remains}

As with most of the excavations in the Western Wall area, also in the present case most of the Islamic periods' remains have been removed in order to expose earlier layers. These were not just any remains. Large vaulted buildings with a monumental façade, partially preserved to full height, have been built during the 12th-13th centuries CE above the Cardo. Part of a large public structure was exposed east of the Cardo. The excavator described the main discovery there:

The central item is a single cist tomb (Locus 4076, Room C3) [...]. Inside the burial chamber was found the skeleton of an adult male, placed [...] on his back in an east-west direction, the head in the west facing southwards. The position of the deceased is typical of Islamic burial [...] The location of the tomb was preserved and emphasized also in later periods.

(Weksler-Bdolah et al. 2009:\#1)

B.Z. Kedar, at the time Chairman of the IAA Council, ${ }^{4}$ discovered that the finds in question were the remains of Madrasah al-Afdaliyya, constructed around the 12 th century CE. Later, the structure was known as the Sheikh 'Id Mosque, named after one of the leaders of the Mughrabi clan; he was buried inside it in the 17th century, and now his burial was discovered. In 1967 Israel demolished the Mughrabi neighbourhood - 'an archaeological crime' (thus Kedar). However, in the Ha-Liba excavations surviving parts of this structure 
were discovered - and then destroyed, including the Sheikh tomb. Built tombs inside buildings are rare, and the question must be asked, who decided to destroy this ancient tomb and who approved this decision? The documents are silent. Kedar relates that by the time he heard about the case, the remains had already been destroyed: 'Had I known it on time, I would have stopped it in person' (quote in Hasson 2012; cf. Kedar et al. 2012).

Currently, there is no procedure that defines which remains should be preserved in an archaeological excavation, and which removed. In university excavations, the excavator acts on his own judgement. In IAA excavations the decision is made either by the excavator or by IAA management.

In 2007, remains of Late Islamic (13th century) ablaq style wall decoration were discovered in the Ha-Liba Building excavations. This architectural decoration appears in public buildings from the Mamluk period, characterized by alternating patterns of light and dark stones, or painted stones (WekslerBdolah et al. 2009: Fig. 17). The IAA Conservation Department instructed workers to cover the decorated parts with sandbags; but after some time it became apparent that the paintings have been damaged: 'The dampness penetrating through the sandbags enables the growth of green scum, and across one painting there is a deep, fresh scratch - apparently the result of various works undertaken at the place without our knowledge' (Document 5.1). ${ }^{5}$

The damage was not intentional, but proper conservation was not carried out, and the drawings were left unattended too long.

Recent years have seen a growing awareness of the need to sift the excavation debris in order to retrieve small finds, such as stamps and seals. One method for this is wet sieving. The use of this method at the Ha-Liba excavations is commendable. However, there was no defined budget, and therefore, the earth was collected in large sacks - nicknamed 'balot' - and left at the site. Every sack had been labelled for context (the precise location in the excavation). The sacks can deteriorate, and then, the finds lose their context - that is, much of their scientific value. In February 2009 the excavator asked to treat 85 sacks from Iron Age contexts and ten from Roman period contexts (Document 5.2), but the work was postponed (Document 5.3). The excavator asked again in May 2009 (Document 5.4), but a year passed before the issue was re-discussed (Documents 5.5-5.6). Ultimately, a solution was found; but while earth from the Iron and Roman periods was sifted, that from the Islamic periods was not.

Meir Ben-Dov, a veteran Jerusalem archaeologist, complained about the attitude towards 'late' remains at the Ha-Liba site:

The publication of the Antiquities Authority discusses Jewish finds. Indeed, Islamic layers are mentioned too, but the lack of details concerning them is blatant. It should be noted that the Islamic and Medieval finds in this area are abundant and significant, and this is not properly reflected in the reports appended to the [Ha-Liba Building] plan.

(Ben-Dov 2012: articles 4, 7) 
The Western Wall Foundation is interested in 'the dominant finds,' and asks to dismantle all the rest fast (Document 5.7). The Cardo, the First Temple building and 'the preservation of the rock escarpment' - they are 'our' important finds. The Foundation publicizes a temporary tour of the HaLiba remains as an opportunity to "visit the remains of the buildings of the ruling administration of the First Temple period, a fabulous Roman street, and Royal rooms that served the VIPs of the people.' Nothing is said about Islamic remains or other people. ${ }^{6} \mathrm{~A}$ few 'late' bits and pieces will be preserved together with the rock escarpment, a sort of a fig leaf. The escarpment is not saved due to them, but because of 'our' remains, as Dorfman explains:

[Concerning] the rock escarpment, the fist intention [of the developers] was to damage it, we said - it is impossible to damage it, it has archaeological values. One sees the Second Temple construction, the aqueduct for water passes [there]. We distanced the building from the escarpment.

(Planning Committee 2010:24)

\subsection{The conservators excavate}

In November 2009 Shlomit Weksler-Bdolah wrote to Jon Seligman, Jerusalem Regional Archaeologist:

A complete lamp and coins were found during works of the Conservation Department between the Cardo stones - carried out without any archaeological inspection [...] I asked to mark on a plan where they have been found and to keep them in the office. I must emphasize that I was told nothing prior to commencement of the work. -Even though I have explicitly written you in the past to express my opinion that during conservation work of the Cardo stones, the presences of an on-site archaeologist must be ensured. In my opinion the conservation work of the Cardo stones should cease immediately and one should ensure proper archaeological inspection.

(Document 5.7)

Conservation of archaeological finds usually begins at the end of the excavation, but in long-term projects, or when unique remains require immediate treatment, conservation can start earlier. Workers of the Conservation Department are not archaeologists; they lack archaeological training and work without excavation licenses/permits. Two days later Weksler-Bdolah wrote a more detailed letter:

Subject: Severe Damage to Antiquities in Conservation Work of the Eastern Cardo-The Western Wall Plaza

About a year ago [...] I sent a letter on December 23, 2008, attached here [not given to us], stating explicitly that: 
'One must ensure that an excavation - even of a few millimetres between the paving stones of the Cardo and the eastern alleys - will be performed under archaeological supervision.'

Ten months have passed since.

Yesterday, after a phone call from Aliza Van-Zaiden [an employee of the Conservation Department] [...] I arrived to the excavation area to see what transpires.

Sadly I must inform you that the Conservation Department has performed a robbery excavation at the Eastern Cardo. Employees of the department, without the presence of an archaeologist, took the liberty of digging sealed fills in the joins between the [paving] stones of the Cardo, as well as digging from the side to a depth of $25-35 \mathrm{~cm}$ beneath stones at the site. In addition, supports were built under the Cardo stones [reaching] a depth of several metres and a width of 0.25 metres or more [...] preceded by a disorderly digging of the sealed fill beneath the [Cardo] paving stones.

[...] Yesterday I received a box with some six sachets, reused tissue boxes and dirty plastic [ $=$ disposable] cups similarly used, which served to store the finds for lack of a better means. [...]

Unfortunately, these findings are of no importance today, since it is impossible to know precisely if they originated from beneath a paving stone, in a wall above the paving, or from a deep fill under the [paving] stone. One sachet included finds that could have definitely settled the date of the Cardo.

(Document 5.8; second page missing)

Small finds (coins, seals, etc.) can date an entire complex, if their context is carefully documented. Conservators lack the expertise for excavating and documenting finds. Without context, the finds lose much of their scientific value.

Accidents occur - but here the excavator warned in advance. Probably the accident reflects an intentional policy: excavating archaeologists are given no say about what happens to the sites following the excavations (cf. Document 5.9). Weksler-Bdolah's readiness to write this letter is commendable. The documents we have do not include a response.

\subsection{Who took the finds?}

In October 2012, an Inspector of the Jerusalem Municipality submitted to the IAA Robbery Prevention Department (in charge of activities against theft and illegal trade of antiquities) information concerning ancient architectural items in Wadi Qadum (an East Jerusalem neighbourhood). The IAA raided the place and confiscated the items. It became apparent that they were not stolen: 
It turned out that the items had been collected by Eitan and Roni ([workers of] Ashmar 2000) [a construction company operating on behalf of the Western Wall Heritage Foundation] from the Ha-Liba Building excavations at the Western Wall Plaza, at the request of the [Western Wall Heritage] Foundation, in order to make room for a sukkah [temporary shed erected for the Sukkot holiday].

(Document 5.10)

However, a few days later Weksler-Bdolah testified that the items did not come from her excavations:

After a conversation with you [Baruch], I met in the [Western Wall] Tunnels with [archaeologists] Haim Barbé and Avi Solomon. It turned out that Avi was familiar with the items, and also knew that the [Western Wall Heritage] Foundation wanted to remove them to their storage unit in the Bar-Giora area before Sukkot; but he asked them to leave them on the bridge, and after that was no longer involved in the matter [...]

According to Avi [Solomon] the origin of the items is: 'Some were positioned along the walls of the "crucifix room" [a space in the Western Wall Tunnels] (from earlier excavations) [...] Others were from various excavations of Alexander [Onn, IAA excavating archaeologist]'.

(Document 5.11)

In order to build a temporary Sukkah for a holiday, a contracting company removed dozens of heavy antiquities without record and without the IAA noticing. A catalogue compiled later (Document 5.12) shows that some of these items had been 'lying around' for years, coming from old excavations by Dan Bahat and even by the Ministry of Religion dozens of years ago.

\subsection{Pillars or Cardo - what will the public see?}

The number and shape of pillars required as foundations for the Ha-Liba Building will greatly affect the view of the antiquities. The IAA excavated before there was a building plan, as Shachar Poni stated: 'When we submitted our comments [to the Planning Committee] we didn't know what the structure's shape would be' (Document 5.13).

The architects drew a plan with 40 pillars. The IAA understood that this meant a 'forest of pillars' (Document 5.13): the visitors might see new concrete pillars instead of the ancient Cardo. The conclusions of Dorfman are missing; what he decided was an enigma even for his subordinates. Yuval Baruch marked on the top-right corner of this document:

'[To] Jon [Seligman]: See the Director's summary, paragraph 2.

What does it mean?' 
Seligman answered:

'I don't know. You were present during the tour!'

(Document 5.13)

Following more discussions, the architects submitted two alternatives: one with 25 pillars and another with 52. Only, the alternative with fewer pillars had a low ceiling (Document 5.14). Architect Eli Elan and Head of the Conservation Department Raanan Kislev emphasized the need to enter into serious discussions regarding the pillars (Document 5.14); but Yuval Baruch was ready to accept the 'forest':

Yuval Baruch: If we begin with the assumption that there is no solution other than basing the upper stories on a system of pillars, we need to deal with two key questions (not related to the anticipated damage to the archaeology): Is it right to sanctify the view towards the Cardo, or other views? I suggest considering a view to the west or the east, since it is more impressive. In the perspective of the Antiquities Authority, the escarpment and the view to the shops must be exposed to the eyes of the visitor.

(Document 5.14)

Buildings cannot float in the air. Erecting a large public building on top of antiquities requires massive foundations that will be inserted into the archaeological remains. The structure will 'bury' the remains in a basement. The IAA promised this to the entrepreneur in advance. All that can be done now is to minimize the damage.

To the IAA participants in the meeting it is clear that the Cardo (street) is the most important find, therefore, it should be protected from the pillars. Only Yuval Baruch proposes that the Cardo can be forsaken for the benefit of another view, whether of the rock escarpment (Figs. 5.3-5.4), or something east of the Cardo (not clear what). Baruch wants to convince the IAA to accept the 'forest of pillars,' so that the building plans will be approved as suggested. If the escarpment is so important, it is difficult to understand how the Ha-Liba Building could be approved at all, given that it blocks the view of the escarpment from the Plaza. As Tsafrir said: 'the building dwarfs the antiquities and obstructs the hewn rock escarpment' (Planning Committee 2010:17).

In an internal discussion the employees of the IAA spoke openly (Document 5.15): Karmi-Melamede's planning ignored the archaeology and was unacceptable ('the damage to archaeology is dramatic' - Raanan Kislev). Shachar Poni suggested an alternative with 28 pillars, better suited to the archaeology, but it meant a major re-planning. After a number of rounds, the IAA reached a compromise with the architects (Documents 5.16-5.17, incomplete).

Document 5.17 (probably written to justify the IAA's position in the Jerusalem planning and construction committee) is a lengthy apologetic. The author claims that 'no approval was given in advance' - but a promise was, 


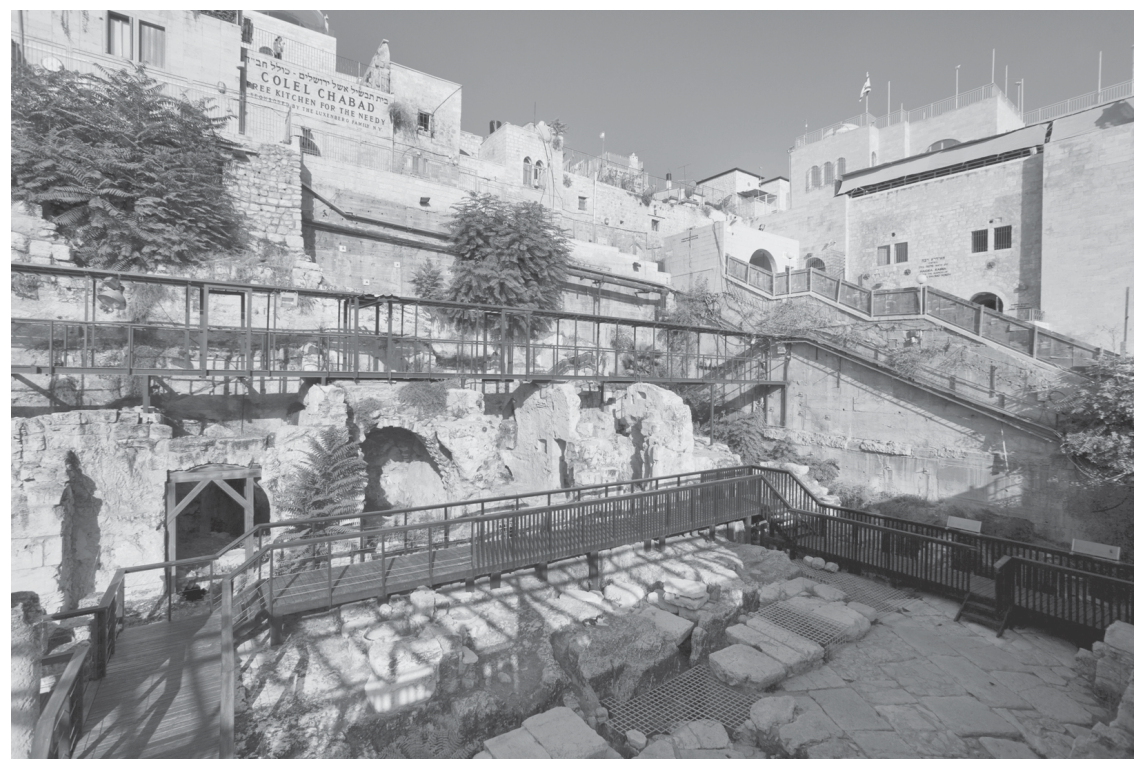

Figure 5.3 The Cardo (below), the shops and escarpment (center) and the Jewish Quarter skyline (top).

Photo Emek Shaveh

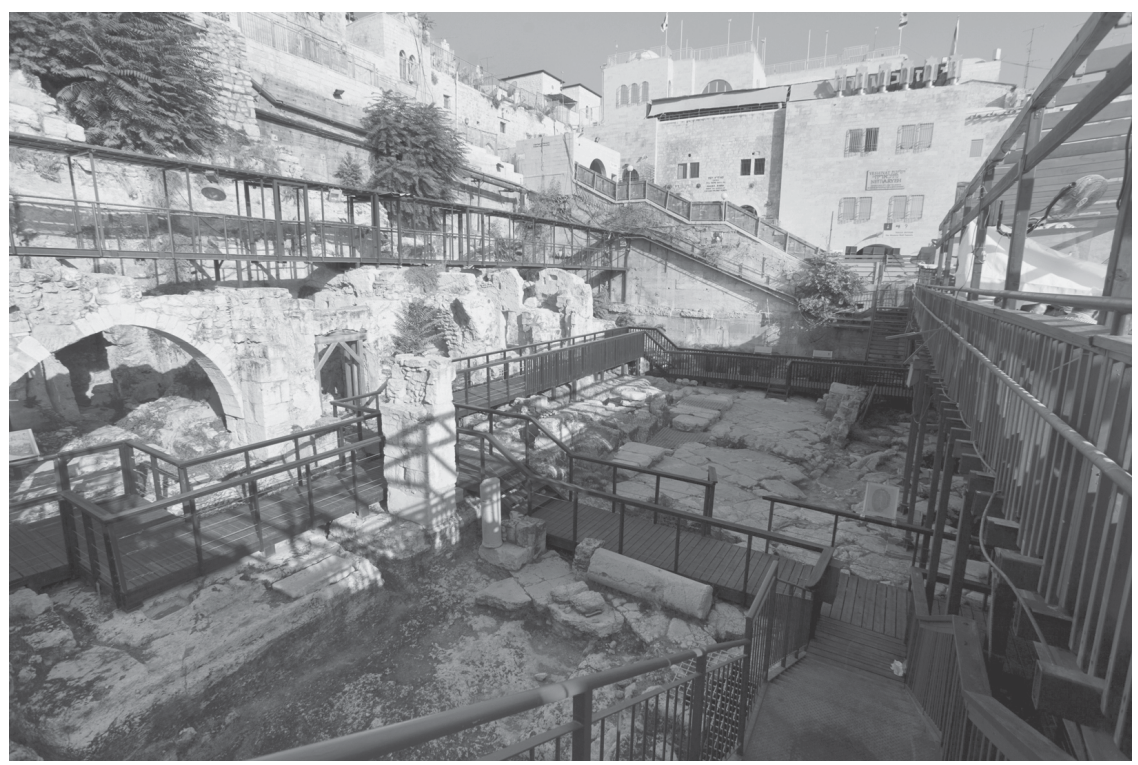

Figure 5.4 The Cardo. It requires maintenance and movement is limited. Enabling movement on the Cardo requires a massive restoration.

Photo Emek Shaveh 
making approval later a technicality. The author suggests that remains from all periods will be exhibited - we saw how nearly all the 'late' remains were removed. Allegedly, criteria for the preservation of the major finds were set from the beginning - this was impossible before the Cardo and the Iron Age building were found - at the bottom of the excavation, after dismantling the 'late' remains. We are told that Karmi-Melamede worked 'hand in hand' with the IAA, while in fact she ignored the archaeology in her plans. The author boasts about discussions in the IAA Board - a toothless body. The public was not asked about the plan. A tour of the National Academy of Sciences is mentioned, but not that this tour was organized by Yoram Tsafrir, as part of the objections to the building.

The IAA succeeded in moving the 'forest of pillars' from the Cardo, a good step that should be commended. Still, at the end of the day, what will the visitors see? For many years (until the realization of the 'comprehensive' plan) the Cardo will be 'buried' under the Ha-Liba Building. Most visitors to the Western Wall will not see it, because the Ha-Liba Building is for them a secondary attraction at best. Once the 'comprehensive' plan is realized, the Cardo is intended to serve as a passageway: 'The exposed Cardo will form an open artery for movement of the public from the Tanners' Postern (a small gate near the Dung Gate) in the south, to the Western Wall Plaza itself in the north' (Document 5.17, p.3).

However, the segment buried beneath the Ha-Liba Building cannot be extricated, and in the plans submitted to the Planning Committee, a staircase descends straight onto the Cardo (Fig. 5.5, north end of the Cardo) an intrusive element of modern architecture that blocks part of it. How will masses of visitors pass there? Amir Shoham, conservation consultant of the Jerusalem Planning Committee, posed this issue to Yuval Baruch:

Amir Shoham:

[...] Don't forget that at the ground level beneath the Ha-Liba Building there are glass walls that divide it. In other words, it is impossible to go there. In order to exit, you go up some kind of 1.20 metre-wide staircase, and pass through a glass door of the Ha-Liba Building, where a guard is standing.

(Planning Committee 2010:100, cf. also 206-207)

Yuval Baruch did not answer. Shoham also asked Dorfman about it:

\section{Mr. Amir Shoham:}

[...] I also see a glass wall that descends in the middle of the Cardo. In other words, a glass wall that separates the space of the Ha-Liba Building from the rest of the space passes through the centre of the Cardo at present. Now, in the future, when you excavate the continuation of the Cardo, this glass wall will also revolve 90 degrees in order to close off the Ha-Liba compound. And then, essentially, a building will stand where 


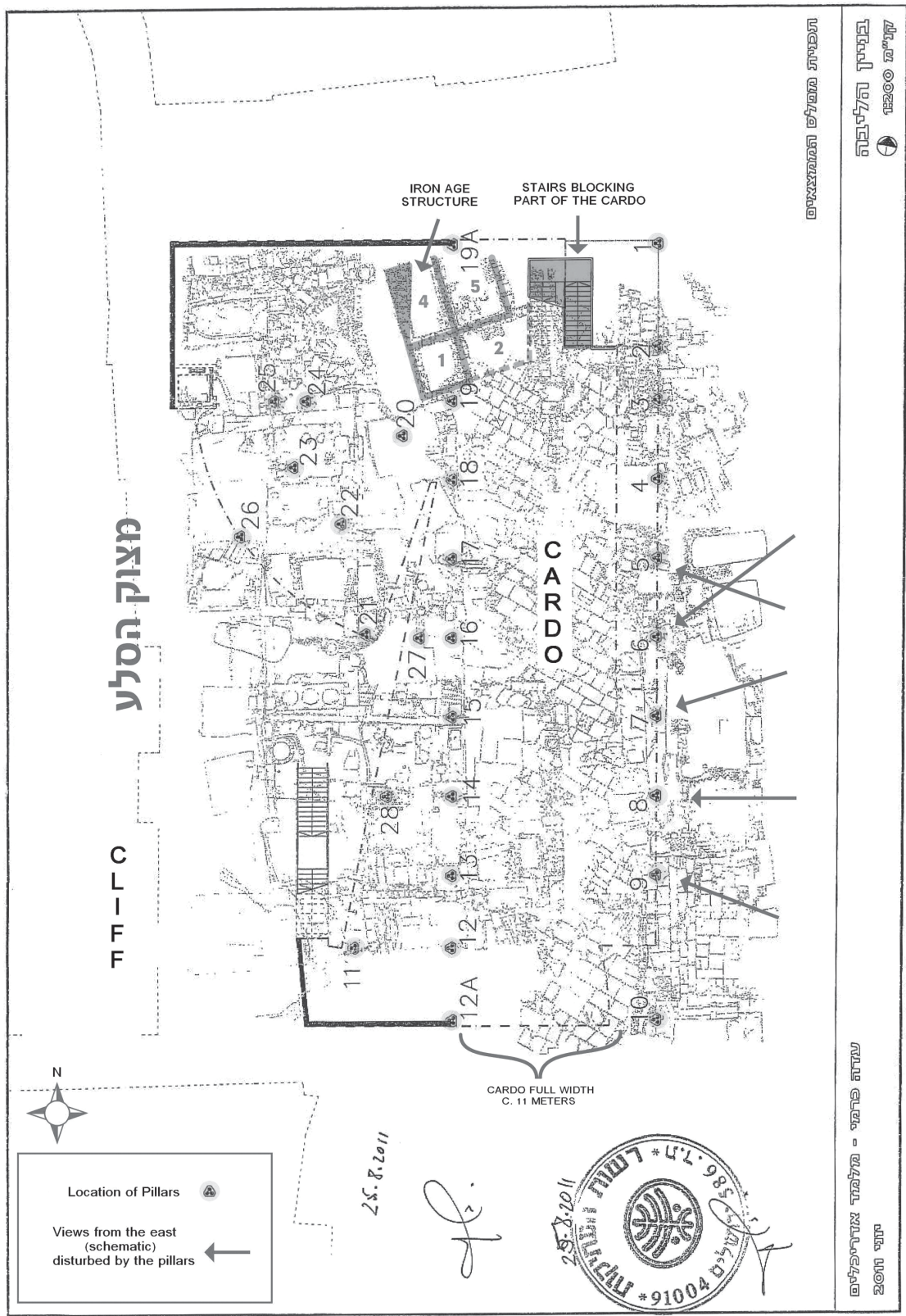

Figure 5.5 Plan by Karmi-Melamede (2011) after the pillars have been removed from the Cardo. The pillars will limit the view; those passing further to the east will see mainly the forest of pillars.

Plan prepared by Lior Cohen for Emek Shaveh, based on the IAA Documents 
there is no free passage through the Cardo; they [the visitors] will arrive at a glass wall.

Mr. Shuka Dorfman:

No.

Mr. Amir Shoham:

It passes through, it essentially closes this Cardo. [...] Currently something is not making sense to me at the most concrete level [...]

Mr. Shuka Dorfman:

I'll respond just to the central idea [...] we already have a work order to excavate the [area of the] Esh Ha-Torah [Yeshiva] ${ }^{7}$ and the idea is to connect exactly, to enter from the Tanners' Postern, to connect with the Cardo, and to walk along it until the Ha-Liba Building [...] We found it at Ohel Yitzhak [synagogue] and we want to connect it from below - that's the intention. The wider vision is that when the Western Wall Plaza is truly excavated, from there they will enter the Western Wall Plaza, and from there, the Western Wall Tunnels. That's the vision. [...] I'm also not very familiar with the security arrangements regarding how the public enters or exits [..., but surely the idea is to enter from below and to walk along the entire path [of the Cardo] from below.

Mr. Amir Shoham:

OK, look at the plan. I'm saying to you that the moment the plan cuts the $[\ldots]$ on this street.

(Planning Committee 2010:26-28)

It must be stressed that the idea of preserving and using the Cardo as an artery comes from those who have opposed the construction of the Ha-Liba Building, trying to keep it open to the sky. For example, at a conference held in 2007 Tsafrir said:

The continuation of this street was discovered in excavations north and south of the Dung Gate. One need not be a great prophet to predict that one day the portions would be connected, turning the place into one of the most important and impressive sites in Jerusalem [...]

But someone already decided that the place is more [suitable] for building [...] Here they do not even deny [it], only offer consolations: all of the ancient structures, as well as the cliff, will be presented to the public. But human reason struggles to understand how this magical act will be achieved: the antiquities will be preserved and not destroyed in the construction of pillars and foundations; the functioning of the building will not be compromised; the rock cliff will be presented; and the Jerusalem skyline, so typical to the Old City, will not be spoiled.

In this case as well, since the authorities do not understand, the public must come forth and insist on its right that cultural property not be destroyed. Room should be made for the hope that one day, all parts of the street will be joined in by excavation and be turned into a wonderful 
example of an urban street in Jerusalem [...] It is also important that a call goes out to the IAA to get a grip on itself, and stand up for its rights and responsibilities of protecting antiquities and not to compromise except in cases when it is truly impossible otherwise.

In 2010 Tsafrir said:

(Tsafrir 2008:50)

The importance of the Cardo is, among other things, in its continuity ... the continuum [is] disturbed only by the Esh Ha-Torah Yeshiva building. It would be fitting to open all of it as a thoroughfare and keep it exposed without a building above it.

(in Planning Committee 2010:16)

In 2010 the Western Wall Heritage Foundation wanted to relocate a container for electric supply near the Esh Ha-Torah building (Document 5.18; see also Document 5.6 and Document 6.15). This required an excavation and the plan was to place the container on the Cardo (Document 5.18). The excavator, Shlomit Weksler-Bdolah, did not realize this at first; when she did (Document 5.19), she wrote a sharp complaint:

On Thursday, July 22, 2010, a discussion took place in the excavation area regarding the location of the container for electricity at the Western Wall Plaza. The discussion was held ad hoc [...] In my view, the placing of any installation on the pavement of the Roman Cardo should be prohibited. The Cardo, as exposed now, must be displayed and conserved in its entirety. Not only for touristic purposes, but mainly for research [...] The research is in its preliminary stages and we must not seal it off immediately with containers for electricity [...]

(Document 5.20)

We did not find an answer in the available documents.

\subsection{The IAA supports a maximal building}

In 2010 Ada Karmi-Melamede presented the Ha-Liba plans in an IAA 'status' meeting:

Following is the summary:

Ada Karmi-Melamede presented the two alternatives proposed for the Ha-Liba Building.

Ada Karmi-Melamede:

We presented the two alternatives to Nir Barakat [Mayor of Jerusalem] [...] You have to decide how to plan the archaeological level.

Shuka Dorfman: The plans you presented look nice. How do we move ahead? 
Dorfman does not understand the problem, so Karmi-Melamede explains:

Ada Karmi-Melamede: We understood from Soli Eliav that Shlomo Eshkol [Jerusalem Municipal Architect] is checking the possibility of establishing the building based on the existing and approved Municipal Building Plan (the brown area)[;] meaning a significant reduction in the area of the lot. The Antiquities Authority must stand its ground in all that pertains to the agreements and decisions made regarding the Ha-Liba Building to date.

(Document 5.21, emphasis added)

The planned Ha-Liba Building (maximal size 3,722 square metres, ground floor 1,400 square metres, lot area 1,840 square metres) is located in two distinct lots (each associated with a different city plan: AM/9 and Jewish Quarter 2185). Part of the building belongs to the Plaza, but the majority is located in the Jewish Quarter. Indeed, one justification for the construction was that most of it would be outside the Plaza. After initial planning, however, the IAA demanded to preserve the rock escarpment, so the Building was shifted to the east, penetrating more into the Plaza. There are different estimations as to the size of the Plaza 'nibbled' by it, 500 or 250 square metres (Bar-Sheshet 2012:10; Holzberg 2012).

Given the objections and delays, the Municipal Architect contemplates using only the 'brown' area of the Jewish Quarter, which is intended for a public building. Thus, one can hardly raise convincing objections to building there. However, this implies a reduced-size building, and hence, a major change in the planning, which is naturally not to the liking of Karmi-Melamede.

Karmi-Melamede pulls the IAA into this struggle by saying that it must comply with former 'agreements and decisions.' Who made a decision in the IAA that the building must have the maximum size? Reducing the building's size is beneficial to archaeology. A certain area of antiquities, already exposed, can remain outside the construction, open to the sky. Even if it must be covered to restore the Plaza, fewer pillars will be necessary (because there is no heavy building atop).

Shuka Dorfman decided as follows:

1. It is the responsibility of the office [of the IAA management] to schedule a working meeting with Shlomo Eshkol [Jerusalem Municipal Architect].

2. The topic of how the archaeological layer is going to be handled and the utility of the antiquities (ofen hashmashat ha-atiqot) will be discussed in the future.

(Document 5.21)

The IAA Director hurries to meet the Municipal Architect in order to speak in favour of the maximalist plan. Rather than support the option that is beneficial for antiquities, he supports the entrepreneur's wishes. Notice that 
building plan 11053 determines that for the benefit of the antiquities, the IAA has the right to reduce the construction area (Ha-Liba Plan 2006:10, \#F13). Meantime, deciding the 'utility' (hashmasha) of the antiquities (an ugly term, fitting commercial objects) can wait (Document 5.21).

The claim that Karmi-Melamede worked 'hand in hand' with the archaeologists from the start (Document 5.17) was far from precise. The excavations began before any plan was presented (Poni, Document 5.13). The initial plans of Karmi-Melamede 'completely ignored' the archaeology (Document 5.15). Even in late 2009, after the end of the excavations, the cooperation with the architect was difficult:

Soli Eliav [Director of the Western Wall Heritage Foundation]: [...] Has the topic of the planning moved forward vis-à-vis Ada Karmi-Melamede, since the plans are prior to submission to the District Committee? [I] am aware that Ada Karmi-Melamede worked according to your directives.

Raanan Kislev: There has been no progress vis-à-vis Ada KarmiMelamede. She cancelled four meetings and was about an hour and a half late to another [...] In effect, nothing has changed and we didn't receive a new plan beyond the theoretical conceptions presented in the past.

(Document 5.22, emphasis added)

In light of the objections submitted to the Sub-Committee of Objections of the National Council for Construction and Planning, the entrepreneur was requested to present alternative plans that reduce the volume of the building. On December 9, 2014, the Jerusalem Planning Committee discussed the suggestions to 'slice' the southern part of the building by 5 or 13 metres. The entrepreneur did not bring true alternatives (detailed plans), but struggled to approve the maximal plan. The architects claimed that all the planning was determined according to the archaeology, and therefore, could not be changed now:

Mr. Gai Teomi:

From the inception of the planning, exactly ten years ago, the connection to the archaeological finds was a connection that could not be cut off. This building sits on the archaeology, is fed by it, all of our planning relates to the archaeology, as well as to ... the finds. To cut the archaeology off from the building now is a severe blow.

(Planning Committee 2014:12)

During the planning the archaeology was ignored (Document 5.15). Now the archaeology is an excuse not to change the plans. The IAA mustered all its power to help the entrepreneur by raising claims against reducing the building:

Mr. Yuval Baruch:

I would like to return to Gai's comment that the plan was made under close cooperation [hadukah, mistakenly transcribed as adukah, 'in a 
religious way'] with the IAA, and, in effect, we [the IAA] wrote the sections regarding the planning of the lower part [...] Clearly, a number of things that were part of our basic conditions were examined thoroughly. Let's begin with the roof level. We demanded that as much of the bottom floor as possible be illuminated and exposed to the sky [apparently meaning the requirement about leaving some part open through the building, from the roof to the antiquities level]. Of course, any narrowing or reduction of the area will infringe on this condition. This is something we view as a deviation from the conditions of the IAA, [our] fundamental conditions. On the floor itself, the basement floor, of course any narrowing will detract from the experience of the wide, high space - [that is,] any narrowing that will reduce the space or lower it. I think that there is no one here who thinks that it will be beneficial to the experience of visiting the place - the reverse is true. We are also concerned, and we tried to evaluate it, although not all of the data are clear - we don't know exactly what the plan is [...] In addition, the southern [or] southwestern part of the building is the more s[ignificant?] part [...] concerning the antiquities[.] The damage will be in the [building's] most critical part, where the remains are higher. Actually, what we, what I am speaking about, is [about the] minimal narrowing. I don't deal with the maximal [reduction of $13 \mathrm{~m}$.]. In my view, it [maximal reduction] will be a problem that we'll have to see whether we can even approve it in the IAA. It is very severe; it will be a mortal blow to the experience of visiting the space.

(Planning Committee 2014:20)

The small area that is open through the entire height of the building can be planned differently. This is not a convincing argument. If an opening to the sky is crucial, why does the IAA oppose the smaller alternative, which leaves more antiquities outside the building? A narrower space does not necessarily mean a lower one, and antiquities in a building can only be seen when it is opened (cf. Bar Sheshet, Planning Committee 2014:42, 59). When the arguments have been exhausted, vague excuses about 'the experience of the visitor' are raised. Yuval Baruch is asked why the experience of the visitor would be compromised, and insists on relating it to the low ceiling:

\section{Yuval Baruch:}

The ceiling will sit on the antiquities.

Mr. Yoram Tsafrir [present as an opponent of the building]:

And if everything is left open?

Mr. Yuval Baruch:

Another matter is safeguarding the open space. We think that creating an open space in such a limited area [after the reduction in size] will not serve the purpose, and in effect, it may turn into a trap for garbage. It will cut [...] the area off from the remains located to the north, i.e., those that will be beneath the building of the Western Wall Heritage Foundation 
[=Ha-Liba Building]. I remind everyone that the requirement [...] was to preserve the experience [of the visitors], an experience that will emphasize as much as possible the continuity of the Cardo from south to north, that would leave a space as wide as possible and enable a high space. Again, the issue of exposure to the sky and to the sunlight. So in our perspective, we don't like this reduction, to say the least. Of course, the maximum reduction [13 m.] will require from my perspective an examination, a much more thorough examination. It is not certain that we will be even able to approve it.

(Planning Committee 2014:20-21)

How will leaving antiquities open lead to their being cut off from what remains beneath the new building? According to the IAA, this excellent building 'floats above the antiquities' and does not cut the antiquities from their environment. In addition to this absurdity, Baruch claims that if they subtract 100 or 200 square metres from the building and leave the antiquities open there, a garbage trap will be created. Cleaning services are necessary in every public space, whether open or not. The Ha-Liba building will cut off the continuity of the Cardo. Any part of the Cardo left outside of it is a benefit.

Since no true alternatives (detailed plans) are presented, the data is unclear, as Attorney Gilad Barnea (representing Mr. Ephraim Holzberg, a resident of the Jewish Quarter who opposed the construction) emphasized:

The area commander [a police officer, whose letter to the entrepreneur was quoted earlier], it is unclear why he volunteered and who asked him to submit a document [...] Likewise [did] the regional archaeologist [Yuval Baruch]. I must say, I am astonished how he is rushing ahead. He did not see a plan [of the alternatives]. He does not know what the story is, but already has conclusions, he has suggestions. I must say, regretfully, that the conduct of the IAA deviates from its mandate. Rather than [act as] the body responsible for the antiquities and the archaeological heritage, it has become essentially a complete partner in the [building] plan [...] It is acting as a consultant for the initiators of the plan, and not as an independent body bound to the objectives stipulated in the Antiquities Law.

(Planning Committee 2014:40, emphases added)

Yoram Tsafrir pleaded:

What were we fighting for? That these antiquities would be exposed, because it is important, it's part of the array of this area of Ha-Liba Building. What has been determined is determined [meaning the building is a fact; the debate now concerns the size only]. We lost, you know. What can be saved is a very large area that can afterwards connect with 'Davidson Park' to where the street continues. It passes the Dung Gate, so why bury it for God's sake? [...] 
All of it can be connected, achieving a continuum that will drive the world wild. In terms of tourists, culturally, values - I don't understand why this alternative of covering everything at the height of the Western Wall Plaza ... is the right [thing]. The whole topic of roofing, [about which] Dr. Yuval Baruch lectured last time, and gave a very broad presentation, [Tsafrir speaks ironically:] which convinced us that we need to cover it, that covering it was the best thing. I immediately ran and told colleagues: let's put a roof over Beth Shean, and I phoned the director of Masada. I told [him], let's put a roof over Masada, and I have friends who work at Pompeii. I told [them], quickly, run put a roof over Pompeii! There are [delicate] things where there is no choice, [such as] if it's a mosaic, if it's a fresco, one must put a roof [to protect them]. No one would oppose that. That is not the present case. It's a fact that everything that is called the Davidson Park, the entire area of the Southern West Wall, has no roofing, and it is standing, the stones that stood there since Herod are standing there very nicely to this day. So I request dismissing this argument altogether.

(Planning Committee 2014:36-38)

Just a decade earlier, the IAA prepared, together with Professor Mike Turner (of UNESCO's Israel World Heritage Committee), the chapter on archaeology for the 'Jerusalem 2000' plan. There, they determined that in the Old City it was essential to preserve 'the entire ancient fabric' with particular caution: 'It is extremely important to maintain close and cautions inspection of plans proposed for the Old City, relative to the inspection of planning at other sites' (Jerusalem 2000: Chap. 11, p.323).

It was determined that open areas are an inseparable part of the city's built heritage and that their preservation is not less important than the preservation of buildings. The Old City and the Western Wall Plaza were defined as areas abounding in special sites and worthy of special protection. Sites there must remain 'visible to the public eye' and preserved in situ, keeping their relation to the surroundings:

A buffer zone must be preserved around the site, and building in the area that is not for purposes of the site should not be permitted ... [as also] construction that 'chokes' and hides the site from the public eye, or makes access difficult.

(Jerusalem 2000:334)

It was explicitly determined that the 'burial' of antiquities within new buildings must be avoided:

As a rule, new construction on the grounds of an antiquities site, where the finds will ultimately be located within the building space, should 
be avoided at all costs. Finds located within a structure (such as the 'Convention Centre,' Site No. 37) entirely lose their original environmental context.

(Jerusalem 2000:335) $^{8}$

Meanwhile, Professor Turner was replaced by an architect identified with the settler organization El-Ad (Hasson and Dvir 2011; Dvir 2011), and the IAA reversed its position. Compare the quotes just cited with the words of Yuval Baruch before the Planning Committee:

Mr. Yuval Baruch:

[...] As far as I know, I hope it is also correct, the construction has been approved, and therefore, I will address [only] the ramifications of the downscaling, should they [sic] be necessary. After we examined the plan, the possibilities, all the possibilities of downscaling the southern part, we think, in this specific context - and I am the representative of the [Antiquities] Authority - that the reduction will significantly detract from the archaeological experience. That's for one.

Mr. Yishai Telor [Representative of the Ministry of Transportation]:

How?

Mr. Yuval Baruch:

I explained it earlier.

Mr. Yishai Telor:

Then I didn't understand.

Mr. Yuval Baruch:

Also the low ceiling that...

Mr. Yishai Telor:

And what if there's no low ceiling? Then it would be fine?

Mr. Yuval Baruch:

I'm talking about what was presented to us, what are the possibilities.

A low ceiling on top of...

Mr. Yishai Telor:

And if there's no low ceiling?

Mr. Yuval Baruch:

Yishai, let me speak.

Mr. Yishai Telor:

But I'm asking a question [and] you're not answering.

Mr. Yuval Baruch:

A low ceiling on top of the remains will be defined... [Rest of sentence missing]

(Planning Committee 2014:51-52, emphases added)

Despite all its contradictions and twists, official forums like planning committees tend to accept the position of the IAA, since it is the official state agency for handling antiquities. Note how Yuval Baruch emphasizes, halfway 
through his words: 'I am the representative of the [Antiquities] Authority.' What matters is not the logic of the arguments, but the fact that the speaker is held to be an authority. As the Jerusalem Municipal Architect reminds the committee:

\section{Mr. Shlomo Eshkol:}

Also in the debate between the archaeologists, there is always the question: The IAA made a very unequivocal assertion. Yoram Tsafrir expressed a different position. We [that is, for us] in our professional discussions, the IAA is the 'professional address', because there is no other way.

(Planning Committee 2010:158)

Sadly, in the case of the Ha-Liba Building, the IAA acted not in the interests of the antiquities, but in the interests of the entrepreneur.

\subsection{What is important to the IAA}

While discussing the Ha-Liba Building in the Planning Committee, Yuval Baruch explained what is important to the IAA:

\section{Mr. Yuval Baruch:}

It is true that the academic issues were not clarified in the excavations then [of the Cardo in the Jewish Quarter, during the 1970s] as they have been clarified today [in the Ha-Liba area]. The method [and] the archaeologists are more precise [today]. Moreover, the resources that the [Western Wall Heritage] Foundation placed at the disposal of science in this case, were infinitely [more] than what was given to other institutions. Yoram [Tsafrir] can attest, as one of the senior archaeologists in Israel, how important resources are for reaching the scientific truth. This thing, it is important that we all should keep it in mind. But this is not what we set as our ideal [omed le-neged eynenu], Heavens forbid.

(Planning Committee 2010:95)

Baruch believes that there is one absolute scientific truth, which is accessible only with a large amount of money. ${ }^{9}$ Members of the committee understood well what he said:

Mr. Yishai Telor [Representative of the Ministry of Transportation]:

In the area of the Ha-Liba [Building], the moment that they gave money to it, they excavated and that's to [their] credit. They excavate, and I am familiar with the IAA. We work with them intensively. The moment you give them a large budget, you always reach compromises with them, and 
Yuval [Baruch] said this in the slip of a tongue, and we noticed here Shaked, Avi and I, and I suppose that others noticed this as well.

Mr. Avraham Shaked [Society for the Protection of Nature, Representative of environmental organizations on the committee]:

I remained silent.

Mr. Yishai Telor:

You remained silent, but I noticed it. He said look, they let us excavate, and they'll give us a lot of money to excavate, and who gave it? The Western Wall Foundation gave it so that they would excavate.

(Planning Committee 2010:114, emphases added)

\subsection{Summary}

An important archaeological excavation was carried out for the Ha-Liba Building, but the entire process surrounding the excavation was fundamentally deficient. The excavator was forced to work very fast (see Eliav and Dorfman in Document 6.6); this can only damage the quality of the work. Most of the remains from the Islamic periods were dismantled, including a 17th century CE Sheikh Tomb. The Conservation Department carried out digging in a manner resembling robbery digs. Archaeology is pushed to the margins and antiquities will be 'buried' in a basement floor, cut off from their surroundings.

We do not determine here if such a massive building, with a fortified front and narrow slit-like windows (Jacobson 2015), fits this place. Archeologically speaking, the problem lies with the advance promise that the IAA made to the entrepreneur. The entire chain of events that ensued was a result of this promise. The IAA was drawn into a series of embarrassing performances on the stage of the planning committees, repeatedly bearing its full weight in favour of the entrepreneur, supporting plans that compromise antiquities.

The Ha-Liba Building was finally approved with a reduced size (Hasson 2015a), and is now under construction.

\section{Notes}

1 In the interest of proper disclosure, the present author wrote an academic study on Iron Age figurines from the Ha-Liba Building. This study was completed and submitted to the excavator in 2009. At that time the author knew nothing about the documents discussed here.

2 Cardo is the main street in Roman period cities. In Jerusalem there were two: the Eastern Cardo mentioned here, and the Central Cardo, whose remains were exposed by Avigad in the Jewish Quarter.

3 This is not final minutes, but 'raw' transcription based on recordings. Some words were unclear, perhaps obscured by noise.

4 Sort of a board of the IAA, wielding little power; not to be confused with the Advisory Archaeological Council. 
5 In a 'Status' meeting on the same day (January 23, 2013) Yuval Baruch complained about this letter in 'wide distribution' by Weksler-Bdolah, saying 'this is not the way to solve things.' Dorfman concluded: 'the Archaeology Administration is responsible to update Shlomit Weksler Bdolah that problems of this sort should be solved with her superiors.'

6 See www.thekotel.org/western_wall_sites/core_excavations.

7 The Esh Ha-Torah building, established years before the Cardo was found, protrudes towards the Plaza from the Jewish Quarter.

8 At the Convention Centre of Binyanei Ha-Uma in Jerusalem, excavations in the 1990s turned up remains of a large industrial area. Some remains are displayed beneath a glass floor inside the new building. This is not a success - the remains are sort of forgotten, hardly drawing visitors.

9 As for excavation methods, those used by Avigad in the Jewish Quarter in the 1970s were far better than the tunnels excavated in East Jerusalem now. 


\section{The comprehensive plan for the Western Wall Plaza}

\subsection{Comprehensive planning, or 'throwing dust in their eyes'?}

Mr. Dorfman also described the Israel Antiquities Authority's vision for the comprehensive plan, which is the excavation of the entire Western Wall Plaza and the creation of a complete archaeological level underneath it, which will enable archaeological continuity from the City of David to the Western Wall Tunnels.

(Planning Committee 2010: Minutes:6; cf. transcript:25)

The Supreme Court, dealing with the re-building of the Mughrabi Bridge, decided that a 'comprehensive plan' for the entire Western Wall Plaza was necessary before any new construction could be advanced in it.

Various plans for the Plaza (Figs. 6.1-6.4) had been put forward in the past, but all were ultimately shelved (Nitzan-Shiftan 2011; 2017). Following the court's decision, a planning process was initiated in 2008; but unlike common practice in projects of this magnitude, no architectural competition was held. The Western Wall Heritage Foundation hired the architect Gavriel (Gobi) Kertesz to work under the direction of Shlomo Eshkol, the Jerusalem City Architect (Document 6.1). Kertesz presented a plan and no alternatives were considered.

In April 2009 the IAA held a discussion on the 'comprehensive vision' for the Plaza. We received only part of the minutes (Document 6.2). The first speaker, Raanan Kislev (head of the Conservation Department) described the situation: this was a central crossroads, and 'we are being drawn in'; the IAA must be 'fully involved' - but how?

Jon Seligman (Jerusalem Region Archaeologist) said that the IAA bears a responsibility 'beyond the archaeology [...] to be present and to manage the heritage of the Old City.' The same argument was made by those who opposed the plans for the Ha-Liba and Strauss buildings, on the grounds that beyond the excavation, there is a larger archaeological heritage to preserve (though in the planning committees the IAA voiced the opposite view, supporting the entrepreneurs). Seligman added: 


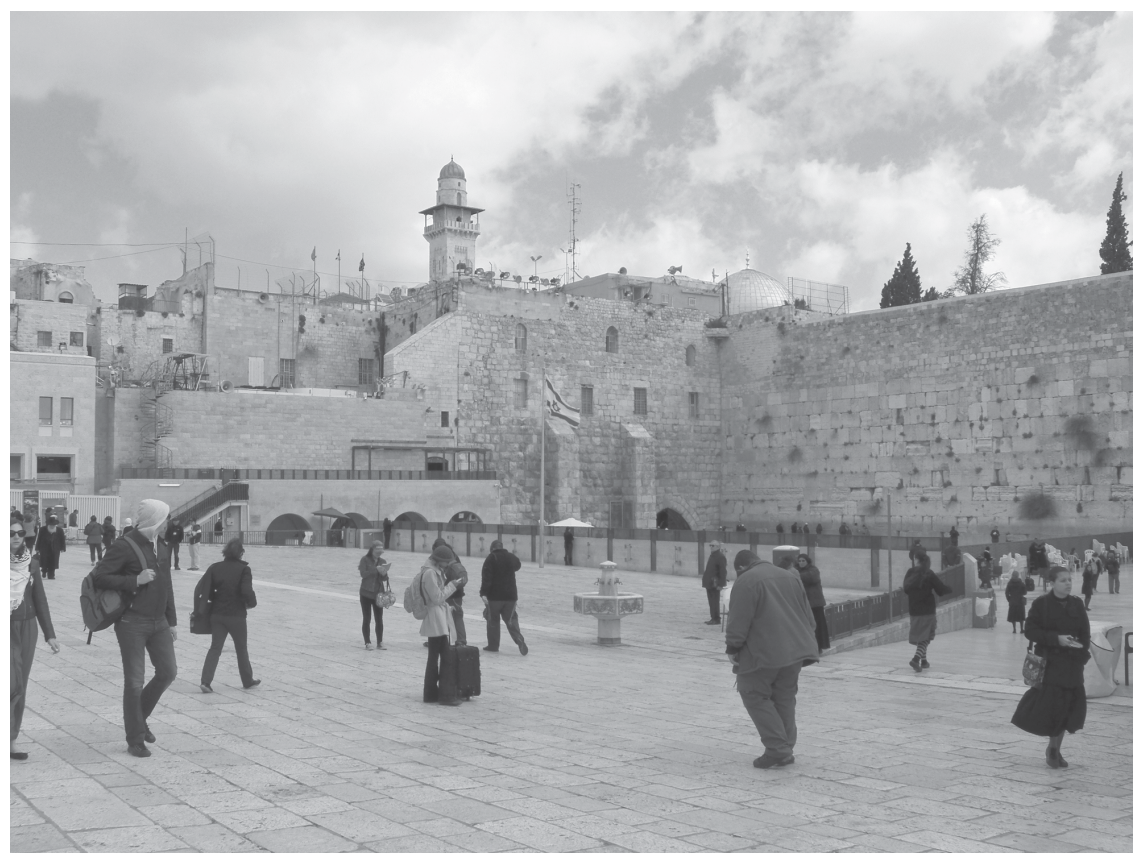

Figure 6.1 The Western Wall Plaza in 2015, view northeast.

Photo R. Kletter

We must be at the centre of this process; not to lead it, but to be a central player. There is a problem with the pressures that are placed upon us, and therefore, it is important that the process advance quickly. There was harsh public criticism of the pressure system that was activated in order to approve the plan for the Strauss Building. It was determined in the municipal plan of the Mughrabi Bridge that no [building] permit would be approved as long as there is no comprehensive plan; and then it was agreed that any future project would also require a comprehensive plan, despite the fact that it has not yet been completed.

(Document 6.2)

Seligman wants to advance the planning quickly in order to avoid public pressures on the IAA. The IAA is not troubled by the potential damage of the development plans, but by criticisms against its support of such plans. Yuval Baruch (then Jerusalem District Archaeologist) spoke next:

A comprehensive plan for the area is like 'tossing dust in the eyes.' ['] We are talking about such an expensive project that it will not materialize. There are a number of projects that are 'happening piecemeal' (the Givati 


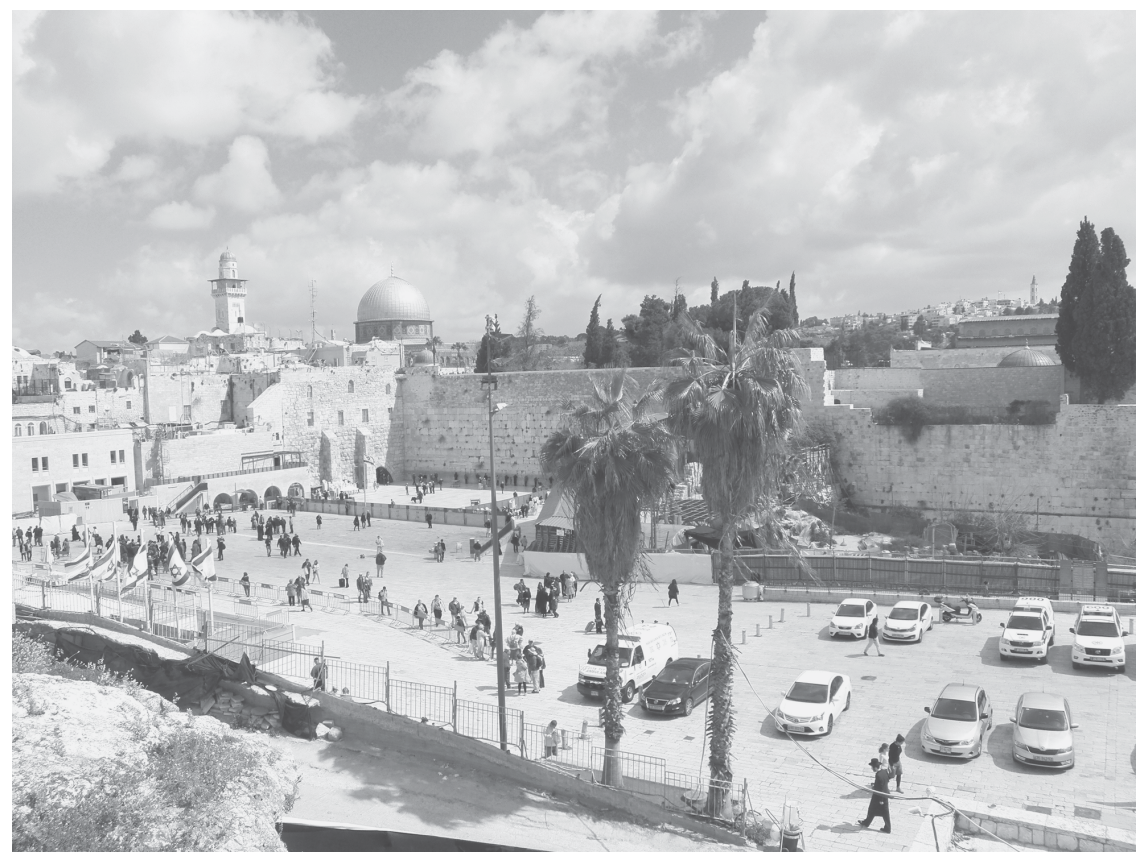

Figure 6.2 The Western Wall Plaza, general view; the temporary Mughrabi Bridge at centre (hidden by the palms).

Photo R. Kletter

parking lot is the prime example of this). We have to set conditions, but should not treat the topic as a comprehensive plan.

(Document 6.2)

Baruch saw to the core of the matter. In his opinion - unfortunately, we have to agree - what was being considered for the Plaza was not a comprehensive plan. This was exactly the view of those who opposed Kertesz's plan in the planning committees. According to Uri Barsheshet (a municipal planner) it is a 'plumber's plan': 'A plumber's plan, meaning that it is designed from the perspective of the plumbing - where the sewage line will go and where the elevators will be $[\ldots]$ but in no sense did they start with a vision' (Planning Committee 2010, Minutes: 105).

Barsheshet stressed that no one outside the direct planners was consulted. Unsurprisingly, the comprehensive plan legitimizes ex post facto all the individual projects that have been put forward beforehand:

In the meantime, according to the plan, we can approve individual projects. These will be advanced as detailed plans that are consistent with 


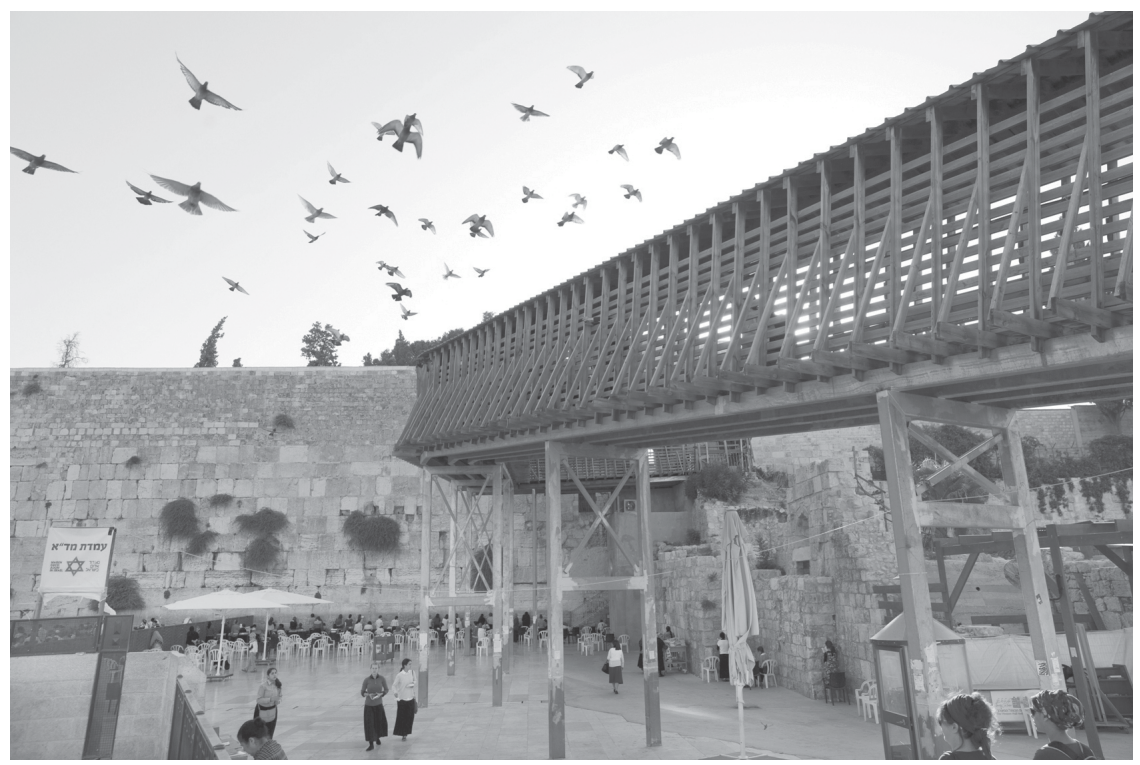

Figure 6.3 The temporary Mughrabi Bridge and the Women section of the Western Wall Plaza.

Photo Emek Shaveh

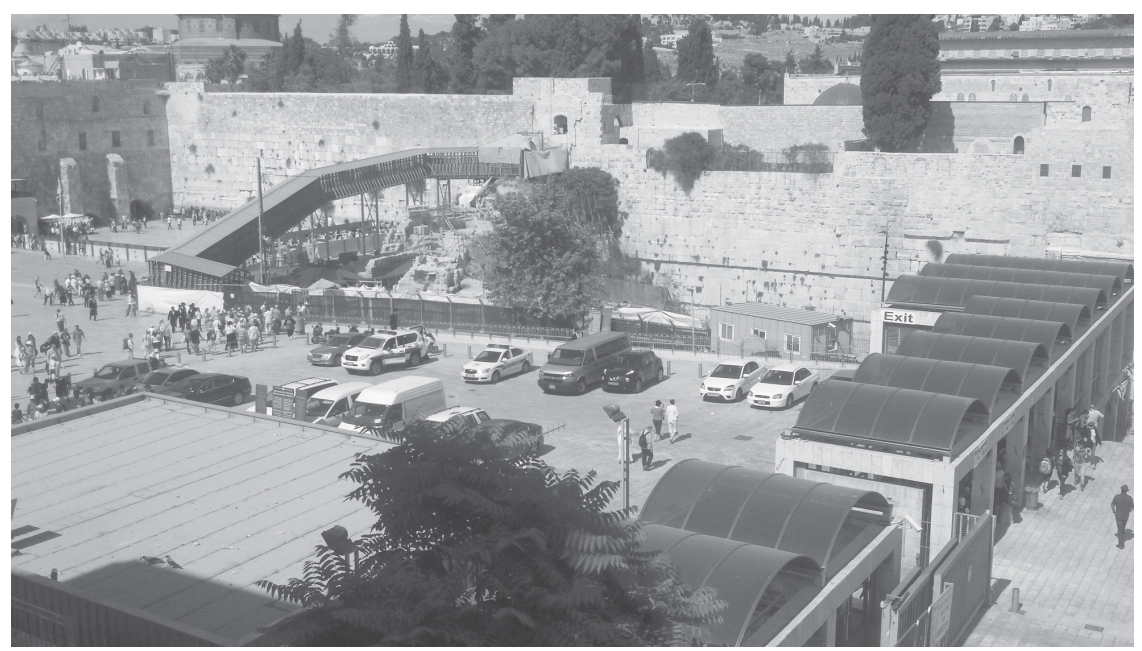

Figure 6.4 The Plaza with the Mughrabi Bridge (left) and security check structures (right). Following Kertesz's plan, the entire area will be dug and new security structures will be built in the 'archaeological' level.

Photo Emek Shaveh 
the masterplan, such as the Mughrabi Bridge, and the Strauss Building together with the Ha-Liba Building. How interesting - all the individual projects, in parallel, fit the masterplan that was created after them.

(Planning Committee 2010:105)

In an internal discussion (Document 6.2) Yuval Baruch admits that there is no comprehensive planning; but in the planning committees he would praise Kertesz's plan. According to Baruch, the way to get things done in Israel is not with a well thought-out, comprehensive plan, but by a 'piecemeal method.' Settler organizations in East Jerusalem work in precisely the same way. Perhaps this is why Baruch mentions the Silwan/Givati site as the 'prime' example of a project that 'happens in a piecemeal fashion.' Before the building at Silwan was planned, and before it received approval by the planning authorities, the IAA promised El-Ad that it would support the construction (Greenberg 2014:7).

The next speaker was Uzi Dahari, Deputy Director for Archaeology:

We must not give up our right to veto according to clause 29 of the Antiquities Law. We need to be involved [in the project/planning] from the basement to the size and shape of the windows. We have to find a mechanism that will allow us to be both partners and overseers. It is important to us to lead the archaeological [and] conservational process from within this building project. We must act through the force of the Antiquities Law and reach decisions accordingly. [I am] in favour of the large project; this is a national project that will necessitate receiving funding from the state.

(Document 6.2, emphases added)

Like Seligman, Dahari believes that things above the antiquities should not be left to architects and developers alone: the IAA must be involved. This is true. The problem is that the IAA wants to be both the implementing body (the excavator) and the supervising body. According to clause 29 of the Antiquities Law, the IAA has the authority to protect ancient sites, preventing activities that damage antiquities: 'Construction, paving, erecting facilities, quarrying, mining, drilling [...] erecting structures or walls' [etc.] (Antiquities Law 1978: par. 29).

Yet, the IAA also wants to receive a budget from the entrepreneurs for conducting salvage excavations. This conflict of interest is especially sharp when the IAA Director has little interest in archaeology, and much interest in development. Dahari believes in this 'large project' - because as a national project it will receive generous state funding.

We were not provided with the conclusions of Dorfman to this meeting, but little hope remains that the IAA would consider the comprehensive plan in terms of archaeological values, or principled thinking. The Mughrabi Bridge is another example of a piecemeal-fashion project: 
Yuval Baruch: According to the proposed plan, an extensive archaeological excavation is required [...] It is a complicated excavation and the question is whether we can create a plan that will not require an archaeological excavation. Supports, grading, and evacuating part of the plaza are called for, and we have to be prepared for that. We have to decide what will be the fate of remains that are discovered. It is already clear now that the excavation will not be complete, and, therefore, I propose that we do not conduct it at all, and find an alternative engineering solution [...]

Shuka Dorfman: Piles for the supporting walls will spare us the excavation, so we should therefore build the wall on piles. We will conduct an orderly archaeological excavation, with the intention of levelling most of the plaza, but decisions will be made according to the remains that are exposed.

Ofer Cohen: We are talking about a gravity wall that goes under the level of the plaza to a depth of a metre and a half. Therefore, there is no sense in constructing piles.

Chen Canari [Head of the Construction Department, Western Wall Heritage Foundation]: The goal of the project is to expand the women's prayer area and, for that reason, it is impossible not to conduct the excavation.

\section{Following are the Director's Decisions:}

a) Parallel to the stabilization [perhaps yitzuv; misspelled as yitzur, 'manufacture'?] of the [Mughrabi] Bridge we should start the additional works.

b) We should coordinate the alternative with the Police.

c) We should advance the planning by piles.

d) Regardless of the permission [for construction], a detailed plan should be advanced and submitted within three weeks. Then we will issue a bid, order the work, and erect the Bridge.

(Document 6.3, our emphases)

An 'extensive' excavation is required, but it 'will not be complete.' Therefore, Baruch proposes 'creating' a plan that allows the IAA to approve the construction without excavating. Dorfman found a method for avoiding archaeological excavations: building on foundation piles (see Chapter 2). There will be a partial excavation, but the word 'levelling' exposes the real intention: not to leave an area full of remains, but a levelled, clean space for construction. This time the method does not work smoothly, since the plan requires a gravity wall, not foundation piles.

\subsection{The 'pilot'}

Architect Gobi Kertesz proposed that all the Plaza be excavated to the depth of a full storey and covered by a cement roof resting on rows of pillars. The 
underground closed level will serve various purposes, though euphemistically named 'an archaeological level.'

However, before Kertesz handed in any plans, the Western Wall Heritage Foundation formed plans of its own for more excavations in the Plaza. Large budgets were available from the right-wing Government for improving Israel's hold in East Jerusalem, so ambitious projects could be planned. As the HaLiba excavations were winding down (except for a limited area under a temporary roof east of the Cardo), a big new project appeared in the 'status' meetings, under the 'Ha-Liba Building' item. It was a 'development' project without any need for development:

Soli Eliav: The Western Wall Heritage Foundation intends to excavate under the stairs that climb towards the Jewish Quarter [in the northwest area of the Plaza]. Also, we intend to expose the continuation of the Cardo to the south, and the aim is not to delay the planning of the Ha-Liba Building. Practically, is it better to extend the excavation to the east or to continue it in the direction of the Cardo [to the south?]. The frame of the Ha-Liba Building is fixed and it does not continue east or south. [...]

\section{Following are the Director's decisions: [...]}

4. We should coordinate an inner [IAA] discussion concerning making an excavation to the east or to the south, in order to examine the issue on a wider scope.

(Document 6.4)

'The frame of the Ha-Liba Building is fixed' - indeed, so the new excavations have nothing to do with it. It is a new project, breaking new ground.

A month later (June 2008) Kertesz joined a 'status' meeting (Document 6.5). Still under the Ha-Liba Building item, Soli Eliav reports that their architect, Eli Elan, suggests to enlarge the stairs descending from Ha-Shalshelet Street to the Western Wall Tunnels, and build more stairs for the Ha-Liba excavations, so 'all the northern part [of the Plaza] will be completely excavated.' This should take about half a year. Meanwhile,

To advance the Ha-Liba Building plan, we were required to advance planning done by Gobi Kertesz, who has studied the needs. After the idea is crystalized, we will focus on detailed planning. We cannot stop the planning [of the various separate projects] until there is a general plan [by Kertesz].

(Document 6.5)

There is no general vision: the Western Wall Heritage Foundation was forced to hire Kertesz, due to the Court's decision, as a means of preventing 
delay to the Ha-Liba Building plan. We can understand that they do not want to stop on-going projects until Kertesz hands in his plan; but should they add new piecemeal projects in the meantime?

As Kertesz presented, first, ideas about the comprehensive plan, Eli Elan continued with his plan for the stairs, although Seligman warned that it might prove very expensive and is, perhaps, unnecessary. Shuka Dorfman was enthusiastic about Kertesz's plan:

Shuka Dorfman: [...] Now we enter into planning the excavation of the entire Plaza. It was agreed to establish a small team that will lead the thinking and suggest how we will excavate. The intention is to leave the level of life [the active Plaza] at the same height, and create underneath it a complete archaeological level. We speak about a project that will last between five to ten years.

(Document 6.5)

Five to ten years? Just the Ha-Liba Building excavations lasted five-six years, and they covered less than $5 \%$ of the Plaza. In concluding the meeting, Dorfman was enthusiastic about all the plans:

1. The Western Wall Heritage Foundation approves in principle the excavation under the southern extent of the Bridge [the eastern, covered area of the Ha-Liba excavations?] [...]

2. Within a month the planning of the [new wide] stairs [to the Jewish Quarter?] will be submitted [...]

3. After approval [by the Western Wall Heritage Foundation] of the excavation estimate [=budget] in the southern area, the IAA will start the excavation.

4. The Western Wall Heritage Foundation approves the making of the excavation in points 3 and 4 [maybe rectangles 3-4, see Fig. 6.5].

5. The spatial [sic] planning presented by Gobi Kertesz will be examined in detail by the IAA [...]. Within two weeks the IAA will submit comments about the presented plan.

(Document 6.5)

There are so many projects involved that one finds it hard to know which is which. Yet they are all desirable, all approved by Dorfman.

Soon the entrepreneur and the IAA discuss the new project under a new title: 'the Excavation of the Western Wall Plaza' (Document 6.6; not to be confused with Weksler-Bdolah's excavations). The discussion is based on the plans of Eli Elan. It does not start from a vision, or from the so-called comprehensive planning, but from technical matters, like diameters of pillars:

Ofer Cohen: We estimate that the diameter of the pillar will be $70 \mathrm{~cm}$. On the one hand, we will examine the archaeological damage and on 
the other hand, the demands of safety. The suggested solution will allow movement of vehicles. We will consider more options. We work in the most efficient way. We should take into account the network of the pillars and therefore, the plan of Eli Elan is efficient and [even] necessary.

(Document 6.6)

Uzi Dahari (head, IAA Archaeology Administration) tries to warn against this plan. He starts with a practical question: whether to excavate as at the Ha-Liba Building (under open skies), or first insert the pillars and excavate around them (also under a temporary ceiling, so as not to interrupt life on the Plaza). Dahari warns that the insertion of piles 'is very problematic and will lead to severe public criticism,' and that there are grave ethical issues involved:

One should discuss this issue and put it to public debate before reaching decisions. In the present case, the exposure of the archaeology is important but is not vital. There is great importance to exhibiting archaeology, but not at all costs. The project is not urgent and one should work slowly.

(Document 6.6)

Dahari's voice is lost in a desert of men of action; for it seems that they just ignore him. They continue discussing technical details, perhaps because talk about ethical principles is foreign to their ears. Chen Canari explains that a roof as in the eastern part of the Ha-Liba Building will require 70 pillars (per unit of $12 \times 24$ metres, based on later documents). The destructive micro-piles are aimed at 'advancing the time table' (sic, just after Dahari recommended working slowly). Soli Eliav adds fuel to the fire:

Soli Eliav: Most of the excavations will take place between Succot and Easter [middle of October 2008 to late April 2009]. The question is, do we want to use the present opportunity for excavating the entire Plaza within six years.

(Document 6.6)

The next speaker, Jerusalem Region Archaeologist Jon Seligman, starts like Dahari with practical issues and ends with ethics. Perhaps the only way for archaeologists to raise ethical issues before such a management is to mask them by practical arguments first:

Jon Seligman: In the upper part we will discover the foundations of the buildings of the Mughrabi neighbourhood and all the rest is open [=unknown]. We should consider whether there are more engineering solutions for roofing the excavation areas. We speak about archaeologic damage on a large scale. Presently we miss a lot of data in order to make such a fateful decision. He suggests organizing a public discussion.

(Document 6.6) 
The practical issue is an uneasy subject: the Mughrabi Quarter was erased in 1967. Seligman gives here only a factual evaluation, but the participants can interpret his words as supporting a quick dismissal of the Mughrabi remains, for they are 'late' and unimportant. Seligman warns, though, that the pillars will cause large-scale damage. Ethically speaking, it is a 'fateful decision.' It should involve public discussion, not just a few powerful entrepreneurs and interested bodies. As usual, Yuval Baruch rushes to support the developers:

Yuval Baruch: There must be a complete, single move, in which we integrate the [general] planning of the Western Wall Plaza with the excavation of the Plaza. Therefore, he suggests defining the project of the excavations as a salvage excavation in the frame of planning and restoring the Western Wall Plaza. If we speak about salvage excavations, we can face public criticism. Such a project has not been done in Jerusalem since the excavations of Benyamin Mazar in the Archaeological Park, and therefore, it is a unique opportunity which would be a pity to miss. Although it is a difficult decision, since clearly the drills would destroy antiquities, one has to grasp the opportunity and approve the excavation on a similar scheme to what has been presented to us. In the past we have approved the building of support walls using micro-piles even at the expense of damage to antiquities (for example, at the Mughrabi Bridge and Givati Parking [=Silwan]). The system of work at the Ha-Liba Building and erecting a light steel-beam and wood ceiling does not fit the type of excavation, when we shall dig to a large depth of c. 15-20 metres.

(Document 6.6)

Baruch favours the new project; the 'difficult decision' is not difficult at all for him. He supports the project exactly as the entrepreneur wishes ('on a similar scheme to what has been presented to us'). Former 'sins' (at the Mughrabi Bridge and Silwan) justify a larger 'sin' now. Baruch imagines very deep excavations, but the entrepreneur plans to reach only the Cardo level, some 6-7 metres deep. An immediate construction is needed just to please the entrepreneur, who does not want to temporarily shut down any part of the Plaza in order to enable proper excavations. The IAA must resist such plans and demand a proper excavation first, in order to protect antiquities.

Shocking is Baruch's suggestion to mask such unnecessary excavations as necessary salvage excavations for 'restoring the Plaza', in order to prevent public criticism. Is cheating the public in order to gain funds for unnecessary projects (paid by the public) one of the aims for which the IAA was established?

The next speaker, Architect Shachar Poni, notes that the plan of Elan is problematic both archaeologically and architecturally. So (we add) why go forward with it? Raanan Kislev (Head of the Conservation Administration) hurries to silence Poni: 'We should separate the technology from the planning. At the moment, the discussion is only about making an excavation in one technology or another' (Document 6.6). 
This would stop all principal and ethical criticism. While Kislev can judge the quality of pillars and foundations, he has no expertise in archaeology. There are accepted, tested 'techniques' for archaeological excavations; they concern carefully exposing and documenting layers, finds and contexts. Inserting pillars is not a technique for archaeological excavation. It is a destructive construction technique that damages the archaeology. No archaeological excavation can or should start by inserting pillars; especially not in such an important site.

With such managers, all that is left is to discuss are diameters and numbers of pillars for insertion into the archaeology. It is not random that the participants in all the 'status' meetings are almost all men - men of action, technocrats, men of high military rank in a militaristic society. Their vision is limited to inserting pillars and erecting massive structures, exposing and removing. They treat the place not with gentle love, but forcefully, as virgin territory to be penetrated, conquered and confined in a cement prison.

Baruch put his finger on one crucial matter, even if he could not understand the ethical implications. The general planning for the Plaza (plan: Gobi Kertesz) should be 'integrated' with the new 'excavation of the Plaza' (plan: Eli Elan). After all, both have the same entrepreneur (the Western Wall Heritage Foundation) and contractor (IAA), and are planned for the same area. How are two Plaza plans being advanced by the same entrepreneur at the same time? Are we repeating the Ohel Yitzhak experience, only without justification (the aim of restoring the synagogue)? The entrepreneur that is supposed to do a comprehensive planning for the Plaza embarks, at the same time, on a 'piecemeal' project in the Plaza; thus possibly ruining any chance of meaningful general planning.

The IAA Director, Shuka Dorfman, is not there to ask questions. $\mathrm{He}$ rushes into realizing the piecemeal project by uttering the magical words 'detailed planning.' God is in the little details, said Mies Van Der Ruhe, but he meant something altogether different, and understood architectural planning. Dorfman is at least aware that inserting micro-piles is 'problematic,' but will he prevent it from happening?

Alexander Onn (an IAA excavating archaeologist), probably shocked by this discussion, asked simple questions, perhaps naïvely, in light of the surrounding company: 'Alexander Onn: The question is, what is the aim of the project? Is it only an archaeological excavation? Is it exposing the archaeology? Why not excavate in smaller squares?' [Meaning, like any proper archaeological excavation] (Document 6.6).

He receives no answers. Soli Eliav spoke next. He cannot answer archaeological questions, but has a vision and shows openness by saying that public support is important. He adds some surprising words:

Soli Eliav: The aim is that through the stones and the exposing of the archaeology we shall teach the next generation, what was here and what 
will be the future (ma haya kan u-ma yihyeh ha-atid). [...] He suggests not to work on the basis of the rate of work in the Ha-Liba Building excavations. The project does not serve religious needs (tzrachim datiyim) and it is not inevitable that the Orthodox world will oppose its execution.

(Document 6.6)

According to Eliav the aim of the project is educational. Can archaeology show 'what will be in the future'? Apparently, it can, if there is only one past, a Jewish past, and one future, a Jewish future; and the one leads inevitably to the other. The role of archaeology is, therefore, to show the Jewish past, the foundation for the future. The project, therefore, has deep nationalistic and religious implications, although Eliav admits that it serves no practical religious needs. Excavating the Plaza does not help to pray there, perhaps the contrary (due to temporary obstacles and limitations). Most surprisingly, the entrepreneur is not pushing the IAA to work in haste, as at the Ha-Liba Building. Will the IAA pay attention, and check its craving for more projects and budgets? Dorfman concluded the meeting:

$[\ldots]$ b) The project is very worthy and the ambitions are legitimate.

c) One should examine the planning [?], which ought to be done correctly. [The word is hitachnut, 'practicability', but it does not fit the context, so perhaps the intention is 'planning'].

d) Undoubtedly the issue will reach public debate, but only after there is a detailed planning for the entire Western Wall Plaza.

e) One should set professional planning teams with the participation of: engineers, architects, and archaeologists.

f) The planning teams will examine all the relations [between various aspects?], will set orders of priorities, and will present three alternatives within two weeks.

g) In principle, the project is approved, according to conditions that will be decided later.

(Document 6.6)

The excavation is a fait accompli: there is no reference to the archaeological warnings and ethical questions of Dahari, Seligman and Onn. Dorfman repeats the magical formulae ('detailed planning,' 'professional planning,' etc.). In his mind we 'ask' the public only after we finish the planning to the last detail. Of course, Dorfman has no intention of asking the public anything: he means that the public will learn by some leak, the later the better. In the professional teams that Dorfman sets up the archaeologists come last. The seriousness of his 'planning' is reflected by the fact that he assigns two weeks for the work. In his mind spending more time is a waste of time, although at stake is the fate of the entire Western Wall Plaza. The three 'alternatives' of planning concern only technicalities: how many pillars of 
which size to stick into the archaeology. The project is approved in principle; conditions can be discussed later, for they are not really important and will not stop the project.

While Kertesz works on his comprehensive plan for the Plaza, the IAA and the Western Wall Heritage Foundation work on their own plans for piecemeal excavations of the Plaza. Sometimes, the entrepreneur pushes the IAA forward:

Soli Eliav: Alternatives to the engineering aspect have been presented. One alternative was accepted by majority view. An official opinion by the IAA was not yet submitted. The plan is to start the excavation in the zone nearer the divide between the upper [men] Plaza and the lower [women] Plaza. We should use the time [until the excavation?] to perform the drillings. Also we should use the winter time [...].

Jon Seligman: The Jerusalem Region started to build the excavation system [meaning prepare for it]. Presently we are collecting the material; when this is done, we will bring it to the approval of the Director.

Ofer Cohen: according to the claim of the soil advisor, we can lower the number of pillars and perform a permanent roofing directly, without performing a temporary roofing.

Decision [by Dorfman]: After Jon Seligman will finish collecting the material, the issue should be summarized in an inner IAA meeting.

(Document 6.7)

At other times, the IAA does the pushing:

Shuka Dorfman: The IAA can submit an estimate for performing the Western Wall excavation within a month.

Chen Canari: We have not yet reached the stage that we can start excavating. We are in the stages of planning and examining. [...]

Ofer Cohen: Before starting the excavation, one must make preparations and take in account the phase of drilling.

Following are the [IAA] Director's decisions:

1. The Jerusalem Region is responsible for submitting to the Western Wall Heritage Foundation an estimate for the excavation of two rectangles $12 \times 48$ [metres], only for the excavation, excluding supports and additional works.

2. The Western Wall Heritage Foundation is responsible for informing the IAA about the start of the excavation one month in advance.

3. The excavation of the first two squares will be defined as a pilot.

4. The Western Wall Heritage Foundation is responsible for presenting a plan for approval in the next status meeting.

(Document 6.8) 
Dorfman orders the entrepreneur to present plans, no matter what, in about a month; and the IAA to stand to arms. The IAA and the Western Wall Heritage Foundation speak the same language, a language of technocrats:

Chen Canari: We drill, we reach the final phase [mofa], and only then the excavation starts. We should take into account that the pillars' module is unified and orderly, and the Western Wall Plaza remains active throughout the period of the excavation.

Ofer Cohen: We defined section 3 and 4 as a pilot, [because] to work next to the women's prayer area [ezrat nashim] is not realistic. The removal of material [will be made] from the side through [units] 1 and 2 . We will put beams and re-pave the Plaza. The excavation shall be made from the top down $[. .$.$] .$

Yuval Baruch: Buildings and cellars of the Mughrabi neighbourhood will be exposed. In the past the area was excavated by Benyamin Mazar; earth fill and not refuse appeared already in the first metre [from the surface]. Shuka Dorfman: Can we start working, regarding the engineering planning?

Ofer Cohen: The engineering planning exists on the principal level. It was agreed that we shall make a pilot for a diamond drill to a depth of 15 metres.

Chen Canari: Perhaps we shall make a percussion drill (a regular micropile). In the first three metres [sic] the excavation will be done by tractor (until we reach an archaeological layer).

Avner Gilead: One should consider that the micro-piles might cause concussions to the work done in the Western wall Tunnels.

Ofer Cohen: There is a reasonable distance which will prevent concussions. Raanan Kislev: The question is what will happen with the excavations, against the work at the Ha-Liba Building, which is close to the pilot area. Shuka Dorfman: The question is whether there will be an excavation from east to west, and whether there are open engineering questions?

Ofer Cohen: There is a large weight to the issues of canalization and general planning.

\section{Following are the Director's decisions:}

1. The making of the pilot [in units] 3 and 4 is approved.

2. One should receive decisions prior to the start of building at Ha-Liba Building.

3. The continuation of detailed planning is approved $[\ldots]$

(Document 6.9)

Concerning the words of Yuval Baruch (and earlier Jon Seligman, Document 6.6): what are the Mughrabi remains, are they archaeological or not? The Mughrabi Quarter was established some 800 years ago; but the entrepreneur 
knows better, and suggests to bulldoze 3 metres for a start! Nobody protests. Dorfman approves the pilot. There are no more archaeological voices, no ethical issues. It seems that only a few details are left to settle, such as the cost:

Soli Eliav: The Western Wall Heritage Foundation approved the continuation of the planning. He asks to receive an estimate for the pilot, in order to immediately approve it. It was agreed to do the drillings in the first phase. We prefer advancing the engineering part and only later advancing the excavation.

(Document 6.10)

This brings unexpected results, as Yuval Baruch (Jerusalem Region the 'inspection people') uses the opportunity to close an account with Uzi Dahari (Archaeology Administration - 'the archaeologists'). At the Ha-Liba Building the Jerusalem Region did not ask enough for the work on the finds. So let Dahari be responsible now for estimating work on finds, before one knows what will be found. Some estimate is required, though, and Dorfman decides that the Jerusalem Region will prepare it (Document 6.10) - obviously too important a task for the 'archaeologists.'

We were not given the estimate. Yet we have a document from the Western Wall Heritage Foundation, unfortunately undated and unsigned. It mentions November 2008 as a date for starting the project, so the document is earlier. Probably it is based on an estimate received from the IAA for the cost of excavating one unit of 12 x 24 metres: 14,141,000 Shekels (Document 6.11: page 1; currently worth about 4.1 million US Dollars). Hence, the cost for one square metre is 49,100 Shekels $(14,141,000: 288$ metres).

As for the entire Plaza, the total volume for excavation is 8,400 square metres $\times 8$ metres depth $=67,200$ cubic metres. This is multiplied by a 'unit' price of 1,500 shekel to reach a price of ca. 100 million Shekels (Document 6.11 , upper row). Whence the sum of 1,500 Shekels is a mystery - the numbers do not add up. ${ }^{2}$ If excavating one unit costs ca. 14.1 million shekel, the cost for the entire plaza is roughly 411 million Shekels (for 8,400 square metres); or 310 million Shekels (for the 22 units in Fig. 6.5, i.e., 6,336 square metres). In any case, the sums are overwhelming.

The rest of the table in Document 6.11 is about heavy construction. It is instructive as well as destructive. The vision that the Western Wall Heritage Foundation advances, with the help of the IAA, is of inserting 120-150 pillars into the archaeology (600 mini-piles, 4-5 per spot, to a depth of 24-30 metres). They will also insert ventilation and light systems, passes, stairs and railings, elevators for the handicapped, and so on, and so forth. The plan (Fig. 6.5) shows the 22 units: the two units without numbers (top left) are those already excavated (or partly excavated) for the Ha-Liba building.

The schematic timetable (Document 6.11, page 3) is a farce. Each year two units must be excavated: one during the entire year and the other in eight months. How is it possible when the units are of equal size? How can 


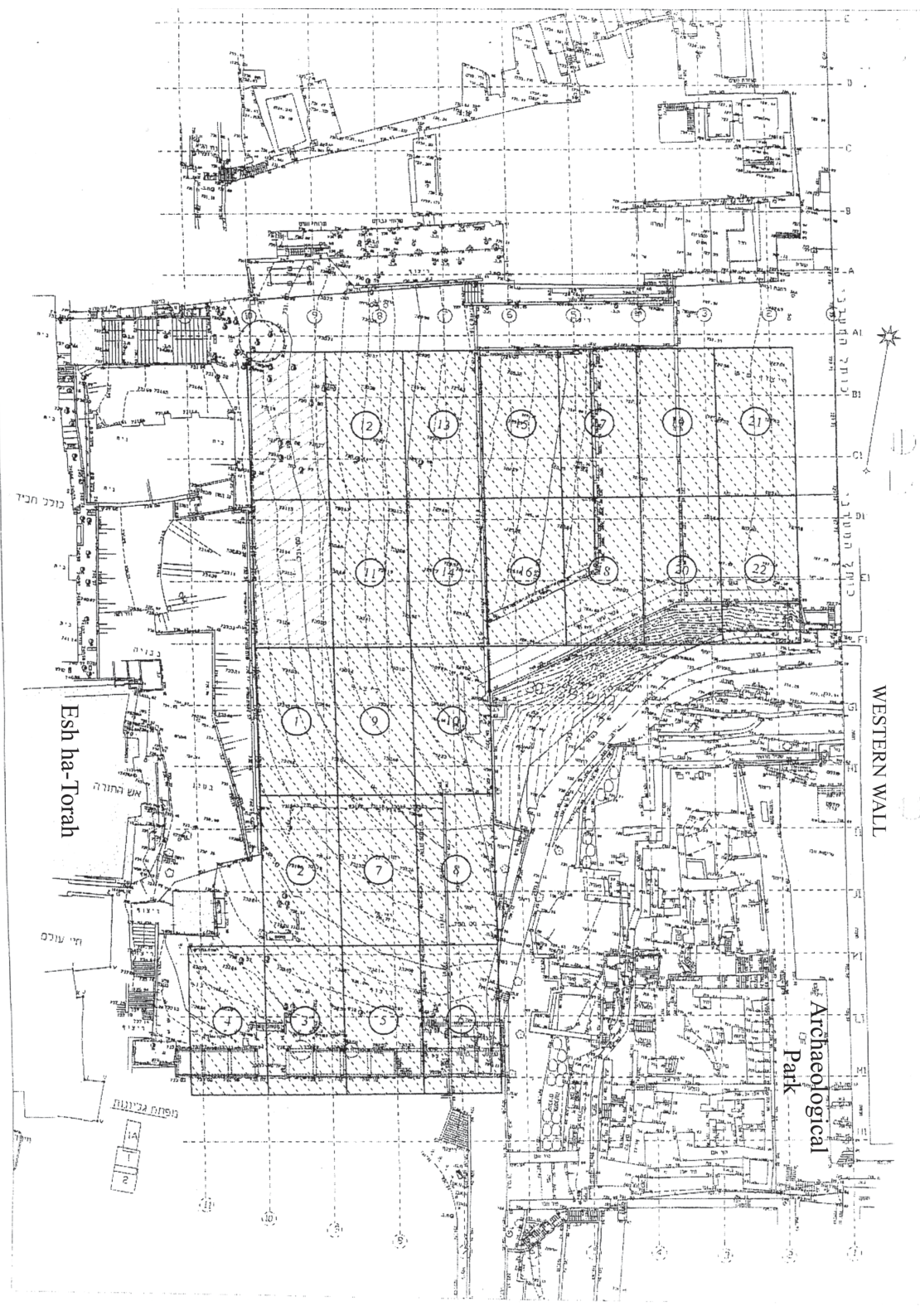

Figure 6.5 Plan for the Western Wall Plaza excavations. The entire Plaza is divided into 22 units of $12 \times 24 \mathrm{~m}$. Each would be excavated to a depth of 8 metres, at a cost of c. 4.1 million US dollars per unit. 
one excavate 6-8 metres in one year? It would be five times faster than the extremely pressured Ha-Liba excavations. Surely the IAA would not agree to work around the clock for ten years like crazy mice, but if it came to the test in the days of Dorfman, who knows... Only a narrow zone of 6 metres would be spared along the Western Wall. Perhaps the planners realized that it is a holy site, so they should not be drilling right on the face of the Western Wall.

After a hiatus in the available data, the entrepreneur resumed the discussion:

\section{Excavation of the Western Wall Plaza}

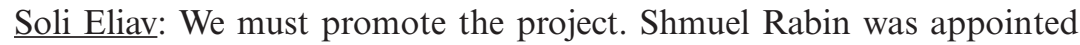
engineer and Eli Elan was appointed architect. The goal is to reduce the number of pillars. I request that a representative of the [IAA] Jerusalem Region will participate in the meetings that take place at the Western Wall Heritage Foundation.

Ofer Cohen: We are talking about minor changes to the plan that was presented in the past.

Decision: It is Shmuel Rabin's responsibility to present the plan in the next status meeting' [Document 6.12].

Next, the entrepreneur asked for a permit to actually drill the 'pilot':

Soli Eliav: We are asking for a permit in principle for drilling and constructing pillars; on the basis of the principle of six pillars for every 12 by 24 [metres] rectangle.

Shuka Dorfman summarized the discussion:

1. We should undertake a pilot of two rectangles, on the basis of 12 pillars [for the two rectangles], east of the Ha-Liba Building excavation, adjacent to the excavation [...]

3. After acceptance of the plans, the Director's Office is responsible for setting a date for a discussion about the execution of the pilot [...]

(Document 6.13)

Dorfman does not hesitate and approves the drilling. The 'pilot' alone will cover almost 600 square metres. The technology is not new, so what is there to test? Apparently, they have to test how much money to ask for:

Soli Eliav: The plan is to do in 2010 a pilot in the narrow tunnel [in the Western Wall Tunnels] and a pilot of excavation in the Western Wall Plaza. We have to draw conclusions, which will serve as a basis for a decision by the government towards 2011 about performing the entire project. We speak about a five year budget. He asks to finish the pilot within six months.

Chen Canari: The plan for the narrow tunnel was [already] finished and presented.

Jon Seligman: The new planning by Eitan Kimmel influences the [Ohel Yitzhak] Area C vaults. The archaeological issue should be considered. 
Soli Eliav: You are right, but the engineering [not the archaeology] is leading here.

Many works are done by the IAA regarding archaeology and preservation, all over the Western Wall Plaza and its surroundings. We present to the Jewish people delightful treasures. The framework that we have established is the right one and the work teams are working properly. The process of work is proper and should be advanced further. First we should start with the Plaza pilot (before Easter), and then with the narrow tunnel pilot.

(Document 6.14, emphases added)

The IAA gives the green light. Only some plans are missing:

Following are the Director's Decisions:

1. The Jerusalem Region and Conservation Administration are responsible for presenting the implications and estimations to the Director, with the aim of getting ready for the start of the pilot after receiving the plans from the planners.

2. The pilot of the Western Wall Plaza will be made in early February 2010, by opening two fields [=the units/rectangles] adjacent to $\mathrm{Ha}$ Liba Building.

(Document 6.14)

The plans are still missing two months later:

Excavation of the Western Wall Plaza

Soli Eliav: We are waiting for the IAA's comments.

Raanan Kislev: We have not yet received the plans. It is already two months that we are waiting for the file of plans.

Chen Canari: We are talking about two grids, 1 and 2, that were already excavated in the past.

Eli Elan: Shmuel Rabin, the project engineer, and I are discussing the topic. I am not pleased with the solution of the pillars. I am still trying to get a plan that I can be satisfied with, and then I will pass it along to the IAA.

Jon Seligman: When the plan is prepared, we can get ready and begin to work.

Uzi Dahari: We are talking about a mega-project; we have to prepare all the aspects.

Yuval Baruch: This is a smaller project than the Ha-Liba Building.

Decision: A working group should be established and decisions should be made regarding all aspects of the pilot.

(Document 6.15) 
Chen Canari perhaps means the eastern area of the Ha-Liba Building. It is impossible to conduct the 'pilot' there, because the Ha-Liba Building requires its own, unique set of pillars, and at the time their location is not yet settled (see Chapter 5). Dorfman specified the precise location: east of the Ha-Liba excavation, not part of it (Document 6.13). Dahari's comment also clarifies that the issue is the entire Plaza, while Yuval Baruch perhaps thinks only of the 'pilot.' Dahari is the only one that worries about this 'mega project.'

A month later, concluding a discussion of a host of other projects, Dorfman remarks:

A. The Western Wall Plaza - we are in principle in agreement [with the Western Wall Heritage Foundation] regarding the plan. We must accept the final plans and approve them. We must prepare an excavation plan, determine who will excavate, and bring it to approval.

(Document 6.16)

He is pleased that there is 'a large volume of work' and wants to maintain it over time (Document 6.16). No doubt the 'pilot' would be beneficial for the IAA's income, even if not for the antiquities.

This is the last time that the 'pilot' is mentioned. A slice of some 600 square metres of the Plaza was on the verge of becoming the first victim of a mega-project that 'happens' bit by bit. We can only marvel at this ludicrous plan. A 'pilot' for a mega-project, which includes a large-scale, massive construction, is advanced without a building permit. It is made in the name of the 'comprehensive planning,' but in fact empties it from essence. This supposedly archaeological project will start by inserting destructive pillars into the archaeology; the uppermost layer will be grazed off by bulldozers. Public funds will be used while the public is fed up with lies about 'restoring' the Plaza and 'necessary salvage excavations.' Those responsible suffer the symptoms of a dangerous megalomania, if not the Jerusalem Syndrome (Van der Haven 2008).

\subsection{Preparing for a mega-project, or tossing dust in the eyes?}

Likely in the wake of Dorfman's conclusions about preparing an excavation plan (Document 6.16), a 'proposal for managing the excavation project of the Western Wall Plaza' was written (Document 6.17). We have only one page, undated and unsigned, but the Jerusalem Region headed by Yuval Baruch is the only body that could write it.

Three alternatives are presented $(\mathrm{A}-\mathrm{C})$ for this 'huge enterprise that will continue for many years' - in a sloppy way. Alternative C is titled 'without the university, ${ }^{3}$ but still assumes the participation of the university in managing the excavation areas. Alternatives A and B speak about a 'modular' excavation. A nice, but empty word in this context. Since the area is gigantic, one 
cannot excavate all of it at once. Adding the word 'modular' does not add sophistication to the plan. All the options assume overall responsibility 'in the hands of the [Jerusalem] Region Archaeologist,' that is, Yuval Baruch. There seems to be no realization that such a mega-project deserves in-depth preparation. The 'archaeologists' of the IAA are not consulted. Ethical questions do not arise. Maybe it is just 'tossing dust in the eyes,' for the person responsible does not believe that such a project will ever materialize (cf. Document 6.2). Or maybe what's important is to rush forward, never mind how. This document is an example of the piecemeal mode of work of the IAA itself.

\subsection{The IAA mobilizes to approve the comprehensive plan}

The IAA participated in the meetings of the 'Western Wall Steering Committee' in the Jerusalem Development Authority, where principles for the planning of the Plaza are formulated; they focus mostly on the design of the new structures. In addition, it is determined that:

4. The Cardo Street will be exposed in stages along all its length and will serve as a public artery. To its west, the rock escarpment that descends from the Jewish Quarter will be exposed along its entire length, as far as possible.

(Document 6.18)

Kertesz's plan was presented in this forum in January 2010 (Document 6.19). The minutes are brief, but we learn that visitors will enter near the Dung Gate at the south of the Plaza. They will proceed at the level of the Umayyad palace, some 7 metres below the current Plaza. The plan will 'enlarge the carrying capacity of the Western Wall area' (Document 6.19). Transportation and parking are the principal issues discussed, not archaeology.

Prior to the discussion in the Jerusalem Planning Committee a preparatory meeting took place and the IAA was requested to submit a document detailing its position on the plan (Document 6.20). It seems that we have one page from this document (Document 6.21), which includes only general statements. Another page, perhaps from the same document, states:

The IAA sees the comprehensive plan under preparation as a necessary means. Thanks to the plan we can keep the balance between the wish to preserve the archaeological remains and display them to the public, and the necessity of development in the Holy Basin.

(Document 6.22)

The most detailed position of the IAA on Kertesz's plan (Document 6.23) attempts to adjust it to the international UNESCO Convention Concerning the Protection of the World Cultural and Natural Heritage (UNESCO 1972). The aim is to prevent criticism in the Planning Committee. The author is aware 
that the Convention stresses the 'variety of communities and cultures' worthy of World Heritage Sites; but the Kertesz plan stresses only 'the city plan from the Second Temple period (including a number of locations where finds from the First Temple were discovered)' and the 'the Roman street plan.' Visitors will enter near the southern wall and move along the Cardo (Document 6.23, page $2, \$ 2.02$ ). The Umayyad public buildings will serve as a visitors' entrance (Document 6.23, §2.03, 2.04). ${ }^{4}$

The author cites criteria II, III and VI for inscribing a World Heritage Sitethe criteria that led to the declaration of Jerusalem as a World Site in 1981 (ICOMOS 1981) - and tries to squeeze Kertesz's plan into this framework:

Accordingly, the planning, conservation, development and building acts included in the comprehensive plan for the Western Wall Compound are done with identification and conservation of the characteristics mentioned in the lists of criteria, and [lit. 'when'] they are found in the background to the most sacred site for Judaism.

(Document 6.23)

The reality is different: the individual building projects and the Kertesz plan ignored the frame of UNESCO/World Heritage Sites. In fact, the declaration of Jerusalem as a World Heritage Site in 1981 was made by Jordan, not by Israel. From time to time UNESCO states that Jerusalem is a World Heritage Site in danger, due to the one-sided actions of Israel, including the projects at the Western Wall Plaza (e.g., UNESCO 2017:52).

The author tries to connect the plan with another international document:

Making the comprehensive plan for the Western Wall Compound is based, beside the identification of the site, on the definitions and instructions of the Convention for World Heritage - and the instructions of ICOMOS [...] concerning exhibition and demonstration of World Heritage sites (document of the general assembly of ICOMOS, Quebec 2008).

(Document 6.23)

The Quebec document (ICOMOS 2008) mentions 'general ethical and professional considerations' in interpreting and presenting World Heritage Sites. It calls for keeping 'the authenticity of cultural heritage sites by communicating the significance of their historic fabric and cultural values and protecting them from the adverse impact of intrusive interpretive infrastructure, visitor pressure, (and) inaccurate or inappropriate interpretation.' It stresses 'facilitating the involvement of stakeholders and associated communities in the development and implementation of interpretive programs.' We are asked to consider that 'meaningful interpretation necessarily includes reflection on alternative historical hypotheses, local traditions, and stories' (principle 2,2). 'The contribution of all the periods to the significance of a 
site should be respected' and 'interpretation should also take into account all groups that have contributed to the historical and cultural significance of the site' (principle 3, 2-3). 'The development and implementation of interpretation and presentation programmes should be an integral part of the overall planning' (principle 5, 1) and 'plans for expansion or revision of interpretation and presentation programmes should be open for public comment and involvement' (principle 6, 3).

In what way does the Kertesz plan fit all this? It is a 'plumber's plan' that justifies separate projects, patching them together. It deals primarily with the practical movement of visitors to/from the Plaza. It has nothing about the spirit of the place, maintaining variety and alternative traditions, protecting remains of all periods, involving the public in the planning, etc.

Around June 2010 the Conservation Department prepared a presentation for Dorfman, of which, again, only a portion reached us. One page defines the 'vision':

- Handling the visitor entrance to the Western Wall Plaza from an overall perspective.

- Creating a public space that will allow visitors to experience a world heritage site in a proper and acceptable way, through exposure, understanding, and display of the different archaeological layers.

- Arranging visitor access in a convenient, accessible, clear, and experiential way, and laying the groundwork for an increase in visitors.

- Preserving the spirit of the site, and creating an appropriate planning frame for it.

(Document 6.24)

Of the four components, only one is archaeological. The issue of the comprehensive plan resurfaced in a meeting of 17 June 2010 (Document 6.25). According to Yuval Baruch, 'We have to refrain from developing [individual] sites, separated from each other. For that reason we have to create a logical connection between the sites in terms of content'; but, 'the separation between the Archaeological Park complex, the City of David, and the Western Wall Tunnels is no less important than regulating visitor movement.' So should they be separated or connected? According to Baruch, the comprehensive plan 'was created in a natural way.' In fact, the Kertesz plan was not created 'naturally,' but forced on the involved bodies by the decision of the High Court. Hiring Kertesz was an effort to legitimate, under a smokescreen of 'comprehensive planning,' the individual 'piecemeal' projects.

Dorfman concluded the meeting by saying that the IAA must continue to lead and influence. It cannot lead a project if it says 'no' to it; so apparently it must always say 'yes.' Dorfman boasted that 'nothing happens without our involvement' (Document 6.25, §2), but complained about the lack of 
comprehensive planning: 'What has been presented is a random collection of many different small projects. On the national level things should not be conducted in this way, since it [the Plaza/Old City] must be planned from a comprehensive perspective' (Document 6.25, §4).

Dorfman is mostly responsible for this situation, by approving and even initiating all the projects that 'happen' in a piecemeal fashion.

Gobi Kertesz's plan was approved in the Jerusalem's Planning Committee on 26 October 2010, after all the bodies mobilized to support it. The mayor of Jerusalem, Nir Barakat, made a personal appearance before the Committee his first - as did also the Director of the IAA, Shuka Dorfman. The IAA rushed to support the final product, without giving thought to the planning process; but: 'Without a proper process it is impossible to make professional decisions on any level' (Mike Turner, letter quoted in Planning Committee 2010:17).

\subsection{Archaeological implications}

The IAA was obligated to discuss the archaeological implications of the Kertesz plan before taking sides. It is not easy to understand the details, since the plan has not been properly presented in public. The following materials are available:

1. Planning Committee discussions from 26 October 2010 (Planning Committee 2010) and 27 September 2011 (Planning Committee 2011: 108-137).

2. Gobi Kertesz's comments during a discussion concerning the Ha-Liba Building (Planning Committee 2013: §29-30).

3. Two blueprints from the IAA documents: one from late 2010 (Document 6.26), the second from September 2011 (Fig. 6.6).

4. Pictures of models from Israeli Media. ${ }^{5}$

5. Various IAA documents referring to the plan (e.g., Documents 6.24-6.25).

The following picture emerges:

A. A parking lot will be excavated south of the Old City wall. Some of this area is currently covered by a road, the rest has been excavated in the past. The area will be excavated to the bedrock and any remains will have to be removed.

B. All the Plaza will be excavated, some 8,400 square metres (Document 6.11). It will be a gigantic excavation. The Cardo and the Herodian road are meant to serve as arteries for the movement of visitors.

C. A significant amount of space will be required for new construction on the lower level. The checkpoint facilities alone will occupy hundreds of square metres (Fig 6.6: marked 1; cf. Document 6.26: area 6). Add staircases, toilets, elevator shafts, a long wheelchair ramp (Fig. 6.6: marked 2), etc. 

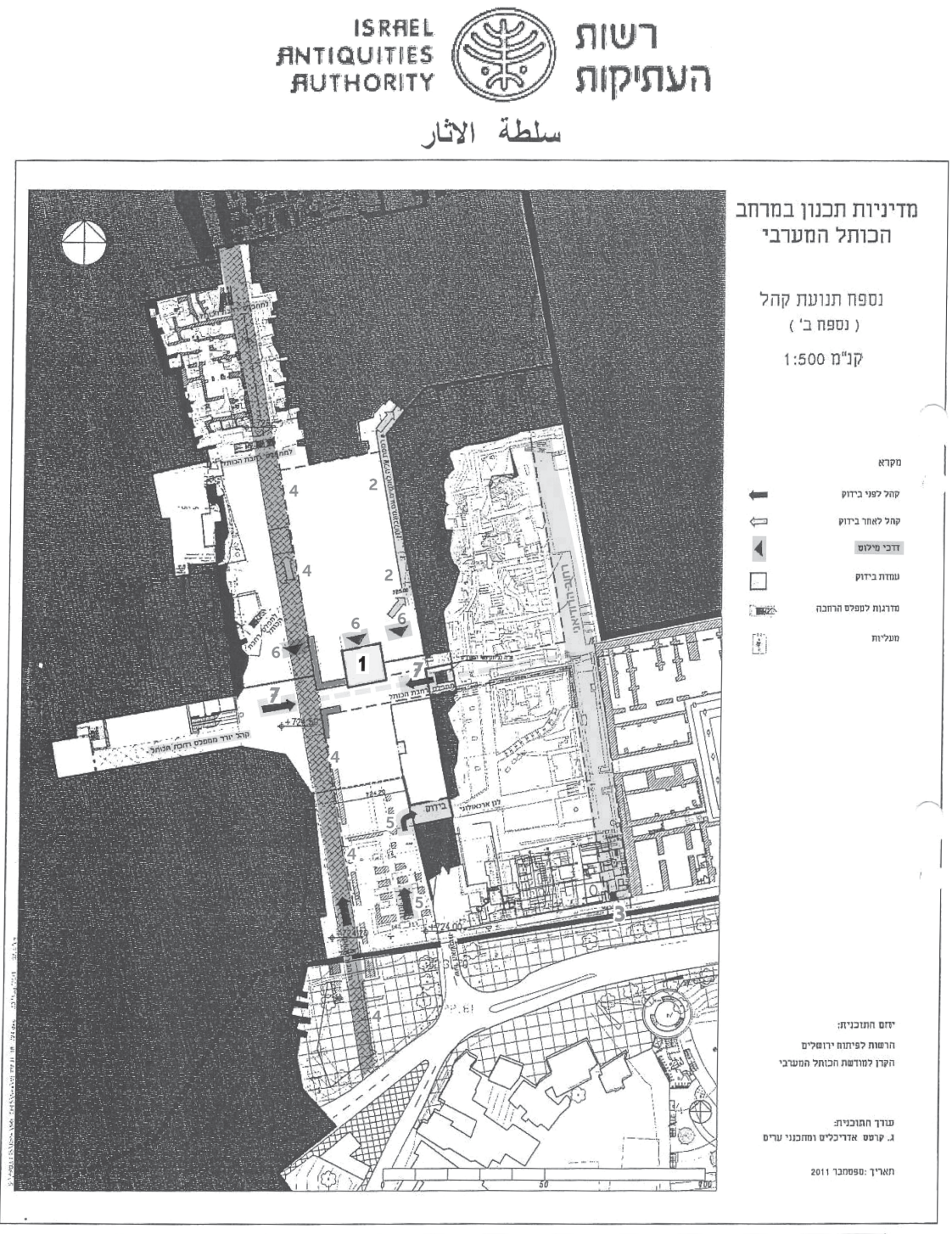

JERUSALEM REGION

منطقة اورشلتم القدس

מרחב ירושלים

מען למכתבים: רשות העת'קות, מרחב ירושלים, ת.ד. 586, ירושלים 02-537-5377027, 91004 טל. 02-2376582 פקס. 02-5371099 P.O.Box 586, Jerusalem 91004 Israel, Tel. 972-2-5377027, 972-2-5376582 Fax. 972-2-5371099 מבלם מרזים website: www.antiquities.org.il - jeru@israntique.org.il

Figure 6.6 Plan by Gobi Kertesz for movement of visitors on the 'archaeological' level, September 2011. The Cardo is cut by security walls/barriers (thin black lines, between 6 and 7).

Legend: 1 - Security inspection facilities; 2 - ramp for wheelchair access; 3 - edge of Herodian road and Old City wall; 4 - Cardo; 5 - visitors entering the 'archaeological' level; 6-7 - visitors exiting on the upper plaza. From IAA Documents, prepared by Lior Cohen for Emek Shaveh 
The archaeological implications are as follows:

1. The plan means a total excavation of the Plaza. Archaeological ethics has emphasized for decades that it is wrong to excavate entire sites. Archaeologists should always leave a significant part unexcavated for future generations. Perhaps they will have new research questions and new methods. Archaeologists in Israel explicitly share this ethical view (see, for example, Reich 1995:188-191; Maeir 2016). Yet when the plan to excavate the entire Plaza was proposed, they kept silent. It seems that the plan was not even discussed in the Archaeological Council. It seems that Nationalistic plans stand above professional and ethical principles.

2. It will be impossible to preserve and display in situ archaeological remains in the areas intended for new construction (earlier, section C). In all these areas any remains found will have to be removed (demolished).

3. Though the plan speaks about diversity, in practice the focus is on 'our remains': the First and Second Temple and the Roman periods (Document 6.23, \#2.02). To reach the 'archaeological' level - the Roman Cardo level - the upper remains will have to be dismantled. They include the last remaining part of the Madrasa al-Afdaliyya (see Chapter 5). It was hoped that some commemoration of this building could be kept (Kedar et al. 2012:287), and allegedly, the IAA promised so (Kedar et al. 2012:283, n. 26); but the Kertesz plan says nothing about preservation of such remains. Similarly, the large Umayyad buildings will become reception and security check areas. They will not be a focus for exhibitions and visits, but an area that visitors pass as quickly as possible. Their fate would resemble that of the Strauss Building toilet walls.

4. The Cardo and the Herodian Street cannot serve as public arteries. The Cardo (Fig. 6.6: point 4) narrows considerably because of a planned staircase. In the Planning Committee Amir Shoham, the conservation advisor for the East Jerusalem Development Company, noticed this fact, and also that four different projects were being planned along the Cardo (a parking lot and an elevator, security inspection building, a lobby and the Ha-Liba Building). He asked Yuval Baruch:

Each one of these structures is entirely different from the rest. Visually, each one is entirely different. That means that the [Cardo] street will have no sense of unity; suddenly you will be confronted with many different things. I'm asking [...] if you think that this design - as it is presented now in the master plan - is good for the Cardo [...]

(Planning Committee 2010, Transcript:207)

He did not receive a proper answer. The Herodian Street near the Western Wall has no fitting opening in the Southern City Wall, and there will not be an additional security facility for movement from this direction. As Nir Barkat, Mayor of Jerusalem, cried when the idea rose to add a security checkpoint at the Ha-Liba Building: 'They won't approve it; there is only one checkpoint 
here below. You can't request the police [to add] another checkpoint team, it is impossible to add another checkpoint. Do you know what it entails to add another checkpoint?' (Planning Committee 2010, Transcript: 207).

The low-level Herodian Street cannot join the upper Plaza unless more stairs or elevators are constructed right next to the Western Wall. The Herodian Street cannot carry large groups of people. It is uneven and partially blocked by the collapse of stones, whether from the destruction of the Temple, or a later earthquake (Hasson 2015b) (Fig. 6.7):

It seems that the most dramatic find is the huge collapse of Herodian building stones on the pavements of the road [...] We left about half of

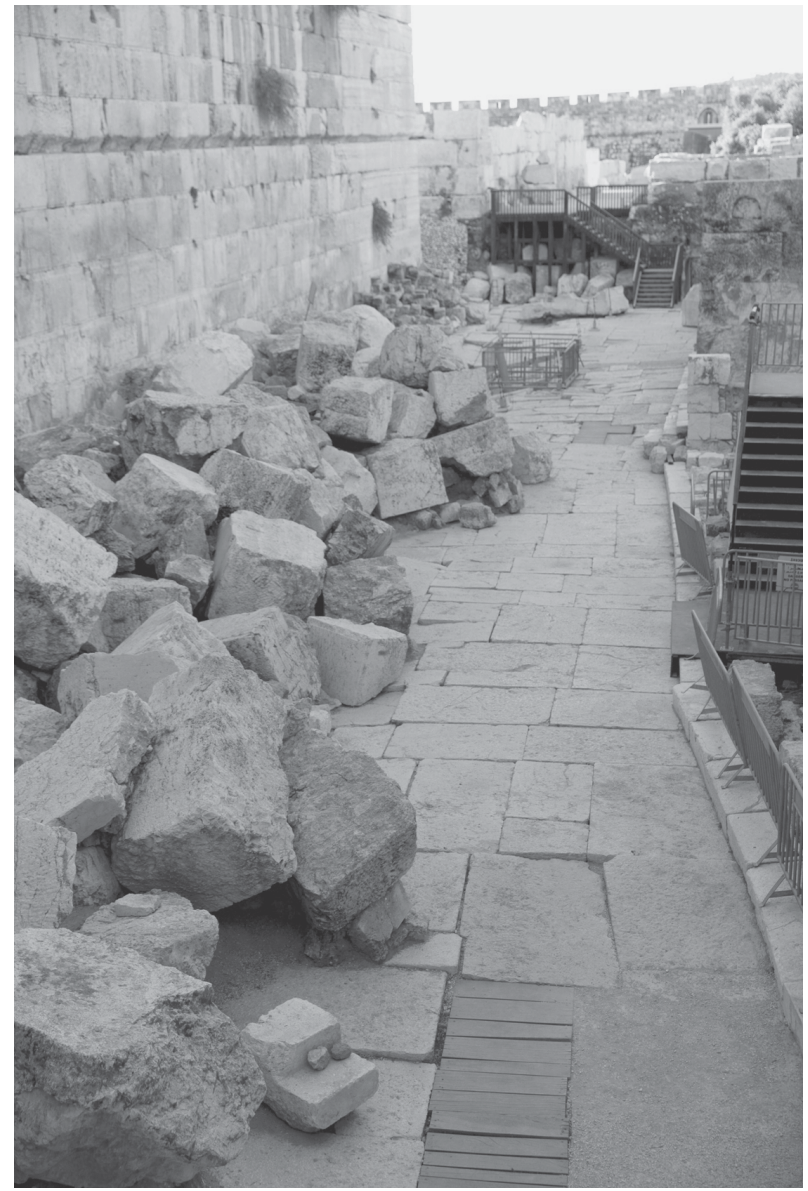

Figure 6.7 The Herodian Street with the collapsed stones. Can millions of visitors go here?

Photo Emek Shaveh 


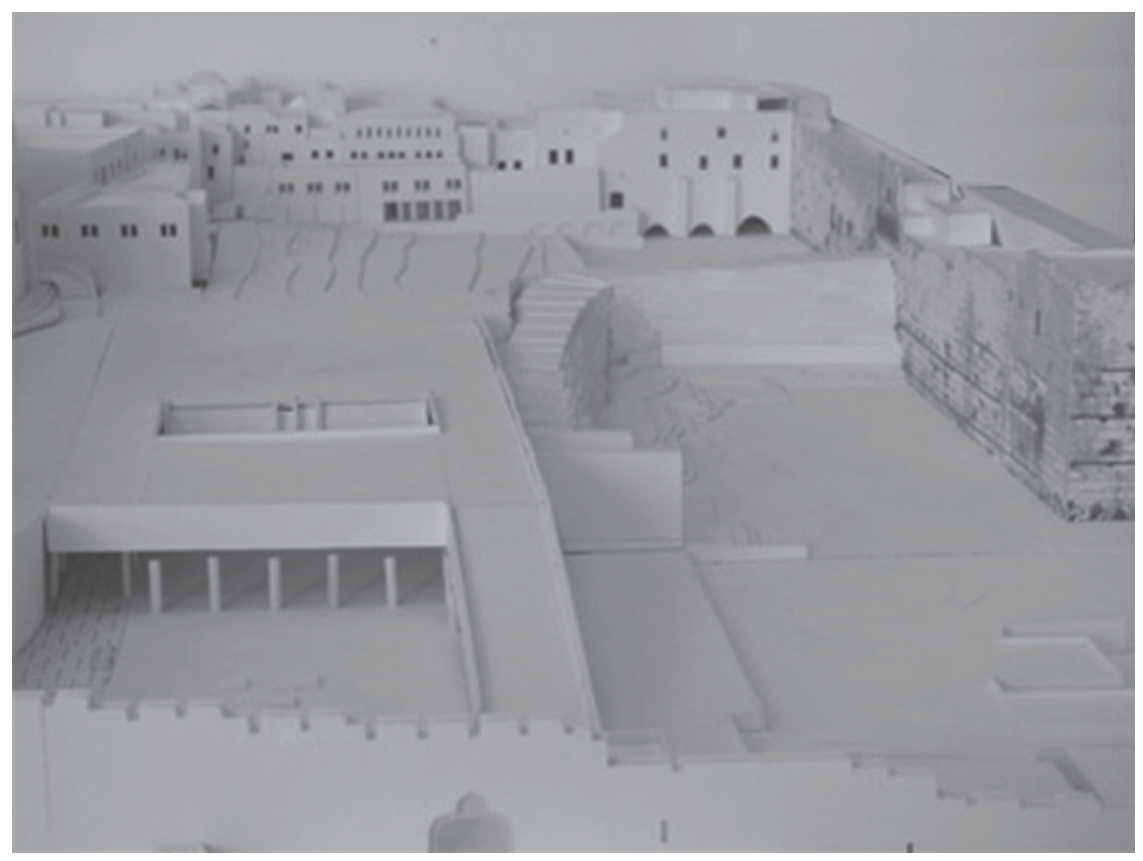

Figure 6.8 A model of Kertesz's plan, view north. The Cardo is the hatched area on the left. The 'archaeological' level is shown empty of remains.

Photo by Hyde Park, published October 2010

the fallen stones in situ at the excavation site as a memorial to the destruction $[\ldots]$ as a monument of dramatic power and historical importance.

(Reich 2007:152)

Will they 'fix' the street and remove this dramatic evidence? One will be forced to open other routes. Kertesz's plan shows this. Visitors will circulate throughout the entire 'archaeological' level (Fig. 6.6: point 5). The Cardo is a very small part of the area designated for movement (Fig. 6.8, the dotted area at left). The Archaeological Park is presented in the models as an empty space. In reality, it is packed with remains, so movement is limited to small groups along narrow, twisting paths (Fig. 6.9).

As for the Cardo, the security inspection facility on the 'archaeological' level is located far from it. A barrier wall will block the Cardo (Fig. 6.6: the thin black line between points 6 and 7; notice also the L-shaped walls along the Cardo, which will further isolate it). Visitors coming from the Dung Gate will head straight to the security facility; no one will walk along the Cardo in order to hit a barrier wall. After passing the security check, most visitors will continue to the Western Wall. Even the minority that will turn towards the Ha-Liba Building will not return to the cardo, but walk straight ahead. 




Figure 6.9 The Archaeological Park. It is unsuitable for passage of millions of visitors. Photo Emek Shaveh

With the Ha-Liba Building, Baruch presented the possibility of a low ceiling above the antiquities (at the level of the Plaza) as a disaster that completely ruins the 'experience of the visitor' (see Chapter 5). Yet the IAA supports the Kertesz plan, which means a huge underground floor with a low $(5-6 \mathrm{~m})$ ceiling at the level of the Plaza. Because of the huge area, the proportions would look much worse than at the Ha-Liba Building.

Kertesz's plan means the end of the dreams about walking on the Cardo in the footsteps of ancient people. In the parts of the Cardo left for walking, the visitors will walk like miners in artificial lights, surrounded by a forest of pillars, under heavy concrete skies.

In addition, Kertesz explained that the 'archaeological' level is intended to serve as a reception and waiting area - an expansion of the current Plaza:

We present here the level [...] of the archaeological space that is, in essence, intended for more expansive reception of visitors [...]. Naturally if these areas adjoining the Cardo will be excavated, it will create a sizeable space, protected from rain and sun, which gives us another option for reception of visitors.

(Planning Committee 2011:111-112)

Similarly, the Mayor of Jerusalem Nir Barakat stated: 'the masterplan means expanding the Plaza, without parking [lots]' (Planning Committee 
2010:155). The chance that another wide, ancient, north-south road will be found under the Plaza is minuscule. How will the millions of visitors move stepping on remains? Kertesz's plan implies a destructive removal of archaeological remains on a large scale to suit the new construction and to make room for the presence and movement of millions of visitors. At the Archaeological Park small groups that come to see the archaeology move in narrow, twisting paths. The millions of visitors on the 'archaeological' level will see mainly security facilities, toilets and pillars, as they move on floors swept clean of antiquities. Calling this an 'archaeological level' is tossing dust in the eyes.

The IAA should have objected to this plan and demanded a full salvage excavation before (not after) the insertion of pillars or any other construction. It should have conditioned the approval of the plan on preserving important finds from all periods in situ (at the place of finding), and on keeping the Cardo as an open artery, open also to the sky. Instead, the IAA acts as a contractor on behalf of the entrepreneur.

\section{Notes}

1 The expression in Hebrew is zriyat chol (literally 'sprinkling sand'); the protocol renders it literally as zrikat chol ('throwing sand').

2 The volume of one unit is 2304 cubic metres [ $12 \times 24 \times 8$ ]; dividing the price for one unit by 2,304 results in 6,138 shekel per cubic metre, not 1,500.

3 The document does not specify any particular university.

4 One hope of the World Heritage Sites programme was that an international view on heritage will unite people and promote peace, whereas the nationalistic view divides them. Israel, like many other states, is happy to participate in this programme, but is reluctant to accept limitations of international conventions for safeguarding heritage (see Omland 2006:246, 252-253).

5 www.hydepark.co.il/topic.asp? whichpage $=38 \&$ topic_id $=2706912 \&$ forum id=20422; see also Hasson 2010. 


\section{Lingua Orientalis Hierosolimitanae}

The language brings it out into the open. Perhaps someone wants to conceal the truth by speaking. But the language does not lie. Perhaps someone wants to utter the truth. But the language is more true than he is. There is no remedy against the truth of the language.

(Klemperer 1999:33)

One cannot expect the IAA documents to be good literature. The genre is limiting and the authors have a lot of work and not much time (or the habit) to do proofing. Men of action (cf. Mayer 2000) - not men of letters - wrote most of the documents under discussion and did most of the talking in the meetings. ${ }^{1}$ However, the written word deserves respect, and can teach us much, for one cannot hide the truth in one's language (Klemperer 1957:11).

The following lines are tentative notes, since I am not a linguist. I use a simple, non-scientific transliteration from Hebrew. Its purpose is to give examples, which will be immediately clear to Hebrew speakers. Other readers will receive a 'taste' of the language - but to them it is not crucial if certain words are written with aleph or ayin, kaf or qof, etc.

I call the language discussed here Lingua Orientalis Hierosolimitanae, or $\mathrm{LOH}$ in short: the language of the United Lands of Jerusalem. It is a Hebrew dialect of our time, not limited to the municipal boundaries of the Holy City. It is spoken in Green Line Israel too, for it is not stopped by fences and checkpoints. After 50 years of occupation, we all speak this language to some extent ('administrative detention' and 'civil administration' - Levy and Lavac 2017; 'administered territories' and 'separation obstacle' - Avnery 2014). Also the occupied: the Hebrew they are likely to pick up is the LOH of the military and labour contexts: the mahsom (road block), the machshir (walkie-talkie) and the menahel (boss); though one can use such words creatively (Hawker 2013; see also Horesh 2016).

How far the LOH has spread is hard to say. With growing bureaucracy it thrives (for bureaucracy tends to feed on itself: bureaucrats produce more and more bureaucracy). Clear talk is clotted with clichés, often uttered to hide something, or just the lack of meaning. 
Militarism. Naturally, in a state where the military is so central (Kimmerling 2008:141-153) the language marches with the ranks. Army slang (which preceded the $\mathrm{LOH}$ ) influences it significantly. Few examples would suffice: the IAA workers are at the 'front of the complex archaeological activity' (behazit ha-asiyah ha-archeologit ha-murkevet) (Dvar Avar 5, 2003:6). Criticism is absorbed like enemy fire (lispog bikoret) (Davr Avar 17, 2012:3) - hinting that the critics are enemies. The IAA story is accompanied by 'dust, resolution, humour, and pride of unit' (gaavat yekhidah) (Dvar Avar 15, 2010:2). The new Conservation Administration allegedly revolutionized the cooperation between the IAA Districts and 'other staff factors' (gormey mateh akherim) (Dvar Avar 19, 2013:5) - as if the IAA has a military 'staff' instead of civilian management. Finances are not merely collected or received, but 'recruited' (meguyasim) implying a more urgent, life-or-death operation (Dvar Avar 18, 2013:5). Military terms are used in describing an annual meeting day of workers (in this case, humorously): 'A commanding position (emdat shlita) of the Administration and Security Department was placed on a small hill to logistically control (lakhlosh) the development of the events' (Dvar Avar 2, 2002:14).

An inner IAA examination is 'real and focused' - amitit u-memukedet (Dorfman, Dvar Avar 3, 2003:3). The combination of 'examination' and 'focused' is meaningless in civilian life. We do not go to the optometrist to pass a 'focused' examination of our eyes, even if the optometrist keeps the instruments calibrated. We do not perform a 'focused' examination of the small-lettered ingredients on food packages, although we may examine them in detail, or attentively. Dorfman's 'focused examination' comes from sikul memukad, a term coined during the Second Intifada, meaning literally 'focused prevention (of terror),' that is, targeted killing. 'Focused' is the image on the screen, drawing near as the missile approaches the target. It is a euphemism, since while the image may remain in focus, the missile explodes with the same power, regardless of the camera. The metaphor of 'focused' is employed in order to move civilians, who often suffer the consequences, out of focus. The proclamation about a 'focused examination' is focused on creating the image that things are properly examined.

Poverty and Originality. A notable feature of the $\mathrm{LOH}$ is its poverty. Poverty of language is inevitable when someone does not have meaningful things to say, because style cannot be created from nothing, and 'le style c'est l'homme' (cf. Klemperer 1957:11). If one has to fill the not very dense page of the 'Director's words' in the IAA Dvar Avar newsletter once or twice a year without having meaningful things to say, one fills it with trifles and clichés.

Another feature of the LOH is lack of originality. There is almost nothing new, but the frequencies of words and their combinations and meanings vary. In all the $\mathrm{LOH}$ material discussed in this book, the only new term that I am aware of is 'synergy,' used rarely and solely by Dorfman (e.g., Dvar Avar 19, 2013:5). It is the supposed better results due to cooperation; a foreign word (the Academy of Language suggests 'igbur' - use it if you wish to sound enigmatic). Synergy, in the context of corporations and organizations, 
refers to merging and acquisition of companies, combining lines of production, etc. However, a merging can also bring negative synergy. Given the lack of measures, a Director that makes a change and soon announces success is blowing his own trumpet. Especially since the change was not in combining two departments, or creating a new one, but only in enlarging and changing the title of an existing department (from Conservation Department to Conservation Administration). How does such a change produce 'synergy'?

Planning. This term deserves special attention. In the LOH everything is planned, nothing happens accidentally. The IAA management is enamoured with 'detailed' (meforat or partani), 'thorough' (maqif) and (militarism again) 'strategic' planning (tichnun estrategi) (Dvar Avar 8, 2005:8). The managers are fond of the expression 'in the field' (bashetach or basadeh), as if excavations and inspections can happen outside the field. An obsession with 'work plans' comes at the expense of work. Adding the word 'plan' to every second sentence becomes proof of sophisticated planning. Dorfman concludes one meeting: 'Within a month the planning of the stairs will be submitted [...]. We should reach a planning that will be convenient to the public and [at the same time also] serve the excavation' (Document 6.5).

What sort of planning is it? Dorfman should not pressure the planners too much, for no benefit will be achieved by plans conceived in haste. Development plans do not 'serve' archaeological excavations. Rather, they cause damage to archaeological remains. Dorfman's job is to guard antiquities (as far as possible) against damage, not advance the plans of developers (cf. Greenberg 2008).

An obsessive use of 'planning' hides a lack of planning: 'The Western Wall Plaza - we are in principle in agreement regarding the plan. We must accept the final plans and approve them. We must prepare an excavation plan, determine who will excavate, and bring it to approval' (Document 6.16).

The IAA already agreed with the entrepreneur to excavate the entire Plaza. So the words about final plans and excavation plans are secondary details. The important matter is not proper planning, but approving the project fast (hence all the 'must' talk, as if there is no other choice). 'Bring it to approval' does not mean serious planning before approval, but reaching the blessed moment of receiving a binding commitment from the entrepreneur (a signed 'invitation of work' letter). In view of the obsession with 'planning,' the following remark is ironic: 'The Old City was created without anyone planning it, and here lies its beauty' (Dorfman, Document 2.1).

Many houses and public buildings and walls and gates were planned in Jerusalem, as also acts of destruction, including the one that created the Western Wall Plaza. Perhaps there were no detailed, central plans on paper; but this does not mean lack of planning. The beauty of Jerusalem comes from centuries of building and modifying; wear and tear; the variety of styles on and beside each other; the colourful clothes that hang to dry and the bullet holes of wars. It is in the eyes of the beholders, since it comes from feelings and memories, not just fixed, inherent traits. Perhaps one should modestly reflect that whether planned or not, such beauty is hard to improve and easy 
to ruin. Reflection and modesty were not the strong sides of the then IAA Director.

In an introduction prepared before a meeting in the Planning Committee on the comprehensive plan, the effort to present a logical process of planning breaks down:

As a basis for defining the conservational value of the elements included in the site, a thorough documentation file is being completed [holech vemushlam], which analyzes the components of the tangible and intangible [gashmit ve-al-gashmit] heritage found in the area of the site (IAA, Conservation Administration, 2010), and is attached to this document.

(Document 6.23)

The awkward wording about the 'thorough documentation file' as being on the verge of completion hints that the IAA is preparing a file fast to convince the committee. How 'thorough' would it be in such circumstances? Supposedly, this as yet unfinished file lays the foundation for defining the "conservational value of the site.' However, in reality the IAA position concerning the comprehensive plan for the entire site has already been decided, without such a file being consulted, for it did not yet exist. If the above-mentioned file is not yet completed, how can it be attached 'to this document'? Did the author leap to the future, grab the completed documentation file and bring it back to the present? As Holmes tells Watson, there is a simple, logical explanation: the 'thorough documentation file' will be finished - no matter what - before the discussion in the committee, and then attached to this document. The IAA cares less about thorough documentation than about approving the entrepreneur's plan in the meeting.

Neoliberalism. The IAA management worships a capitalistic God (cf. Yuval Baruch on the relation of scientific truth and large budget, Section 5.8; on Israeli neoliberalism see Krampf 2018). Dorfman constantly repeats that the workers are the most important 'resource,' but can this be corroborated by facts? For example, did the gaps between salaries of most employees and of managers increase or decrease during his tenure as the IAA Director?

In the neoliberal global village we have projects. ${ }^{2}$ The Hebrew for project, meyzam, is not a new word. The IAA is now full of meyzamim, there are projects for conservation (meyzamey shimur) and for education (meyzamim hinukhiyim); national projects (meyzamim leumiyim) (Dvar Avar 15, 2010:3) and community projects (meyzamim kehilatiyim) (Davr Avar 18, 2013:3). A department is to be praised for 'initiating many projects' (yozemet meyzamim rabim) (Dvar Avar 18, 2013:3). Not just projects are idealized, but also those that initiate them - the entrepreneurs or yazamim. Not just entrepreneurs, the IAA managers (read Dorfman) are also yozmim or 'initiators' that move the 'doing' (movil et ha-asiyah) (Dvar Avar 15, 2010:3; cf. Dvar Avar 18, 2013:5). 'I do not intend to remain in the realm of declarations, but really to take the lead (hovalah) with all that is implied by that,' promises Dorfman - after more than ten years in his position (Dvar Avar 19, 2013:5). ${ }^{3}$ 
The use of Capitalistic terms implies neither knowledge of economic theory, nor integrity (this is true about the entire LOH). For example, one may praise the 'free market,' but devise means to limit competition and secure contracts for excavations for oneself (Section 4.2).

The Capitalism of contract archaeology leads to alienation of archaeological work and of the archaeologists, undermining their role as researchers and their critical and reflective roles as scientists and intellectuals (Zorzin 2014:118). Archaeology becomes a market or business, with negative influence on careers (the archaeologists learn that they are dispensable; jobs are precarious, etc.). One either drops out, or becomes accustomed to accepting the wishes of managers/developers (Zorzin 2014:123-124). The language reflects the 'contrast between the rigour of the standardised archaeological fieldwork operations and the futility of its aims' (Zorzin 2014:125). Work becomes routine and the archaeologists are relieved of their responsibilities, except "the obligation to "clean" the site in an appropriate rigorous and technical way' (Zorzin 2014:129).

Academic discourse is hardly a source of inspiration for the $\mathrm{LOH}$, for it is no longer considered hard currency. Using it in forums like status meetings may fall on deaf ears. An exception is 'multidisciplinary' (rav tkhumi), even if it may have strange effects: 'This multidisciplinary activity has affected greatly many fields of life, both professionally and qualitatively' (Dvar Avar $15,2010: 3)^{4}$

Professionalism. A key expression in the IAA discourse, which relates to Capitalism, is 'professionalism' (mikzoiyut'): 'The professional issue (ha-noseh ha-mikzoi) occupies (maasik) the IAA workers in all the fields that they deal with (tkhumey asiyah)' (Dvar Avar 3, 2003:2).

There are 'professional stresses' (hedgeshim mikzoiyim) everywhere (Dvar Avar 15, 2010:3). Relations of the IAA with other bodies are 'professional' and close (kesher mikzoi haduk) or daily (kesher mikzoi shotef) (Dvar Avar 16, 2011:3). Professionalism is so crucial that one must not let it go loose (asur leharpot) (Dvar Avar 18, 2013:3), or hurt it by the pressures of work: 'We must not be carried away (le-hisakhef) into the burden and the pressure of work, and by this hurt the values, principles, rules and professional quality [of the IAA]' (Dvar Avar 2, 2002:2).

Professionalism is the answer to the grave problem of wasting funds on research: 'No doubt, each archaeologist and each employee that works in interdisciplinary science is interested in the highest-quality, maximal realization (mizuy), but every one of us must believe that research has borders and budgetary limitations' (Dvar Avar 3, 2003:2).

Scientists must believe in something after all ... In the LOH managers and managing are at the centre, and expressions that originate from 'to manage' are rife. The IAA has a hitnahalut, roughly the way of managing, the organizational 'culture' (e.g., Dvar Avar 2, 2002:2). The way of managing can be 'general' (hitnahalut kolelet) (Dvar Avar 2003:2) or project-based (hitnahalut proyektalit). Those that lead are 'managers' (menahalim), and 'administrations' 
(minhalim) are added (e.g., Dvar Avar 15, 2010:3) at the top of the hierarchy, reflecting the importance of managing. ${ }^{6}$

Since the IAA is always professional, scientific, transparent and 'detached from pressures and all the various sorts of politics,' it is clear to Dorfman that criticisms of the IAA (or rather, of his decisions) are merely 'background noises and disturbances' (in the case of the Mughrabi Bridge). Even if some 'disturbances' come from within the IAA (raashey reka ve-hafraot mikhuz lairgun u-be-tocho) (Dvar Avar 11, 2007:3) - that is, from the Director's excellent 'human resources.'

In elaborating - combining several sentences together - the construction often becomes heavy, since the joints are clumsy and the factual basis narrow. Here is an example about professionalism:

The definition of professionalism is not simple, it is the combination of endless ingredients. I do not intend to discuss the definition of professionalism [here], but only write: professionalism is measured on a complex basis over a long duration, while creating acceptable image and reputation, with persistence and unstopping examination of the components of the professionalism and their quality (markivey ha-mikzoiyut ve-ekhutam). In this way, a shared foundation of understanding (bsis havanot meshutaf) and shared values are created among those that deal in the profession (and it is not important which kind of profession).

(Dorfman, Dvar Avar 3, 2003:2)

What is the aim of this paragraph? It is not defining professionalism, fine. Maybe to discuss how professionalism is measured? Nothing valuable is said on that. What logic directs the move from the definition of professionalism, to measuring it and the quality of its components (what 'components' exactly?), and to the nirvana of a 'shared foundation of understanding'? Evidently, Albert Einstein was a professional scientist. Understanding Einstein depends more on ours than on his professionalism, that is, we have to do the hard work of reading what he wrote and what other scientists wrote about him. When each sentence does not stand firm, and the logical flow is impaired, the sum of the whole is zero: a collection of distorted clichés. The next quote connects criticism and professionalism, but does not lift the fog: 'Even when we absorb criticism (lispog bikoret), sometimes even harsh criticism, we take extra care about professionalism' (makpidim hakpadah yeterah al mikzoiyut) (Dorfman, Dvar Avar 17, 2012:3).

Maybe it means special earplugs that prevent the sounds of criticism from reaching the carefully maintained professionalism. The following quotes explain better why it is important to talk about professionalism:

The Professionalism creates strength in positioning (ha-mikzoiyut yozeret hosen be-mizuv) the IAA in the archaeological community, the public, and among the decision makers. 
As an organization, we strive for exposure, which will position us as a creative, innovative and professional organization.

(Dvar Avar 18, 2013:3)

The aim is not professionalism, but receiving accolades about it from others. It seems that Dorfman grasps professionalism in terms of a production line: "The "archaeological creation" process, from issuing the excavation license until its publication, is very professional. This process is all the time examined and adjusted to the needs, while continuously taking care of the highest standards' (Dvar Avar 15, 2010:3).

Can he give examples for the highest standards in issuing excavation licenses? Or in publishing excavations? Behind the empty talk about 'professionalism' stands the lack of professionalism of the speaker, who has no education in archaeology and related fields. Constantly talking about professionalism and demanding it from others masks his own deficiency.

A final quote on professionalism - without comment: 'Throughout the years, the basis for the activity of the IAA has been built, the ways of work have been crystalized, and the professional multidisciplinary stresses that are dealt with by the Authority [IAA] have been designed' (uzvu ha-hedgeshim ha-mikzoiyim ha-rav-tkhumiyim she-ha-rashut oseket bahem) (Dorfman, Dvar Avar 15, 2010:3).

Galilean $\mathbf{L O H}$. In a page introducing a Dvar Avar volume, Dror Barshad, then Head of the IAA Northern District and later Head of the Educational Administration (minhal hankhalah), showed his mastery of the LOH: 'The Northern District [of the IAA] is active in well-known landscapes, which are wrapped by the dress of settlement, transportation, industry areas, agriculture, gas, roads, drainage systems, tourism and accelerated development' (Dvar Avar 18, 2013:4).

'Transportation' does not already include 'roads'? The 'dress' is the same old, 1930s cement dress of 'Morning Song' by Nathan Alterman (1910-1970). Alterman wrote this poem when there was still much sand and not many buildings in the dunes around Tel Aviv: the catastrophes of hasty, irresponsible development were not yet realized. The 'dress' of development is not a gentle, loving caress: it forcibly modifies and damages the landscape and the archaeological remains. Let contractors utter such words, not those that should speak for archaeology.

The workers of the Northern District stand guard in order that those things that tell the history of this land will be preserved as far as possible, or be studied with the proper attention (if their fate has been settled to be covered or to disappear under the new landscapes of development). This commitment is the basis of the values on which the goals of the Northern District are established, which imbibe from the vision of the IAA (yonkim mitoch khazon rashut ha-atiqot).

(Davr Avar 18, 2013:4) 
What is the 'basis' of values on which 'goals' are 'established'? A person is what he imbibes, but a crudely mixed cocktail of raw ingredients can harm the delicate brain. The following quote is optimistic, it relates to children, perhaps:

The [Northern] District gives attention to the education of future generations, integrating the community and maintaining cooperation over time with public bodies that influence the planning of the North, such as municipalities, councils, authorities, governmental offices, planning committees and planners, entrepreneurs and representatives of future generations (nezigey hadorot habaim).

(Dvar Avar 18, 2003:4)

Concerning style, Jorge Luis Borges employed long lists of seemingly strange, unrelated items and concepts; or references and sources. They blur the reader's distinction between reality and fiction (Corry 1997). In the preface to the first edition of 'A Universal History of Infamy' (1935), Borges called them 'mismatched lists.' For example, to explain that the Library in Babel included everything, Borges writes:

All - the detailed history of the future, the autobiographies of the archangels, the faithful catalog of the Library, thousands and thousands of false catalogs, the proof of the falsity of those false catalogs, a proof of the falsity of the true catalog, the gnostic gospel of Basilides, the commentary upon that gospel, the commentary on the commentary on that gospel, the true story of your death, the translation of every book into every language, the interpolations of every book into all books, the treatise Bede could have written (but did not) on the mythology of the Saxon people, the lost books of Tacitus.

(Borges 1999:115)

No, Borges does not seem to be the origin of the dull, long lists that emanate from the Northern District of the IAA. They are just a train of thought that did not find the right moment to stop before exhaustion.

Perhaps 'education of future generations' means children living today; but how many 'future generations' live today, and does one cooperate with 'representatives' of children? Or, maybe the future generations have sent back in time their already grown-up representatives, unable to resist tempting, longterm cooperation with their ancestors from the Northern District. In that case the only remaining obstacle is grammatical:

How to describe something that was about to happen to you in the past before you avoided it by time-jumping forward two days in order to avoid it. The event will be described differently according to whether you are talking about it from the standpoint of your own natural time, from a 
time in the further future, or a time in the further past and is further complicated by the possibility of conducting conversations whilst you are actually travelling from one time to another with the intention of becoming your own father or mother.

(Adams 1980:99)

Given that managers in the IAA can integrate school children into a site (shulvu bo yaldey batey ha-sefer) (Dvar Avar 18, 2013:5) - imagine them planted in flowerpots in rows - everything is possible.

Clarification. It is important not to throw out the baby with the bathwater. Many articles in Dvar Avar are excellent. They describe sites and excavations, interesting finds and events related to IAA work. Some articles are academic, others popular and yet others humorous. I did not quote them because they have little relation to the $\mathrm{LOH}$. The present chapter concerns the huge contrast between what they write and the LOH introductions and words of blessing around them. The LOH corrupts their work.

Having few written sources, except preliminary reports by excavators, Galor (2017:154-157) dedicates only a few pages to the recent excavations in the Western Wall area, mostly giving details of discoveries. In one place, discussing the tragic events of opening an entrance to the Western Wall Tunnels in 1996 in the Muslim Quarter (cf. Greenberg 2009b:274), she forgets to mark a direct or nearly direct quote; but the $\mathrm{LOH}$ is unmistakable: '[The 1996 events] led to the IAA applying more scientifically and methodologically conscientious professional procedures and using more carefully designed public communications' (Galor 2017:154).

One 'conscious' about methods does not excavate in tunnels. In the following $\mathrm{LOH}$ example removing the jargon will leave only emptiness: 'The painstaking nature of the planning procedures and the assurance to follow the highest professional standards' (Galor 2017:157). To her credit, Galor remains critical, and these few places do not detract from the merits of her book.

Beneath the Surface. Another clarification concerns Dorfman's (2015) book, 'Beneath the Surface.' This book reveals little and conceals more than it reveals. The LOH exists, but not in all the chapters. To give two examples:

In order to prevent a situation in which the Director of IAA is the sole decision-maker, I acted to create an efficient, professional advisory system that will give me an orderly, transparent, supported (megubeh), and therefore also decisive (machriah) procedure of decision-making. This process I called 'a policy of participation' (mediniyut shel hishtatfut) and in its frame the IAA passes to the entrepreneur in advance all the relevant archaeological data that it has before and during the planning.

(Dorfman 2015:22)

The 'conclusions' of the status meetings by Dorfman prove that this description bears little relation to reality. Dorfman remained a sole decision-maker, 
sometimes against the advice of his subordinates. The professional, efficient (etc.) 'policy of participation' is designed for the benefit of entrepreneurs. A second example is the title of Chapter 2: 'Archaeology and national politics: between salvation (yeshu'ah) / rescue / establishing / necessity / policy / redemption (ge'ulah) / homeland (moledet) and an overdose' (Dorfman 2015:25). An overdose of what - of words in a title?

Principles. I close the discussion of the LOH with 'principles.' Like the immortal municipality clerk Joseph (Yossef) of Dudu Geva, the IAA has principles (ekronot). ${ }^{7}$ They are always scientific, professional and objective (inyaniyim). The IAA process of work involves a 'deep and real' (amitit umaamika) analysis, while constantly taking care of (toch hakpadah kvuah) remains of all periods (this reflects the 'removal' of 'late' remains at the HaLiba Building) (Document 5.17). The latter principle was so important that it was given an 'additional stress' at one point (nitan dagesh nosaf al ekaron $z e h$ ). One can count on the IAA to 'consider all the considerations' (shoklim et kol ha-shikulim) (Document 2.10); an entire 'system of considerations' (maarechet shikulim) (Dvar Avar 11, 2007:3).

In one case, using a new material at Ohel Yitzhak means that a reconstructed vault will exhibit the new material, instead of authentic-looking stone construction. The IAA Director decided that the matter is not principal, but only professional. Hence, logically, the best professionals to decide about it are himself and the entrepreneur. Since the matter is not principal, but professional, the two non-professionals will hold a principal discussion about it:

Following are the decisions of the Director:

The issue of the [new] material is a professional and not a principal (ekronit) question, therefore, the decisions shall be accepted by the entrepreneur and the IAA Director, after holding a principal (ekroni) discussion of the issue.

(Document 5.5)

In view of the language, such a discussion - if it was ever held - was neither professional nor principal.

\section{Notes}

1 The present IAA Management includes 16 members: one woman and 15 men (data from January 2019, see www.antiquities.org.il/article_eng.aspx?sec_id=46\&subj_ id=278).

2 Project workers are often temporary workers. This is not the norm in the IAA so far; but managers that come from the Military are used to the high turnover of lower-rank soldiers, which are conscripted for two-three years.

3 Compare Kingwell (2011:21-22) on the 'bullshit language' of work: it does not reject truth, it pays no attention to truth.

4 In Hebrew there is cultural heritage - moreshet tarbut (Dvar Avar 15, 2010:3) - but also moreshet krav - literally 'battle heritage'; roughly military history. It is mostly a 
popular genre used for educating and motivating soldiers. In the $\mathrm{LOH}$, our cultural heritage can be 'aggrandized' (haadarat moreshet hatarbut) (Dvar Avar 16, 2011:3).

5 There is a lot of stupid show-off in the culture of 'pressures of work': they become a matter of pride, proof of doing more work.

6 One IAA workers' meeting began with an introductory lecture by an academic expert in business administration. The essence of the talk was the difference between 'leaders' and 'managers,' and how top corporations strive to find leaders. At the end Dorfman rose and said, well, what we've heard is very nice, but in the IAA I lead and I make the decisions. One could not help notice the lecturer's shock by the dichotomy between his lecture and Dorfman's response.

7 For the sake of disclosure, the late Dudu Geva was a distant relative of the author. The best-known hero of Geva, the duck, exists now as a Tel Aviv street sculpture (Neiman 2015). 


\section{Pilegesh at Givati - Little Tel Aviv in East Jerusalem ${ }^{1}$}

What are you building? - I want to dig a subterranean passage. Some progress must be made. My position up there is much too high.

We are digging the pit of Babel.

(Kafka 1961:35)

The previous chapters are based on documents from the IAA and deal exclusively with its activities in the Old City of Jerusalem. Hence, readers may think that the discussed ethical and professional issues are limited to the IAA, while academic researchers steer clear of them. The present chapter warns against such an impression.

When the discussion in the Planning Committee on objections to the HaLiba Building approached (see Section 5.7), Dorfman 'asked to consult with additional archaeologists to solicit their opinion on the topic,' inviting them to tour the site with him in January 2013. Dorfman did not seek advice, but opinions favouring the maximalist building plan, in order to convince the committee (Document 8.1, on p. 161).

At stake was the idea expressed by the late Professor Yoram Tsafrir of the Hebrew University (and others), to keep the Cardo open to the sky and eventually restore it as an artery, so visitors would follow in the footsteps of the ancients who walked for centuries on the same stones.

Dorfman chose carefully his invitees. Professor Ronny Reich was then the Chairman of the Archaeological Council, but earlier the excavator on behalf of El-Ad, who renewed the 'method' of excavation by tunnels in East Jerusalem (see more in Chapter 9). For years he served as an adviser to $\mathrm{Mr}$. Dorfman. Reich's opinions cannot be considered independent.

Of the three other participants, all from Tel Aviv University, one (Lipschits) is not an archaeologist. The second (Finkelstein) is an archaeologist, but he does not need to hear explanations at the site. He knows what is expected of him and delivers the goods by phone.

The one who talked the most (Lipschits) was confused in thinking that the antiquities would have a glass ceiling open to the Western Wall Plaza. There will be a small opening at the roof of the Ha-Liba Building, but the antiquities will not be visible at all from the Plaza. Every excavation that remains 
for several years without preservation and maintenance will not look good (only preliminary conservation was carried out at the Ha-Liba Building so far). This is not a logical argument in favour of 'burying' the antiquities in a basement.

Notice the names of scholars from Bar-Ilan University at the bottom. Perhaps the days of the Messiah have arrived, for usually the Bar-Ilan professors argue in heated (academic) debates with their Tel Aviv colleagues under every green tree. Bar-Ilan University does not support this enterprise for the love of Shuka Dorfman. Rather, as a national-religious university, it supports national enterprises. Additionally, the Western Wall Heritage Foundation and Bar-Ilan University are both religious bodies, sharing similar worldviews. Somewhat embarrassingly, a few of those Bar-Ilan professors signed a petition against the building five years earlier. The change in position is not related to changes in religious dogma, but reflects the growing nationalism in Israel. More and more matters are judged by simplistic scales of 'us' or 'them.' Objection to the Ha-Liba Building is branded as 'leftist' and antiZionist. This suffices as a conclusive proof of wrongdoing.

\section{Document 8.1}

[Stamp: Israel Antiquities Authority]

Jerusalem, January 6, 2013

L-21607

\section{Subject: Ha-Liba Building - Plan No. 11053}

In view of the affidavit of Prof. Yoram Tsafrir, I have asked to consult with more archaeologists in order to receive their opinions on this matter.

A tour of the site was carried out on January 3rd, 2013, the archaeology was presented, the building plan, as well as the [written] opinion of Prof. Yoram Tsafrir. The responses are as follows:

Professor Ronny Reich: [I] think that the role of the Antiquities Authority is to preserve antiquities, and [it] should not represent and speak in the name of anyone (architects, planners, etc.). I am generally in favour of covered places above archaeological sites, since this serves the mandate of the protection of the antiquities of Eretz Israel and of preserving the antiquities from disintegration, dirt and wear. I don't think it's suitable that the Archaeological Council discuss the matter again, since a number of discussions were held in the past.

Professor Oded Lipschits: I think that the level [of the remains] should be viewed as an archaeological level that will reach [the level] of the Western Wall Plaza, with a glass ceiling above it. Everything that happens above the antiquities is a matter for architects and planners. 
I reviewed all the general plans of the compound, and in my opinion, in a situation where there is a commitment to fully consider the matter of archaeology, then the building can certainly be built. The way the site is now, looking as bad as it does, it will be worse if we leave it open, and therefore, one should build over it in one way or another.

Prof. Nadav Na'aman: I agree with the opinion that it is possible to build the structure above the site to the benefit of protecting the finds and the site.

Prof. Israel Finkelstein (in a phone conversation): I support and accept the position of the Antiquities Authority regarding the manner in which the archaeology is presented in the Ha-Liba Building. From his [Finkelstein's] perspective, he makes a distinction between the archaeological consideration and all other matters. As long as the archaeology is preserved and displayed appropriately he does not interfere, since other matters (as they appear in Prof. Tsafrir's affidavit) are not the concern of archaeologists.

Sincerely yours,

[Signature]

Shuka Dorfman

Director of the Israel Antiquities Authority

Attached [missing]: my [Dorfman's] response to the plan, the positions of Dr. Uzi Dahari, Prof. Daniel Sperber, Prof. Joshua Shwartz, Prof. Aren Maeir, and Prof. Zeev Safrai.

How should we explain the position of the three Tel Aviv professors? They are not religious and have no close ties to the Western Wall Heritage Foundation. However, at the same time (in the latter part of 2012) the Tel Aviv University Department of Archaeology, led by Oded Lipschits, started excavating in the City of David/Silwan. The funds for this excavation came from El-Ad, as well as part of the salary of the Tel Aviv archaeologist directing it. The funds passed through the IAA and the University claimed it had no knowledge about it and no connection with El-Ad (but see Nesher and Hasson 2012; Hasson 2013). All the former excavations for El-Ad in the City of David were performed by the IAA as salvage excavations (under permits). Now the IAA agreed to let Tel Aviv University have this excavation, as an 'academic' excavation (under license). After Dorfman helped launch the excavations of Tel Aviv University in East Jerusalem, he could count on the support of these three Tel Aviv professors for burying antiquities under the Ha-Liba Building.

The professors gave their blessing to the construction, but it is a curse to archaeology, for it might become a precedent. How will archaeologists protect antiquities from construction plans? Anyone who wishes to erect a building above antiquities can rely on these opinions, which received a stamp of approval from the IAA. 


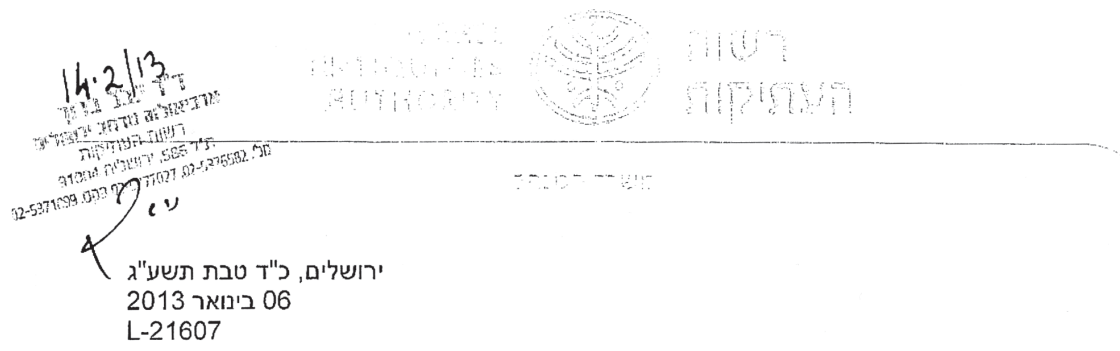

הנדון: בניין הליבה - תכנית מoפר 11053

לאור התצה'ר של פרופ' יורם צפר'ר, בקשתי להתייעץ עם ארכיאולוגים נוספים ולקבל את חוות דעתם לנושא.

ב- 3 בינואר 2013 נערך סיור באתר, הוצגה הארכיאולוגיה, תכנית הבנייה ומן את חוות דעתו של פרופ' יורם צפריר. להלן ההתייחונויות:

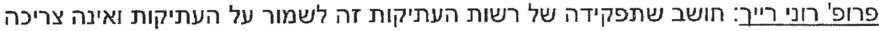

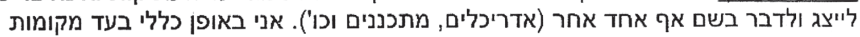

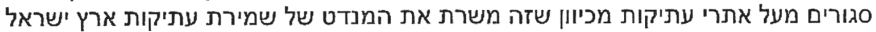

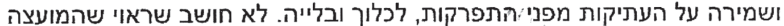
לארכיאולוגיה תדון בנושא פעם מפיה נוספת מכיוון שנערכו מבליה. לאפר דיונים בעבר.

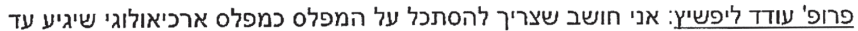

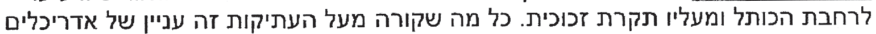

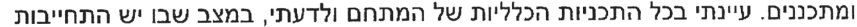

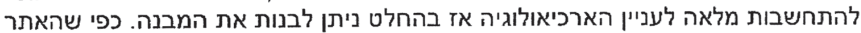

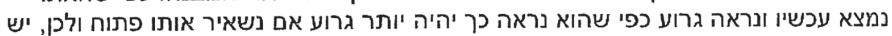
לבנות מעליו בדרך כזו או אחרת נרועית.

פרופ' נדב נאמן: מסכים עם הדעה שניתן לבנות את המבנה מעל האתר לטובת שמירה על הממצאים והאתר.

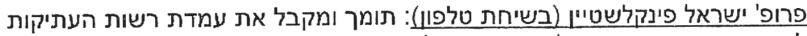

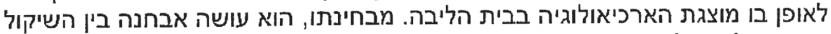

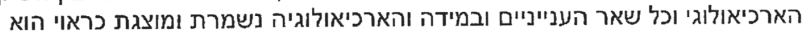

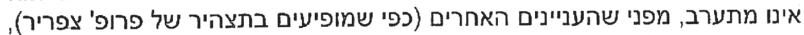

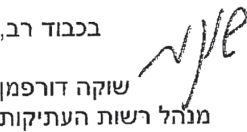
אינם מעניינו של הארכיאולוג.

לוטה: תגובתי לתכנית. עמדת ד"ר עוזי דהרי, פרופ' דניאל שפרבר, פרופ' יהושע שוורץ, פרופ' אהרון מאיר ופרופ' זאב ספראי דירי

Figure 8.1 Document of January 6, 2013. 
IAA excavating archaeologists do not enjoy academic freedom: refusing participation in excavations can bring dismissal from work. If the refusal can be interpreted as a political act, they risk dismissal without compensation (pizuyey piturin), because they are considered civil servants (who cannot be active in politics in relation to their work). The Tel Aviv professors enjoy academic freedom. They could choose any other site in Israel, but chose East Jerusalem and working for El-Ad. ${ }^{2}$ El-Ad is pleased to have such collaborators, for the scientific credentials of Tel Aviv University are better than those of the IAA. More crucially, in the public mind Tel Aviv University as a whole (regardless of different individual positions) represents the 'left' side of the political map; archaeologists from this university reject the 'historicity of the Bible. ${ }^{3}$ If even professors from Tel Aviv University cooperate gladly with El-Ad, opposition to the activities of El-Ad in East Jerusalem become more difficult.

This was only the beginning: by now Tel Aviv University archaeologists, directed by Yuval Gadot, work for El-Ad in the Givati parking site in Silwan. This excavation for El-Ad, from their and probably also Government funds, is carried on at the bottom of the former IAA excavations (Ben-Ami 2013), after the IAA has already finished work and released the area for development. The Tel Aviv people chose this site in order to find 'our' dear remains. Formerly they excavated on a slope outside the city, an area that served for dumping garbage. The nature of the area was noticed by former scholars and the finds were hardly spectacular.

Then came the ingenious idea of the 'Old City Cable Car Project,' running from Mt. Zion to Silwan and to the Mt. of Olives (Mizrahi 2018). The first phase, the Mt. Zion to Silwan section, was approved as a 'national project' in a hurried procedure; thus bypassing the planning authority with its professional analysis (for example, surveys on the environmental impact) as well as hearing objections from the public. The estimated, not final, cost is 200 million Shekels, taxpayer money. The plan is to connect the cable car to the top of the (not yet built) El-Ad visitor centre (Givati site) in Silwan. In this way every traveller can land in the warm embrace of El-Ad. The planned building is only $20 \mathrm{~m}$ from the Old City Wall in an area that was supposed to be kept free of buildings. Now this building (ca. 15,000 square metres) will be enlarged even more and made higher - or rather, deeper.

Since the cable car will occupy a floor or two at the top of the building, ElAd receives compensation in the form of more underground floors, and the Tel Aviv team is happy to dig the floors for El-Ad. ${ }^{4}$

The planners speak about 72 cars per hour, a risky enterprise whose transportation benefits are doubtful, since there are already public buses to the area and a light rail is planned as well. The damage to the skyline of Jerusalem will be enormous. No other World Heritage city would plant such a cable car system in its midst (imagine inserting one in the centre of Venice or Rome, with ugly, massive pillars to support the cable, some of them eight storeys high - it is inconceivable). 
The only raison d'être of this plan is political. An arm of metal will cut through the skies of the city, from west (Mt. Zion) to east (Silwan and Mt. Olives), making it more difficult to reach a future peace agreement with the Palestinians. ${ }^{5}$ Cable cars with Israelis and tourists, and guides from El-Ad perhaps included in the deal, will rush above Palestinian neighbourhoods in East Jerusalem. The cars can bear colourful pictures of the type of the Givati fence (Chapter 1). From above (at some points just a few metres above private houses, at others at a great height) the passengers will gaze down at the untermenschen underneath. So far, Israel has only planted smart new neighbourhoods on the horizons of East Jerusalem; and organized the 'separation' fence to keep Jerusalem inseparable, however cutting parts of it off (whole neighbourhoods that were made part of Jerusalem in 1967 are now outside the fence); and spontaneously spread houses with fanatical settlers in the midst; and dug historical tunnels underneath. Now the Palestinians will also be caged-in from above, disturbed by the noise and humiliated by the gazes of passengers. Jerusalem will be a horrible place. No light to the nations shall emanate from this new Zion.

It does not disturb the professors. From their high academic positions they are digging the pit of Babel at the bottom of the Givati site in Silwan, not for King David and country, but for career and fame.

\section{Notes}

1 Paraphrase on the pilegesh (concubine) at Gibeah (Judges 19).

2 In former decades the Hebrew University performed excavations in East Jerusalem (but not for El-Ad). At present none of their staff excavates there; the sole exception is Eilat Mazar - but she is only affiliated and does not carry the aura of a professor.

3 The public and many politicians tend to have a simple 'all or nothing' view of this historicity. For example, when the former President of Israel, Moshe Katzav, was asked about the debate on the historicity of the Bible, he said:

I do not intend to argue with scholars, my position is not in relation to that of one scholar or another. I treat the Bible as a scientific source that is not inferior to any archaeological find - perhaps even superior. For every archaeological find is damaged in 2000 years, is worn and not complete. The Bible remains as we received it 3000 years ago [...] In my view there cannot be an archaeological find that contradicts the Bible, since the archaeological finds are incomplete and therefore cannot contradict what is written in the Bible.

(Dvar Avar 9, 2005:4)

4 What the Tel Aviv excavators knew when asking for a license to excavate at the Givati site, or what El-Ad told them, we cannot say. However, it was a license for research (type G), not a permit for salvage work. Recently I heard the excuse that the excavations were meant from the start for the cable car, but if that is the case, why the G-type license? Also, do they imply that they embarked on a project before the plan was approved?

5 For a possible division of heritage areas in Jerusalem see Sayej (2013:57, Fig. 1). 


\section{The ethics of East Jerusalem}

\subsection{Legal aspects}

International Law stipulates that occupiers should refrain from archaeological excavations in occupied territories and exporting objects of cultural heritage (including antiquities) from them. Only necessary (that is, salvage) excavations are permitted (The Hague Convention and its second protocol: UNESCO 1954; UNESCO 1999:\#9).

The legal situation of East Jerusalem is complex. International conventions deal with member states, but Palestine is not (yet) a state and Israel did not ratify the second protocol of the Hague Convention (and later conventions that extend it). Jordan occupied the West Bank in 1951; Israel occupied it in 1967 and cut East Jerusalem off from it. The longevity of the occupation adds to the complexity, since the Hague Convention was designed for short-term occupations.

Israeli Law was enforced over East Jerusalem: the land was annexed, but not the people (they were given residency, but not citizenship). The annexation was acknowledged in the 1979 Law 'Jerusalem, the Capital of Israel.' Recently, in rejecting an application against moving cultural heritage objects from East Jerusalem to West Jerusalem, the Supreme Court declared that in East Jerusalem Israeli Law takes precedence (gover) over International Law (Bagatz 2016; Regev 2016; Sfard 2003).

Even if excavators in East Jerusalem are immune from legal prosecution in Israel, they transgress International Law (under which the annexation of East Jerusalem is not valid, Dinstein 2009:18-19; Lapidoth 2011; Dumper 2011), and are not absolved of ethical responsibilities.

\subsection{Ethics and apologetics: the tunnelling}

There is a rich literature on archaeological ethics (Scarre and Scarre 2006; Moshenska 2010; Gnecco and Lippert 2014), but relatively few studies on the ethics of excavating in East Jerusalem. One aspect that was discussed is the tunnelling as an unscientific and unethical way of digging (Greenberg 
2009b:277; 2014; Sulimany 2013; Kletter 2013:425; Thelle 2016:17; Galor 2017:103-104, 167; see also Chapters 3-4 here). Those who support the tunnelling (e.g., Barkay 2013:71-73; Reich 2011) justify it by claiming that other methods are inapplicable underneath built areas. This is poor justification. In some places one can excavate carefully from the top, and later restore the surface remains (see Chapter 3). The main aim of the tunnels is not archaeological: they are a political means of penetrating into and controlling the earth underneath Palestinian neighbourhoods. Exposing heritage in tunnels is usually a secondary goal, but it too serves to appropriate all the heritage as 'ours. ${ }^{1}$ Inner correspondence (exposed recently) by two senior IAA archaeologists reveals that they too see tunnelling as a destructive, unethical way of digging, which no serious archaeologist supports:

The Tunnel underneath the Herodian Street: here for the first time the accepted archaeological [norms] were breached and work was done not according to archaeological methods that are accepted in the scientific world. The excavations were not made from top to bottom, but from the side. I objected to the decision [to approve these excavations], a decision which was finally accepted by Shuka Dorfman. ... The suggested excavation [now] ... is an excavation into the unknown from the side, with archaeological misunderstanding, misunderstanding the context, in complete contradiction to accepted archaeological standards in the IAA and in the world. In fact, it concerns bad archaeology, a situation in which the IAA would not be able to be proud of its research quality, will not be able to claim that it acts in the highest professional level and does not let foreign agendas overcome its opinions.

(Jon Seligman, April 20, 2015; quoted in Emek Shaveh 2017b; see also

Hasson 2017b)

Gideon Avni wrote in an email of January 26, 2016 to Yuval Baruch:

I have so far not found even one serious archaeologist within the IAA or outside it, except you [Baruch], which professionally supports an attitude of excavating a horizontal tunnel where one cannot adequately treat the levels later than the street itself.

(Emek Shaveh 2017b)

Instead of advising the Director to stop the tunnelling, Avni suggested that he approves it as 'a Director's decision.' The IAA Director has the legal power to issue (or not) excavation licenses - but why mention this now? Avni realizes that the Director will approve the tunnelling, however unethical and damaging. A 'Director's decision' may help keep a clean conscience: I objected, it was his decision. Only, it neuters the objection by suggesting compliance with the decision. 


\subsection{More apologetics}

In a 2013 article, Jon Seligman blamed the critics of the excavations in East Jerusalem for being post-modernists, quoting Zagorin to the effect that postmodernists are sceptics and relativists, they 'cut the ground from any moral or political stand' (Seligman 2013:181). Such labelling is extremely simplistic: it makes a caricature of post-modernism, identifying all those that do not agree with Seligman as nihilists and ascribing to them a sort of simple, absolute 'relativism' (see Hamilakis et al. 1997 and the following discussions there). This crude effort to dodge criticism by labelling other scholars 'postmodernists' or 'relativists' is not scientific argumentation. It does not support any claim to objectivity by Seligman, but rather exposes his bias.

Seligman is convinced that the overt nationalism of early Israeli archaeology is gone and today it is scientific and ethical. In his view, many of the critics lack archaeological knowledge; their criticism is based on: 'Impressions selected from interviews of specifically chosen, usually anonymous, individuals or the writings of post-modern political journalism [...] rather than the more precise research of archaeological writing' (Seligman 2013:185). ${ }^{2}$

Seligman adds: 'we should honestly, objectively, and critically present the data we find as we find it' (Seligman 2013:195). The present book works towards this goal and is based on thousands of documents, presented here for the first time. However, the picture that emerges does not support Seligman's claims about current archaeology in East Jerusalem.

Allegedly, data on 1,050 excavations in Jerusalem from 1967 to ca. 2013 proves the 'objective scientific policy' of Israeli archaeology, since it gives 'equal weight to the excavation and publication of finds from every period' (Seligman 2013:188; but see Greenberg 2009b:271-272).

Seligman does not separate East and West Jerusalem - though the critics did not criticize every excavation, especially those in West Jerusalem. The list of excavations is irrelevant for aspects such as removal of 'late' remains and using sites to support one-sided ideologies. ${ }^{3}$ Seligman (2013:191) acknowledges such problems at Silwan:

It is clear that patterns of state sponsorship and influence to excavate the City of David are certainly a return to paradigms evident in the first decades of Israel's existence. However, just as in earlier periods of Israeli archaeology, a nationalist influenced archaeological dialogue is almost completely absent from the professional archaeological reports of the same site, a fact more telling of real archaeological practice than any finger pointing.

(Seligman 2013:192)

Yet he moves immediately from (the vaguely described) problems to 'professional' archaeological reports. Excavation reports are a poor source for the history of archaeology, but even they cannot escape the spirit of their 
time. Thus we read that Beer Sheba was a fortified city in the 'Israelite period' (Aharoni 1973:2). We are told in the Ramat Rahel report that this new term 'Israelite period' - is used only in a chronological sense and for 'simplicity,' though Ramat Rahel was Judean, not Israelite (Aharoni 1962:2 n. 2, 10 n. 30). Maybe Seligman reads only excavation reports, missing the many IAA press releases on 'the rocks of our existence. ${ }^{34}$ More telling about real archaeological practice is the fact that the Islamic remains described in the professional report of the Givati excavation (Ben-Ami 2013) exist only on paper. They have been dismantled in order to reach 'our' deeper remains.

Among the earlier-mentioned 1,050 excavations in Jerusalem, can Seligman cite a dozen where Islamic remains have not been removed to reach 'our' remains? Where they are preserved and exhibited (not inside toilets), with guides taking visitors to see and hear about them? Seligman justifies the 'agenda based' presentation of sites like Silwan as a fair balance to the illegal Wakf excavations at the Temple Mount. What kind of justification is that? We are like them - only we started first:

As the entrance to this area was located in the Western Wall plaza, which was a declared holy site, archaeologists were prevented from supervising the works. For almost twenty years the work at the tunnel was characterized by uncontrolled digging that contravened all ethical principles of archaeological investigation.

(Avni and Seligman 2006:275-276)

During the excavations in the Jewish Quarter and beside the Southern Western Wall in the 1970s, lorries carried huge quantities of dug earth and debris outside the city bounds, dumping them in a central [dump] area. For years the people of the adjacent village used to borrow/rummage in this earth and sieve it, finding all sorts of small finds that were not noticed by the excavators, selling them to antiquities dealers in Jerusalem.

(Avigad 1991:61)

In another paper, Seligman (2011) discussed the archaeology of Jerusalem since the Mandate period. ${ }^{5}$ An analysis of the 18 figures in this article show bias, which in his view does not exist. The figures show only Western and Israeli scholars and officials. Photos with explicit legends present only 'our' remains: the broad wall in the Jewish Quarter, the 'Tomb of the Sanhedrin' and a paleo-Hebrew inscription from Givat Hamivtar. One Christian site is also acknowledged (the Cathisma Church). There is no picture of an Islamic site or antiquity with a legend announcing it as such. ${ }^{6}$ The Haram al-Sharif is shown once - but it is also the Temple Mount, and comes only as a reference to another publication by Seligman. In one place Seligman balances the fate of persons who lost their homes and became lifelong refugees in the 1948 Naqba with that of persons who lost access to a library or museum: 'Jewish workers of the previous Mandatory body were unable to access the [Rockefeller] 
building, and, similarly, Arab workers abandoned their posts in areas now occupied by the new State of Israel' (Seligman 2011:131). ${ }^{7}$

An article by Gabi Barkay (2013) also limits much of the discussion to the 'professional' discourse. Barkay is not worried about the origins of the funds for the excavations: any source is presumably legitimate. Barkay acknowledges that the archaeology of Jerusalem is unique:

The high level of expectations in excavations is typical to Jerusalem. Nowhere else does one hope to find fabulous things from the days of David and Solomon, to expose the tombs of the Kings from the House of David, to find the tomb of Jesus the Christian [sic] and his family members, or to expose the ark of covenant and the tools of the temple.

(Barkay 2013:69)

Who is interested to find such remains? Four of the five expectations are 'ours,' and (typically) the remaining one is Christian (cf. Greenberg 2018:374). Islam is a rich tradition, but Barkay does not cite an expectation that fits it (finding the reigns of al-Burāq?). Indeed, what can a Palestinian expect from a current excavation in East Jerusalem?

Since most archaeologists enjoy freedom of writing reports and are not religious, all is fine:

I work for more than eight years now [...] in sifting the soil that was illegally removed from the Temple Mount. The funding of the sifting project is by the El-Ad organization, which has a clear political colour. However, throughout all those years nobody interfered in interpreting the finds, which periods to stress and which to ignore, there was never any interference in the professional archaeological considerations, and this is currently the situation also in all the excavations in the City of David.

(Barkay 2013:71, emphasis added)

An archaeologist who 'stresses' some periods and 'ignores' others is not an ethical archaeologist. Archaeologists that work with El-Ad know what to stress and what to ignore (never admitting this, of course), and El-Ad does not need to teach them this important principle of work in East Jerusalem. Scientific reports, which few people read, are not crucial to El-Ad - why interfere with them? More importantly, the archaeologists today do not interfere with El-Ad's work. ${ }^{8}$ They help El-Ad by exposing 'our' remains and supporting development plans, leaving El-Ad free to design and operate sites, indoctrinate visitors and develop Apartheid in East Jerusalem (Greenberg 2009a:42-43).

The model secular archaeologist in East Jerusalem, well-equipped for the task, is Professor Ronny Reich, digger of tunnels for El-Ad and advisor to Shuka Dorfman. In 1995 he published an introductory book, 'Invitation to Archaeology,' presenting archaeology to the general Israeli public. ${ }^{9}$ The 
author, as if objective, criticizes the use of archaeology for political reasons by everyone - 'Christians, Jews, and Muslims' (Reich 1995:196). However, the Muslim case is different from the rest, it is their negative imprint:

The area of the State of Israel is strewn with thousands of antiquities sites, remains of past cultures, which existed here hundreds and thousands years ago. These remains represent extinct past cultures as well as cultures and religions whose birthplace is here - Judaism, Christianity and to a certain extent also Islam. One cannot exaggerate the importance of the archaeological remains left from the Jewish settlement of Eretz-Israel throughout the periods ... They perhaps form the most tangible proof for the connection between the Jewish people and Eretz-Israel. Indeed, there never occurred in Israel an archaeological excavation or survey on behalf of a Muslim institution, or whose researches are Muslim, or arrived from a Muslim country [...] However, the relation between archaeology [of the Land of Israel] and the Muslim World exists. It exists, for example, in a negative way. Since the Six Days war, institutions and scholars avoided continuing excavations and surveys in Israel. British, German and other institutions [...] have stopped dealing with the study of the biblical period and the Second Temple period (the days of Jesus), and have shifted the focus of their activity to archaeological work in Arab countries, especially the Kingdom of Jordan. They have also started to deal with research of the Early Islamic, Crusader, and Late Islamic periods in Eretz-Israel.

(Reich 1995:198, emphases added)

The embroidery and wording tell the reader about the subtext: the Land of Israel is not really important to Islam. The important remains, which prove ownership of the land, are only the Jewish remains. Muslims are presented as a monolithic, negative entity. Notice the skilful play with 'Israel,' which sometimes denotes the entire land, but sometimes only the State of Israel after 1948, allowing Reich to make half-true statements. Palestinians did archaeology when they could: in Israel/Palestine during the British Mandate period and in the West Bank under Jordanian rule (until 1967). What are the chances of a Muslim Institution, or Muslim researches from a Muslim country receiving an excavation license from the State of Israel? Without a license one cannot excavate, and requesting one acknowledges the issuing authority. Should we condemn Israeli scholars for not asking for excavation licenses from the Syrian or Lebanese governments? Notice how Reich teaches the readers which periods are important and which are not. Periods with Israelite/Jewish remains are important. Periods of foreign rule by Crusaders and Muslims are not: it is a pity that scholars focus on them, instead of on 'our' periods. Christianity should focus on the days of Jesus, which luckily fit one of 'our' periods. Thus, an Apartheid worldview is translated into Apartheid research, where scholarly fields of study are determined by kin. The people of Israel study the Bible and Second Temple (one cannot exaggerate how important these periods are). 
Christians should focus on the days of Jesus. British and German scholars must not be wasted on unimportant Islamic periods; leave this rubble to the Arabs (but keep the Land of Israel clean of Muslim scholars).

This islamophobic, orientalistic text appears in a chapter titled 'archaeological ethics.' El-Ad has no reason to interfere with the scientific reports of Reich, a master in the art of stressing and ignoring. ${ }^{10}$

Reich's Excavating the City of David (2011) is a good example of this art. ${ }^{11}$ In the ca. 60 pages long 'brief history' on all periods (Reich 2011:279-343), the early periods (before the Iron Age) occupy 11 pages; 'our' remains ca. 35 pages; and the Islamic periods barely five pages; but even for Islamic periods the focus is on us (for example, in the Early Islamic period comes 'the renewal of Jewish settlement'). The author adds (partial) little revelations of illegal, unethical acts. Sometimes he boasts about these deeds, turning them into little jokes - at the expense of others. Other times he takes them for granted, because great discoveries justify any means. The author is so full of himself that he does not notice the nature of his little colonial enterprise within the larger Israeli enterprise in East Jerusalem.

Except for one assistant, the Palestinians appear in the book as anonymous manual workers. Reich (2011:85) boasts that he offers paid work to 'the finest youth of Silwan.' In presenting this great favour he unintentionally betrays the reality. The finest Israeli youth can hope to learn and make a career, becoming successful IT experts, scholars or maybe engineers - the sky is the limit. The finest youth of Silwan can hope for hard manual labour, without chances of promotion, a permanent job or honour (they serve the occupation). Reich (2011:134) blames Professor Raphael Greenberg for 'pressuring' these youth to quit their lucrative work. Reich even blames Greenberg for the fact that all these youth remained, 'to the best of my knowledge,' unemployed afterwards. How does he know? From 'our finest youth' in the security organs? Most of the work in a place like Silwan comes from Israeli employers: the system was built to maintain the economic dependency of the territories on Israel. ${ }^{12}$ The security organs have been briefed about this khuzpah of resigning, and their hand can be heavy. Is Greenberg the only adult responsible for employment in East Jerusalem? Did Reich try (for example) talking to even one employer in favour of even one of his former beloved workers?

The care of the scientist for the natives is moving:

Our great luck was the character and vigour of our workers. All young guys, the finest of the Palestinian youth of the village of Silwan. We, on our side, could offer them paid work for a long period, and the fact that they were locals from the neighbourhood ensured that the work will not be stopped even during the days of the [second] Intifada [Palestinian revolt, ca. 2000-2005]. Furthermore, they performed the work quite fast. From many years of experience with manual workers in the Jewish Quarter, Mamilla and near the Temple Mount, [I know that] the bottleneck is always removing the earth out of the excavation square as it deepens. 
The best way is to fill sacks with the excavated earth and lift them with a crane or tractor [...] It was impossible [to do so] at the slope of the City of David, inside a visitor centre [...]. The common alternative is to raise the earth buckets out of the square with a pulley, bucket after bucket, slowly. Another method, common in excavations with plenty of volunteers, is to put a line of workers on a wooden ladder climbing out of the excavation square, and raise the buckets with a chain of hands, that is, from hand to hand; but this method is a waste of human resources. Our young group of workers employed another method, much faster. Instead of filling the buckets to the rim with earth, they filled them by half. Thus, one at the bottom of the excavated square could throw the bucket with force upward to the rim of the square, and there another boy caught it [...]. At the time when one bucket would have gone up slowly by pulley, it was possible to remove and throw, easily, ten buckets and even more. Thus, although we excavated the fill by hand, it [the work] proceeded with a speed that is worthy of mention.

(Reich 2011:85, our translation and emphases) $^{13}$

After many years, Reich appears to be used to modern slavery, and can tell funny anecdotes about slaves' life. Achieving speedy work is an important requirement of any colonial manager. One can waste manpower with Western volunteers, but not with hired natives. What makes this case worthy of mention is not the speed of work, but that the natives found how to speed up their own work. Reich could also tell something about their (low) wages, but that would not be funny, and he couldn't care less. Strangely, Reich is not aware of conveyor belts. Yet why waste funds of El-Ad on technological solutions, when cheap natives are available. This anecdote, and the photo of the workers, recall the Soviet book on Belomorkanal, with the smiling zeks (Gorky 1935).

A few steps up the steep ladder of work is Eli Shukron (then an IAA employee). Reich is full of admiration for Shukron - a full partner, registered on the licenses (in second place?), sharing 'the full rights and duties' (Reich 2011:82) - but not writing this book, or even one chapter. Reich says, rather enigmatically: 'I see as my biggest non-archaeological contribution to the study of Jerusalem the fact that I managed to maintain my cooperation with him [Shukron] throughout all the years in the City of David' (Reich 2011:114).

He adds:

Yigal Shiloh enjoyed the support and mainly lack of jealousy (firgun) of the entire archaeological establishment and all his professional colleagues. However, I did not have this feeling all the time in the IAA. A fact is that they occasionally tried to rid Eli [Shukron] of the mutual work with me (Eli, who was a partner, not an assistant), and I wasted much time on archaeo-politics, that is, meetings and talks in order to maintain this cooperation between me and him. What disturbed many is this symbiosis between us. Archaeologists should quarrel among 
themselves sometimes, and here it did not happen. It seems that different types of ability, skill, and personalities worked here together [...] Each one contributed the fitting measure of skill, vision, talent, knowledge, organizational skills, khuzpah, scepticism, daring, persistence, reputation, and maybe also a bit of luck. This, it seems to me, was intolerable to some of my colleagues.

(Reich 2011:147)

Suddenly this symbiosis ended, and then Shukron's work in the IAA also came to a hasty end. Did Reich, an advisor to Shuka Dorfman, try to speak in favour of his former partner?

For the history of one invention Reich's book is important: tunnelling under Palestinian houses. It is presented as a comedy of errors with one wise, tireless hero, and some clowns. Some characters are masked, especially grown-up Palestinians that put obstacles in the hero's scientific road (there is no harm in mentioning the natives as innocent youth and happy workers; but to tell readers that they have political views and even legal rights is something different). We took the liberty of adding them (in square brackets) to the story. For fun, try replacing 'Palestinians' with 'Israelis' or 'Englishmen' - it can hardly be imagined, and will make the entire story unintelligible:

We could not excavate the area because it exceeded the borders of the excavation license issued to us only for cleaning the channel. One could not also excavate from the surface down because of an issue of ownership [of the land, by Palestinians]. From the IAA we were told [by whom?] that the Law enables [us] to excavate under the surface also in areas of others (shtahim shel aharim) [who happen to be Palestinians]. In truth, I did not believe this claim, and hoped that if someone will object, the issue will be dealt with by lawyers and not archaeologists [So that I will not be involved? Or, that my archaeological colleagues will not do more stupidities?]. We started to excavate a small section to the north [...] even though it exceeded what was permitted in the license [and also transgressed private property of Palestinians?]. I thought that maybe seeing will manage to persuade Dorfman to order us to continue.

We began excavating a side tunnel [in the private Palestinian area]. I shall say already now that in regard to archaeological methodology, this [tunnelling] is a wrong thing (maaseh lo-rauy). It was the second time we acted in this way [...]. In both cases the excavation was done out of a very well-calculated consideration (shikul mekhushav meod), based on knowledge of the earth that was excavated in this way by meticulous handwork (avodah yadanit medukdeket) [...].

The IAA people visited us at the site all the time, including Jon Seligman, responsible over the Jerusalem District of the IAA, and [he] did not see any need to stop us because we were working outside the frame of the area defined in our excavation license! The 'blast' came when 
Gideon Avni, Head of the Excavations [and Surveys] Department of the IAA arrived to a visit and claimed that we transgressed the Antiquities Law, a claim that I certainly agree with.

We were called to a clarification [talk] with Shuka Dorfman, IAA Director. To our good fortune he visited the area earlier and was himself impressed with the discovery. I opened by saying that this is a classic case of 'fine or prize'. Dorfman, the former military man, fixed me and suggested an expression from his lexicon: 'commendation or [lowering to] lance corporal' (zalash o tarash). He thought that the discovery was very worthy. He could not make excuses about the fact that the Jerusalem District Archaeologist fell asleep during guard. We received [from Dorfman] permission to continue.

The matter did not pass smoothly. Professor Yoram Tsafrir rushed to raise the Archaeological Council, surely because of political reasons...

(Reich 2011:128) ${ }^{14}$

None of Reich's acts is political, for he is a man of pure science. Only the 'leftists' that oppose him have political motives - dirty political motives. There is no need to cite the continuation of this story, how the invention caught on: one tunnel after another.

The core of the matter involves not one but two transgressions, but the transgressor - Reich - is not very good at explaining the details, and ties the legal issue to either excavating from the top or from the side, as if this matters. One transgression, of the Antiquities Law, is excavating outside the area specified in the conditions of the license. This can happen by mistake, though here it is intentional. Reich can convince Dorfman to ignore this transgression, thus closing the case. ${ }^{15}$ The second transgression is quite different: to the Law of Property (a person is owner of land to all its depth, not just the surface) and to the 1992 Basic Law of Human Dignity and Freedom (paragraph 3 forbids doing harm to the property of a person). General Dorfman cannot absolve Corporal Reich from such wrongdoings, but knowing passes the responsibility to him, for the guilt of the corporal is small in comparison to that of the general. How lightly they both treat the property of Palestinians! They gloat in humiliating them, telling such stories as jokes for the Chosen People. There is no place for democratic laws in wild East Jerusalem, our little Bantustan (cf. Kedar 2003; Veracini 2006:25).

In addition there is the ethical transgression of digging from the side in tunnels, which Reich knows is a wrong thing; but the end justifies the means. Notice the language Reich uses in trying to justify the tunnelling: 'very wellcalculated consideration' - or Lingua Orientalis Hierosolimitanae for 'an excuse,' since one cannot predict in advance what will be found. Similarly, 'knowledge of the earth ... by meticulous work' is another excuse, because before one excavates the earth, one cannot know it 'meticulously.' Digging it from the side is the opposite of being meticulous. 
Seligman 'did not see any need to stop us' - read: Reich did not see any need to tell Seligman what he did. Honest persons do not suspect that a respectable man of science is wilfully transgressing the Law.

'From the IAA' an unnamed person urges Reich to continue 'also in areas of [Palestinian] others.' This cunning person holds some status (people consult with him), but betrays his IAA colleagues by keeping them in the dark about Reich's expansion and tunnelling plans. In the English version of the book Reich exposes this person: he is no other than Shuka Dorfman. ${ }^{16}$ So the Director of the IAA supported and urged the settlers and their servant Reich to breach the Law - behind the back of his own employees. After Reich was caught, Dorfman feigned the 'clarification' scene, pretending to be an innocent bystander, absolving Reich of a transgression to the Law that was conceived by both. One can hardly trust Reich as a source. Yet the picture of a director of a public authority (responsible for the Antiquities Law) that plots with the settlers about how to breach the Law behind the back of his own officials indeed exemplifies the values of the current archaeology of East Jerusalem.

\subsection{Professional ethics are human ethics}

In the past, discussions in archaeology stressed the responsibility of the archaeologies to material remains - the 'archaeological record.' However, the responsibilities of archaeologists are not limited to material remains, for archaeology does not happen in a void. They concern relationships with people, and hence, archaeological ethics must acknowledge power relations and politics:

A professional ethic should be about relationships that an archaeologist and his or her profession seek, establish, maintain, and nurture with people. Once we recognize that our professional relationship with people is the main thing, then a professional ethic concentrated on an entity such as the archaeological record [...] melts away.

(Williams 2013:288; cf. Sayej 2013:48; Haber 2014; Zorzin 2014:116; Moshenska and González-Ruibal 2015:4)

Realizing this, we understand how limited the discourse of 'professionalism' and 'objective science' is. It uses ethical terms 'to promote the perception that an organization's activities are driven by morally superior principles,' masking economic and political aims (Zorzin 2014:133-134). The 'quality control' of archaeological excavations (our excavations are professional, performed with the most advanced technologies) becomes evidence of 'being ethical' (Zorzin 2014:135). The notion that archaeologists are professionals, above everything else, diverts them from attention to other roles they have as citizens and human beings. Archaeologists that identify their role in relation to 'the archaeological record' tend to forget that this record is collected, 
arranged and interpreted by us, and therefore, is not detached from the present world (Hamilakis 2007:21-22).

Since social and political identities are affected by the ways in which we grasp the past, the archaeologist (who 'translates' the past for those living now) holds a position of power. Ethical archaeologists 'must not separate knowledge from the context in which it is produced' (Strich 2013:147). They have complex and often conflicting responsibilities to different persons (Moshenska and González-Ruibal 2015:12-13), including labourers on an excavation, colleagues in academic and other institutions, entrepreneurs, coauthors in publications, and readers.

Excavating in East Jerusalem involves difficult ethical choices, since archaeological work, especially in this area, cannot be politically neutral (McGuire 2008:224, 229; Phillips and Ross 2014:27; Moshenska and González-Ruibal 2015:9; Greenberg 2018). In the maze of conflicting responsibilities, each archaeologist must find her/his way. Ethically, the question whether East Jerusalem is occupied or free, ours or theirs, is of secondary importance. The way archaeologists should (or should not) act in an area of conflict like East Jerusalem must be answered on ethical grounds, not by arguing that this area is ours (or theirs). An ethical archaeologist that works in such areas cannot dismiss International Law and ethics in favour of nationalistic convictions.

Ethical archaeologists should enquire about the aims of the excavation: is it necessary or scientifically required? Who earns from excavating, preserving or dismantling certain remains? Who finances the excavation and why (Hamilakis 2007:28-29; Greenberg 2009a:46)? Some excavations in East Jerusalem are legal, such as salvage excavations before building a road or a school for Palestinian dwellers. However, Israel tends to label many excavations that are not salvage work as salvage work, in order to blur their contradiction of the Hague Convention. Many excavations are indeed salvage excavations, but whom do they benefit? Not even one excavation in East Jerusalem since 1967 was made by a Palestinian scholar (Greenberg 2009a:44-45) and very few benefitted Palestinian residents. An examination of excavations in the West Bank in 2007-2014 reveals that 106 of 118 requests for excavations defined as salvage work were for the benefit of Israel, mostly for the settlers (Emek Shaveh 2017a; see also Greenberg and Keinan 2009). Such excavations serve the occupation and transgress International Law.

East Jerusalem has 50 shades of grey areas. Archaeologists are likely to find themselves not at the outer edges, where the ethical obligations are clear, but somewhere in the grey middle. They must draw clear lines, for crossing one grey area is likely to lead to crossing more. Those who finance the excavations influence the archaeologists' worldviews and conclusions (see Trouw 2010; Greenberg 2015:22).

Being ethical is not a one-time decision, but a dynamic process. The goal is not a nirvana-like plateau, but moving in the right direction. Nationalistic archaeologists in Israel often misunderstand this, pointing at someone's past as a stain that can never be removed: Raphael Greenberg worked in the West 
Bank at 'Joshua's Altar' and in the 'City of David.' Yes, but he has progressed since (Greenberg 2015:19-21). In the grey zones not all share the same position and responsibility. For example, university professors are free to choose any site for excavation, while IAA excavators that refuse to excavate risk losing their job.

What about the ethics of archaeologists not as individuals, but as a community? Only one ethical code was written in the entire history of Israeli archaeology, but it did not make any impact (Kletter and Sulimany 2010). Ethical codes cannot not solve all problems, but they may put some limits on power wielders in the archaeological establishment (both IAA and universities). For the last 20 years there has not been any strike by archaeologists in Israel, though the majority of archaeologists work in low-level positions, as salvage excavations' 'diggers,' inspectors and part-time academic staff. Many absorbed the Capitalistic discourse to the extent that they do not even notice it. The Supreme Archaeological Council is anaemic (see Section 2.4). It has de facto power regarding excavation licenses, but its work is entirely non-transparent. Where is the archaeological community? One sees mainly institutions dominated by narrow castes, each taking care of its own interests.

Is Israeli archaeology as a whole unethical? Not at all. Many archaeologists and excavations in Israel are professional and ethical (the two are not unrelated). One cannot avoid completely excavations in areas that are occupied for so many years. The solution can only be political, but excavations cannot completely cease until it is found. Israel holds moral rights to certain sites in East Jerusalem, like the Western Wall, but claiming acknowledgment of such rights must also recognize that the Palestinians have rights too, even in West Jerusalem (the Mamilla cemetery is an example).

Israeli archaeology as a whole is not unethical, but the archaeology of East Jerusalem (and the West Bank) is. It is colonial archaeology (Greenberg 2009b:275; Greenberg 2015:29) that corrupts everything that it touches. Its supporters live in ignorance of the post-colonial discourse in archaeology, years of light away from discussions like Smith and Wobst (2005), Hamilakis (2012) or La Salle and Hutchings (2018). ${ }^{17}$ This archaeology is motivated by hatred, desiring everything for itself, leaving nothing for the other. How can excavation be fun (according to Reich, 'rolling fun,' hagigah mitgalgelet) when just outside the square, or the tunnel, the garbage bins are overflowing and people live in poverty under Apartheid? In 2015 there were 320,000 Palestinian residents (36.8\% of the population) in Jerusalem. Some $75 \%$ of the adults and $84 \%$ of the children lived below the poverty line. They suffered a shortage of 1,000 classrooms and $43 \%$ of the existing municipal classrooms were defined as inadequate. In school $26 \%$ of the children dropped out in the 11 th grade and 33\% in the 12th (East Jerusalem 2015; cf. Hasson 2017c:90).

The 'rolling fun' leads to Kafkaic situations. In 2006 a municipal surveyor measured the Badran family house at 'Aqab Village, two kilometres southeast of Ramallah. The surveyor stated that $52.2 \%$ of the house is located in the occupied territories (i.e., the West Bank), and $45.8 \%$ in Jerusalem. ${ }^{18}$ 
The bedroom is in Jerusalem, but the living room in the West Bank. As a result the family lost the status of residents of Jerusalem: they were no longer entitled to enter Jerusalem freely, work there and receive social benefits from the Municipality. The family claimed that since the bed where they sleep every night is part of Jerusalem, they spent most of their life there, and are entitled to residency; but this argument did not convince the court (Hasson 2017c:88). A second, archaeological example: two brothers, Palestinian antiquities dealers from Hebron, were used to sending their merchandise to the antiquities shops in the Old City of Jerusalem. Israel did not abolish 'legal' antiquities trade, and such shops exist in Tel Aviv too. ${ }^{19}$ So the brothers could not be charged for being antiquity dealers. Instead, they were charged by the Israeli Military Court in Hebron, under the stipulations of the Jordanian Antiquities Law, not for dealing with antiquities, but for transferring antiquities without an export license to a 'foreign territory,', that is, (East) Jerusalem. At the same time, Israeli citizens like General Moshe Dayan freely transferred antiquities without export licenses from the West Bank and Gaza Strip to Israel (Berman 1987:356-359; Lapidoth 2011:25; Kletter 2003; 2013:419).

Finally, it is not a question of archaeological ethics, but of human ethics.

\section{Notes}

1 'Developing' sites, closing them and setting entrance fees already denies access to many Palestinians, due to their poverty. More crucially, they cannot feel welcomed in sites controlled by bodies like El-Ad, where the Islamic heritage is erased.

2 Concerning 'precise research of archaeological writing', Wright (1966:115) said, long before post-modernism: 'what excavators are trying to do and what they do are not identical, and neither may mirror what they say they are doing.'

3 Seligman objected to some of the tunnels in inner discussions, but kept silent about them in public. This puts loyalty to (improper) decisions of the IAA Director above loyalty to the profession. To be fair, from the documents it appears that Seligman does not hold extreme views; he also tried to prevent some decisions that damage archaeological remains (e.g., see Section 4.2 and Documents 4.25; 6.5-6.6).

4 It is not just the IAA press releases. Compare the media coverage of the excavations of Eilat Mazar in East Jerusalem (Trouw 2010).

5 Seligman (2011:125) thought that the British Mandate authorities made antiquities state property. This is not so: the British cherished private ownership of antiquities. Finders of antiquities only had to notify the Mandatory Department of Antiquities, which could - but was not obliged to - purchase the antiquities (Antiquities Ordinance 1929:\#6-7). This was also the custom in the early years of the State of Israel.

6 This bias runs deep in Israel today, often unnoticed. For example, the liberal newspaper 'Haaretz' listed the top biblical archaeology and Christian archaeology stories of 2018 (Schuster 2018). The subtitle read: 'Who exactly did ancient Jews really worship, and what did Jesus really look like?' The first sentence of the report was: 'The year 2018 was an extraordinarily rich one for biblical archaeology, in both the Jewish and Christian worlds, and for pagans too.' Even mice 'got their moment in the sun' as saviors of Jerusalem. We traveled to far Iceland 
for the conversion of Celts and Vikings, and were impressed by the miracle of the Israeli gardener born on Christmas evening who found a ring with an image of St. Nicholas. Our archaeology accommodates Christians and Jews, pagans and mice, Vikings and Celts, but not Muslims.

7 These were people like Na'im Makhouli, Inspector of Antiquities in the Galilee; but also antiquities guards like Mohamad Ismail Radi, who worked at Ashkelon. He did not 'abandon' his post but was forced out of it: a photo taken after the war (in 1949) shows him still in his post (Kletter 2006:46-51, 119, Fig. 15).

8 Until the 1990s the IAA objected to El-Ad's activities in the City of David/Silwan, see Greenberg 2014.

9 The following lines are a revised version of Kletter and Sulimany (2016:189-190).

10 So far, Reich did not publish any final report on his large excavations in Jerusalem.

11 All quotes are translated from the original Hebrew book, except when stated otherwise.

12 In recent decades foreign workers from Thailand and the Philippines have replaced some of the Palestinian workers.

13 Reich never reflects why his laborers are all "young guys". The reasons are the hard work and low wages. Another anecdote, no comments:

All that was found was a small, narrow tunnel. Eli [Shukron] persuaded one of the skinny youth that worked with us to crawl in it to the southeast direction, and indeed, the youth disappeared into some space beyond the eastern edge of the area.

(Reich 2011:132)

14 We explain some terms that may confuse readers: 'Cleaning' - digging horizontally, from the side. 'Excavating under the surface' - the same as 'cleaning.' 'Fell asleep during guard' - the meeting of Reich and Dorfman is full of military slang. For Reich it is a way to demonstrate his intimate relations with Dorfman. The two have much in common, though it is hard to imagine real intimacy between two such super-egos. Notice the glee in mentioning, again, Seligman's mistake.

15 'A claim that I certainly agree with': Reich is proud about transgressing the Antiquities Law, for he and his important discoveries stand above the Law. The other transgression he glosses over, omitting its Colonial essence by not mentioning who are the property owners.

16 Pp. 233-236: 'Davidleh, the director of Elad, had spoken with Dorfman, and [Dorfman?] had made clear to him that the law allows excavation beneath property belonging to others.' Either Dorfman told Davidleh, or, in the fantastic reality of East Jerusalem, the settlers explain the Law of Antiquities to the head of the Antiquities Authority. In either case, Dorfman became aware of and agreed to Reich's plans.

17 Colonialism is discussed by Israeli scholars in modern history, literature and other fields (see for example Bar-Yosef 2013); but not in archaeology (with very few exceptions).

18 Because Israel enlarged the borders of the city in 1967; earlier the entire area was part of the West Bank.

19 On the trade in antiquities in Israel/Palestine see Kersel 2006; 2008; al-Houdaliteh et al. 2017. 


\section{Conclusions}

There is no 'pure' archaeology free of power relations, unless we agree to cut archaeology off from the world of the living and never lift our eyes from the excavation squares. The professional work of the IAA excavating archaeologists in East Jerusalem is surrounded by a turbulent sea of unprofessional situations, considerations and decisions. Decisions by the entrepreneurs and the IAA management of where to excavate, for what purpose and how to present the remains have political effect on the Israeli-Palestinian conflict. Each side seeks to demonstrate its rights to the city, but the conflict is extremely uneven, since Israel rules the city and holds almost all the keys.

The IAA supported every plan of development in the Western Wall Plaza, influenced by political and financial considerations. The support was at times given without serious examination (as in the case of the comprehensive plan, Chapter 6), limiting the ability to stop or change plans later and hence, to prevent the 'removal' of remains.

In the Ha-Liba and the Strauss excavations, the IAA Director ignored accepted work procedures, promising in advance to the entrepreneur that the IAA will not prevent construction. At the Strauss Building the IAA gave up the opportunity to document remains by waiving a full salvage excavation.

In excavating under 'inspection' the IAA puts itself above the Law. The Antiquities Law (1978) stipulates that every archaeological excavation in Israel requires a license issued by the IAA. However, at Ohel Yitzhak and the Western Wall Tunnels the IAA performs excavations and cuts tunnels (claiming that tunnelling is archaeological excavation) without licenses (or even permits, which are considered as valid licenses by the IAA). This means that instead of a full team, the works are performed under an inspector or two. Inspectors are often early-career, less experienced archaeologists. Dedicated as they are, they cannot employ scientific methods of excavation (slow, stratigraphic work with careful separation of layers and meticulous registration) in an inspection. They are also not obliged to publish anything. When others dig without licenses in antiquities sites, the IAA treats it - rightly - as a crime and issues warrants stopping the work. The 'patent' of performing archaeological excavations under inspection is illegal and unethical; it is a degradation of professional norms. 
In all the sites under discussion, remains from Islamic periods are treated as unimportant and usually dismantled. The heritage of the 'other' is 'orphan heritage' (Price 2005). In all the sites there are no signs in Arabic (cf. Strich 2013:155-157), although until 2018 Arabic was an official language in Israel. The entrepreneurs in East Jerusalem aim at exposing our heritage (mainly the First and Second Temple periods) and ignoring or silencing 'theirs.' The IAA management does not manage - at times perhaps does not care - to stand in their way. Thus, at Ohel Yitzhak (Chapter 4) two stones in a Roman period wall were more important than a nearly complete Mamluk period bathhouse. At the Ha-Liba house (Chapter 5) a Sheikh's Tomb of the 17th century AD was destroyed. ${ }^{1}$ The comprehensive plan for the entire Plaza (Chapter 6) implies large-scale destruction of 'late' remains. At the Strauss Building (Chapter 2) the IAA preserved 'late' walls of the Mughrabi neighbourhood only because funds were available and demolition was not necessary. The walls are located inside active toilets and are 'exhibited' without any signs to 'visitors' that come to use the toilets. What is the educational, scientific or professional merit of this work? It is not management of heritage, but another step (albeit more cynical) in the erasure of the Mughrabi Quarter.

Unlike the vast majority of development projects in antiquities sites elsewhere in Israel, the main, and at times the only, aim of development in the Western Wall area is neither archaeological, nor touristic or religious, but political. The entrepreneurs, backed up by the authorities, use the antiquities to deliver a one-sided nationalistic narrative. The 'silencing' reflects a black and white image of the world. Whatever can be 'theirs' is silenced, while we aggrandize whatever we can call 'ours' - including remains related to King Herod, whom Josephus and other sources describe as a horrible person, a tyrant and a murderer (he murdered his own wife and three of his children, among others) (Berlin 2015). ${ }^{2}$

It is surprising how little of the new development answers religious needs, though the entrepreneurs are religious bodies (cf. Document 6.6). ${ }^{3}$ An exception is the restoration of the Ohel Yitzhak Synagogue - but no religious needs are served by the spaces under the Synagogue, in Area C east of it, or in the tunnels connecting it to the Western Wall Tunnels. ${ }^{4}$ The driver of the development is the goal of controlling East Jerusalem and preventing a peace process that requires a division of Jerusalem. This goal is tied to religious, or more exactly Messianic, hopes. The Western Wall Heritage Foundation is perhaps not politically extremist (unlike El-Ad or Ateret Cohanim); but it ties itself to the nationalistic goal in the perception or hope that it leads (it is hard to see how) to religious salvation (geulah). The marriage of extreme real-politic nationalism and Messianic dreams is dangerous. In the dimly lit underground spaces, the archaeological remains add mystery and aggrandize the 'experience' of the visitors. What do they take with them when they return to the light of a politically torn Jerusalem? How many interpret the dream as a call for concrete acts in this world? 
Working closely with bodies like El-Ad means that the archaeology of the IAA, the Tel Aviv professors (Chapter 8) and others is not detached from the ideologies of those that order and finance their work. The excavations give legitimacy to the entrepreneurs, expose 'our' remains and silence those of 'the other.' Many realized this about the Givati site at Silwan (Greenberg 2009a; 2014; see also Rapoport 2009; Behrman 2010; Mizrahi 2012; Mizrahi and Veeder 2013; Hasson 2013; Selimovic and Strömbom 2015; Galor 2017:119-131). The entrepreneurs have no reason to interfere with the scientific work of the archaeologists. This is because the archaeologists do not interfere with the plans of the entrepreneurs (how to use the sites, what to build above them, what to tell visitors, etc.). The entrepreneurs need not worry what archaeologists write in scientific reports, because few people read such reports, they are a drop in the flood of popular media about the 'rocks of our existence.' In addition, the entrepreneurs do not need to teach an important foundation of the work in East Jerusalem - the art of 'stressing' (our periods) and 'ignoring' (theirs). Archaeologists like Ronny Reich come well equipped for this task (Chapter 9). In the past one could hope that the Givati excavation was an exception. The present study demonstrates that this is the common modus operandi in East Jerusalem now. Formerly El-Ad had to raise the funds and to overcome objections from the authorities, today the authorities supply funds and encourage the activities. Formerly the IAA opposed to building in the City of David, today it pushes the entrepreneurs to excavate and to tunnel (Chapter 3).

We do not refute the necessity of some development in the Western Wall Plaza. The visitors deserve adequate facilities (such as safe access, toilets, first aid and police services), and the operators of the site require some work space. However, much of the development is over-development (lecture halls, exhibitions that do not relate to the archaeology/history of the site, spaces rented out for events, etc.). The result is commercialization of the Western Wall. Instead of free, equal access and the freedom to interact with the place as one chooses, the site becomes a Disneyland-like attraction, where the operators lure the visitors to additional paid activities and educate (or rather, indoctrinate) them (on the ethics of tourism see MacCannell 2011).

In all the sites treated here, the process of planning and decision-making is fundamentally flawed. It is detached from normative principles of heritage management today. The planning is often rushed, and so are the excavations. Financial and nationalistic considerations take priority (cf. already Raab et al. 1980). The developers are considered as the owners of the heritage. The public and other stakeholders are ignored. The planning becomes a technical matter (how many pillars, what diameters) and ethical questions are not asked. Decisions are accepted in a militaristic fashion, almost solely by men. They move and remove, tunnel and penetrate, dismantle and erect. They try to conquer what has already been conquered in 1967, to make a name for themselves on the Western Wall, but not in modest notes between stones. Examples of hurried planning are many - the support of the comprehensive plan without 
serious analysis; the efforts to create for this plan a semblance of adherence to international standards (World Heritage Sites, the Quebec document); decisions by one voice (IAA Director) in narrow forums (status meetings); justifying destructive tunnelling, etc. Proper decision-making in management of cultural heritage requires to consider ethics and all the stakeholders (Mackay and Palmer 2015:169; Hamilakis 2007:24; Strich 2013:160; Moshenska and González-Ruibal 2015:8).

The corruptive effects of the work in East Jerusalem is expressed in language: the Lingua Orientalis Hierosolimitanae ( $\mathrm{LOH}$ ) - the language of the United Lands of Jerusalem (Chapter 7). It is a Hebrew dialect of our time, spoken all over the land, by occupiers and occupied alike. This relatively poor dialect is affected by military slang ('focused examinations' - deriving from 'focused prevention,' that is, targeted killing) and the neoliberal discourse (we are professional, efficient, objective ...). Archaeological expenses can be cut since 'every one of us must believe that research has borders and budgetary limitations' (Dorfman, Dvar Avar 3, 2003:2). Criticism is as dangerous as enemy fire, even if it only produces 'side noises and disturbances.' The responsible managers 'maintain cooperation over time' with 'representatives of future generations' (Dvar Avar 18, 2003:4). How many future generations live today? Or, maybe we do not cooperate with 'representatives' of children, but with grown up representatives of future generations that have travelled back in time, in order to work together with their ancestors from the IAA.

In the United Lands of Jerusalem, our acts are always objective, scientific and professional. There is one scientific truth, but reaching it requires a lot of funds for excavations (Yuval Baruch, Section 5.8). Those that criticize us are motivated by dirty politics. Before any decision we 'consider all the considerations.' This might end up in complete 'loops' of logic, confusing cause and effect, principles and jargon. Thus, when the use of new materials to restore a vault might end up with inauthentic appearance, the IAA Director Shuka Dorfman concludes:

The issue of the [new] material is a professional and not a principal (ekronit) question. Therefore, the decisions shall be accepted by the entrepreneur and the IAA Director [two famous professional experts], after holding a principal (ekroni) discussion of the issue.

(Document 5.5)

In view of the language, such a discussion (if it was ever held) was neither professional nor principal.

While excavators in East Jerusalem are immune from legal prosecution in Israel, they transgress the International Law and are not absolved from ethical considerations. Formerly, archaeological ethics were focused on responsibility to the archaeological record - the material remains. However, the archaeological record is collected, arranged and interpreted by us, and hence, is part of the present world (Hamilakis 2007:21-22). Archaeological ethics concern first 
and foremost relationships with living people, and hence power relations and politics (Williams 2013:288; Zorzin 2014:116). Nationalistic archaeologists may claim that an area of conflict (like East Jerusalem) is 'ours,' hence we are free to do there as we please. However, ethical archaeologists cannot dismiss International Conventions and ethics in favour of nationalistic convictions.

Excavating in East Jerusalem involves difficult ethic choices and is not politically neutral (McGuire 2008:224, 229; Moshenska and González-Ruibal 2015:9; Greenberg 2015). The vast majority of these excavations benefits the settlers, not the Palestinians, and therefore (even if salvage work) they transgress International Law. The archaeologist is likely to find himself/herself in confusing grey areas of conflicting loyalties (Moshenska and GonzálezRuibal 2015:12-13). Drawing ethical lines is an on-going, personal process, a long-term travel rather than a single ride. While some can avoid involvement more easily (university staff enjoy academic freedom and can choose sites for excavation), others face difficult decisions (IAA archaeologists that refuse to excavate might be fired, even without compensation).

Unfortunately at present there is no written ethical code (cf. Kletter and Sulimany 2010), and no professional association of archaeologists in Israel. ${ }^{5}$ Many submit to the discourse of 'professionalism': 'Work is controlled by a simple ticking of boxes, which in the end, completely relieves archaeologists of all their responsibilities, apart from the obligation to "clean" the site in an appropriate rigorous and technical way' (Zorzin 2014:129).

This discourse is 'ethics-washing' (Zorzin 2014:133-135). It tries to promote a perception that the IAA and the other institutions that work in East Jerusalem are driven by ethical and moral considerations, masking the financial and political aims. The state reduces its responsibilities ${ }^{6}$ and the entrepreneurs become owners of the heritage. The professional status of the archaeologists deteriorates (they learn that they are dispensable, many work as low-level 'diggers' or 'teachers from the outside'). The notion that archaeologists are professional above everything else diverts them from paying attention to other roles they have, as citizens and human beings.

Is Israeli archaeology as a whole unethical? Not at all. Many archaeologists and excavations in Israel are professional and ethical (the two are not disconnected). One cannot avoid completely excavations in areas that are occupied for so many years. The solution can only be political, but excavations cannot completely cease until it is found. Israel holds moral rights to certain sites in East Jerusalem, like the Western Wall, but claiming acknowledgement of such rights must also recognize that the Palestinians have rights too, even in West Jerusalem (an example is the Mamilla cemetery). Israel holds responsibility for all heritage, not just 'our' heritage.

This book is not written to condemn Israeli archaeology or to support Palestinian claims. It criticizes only the current archaeology of East Jerusalem and its corrupting effects. It is unethical, colonial archaeology (Greenberg 2009b:275; 2015:29), whose supporters live in an imaginary pre-postmodernist world or 19 th century slavery estates. To justify the aim any means 
becomes 'kosher,' from bribes and use of prostitutes by settlers to seal deals in property, to unscientific, destructive digging of tunnels and erasure of 'their' remains. This archaeology desires everything to itself, leaving nothing to the other. Archaeological ethics without compassion is not ethics at all. It is finally not a question of archaeological ethics, but of human ethics. Doing archaeology as it is done in East Jerusalem today is pitiless robbing of a poor man's lamb (2 Samuel 12). It is repeating the sin of David in the City of David.

\section{Notes}

1 The entrepreneur is a religious, orthodox body - opposed on religious grounds to archaeological excavation of tombs. Apparently the respect of the dead is limited to 'our' dead.

2 Herod's mother was a Nabatean. Perhaps the Jewish halacha that recognizes Jews only by matrilineal descent was not yet universally accepted during Herod's time (see Cohen 2001:13-24), but my point concerns the acceptance and admiration of Herod today.

3 Some spaces in the Western Wall Tunnels have religious functions. They are a result of over-development: generous budgets are given so spaces are cleared and used, but they are not required for visiting the Plaza or praying before the Western Wall. At the same time, religious needs of non-establishment groups like the 'Women of the Wall' are denied for decades.

4 The restoration of Ohel Yitzhak is politically motivated by its location in the Muslim Quarter. Notice that we did not criticize the IAA in this relation. Once a building plan is approved the IAA must excavate in order to document remains before construction. Our criticism starts with the development of the underground spaces beneath the Synagogue (deviating from the building plan). Sadly matters 'spilled' farther, to Area C and the new tunnels.

5 An ethical code is not a magic solution, but it can supplement legislation and limit excesses by power wielders. Currently there is an intiative to re-establish an archaeological association in Israel.

6 Recently, the Ministry of Finance threatened to remove salvage excavations from the IAA to private companies - not for the love of archaeology, or worry about conflicts of interests, but in the name of 'efficiency.' The aim is reducing costs of excavations, which might lower professional standards. Will this materialize, and will other models be considered (such as in France), one cannot say. 


\section{Appendix \\ The documents}

\section{To Chapter 2: Strauss Building}

Document 2.1

Jerusalem, July 6, 2008

L-37801

Subject: Advancing the Strauss Building and the Excavation of the Western Wall Plaza - Summary of the Meeting of 6/7/08

Participants: Shuka Dorfman, Uzi Dahari (in part), Jon Seligman, Yuval Baruch, Raanan Kislev, Shachar Poni, Alexander Onn, Soli Eliav, Chen Canari, Ofer Cohen, Eli Elan, Dany Rahat.

Following is the summary:

\section{The Strauss Building}

The model [of the building] was presented.

Soli Eliav: The Police building was dismantled and today there is no Police Station [at the Plaza]. The new planning will pass an accelerated process of [construction] permit. We speak about a general plan, so that the Police Building will be part of the plan of the Strauss Building, at the Western front [?] of the Western Wall. The idea is to widen the façade, but not beyond the present façade. The façade will not protrude into the Western Wall Plaza compound. The façade is located at the lobby entrance to the Western Wall Tunnels. In order to hang a façade and build a storey above it, until beneath the windows of the [Western Wall] Rabbi Office, we need approval for several drills. The [Jerusalem] Municipality approved the plan.

Generally speaking, the instruction given to [Architect] Ada KarmiMelamede was that visitors to the Western Wall would give their attention to the Western Wall, therefore, a modest and 'quiet' building was planned.

The plans of the Strauss and Ha-Liba buildings will be submitted each separately. The Strauss Building proceeds in the regular route to the committee 
of security installations. Only the Police storey proceeds in an accelerated process.

We should examine the possibilities, in cooperation with Yossi Gordon, including connection to the [existing] building, in order to perform a minimum number of drills.

Raanan Kislev: The planning must be in the same style as the Ha-Liba Building.

Dany Rahat: The Municipality approved a different façade, which connects to the site. The façades in the model [you see] are out of date. The new façades were approved by Shlomo Eshkol [the Jerusalem City Engineer]. Concerning volumes we work according to the IAA instructions.

Jon Seligman: Ada Karmi-Melamede did not analyze the surroundings. The planning is detached from the existing surroundings. There is no reference to the Old City. There is no division of the fifth façade of the Old City ['fifth façade' means the area of the roof, especially of flat modern roofs; the expression was coined by Le Corbusier].

Shachar Poni: One should separate between the volume and the façade. The model is reasonable. One should lessen from the problem of the façade, which should be considered with Ada Karmi-Melamede. The volume and the height are correct.

Yuval Baruch: One should condition the building on a salvage excavation, as a condition for approving the plan and for executing it later. One must present an accurate foundation plan. The works done in the past in this area were documented by the Conservation [Department].

Chen Canari: We speak about ca. 30 drills.

Dany Rahat: The approval of the IAA is required for making two drills in a diameter of $20 \mathrm{~cm}$ [each], in order to create a foundation for casting the ceiling. The intention is that the Western Wall Heritage Foundation will build in the upper part and the IAA will excavate in the lower part.

Shuka Dorfman summarized the discussion:

a) Indeed, Ada Karmi-Melamede referred to the entire Western Wall Plaza.

b) The Old City was created without anyone planning it, and here lies its beauty.

c) The [new] building is not protruding and is being built with up to date technologies.

d) The project will be approved after a detailed plan with a minimum number of drills is presented.

[...] [For the rest see Chapter 6, Document 6.6] 


\section{Document 2.2}

[Top: IAA letterhead]

Jerusalem Region

15 September 2008

Kotel $/ 5 / 2220$

Reference J-J 35498 activity number 69151

To: Mordechai (Soli) Eliav

The Western Wall Heritage Foundation

Jerusalem

Dear Sir,

Subject: Scheme for Reference to a City Building Plan in Preparation 12996 The Western Wall Plaza, Aqabat Abu Meidan St. (Strauss Building)

1. The IAA has not yet completed the examinations required for approving this plan. Therefore this letter includes general references, which will be a scheme for an approval that will follow later.

2. The consequence of the asked addition of a storey above the existing structure on the Old City topographic layers was not yet examined. The IAA will draw its position concerning the additional construction only after the said examination.

3. The location and the number of the pillars will be decided only at the end of the examinations of the IAA, and this letter does not form an agreement for this part of the plan at this stage.

4. The IAA will be ready to approve the plan in principal, on the condition that the regulations of the plan will include 'an antiquities item,' which will be an inseparable part of the above mentioned agreement in principal, and will include in it the items detailed as follows:

5. The area affected by the plan is a legally pronounced antiquities site, and of exceptional importance in that is forms part of historical Jerusalem. Therefore, it can happen that the discovery of antiquities will force major changes in the planning and in the mode of the works in a manner that will ensure protection of the antiquities, their safekeeping and restoration, and among other things the opening of the site to the public; all under the conditions of the [IAA] Director, which will be made under his authority according to the Antiquities Law, 1978.

Scientific archaeological excavations must be conducted in the entire area under discussion. Only after the completion of the excavations, and depending on their results, will the IAA determine the conditions and requirements for approving construction, as well as what demands it will have for changing the plan according to the City Building Plan. 
If during the excavations antiquities will be found, which in the opinion of the IAA require preservation at the site, then the preservation of the antiquities and leaving [the site] as an open site will be a condition; it will not be possible to make any building works at the site without [fulfilling] this condition. A survey of the place and of the archaeological finds at the place has to be done, both historically and mainly for identifying and defining the values, so that it is clear what should be preserved and how. One should examine the integration of the new building, so that it does not damage the surroundings context, skyline, fifth façade, building materials, eastern façade, and a typological analysis of nearby buildings.

The entrepreneur commits to safekeeping the antiquities and performing acts of maintenance and preservation, which will ensure the keeping of the antiquities against nature calamities or human acts. [Page 2]

The entrepreneur is responsible that the site will be open to the public according to conditions set by him with approval of the Jerusalem City Architect, and following common procedures for the entry of the public in similar sites.

Since it concerns an old city that is defined as a proclaimed antiquities site in one unit, all the details of the construction must be coordinated with the IAA, and include references to façades, roofs, external installation and details of finish as required by the instructions of planning in the new general City Plan.

In any case, the plan will not give rights of building of any sort for the area, until the archaeological excavations will be finished and the IAA will set conditions for building according to the plan.

Should the rights on the property be transferred to a third side, the entrepreneur takes upon himself to inform the buyer or the new owner of rights about the conditions of the IAA, and also ensure that the conditions detailed in this letter will form an inseparable part of the agreement [of transferring the rights].

The things as mentioned above form an inseparable part of the instructions of the [City] Building Plan and of the section concerning antiquities, which will be detailed as follows:

Following are the instructions of the Antiquities Item that must be included in the plan. These items may change after the completion of the [initial] examination stage of the plan and are not final instructions:

1. The area of the plan is located in the Old City of Jerusalem, which is a legally proclaimed antiquities site (O[fficial] G[azette] 1390 of 31/8/67), which has an exceptional scientific and historical significance.

2. Therefore, a building permit will not be issued and the plan will not give rights for building and no construction shall be allowed according to the plan, unless after the completion of a full archaeological excavation over the entire area of the plan, according to the conditions of the [IAA] Director, as detailed below; and additionally those parts that the Director set for preservation, as part of these conditions, will be preserved.

3. Prior to submitting an application for a [building] permit, the entrepreneur will conduct full archaeological excavations, at his own expense, 
according to the conditions of the [IAA] Director by the instructions of the Antiquities Law, 1978.

4. The antiquities exposed in the area will be preserved in situ, according to the conditions that will be set by the Director during and immediately after the excavation.

5. Should there be found in the area, as mentioned above, antiquities which require on site preservation, all the acts for preserving the antiquities shall be made and also the entrepreneur will act over the years to maintain and to guard the antiquities in place.

6. The owner of [building] permit will allow opening of the discovered antiquities to visits of the public. Conditions of opening [to the public] will follow those of other similar sites, according to conditions set for the owner of permit by the Jerusalem City Architect.

7. The IAA Director shall have the power to set conditions, based on the results of the excavation, concerning the height of the space between the excavation and the floor of the building, and the location of the necessary foundations as well as the finish of the construction in relation to the antiquities.

8. The architecture and all the building details (the building appendix) must be coordinated with the IAA, to receive its approval, while [making] an explicit reference to the masterplan for the Old City No. 10276, including analysis of the surrounding of the building and the integration of the suggested building with it. [Page 3]

9. Only at the end of the excavation, and according to the conditions of the Director, will it be possible to submit an application for building permit. The application requires approval of the IAA Director concerning the relation between it and the antiquities.

You are asked hereby to notify us in writing about your agreement and approval of the said IAA conditions. With the acceptance of your said letter, the IAA will approve the deposition of the [building] plan by signing the regulations of the plan.

I also stress again that the IAA has not completed the examination of the plans and therefore, this letter is only a scheme of the IAA way of thinking. The district and regional committees will have to re-ensure the conditions of the IAA for the plan before it is deposited.

Sincerely, Jon Seligman, Jerusalem Region Archaeologist

[Copies: a long list - Shuka Dorfman, Yuval Baruch, Raanan Kislev, Shlomo Eshkol, Eli Elan, Amnon Arbel (Department for City Planning, Jerusalem Municipality) and the Jerusalem District Committee for Planning and Building] [Fax stamps indicate that the letter was sent] 


\section{Document 2.3}

[Top centre: Letterhead of the IAA]

To: Mr. Jon Seligman

Jerusalem Region Archaeologist

IAA

Subject: Strauss Building: The IAA's Position in the Regional Council

Shalom!

Following is an initial proposal I have prepared concerning the Strauss Building for the [coming discussion at the] District Council. This proposal is based on my understanding of the conclusions of the meetings held by Shuka [Dorfman]:

We analyzed the plan according to a detailed documentation file that had been prepared. In accordance with the means currently at our disposal, and based on a study of the proposal according to the criteria established in plan 10276 (in process) [the Jerusalem city master plan], and on a thorough examination of the proposal's compatibility with existing topography, current construction styles, issues of visibility and effect on the cityscape.

One may see four major issues which require, in our view, consideration: A) Functional-pragmatic considerations. B) The impact of the proposed volumes [of the new construction], from an overall perspective. C) The compatibility of the proposed exterior and building elements with, and their overall impact on, the design of the Western Wall Plaza. D) The potential damage to valuable [archaeological] remains. The first three issues mentioned above necessitate a more comprehensive perspective, beyond an examination of the building itself. In consideration of this requirement, the preparation of a comprehensive plan for the Western Wall Plaza has begun.

However, in our opinion the advancement of the suggested plan should not be dependent on the completion of the comprehensive [entire Plaza] plan and its statutory status. This is because it is recognized that the majority of the proposed functions [of the building] indeed address real needs. The proposed scale of construction (when checking the topography and nearby construction) is also appropriate and reasonable. One should call for a fast completion of an initial general plan as a guiding document, and advance the specific [Strauss] plan at the same time with the advancement of the general plan. At the same time, fixing the structure's façade, etc., in accordance to the data accepted by the general analysis, and adjusting the various functions according to the general analysis. However, as already said, [one should] not condition the approval of the plan [for the Strauss Building] on the statutory approval of the overall plan [for the Western Wall Plaza] (as we also think is true for requests concerning small additions to private homes in the Old City: one should consider them by strict criteria, but not condition the additions upon [approval of] new general plans).

Concerning changes in ancient walls that appear in the plan [for the enlargement of the Strauss building]: The IAA, as the body responsible on 
protection of antiquities, objects to any act of destruction of the Medieval remains that are included in the plan and calls the [District Planning] Council to demand other solutions to the elevator and staircases.

\section{Document 2.4}

Jerusalem, 22 April 2009

J-40095

\section{Subject: Strauss Building - Summary of a Meeting of 22/4/09 Amendment}

Participants: Shuka Dorfman, Yuval Baruch, Shachar Poni, Eli Elan.

Following is a summary of the main issues:

Shuka Dorfman: I spoke with Dalit Zilber [of the Planning Council], and she is not willing to approve the plan, until the problem of the elevator is solved. Eli Elan presented the plan.

The elevator is planned for giving access to handicapped persons.

Shachar Poni: The functions that sit [sic] in the buildings do not change. Must there be, from a legal point of view, an elevator also to the third floor?

Eli Elan: Yes, since this is a public building. There is a new construction of a third floor at the top. We can make efforts not to create the staircase, at the stage of approving [meaning asking for approval of the plan], but if an approval will not be granted, we are required to give a solution. With any other solution, we will have to destroy [old] vaults.

Shachar Poni: According to my understanding, the vault is later, and then I see no reason to avoid destroying it.

The question is whether we can locate the elevator at another place. Building an elevator will cause physical damage, but if something external will be built, it will cause visual damage.

Yuval Baruch: There is a building [meaning Strauss], and we don't know when it was built. It seems that the vaulted buildings was modified in the last 300-200 years. It has a limited archaeological value for the Strauss Building, and as far as I am concerned, one can penetrate the vault with an elevator well, as long as there is damage [written pgishah, 'meeting'; we assume it is a misspelling for pgi'ah, 'damage'] only to the vault and only for the aim of an elevator. He notes that at Ohel Yitzhak we have approved building an elevator even at the cost of dismantling a façade wall [of a Mamluk Period bathhouse]. Similarly at the House of the Israel Defence Forces, and these are buildings of a similar type.

Shuka Dorfman summarized the discussion:

A decision will be accepted in the future.

Registered by: Re'ut Eliyah

Distribution: [to the] Participants 


\section{Document 2.5}

[Top: IAA letterhead, Jerusalem Region]

31 March 2009

Kotel1

To: Dalit Zilber

Planner, the Jerusalem District

Ministry of the Interior - Jerusalem District

Jerusalem

Dear Lady!

Subject: The IAA's Position Regarding the Plan for the 'Strauss Building'

On March 24, 2009, during a hearing about the plan for the 'Strauss Building,' the IAA's position was presented in a detailed manner.

I wish to highlight two subjects that were, perhaps, not adequately stressed in the hearing itself:

1) Regarding the changes to ancient walls that appear in the plan - the IAA as the body responsible for preservation of antiquities opposes any destruction of medieval remains included in the plan.

2) Insofar as the structure rests on foundation piles, in accordance with an agreed engineering plan, the IAA will not condition the implementation of the project on an archaeological excavation in the designated construction area, but solely on close archaeological inspection. A rediscovery of archaeological finds that will possibly require a reassessment [of this decision] during the [building] works.

Sincerely

[Signature]

Yohanan (Jon) Seligman

Copy:

Shuka Dorfman- Director IAA

Yuval Baruch - The Jerusalem District [Mahoz] Archaeologist

Shachar Poni - Architect of the Old City District [Naphah]

\section{Document 2.6}

[Top: IAA letterhead]

08 July 2009

Kotel $/ 2 / 2220$

[In handwriting:] Shuka

Draft for your approval

Before sending

[Signed: Jon [Seligman] [Stamp] 
To: Mordechai (Soli) Eliav

The Western Wall Heritage Foundation

Jerusalem

Dear Sir,

\section{Subject: Approval of City Building Plan in Preparation 12996 (Version 13) - Western Wall Plaza, Aqabat Abu Meidan St. (Strauss Building)}

1. The IAA will be ready in principle to approve depositing the plan on the condition that the instructions in the protocol of the plan, which will be an inseparable part of the above mentioned agreement in principal, will include the items detailed as follows.

2. The area affected by the plan is a legally pronounced antiquities site, and of exceptional importance in that is forms part of historical Jerusalem. Therefore, it can happen that the discovery of antiquities will force major changes in the planning and in the mode of the works in a manner that will ensure protection of the antiquities, their safekeeping and restoration, and among other things the opening of the site to the public; all under the conditions of the [IAA] Director, which will be made under his authority according to the Antiquities Law, 1978.

Scientific archaeological excavations must be conducted in the entire area under discussion. Only after the completion of the excavations, and depending on their results, will the IAA determine the conditions and requirements for approving construction, as well as what demands it will have for changing the plan according to the City Building Plan.

[A large question mark added on the margin, next to the paragraph 'full archaeological excavation over the entire area,' with a handwritten comment underneath:]

Okay - but as far as I can recall, there is no excavation? Sh[uka] D[orfman]

The entrepreneur is responsible that the site will be open to the public according to conditions set by him with approval of the Jerusalem City Architect, and following common procedures for the entry of the public in similar sites.

[...] [Standard clause about coordinating all the construction details with the IAA]

In any case, the plan will not give rights of building of any sort for the area, until the archaeological excavations will be finished and the IAA will set conditions for building according to the plan.

[...] [Standard clause in case the entrepreneur sells/gives the property to a third side]

Insofar as the structure rests on foundation piles, in accordance with an agreed engineering plan, the IAA will not condition the implementation of the project on an archaeological excavation in the area destined for building, but only on close archaeological inspection. In any case, the discovery of 
archaeological finds that will require a reassessment of the plan during the work is possible.

The things as mentioned above form an inseparable part of the instructions of the [City] Building Plan and of the section concerning antiquities, which will be detailed as follows:

Following are the instructions of the Antiquities Item that must be included in the plan. These items may change after the completion of the [initial] examination stage of the plan and are not final instructions:

1. [...] [Same clause as in Document 2.2].

2. Therefore, a building permit will not be issued and the plan will not give rights for building and no construction shall be allowed according to the plan, unless after the completion of a full archaeological excavation over the entire area of the plan, according to the conditions of the [IAA] Director, as detailed below; and additionally those parts that the Director set for preservation, as part of these conditions, will be preserved.

3. Prior to submitting an application for a [building] permit, the entrepreneur will conduct full archaeological excavations, at his own expense, according to the conditions of the [IAA] Director by the instructions of the Antiquities Law, 1978.

[...] [Clauses 4-7 on preserving the antiquities in situ, maintaining and guarding them, opening the site to the public, and the power to set conditions about height, location and finish of the foundations. They are all identical to Document 2.2: clauses 4-7.]

8. Insofar as the structure rests on foundation piles, in accordance with an agreed engineering plan, the IAA will not condition the implementation of the project on an archaeological excavation in the area destined for building, but only on close archaeological inspection. In any case, the discovery of archaeological finds that will require planning modification during the work is possible.

[Document incomplete]

\section{Document 2.7}

[Top: IAA letterhead. Stamp: Jerusalem Region, sent by fax 14.7.09; handwritten: 'original sent by post']

14 July 2009

Kotel $/ 2 / 2220$

To: Mordechai (Soli) Eliav

The Western Wall Heritage Foundation

Jerusalem

Dear Sir, 
Subject: Approval of City Building Plan in Preparation 12996 (Version 13) Western Wall Plaza, Aqabat Abu Meidan St. (Strauss Building)

[This is the final from, based on Document 2.6. We translated only relevant items that have been significantly revised.]

[...] [The beginning of the letter includes practically the same clauses as in Document 2.6.]

2. [...] In the said area, scientific archaeological excavations of the entire area are necessary; only after the end of the excavations and according to their results will the IAA set the conditions and demands for approving the building, and which requirements it may have for changing the planning according to the City Building Plan. Insofar as the structure rests on foundation piles, in accordance with an agreed engineering plan, the IAA will not condition the implementation of the project on an archaeological excavation in the area destined for building, but only on close archaeological inspection. [...]

Following are the instructions of the Antiquities Item that must be included in the plan. These items may change after the completion of the [initial] examination stage of the plan and are not final instructions:

[...]

2. Therefore, a building permit will not be issued and the plan will not give rights for building and no construction shall be allowed according to the plan, unless after the completion of a full archaeological excavation over the entire area of the plan, according to the conditions of the [IAA] Director, as detailed below; and additionally those parts that the Director set for preservation, as part of these conditions, will be preserved, and all this is dependent upon that written in item 8 , below.

[...]

8. Insofar as the structure rests on foundation piles, in accordance with an agreed engineering plan, the IAA will not condition the implementation of the project on an archaeological excavation in the area destined for building, but only on close archaeological inspection. In any case, the discovery of archaeological finds that will require planning modification during the work is possible.

\section{Document 2.8}

[Copy of Email]

From: Jon Seligman

To: Eli Elan

CC: Shuka Dorfman

Sent: 11:42 28 July 2009

Subject: Re: The Strauss Building - Planning 


\section{Dear Sir,}

Items 1-5, 7-9 of my letter of 14.7.2009 are covered in the protocol of the plan. Items 6 and 10 (as follows) are not mentioned and should be added to the protocol. Additionally the [Western Wall] Foundation must deliver a letter to the IAA expressing agreement to the items that appear in the first part of the letter (copy attached).

6. The owner of [building] permit will allow opening of the discovered antiquities to visits of the public. Conditions of opening [to the public] will follow those of other similar sites, according to conditions set for the owner of permit by the Jerusalem City Architect.

10. Only at the end of the excavation, should it be carried out (see item 8 above), and according to the conditions of the Director, will it be possible to submit an application for building permit. The application requires approval of the IAA Director concerning the relation between it and the antiquities.

\section{Document 2.9}

[Letterhead: Bar Ilan University, Faculty of Jewish Studies, the Martin (Susz) Department of Land of Israel Studies and Archaeology]

Jerusalem, 19.10.2009

To:

Chairman of the Jerusalem Local Committee for Planning and Construction,

Honourable Sir,

Following is an objection to Building Plan no. 12996, called 'Strauss Building,' in the Western Wall Plaza.

The area we call 'Western Wall Plaza' was formed within a short duration of about two weeks after the Six Days War. The Mughrabi Quarter and the wall that closed the Western Wall Street were destroyed by mechanical tools [widespread archaeological euphemism for Tractors]. The result was a slightly west-to-east slope bounded on the south by the ramp of the Mughrabi Bridge. The level of the Plaza was lowered by c. 2 metres on the east side, thus the Western Wall was 'heightened' and the surface of the area was improved by additional development acts, which cannot be described in detail here. The area of the Plaza extend between the Western Wall, which is the support wall of the Herodian complex, and the rock escarpment on the west, which is the border of the upper city of the late Second Temple Period. Between these two borders was also the lower flow of the central valley, called Tyropoeon. The Western Wall Plaza, as well as the central valley, separates between the eastern and western hills, on which Jerusalem was built throughout the ages. This Plaza is the most important prayer place for Jews and dozens of thousands come here during holidays, Saturdays, and other times. Here, at the Plaza, 
join archaeological and religious interests which have no comparison [elsewhere]. The archaeology and topography of the present Western Wall Plaza have created, thanks to the varied factors that accumulated here, a system of unique cultural values that necessitates careful, cautious attitude to any further change and additional development.

In the said area of the Plaza streets were built and laid in the different periods of the city, since the Early Roman, that is, the Second Temple period. The monumental street exposed along the Western Wall, from the century that preceded the destruction of year 70 [AD], closes [the Plaza] on the east side. Another fabulous street, called the Eastern Cardo, was paved some $90 \mathrm{~m}$ in parallel to the former street, along the contour of the central valley from the Samaria [Shechem] Gate in the north, [leading] south and closing the Plaza on the west side. The Eastern Cardo was built in the middle of the second century BC and it functioned throughout the Late Roman, Byzantine, and Early Islamic periods. These two streets create a frame line for the Plaza and they are stressed by the Western Wall on the east and the rock escarpment above which the Jewish Quarter is built on the west. It seems that here the ancient streets, which have been exposed by the extensive archaeological excavations since the Six Days War, join the Western Wall itself and the escarpment on the west to weave an amazing, fascinating cultural tapestry. Based on the results of the excavations that have been performed in the past in the rectangular area reviewed here, it is reasonable to assume that also the area in between them [the two ancient streets] will include public and private buildings, perpendicular streets on an east-west direction, water reservoirs, Miqva'ot, and even internal fortifications. This should not be taken as a call for immediate excavation, but as drawing attention to the potential of this important archaeological area and for giving direction for future development. AS mentioned earlier, the religious use of this large rectangular area is what makes it special.

Preserving the given character of the Western Wall Plaza demands avoiding making any damage or change to this wonderful tapestry.

Unfortunately and sadly, the rectangular area called the Western Wall Plaza has no general plan. The area, therefore, must remain undamaged by any additional construction. The proposed construction on the northern edge of the plaza in plan number 12996 threatens to damage the delicate and complex fabric [of the Western Wall Plaza] presented here. Though the façade of the proposed building would protrude 'only' a few metres south of existing structures currently in use, it represents a danger of eroding the entire delicate and fragile framework. I do not take the liberty of discussing the architectural merits of the suggested construction; I leave that to my planning colleagues. [Yet] clearly the proposed construction is a significant blow to the archaeological environment. Archaeology deals in general with underground structures and finds; but there is, nonetheless, an archaeological environment, a combination of ancient treasures and their preservation in their present condition, even if with addition of modern use. The proposed construction plan threatens to cause significant damage to the archaeological environment. 
According to paragraph 99 to the Law of Planning and Building, the legislator set an instruction concerning preservation of an archaeological/historical site, and accepting approval of the Minister of Education [at the time, responsible over the IAA] for each change and construction in such a site. It seems that this issue too was not properly handled. I suggest to the planning authorities avoid the ravage which is suggested in plan 12996 and to alert the entrepreneurs to find answers for daily running of the Western Wall Plaza in existing buildings in the vicinity.

I shall be glad to stand at your disposal for any question or for [additional] data.

Sincerely,

[Signed]

Prof. Amos Kloner

\section{Document 2.10}

Jerusalem, 16 December, 2009

L-17877

\section{Subject: Extraordinary Meeting of the Archaeological Council - Summary of the Meeting of 16/12/09}

Participants: Prof. Ephraim Stern, Prof. Joseph Patrich, Prof. Yoram Tsafrir, Prof. Amos Kloner, Prof. Steve Rosen, Dr. Michal Dayagi-Mendels, Prof. Arieh Zaritzki, Mr. Oded Wiener, Mr. Joseph Aviram.

Additional Participants: Mr. Shuka Dorfman, Dr. Uzi Dahari, Dr. Gideon Avni, Architect Raanan Kislev, Mr. John Seligman, Mr. Yuval Baruch.

Following is a summary:

\section{The Strauss Building and the Projects in the Western Wall Plaza}

Jon Seligman and Raanan Kislev presented the issue

Amos Kloner: Everyone agrees that the present Western Wall Plaza was created gradually since the Six Days War. Through the years we received a Plaza that has cultural, archaeological, historical, and religious value, which has no equivalent in Jerusalem and all over the World. There is here a representation of all the period. The Western Wall Plaza, in its present condition, is handled very properly in regard to excavations. I do not criticize the act of the IAA, since good archaeological and preservation works are being done. With the plan called 'Strauss Building' one ads 950 square metres of construction, of which 360 square metres of addition in the ground floor, performed as building woks - without an archaeological excavation. This is the reason why we've asked for the meeting. In my objection I stressed that the building of 360 square metres on the ground is planned for two functions: toilets and an additional 160 square metres of a lobby. I ask the support of the Council to 
my opinion, that in such place no building works should be allowed without an archaeological excavation. According to the Antiquities Law, the decision is at the hands of the IAA Director. However, also in the Western Wall Plaza the Antiquities Law should be implemented. I am against any construction anywhere in the existing area of the Western Wall Plaza, including the area of the excavation by Shlomit Weksler, performed on behalf of the Western Wall Foundation, for the intention of building a building there. In the objection I submitted with more people to the Local and District Committees we have given suggestions where additional toilets and police station can be established, without building these 900 square metres - which will be added to the building and which include 125 square metres for the 'journey to Jerusalem' hall, 100 square metres for a Beit Midrash [religious school] and the rest for offices, maintenance, places for eating and for dressing up of employees. The main problem is the construction on the ground, and should one build at all? If one decides to build, full archaeological excavations are required. In my opinion the Western Wall Plaza should not be excavated today, and should be kept in its existing state. Let us preserve what has been already excavated and develop the exiting Plaza. In the suggestion building they take 360 square metres from the Plaza, which form the entrance to the underground tunnels, build over it, and then, those who go to the toilets will enter from the Plaza itself. The main issue is that the Western Wall Plaza was formed in different stages and it is an existing situation. It has cultural and religious values that are incomparable, let us not build there!

One of the problems is that currently there is no plan agreed by all the bodies for handling the Western Wall Plaza.

Architect Gobi Kertesz was nominated to find the balance between the needs of all the various bodies. There is at present no general plan and today they tend to approve the 'Strauss Building' [plan]. Archaeologically, we must not give hand to any construction in the Western Wall Plaza before there is a plan agreed by all the involved bodies. The Western Wall Heritage Foundation must find solution for maintenance of the Plaza in nearby existing buildings. The IAA Director approved the construction of the Strauss Building with no archaeological excavation, on the basis of [the builders using] foundation piles.

\section{Arieh Zarizki: How much is 'robbed' from the Western Wall Plaza?}

[Second page] Amos Kloner: Currently there is a lobby built of six arches, to which 6 more metres will be added on the south, reaching an addition of 360 square metres, constructed at the expense of the Plaza.

Shuka Dorfman: True, I approved, but the Western Wall Heritage Foundation is not the issue here. The Western Wall Plaza is not damaged by the construction of the 'Strauss Building.' The building will extend till the stairs near the water fountain and the building does not damage the Plaza at all. The IAA is not the planning and construction committee and our position is a worthy 
one, dealing with aspects of archaeology and conservation. Criticism is legitimate [but] as to your question - why did you approve building without an archaeological excavation, in the case of the Strauss Building: we decided about drilling foundation piles for stabilizing the building. The piles have a relatively small diameter and this is common practice with us. We held several discussions and consultations about it. We approved the foundation piles, because we are heading toward an excavation project of the entire Western Wall Plaza. In archaeological excavations one has to compromise sometimes, since if we excavate the entire area that it means giving up less than 10 metres where they will put the piles, which will not be excavated. We should put things in proportion. When you talk about the Western Wall Plaza you don't talk only about archaeology. If one excavates the entire Plaza, it is already a drama. Except the area of the 'Strauss Building,' everything around will be at the end of the process excavated. The IAA is partner to all the discussions, we consider all the considerations and the responsibility is finally mine. According to estimates, eight million people visit the Western Wall Plaza each year and this aspect should also be remembered. The general planning of Gobi Kertezs was my personal demand. We speak here about minimal things that are required in order not to damage the archaeology and allow life in a holy site.

Arieh Zaritzki: Will the piles be excavated in an orderly way?

Shuka Dorfman: No, one cannot excavate where foundation piles have been inserted.

Joseph Patrich: The subject of the Ha-Liba Building deserves a separate, proper discussion. Concerning the 'Strauss Building,' we discuss the question what is to be done about the construction of the façade of the 'Strauss Building' [meaning the enlargement]. Regarding data about the construction, when they say eight piles, it is a fact, it is not the placing of the building on pavements. It is building on drills [meaning foundation piles]; it is a fact that damages the archaeology. Now, we hear that the entire area under the existing building is holed by other infrastructure, but we did not see any map of that. The argument presented by Prof. Kloner is worthy. The question is what the IAA policy on the matter is. As a Council member, in my view this is a wrong (pasul) thing and might become a legal precedent; so in other places you [the IAA] will be unable to stop entrepreneurs from building structures based on foundation piles above an archaeological site. It is a damage to archaeology. It damages the foundation of the Antiquities Law itself, therefore it is a wrong thing. Secondly [maybe meaning 'a different matter'], it will be a huge achievement to excavate the entire Western Wall Plaza. There is a principle here, in my view the IAA should not allow someone to build such a building, unless it 'floats'; if not, one should excavate deeply anywhere where they [the builders] penetrate the ground.

Shuka Dorfman: The matter of foundation piles is a common practice [in the IAA]. There are cases when one gives up certain areas and performs a full excavation in another area. 
Yoram Tsafrir: I do not oppose the excavation of the Western Wall Plaza and the idea that this area will be excavated makes me excited. It did not think that such a possibility exists and this initiative, if done wisely, is blessed. If one excavates, the excavation should be an archaeological excavations as we have been taught, and not by inserting foundation piles. One cannot excavate around pillars. All the discussions made on the subject were professional and not principal as to whether excavate or not. What the state of Israel is going to do now [in excavating the entire Plaza?] is a very daring act and what the IAA is doing is a wrong act. I agree that the IAA Director does not decide about construction, but these things should be held in public discourse. However, the IAA has taken one side here. It pains me to say that the IAA has taken sides here, supporting the construction from the beginning, even before the digging had started. It was said here that because Ezri Levi [advoacte, Director General of the Jerusalem Development Authority] signed the plans, the IAA approved the building. How can one take Ada Karmi [the Architect of both Ha-Liba and Strauss Buildings] to design a building before a principal, ethical discussion is held on the subject [whether to build]?

Shuka Dorfman: This is not what I said. We sat with Ada Karmi before there was one line on the map, we told her nothing will be built there until the entire area is excavated. Until now she does not have a finished plan for the Ha-Liba Building. All the plans were presented to us in free discussions without the presence of entrepreneurs, and the decisions were objective.

Ephraim Stern: What is your practical suggestion to the Council?

Yoram Tsafrir: I just wish to say that I am very sad that the IAA has forsaken its original mission. He thinks that the enthusiasm of bodies within the [IAA] system to act and plan without discussion and supervision does not need to be your [in plural, meaning the IAA] way.

[Third page] Oded Wiener: I have no doubt that Prof. Tsafrir and Prof. Kloner talk from an archaeological point of view and see matters professionally. But after the words of Shuka, who said very clear things about the nature of the procedures, no further questions should be asked. He wants to note that he accompanies the project in the Western Wall Plaza already for many years. The archaeological excavations there, all aspects included, were performed well. If people think that things were done not according to proper procedures, they are wrong. On the contrary, public persons complain how much time we can wait to the IAA to receive approvals. The process takes years, the plans were discussed in wide forums and have received exposure to the public. It passed all the different forums. Every centimetre in the Western Wall is inspected by the IAA. The Western Wall Plaza is a complex, the effort here is to give minimal services while doing archaeological and preservation works. The work of the IAA in the entire Old City gives an amazing upgrade to archaeology and to preservation. Therefore, to come with criticism on these 6 metres in the Strauss Building, when one receives hundreds of metres of an 
orderly excavation [elsewhere in the Plaza] is unjustified. There is no place in the Old City that is not inspected and controlled by the IAA. One should see everything in the right proportion and understand the picture which we will receive in the future and the benefit to future archaeological excavations in the Western Wall Plaza.

Amos Kloner: I want to stress that in my objection I did not mention the IAA. The intention was only against the construction. To allow it despite everything said and [to say that] it is 'only 6 metres and there are already damages underneath' - it is true, but only partially. It is on its own a complex issue, but if one builds it requires a full excavation.

Ephraim Stern: Did you know before sending your objection that they are going to excavate the entire Western Wall Plaza?

Amos Kloner: No, but I do not believe that such excavation will materialize. The archaeological interest is not to build; but if one builds one must have a full excavation.

Joseph Aviram: I approach this issue from two points of view. As a Zionist Jew who made Aliyah to the land 72 years ago, and [back then] reaching the Western Wall was done secretly, in a difficult way, always with fear. After the Six Days War the Plaza was opened. It bothers me that they will build a modern building near the Western Wall. There is no lack of places for learning about Judaism, [but] to the Western Wall should arrive all those who want pray and all those who want to see the Western Wall in all its glory. So why are they going to build modern buildings there, of all places, occupying parts of the Plaza which is important and unique on a World scale? This will degrade the honour of the Western Wall. Archaeologically, I will be glad if one can excavate; however, if one builds this structure, then the IAA should have said that they will first excavate and only then [let them] build this structure, and not waive the excavation because they are planning to undertake a larger excavation [elsewhere in the Western Wall Plaza].

Shuka Dorfman: I said earlier that we are not the planning and building committee. I am offended by Yoram's comment; we seriously deal with what we are entering into. There was never such a close inspection in the Old City before we have entered work. When you want to do such inspection you should also enable and see the dynamics in relation to general behaviour. I wish to lead the process when I control what is being done there. We are not free of mistakes, but you cannot see everything in a narrow perspective. Archaeology is meant to serve the public needs. True, we do not make the wide public partners to every decision; but from here to go to the extreme [position] that it is impossible to build a building [by allowing it to be] based on foundation piles, it is exaggerated.

Yoram Tsafrir: In all my expressions, I said that a day will come when they will build above the excavation of Shlomit Weksler [at Ha-Liba House]. I said 
more than one that was done was an injustice ['avel]. The matters should be open for public debate.

Ephraim Stern: I did not know that the entire Plaza will be excavated, in my view it completely puts in other proportions the matter of the Strauss Building. The aim of this meeting in my eyes was to clarify the arguments of the Council members against the IAA and to discuss matters openly. In this meeting the matters have been properly discussed.

\section{Document 2.11}

[Partial email, cut lengthwise; parts of sentences missing. The dates 3.12 and 9.12.09 are of various correspondences; original date is December 2, 2012]

Re: The Archaeological Council

[Sender almost certainly Amos Kloner]

To Members of the Archae[ological] Council,

In approximately one month construction will begin on the addition to the Strauss Building, located in the northern part [of the Western Wall Plaza]. The construction has been approved without an excavation at the site, one of the most important in Jerusa[lem. It is planned that] only a very minor trial excavation will be undertaken at the site on a few square metres, to a [minimal? dep]th, for the needs of an underground utility and installation box. The construction itself will [take] place in the midst of the accumulated remains expected to be found in the Tyropoeon Valley [the Tyropoeon or 'Valley of the Cheesemakers' separates Mount Zion to the West and the Temple Mount to the East. Today it is partially filled]. The [same] subject was raised for discussion three years ago, and the minutes of that [meeting of the] Archaeological [Council] are enclosed with my letter. Without underestimating the achievements of the important and comprehensive excavation work of the Antiquities [Authority] in Jerusalem, it seems that the considerations that led to the waiver of the excavation here go against the [logic?] and best interest of archaeology; this is the reason for my request [for discussion]

With best regards...

[List of names of addressees, discussing 'a new date for the Council meeting']

\section{Document 2.12}

[Logo:] E.D. Bahat Engineering Co. Ltd

Eliezer Rahat

Daniel Rahat

The Western Wall - Strauss Building

Date: 24.5.201 
To: Shachar Poni

\section{Subject: Approval of Pillars and Beams}

Enclosed in the plan of the foundations and the beams under the entrance floor of the Strauss Building.

Also the plan shows the passage of the infrastructure.

The passage can also be made without construction - that is, by hanging the pipes from the entrance floor; however this detail can be closed only after digging about two metres [in depth] for the entire structure.

The intention was to base the deep foundation on the bedrock and inside it [that is, by drilling]; then to dig down two metres where necessary for placing the beams;

[Then] to install the beams and the floor, and to proceed with the construction upward.

This method, which is called up down [English words for 'up down,' written in Hebrew letters], will allow the IAA to perform an excavation under the structure even during the building of the upper building.

I shall be grateful if you will approve the system of foundations and walls.

I shall be glad to me you if necessary.

\section{Document 2.13}

[Letterhead: The Movement for Quality Government in Israel]

Date: $24 / 4 / 13$

To:

Mr. Shuka Dorfman

Director, IAA
To:

Dr. Zvi Greenhut

Head, Department for Treatment of Finds

IAA, POB 586, Jerusalem

IAA, POB 586, Har Hozvim, Jerusalem

[Letter of complaint, we translate here only one item relating to Strauss Building:]

$[\ldots]$

6.4.1. Recent works at the site 'Strauss Building' in the Western Wall Plaza, which according to photographs include the use of heavy machinery, raising concerns that antiquities located there might be damaged $[\ldots]$

7. Expecting your fast answer,

Sincerely,

Zeev Rubel

[Signed]

Public Contacts Department
Adv. Zruyah Medad-Luzon

[Signed]

Legal Advisor 


\section{Document 2.14}

[Copy of email from Shachar Poni to Yuval Baruch, forwarded to Shuka Dorfman on April 11, 2013]

From: Shachar [Poni]

Sent: Wednesday, April 10, 2013 5:31 PM

To: Yuval Baruch

Subject: Strauss Building

Shalom Yuval,

The area planned for construction at the façade of the Strauss Building includes: 387.2 square metres.

According to the plan one must drill 16 drills.

The area that would be damaged by the plan (diameter [of drill] $60 \mathrm{~cm}$ ): 5.4 square metres.

After the enlargement to $70 \mathrm{~cm}$, the area that would be damaged is: 6.1 square metres.

Should the drill be $80 \mathrm{~cm}$ in diameter, the total damaged area would be: 8.0 square metres.

Sincerely,

Shachar [Poni].

\section{Document 2.15}

[Copy of email by Yuval Baruch, asked to comment about some items in Document 2.13]

From: Yuval Baruch

To: Moran

Sent: 14:14, Thursday 16 May, 2013

Subject: procedures and policy of decisions about antiquities sites - the letter of the Movement for Quality Government in Israel

Dear Moran,

Following is my reply to the two relevant items in the said document [=letter], which concern the Jerusalem Region:

The Strauss Building - the construction plans for the Strauss Building were thoroughly examined by the IAA, which even prepared a comprehensive conservation file for it. 
Due to the importance of the project, it has been discussed several times within the IAA in different forums, and a discussion was even devoted to the topic by the IAA Council. The plans themselves were approved by the IAA subject to various conditions, including conditions related to inspection, conservation, and archaeological excavations. On these grounds the required building permits were issued.

The planned excavations at the site will be performed after the site is prepared from an engineering perspective. Up until that point all work at the site will be done under close archaeological inspection. In addition, conservation work is being performed at the site by IAA experts, with constant engineering supervision.

[Paragraph about an ancient capital south of Jerusalem - not translated]

Yuval [Baruch]

\section{Document 2.16}

[Copy of email from an inspector to Yuval Baruch, forwarded to Shuka Dorfman]

From: Ortal Chalaf

Sent: Wedensday, April 10, 2013 9:23 PM

To: Yuval

Subject: Drills [at] Strauss Building

Dear Yuval,

Shachar [Poni] asked me to send you a report on the drilling today and yesterday.

Yesterday we drilled one borehole (borehole number 10 in the plan), to a depth of ca. 16 metres. Into this borehole we inserted a camera (we shall insert a camera also to the other [boreholes]).

This borehole starts at the level of 731 metres.

With the camera I saw the following:

After one metre there is something that looks like fallen stones.

8 [metres deep], the remains of a wall.

9.8 [metres deep], a wall.

10.4 [metres deep], a wall.

12.8 [metres deep], a wall.

16 [metres deep], the bottom of the borehole.

They poured 16 cubic metres of CLSM [a type of concrete] into this hole, and 4 metres still remain to the top of the borehole. According to the calculations, 8 cubic metres should have been enough to fill the entire hole. 
In the second borehole (number 1) they drilled to a depth of 14 metres and then reached bedrock. When they tried to drill into the bedrock, the sidewalls started to collapse.

In the third borehole (number 9) they drilled to a depth of 5 metres, but the earth was very wet and this caused a massive collapse of the walls of the shaft, and for this reason they stopped drilling.

In the fourth borehole (number 11) they reached the depth of 12.5 metres, and hit something hard, maybe a rock. Tomorrow they want to continue drilling it.

In this borehole I have identified after one and a half metres a wall plastered by pool-plaster with lots of sherds in it. At the depth of 9.5 metres building stones came out.

Right now I understood from Shachar that every new borehole must be approved separately, and all the pouring will be performed inside a sleeve. Sincerely Ortal Chalaf

\section{Document 2.17}

[At the top, in handwriting:] Urgent

[Letterhead:] Moreshet ['Legacy'] Simha Holzberg

1924-1976

Israel Prize Winner

Father of the IDF Injured

Date: June 1, 2013

To: Judge Yosef Shapira, the State Comptroller

\section{Subject: Transgression to the Antiquities Law - Irretrievable Damage by Governmental bodies}

\section{Strauss House, Western Wall Plaza}

According to the Antiquities Law (par. 29) the Director of the IAA does not have the authority to give an excavation license to excavate a place proclaimed as a religious site, unless under approval of three Ministers: the Ministers of Religion, Education, and Justice.

The Director of IAA together with the Western Wall Heritage Foundation joined together in violating the said Law, for improper aims and in a way that does not fit honest bodies.

For many weeks now they dig deep foundations with the help of a drilling machine, to a depth of ca. 17 metres, in a diameter of ca. $80 \mathrm{~cm}$, in order to build the 'Strauss Building' on which and on what stands behind it much had already been written. This drilling destroys all the antiquities which surely exist in the various layers, all the layers of Israeli history.

Except Prof. Amos Kloner and Prof. Joseph Patrich, who came out openly against this archaeological destruction, there are many research archaeologists 
who think that this is an unforgiveable crime, as mentioned in the attached report [in Maariv Newspaper]. They say that they have no more power to fight the wrongdoing and the improper management of the IAA. In addition, archaeologists are afraid to complain, fearing revenge on a practical level, since they are dependent upon the IAA.

The cooperation between the IAA and the Western Wall Heritage Foundation is transparent, and depends upon the shared activity and wide dependency in the acts that take place in the Old City and Western Wall Plaza area.

Therefore, it seems that the only institution that can intervene and save the People of Israel from this horrible process is your honour, as the [State] Comptroller who criticizes acts and leads to a fair, just, and legal way.

I shall be grateful if you will check as soon as possible the deed, and do whatever you can to stop this said process.

Sincerely,

[Signed]

Ephraim Holzberg

Attached copy of a report this week from Maariv [Newspaper]

[Stamp:] accepted by the State Comptroller Office, 02-06-2013

\section{Document 2.18}

[IAA response to the letter of Holzberg. Partial, no date/author]

As part of preparing the plans for the building known as the 'Strauss Building,' located at the entrance to the Western Wall Tunnels, the IAA compiled a documentation file, by one of its conservation architects, in which the guidelines for the construction were outlined from a conservation and archaeological perspective. The plan [meaning documentation file] was even presented to the [Jerusalem] municipal planning committee.

With the approval of the plan by the relevant planning authorities, the IAA granted the building permit for the structure subject to certain conditions handed out to the entrepreneurs (our [letter] of 22.3.2012).

These conditions included, among others, rescue excavations in the entire area underneath the building floor.

The first stage of these rescue excavations began a week ago and they are being undertaken under the authority of Dr. Peter Gendelman (permit number 6876/2013).

In order to implement the plan, the developers were forced to base the new part of the structure on a system of piles that will carry its floor. The IAA approved the drilling for the piles (16 in total), even if this directly causes damage to antiquities. In the IAA's view, this damage will be proportional when compared with the area that will be excavated (some $3 \%$ of the construction area). Our letter on that was sent to the entrepreneurs on 4.1.2012. 
The drills were made under close archaeological inspection, in addition to continuous geological examinations.

Among other considerations that led the IAA to permit building the structure using foundation piles is the fact that the excavation underneath the new part of the Strauss Building is part of a larger assemblage of archaeological excavations that have been, until recently, conducted in the Western Wall Plaza, and which are meant to continue in the future as part of an excavation of the entire plaza. All these considerations are derived from an overall planning vision for the Western Wall Plaza [...] and in light of specific consideration given to the construction plan itself, following the documentation of and research into the system of cavities underneath the site.

It is important to note that conducting archaeological excavations in such a complex site, in which the archaeological remains extend from the surface deep down (14-20 metres), requires complicated engineering solutions, including, among others, the construction of engineering supports and retaining walls that will allow it to be implemented.

\title{
Document 2.19
}

[Page from a work plan for the Strauss Building excavation]

\section{ARCHAEOLOGICAL REMAINS IN THE BOREHOLES}

Upper phase, depth of 1 metre and beneath: walls, installations - Medieval Lower phase, depth of 2 metres and beneath: massive walls, vaults - Roman

[Schematic drawing of the location of the boreholes, with legend added in handwriting, giving the numbers of each borehole (each borehole becomes a foundation pile, once filled with concrete), depth, etc.]

[Title at bottom:] 22 July 2013, IAAA- Jerusalem Region.

\section{Document 2.20}

[Page from a work plan for the Strauss Building excavation] [Plan of area with the system of foundation piles and beams] [Title below:]

\author{
WORK PLAN - PHASE A: SOUNDINGS AND
} PREPARATION OF AREA

[Details given in two lists:] 
Aims:

Pinpointing the antiquities

Removal of debris

Arranging routes for movement and removal of dirt

Bringing equipment

Arranging initial engineering

Setting grid of [excavation] squares

[In a box near the left column:] 3 WORKDAYS
Personnel:

Inspector

2 workers

[Mechanical] excavator Surveyor

\section{Document 2.21}

[Page from a work plan for the Strauss Building excavation] [Plan of area, similar to that of Doc. 1.18]

[Title below:] WORK PLAN - PHASE C: CLOSING STAGE

[Box at centre:] 1 WORKDAY WITH WORKERS + 5 TEAM DAYS [Two lists with details:]

Aims:

Moving the finds to the stores

Finishing measurements and photography

Preparing preliminary report [to the entrepreneur] 20 workers for a single day.
Personnel:

Director of Excavation

Area Supervisor

\section{Document 2.22}

[Page from a work plan for the Strauss Building excavation]

\section{BASIC WORK ASSUMPTIONS}

- 600 square metres for excavation or less, according to the extent of remains

- Duration of 15 workdays with workers in the field (to a depth until 2 metres)

- Possible changes in schedule [concerning] stage of work and number of [excavation] squares according to the finds, development of finds and engineering

- High expectation for [finding] the Mughrabi Quarter in the upper layers

- High expectation for [finding] Monumental remains in the lower layers

- Expectation of involvement of engineering/conservation

- The excavation will be carried out without breaks starting from July 2013 for about one month (Eid al-Adha Vacation) 
- The Jerusalem Region holds professional and management responsibilities to the project

- The estimate [of the excavation budget] has been prepared in such a way that allows the excavators to implement a large part of the sorting and initial processing of materials in the field

\section{Document 2.23}

[Hebrew-English letterhead:] A.D. Rahat Engineering Coordinator and Management Ltd.

Eliezer Rahat

Daniel Rahat

Jerusalem, 25.7.2013

Our number: 0172

\section{The Western Wall - The Strauss Building}

\section{Subject: Summary of Coordination Meeting with the IAA of 25.7.2013}

Participants:

Amit Reem - Jerusalem Region Archaeologist [sic]

Peter Gendelman - [Excavation Director] IAA, Excavation and Surveys [Department]

Johny - IAA, Conservation

Yossi - IAA, Conservation.

Yaacov Shem Tov - Ispector, A.D. Rahat

Amichai Lev - Project Manager, A.D. Rahat

Yossi Sandin - Work Manager, A.D. Rahat.

Mustafa Adeileh - Work Manager, A.D. Rahat

\section{The Excavation:}

Over the course of next week, permission will be granted to begin excavation at the work site - the beginning of the work will be coordinated between Peter [Gendelman, the excavating archaeologist] and Amichai [Lev, the project coordinator on behalf of Shoham Engineering Co.]; the expected [start of excavation is] Tuesday, 30/7/13.

For the excavation work it is necessary to 'arrange' [make available] a JCB [tractor] and trucks/containers for excavating and removal of material [dirt]. In addition, one should be prepared for manual excavations by c. forty workers, of which ten will be workers from the [Israel Antiquities] Authority.

The work stages will be determined by Peter [Gendelman] after the trial excavations.

During stage A the excavation will be carried out until the [start of the?] basement excavation level. 
Strengthening the structure by anchors:

The approval for strengthening the 'Idra' corner [of the existing structure] by anchors has been approved.

Work to be carried out under archaeological inspection.

\section{Document 2.24}

Report of a visit: Underground Cavities under the Men's Toilets

\section{At the Entrance to the Western Wall Tunnels}

Architect Shachar Poni, Bilal Tori

IAA

On 14.6.1 we visited the cavities under the men's toilets at the entrance to the Western Wall Tunnels. The descending shaft is located at the north-western corner of the toilet hall, behind a glass door. The size of the shaft is $60 \times 70 \mathrm{~cm}$ and entering was achieved by means of a frame, harness, and pulley.

\section{CAVITY NO. 1:}

The entrance shaft is located above the eastern edge of a broad hall, near a separation wall between this hall and another one located west of it. The rectangular hall is 4.5 metres long (east to west) and 3.25 metres wide (north to south) near the eastern wall. It is slightly narrower on the west side. It is vaulted by a 'low' barrel vault (meaning: the radius of the vault is much larger than the width of the hall at its centre, see section). [More details]

The hall is bounded on the east by a plastered wall, with an opening broken through it, about a metre wide, leading to cavity no. 2.

\section{CAVITY NO. 2:}

The hall is rectangular, [measuring] 5.57 metres long (from east to west) and 3.7 metres wide (from north to south). The hall is slightly wider on the east side. It is roofed by a perfect barrel vault (meaning, the radius of the vault is nearly equal or equal to the measure of the width of the room in its middle (photographs 8, 10), evident on the south and north walls, built of nice ashlar construction. On the west the hall is bounded by a wall separating it from Cavity 1. This wall is built of ashlar stones, with $60 \mathrm{~cm}$ high courses on average. Within the (presently seen) lower course there is a lintel stone, $58 \mathrm{~cm}$ high and $210 \mathrm{~cm}$ long. A relieving arch is built in the course above it, at a height of $64 \mathrm{~cm}$ and a general length of $298 \mathrm{~cm}$ from side to side [...]

[More details given; also photographs are included. At some point the measures change to feet.]

The passage between these two rooms is 4 feet and 6 inches wide, roofed by a lintel at the height of 1 feet and 9 inches with a relieving arch. On purpose, an opening was broken to a depth of 4 feet west of the western wall (of the 
western room), but no continuation was exposed (to this cavity). The western room is perhaps a later addition to the eastern room. A fragment of a Greek fluted [?] capital was found in the eastern room.

An assumption was raised that these rooms form a corridor or guard room to the internal side of the City Wall. Nothing similar to the eastern room was found in Jerusalem.

1. We thank Chen Canari of the Western Wall Tunnels and Beni Ajami, Safety Advisor on behalf of 'Terem Safety', for their considerable help.

\section{Document 2.25}

Jerusalem, March 11, 2013

L-21812

\section{Subject: Presenting the Planning of the Strauss Building - Summary of Meeting of 11/3/13}

Participants: Shuka Dorfman, Soli Eliav, Chen Canari, Ada Karmi-Melamede, Raanan Kislev, Yuval Baruch, Amir Reem, Shachar Poni, Gai Teomi.

Following is the summary:

Shachar Poni presented the subject

Gai Teomi presented the specifications.

Ada Karmi-Melamede: Because of the finds that have been exposed and the need to build the toilets, since this was the sole location [possible], we thought about leaving the walls exposed as much as possible. It is important that the place will look good and also be durable against vandalism, and also enable the construction of toilets. It is better to avoid using tiles as much as possible, and therefore, we have suggested to use glass. It comes in large plates and this would be a friendly solution towards the place also in view of dirt and vandalism. The glass would not touch the stone wall, it is kept far from it and holds onto the toilet bins. It is always far from the wall, so there would be a light point that lights the finds. One should take off parts of the glass [plates] so that the systems [of lights, etc.] can be entered.

Soli Eliav: How do we do maintenance?

Chen Canari: It is not a problem.

Shuka Dorfman: How do we prevent vandalism? We have to take into account that the lighting causes green scum, according to our experience in the Davidson Centre.

Ada Karmi-Melamede: Everywhere in the world they place a guard. Glass is the most simple [material] for maintenance. 


\section{Appendix}

Chen Canari: We chose the appropriate and most durable solution against vandalism. In essence, we compromised about beauty in favour of [protection against] vandalism.

Shachar Poni: The idea is correct and this is the function [?]. I would have added a system that shows the exposed arches. We should contemplate how they can be shown and accessed.

Shuka Dorfman: The idea will cause us to lose [meaning: a reduction in the number of] toilet booths.

Chen Canari: Who decided that there will be 70 toilet booths?

Gai Teomi: We did, and even this is relatively a little, [but] it got the approval of the Ministry of Health.

Raanan Kislev: If as a work hypothesis we assume that there are 70 toilet booths, it implies a simple geometry, so it leaves few possibilities and ways to play [with options]. The overall idea is right but it is important that the visitor understands the space. Putting the toilets here is problematic, but the direction [probably meaning the solution of using glass] is a good one.

Yuval Baruch: In the documentation file we did not know that this is the find that would be discovered.

Soli Eliav: One cannot take people out of the Plaza [meaning, there must be toilets within].

Amit Reem: The plan is acceptable. The cavities are archaeologically documented. [Performing] a minor archaeological examination is important, in order to reach the vaults that relate to the dating of the 'secret passage' [in the Western Wall Tunnels], and can give an answer for a reasonable expenditure [beofen midati, literally 'in a proportional manner']. We need to consider that visitors will ask questions and, therefore, there needs to be an explanation based on knowledge.

Ada Karmi-Melamede: There will be glass [hanging] on the long walls, on which one can tell the archaeological story, including a map.

Yuval Baruch: It's a good idea. I'm not ruling out the option of plastering over part of the walls, despite the fact that in the past they were not plastered. This helps with the maintenance of the area.

Ada Karmi-Melamede: I prefer not to plaster [the walls].

Yuval Baruch: In the Davidson Centre it is partly plastered and it works fine.

Chen Canari: We always chose not to plaster.

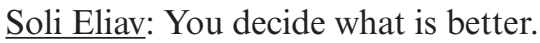

Raanan Kislev: The question is what the time table is, in order that we can understand the situation of the space and perform the planning and the preservation work. 
Yuval Baruch: We must define schedules concerning the excavation at the southern part of the Strauss Building.

Soli Eliav: It depends on the advancement of the project. For us, it is important to make the toilets usable by the Succoth 2013 holiday.

Ada Karmi-Melamede: We should make one room as an example.

Yuval Baruch: That means a lot of conservation work.

Chen Canari: The conservation work will be completed soon.

Soli Eliav: We gave you [IAA] the green light, and I'm asking that you proceed with the work as quickly as possible. The handling of the security checkpoint was delayed by the Prime Minister's Office and the drilling will be done after Easter 2013. 


\section{To Chapter 3: Davidson Centre/Archaeological Park}

\section{Document 3.1}

[Letterhead: the IAA - 20 Years]

[Top left, handwritten:] Sent by Jon

July 13,2010

Kotel4

To: PM Nizan Hurwitz,

The Knesset [Parliament], Jerusalem

$\mathrm{D}[\mathrm{ear}] \mathrm{S}[\mathrm{ir}]$,

\section{Subject: Conference on the Subject of the Western Wall Plaza}

I was invited by you, in short notice, to appear in front of a lobby for pluralism concerning the Western Wall Plaza. As a representative of a governmental authority, and out of the deep respect we feel for the Parliament, I have cancelled scheduled meetings in order to come and express the response of the IAA to the issue, according to your invitation.

Unfortunately, you did not apply to me so that I can express the response of the IAA. Regardless of the waste of my dear time in arriving to a discussion which did not relate to the daily matters of the IAA, I shall note that incorrect things were said about the prayer arrangements at Robinson Arch.

I would like only to note that the Israel Antiquities Authority set up the archaeological park in Jerusalem in order to balance the presentation of the Western Wall legacy for the public, in a place where the subjects of Jerusalem and the Western Wall are explained by various religious organizations. The purpose of founding the park was to offer a secular, research-based perspective on the history of Jerusalem and the Western Wall to the people of Israel in general and also to tourists from abroad. Unfortunately, the Supreme Court has obliged us to agree to prayer in the area of the park when in fact we felt, and still feel, that this may become a slippery slope whereby religious groups will take over the park piece by piece. This has been manifested today in the discussion when a representative on behalf of the Conservative Movement stated that in order to expand prayer in the park he is requesting to extend prayer times, to enable free access to the park for the purposes of prayer, and to set up permanent facilities for religious purposes. This undermines the Archaeological Park as a place where anyone can come to learn about the Western Wall, without being subject to religious coercion or religious features. Unfortunately, I foresee that these demands by the Conservative Movement will only increase in next few years.

In my opinion, safeguarding the archaeological park as the only secular site in the vicinity of the Western Wall is also part of your responsibility as a lobbying group for pluralism. 
It is a piety that we were not given the opportunity to express those things in the discussion, as you have asked [me to do,] by your invitation.

Sincerely,

Jon Seligman

Jerusalem Region Archaeologist

\section{Document 3.2}

Jerusalem, September 23, 2012

L-21249

\section{Subject: Status Update, Projects in the Western Wall Plaza - Summary of Meeting, 23/9/12}

Participants: Shuka Dorfman, Uzi Dahari, David Gabay, Raanan Kislev, Yuval Baruch, Amit Reem, Eran Chemo, Johny Ivanowski, Soli Eliav, Chen Canari, Ofer Cohen, Rafi Kutchmar, Amir Gilead, Amos Goldstein Following is the Summary:

[First six (mostly brief) items not translated, except their titles, as follows:]

1. The Mughrabi Ramp

2. Ha-Liba Building

3. Esh Ha-Torah Building

4. Rooms 4, 5, 6 [Western Wall Tunnels]

5. The 'Maquette Hall' [Western Wall Tunnels]

6. Wilson Arch

\section{Damage to a House above Area $C$}

Yuval Baruch: The issue is being handled by Chen Canari [of the Western Wall Heritage Foundation].

Chen Canari: We agreed that the Western Wall Heritage Foundation will only fix the damage. 'Ashmar' Company started working, but the owner of the house disappeared. A notice was given to Avi Biton and we have, in fact, finished the work.

\section{The Sewage Tunnel}

Yuval Baruch: The issue is attended to by the Western Wall Rabbi.

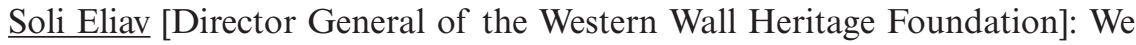
will excavate there.

Shuka Dorfman: The 'stick must be transferred' to the Western Wall Heritage Foundation. 
Decision: It is the responsibility of the Western Wall Heritage Foundation to initiate a meeting with David Be'eri [Director General of El-Ad] and Yuval Baruch.

\section{General}

Yuval Baruch: Shlomit Weksler-Bdolah took upon her the responsibility of working on the finds from the excavations of the late Alexander Onn. An orderly plan was worked out, and now budget should be allocated according to the said plan.

Following is the decision of the Director:

1. The Jerusalem Region must prepare a list of all the excavations [of Onn] and present it to the Western Wall Heritage Foundation.

2. These publications [excavation reports] will be dedicated to the memory of Alexander Onn.

Registered by: Ashrat Zecharyah

Distribution: the participants.

\section{Document 3.3}

[Copy of emails dated April 2, 2012. Yuval Baruch was asked to send plans of work to Ofer Cohen, and answered that he will as soon as they were ready. The email to Yuval Baruch is titled 'Status Update of Projects -Western Wall Plaza - Summary of Meeting of 18/3/2012,' and includes part of the protocol of this meeting, probably to remind Baruch about the plans.]

\section{The Sewage Tunnel}

Yuval Baruch: We completed the excavation in the area of the El-Ad Foundation. The question is what to do now.

Soli Eliav: Prepare a plan. We support continuing the excavation along the current route. It is important to us that it will link up with the Western Wall Tunnels.

Yuval Baruch: We are removing the soil [from the sewage tunnel] out at the Givati Parking Lot. Everything is in place [meaning ready for continuation of excavation]. It is possible to continue excavating in a south-north direction.

Soli Eliav: Regarding removal of soil, we shall accept any advice that you give. The work will be done by funding of the Western Wall Heritage Foundation. We stand behind it and you will do the inspection. 
Ofer Cohen: Until now we have not received the plans of congruence [Hebrew khafifah, meaning how the Sewage Tunnel joins the Western Wall Tunnels]. It will be better to connect [to the Sewage Tunnel] from the area of the [Western Wall] Tunnels. It is important for me to know the exact graphics in relation to the Western Wall Plaza. The IAA surveyor does not know how to connect to the national grid.

Soli Eliav: We are interested in a physical connection to the [Western Wall] Tunnels.

Following are the [IAA] Director decisions:

We should set a meeting chaired by the [IAA] Director, with the participation of: David Beeri, Soli Eliav, and Ofer Cohen.

\section{Yuval Baruch is responsible to deliver the plans to Ofer Cohen.}

It is the responsibility of the IAA Surveyors to check where the [Sewage] tunnel passes in relation to the Western Wall.

\section{Document 3.4}

[Standard letter presenting the budget of an excavation to the entrepreneur]

To: Uriyah Dasberg

Request no.: 103480

El-Ad Foundation

POB 10349

Jerusalem 91102

Dear Sirs,

Subject: Conditioning a Salvage Excavations at an Antiquities Site

\section{The Sewage Trench - May 2013}

We approve receiving your letter on this issue.

1. In continuation to your notification that you would like the IAA to perform for you the salvage excavations on the said property, according to the details in the attached and signed plan, we hereby notify you as follows:

2. The IAA estimates the cost of performing the excavation for the duration of 66 workdays in the field, total estimate 335,468 NIS including insurance, management and general expenses of 43,757 [NIS]. See detailed estimation below. 


\begin{tabular}{|c|c|c|c|c|c|c|c|c|c|}
\hline \multicolumn{5}{|l|}{ Personnel } & \multicolumn{5}{|l|}{ Means } \\
\hline Position & A & Days & Price & Total & Means & A & Days & Price & Total \\
\hline $\begin{array}{l}\text { Workers } \\
\text { paid by } \\
\text { entrepreneur }\end{array}$ & & 44 & 0 & 0 & $\begin{array}{l}\text { Equipment } \\
\text { etc., as } \\
\text { needed }\end{array}$ & & 440 & 33 & 14,520 \\
\hline $\begin{array}{l}\text { Supervisor for } \\
\text { safety }\end{array}$ & & 2 & 1801 & 3,603 & $\begin{array}{l}\text { Cars } \\
\text { estimated }\end{array}$ & & 50 & 403 & 20,150 \\
\hline $\begin{array}{l}\text { Director of } \\
\text { excavation }\end{array}$ & & 50 & 945 & 47,250 & $\begin{array}{l}\text { Transport } \\
\text { for } \\
\text { Workers }\end{array}$ & & 0 & 80 & 0 \\
\hline $\begin{array}{l}\text { Packaging/ } \\
\text { moving finds }\end{array}$ & & 3 & 852 & 2,556 & & & & & \\
\hline Surveyor & & 20 & 996 & 19,920 & & & & & \\
\hline Photographer & & 5 & 996 & 4,980 & & & & & \\
\hline $\mathrm{C} 14$ & & 2 & 1259 & 2,518 & & & & & \\
\hline Administrator & & 6 & 1194 & 7,164 & & & & & \\
\hline $\begin{array}{l}\text { Excavation: } \\
\text { work on } \\
\text { finds and } \\
\text { publication }\end{array}$ & & 70 & 852 & 59,640 & & & & & \\
\hline $\begin{array}{l}\text { Preparing for } \\
\text { publication }\end{array}$ & & 10 & 852 & 8,520 & & & & & \\
\hline Geologist & & 3 & 867 & 2,601 & & & & & \\
\hline $\begin{array}{l}\text { Technical } \\
\text { work on finds }\end{array}$ & & 70 & 852 & 59,640 & & & & & \\
\hline
\end{tabular}

[Note: Column A = amount of items, left empty]

\section{Document 3.5}

[Partial protocol of a 'Status' meeting]

\section{Subject: The Sewage Tunnel, City of David - Summary of Meeting of 12/2/12}

Participants: Shuka Dorfman, Raanan Kislev, Yuval Baruch, Shachar Poni, Eran Chemo, Eran Mordechovitz, Ofer Cohen, Yael Rosenthal

Following is the Summary:

Yuval Baruch: The El-Ad Foundation signed an agreement with Arie Rahamimoff, to hire him as the architect of the Sewage Tunnel project stretching from Hezekiah's Pool to the Mughrabi Bridge. At the same time, Etan Kimmel is preparing the planning of the exit in the area of the Robinson Arch. 
Ofer Cohen: Our idea is to handle sections, without closing them to public passage. There are several ideas as to how to perform the preservation work.

Raanan Kislev [Head of Conservation, IAA]: The work that has been presented shows that some 70 percent of the tunnel is [preserved] in its original condition. Which means that 70 percent of the work will be done for preserving the existing situation. As of today, architectural planning, which includes light, pavement, hand grips, etc., should be discussed with the El-Ad Foundation. It is necessary to take an operative decision on how to begin the work. Now, we must complete the planning for the whole length of the tunnel and prepare general plans for execution.

Shuka Dorfman: Can one walk safely today inside the tunnel?

Ofer Cohen: At the moment yes. We make tours on a regular basis. The [safety] approval for the tunnel was valid for three months. At present the tunnel is not in any dangerous condition, but it requires handling. After detailed planning, we would be able to define priorities of work. If there won't be a danger [meaning, an emergency requiring immediate response], the work will be done following the planning and keeping the tunnel open to visits of the public.

Yuval Baruch: Safety files exist only where we are working. The safety issue, in the part where there are no archaeological excavations, is handled by Ofer Cohen and the El-Ad Foundation. He suggests waiting to the general planning by Arie Rahamimoff.

Eran Mordechovitz: Engineering has a role too, and should be adjusted to the architectural planning.

Shuka Dorfman summed up the discussion:

1. It is the responsibility of the Jerusalem Region to ensure that a safety file exists, identical to the file prepared for the Western Wall Tunnels, and including the signature of Eng. Ofer Cohen that the public can be taken through the Sewage Tunnel.

2. The IAA is not replacing El-Ad in managing [the site], but it bears a responsibility as the organization that excavated the site.

3. The presented pilot is approved, but the replacement of the new elements is problematic and must be adjusted already now with the architectural planning.

4. Yuval Baruch is responsible to ask Rafi Ben-Basat to create a work team for safety, contents, signs, etc.

5. Work will start immediately upon receiving a work request.

Registered by: Oshray Zechariya

Distribution: the participants. 


\section{Document 3.6}

[Letterhead IAA]

Preservation Administration

Summary of Meeting

\section{Subject: Preservation-Engineering Survey - The Sewage Tunnel in the City of David}

Place: Preservation Administration - IAA

Date: 29.4 .2012

Present: Mr. Rafi Ben-Basat, Mr. Yudah Mali, El-Ad

Raanan Kislev, Eran Chemo, Eran Mordechowitz, Preservation Administration - IAA

Shachar Poni, Jerusalem District [Mahoz] - IAA

Ofer Cohen, Yael Rosenthal - Ofer Cohen Engineering.

Copies: to the participants, Yuval Baruch, [Jerusalem] Region Archaeologist.

The survey of the physical-engineering and preservation state, and the main conclusions [deriving] from it, were presented to the El-Ad people.

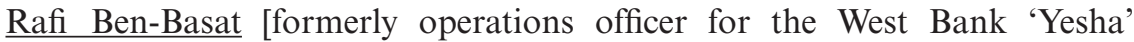
Council and Deputy Chairman of the Binyamin Area Council]: We chose an architect who will plan the tunnel and its environs (exits, systems, etc.) - Arie Rahamimoff. We should be ready for a process of planning of about $1 / 2$ year. The budgetary implications of the recommendations should be understood, and [we should] see if we can allocate this budget and what phasing it will require. One should find out how to do the project without closing all the tunnel simultaneously.

Yehuda Mali [one of the heads of El-Ad]: Now we must think about adding content and what would be the experience of the visitor in the tunnel.

Ofer Cohen: The state of the tunnel and of its modern supports necessitates significant intervention in the medium and long run. The present construction does not fit the special conditions of the tunnel and will not be sufficient in the next few years. Local engineering problems can be solved until the range of one year - not longer. We should start making stabilization acts and replacing the current supports within half a year to a year.

Raanan Kislev: Already now we should define a planning team to discuss the four major issues - architecture, preservation, engineering and operation.

The documentation of the relatively authentic tunnel parts, which form a large percentage of the entire tunnel, must be done both for local engineering works (especially on the roofing stones) and for the general preservation planning. 
The project must be statutorily approved by the IAA (by the [Jerusalem] Region and District). The work can be done by the Preservation Administration or any other body - under approval of the Preservation Administration.

Eran Mordechovitz: One must ensure cooperation with the architects of the northern part of the Sewage Tunnel (the exit of the Warren Shaft), in order to achieve one architectural and preservation language along the entire tunnel. At the phase of documentation we should see that it will be done under proper conditions, to ensure its effectiveness, since it is an active work site with significant limitations of space and work.

[This is not a meeting headed by Shuka Dorfman, so there is no 'mandatory summary' by him]

\section{Document 3.7}

[Copy of email from Yuval Baruch to Shuka Dorfman, September 11, 2013, at 19:35]

Subject: Completion of the Excavations at the Basis of the Western Wall Shuka [Dorfman] Shalom,

The following is my opinion regarding your request to complete the excavations along the base of the Western Wall as far as its southwestern corner:

1. The excavations are possible from an engineering point of view, and carry considerable scientific interest. -The exposure of an entire corner of the Temple Mount foundation, at the point where clearly the construction of the Western Wall began, progressing northward. It is also an opportunity to consider also an excavation alongside some part of the southern wall [of the Temple Mount], but this is a matter for a more serious conversation.

2. In my opinion it is possible to complete the work within about two months.

3. It will be most appropriate if Eli Shukron completes this work.

Regarding the same matter, I remind you that the validity of the permit [for excavation] of Eli Shukron is supposed to expire at the end of September, and he has not completed the excavations.

Yuval [Baruch]

\section{Document 3.8}

[Two pages of guidelines, written by Ofer Cohen, though not signed]

December 17, 2013 


\section{Archaeological Excavation and Supports near the Western Wall}

INSTRUCTION FOR WORK:

- Supports for the excavation and proceeding southwards will be performed like the work done in the excavation [from the Givati Parking?] directed northwards.

Attached are plans of the construction [for support] of 19/8/2012, which are fitted for the continuation of the work.

STAGES OF WORK:

- Excavation to a depth of c. $50 \mathrm{~cm}$ and width of until $200 \mathrm{~cm}$.

When breaching a wall, one should excavate horizontally the upper $50 \mathrm{~cm}$, then perform the breaching vertically according to the measures mentioned above.

- Placing secondary beams (width beams) on temporary Mesco legs [parts of scaffolds], two Mesko legs on each side. Above the width beams will be a $5 \mathrm{~mm}$ thick steel sheet, which will be welded between the width beams.

- The space created between the steel sheet and the roof of the excavation will be closed by a filling of sacks of soil or construction.

- After advancing to a depth of 2 metres (when every $50 \mathrm{~cm}$ a secondary beam exists), one must place major (length) beams and steel legs as detailed in the attached plans, and remove the Mesco legs.

- Achieving full contact between the base plates of the steel beams and the rock/stone wall will be made by grout [a fluid form of concrete used for filling gaps].

- In the case that a steel leg damages the archaeological finds, one should receive instructions from the planning engineer for changing the location of the leg.

- One should complete the work of support in the northern part of the excavation that was [already] finished.

- The northern shaft was left without access, not supported, and composed of sections of exposed earth.

- Left are unstable heads of walls.

- The location of the northern steel pillars is not final, because they are based upon untreated stone walls, and it was not yet decided whether they [the walls] will be dismantled or stabilized and preserved.

- There are 'floating' stone walls which require revetment in order to stabilize them and the earth section underneath them.

- One should perform preservation work for all the exposed stone walls. The preservation work stabilises the stones, improves the carrying capacity of the stone walls and prevents physical deterioration of the finds.

[Page 2: plans showing the support system]. 


\section{To Chapter 4: Ohel Yitzhak}

\section{Document 4.1}

[Letterhead: IAA]

February 28, 2006

To: Jon Seligman

Here

Subject: Ohel Yitzhak - Donor File

Summary of meeting of 27/2/06, present: Yael Aleph, Moriah Shlavin, Shachar Poni, Tawfiq Da'adli

1. Following the request of the Ateret Cohanim organization, the Conservation Department has started preparing a 'donor file' on the matter of Ohel Yitzhak

2. In a work meeting held yesterday at the site we defined the following issues:

1. The file will be prepared by Faina, accompanied by an archaeologist on behalf of the [Jerusalem] Region or the director of the excavation, Hayim Berbé.

2. The archaeological follow-up will be performed by allocation of workdays from the project [budget].

3. Contents of the [Donor] file:

A. The file will include only historical, archaeological, and figurative data.

B. The file will include a summary about the excavations and the finds at Ohel Yitzhak.

C. Data will be collected on the history of the area, whose borders were presented by Faina.

D. [IAA employee, architect] Faina [Milstein] will receive all the plans, photographs and drawings made during the excavations.

E. We should explicitly define the issue of authors' rights and rights of using the materials in the file.

Sincerely,

[Signature]

Yuval Baruch, Jerusalem Region Archaeologist

Copies: Raanan Kislev, those present. 


\section{Document 4.2}

Work Plan-Archaeological Excavations - Ohel Yitzhak, Jerusalem DEFINITION OF THE AREA:

The area designed for the work is an area in which the IAA has excavated in the past, attached is a plan marked as appendix 1 .

DEFINITION OF THE WORK:

A. Area A will be excavated everywhere possible to the [layer of the] Second Temple Period.

B. Area B will be excavated to the floor of the Cardo [the street dated to the Roman period].

C. Area $\mathrm{C}$ will be excavated at certain points that need to be completed, according to the considerations of the excavating archaeologist.

[Not translated - technical matters, e.g., cement construction to stabilize the building during the excavations, and who supplies the equipment and workers.] Start of Work

Start in 2007.

\section{Document 4.3}

[Letterhead: IAA. Stamp: Jerusalem Region, sent by fax 23.1.06]

[Handwritten: sent to Mevaseret Zion]

December 25, 2006

To: Buki Boaz (representative of the entrepreneur)

Ohel Yitzhak Project

Jerusalem

Dear Sir,

Subject: Ohel Yitzhak, Summary of Work Meeting

Present: Jon Seligman, Raanan Kislev, Hayim Barbé, Yuval Baruch (IAA), Buki Boaz (on behalf of the entrepreneur)

1. The plan of the excavations was presented by Mr. Buki Boaz, according to data given by Hayim Barbé.

2. The representative of the entrepreneur and the excavator will deliver to the Jerusalem Region a detailed work plan for executing the excavations, as a condition for starting them.

3. The entrepreneur intends to establish a museum for the history of Jerusalem and its archaeology beneath the synagogue. 
4. Buki [Boaz] presented the intention of the entrepreneur to dismantle the cement supports, replacing them by steel beams, as a preliminary phase before the excavations.

5. The entrepreneur intends to preserve the ancient layers under a transparent floor; its level will be determined after the excavation work has been completed.

[Items 6-8: Choosing Engineer Hayim Finkelstein as construction engineer that accompanies the excavations and arranging this aspect.]

9. The Conservation Department will prepare a conservation report for an initial conservation of remains under immediate danger.

10. The entrepreneur agrees to complete the initial and necessary conservation work before any other work.

11. After the [present] phase of the excavations, a conservation plan will be prepared for the building and for the exposed remains.

12. The Jerusalem Region will prepare [budget] estimate for the excavations and for the necessary conservation works.

13. The IAA conditions its approval for executing the works on archaeological or conservation inspection of all the works that concern excavation and professional preservation.

14. The IAA will deliver the conditions of inspection to the representative of the entrepreneur before the start of the work.

Sincerely,

[Signature]

Yuval Baruch

Jerusalem Region Archaeologist

\section{Document 4.4}

[Letterhead: IAA. Stamp: Jerusalem Region, sent by fax 14.1.07]

January 11, 2007

To: Buki Boaz (representative of the entrepreneur)

Ohel Yitzhak Project

Jerusalem

Dear Sir,

Subject: Ohel Yitzhak, Summary of Meeting, January 8, 2007

[Confusingly giving also another date in the title, 11-01-2007]

Present: Jon Seligman, Raanan Kislev, Shachar Poni, Eran Chemo, Avi

Peretz, Yoram Saad (IAA), Buki Boaz (on behalf of the entrepreneur) 
1. The intention of the entrepreneur to change some of the agreements reached on 25/12/06 was presented.

2. The entrepreneur intends to start the excavations immediately, rather than wait until the dismantling of the cement supports is completed.

3. The developer has again repeated his view [sic, should be: his wish] to develop the structure as an open museum.

4. The IAA will give the entrepreneur an estimate for the archaeological excavations, including the cost of the workers.

5. The estimate and the area for excavations was [read 'were'] determined in keeping with the intention of the developer to present remains from various periods there and [these] are not rescue excavations.

6. The IAA demands that necessary conservation works will be done in parallel to the excavations.

7. The IAA will send an estimate for the execution of the conservation works.

8. The IAA would like to begin preparing a preliminary program for the preservation and development of the site.

9. Following the request of the entrepreneur, the IAA will deliver an estimate for making the preliminary program.

Sincerely, Yuval Baruch

[Signature]

Jerusalem Region Archaeologist

\section{Document 4.5}

[Letterhead: IAA. Stamp of Yuval Baruch and his signature]

March 7, 2007

J-33564

\section{Subject: Ohel Yitzhak, Summary of Meeting 7/3/07}

Participants: Shuka Dorfman, Yuval Baruch, Raanan Kislev, Buki Boaz

\section{Following is the summary:}

Buki Boaz: I am responsible for many archaeological projects, one of them is the project of Elath Mazar in the City of David. I am not acting as an archaeologist. I have an agreement with the Hebrew University, with the Institute of Archaeology. The agreement was approved by the Legal Advisor of the University.

I direct the Ohel Yitzhak project for the Moskowitz family, the funding is from the inheritance money. There is no connection between Ohel Yitzhak and Ateret Cohanim. Matti Dan [head of Ateret Cohanim] has various other interests than those of the Moskowitz family, which is the landowner. We want 
to continue the excavations in the portion beneath the synagogue. We would like to finish the excavations during the present season. One cannot excavate further due to safety issues. [He presents] the planning of a glass floor, and establishing a museum open to the general public. In the long term, we would want to excavate the eastern [vaults] and then establish an active museum for the general public. The Moskowitz family will finance all the excavations. We have not yet appointed an architect, we presented to the IAA a preliminary program. The debt on account of the donor's file will be handled in due course. Every agreement of mine with the IAA will be supported by the Moskowitz family.

Shuka Dorfman: The Institute of Archaeology of the Hebrew University claims that they have no interest in performing a salvage excavation. Such considerations of universities are not the business of the IAA.

Yuval Baruch: Buki Boas applied to the IAA about half a year ago. We demanded to see power of attorney, which we received. Ohel Yitzhak is divided into two [parts]: the synagogue, administered by Eliezer Avni for the Moskowitz family; [and] the lower part which is being administered by Buki Boaz. We have defined the planning and conservation requirements. We clarified that archaeology will not be dismantled: the finds must be preserved according to their importance. Archaeological requirements were defined for the excavation. The excavation was estimated to be medium to small, not including the excavation in the eastern spaces. Jon Seligman approved the excavation in the eastern spaces, $[\ldots]$

[Second page missing].

\section{Document 4.6}

[Letterhead: IAA, Conservation Department]

[Handwritten:] Draft. Not sent. For proofing.

April 25, 2007

To: Eng. Eran Chemo, Head of Planning Department, IAA

Subject: Ohel Yitzhak Synagogue Complex, Program for presenting the Archaeological Excavations to the Public - Summary of Meeting with the Entrepreneur

\section{Dear Sir,}

A meeting for 'coordinating expectations' was held on 19.04.07 between the IAA - Architect Faina Milstein, responsible for the project; and $\mathrm{Mr}$. Buki Boaz, the representative of the entrepreneur [concerning a] program for presenting to the public the archaeological layer at the Ohel Yitzhak Synagogue complex. 


\title{
232 Appendix
}

The sides agreed as follows:

- The Ohel Yitzhak Synagogue compound is passing now a process of building, reconstruction, and rehabilitation. The reconstruction of the building is made after a series of studies and a series of archaeological excavations and planning works, carried at the site since 1995.

[Not translated: Three more items about the survey made in 2000, giving recommendations for restoration of the synagogue; and the archaeological excavations carried out in 2003-2005, finding important layers and finds that deserve preservation and exhibition.]

- The Synagogue compound is composed of two layers on a vertical axle: the archaeological layer is located, at this stage of the excavations, on different levels, the lowest of which is ca. 8 metres under the Ha-Gai Street level; and the historical layer which is located at a level of 5.60 metres above the Street - this layer is the Ohel Yitzhak Synagogue. The engineers responsible for the supports on the archaeological layer are Y. Echbert, and recently $\mathrm{H}$. Finkestein.

- The sides agree to check with the Director of the IAA about the possibility of connecting the Ohel Yitzhak compound with the Western Wall Tunnels. The reason for this comprises three professional aspects: the aspect of safety at archaeological sites in Jerusalem, the archaeological aspect, and the architectural-touristic aspect.

- The proximity between [these] two important sites in Jerusalem gives an opportunity to create a circular complex with emergency exits/ entrances.

- Identity and continuity in periods: the historical, archaeological and architectural [identity/continuity] naturally calls for connecting the two sites, [a connection that will] offer the visitor a broad and more varied view that includes the Museum [for the] Archaeology and History of Jerusalem.

[Aerial photograph of the compound, showing the relation to the Western Wall Tunnels]

\author{
Sincerely, \\ Engineer Faina Milstein \\ Conservation Department, IAA \\ [Copies: Buki Boaz, various IAA managers]
}

\section{Document 4.7}

[Letterhead: IAA, Conservation Department]

[Handwritten on the upper left side:] Jon,

1. From my point of view it is fine. 
2. It is worthy to present [this] to Shuka [Dorfman], but by whom? We, or the entrepreneur?

3. Who sends to the entrepreneur - we, or the Conservation [Department?]

[Stamp and Signature:] Yuval Baruch

May 10, 2007

To: Eng. Raanan Kislev, Head of Conservation Department, IAA

Subject: Ohel Yitzhak Synagogue Complex: Principles of a Program for presenting the Archaeological Excavations to the Public

[Not translated: first part of the document repeats Document 3.7, explaining the history of the restoration of the Synagogue and the 2003-2005 excavations]

\section{Defining the Compound's Parts}

Due to the size and volume of the archaeological excavations, two separate projects started to be performed at the compound, related to two different levels of life found at the site. Despite the division, the works of restoration and rehabilitation demand a general overview of the entire compound.

The Synagogue compound is composed of two layers on a vertical axle:

1. The historical layer: The Ohel Yitzhak Synagogue, which begins at the level of Ha-Gai Street and ascends (henceforward: 'the Synagogue').

2. The archaeological layer: a museum for the archaeology and history of Jerusalem. This layer includes two parts: the western part and the eastern part (henceforward: 'the museum').

1. The Ohel Yitzhak Synagogue passed a process of conservation of architectural remains and re-building the structure.

2. The museum for the archaeology and history of Jerusalem is still under planning.

The IAA demanded from the entrepreneur that invited the museum project to make a program for exhibiting the archaeological finds [discovered] in the entire area of the [future] museum.

AS mentioned earlier, the museum is composed of two parts:

- $\quad$ The - excavated - western part extends over the area of the former 'Kollel Shomrei HaChomot' (the Ohel Yitzhak Synagogue), located at a level of some eight metres beneath Shaar Ha-Gai Street.

- The eastern part - 'The eastern halls' - is only partially excavated and is found today at a level of three metres above Ha-Gai Street. 
At this stage of the project, the program will be implemented only for the western part.

\section{Principal of the Program for the Western Part}

1. The cultural aspect is the main aspect of the museum.

2. Finishing the excavation works as required by the instructions of the IAA.

3. The museum will exhibit the history of Jerusalem on three major levels:

- Presenting the building of the museum itself, as an example of an assemblage of periods that represent the history of Jerusalem.

- Exhibiting the archaeological and architectural finds [discovered] at the site in a way that will permit maximal understanding of past cultures. For that aim an architectural plan will be prepared, clarifying among other things the correct array of movement between the various levels, light systems, etc. The plans must receive the IAA's approval, as usual.

- Exhibition of small finds (clay, glass, coins, etc.) in a museal way (in showcases), etc.

After completing the program for the western part, and conducting the necessary excavations, a plan will be prepared for the western part in keeping with the program, and immediately afterward, it will be possible to implement the plan.

In parallel to the planning of the western part, one must make a general plan that encompasses the entire compound (see the attached map) [not delivered to us].

\section{Document 4.8}

Jerusalem, Juny 13, 2007

J-34450

\section{Subject: Ohel Yitzhak - Summary of Meeting of 13/6/07}

Participants: Shuka Dorfman, Jon Seligman, Raanan Kislev, Eran Chemo

Following is the summary:

Jon Seligman: He presented a letter of agreement, which can serve as a basis for making the program.

The entrepreneur presented his wishes and now we must examine the archaeological requirements and analyze what finds to present and exhibit in the structure that will be established. The document is complex and we must determine whether to approve the project. There will be no excavations beyond the boundaries of the structure, and the existing area will not be expanded. It is not easy to acknowledge the fact that we are again excavating in the Old City 
without [general?] planning. The eastern area, which is not owned by them, must be considered. The fundamental problem is that the entrepreneur does not define the content of this museum. I propose not sharing the document with the entrepreneur.

Raanan Kislev: Faina Milstein met with Buki Boaz, corrected the document, and defined the principles of the IAA. The document will be distributed to the entrepreneur only after approval of the [IAA] Director. The document is divided into a historical layer and an archaeological layer, and it is necessary to examine how to connect them and what will be done in the western part. Two planners were appointed [to work on] the project. I suggest carrying out Stage 1 [synagogue, historical level] so that we will be able to carry out Stage 2 [beneath the synagogue, archaeological level] and only then check the feasibility of Stage 3 [the eastern part], which at present cannot still be implemented. We ordered that a designer be appointed. Progress can [meanwhile] be made in the western part, according to the conditions of the document [of the principles].

Yuval Baruch: We have changed the façades, and stopped the work for half a year. The entrepreneur committed to making preservation works of the Syangogue plaster. We must complete the excavation in the western part. In order to begin planning, the excavation must be completed. The extent of the area is the Ohel Yitzhak building in the lower portions (the pink coloured plan). We demanded that the entrepreneur will make test drills to see where the bedrock is located. The program will define what is to be conserved. One should finish the excavations season and nominate a prominent architect in order to advance the project. The entrepreneur has understood that conservation is the leading element.

Eran Chemo: The space shall be an entrance point to the space in continuation [probably using the map to show what he means].

\section{Shuka Dorfman Concluded the meeting:}

1. We must study the western space and define the length and breadth of the excavation.

2. The Jerusalem Region and the Conservation Department are responsible for recommending how the space shall remain at the end of the archaeological excavation.

3. After the examination [meaning point 1] we shall make a tour, and reach decisions what to preserve and what not to.

4. At the end of the excavation and exposure, the IAA will give the entrepreneur instructions, on the basis of which he can start the planning stage, which will be brought to the IAA for approval of each and every detail.

5. The document will not be distributed to the entrepreneur.

6. The IAA will not be a partner in the planning, but will retain the ability of monitoring.

Registered: Ashrat Zecharyah

Distribution: to the participants. 


\section{Document 4.9}

[Summary of meeting of June 26, 2007, between the representatives of the entrepreneur, the IAA, the responsible engineers and two work contractors. Not translated, because it discusses various technical matters, such as doing test drillings, checking the cement supports, etc., and some arrangements before the excavations. One detail is worth mentioning:]

[In the list of participants:] Representative of the entrepreneur - Davidleh [David Beeri, Director of El-Ad]

\section{Document 4.10}

July 08, 2007

[Stamp and signature of Yuval Baruch, Jerusalem District Archaeologist]

\section{Internal \\ Subject: Status of Works and Plans for the 'Ohel Yitzhak' Compound}

The compound includes three different parts (attached is a location map): [map missing]

1. The historical Ohel Yitzhak Synagogue.

2. The archaeological layer, Ohel Yitzhak Synagogue (within the building of the Hammam a-Shifa').

3. A system of Medieval vaults east of the 'Ohel Yitzhak' compound, in a level similar to that of the archaeological layer.

[Rest of document details what was done so far in parts $1-2$, we translate partially:]

2. 'Ohel Yitzhak' Synagogue, the archaeological layer:

A. Following the demands of the [Jerusalem] Region and the request [of work] by the entrepreneur, the Conservation Department starting making a program for exhibiting and preserving the remains. [...]

C. Following our recommendations, several drills were made in order to locate the bedrock, which we estimate to be ca. $10 \mathrm{~m}$ under the present surface.

D. The results of the drilling [indicate] a much lower probability of the chance to expose parts of the early levels of occupation that exist in this area, including exposing the bedrock itself.

E. We delivered to the entrepreneur a plan for completion of the excavations in five spots for a duration of about three months. [...] 


\section{Document 4.11}

[Date missing; draft with Yuval Baruch's comments in handwriting. At least 26 pages, of which we have received about a half; the document includes many photos and plans]

[At bottom, logo of IAA, Conservation Department, and title:]

Jerusalem - The Old City

Ohel Yitzhak Compound
Program

for Exhibiting Archaeological Excavations
[Page 1] Entrepreneur:

Execution:

Architect:

Professional assistance:
Everest Foundation

IAA, Conservation Department

Faina Milstein

Hayim Barbé, Excavating Archaeologist

Architect: Shachar Poni

No. of project: 37714

[Coordinates and the Jerusalem Region and District]

Date of execution: September 2007

[Picture with caption:] Remains of a Second Temple structure, photo from 2004.

[Page 3]

\section{Introduction}

The site of Ohel Yitzhak Synagogue is located in the Old City of Jerusalem, in the Muslim Quarter, on the south end of Ha-Gai Street. It is situated in a compound that unites some of the most important focal points of ancient Jerusalem; these focal points include various historical and archaeological site of more than 3000 years old. [Marking for deletion are all made in handwriting by Baruch].

The area is made up of impressive arehaeologieal and arehiteetural sites assoeiated with various eultures, which exhibit the history of settlement in aneient Jerusalem from the First Temple Period to our days. [Baruch comment on the right margin:] redundant

[Baruch adds: 'In'] The of the Ohel Yitzhak compound was exposed [Baruch changes 'exposed' to 'excavated'] only partially on underground levels, due to the sensitivity of the site on all aeeounts, and beeatuse of the high eoneentration of important arehaeologieal sites loeated on the surfaee.

In view of the above, the sites requires special attitude and full exhibition to the public.

[Page 4] The Ohel Yitzhak compound goes now through a process of rebuilding, restoration, and rehabilitation. The compound's rehabilitation is done after a series of research steps [Baruch: after methodical research]; a series of sens of archaeological excavations and planning works, performed at the site since 1995 .

[Not translated: items about the conservation survey of the synagogue and the request of the IAA for the 2003-2005 salvage excavations] 
- During 2005, three stages of archaeological excavations were completed in the Synagogue compound (the IAA began the excavations in 2003 tnder the arehaeologist [Baruch: at first, under the direction of] Dr. Rina Avner, [Baruch adds: and later under the direction of] H. Barbé, and the archaeologist T. Da'adli. Two more seasons we performed.

- In 2007, the Israel Antiquities Authority deeided together with the eommissioning elient to earry out an additional season of [Baruch: according to the demand of the entrepreneur, it was decided to complete the] archaeological excavation [Baruch adds: at the site]; as a eontinuation of the previous exeavation season, in order to deepen the areas as far as possible to the level of the Seeond Temple Period [Baruch replaces this sentence with: Prior to the excavation, drilling of the ground was done to check the depth of the layers and of the bedrock]

The excavations exposed important early layers of the history of Jerusalem, which require preservation and exhibition.

\section{Definition of the Parts of the Compound}

Following the size and volume of the archaeological excavations, two separate projects that relate to different layers of life found at the site began. Despite the division, the works of rehabilitation and rebuilding demand a general concept of the entire compound.

The Synagogue compound is composed of two layers on a vertical axle:

[Repeating the 'historical layer' of the Synagogue and the 'archaeological layer' of the museum, exactly as in Document 3.7]

This [archaeological] layer is composed of two parts:

- The western part within the boundaries of the historical [Synagogue] building - including the Kolel Shomerey Ha-Chomot and the Ohel Yitzhak Synagogue (henceforward, 'Ohel Yitzhak').

- The eastern part - Khan Fahr al-Din [Baruch adds: this area is not part of the project].

[Page 5: section drawing with the two parts, Baruch marks lines for deletion and writes on the eastern part: 'not part of the project'...]

- The eastern part - 'the eastern halls' - is only partially excavated and is locvated at present at the level of c. 3 metres above the Ha-Gai Street. [Baruch marks in the margin: 'not part of the project']

At this stage of the project the program will be executed for the western part only [Baruch adds: 'superfluous - it's obvious']

Notes: [as in Document 3.7]

- After completion of the program for the western part, and conducting the necessary excavations, the plan for the western part [sic] will be devised 
according to the program; immediately after that it will be possible to implement the plan.

- At the same time as 'Ohel Yitzhak' is planned, an overall plan should be undertaken for the entire compound $[\ldots]$

[Page 7] Graph of the order of Planning and Executing Works at the Ohel Yitzhak Compound

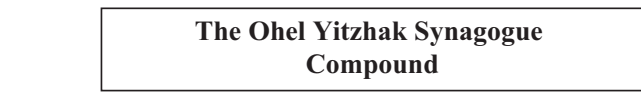

\begin{tabular}{|c|}
\hline The \\
Synagogue \\
\hline
\end{tabular}
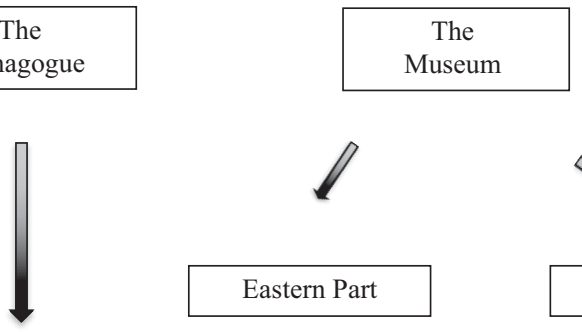

Eastern Part

Western Part

Phase A

\begin{tabular}{c|c|}
\hline Phase B & $\begin{array}{c}\text { Completing } \\
\text { building } \\
\text { the } \\
\text { Synagogue }\end{array}$ \\
\hline
\end{tabular}

Making a programme for the western part

Phase C

\begin{tabular}{|c|}
\hline Making a \\
programme for the \\
eastern part
\end{tabular}

Completion

of Excavations

Making a detailed plan for the western part according to the programme

Phase D Making a detailed plan for joining the western part, the eastern part and the Synagogue

Executing the western part combined plan 
[Page 13] Instructions of the IAA for a program of a Museum for the History of Jerusalem (name according to the request of the entrepreneur)

[Most items missing].

6. The museum will enable exhibition of the history of Jerusalem through material history [sic], archaeology, architecture and art, writings, iconographic material., etc.

7. The exhibition of the museum's structure as a compound composed of architectural and archaeological layers from the Second Temple period until our days.

[Caption of photo:] Part 4 - the secondary Cardo [Street]; combined view of five archaeological layers within the Ohel Yitzhak Synagogue building:

- The Byzantine period - remains of the secondary Cardo;

- The Early Islamic period - remains of a building;

- The Crusader period - remains of a building: continuation of the Early Islamic period wall;

- The Mamluk period - remains of the bathhouse of Darj el-Ain;

- The Ottoman period - the remains of the Ohel Yitzhak Synagogue: foundation vaults, walls and vaults of the ground floor.

[Page 5, part of list, points 6-10]

10. Part 4 forms an impressive section of the five layers of the history of Jerusalem. We recommend planning for this part an array of movement that enables descending to the Cardo level of the Byzantine period and building a glass floor to complete the view on the said section.

[Page 25] After the exhibition of the Dressing Hall of the Hamman in part 1 the visitor must feel it also in parts 2 and 3 of the museum. The difference is that in part 1 one can see the complete architecture of the Mamluk period and in the following parts one can see the remains of the Hammam in certain places.

\section{Document 4.12}

[Top right:] BSD [Aramean initials, lit. 'with the help of God,' hence 'with God's willing']

\section{Meeting for Coordination of Inspection - Ohel Yitzhak}

December 26, 2007

Participants: Soli, Rony, Etan[,] Raanan, Eliezer Avni, Jon, Aharon Osterreicher, Bembi, Yuval Baruch, Eitan Kimmel, Maayan, Shimshon Zaltzman, Zalman Deutsch and Chen. 
- Casting the roof of the Synagogue will be completed in a month and half.

- After the casting the work on preserving the stucco plaster by the IAA will begin.

- Until then, the IAA personnel will prepare instructions for conservation.

- The advisors will deliver plans (air-condition, light, sewage, etc.). [...]

- Raanan will push forward the work of preserving the 'stucco' on the walls, so that it will be finished until April 15, 2008 [...]

- Architects Etan Kimmel, Shimshon Zaltzman and Zalman Deutsch will meet to decide the final location of the elevator.

- The western Wall Foundation will prepare a program for Aera A within three weeks and present it to the IAA for approval. [...]

- Coordination meetings will be made every three weeks with the same participants

- Registered: Mordechai (Soli) Eliav

- Copies: to the participants.

\section{Document 4.13}

[Partial document, no letterhead, date, or list of participants]

Status of the Project

Western Wall Tunnels 'Ohel Yitzhak'

1. General:

Breaching and digging a passage way between the Western Wall Tunnels and Ohel Yitzhak, at the eastern path, [length] ca. 19.70 metres and western path ca. 27.30 metres.

2. Planning:

Engineering planning was made by Eng. Ofer Cohen.

Execution according to the plans and instructions given in the field.

3. Archaeology:

An initial document was prepared by the Southern Region [sic] concerning work procedures, inspection team and documentation during the works.

4. Safety:

[One line unclear, probably about preparation for a safety file] [...] Later by Avi Moshe - Responsible over Safety, IAA; and Chen Canari - Execution Engineer on behalf of the 'Western Wall Heritage Foundation'.

5. Execution:

Executing contractor 'Avner Gilead' and accompanying conservator under the responsibility of Conservation Department.

The preparation has been completed. Continuation following the instructions.

Estimated schedule for the execution of the eastern path ca. 8 weeks, dependent on limits of engineering and archaeology. 
6. Estimation of costs:

Ohel Yitzhak eastern path ca. 930 thousands Shekel.

Ohel Yitzhak western path ca. 1,295 thousand Shekel

7. Contracting:

The contract between the Western Wall Heritage Foundation and the IAA- is not attached.

\section{Document 4.14}

[Letterhead] Avner Gilead, Preservation and restoration of buildings

$$
\begin{gathered}
\text { Safety File } \\
\text { Works of the Western Wall Tunnels - Tunnelling Ohel Yitzhak } \\
\text { January } 2008
\end{gathered}
$$

\section{Introduction}

[Not translated: defining the aim of this safety file 'in the Western Wall Tunnels during the next few months,' general words on safety regulations, call to workers to be careful, etc.]

\section{Description of the Project}

GENERAL

The Western Wall Foundation, through the IAA, intends to make digging works for creating a passage between the Western Wall tunnels and 'Ohel Yitzhak' the Western Wall [sic].

\section{DESCRIPTION OF THE WORK}

Breaking a passage to a length of 19.70 metres, defined as eastern [passage], between the entrance corridor [named] the secret passage and 'Ohel Yitzhak'. Horizontal archaeological excavation by hand to free the passage, while [making] engineering support by roofed steel frames IB140, according to the engineering plan. The soil will be removed toward the west, through Ha-Gai Street to an approved place of disposal.

[Second Page: table of budget concerning the Western Passage; we translate only some of the items, without the table format:]

01.02. SUPPORT AND LINING

01.02.2010. Lining the dug tunnels by steel profiles type IPB in different sizes (sections sized 140) and different length $(210-230 \mathrm{~cm})$. This item includes supply and HARKAVAH of the profiles ... 11 tons, price [unit] 27,720.00, total 304,920.00 [Shekels]. 
01.02.2020. Wooden plates $50 \mathrm{~mm}$ thick and $200 \mathrm{~mm}$ wide, to line the sides and floor of the tunnels [...] 12 cubic metres, price [unit] 8,085.00, price total 105, 105.00 .

01.02.2030. Repeated filling with cement stabilization behind the steel and wooden lining 75 cubic metres, price [unit] 3,811.00, price total $285,825.00$

Total for lining and support $695,850.00$

\subsection{EXCAVATION QUARRYING AND REMOVAL}

01.03.0010. Excavation in archaeological fill of varied consistency, from solid earth fill to sandy-soil loose [fill] and walls and parts of buildings. Volume calculated in theory, cubic metres 160.00 , price [unit] 1,500.00, price total 240,000.00

01.03.0020. Removal of all the dug and quarried material until a licensed site of disposal, including all what it takes to take the material out of the Western Wall tunnels until after dumping, including all the necessary fees. Volume calculated in theory including x1.5 for expansion, cubic metres 240.00 , price [unit] 1,150.00, price total $276,000.00[\ldots]$

Total for the western passage $[\ldots] 1,215,850.00$

[General expenses, insurance, etc., 80,000 Shekels

[Third Page is similar to the second, but on the eastern passage. Total sum 890,117.50 Shekels, general expenses 59,000 Shekels].

\section{Document 4.15}

Date of printing: February 2, 2008

[Handwritten note:] Izabel, open [a file?] from contract. The name Ohel Yitzhak 'Vaults'. Yuval [Baruch]

\section{Estimate for Performing a Project}

Date of request: 22/01/08 type of project: excavation

[Region:] Jerusalem

[Entrepreneur:] The Western Wall Heritage Foundation

No. of workdays: 66 Name of Project: Vaults east of the Ohel Yoitzhak Synagogue

[Details on dates and maker of the estimate; 'excavation license/excavators' not filled in]

[Table of budget items, we translate in part:] 


\begin{tabular}{|l|l|l|l|r|}
\hline Position & Quantity & $\begin{array}{l}\text { Work } \\
\text { days }\end{array}$ & $\begin{array}{l}\text { Price per } \\
\text { day }\end{array}$ & $\begin{array}{l}\text { Total per } \\
\text { position }\end{array}$ \\
\hline Director of excavation & 1 & 66 & 761 & 50,226 \\
\hline Expert researcher & 1 & 12 & 698 & 8,376 \\
\hline Administrator & 1 & 15 & 962 & 14,430 \\
\hline Surveyor & 1 & 14 & 803 & 11,242 \\
\hline Photographer & 1 & 10 & 803 & 8,030 \\
\hline Conservation planner recorder & 1 & 4 & 719 & 2,876 \\
\hline Conservation inspector & 1 & 4 & 656 & 2,624 \\
\hline Safety engineer & 1 & 3 & 737 & 2,21 \\
\hline Preparation for publication & 1 & 8 & 613 & 4,904 \\
\hline Technical work on finds & 1 & 80 & 656 & 52,480 \\
\hline Package/transfer of finds & 1 & 5 & 656 & 3,280 \\
\hline Scientific work on finds & 1 & 80 & 613 & 49,040 \\
\hline Workers paid by entrepreneur & 12 & 60 & 0 & 0 \\
\hline Total & & & & 209,719 \\
\hline
\end{tabular}

[Total estimate 280,830 Shekels]

\section{Document 4.16}

[Letterhead:] Daniel Seidemann Meira Noam

Jerusalem, January 8, 2008

To: Mr. Meni Mazuz, Adv.

The Government Attorney General

Ministry of Justice

$\underline{\text { Here }}$

Honorable Sir,

Subject: Illegal Project under the Muslim Quarter of the Old City of Jerusalem

On behalf of my client, the 'Ir Amim' [City of Peoples] association, I hereby apply to you concerning what follows:

1. Since 2004, archaeological excavations are carried out under a building known as 'Ohel Yitzhak' in the Ha-Gai Street [...]

2. The excavation works have already reached a depth of ca. 10 metres underground, all without a legal license for excavation and without the approval of the Supreme Archaeological Council. The works are done solely on the basis of a permit by the IAA - hence: these are salvage excavations -despite the fact that these are not at all related to the 
construction that is done above the compound [meaning the re-building of the Synagogue].

Moreover, excavation on such a large scale require the building of steel beam construction to support the exposed spaces - acts that require giving a building permit on the basis of an approved city plan. In the case of the excavations at 'Ohel Yitzhak', a building permit for such construction was not given, and there is no approved city plan allowing these [acts].

3. Following reports in the papers some two months ago (see the report of Nadav Shragai in 'Haaretz' newspaper of 2.11.07), a new tourist project is materializing: a tunnel to connect the Western Wall tunnels and 'Ohel Yitzhak', together with opening an underground museum and educational centre at the place. Following the reports, a contract was signed between the 'Western Wall Heritage Foundation' (a governmental foundation close to associations of settlers in East Jerusalem, responsible for operating the Western Wall Plaza), and the Moskowitz family (the patron of the settlers' associations and the owner of the Ohel Yitzhak building), according to which the foundation will develop the project and direct it.

4. Naturally such a project is complex both legally and practically:

A. It requires depositing a city building plan, for public view, receiving objections from the public, and approval of it [the plan] by the statutory bodies of planning.

B. As mentioned, ownership of land occupies all the area under the surface (par. 5 to the Law of Land property, 1969). Since the tunnel and large parts of the entire compound pass underneath the houses of the Palestinian Muslim Quarter residents, it requires accepting the agreement of all the above mentioned landowners to any construction under their houses.

C. The involvement of the Western Wall Heritage Foundation in a project inside and under the Muslim Quarter is, allegedly, illegal, since it is a clear example of deviation from authority of a public body that is answerable to administrative laws. See, for this matter, the view of one of your formers in position, the Attorney General Harish of the early 1990s, which forbade the Company for the Development of the Jewish Quarter to act outside the geographic area of the Jewish Quarter.

[Point D warns that the area is sensitive, requiring caution and approval of all the security bodies. Next Seidemann asked the Attorney General to act, stressing that the project is not done innocently. Seidemann assumed that security bodies and senior governmental levels did not give their approval, but it is likely that they did. Seidemann asked the Attorney General to check the allegations, including:].

C. How did it transpire that all (over ten) the archaeological excavations carried out in the Old City [some words unreadable, perhaps: are done 
for] the settlers in East Jerusalem and their direct supporters and with their financing? Is this consistent with the official, scientific and independent character of the IAA, as stipulated by the Antiquities Law? Does this not constitute illegal politicization of a governmental authority and of the Israeli scientific discipline of archaeology that takes place under its aegis?

$[\ldots]$

[Seidemann asked the General Attorney to order that all the various works will be stopped and that a criminal enquiry be opened against those responsible]

\section{Document 4.17}

[Letterhead IAA, stamp of the Jerusalem Region, 'sent: 7.2.08']

To: Adv. Bar Sela

February 6, 2008

Legal Advisor, IAA

Jerusalem

Dear Sir,

Subject: Excavations at Ohel Yitzhak - the Application of Adv. Daniel Seidemann

1. The IAA is performing archaeological excavations at Ohel Yitzhak since 2004 by invitation of the owners of the building. This excavation started as part of handling municipal building plan for the rehabilitation of the Ohel Yitzhak Synagogue which stood at this place until 1936.

2. The claim that the excavation are performed without legal license is unfounded. The excavation, like any [other] excavation, is done under a legally issued permit signed by the IAA Director (permits 4161, 4436, 4763, and 5152).

3. The IAA excavates on behalf of the Antiquities Law and not by the building and planning Law; in other words, there is no direct relation between depositing a municipal building plan for executing the excavation. There is no legal necessity to receive a legal permission for an archaeological excavation according to the Law of building and planning.

4. It is true that the IAA performs excavations as a result when a change in an antiquities site is requested as a result of applying for a change in a municipal construction plan. However, an act by par. 29 of the Antiquities Law is done after each application, regardless of the issue of the planning and building Law. We add that the IAA also makes excavations as a preliminary act for making a program and depositing a city building plan, in order to collect the data that is necessary for planning.

5. In the present case a governmental body, the Western Wall Heritage Foundation, asks to make an act that requires an archaeological excavation, following par. 29 to the Antiquities Law - 1978. 
6. Issues related to depositing a city building plan, if that is necessary, are the full responsibility of the Western Wall Heritage Foundation.

7. Unlike what was written in Seidemann's letter, all the acts performed in the Western Wall Tunnels and Ohel Yitzhak are done by full knowledge of all the relevant security bodies [...]

9. One must completely reject the claim about politicization of the IAA work. The IAA makes many excavations in Jerusalem, the vast majority [of them] for governmental and public bodies and not any sort of associations. The IAA acts where landowners do changes in antiquities sites, and does not seek a certain type of entrepreneur. The claim that the IAA is affected by the identity of the entrepreneur [lit., 'inviter of work'] is insulting and touches directly the professionalism of our work. Such excavations, and also the excavations performed for Ateret Cohanim and Eldad, are made in a high archaeological level [of expertise], independent of the identity of the entrepreneur. The results of the excavation are published as is without any influence by the entrepreneur. In addition, the identity of those who commissioned [this project] and their political agenda might have led us towards an improper search of 'Jewish layers.' Surprisingly [said with irony], the Antiquities Authority excavated an Ayyubid-Mamluk bathhouse at Ohel Yitzhak and presented precisely this fact. In addition to these facts, one should notice that the Western Wall Heritage Foundation is a governmental foundations affiliated to the Prime Minister's Office. Hence the work in the Western Wall tunnels and at Ohel Yitzhak is done by a governmental institute and not for some association.

10. The excavations in the Western Wall tunnels do not violate anyone's property. While they are being conducted beneath the Old City, there is nothing in this that violates the rights of a person to his home or his property. It should be recalled that antiquities in Israel are the property of the nation. Since the Authority acts in the realms of the archaeological layer, it is operating within the realm of its authority.

Sincerely,

Jon Seligman

[Signature]

Jerusalem Region Archaeologist

Copy: Shuka Dorfman, IAA Director

\section{Document 4.18}

[Letterhead IAA; stamp of the Jerusalem Region: 'sent: 5.03.08']

March 4, 2008

Musqt2 2800

To: Adv. Bar Sela

Legal Advisor, IAA

Jerusalem 
Dear Sir,

Subject: Excavations at Ohel Yitzhak - the Application of Adv. Daniel $\underline{\text { Seidemann }}$

1. In continuation to my former letter of February 6, 2008, I wish to add the following details.

2. The Ohel Yitzhak project is based on municipal building plan 5480, validated on $1 / 3 / 2002$ and approved by the IAA on 28/1/2000. [The plan was deposited and approved by the IAA before its legal approval in 2002]

3. The IAA is excavating from time to time at Ohel Yitzhak since 2004 under the archaeological supervision of Hayim Barbé and Tawfiq Da'adli according to legally issued permits signed by the IAA Director [...]

4. Following is a description of the finds at the site:

[Details arranged by periods - Early Roman, Late Roman, Byzantine, Early Islamic, Crusader, and Mamluk. We translate the details on the Mamluk period:]

The Mamluk Period (14th-15th centuries AD): In this period the entire site is occupied by a public bathhouse (Hammam). Despite destruction at the centre of the structure due to the building of a water reservoir and some existing buildings in the Ottoman period, the plan of the Hammam is nearly fully exposed, including its western façade. The dressing room is fully preserved. A cross vault covered a monumental door with benches on its sides, which was blocked at the end of the Mamluk period (end of 15th century AD). A sewage system to drain the service rooms was preserved in the hot, dry rooms that lead to the heating ovens. East and west of the octagonal room there were small rooms [one sentence misprinted] [...] with the base of a dome and a few brick courses decorated with stucco. The plastered pools were built above heating ovens that produced steam and a double system of channels transferred hot air. The plan of the Hammam is identical to that of the Hamman Al-Ein to the north, although slightly smaller in scale. An archive text from 1531 allows to identify the Ohel Yitzhak Hammam with the Mamluk Hammam known as 'Mustaham Darj El-Ein' [name also in Arabic]. A hall with large vaults was discovered east of the bathhouse, connected to the inn established for [=near] the Cotton Market. Work is underway to remove the fill from these vaults, as well in as the vaults located in the space between the large bridge, over which Ha-Shalshelet Street passes, and the this hall of vaults.

Sincerely, Jonathan (Jon) Seligman [Signature] Copy: Shuka Dorfman - IAA Director Jerusalem Region Archaeologist 


\section{Document 4.19}

March 11, 2008

To

Mrs. Dafnah Glock

Advising and Legislation

The Ministry of Justice

Jerusalem

Dear Lady,

Subject: The Excavation of 'Ohel Yitzhak' Mr. Seidemann's Letter

First, I apologize for the delay in answering you.

\section{The Ohel Yitzhak Synagogue}

The Ohel Yitzhak Synagogue is located in the Muslim Quarter on Ha-Gai Street, not far from the Western Wall Plaza. The building is situated between the 'Cotton Market' and the remains of the ancient bridge the probably connected the upper city and the temple mount. The Synagogue was likely built in the early former [20th] century and evacuated in 1936 by the British due to the fear of disturbances.

The property owners initiated a municipal building plan no. 5840. It was approved and published [...] The aim of the plan is to set instructions for rebuilding and restoring the Synagogue as it was and to add an addition above it. The uses permitted for this area will be the Synagogue of course, learning and exhibition rooms, a library, a guest room, offices, etc.

[The letter explains the involvement of the IAA in making excavations and the important, major discoveries found.] Some of the finds will naturally require restoration, preservation, etc.

\section{The Archaeological Excavation}

[Stressing that the excavation was legal, done by a permit signed by the IAA Director. Among other things, the letter states:] The archaeological excavation was done by the IAA according to a permit given by the IAA Director. As is known, the IAA was authorized to make archaeological excavation by Law (paragraph 5b(1) to the Antiquities Authority Law - 1989) [...]

The beginning of the excavation is a rescue excavation, since it [permission] was given based on a condition [of the IAA] following a [city construction] plan or permit [5480]; but due to the scientific and historic importance of the area and because this is a one-time opportunity to conduct an archaeological excavation in the Old City to the greatest depth possible, this excavation is not only considered a rescue excavation but [also] a real scientific excavation. 


\section{The Spaces, Vault Structures, Arches, and Rooms}

During the excavation taking place in the area of the 'Ohel Yitzhak' building, spaces, rooms, vaulted structures, and arches were discovered that spill outwards from the area of the [synagogue] structure and continue southwards towards the vaults of the ancient bridge structure [above the Ha-Shalshelet St.]. All these buildings are ancient, though dating them is not yet completed. These spaces and rooms were found in a complete, fine state [of preservation] and they are filled with rubbish and refuse [sic, asphah and psolet] gathered in them throughout hundreds of years. The excavation taking place [now] is in effect the removal of the waste [psolet] from the existing spaces, rooms, and vaulted structures.

[Section 4 on the Western Wall Tunnels, pretending that they have received legal licenses since 1967, and now excavated under permits for salvage excavations, etc.]

\section{The Underground Connections}

All the spaces known as the Western Wall Tunnels are joined together. So are the rooms and the arches that were exposed by the excavations in the Ohel Yitzhak synagogue compound, they are all joined together. Removal of the rubbish [sic, ashpah], which is performed by way of an archaeological excavation, reveals these spaces, vaulted structures, and rooms. Ultimately, they connect with the spaces in the Western Wall Tunnels and particularly with the area exposed beneath the formerly mentioned ancient bridge. All the excavations are performed under full inspection of engineers. Since the excavation exposes existing buildings that are physically sound, there is no danger of any damage to buildings found above them. It should be said here that there is no property ownership arrangement in the Old City compound. Therefore, perhaps there is no dispute over the right of the claim-holders [Hebrew ba'aley hezkah] who live or are located above these spaces. However, they have no right of ownership on the ancient spaces. To this matter see paragraph 2 of the Antiquities Law - 1978.

All these excavations are done by cooperation with all the governmental bodies that need to know about these excavations.

\section{The Western Wall Heritage Foundation}

I did not refer in this opinion to the involvement of the Western Wall Heritage Foundation in the building and development. The Western Wall Heritage Foundation is a governmental association funded by the Ministry of Religion. It seems that since the authorities of the Ministry of Religion were transferred to the Prime Minister's Office, the Foundation is under their authority. I did not check and do not know what are the role and authority of the foundation; it will be easier to you to check this matter with the Prime Minister's Office, if you would like to.

[Brief summary, claiming again that the excavations are legal.] 
Sincerely yours,

[Copy, not signed]

Yoram Bar Sela, Adv.

Copy: IAA Director

Jerusalem Region Archaeologist

\section{Document 4.20}

[Letterhead] Udi Armoni

Project Managing and Media Advise to Museums and Visitor Centres

[Document formatted as a table, we render it in a letter form]

March 19, 2008

The Herodian Room

Western Wall Tunnels

First Meeting of the Steering Team [for] Ohel Yitzhak-Area A

\section{Subject: Content Meeting, Ohel Yitzhak}

Participants: Shachar Poni and Yuval Baruch - IAA;

Dov, Shachar, Micahl, Eli, Raheli, and Soli [Eliav] -Western Wall Heritage Foundation;

Maayan and Eitan of Kimmel Architects; Orit Gover-Shacham, Udi -from the planning team.

A discussion was held regarding the essence of the content, and it was agreed that the content message intended for the place [is] 'we all pray.'

This idea will make a connection, as far as possible, between the archaeological content of the site and the intended museum content, by using the descent into the layers of Jerusalem offered by the site in order to deliver the message of the idea [meser raayoni].

The essence is an archaeological tour in the layers of time that Jerusalem offers, while being exposed to the topic of prayer.

There is agreement with the IAA regarding the details of the planning. Eitan Kimmel and Shachar Poni of the IAA will finalize the last details [that need to be discussed]. The planning team will present a script of ideas that will include the description of the experience [of the visitors] and its contents. We should go out [sic] with an orderly procedure in order to receive price suggestions for making a virtual demo of the site. Within one month the planning team will present to the Steering team an initial script and within three month the content of a virtual demo of the site. The aim is to enter the project within one year (July 09) to a phase of presenting it to [testing by] focusing groups [kvutzot mikud].

Eitan [Kimmel] through Chen Canari and Rafi Kutschmer will issue an orderly schedule of the entire project. 
The connection from [Area] C [to Area A] will be considered in the future. At present we assume that the entry will be from the street.

Distribution: participants, office, Rafi Kutschmer, Chen Canari, Bembi, Dani Fichman.

\section{Document 4.21}

[One page from a 'status meeting,' missing almost the entire discussion, and the details of date, participants, etc.]

[...] the dark will result in that the visitor will not understand where he is. One should consider the timetable, as well as the possibility that it can happen that we will work in Area $\mathrm{C}$ and expose finds that will lead to a change in the planning.

Raanan Kislev: We create a restoration and exhibition of the building. The question is how to make the visitor realize, that he passes between the archaeological periods, without damaging the sequence. It is important to combine the experience in the building with that of the periods. We should examine how to combine the infrastructure and how it affects the building.

\section{Shuka Dorfman summarized the discussion:}

1. The creation of the sequence must be examined in a wide perspective.

2. It is important that one planner will bring a systematic view, including [for] the connection with the Western Wall Tunnels.

3. The idea to let the visitor see the agenda [...] Area C [...some words obscured]

4. Establishment of the exhibition must be made in coordination with the Department of the Treasures of the State in the Antiquities Authority.

5. The idea of prayer is acceptable, but it is important to ensure that the archaeological part is being expressed and is properly expressed.

6. Much information in a short time span will create a problem in showing and in understanding. It is important to think about something catchy that operates on the senses, which will attract the attention of the visitor.

7. In the past, an initiative that [later] failed was launched, to create unified coordination and management of all of the projects in the Western Wall Plaza. Today, every initiative operates as it pleases and we have no control over it.

8. I suggest to leave the option to the visitor to visit also the secondary routes [in the museum].

9. We should define detailed plans, as part of the duties of the steering committee.

10. To the extent that area A is crowded, it is possible to use Area C.

11. The Antiquities Authority will provide instruction on archaeological matters and will advise about matters of content.

Registered by: Ashrat Zecharyah

Distribution: the participants (internal) 


\section{Document 4.22}

['Status meeting' headed by Dorfman, partial]

[...] Ohel Yitzhak - Area C

Johny Ivanowsky presented the status [sic, meaning the current situation at the site]

Ofer Cohen: In the next week we will release [for work/use] rooms 5 and 6 [of the Western Wall Tunnels]. This relates to removal of [potential] danger. We delayed with the steel supports, since the sections were complex. The work is delayed due to estimation of the material [?]. In two months we will finish the preparatory work in the white and green areas [obviously referring to a map, which was not delivered to our hands]. The vault is full and therefore, it was not excavated. It can stay as is for a year, if we will put a lining made of [soil filled] sacks.

Soli Eliav: The question is what the cost of connecting Area $\mathrm{A}$ and Area $\mathrm{C}$ is. I ask to receive an estimated timetable for [making] an entrance by stairs below.

Ofer Cohen: We cannot connect by the stairs from below. The work will take two years because it is a very low level.

Chen Canari: The [steel] support is not related to the danger [treated in rooms 5 and 6]. First, one should remove the danger in the upper area. This is a complex issue [requiring cooperation] with the police and the municipality. The room should be lined with steel [plates].

\section{Ohel Yitzhak-Area A}

Soli Eliav: We stopped the work although we have received a certain budget. The plan is to prepare a route for visitors that are VIPs and create a circulation. We should make a partial breakthrough of walls, in order to be able to allow passage and to describe to VIPs the potential of the place.

Decision: At this stage the project is 'frozen', except arranging the route for VIPs.

[Discussion of areas in the Western Wall Tunnels]

\section{Document 4.23}

['Status meeting' headed by Dorfman, partial]

\section{[...] Ohel Yitzhak - Area A}

Soli Eliav: We are making progress concerning the elevator, which belongs to Area B and to Area A. The cement cast was part of the elevator project. 


\section{Appendix}

Concerning Area A, we intend to open paths, in order to allow passage of visitors following the final route. It is not yet [final] work for visits of the public. We can allocate 22 thousand shekels for documentation and survey. The plan is to finish all the works in Area A during 2009.

Chen Canari: The cost is 300,000 shekels. The cement cast appears in all the plans that were delivered to you, which you [IAA] have approved. The mishap was not notifying you during the time of performing the cast work.

Yuval Baruch: We asked to meet in order to convey the IAA requests to you. The cement cast was an unnecessary mishap, but the damage is insubstantial. It is important to complete the conservation plan with the architect. We must receive the plans for approval.

Raanan Kislev: The conservation administration [the unit was upgraded from 'department' to 'administration' at that time] gives conservational support. We suggested completing the documentation before the start of the works and made an estimate several months ago. We are talking about breakthrough and intervention in parts of [the] existing building. A conservation plan was never prepared.

Jon Seligman: It is all connected to one building, one cannot plan only one part of it. The planning must be complete and the execution done in stages.

Dan Bahat: The question is whether it has been decided what we want to exhibit to the public. At this stage there is no need to make a general conservation plan.

Following is the decision of the [IAA] Director:

1. The Conservation administration is responsible to deliver an estimate for making a conservation plan to the Western Wall Heritage Foundation.

2. Every work by the Western Wall Heritage Foundation will be made by knowledge of the IAA.

\section{Document 4.24}

[Letterhead IAA]

August 20, 2009

To: Yuval Baruch

Jerusalem Region Archaeologist

IAA

Here

[Stamp and signature of Yuval Baruch, written: 'to the file of Ohel Yitzhak'] 
Shalom!

Following is a summary of a work meeting at the site on 25.8.09, about finding solutions to the changes required in the plan (due to discovered finds and the progress of work).

1. The elevator between the entrance corridor and Ara $\mathrm{C}$ : deepening until the level marked in the plan is necessary, including damaging the eastern vault of the ovens' room. This damage was contemplated in advance when making the plan. Recommendation: approve the continuation of the works according to the original plan.

2. The elevator on the side of the corridor (near the 'acceptance' room): during the meeting we discovered that the elevator can be installed without any more excavation or damage to antiquities, which have already been excavated at the place. Recommendation: creating a covering layer to the exposed finds (under the supervision of Johny Ivanowsky), as well as a plaster layer to the walls that 'create' the shaft of the elevator. Approve of the continuation of the works.

3. The passage along the 'Roman wall': one can stabilize the roof of the passage by the following ways: inserting beams I. (minimum number, as possible) to the wall itself, finishing by cement and plaster while leaving the Roman wall surface exposed. B. supporting the beams by steel pillars along the wall. Recommendation: despite of the physical damage (that derives from an engineering necessity), we should prefer the first solution that keeps a clean face of the Roman wall, to placing a row of steel pillars.

4. The passage to the room, where the Second Temple period stairs are located: decision on this was deliberately delayed until the exposure of the Roman wall. Recommendation: A. Re-discuss this issue. B. In my opinion we should create only one passage at the southern side of the [Roman] wall by dismantling several stones from the upper course.

5. The passage under the 'hot room' (the lying pillar): It seems likely that we can make a minor change in the plan, in a way that will allow passage under the [lying] pillar without removing or damaging it. [It was] Agreed that this issue will be examined by architect Kimmel.

6. Cement support of the sides of the dressing room foundations: it was agreed that casts will be made only when clearly required. The rest of the walls will remain as they are.

7. Digging the core of the Roman wall in order to allow the installation of the central elevator: [it?] cannot be done [...] [rest of letter missing]

\section{Document 4.25}

September 24, 2009

J-41420

Subject: Ohel Yitzhak - Area A, Summary of Meeting of 24/9/09 
Participants: Shuka Dorfman, Raanan Kislev, Eran Chemo, Johny Ivanowsky, Jon Seligman, Yuval Baruch, Shachar Poni.

\section{Following is the summary:}

Shachar Poni presented the solutions for the required changes in the plan concerning the progress of works at Ohel Yitzhak - Area A.

Jon Seligman: [one line misprinted, some words unclear] The monumental [?] finds at Area A [forced?] changes [,] [and] the work that is being done [there is] improper [bilti re'uyah]. Alexander Onn [the excavator] has reached a new interpretation of the compound, which he will shortly present.

Yuval Baruch: In Area A we do not fulfil all the potential of the archaeological excavation, but [only] adjust [the excavation] to the needs of the [conservation?] planning and development. We should enlarge the excavation in order to study the area. It is wrong to remove the [lying] pillar. We should consider that we have instructed the entrepreneur and the planner to reach an understanding of all the remains.

Jon Seligman: In the passage under the hot room, the statement that the [lying] pillar is part of the Cardo is not unequivocal. If we remove the pillar, we commit to continuing the excavation. We should consider the dismantling of the side walls [instead?]. He feels uncomfortable, that the entrepreneur is trying to make the bathhouse disappear [Hebrew le-ha'alim].

Johny Ivanowsky: Enlarging the excavation has far-reaching engineering implications.

Yuval Baruch: Two weeks ago I visited the site in order to check other directions. We try to understand the monumental building from the Second Temple period. If it was part of Wilson's Arch, would we have permitted damaging it [?]. Anyway, it is a similar size structure. The architectural plan of the passages must fit the finds at the site, therefore, he recommends not to damage the walls.

Raanan Kislev: The condition by the IAA concerned the entire system of passage, the aim was that [visitors] can understand the compound with all its parts and periods. It is important not to limit the capability of the visitors to understand. Completing the data and further planning efforts are needed in order to find better solutions.

Jon Seligman: Handling the said part (the remains from the Second Temple period) will affect the future, including the connection to Area $\mathrm{C}$. We should check the access to the said Area after understanding the Roman building. Anyway, we must not allow damaging the wall.

Johny Ivanowsky: First, we must exhaust the potential of the archaeological excavation, in order to classify the importance of the remains, finally exhibiting the most important finds. 
Raanan Kislev: The passage within Area A is complex and difficult to understanding, concerning the various periods of the remains.

Shachar Poni: The situation at the moment concerning the passage from the foyer of the dressing room to the paving of the Cardo [is], [that] the engineer changed his mind, and that, although the planning was based on his earlier guidelines. Indeed there is an aesthetic dilemma and the solution is not simple.

Jon Seligman: It is not right to approve the passage through the corner of the bathhouse.

Yuval Baruch: Eitan Kimmel [the architect on behalf of the entrepreneur] is planning the route, the content is being examined in another channel, by a steering committee that makes progress in its work [...] The archaeology is located only in the background, there is content that is supposed to be exhibited, which is not related to the site.

[Rest missing]

\section{Document 4.26}

Jerusalem, November 1, 2009

$\mathrm{J}-41653$

Subject: Ohel Yitzhak - Area A, Summary of Meeting of 29/10/09

Participants: Shuka Dorfman, Raanan Kislev, Jon Seligman, Shachar Poni, Ofer Cohen

Following is the summary

Raanan Kislev: The last decision of the Director was to stop the works and examine with Eitan Kimmel if and how to change the program. The issue was examined by Shachar Poni with Eitan Kimmel, who [Kimmel] remains persistent about his plans.

Following are the decisions of the Director:

1. The two elevator piers in the north-western part of the structure - are approved. The technical specifications of the elevators should be delivered [to us].

2. The corner of the Mamluk bathhouse - the director adopts the suggestion of architect Eitan Kimmel, the significance [being] passage through the corner of the Mamluk bathhouse. [He] approves the work with archaeological-conservational [sic] supervision and after plans have been delivered [to the IAA].

3. The pillar in the area of the warm room of the bathhouse - is subject to the decision of the planners. It can be moved and it can be left.

4. The Roman wall in the north-eastern part of the structure - breaking through the wall to the north is not approved. We should plan viewing [point] on top of the wall or near it. 
5. Central elevator (for exit from the building) - an offer should be brought, which does not damage the underground and the building.

6. The continuation of the works should be planned according to the accepted procedures, taking care about order and safety during the execution, and full cooperation with the IAA.

Registered by: Ortal Bayse.

Distribution: participants

Yuval Baruch.

\section{Document 4.27}

[Letterhead]

\section{Udi Armoni Script}

Scripts, Producing [sic, hafakah] Museums and Visitor

Centres

November 23, 2009

To:

Mr. Soli Eliav

Director General, the Western Wall Heritage Foundation

$\mathrm{D}$ [ear] S[ir],

\section{Subject: Trail of accessing in the Ohel Yitzhak Project (Area A)}

Soli Shalom,

Regarding the plan to eliminate the octagonal elevator, which was supposed to take the visitors outside from the visitors' centre; and following your instruction that the disabled should also be able to visit the entire length of the visitors' centre, the planning team prepared an alternative that gives access to the disabled to most of the trail and takes the public outside through Area C.

This substitute includes changes that require the approval of the IAA.

The suggested changes affect all the aspects of the centre (circulation, content, budget, schedules, etc.). Therefore, we wish to receive a principal approval that these changes are acceptable to the IAA, before continuing the work of planning and update the execution plans.

Following are the desired changes:

1. Taking down the elevator at $\mathrm{F}$ axle [referring to some plan] (the elevator next to Area $\mathrm{C}$ ) to the level of the basement and creating a passage under the cement floor 0:0.

2. Taking down the elevator on Axle $\mathrm{C}$ (the one not yet approved) one more level, while dismantling the remains found beneath it.

3. Enlarging the height of the entrance on Axle 3 that connects the lobby to the first hall. 
4. [Adding] a light staircase that will rise to the gate found at the passage from Area C, which forces re-working the top of a wall that is located perpendicular to the Roman wall.

5. Approving the new plan makes redundant the need for creating openings in the Roman wall on the south side of Axle F6.

We note that in the location of the new trail, the visitors will experience the hot complexes of the Mamluk Hammam, an area that was outside the former trail of the project.

Attached are the new plans of access [missing].

Sincerely,

Udi Armoni

[Signature]

Manager of the Production

Copies: Mr. Yosi Lazar, the Office of Shuka [Dorfman], Architect Eitan Kimmel, Rafi Kutschmar, Architect Poni Shachar, Mr. Yuval Baruch.

\section{Document 4.28}

Jerusalem, December 20, 2009

L-17913

Subject: Ohel Yitzhak and the Western Wall Tunnels - Summary of Meeting of $17 / 12 / 09$

Participants: Shuka Dorfman, Jon Seligman, Yuval Baruch, Raanan Kislev, Shachar Poni, Alexander Onn, Ofer Cohen, Rafi Kutschmar, Eitan Kimmel, Ronny Marciano, Eitan Stekel.

[First item the Ha-Gai Street, not translated]

\section{Ohel Yitzhak}

ELEVATOR 1

Eitan Kimmel: The new plan is to descend an additional level.

Shachar Poni: The elevator descends to a place that hasn't yet been excavated.

Yuval Baruch: I don't understand the insistence on taking the public down to the area of the ovens and the hexagonal [room]?

Eitan Kimmel: That's how we solve the problem of the disabled and this route is also related to content that we wanted to present.

Decision [by Dorfman]: The Jerusalem Region is responsible for checking if there is damage to antiquities, after the new planning. If there is damage to antiquities the excavation at the place should be completed. Approving 
the new plan will be made on the level of the [Jerusalem] Region and the Conservation Administration, to be brought to the attention of the Director only if needed.

ELEVATOR 2

Eitan Kimmel: The new plan is to descend an additional level.

Alexander Onn [excavating archaeologist]: There are insignificant water pools beneath the elevator, but we do not know what lies beneath them.

Decisions [by Dorfman]:

1. Alexander Onn will supervise the work. If an important find is discovered, it will be necessary to stop and reconsider the continuation. Approval of the planning will be carried out by the [Jerusalem] District and the Conservation Department, to be brought to the attention of the Director only if needed.

2. The Jerusalem Region is responsible to issue an invitation of work [form], which will be approved by the Western Wall Heritage Foundation.

REMOVAL OF TWO STONES FROM THE ROMAN WALL

Eitan Kimmel: The plan is to dismantle two stones from the upper course in the wall, in order to complete the stairs in a more convenient manner.

Decision: Removing the stones is not approved. One should plan the stairs so that they do not damage the stones.

\section{Document 4.29}

March 14, 2010

[Stamp: IAA, accepted 25.03.2010; stamp and signature of Yuval Baruch]

To

Jon Seligman

Jerusalem Region Archaeologist

[Stamp and signature of Yuval Baruch; 'to the file of the Western Wall Tunnels']

Dear Sir,

Subject: Violation of Agreements for Ohel Yitzhak Excavations

In 2004 we were responsible for the archaeological excavation project carried out as part of the restoration and conservation of the Ohel Yitzhak Synagogue. As early as the first season, it appeared that the Ottoman building was based on impressive remains of a Mamluk bathhouse, which, according to the sources, was called Hammam Darj al-'Ein. 
This public bath, which has the same layout as the adjacent Hammam al'Ein, was built in the Mamluk Period, during the renovation of the Cotton Market Quarter.

In many work meetings we emphasized the importance of preserving vast portions of the remains of the bathhouse, in order to exhibit them to the general public. Our view was supported by various IAA officials, even though it was contrary to the position of the capitalizers ['those who finance,' memamnim]. We also maintained our position in our meetings with the architect of the future museum.

Unfortunately, a few days ago Haim Barbé visited the site, and was shocked to discover the destruction of part of the façade of the building next to the monumental entrance, as well as the destruction of one of the heating pools, in order to install an elevator and access route to the site. We must state that the facts on the ground indicate that the wish of the donors supersedes the wish to preserve past heritage. We decry this situation and regret that we have become partners to activities to which we are opposed.

Sincerely,

[Signatures]

Haim Barbé and Tawfiq Da’adli

\section{Document 4.30}

[Letterhead IAA, Jerusalem Region]

To

April 1, 2009

Hayim Barbé

Tawfiq Da'adli

Dear Sirs,

\section{Subject: Ohel Yitzhak - Your Letter of Thursday, 14/03/2010}

I apologize for the delay [... a few unclear words]. Your letter shows misunderstanding of the regular procedures in which we, as employees of the IAA, take part in our daily work in antiquities sites that are excavated as part of development processes, or even for research aims.

There is no dispute about the importance of the Mamluk bathhouse, at the time of your excavation and also now. This importance, and [that] of the other layers, determines all our policies concerning future development of the site and is stressed in every meeting with the entrepreneurs and architect. Yet we must find ways, even if sometimes through compromises, to make plan for the passage of the public at the site in order to exhibit it to the visitor. This requires logical solution that will enable access to the public and to the disabled as the Law stipulates and the entrepreneurs wish. Discussions were made regarding every dismantling or breaching of passage in various forums 
in the IAA, with the participation of the Director, in order to find agreed solutions with minimal damage to the finds.

In this case too, a discussion was made and it was decided (I note that this decision was accepted against my opinion) to allow breaching a passage that damaged part of the corner of the façade of the bathhouse. In addition it was decided to allow placing an elevator on one of the ovens, but at the same time, eliminating another elevator that was supposed to exit through the opening in the roof of the entrance room of the bathhouse. At the end of the development process, the main elements of the bathhouse will be presented to the public, including the building's façade, the foyer, the octagonal room and the ovens' room, together with additional elements from other periods.

As at each site, the balance between preserving the finds and the other needs is set while pondering and studying. We must be sufficiently flexible to find the best compromises between our wishes as researchers and the legitimate wishes of the entrepreneur. In my opinion, this balance is kept well at Ohel Yitzhak, in order to exhibit the finds of all the periods in the best way.

Copy:

Sincerely, [Signature]

Jon Seligman

Jerusalem Region Archaeologist.

Dr. Gideon Avni

Dr. Yuval Baruch

\section{Document 4.31}

[Copy of email correspondence; fisrt an earlier letter by Barbé, missing at least one page, second an answer from Yuval Baruch. We present the letters in chronological order and not according to their order on paper]. To: Dr. Gideon Avni

From: Harve [Hayim] Barbé

August 19, 2010

Subject: Ohel Yitzhak Project [...]

Subject: Managing Excavations at the Ohel Yitzhak Project (Jerusalem)

Following the work meeting at the Ohel Yitzhak site on 11.07.2010, with the participation of Dr. Gideon Avni, Mr. Jon Seligman, Alexander Onn, Dr. Avi Solomon, and Mr. Hayim Barbé, the following items were agreed:

- Managing the excavations in the project will pass from Mr. Alexander Onn to Mr. Hayim Barbé. 
- Before resuming the excavations, Dr. Avi Solomon will function as an inspector, performing the necessary acts for the conservation work.

Despite the above mentioned agreement, during a visit to the site on 11.09.2010, I discovered that archaeological excavations have been performed in Area C (Khan Fakhr al-Din) without my knowledge.

Therefore, I talked on the phone with Dr. Yuval Baruch and found out that no changes have been made in the [excavation] permit, despite what was agreed in the meeting of 11.07.2010, and as a result I have no authority to manage this project [of excavations].

In addition, I saw that a support arch from the Ottoman Period was dismantled during the 'conservation' work [quotation marks in original], apparently, without documentation. Two support arches of the same style, which are still standing complete in the field, will also be dismantled. The Khan built by Sultan Tanqiz in the start of [... second page missing].

[Second email] From: Yuval Baruch

To: Hayim Barbé

August 19, 2010

Copies: Jon Seligman, Gideon Avni, Uzi Dahari [...]

\section{Dear Sir,}

I am not aware of any agreement about changing the [excavation] permit owners, therefore legally and formally Alexander Onn remains the sole owner of the [excavation] permit at Ohel Yitzhak.

All the works done at Ohel Yitzhak, including dismantling the walls, are done only after an archaeological examination, conservational opinion, consulting with the architect of the plan (c/o Shachar Poni) and with knowledge of the Director.

It was agreed that Avi Solomon will be professionally supervised by Alexander Onn - in excavations as well as in inspection; while managing responsibility for him lies with the Jerusalem Region. Preservation inspection in the Western Wall compound is done by the Conservation Administration, under the responsibility of Johny Ivanowsky.

To remind you, all the details of the archaeological work in the Western Wall [Compound] are coordinated in the Western Wall forum that meets every month under the IAA Director.

Sincerely, Yuval Baruch Jerusalem Region Archaeologist 


\section{Document 4.32}

Jerusalem, February 7, 2011

L-19358

Subject: Work Plan, Western Wall Tunnels 2011 - Summary of Meeting of 7/2/11

Participants: Shuka Dorfman, Raanan Kislev, Yuval Baruch, Shachar Poni, Eran Chemo, Johny Ivanowsky

Following is the summary:

Johny Ivanowsky presented the issue.

Yuval Baruch: The Machkama - the Border Police building, is falling apart, apparently due to works in the tunnels; there is damage and falling of stones there. In the tunnels there are presently four excavations, but if we open another area, it will become a mess and will it difficult to work. Room 22, we should think about the architectural solution parallel to doing the excavation; maybe even dismantle the late vault.

Raanan Kislev: We are adjusted with the Western Wall Heritage foundation on all levels [...] $t$ is important that in the next status meeting Ofer Cohen will present the entire issue of engineering in the [Western Wall] compound.

Shuka Dorfman summarized the discussion:

1. We should make a status meeting for Ohel Yitzhak Area A including presenting the contents of the planned experience.

2. Raanan Kislev is responsible to check the insurance coverage of the IAA at the Western Wall Tunnels.

3. One should be aware of risk concerning buildings located above the tunnels and check that all the engineering material exists.

4. We should not continue work at Ohel Yitzhak Area C until the money arrives from the Western Wall Heritage Foundation. The Director is responsible to talk with Soli Eliav about it.

5. One should receive from the Western Wall Heritage Foundation an estimate about advancing central projects in the compound.

6. One should see that someone will coordinate and concentrate the execution of all the works in Areas A and C. The connection between the areas is crucial. Removing the danger is first priority.

7. The Conservation Administration is responsible to issue a letter about the danger at the Western Wall.

8. One should check the dose between activity and engineering risks, in order that there will be no burden [of work] in the tunnels

9. Ofer Cohen is responsible to presenting the engineering issue in the next status meeting.

10. Eran Chemo is responsible to inspect all the safety files, all the procedures of work, invitations of work, plans of work and word diaries, together 
with the safety officer, and issue a report. The inspection will be made in both archaeology and conservation.

Registered by: Ortal Bayse.

Distribution: The participants.

\section{Document 4.33}

Jerusalem, November 12, 2012

L-21389

Subject: Area A - Planning and Execution-Summary of Meeting of 12/11/12

Participants: Shuka Dorfman, Raanan Kislev, Amit Reem, Eran Chemo, Faina Milstein, Johny Ivanowsky

Following are the items being discussed:

Johny Ivanowsky presented the issue.

Raanan Kislev: According to the Western Wall Heritage Foundation, this is one of the large projects that they want us to do. From our standpoint, the work can begin immediately. Concerning a maintenance plan, Ofer Cohen has a follow-up system that he developed for the Foundation. We agreed that Johny Ivanowsky will examine all the spaces that require preservation and define the acts required for daily maintenance. The maintenance program will be based on the plans and on the monthly examination carried out at the site. Eitan Kimmel's plan and the plan to turn the compound into a museum have been cancelled at this stage.

Shuka Dorfman: Regarding planning, what is the implications of starting the work in Area A?

Eran Chemo: Following the Gantt [chart], the first stage of planning is ready and we are prepared to work in parallel [on] planning and execution. We should complete the engineering planning.

Shuka Dorfman summarised the discussion:

1. It is the responsibility of the office of the [IAA] Director to schedule a meeting on the topic, with the participation of Soli Eliav and Raanan Kislev.

2. It is the responsibility of the Western Wall Heritage Foundation to present a plan and priorities, which will explain the entire operation of all the excavations and projects, with an overall view of the entire Western Wall compound (Area A, Area C, secret tunnel, emergency exit, etc.)

3. It is important to understand the implications of the museum's cancellation. How will they operate Area A and would it be opened to the general public [?].

4. At the time, the plan for a museum of prayer had a steering committee of which Yuval Baruch was a member. One must consider how to continue after the cancellation of the plan. 
5. Regarding exhibition and signs, the IAA must be involved in all the stages.

6. Regarding management of the project and coordination of the work, someone must take responsibility for this. The matter must be properly addressed.

Registered by: Ortal Bayse.

Distribution: Participants, Yuval Baruch

\section{Document 4.34}

Jerusalem, December 25, 2012

L-21551

Subject: Area A - General Concept - Summary of Meeting of 25/12/12

Participants: Shuka Dorfman, Soli Eliav, Chen Canari, Raanan Kislev, Yuval Baruch

Following is the summary:

Soli Eliav: In fact we are ending one channel and start the other channel. The work continues without a break and is divided into conservation, ending the construction and the development, and exhibition. The Conservation Administration has submitted a very high budget estimation and we demanded detailing.

Raanan Kislev: It was agreed that we would do a new estimation. The work should continue for about half a year and we can enter work immediately after the entrepreneur approves the budget estimation.

Chen Canari: It was agreed that the Conservation Administration will submit an updated estimate for the preservation of all the spaces in the A compound in a very high resolution. Since the budgets are so high, it has been agreed to finish the conservation and engineering works, and [postpone] accepting the decisions about turning the compound into a museum to a later date.

Soli Eliav: I need to get to the level of complete finish, and this prior to the display. The work on the display will only begin some eight months from now.

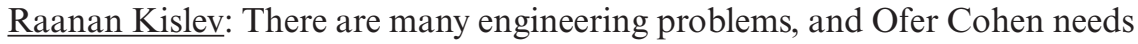
to enter the planning, which has not begun yet, and which will affect the conservation work.

Soli Eliav: You start the conservation work, and meanwhile, we will finish the engineering planning as well as the development planning, including railings. We'll complete the topic of the display in about three weeks. Before conservation enters [the picture], we will have finished the planning by Ofer Cohen, which is marginal relative to what there is at the moment.

Yuval Baruch: The display can change the entire concept. 
Chen Canari: That's not true; the entire infrastructure [-] the systems of airconditioning, light, and communication [-] will be beneath the wooden deck.

Soli Eliav: When we talked about exhibition on the basis of light, we received price offers on a total of ca. 6 million shekels, and finally we reached [meaning chose, or found available only] one product. During your work, we will 'catch up' with the final planning of the stabilization and also the planning of the walkways, which already exists. Afterwards we'll recruit a donor for the exhibition. The visitors' route has not changed. The steering committee for the content made a decision a year ago [about the museum], but it cannot be implemented in terms of budget. Within a month we will be able to reach new understandings.

Yuval Baruch: I participated in the steering committee about four years ago, and I understood that the issues are not related to archaeology and that it [the bathhouse?] will be only the background setting for the archaeology.

Shuka Dorfman: How will the connection between Area A and C be done?

Soli Eliav: It was agreed to check the possibility for an elevator or stairs in the western part. It is impossible to advance the planning of the connection from the exhibition aspect. [?]

Chen Canari: It was agreed that we will create a sized-down elevator shaft in order not to damage the base of the pilasters.

Shuka Dorfman: What will you do with Area C, it should be made functional?

Chen Canari: The stabilization work should finish in less than one year.

Soli Eliav: At this stage it is unclear whence the public will enter, whether from Ohel Yitzhak or from the Western Wall Tunnels. The idea is that this space (C?) should be a continuation of Area A. We put in the entrance to the Western Wall Tunnels a stand for information, in the entrance to the men and women parts. The stand is at the service of the audience. We learned that ca. 100 visitors ask questions [every day?] and possibly Ara C can [be used to] support the work of this stand.

[...]

Raanan Kislev: One should see that all the things join together and that is a general concept and general planning. We are making a more exact budget estimation [...] One should consider room 22, which had not been preserved so far. It is an important room that must be treated. More than two years have already passed since it was exposed.

Chen Canari: I am aware of the significance of this matter, but the consideration was that if we recruit a donor to handle the space we shall do everything together. It is not any immediate danger.

Shuka Dorfman summarized the meeting: 
1. The Western Wall Heritage Foundation is responsible for scheduling another discussion in the steering committee about the exhibition in Area A, with the participation of Yuval Baruch.

2. The Conservation Administration is responsible for delivering a more exact budget estimate for the conservation works in Area A.

3. The Western Wall Heritage Foundation is responsible for recruiting budget for preservation works in room 22.

Registered by: Ashrat Zecharya

Distribution: The participants.

\section{Document 4.35}

[Copy of email correspondence]

\section{[A: Email from Yuval Baruch to Shuka Dorfman, January 31, 2012]}

Shuka Shalom,

1. As part of the engineering stabilisation work in the tunnels between Ohel Yitzhak and the [Western Wall] tunnels (in the area excavated by Hayim Barbé), a limited excavation is needed in order to base one of the support pillars of the vault (the required excavation is to a depth of about one metre and an area of 2 square metres at the most).

2. This year we did not issue a permit for an excavation, and I think that there is no need to issue a new permit for such a limited excavation.

3. I ask your approval for performing the excavation in the framework of inspection.

[B: Email from Yuval Baruch to Chen Canari, February 13, 2012, showing that Dorfman approved the request]

Shalom Chen and good morning,

1. I wanted to notify you that one can complete the building of the support wall under the 'leg' of the Model Hall (at the western side of the hall), as presented to me yesterday. The building of the wall will be done only after completing the documentation (photography and drawing), under the inspection of Ortal Chalaf, Alexander's assistant.

2. Your request to deepen the excavation (until about one metre) in the room before the secret passage is approved. The works in this part will be done under archaeological inspection by Avi Solomon.

Sincerely, Yuval Baruch [...] 


\section{Document 4.36}

[Handwritten note] To the file of Ohel Yitzhak, August 22, 2013

[Blurred writing, but can still be read]

[To] Amit,

Enclosed please find a request of the [Western Wall Heritage] Foundation for settling the passageways between the Western Wall Tunnels and Ohel Yitzhak [Area] C.

I checked the requests with Raanan [Kislev], and it can be done by a condition of inspection (within the existing framework in the [Western Wall] Tunnels) and preliminary documentation. Under the responsibility of Haim Barbé and Avi Solomon.

\section{Urgent!}

[Signature on the left bottom, partially overwritten by a later note:] Yuval [Note added below:] 26/8/2013. A tour was carried out in the field with Chen, and [it] was dealt with under the inspection of Avi Solomon [unclear or partial signature]

\section{Document 4.37}

[Copy of email]

From: Jon Seligman

February 20, 2014

To: Yuval Baruch

Copy: Amit Reem

Subject: Conservational Accompanying - Hayim Barbé

I am sending for signing the request for [excavation] license on the name of Hayim Barbé at Ohel Yitzhak.

In continuation of the conversation I have held today with Amit [Reem], I understand that we speak only about conservational accompanying. Hayim, as you know well, must return to the Office to work on materials, so he will only accompany. The inspection will have to be done by an inspector of the [Jerusalem] Region. Additionally, signing the request here does not express agreement for managing a future excavation at Ohel Yitzhak for connecting the bathhouse [Area A] and the large hall [Area C]. On this we shall talk when it becomes relevant.

Incidentally - the project page [a budget page, with list of items and numbers of approved work days per item] does not have days for working on finds, I understand that you will receive them later if there will be finds.

Sincerely, Jon [Stamp and IAA logo] 


\section{Document 4.38}

[Standard IAA letter of request for inspection, September 1, 2009; a second page is missing. The standard formula states that the land is part of a legally declared antiquities site, where any work requires the IAA approval. The IAA conditions the work on the presence of an IAA inspector, whose instructions about antiquities must be obeyed. The IAA notifies the estimated work days required, etc. In the present case, the form was sent to Chen Canari of the Western Wall Heritage Foundation, and the IAA estimated the duration of the inspection as 44 days; each day would cost the Foundation 1,022 Shekels. Important is not the form itself but two handwritten comments on it. The first is near the top:]

What does all this mean?

Is there a request [for inspection by the entrepreneur]? Is there a commitment [for payment by the entrepreneur]?

[Signed] Ronen

[Second comment underneath:]

Ronen,

To remind you, the work of Al[exander] [Onn] - [the name Alexander crossed over, replaced by:] Avi [Solomon] in the [Western Wall] Tunnels was carried out in the framework of inspection.

[Signed] Yuval [Baruch]

\section{Document 4.39}

[Letterhead:] THE WESTERN WALL HERITAGE FOUNDATION

\section{Summary of Meeting}

[Details in a table, which we render in a simpler form] Project: Ohel Yitzhak A

Subject: Presenting a general planning

[Place of meeting:] the Hasmonean Room [in the Western Wall Tunnels]

Participants: Yuval Baruch, Raanan Kislev, Poni Shachar - IAA; Soli eliav, Chen Canari, Dov Rabinowitz - The Western Wall Heritage Foundation; Amir Berner, Saar Litman, Yael Tevet, Maayan from Eitan Kimmel [Architects], Udi Armoni - the steering team.

Subject: Presentation of the detailed plan for the content of Ohel Yitzhak A to the IAA 
With the end of the detailed planning for the contents of Ohel Yitzhak [Area] $\mathrm{A}$, we have presented the detailed planning including the history to the IAA people.

The content-wise use of the various spaces and the division of the content [sic] was explained in detail.

The central story is based on the exegesis (midrash): 'When the Temple was destroyed the Holy One Blessed be He dispersed the stones all over the world, and in every place where a stone fell - a synagogue was one day built there'

\section{Entrance Displays}

The passage to the central room and the opening [display?] [.] In the central room [,] prior to the display [there], they will tell the history of the site, the structure of the site and the significance of the archaeology discovered in the place.

\section{First Part - The Central Hall}

Jerusalem in its glory with the Temple standing. The Temple is destroyed and splits into dozens of sparks of light that are dispersed throughout the world. Each such spark is a prayer of yearning, a fragment of the great perfection.

\section{Second Part - The Walking Route}

Prayers of yearning - parts of the whole, which in every exile take on a different melody [.] Exhibits that become visible as reliefs of synagogues when viewed from close.

\section{Last Part - The Steps to the Second Temple}

The first return of the harmony, to the sensory experience of perfect unity... This is still not the complete perfection, but the process begins and nothing can stop it. The synagogues turn into beams of light that gradually multiply, creating a gate of light. At the end of the road, the lights that guided us join into a single body [-] 'an imperfect geometry' of the original body.

\section{The Tools}

THE 'ARCHAEOLOGICAL SOUNDTRACK':

A special narrator that will explain the archaeological components of the site.

THE MUSICAL SOUNDTRACK:

The main actor! It leads us to the heights of emotion, yearning, and to the chance of hearing again the music that we yearn for. The great music splits 


\section{Appendix}

into the prayers of yearning of the people in the synagogues dispersed all over the world... and begins to be rebuilt with our return here.

THE PRAYERS OF LONGINGS:

Authentic prayers will be added to the continuous musical soundtrack: the prayers of the Levites in the Temple, the prayers of longings in various versions and prayers of praise and thanksgiving.

THE SCRIPT OF THE NARRATION:

A delicate addition of narration (mostly verses) [of Halacha, Bible, etc.] that strengthens the soundtrack and gives it emphases.

\section{LIGHT:}

Systems of light, supported as needed by systems of projection

The three ideas examined so far for dispersion of the lights were shown, and the project files (Diamond, Rose, Sphere) were demonstrated.

A demonstration of the Hoberman Sphere, chosen for detailed examination, was given (during February, the tender for acquiring and installing it will be issued).

\section{Summary}

1. Once more the circulation of the audience and the division of the areas were approved.

2. An urgent meeting should be set between the rehabilitation [shikum] team and the planners in order to pinpoint the launch points for the systems, so that walls will not [have to] be opened after the end of the rehabilitation work.

3. All the archaeological contents, once final versions are written, will be given to the examination and approval of the IAA.

4. The moment we have final plans of construction, electricity, air-condition, light, etc., they must be delivered to the IAA.

Registered by Udi. 


\section{To Chapter 5: Ha-Liba Building}

\section{Document 5.1}

[Copy of email]

From: Shlomit Weksler-Bdolah

Sent: January 22, 2013

To: Raanan [Kislev, Conservation Department]

Subject: Preservation of Ablaq Style wall Paintings in the Western Wall Plaza

Dear Raanan,

In the Western Wall Plaza, in one of the hewn cells that functioned as shops along the Roman street and later was incorporated in the Islamic buildings, we have found during the excavation (in 2007) lower parts of wall paintings (frescoes) in Ablaq style. These were known so far (in Jerusalem and in our region) in stone façades of the Mamluk period.

It is a highly important and unique find, which has (as yet) no known comparison, whether in Jerusalem or in the World. It was preserved on narrow sections, whose size on the various walls reaches until 1 metre in length [and] ca. $25-40 \mathrm{~cm}$ height from the floor of the room.

At the end of the excavation (January 2009), the instruction of the Conservation Department was to cover the decorated parts of the walls with sand bags, placed on the floor of the room; this we did.

In a visit of the place a few days ago with Dr. Katia Cytryn-Silverman, who is writing an article about the wall paintings to the final excavation report, we discovered that the paintings do not look good. The dampness penetrating through the sandbags enables the growth of green scum, and across one painting there is a deep, fresh scratch - apparently the result of various works undertaken at the place without our knowledge (building a fence, etc.).

In the opinion of Katia, to which I agree, the uniqueness of the paintings makes it necessary to remove them from the place and to treat them. She suggests applying to the Israel Museum and asking them to treat the paintings and, if they wish, exhibit them to the public.

With the recommendation of Gideon [Avni, Head of Excavations and Survey Department] - I apply to you first with a question - what is your opinion?

I have to note that the excavation has no budget to treat the wall paintings at this stage.

Attached to my letter is a preliminary report on the paintings and their importance, prepared by Dr. Katia Cytryn-Silverman.

I would be grateful to your reply-instruction as soon as possible,

Sincerely

Shlomit

Copies sent also to Uzi [Dahari], Gideon Avni, Jon Seligman, Yuval Baruch, Shachar Poni and Katia. I will be glad to have your responses. 


\section{Document 5.2}

[Copy of email]

From: Shlomit Weksler-Bdolah

To: Jon Seligman

Copies: David Amit, Yuval Baruch, Zvi Greenhut

Sent: February 19, 2009

Subject: Wet-Sieving from the Western Wall Plaza Excavations

Dear Jon,

Following the request of Shuka [Dorfman] - here is the data concerning the necessary wet-sieving.

Left in the field [is] a total of ca 85 balot [huge industrial bags; the term probably originates from English 'bale'] with Iron Age material. In addition, 10 balot with Roman period material - which we wanted to sieve in drysieving. It is important to sieve all the Iron Age material, that is, all the 85 balot. If possible, it is worthy to invest in ca. 50 balot, as follows:

Ca. 30 balot from dismantling floors and earth fills immediately above floors - very important.

Ca. 20 balot from fills under floors and [fills] slightly higher above floors very important.

The rest of the Iron Age material - mainly from quarries outside the building important, but less so.

With 8 good workers one can sieve 1 bala [sing. of balot] per day.

Summary: 400 workdays for 50 balot.

It is important to stress that it cannot be done from the [existing] budget of the work on the finds [of the excavation].

Sincerely,

Shlomit.

\section{Document 5.3}

Jerusalem

April 19, 2009

J-40051

Subject: Update on Western Wall Plaza Projects - Summary of Meeting of 19/4/09

Following is the summary:

\section{Ha-Liba Building}

With the participation of: Shlomit Weksler-Bdolah 


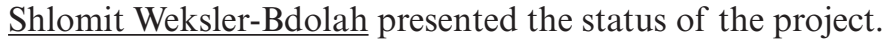

During the Easter vacation [only] a little wet-sieving was made. Left are 90 balot waiting for sieving; it is very important to do 30 of them, since they gradually crumble, and it is a pity. At this stage there is no archaeological activity in the field. For sieving the said 30 balot one needs 250 workdays.

[...] [Discussion of conservation work (an estimate of 291,000 shekels not yet paid by the entrepreneur); and of potential dangers]

Soli Eliav: It is important to prevent [potential] danger. The budget is halted, because the process of [receiving a building] permit is delayed.

Jon Seligman: Concerning sieving, an estimate was sent and now we wait to the approval of the Western Wall Heritage Foundation.

Chen Canari: The final account was submitted and approved, [but] the sieving of the 30 balot is an extension from the approved budget. One should take into account that the budget has ended.

Following are the decisions of the [IAA] Director:

1. The work for removing [potential] danger, according to priorities to be set in a tour, is approved.

2. The plan of the Company for the Development of the Jewish Quarter about the support system will be given to the IAA before execution.

3. Doing the 30 balot is not approved. If necessary the existing balot should be replaced with new ones, in order to prevent crumbling.

\section{Document 5.4}

[Copy of email]

May 25, 2009

To: Jon Seligman

From: Shlomit Weksler-Bdolah

Subject: Wet-Sieving of Important Material left from the Western Wall Plaza Excavations

Dear Jon,

Following our verbal conversation I apply to you concerning wet sieving of very important balot left from the Western Wall Plaza excavations. To remind [you], at the end of the excavation (January 2009) ca. 100 balot were left for sieving at the place of the sieving. Of them, ca. 40 include very important material that comes from dismantling the floors of the Iron Age Building and from fills that immediately covered these floors. Inside these balot there is, in my view, a high chance of finding very important finds, including personal seals. Otherwise, there are also ca. 40-50 balot with Iron Age fills above and on floors of the Iron Age Building, and about 10 balot with Roman [period] fills from the layer that included many finds from the years 70-130 ACE. 
As you know, the balot bags are made of plastic, which is deteriorating very fast. At present they cannot be lifted with a carne and transferred, or entered into new bags. The registration on the bags is also fading fast. Therefore, sieving the soil in these balot is very urgent, for otherwise the balot will crumble, the soil dispersed, and the finds will be lost [meaning will lose their archaeological context].

I therefore apply asking employment of labourers on behalf of the IAA, preferably project 500 workers, who did such job in the past, know it well, and already found important finds. I estimate that with 8 workers we can finish the sieving of the important balot in a month and a half ( 30 workdays). Two months will suffice for sieving everything.

\section{Sincerely, Shlomit Weksler-Bdolah}

\section{Document 5.5}

Jerusalem

March 7, 2010

L-18203

\section{Subject: Update on Projects - Western Wall Plaza - Summary of Meeting of $7 / 3 / 10$}

Participants: Shuka Dorfman, Uzi Dahari, Raanan Kislev, Jon Seligman, Yuval Baruch, Shachar Poni, Eran Chemo, Yoram Saad, Johnny Ivanowsky, Alexander Onn, Amos Goldstein, Soli Eliav, Chen Canari, Rafi Kutschmer, Ofer Cohen, Avner Gilead, Amir Gilead, Eli Elan.

Following is the summary:

\section{Ha-Liba Building}

With the participation of: Shlomit Weksler-Bdolah.

Shlomit Weksler-Bdolah: In fact, we have not dealt so far with the sieving of the Iron Age material, which is located in the Archaeological Park [meaning the physical location of the balot]. This means 100 balot, of them 40 balot from floors must be sieved.

Chen Canari: The Jerusalem Region delivered [to the Western Wall Heritage Foundation] an estimate of 380,000 shekel, which was not approved.

Uzi Dahari: The labourers make it more expensive. He suggests to put the burden on the project of work for unemployed, or use volunteers.

Yuval Baruch: The estimate was based on real expenses. It is a project that would last three months. 
Johnny Ivanowsky: The [conservation] work was stopped by the excavator. The weather has caused no damages.

Shlomit Weksler-Bdolah: I did not ask to stop the work, but [only] to be involved [with it].

Jon Seligman: There is an archaeological problem, and therefore, we have stopped the conservation work.

Shuka Dorfman: What about the connection to the 'Esh Ha-Torah' Yeshiva?

Soli Eliav: The issue will be handled with the usual solution [?], only after the IAA and Gobi Kertesz will reach agreement with the 'Esh Ha-Torah' Yeshiva. Concerning the part that is owned by the Western Wall Heritage Foundation, we plan to lower all the containers of electricity [equipment] that are found at the top. [Cf. Document 5.15]

Shachar Poni: We had a discussion with the 'Esh Ha-Torah' Yeshiva, we clarified to them that, together with the Municipality, we have decided that the full solution is that the courtyard will be at the level of the Western Wall [Plaza]; but this is against their wishes.

Shuka Dorfman: What about the stairs? Is an archaeological excavation necessary in the area of the stairs?

Eli Elan: This is the compound that is planned for the technical systems of Ha-Liba Building.

Shlomit Weksler-Bdolah: There is well-preserved architecture in this area, so it should be excavated, exposed, and preserved.

Soli Eliav: This issue should be coordinated with the Western Wall Plaza Work Committee.

Shuka Dorfman: A meeting was held with Ada Karmi-Melamede to present the [architectural] planning, and it was discovered that the building is not attached to the rock [escarpment of the Jewish Quarter] on its western side.

Raanan Kislev: The issue of keeping clear of the rock was done according to our request, with the aim of giving equal exhibition to all the periods.

Jon Seligman: The problem for the [Jerusalem] City Engineer is the façade in the [suggested] city building plan.

Following are the Director's decisions:

1. The Jerusalem Region is responsible to check with Gabi Barkay [who deals with the sieving of the Temple Mount earth] what the cost of sieving 20 balot, 40 balot and 100 balot is. 
2. The estimates for sieving 20 balot will be send to the approval of the Western Wall Heritage Foundation.

3. One should examine the plans for the area under the stairs.

4. The IAA demands that the [Ha-Liba] Building will be located far from the rock [escarpment], in order to present all the periods [in opposition to the opinion of the City Engineer]. [...]

\section{Ohel Yitzhak Area C [partially translated]}

Raanan Kislev: [...] One should consider that the new cementing material is good, but it creates a situation of using [this] material instead of stone [...] Until now the aim was to build the vault from stone, but in practice this shall not happen, the vault will be built from the new material [...]

Following are the decisions of the Director:

1. The issue of the [new] material is a professional and not a principal (ekronit) question, therefore, the decisions shall be accepted by the entrepreneur and the IAA Director, after holding a principal (ekroni) discussion of the issue $[. .$.$] .$

\section{Document 5.6}

Jerusalem

July 8, 2010

L-18605

Subject: Update on Projects - Western Wall Plaza - Summary of Meeting of 8/7/10

Participants: Shuka Dorfman, Raanan Kislev, Jon Seligman, Shachar Poni, Eran Chemo, Johnny Ivanowsky, Alexander Onn, Amos Goldstein, Hayim Barbé, Soli Eliav, Chen Canari, Rafi Kutschmer, Ofer Cohen, Amir Gilead, Eli Elan. [Shlomit Weksler-Bdolah not listed]

Following is the summary:

\section{Ha-Liba Building}

Shlomit Weksler-Bdolah: The area of the site is dirty and therefore, she suggests taking care of periodical cleaning. Additionally, treatment and removal of vegetation at the site should be taken care of. Large groups of soldiers visit the site; they step outside the [wooden] boards, reaching dangerous places. This should be avoided on account of the danger. The southern shop/cave is still untreated. This is a nice space that deserves investment. One should also treat the sewage canal. The Miqveh [ritual bath] at the upper escarpment was filled with refuse of a contractor and should be cleaned. She still waits for approval 
from the Western Wall Heritage Foundation for sieving the balot. Their condition deteriorates and treating them should be made faster.

Ofer Cohen: Visitor groups are not allowed to step off the wooden boards.

Jon Seligman: We have to complete [excavating] at the section of the excavation, following the engineering instructions. Then the excavator can return to complete the excavation.

Ofer Cohen: We shall have to install anchors in the area of the wooden deck.

Chen Canari: In regard to the sieving of the balot, you handed an estimate on the total sum of 380,000 shekel. This is an unacceptable sum.

Soli Eliav: We can make the sieving only at a reasonable price. He suggests to continue excavating the Cardo toward the south, under the Esh Ha-Torah Yeshiva. I favour continuing to excavate and expose as much as possible. I am ready to invest funds to advance this subject and promise to act according to your instructions.

Jon Seligman: As long as it is refuse and filling, the area can be removed with a tractor; but later, it means making a full archaeological excavation. We should set the borders of the excavation.

Following are the Director's decisions:

1. The Western Wall Heritage Foundation is responsible for treating the vegetation, the maintenance and the cleaning of the site.

2. Shlomit Weksler-Bdolah is responsible for making a tour of the site, together with Soli Eliav, in order to present to him all the items that require treatment and the involvement of the [Western Wall Heritage] Foundation.

3. The Jerusalem District and Ofer Cohen are responsible for examining the implication of excavations [under 'Esh Ha-Torah'?] and covering, which will enable life [as usual] above.

4. The practical, engineering and archaeological implications of continuing to excavate the Cardo under the 'Esh Ha-Torah' Building will be handed [to me] until the end of next week.

[Rest not related to Ha-Liba Building]

\section{Document 5.7}

[Copy of email]

November 23, 2009

From: Shlomit Weksler-Bdolah

To: Jon Seligman

Subject: Conservation Works at the Eastern Cardo - The Western Wall Plaza 
Dear Jon,

Following our verbal conversation, I hereby bring to your attention that I have received two phone calls from Aliza Van-Zaiden in the last two weeks. She notified me that a complete lamp and coins were found during works of the Conservation Department between the Cardo stones - carried out without any archaeological inspection. Since I had been ill at the time of the phone calls, and assuming that this was done with your knowledge - I asked to mark on a plan where they [the finds] have been found and to keep them in the office.

I must emphasize that I was told nothing prior to commencement of the work. -Even though I have explicitly written you in the past to express my opinion that during conservation work of the Cardo stones, the presences of an on-site archaeologist must be ensured. In my opinion the conservation work of the Cardo stones should cease immediately and one should ensure proper archaeological inspection.

I would also have been glad if they applied to me when planning the route [of the wooden boards] for the visitors at the site. Probably there were several details, which should have been examined [archaeologically] before placing the boards.

I shall be grateful if you notify the planning bodies that in every treatment of an antiquities site the accepted procedure is to consult with the excavating archaeologist.

Sincerely,

Shlomit

\section{Document 5.8}

November 25, 2009

To: Jon Seligman, Yuval Baruch, David Amit - Jerusalem Region

Raanan Kislev, Johnny Ivanowsky, Markus Edelkopf - Conservation Department

Gideon Avni, Zvika Greenhut - Excavation and Surveys Department

Uzi Dahari - Deputy Director of IAA

From: Shlomit Weksler-Bdolah

Subject: Sever Damage to Antiquities in Conservation Work of the Eastern Cardo - The Western Wall Plaza

Dear all,

About a year ago, architect Marcus Edelkopf from the Conservation Department completed his plan for conservation of the antiquities in the excavations of the Eastern Cardo at the Western Wall Plaza. Among the recommendations he wrote explicitly about the need to treat the walls (of the Iron Age building) and the stones of the floor (of the eastern Cardo) by 'filling the joins with cementing material on a lime basis'. 
In response, I sent a letter on December 23, 2008, attached here [not given to us], stating explicitly that:

'One must ensure that an excavation - even of a few millimetres between the paving stones of the Cardo and the eastern alleys - will be performed under archaeological supervision.'

Ten months have passed since.

Yesterday, after a phone call from Aliza Van-Zaiden [an employee of the Conservation Department], in which she told me about a complete lamp, two coins, and several more finds discovered between the Cardo stones, I arrived to the excavation area to see what transpires.

Sadly I must inform you that the Conservation Department has performed a robbery excavation at the Eastern Cardo. Employees of the department, without the presence of an archaeologist, took the liberty of digging sealed fills in the joins between the [paving] stones of the Cardo, as well as digging from the side to a depth of $25-35 \mathrm{~cm}$ beneath stones at the site. In addition, supports were built under the Cardo stones at the edge of the Iron Age area and elsewhere. These supports, [reaching] a depth of several metres and a width of 0.25 metres or more, were preceded by a disorderly digging of the sealed fill beneath the [Cardo] paving stones.

Aliza Van-Zaiden, who understood the magnitude of the damage, asked the workers to set the finds aside. Yesterday I received a box with some six sachets, reused tissue boxes and dirty plastic [=disposable] cups similarly used, which served to store the finds for lack of a better means. [This,] since Aliza did not have a graphic diary, or even simple bags for storing finds. Aliza attached a schematic map to the finds - attached here [we did not find it], showing the location of the finds in activity areas 1, 2, 3, [and] 4, along 45 metres of the Cardo.

Unfortunately, these findings are of no importance today, since it is impossible to know precisely if they originated from beneath a paving stone, in a wall above the paving, or from a deep fill under a [paving] stone. One sachet included finds that could have definitely settled the date of the Cardo.

[Missing a second page, with recommendations for the future?].

\section{Document 5.9}

[Copy of two emails]

[Sent by Yuval Baruch]

November 9, 2011

Dear Shlomit,

I understand your anger. Yet you should have applied to Shachar [Poni] and Raanan [Kislev] so that they would explain to you the conservational considerations (since we speak about a pure matter of conservation). 
Shlomit, you should know that Shachar [Poni]'s suggestion for the plan [that was] suggested and approved [by the IAA] was born after a thorough examination of the assemblage of elements at the site, and analyzing how the shape of the plan of the pillars [of Ha-Liba Building] fits the general pan of the Western Wall Plaza prepared by Architect Gobi Kertesz.

This plan materialized only after other former ones were rejected by the IAA. Finally the present plan was accepted (it can also be defined as Shachar's plan).

I think that you have no reason to complain. Many times conservational decisions concerning Ha-Liba Building were accepted after consulting with you. At the end we had to decide, and in my opinion the accepted result is the most reasonable in the current circumstances.

Please accept my offer; and to appease you, apply to Shachar so that he can explain to you the planning and conservational considerations that led to the forming of the plan.

Yuval [Baruch]

From: Shlomit Weksler-Bdolah

Sent: Wednesday, November 9, 2011

To: Yuval Baruch

Subject: Position of the Pillars at the Western Wall Plaza Excavations (HaLiba Building)

Hi Yuval,

Thank you for the long and detailed answer.

I am certain that there were many pressures, and I am certain that the Conservation Department including Shachar and Raanan did their best.

Yet - I find it hard to understand how no one spoke to me regarding the matter, even once, since there was a clear directive from Shuka [Dorfman] on the matter.

Still, I will certainly apply to Shachar. I very much appreciate his professionalism and good will.

It is a pity that they did not contact me about this matter.

\section{Document 5.10}

October 10, 2012

To

Shuka Dorfman

IAA Director

Here

Dear Sir,

Subject: An Assemblage of Items from the Western Wall Plaza 
Data given to the [Jerusalem] Region by a municipality inspector of construction led to confiscation of an assemblage of stone items, which were discovered in a storage place for construction materials in Wadi Qadum by the [IAA] Robbery Unit.

It turned out that the items had been collected by Eitan and Roni ([workers of] Ashmar 2000) [a construction company operating on behalf of the entrepreneurs/ IAA in the Plaza] from the Ha-Liba Building excavations at the Western Wall Plaza, at the request of the [Western Wall Heritage] Foundation, in order to make room for a sukkah [temporary shed erected for the Sukkot holiday].

Copies

Yuval [Baruch]

Amit Reem, Jerusalem District Archaeologist

Shachar Poni, Jerusalem Area [Conservation]

Amir Ganor, Head of Robbery [Prevention] Department

\section{Document 5.11}

[Copy of email]

From: Shlomit Weksler-Bdolah

October 14, 2012

To: Yuval [Baruch]

\section{Subject: Architectural Items from the Western Wall Plaza, at the Rockefeller [Museum]}

Dear Yuval,

Following your request I met Shai from the Robbery Unit this morning and he showed me the architectural items that have arrived there [Rockefeller]. I did not identify them, meaning, they do not belong to the [Ha-Liba] Western Wall Plaza excavation.

After a conversation with you [Baruch], I met in the [Western Wall] Tunnels with [archaeologists] Haim Barbé and Avi Solomon. It turned out that Avi was familiar with the items, and also knew that the [Western Wall Heritage] Foundation wanted to remove them to their storage unit in the Bar-Giora area before Sukkot. However, he asked them to leave them on the bridge, and after that was no longer involved in the matter.

According to Avi [Solomon] the origin of the items is:

Some were positioned along the walls of the 'crucifix room' [one of the spaces in the Western Wall Tunnels] (from earlier excavations), recently removed to the Bridge. Other items were from various excavations of Alexander [Onn].

I asked Avi to be in touch with Shay and identify that indeed, these are all the items.

Sincerely,

Shlomit

[Top: Yuval Baruch forwarded to Shuka Dorfman on October 15, 2012] 


\section{Document 5.12}

[Catalogue of items with several pages and photos. We translated one page]

\begin{tabular}{|c|c|c|c|c|}
\hline No. & Short description & Period & Present location & $\begin{array}{l}\text { Comments [and] } \\
\text { comparisons }\end{array}$ \\
\hline 53 & Capital & $\begin{array}{l}\text { Byzantine- } \\
\text { Islamic }\end{array}$ & $\begin{array}{l}\text { Courtyard } \\
\text { grass } \\
\text { Rockefeller }\end{array}$ & $\begin{array}{l}\text { A. Onn's excavations } \\
\text { large hall }\end{array}$ \\
\hline 54 & Lintel & $\begin{array}{l}\text { Second } \\
\text { Temple }\end{array}$ & $\begin{array}{l}\text { Courtyard } \\
\text { grass } \\
\text { Rockefeller }\end{array}$ & $\begin{array}{l}\text { Ministry of religion } \\
\text { excavations }\end{array}$ \\
\hline 55 & Paving stone & $\begin{array}{l}\text { Second } \\
\text { Temple }\end{array}$ & $\begin{array}{l}\text { Courtyard } \\
\text { grass } \\
\text { Rockefeller }\end{array}$ & $\begin{array}{l}\text { Ministry of religion } \\
\text { excavations }\end{array}$ \\
\hline 56 & Column drum & $\begin{array}{l}\text { Second } \\
\text { Temple }\end{array}$ & $\begin{array}{l}\text { Courtyard } \\
\text { grass } \\
\text { Rockefeller }\end{array}$ & $\begin{array}{l}\text { Ministry of religion } \\
\text { excavations }\end{array}$ \\
\hline 57 & $\begin{array}{l}\text { Pillar of a Church } \\
\text { screen }\end{array}$ & Byzantine & $\begin{array}{l}\text { Courtyard } \\
\text { grass } \\
\text { Rockefeller }\end{array}$ & D. Bahat's excavations \\
\hline 58 & $\begin{array}{l}\text { Decorated plate of } \\
\text { a Church screen }\end{array}$ & Byzantine & $\begin{array}{l}\text { Courtyard } \\
\text { grass } \\
\text { Rockefeller }\end{array}$ & $\begin{array}{l}\text { A. Onn's excavations } \\
\text { large hall }\end{array}$ \\
\hline 59 & Rolling stone & $\begin{array}{l}\text { Second } \\
\text { Temple }\end{array}$ & $\begin{array}{l}\text { Courtyard } \\
\text { grass } \\
\text { Rockefeller }\end{array}$ & D. Bahat's excavations \\
\hline 60 & Corinthian capital & Byzantine & $\begin{array}{l}\text { Courtyard } \\
\text { grass } \\
\text { Rockefeller }\end{array}$ & $\begin{array}{l}\text { A. Onn's excavations } \\
\text { Teshuva's tunnel }\end{array}$ \\
\hline
\end{tabular}

\section{Document 5.13}

Jerusalem, August 30, 2010

L-18784

\section{Subject: Position of the Pillars at Ha-Liba Building - Summary of Meeting of 30/8/10}

Participants: Shuka Dorfman, Raanan Kislev, Yuval Baruch, Shachar Poni, Gay Meiri, Ilan Elan [sic, should be Eli Elan].

Following is the summary:

Eli Elan: It was agreed to submit the city building plan of Ha-Liba Building. A discussion in the committee [for planning and construction] will be held on September 5, 2010. Kobi Kachlon [at the time Deputy of Jerusalem Mayor 
and head of the District Planning and Construction Committee] agreed to the plan. A tour of the site was made in order to examine the super-position of the building on the archaeological level. One cannot submit a city building plan for a 'floating' archaeological site. We shall not agree to an irreversible solution [?]. We speak about a planning at a city building permit stage (preliminary). The engineering system is not yet fully settled; the suggested solution is only tentative. We think it is important to present the solution to the IAA before the discussion in the [planning and building] committee.

Guy Meiri: He presented the planning. Much preparatory work has been done with the cooperation of all the consultants (safety, constructor, accessibility, etc.). We speak about 5.5 metresw from the Cardo level. The part open until the [rock] escarpment will be roofed by glass. The planned pillars, which will enter into the [bed] rock, are $45 \mathrm{~cm}$ in diameter. Forty pillars are planned, located according to the planned building on an area of 1,800 square metres (on the archaeological level). The plan is that the visitor will pass between the pillars on the lower level, and on the upper level the floor will be smooth.

Shachar Poni: What is the implication of the quantity of pillars in terms of enlarging the height of the beam, and can we have less pillars?

Yuval Baruch: There is damage to the archaeology. It is a significant forest of pillars. One should also consider the wooden deck, which is not related to the archaeology. City building plans do not treat pillars, but [construction] volumes.

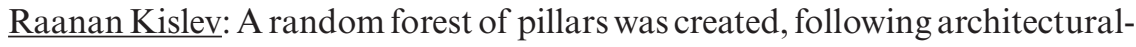
engineering requirements. We understood that there is no damage to a sensitive archaeological spot, but the question is legitimate: will the visitor see a forest of pillars, or archaeology [?]. There is a lot of value to offering alternatives, or order to reach a [proper] decision. One should also present the rest of the systems, which are going to be entered into the archaeological level.

Eli Elan: At this stage of the city building plan we present what is needed. If we will be able to lower the number of pillars, we will.

Shachar Poni: When we submitted our comments [to the Planning Committee], we didn't know what the structure's shape would be. Currently the shape and the openings are different. Theoretically, the question is, can wider pillars be planned, thus lowering the number of pillars [?].

[Missing second page with Dorfman's summary]

[Handwritten comment at the top:]

[To] Jon [Seligman]: See the Director's summary, paragraph 2.

What does it mean?

Yuval [Baruch].

[Answer on top left:] I don't know. You were present during the tour [at the site]!

[Comment below:] Jon, we need to talk, Yuval 12.9.10 


\section{Document 5.14}

Jerusalem, February 3, 2011

L-19330

\section{Subject: Position of the Pillars at Ha-Liba Building - Summary of Meeting of 3/2/11}

Participants: Shuka Dorfman, Uzi Dahari, Raanan Kislev, Yuval Baruch, Shachar Poni, Soli Eliav, Chen Canari, Yossi Gordon, Eli Elan, Dany Rahat, Gai Teomi

Following is the summary:

Gai Teomi presented the positions of the pillars following shared planning with Yossi Gordon. Two alternatives were presented, one with 25 pillars and the other with 52 .

Soli Eliav: It is important that the visitor will be able to see the Cardo from several observation points

Yossi Gordon: Originally, we located the pillars in places approved by the IAA. It is important that the visitor will understand the site. As a matter of fact the position of the pillars is not related to the building itself. We speak about spaces, openings, and large weights of the new building. To every pillar we will build a platform of tin or wood, and on it we shall create the foundation inside the rock, this will demand dismantling the archaeology in that place, probably leading to a minimal damage [to the archaeology].

Dani Rahat: A decision has to be accepted for every pillar, the type of foundation, and the location of the pillars. Also, we should consider the low height of the ceiling in the 25 pillars' alternative.

Eli Elan: The principal question is whether the preferred location for the pillars is at the edges of the Cardo; is it good to maintain the view to the Cardo? Before we decide, we should consider that no discussion [of this issue] was done until now.

Raanan Kislev: Before reaching decision, a long [term] dialog should be established between the IAA and the planning team. In order to achieve the correct solution, we must enlarge the [scope of the] dialogue. He wishes to note that so far no thorough discussion was held on this subject and the alternatives have not been presented to us.

Dani Rahat: In order to keep a dialogue and understand the location of the pillars, one should take measurements in the field.

Yuval Baruch: If we begin with the assumption that there is no solution other than basing the upper stories on a system of pillars, we need to deal with two key questions (not related to the anticipated damage to the archaeology): Is 
it right to sanctify the view towards the Cardo, or other views? I suggest considering a view to the west or the east, since it is more impressive. In the perspective of the Antiquities Authority, the escarpment and the view to the shops must be exposed to the eyes of the visitor. We should also decide about the type of roofing, whether by cement or light roofing.

[Missing a second page with the Dorfman's decisions]

\section{Document 5.15}

Jerusalem, February 28, 2011

L-1944

\section{Subject: Position of the Pillars at Ha-Liba Building - Summary of Meeting of} 28/2/11

Participants: Shuka Dorfman, Raanan Kislev, Yuval Baruch, Shachar Poni, Eran Chemo

Following is the summary:

Raanan Kislev: There are three basic alternatives:

1. That the planned building dictates the engineering [implying acceptance of the plan as is].

2. That the archaeology dictates the location of the pillars [implying rejecting the plan]

3. That we chose an engineering alternative with few pillars, implying replanning a new building.

We promised to come up with a clear position of the IAA as to how to find the right solution. We made an experiment with the pillars in the field following the first alternative, so everybody understood that this is nearly impossible and very problematic. Therefore, they asked us to place the pillars where we think they should be placed according to the archaeological finds. Shachar Poni suggested to spread the pillars so that they will fit the archaeology, about 28 pillars [in total]; but his suggestion does not fit the planning of the current building.

Shacahr Poni presented the three suggested alternatives [mentioned by Kislev above].

Yuval Baruch: When we started the project we defined three central parameters, which are the Cardo, the escarpment, and the First Temple Period building, but Ada Carmi completely ignored it. Shachar Poni and Eran Chemo issued a scheme of the pillars according to the parameters that we defined. The question is, should we accept the plan of Ada Carmi as an accomplished fact and adjust ourselves to it? He suggests setting criteria as to what we want to 
see in the archaeological space if we would tell her to re-plan the building from scratch. Maybe even one can slightly modify the design of the building [and not start from scratch]. I am not certain that we should give the solution, rather we should give the rules. The solution should not come from us, but from Ada Carmi.

Eran Chemo: In the planning of Ada Carmi there is no reference at all to accommodating the archaeology. One should plan the building out of the archaeology, but this implies doing the entire architectural plan from the start.

Shachar Poni: We should let them cope with the suggestion that the location of the pillars is based on the archaeological finds. This [suggestion] is a system that allows us to accept the pillars at the site, and they will have to find the balance. I also consulted with Ofer Cohen to receive an engineering opinion.

Raanan Kislev: We must consider the subject of the foundation for the pillars, since in the suggested plan the damage to archaeology is dramatic. Shachar's suggestion is an alternative with which we can live, after further examinations. Following the meetings with the planners and the Western Wall Heritage Foundation, we have prepared a letter of response. In it [we say that] they should know how to manage with the suggested drawing [of Shachar's plan], and also lower the diameter of the pillars and [modify?] the system of the foundation. If they can manage with our instructions we can move forward. Ofer Cohen said, that in similarity to the way they work at Wilson's Arch, they can make one drill (with a large diameter) going down to the bedrock, and this [enables to] lower the area of the foundation of the pillars.

[Rest and Dorfman's decisions missing]

\section{Document 5.16}

[Letterhead of the IAA, stamp of Yuval Baruch]

May 18, 2011

To

Raanan Kislev

Head of the Conservation Administration

\section{Subject: Position of the Pillars at Ha-Liba Building}

\section{Dear Sir,}

Following is the last suggestion received from the office of Architect Ada Karmi, concerning the location of the pillars of Ha-Liba Building.

This suggestion is the result of several former versions, which were presented to us, fixed by us, sent to the office of Ada Karmi and sent back to us, and so on, and so forth. 
Generally, for the western area of the Ha-Liba Building we reached a final position, with which the office of Ada Karmi 'can live'; we too can adopt it as a reasonable solution in regard to preservation and architecture.

For the eastern area [of the building] there is a dispute concerning the location of pillars inside the area of the open [meaning exposed or excavated] Cardo.

The foundation of the pillars will be done by drilling piles without 'heads of piles', that is, the diameter of the drilling will not exceed the diameter of the pillar (or the diameter of the contour of three pillars, when one places three pillars [joined together]) plus $10 \mathrm{~cm}$.

Following are detailed comments about the location of the pillars:

Pillars 1-5: the pillars should be moved to the east, to the place where the 'original' pillars have stood (the green-coloured broken line). One should see the Cardo, already now, as an artery of movement [of future visitors] from the Tanners' Postern [in the south - a small gate near the Dung Gate] to north of Ha-Liba Building [in the north]. The vertical 'frame' of the street is the rows of pillars, therefore, one cannot agree to a deviation [in their location] of 2.4 metres inward [that means right on the street]

(The counter argument that was presented): ${ }^{1} \mathrm{~A}$. Engineering: it will force the use of a very high beam, which will seriously damage the archaeological space. [Rest missing. The author is an expert working for/in the Conservation Administration (see the addressee). The language is precise and clear.]

\section{Document 5.17}

[Letterhead IAA]

[A draft written by Yuval Baruch and presented to Shuka Dorfman. It was probably written in anticipation of a discussion in the Jerusalem planning and construction committee]

\section{The Western Wall Plaza: Ha-Liba Building: The Process of Work}

[Name of author added in handwriting:] Yuval Baruch

A. Analyzing the Proposal and Conditioning an Excavation: With the presentation of the principal idea of establishing a building by the Western Wall Heritage Foundation, the IAA conditioned the advancement of the plan on making an archaeological excavation. One should note that from this stage until the re-examination of the plan at the end of the excavation, no approval was given in advance for building any type of building until we received the complete archaeological 'picture.'

B. Performing an Archaeological Excavation: An archaeological excavation was performed in the field over several years by the archaeologists Alexander Onn and Shlomit Weksler-Bdolah. During the excavation several discussions were made regarding the progress of the work, while always taking care [toch 
hakpada kvi'ah] to exhibit remains from all the periods exposed at the site. Towards the end of the excavation, additional stress was given to this principle [nitan dagesh nosaf al ekaron zeh].

C. The Preservation Principal - already at the start of the excavation the IAA set guiding criteria for preservation: A. Preserving the escarpment, and the row of hewn shops along it, in the west. B. Preserving the remains of the Cardo. C. Preserving the remains of the First Temple period building.

D. Preparing a Conservation Plan: towards the end of the excavation we prepared a 'conservation plan', presenting the site in its final state, as a site open to the public after the excavation is completed. The plan also set criteria for a more detailed planning of the physical preservation of remains, and defines the first criteria that will allow to integrate a new building above the excavated area.

E. Inspecting the plan and design of the building: Hand in hand with the progress of the archaeological excavation, the architect [Ada Karmi] examined various possible options for the building, in terms both of its mass and its height and number of stories. Special stress was given to the design of the façades of the building. The façades, especially the eastern façade, passed changes time and again until the most fitting design for this place was chosen. This process was done in parallel to exposing the [archaeological] remains.

F. Discussions by the Archaeological Board of the IAA: throughout the process of the work, many discussions were held with the members of the Archaeological Board. In these discussions were reviewed principal questions concerning opening [Second Page] the site to the public, also the principal question whether one can build a modern building above the excavated area was raised time and again.

G. Visit of the Members of the National Academy of Sciences at the Site: at the midst of the work at the site a tour was carried out with the participation of the members of the National Academy of Sciences. In this tour the abovementioned principal questions were discussed.

H. Performing Preservation and Development Work: in parallel to the archaeological excavation and especially with its completion, works of conservation were made at the site. The work included engineering stabilization, treating stones, filling, grouting, installing lattices, etc. In addition, after the completion of the excavations the site was prepared for visits of the public (under guidance) by installing wooden boards and creating a temporary touristic route.

I. General Planning of the Western Wall Plaza: For a deep and real [amitit] analysis of combining the exposed remains within the general framework of the Western Wall Plaza, the [Western wall Heritage] Foundation was required 
to advance a general planning for the area of the Western Wall Plaza. This demand was presented to the entrepreneur both by the IAA, the Jerusalem Municipality, and the Office of Planning within the Ministry of the Interior (the district committee [for planning and construction]). The plan was made by Architect Gobi Kertesz, with the supervision of a professional team from the three bodies mentioned above. The Major [of Jerusalem] stood at the head of the supervision team. The plan [of Kertesz] combined, for the first time, references to various issues out of a wide perspective. The major issues discussed in the plan [are]:

1. Shaping the area of the Plaza: the prayer plaza and the upper plaza.

2. Analyzing movement requirements to and from the Western Wall Plaza, as well as analyzing requirements of movement in the Plaza itself. This plan also referred to, for the first time, the parking lots in the area of the Dung Gate and also to the possibility of arriving to the Western Wall by public transport.

3. Redesign of the array of entrances to the Western wall Plaza.

4. Planning the sides of the Plaza: the northern side (the Strauss Building), the western side along the Cardo Street, and the southern side along the major entry axle. According to the plan, a building established at the western side of the Plaza [meaning Ha-Liba Building] will give an answer to the needs of operating the Western Wall, will combine well in the area as a whole, and will create a clear western side for the Western Wall Plaza. [Third Page]

\section{J. Examining the Possibility of Building a New Building above the Excavated}

Area: this issue was examined out of three different points of view:

1. The level of physical damage to the exposed remains, due to engineering requirements for establishing the building: various options were examined for placing the [foundation] pillars. After repeated rejection of many suggestions, an agreed plan was finally reached concerning the positioning of a minimum number of pillars as possible. In addition the pillars were designed to accompany mostly the layout of the original [Cardo] pillars; in any case they will not be placed in the open area of the Cardo.

2. The combination within the general layout of movement, following the father plan [of Kertesz]: according to the plan, the exposed Cardo will form part of an open artery for movement of the public from the Tanners' Postern (a small gate) in the south to the Western Wall Plaza itself in the north [This section was based on the conclusions reached in a former discussion, see Document 5.16, the paragraph beginning with 'pillars 1-5']

3. The combination with the early topographical system: major changes were made to the plan of the [Ha-Liba] Building, so that a considerable 
distance will be kept on the southern [sic] part of the site between the western façade of the building and the rock escarpment. This distance will allow a clear view of the rock escarpment from the level of the (Cardo) Street.

[Added in handwriting:]

From Yuval Baruch Jerusalem Region Archaeologist Presented to the IAA Director

\section{Document 5.18}

[Letterhead: The Western wall Heritage Foundation; initials for 'with God's willing']

[Handwritten]

March 8, 2010

To: Jon Seligman

Subject: Completion Excavation for an Electricity Room, Ha-Liba Building

Dear Jon,

As we have spoken on the phone, we should complete the excavation on the southern part of Ha-Liba Building in order to put a high voltage electricity container.

The excavation [would be] in an area of $5 \times 6$ metres and to a depth of ca. 2 metres, until the exposure of the Cardo.

We should start soon.

Thank You,

Chen [Canari]

[Comment added below the letterhead:]

Yuval [Baruch],

Please prepare an estimate for completing the excavation at Ha-Liba Building. [Signed] Jon [Seligman]

\section{Document 5.19}

Subject: Excavations of the Western Wall Plaza (A-5835). A Brief Report

June 1, 2010

Dear Jon [and] Yuval,

Following our verbal conversation, here is a brief report on the affairs of the present excavation in the Western Wall Plaza ([permit] A-5835):

At the start of the excavation season we received from the entrepreneur workers for lowering the top of the walls under archaeological inspection by Shua [Kissielevitz]. Later we continued excavating with our workers (we used 148 days of workers and 19 days of an archaeologist). Last week we also received help from a group of American students (volunteers). We exposed 
and documented floors and walls that belong to an Islamic building built above the Cardo. The finds join those that were discovered and studied in the former season of excavation.

[Reporting the depth and area reached, etc.]

Tomorrow (2.6.10) Shua is supposed to inspect the entrepreneur's workers in three assignments: 1 . Cement casting in the corner under the Esh Ha-Torah [Yeshiva] storage [building]. 2. Dismantling the walls of the Islamic building after their documentation. 3. Lowering and making graduation of the side (earth fills) south of the excavation [...].

[Asking for six more days to finish the excavation and that 'the inspection days of Shua will not be taken from the budget of the excavation']

One more comment - this season of excavation started with the aim of exposing the Cardo on the southern side of the [former] excavations, under the storage of the Esh Ha-Torah Yeshiva. Today it was brought to my knowledge that the entrepreneurs plan to lower the electricity room to this area. It is important to note that there are walls in this area, and the Cardo pavement underneath them. The walls we intend to dismantle, but the placing of an electricity room directly on the Cardo stones (even with an insulation layer) seems unreasonable to me. With the end of the excavations one would have to discuss this issue.

Sincerely, Shlomit and Shua

\section{Document 5.20}

July 27, 2010

To: Jon Seligman, Raanan Kislev, Gideon Avni, Yuval Baruch, and Shachar Poni From: Shlomit Weksler-Bdolah

Subject: Location of an Electricity Room at the Excavations of the Western $\underline{\text { Wall Plaza }}$

Dear Jon, Raanan, Gideon, Yuval, and Shachar,

On Thursday (July 22, 2010) a discussion took place in the excavation area regarding the location of the container for electricity at the Western Wall Plaza. The discussion was held $a d$ hoc with the participation of Soli Eliav and Ofer Cohen of the Western Wall Heritage Foundation, and Jon Seligman, Shachar Poni and Shlomit Weksler-Bdolah of the IAA. Ofer Cohen presented the following data in the meeting:

The [electricity] room will include four containers, two placed on two, in a general area of $6 \times 9$ metres. The location of the electricity room asked for by the Western Wall Heritage Foundation is on the paving of the Roman Cardo, at the junction of the Cardo and a street turning southward, towards Berkley Gate (see no. 1 in the attached map [map missing]).

In my view, the placing of any installation on the pavement of the Roman Cardo should be prohibited. The Cardo, as exposed now, must be displayed 
and conserved in its entirety. Not only for touristic purposes, but mainly for research. As someone who studies the Roman city planning, I know that the research is in its preliminary stages and we must not seal it off immediately with containers for electricity. This junction of streets is very important for the study of the Roman municipal system opposite the Temple Mount in the early stages after the year 70 destruction. The monumental size of the Cardo here is extraordinary and unique. To date, this is the only known Roman road in the Old City of Jerusalem, and in the entire region - with a width of 11 metres. Even its date is earlier than we thought, and all this makes the Eastern Cardo a special road. It is important that researchers be given time and the possibility to study.

In light of all this, I proposed to those present at the meeting another possible location for the container, so that the Cardo would not be damaged [...] I suggest placing the containers on a high rock surface located northwest of the line of stores, west of the street [Cardo]. While this is also a painful compromise, the damage caused by it is less than the damage from placing the containers on the Cardo itself.

[Necessary acts if the suggestion is accepted - filling a small area, excavating another, etc.]

Attached is a general plan with marking of the area I have suggested (2) and that asked [by the Western Wall Heritage Foundation] (1).

Sincerely,

Shlomit

Copy: Zvi Greenhut

\section{Document 5.21}

Jerusalem, March 7, 2010

L-18218

\section{Subject: Presenting the Planning of Ha-Liba Building - Summary of Meeting of 4/3/10}

Participants: Shuka Dorfman, Raanan Kislev, Architect Ada CarmiMelamede, Architect Gai Teomi

Following is the summary:

Ada Karmi-Melamede presented the two alternatives proposed for the HaLiba Building.

Ada Karmi-Melamede: We presented the two alternatives to Nir Barakat [Mayor of Jerusalem]. I like more the alternative of the building with two storeys on the eastern façade and three on the western façade, and the western line of the building keeps a certain distance from the rock escarpment. You 
have to decide how to plan the archaeological level - as a closed space with fitting lighting and whatever is needed so that the presence of the antiquities will be exhibited in the best way; or as an open space. You should also reach decision about the two alternatives for the façade of the building, whether closed or not.

Raanan Kislev: The [Western Wall Plaza] work committee discussed the eastern façade of the building, its joint with the rock on the western side and the line [border?] of the lot. We stressed in the discussion the position of the IAA about the importance of maintaining distance from the rock, in order to exhibit properly all the periods; and the relation between the building to the archaeological level so that the finds will not be damaged (from the foundation system).

The two alternatives you have presented (including the alternatives to the eastern façade) seem worthy.

Shuka Dorfman: The plans you presented look nice. How do we move ahead?

Ada Karmi-Melamede: We understood from Soli Eliav that Shlomo Eshkol [Jerusalem Municipal Architect] is checking the possibility of establishing the building based on the existing and approved Municipal Building Plan (the brown area)[;] meaning a significant reduction in the area of the lot. The Antiquities Authority must stand its ground in all that pertains to the agreements and decisions made regarding the Ha-Liba Building to date.

Shuka Dorfman summed up the discussion:

1. It is the responsibility of the office [of the IAA management] to schedule a working meeting with Shlomo Eshkol [Jerusalem Municipal Architect].

2. The topic of how the archaeological layer is going to be handled and the utility of the antiquities (ofen hashmashat ha-atiqot) will be discussed in the future.

$[\ldots]$

Copies: the participants (internal), Jon Seligman, Yuval Baruch, Shacahr Poni.

\section{Document 5.22}

Jerusalem, August 30, 2009

J-41170

Subject: Update on Projects in the Western Wall Plaza - Summary of Meeting of 30/8/09

Participants: Shuka Dorfman, David Gabay (in part), Raanan Kislev, Jon Seligman, Yuval Baruch, Johnny Ivanowsky, Amos Goldstein, Soli Eliav, Chen Canari, Rafi Kutschmer, Ofer Cohen, Dan Bahat, Amir Gilead, Eli Elan. 
Following is the summary:

\section{Ha-Liba Building}

Soli Eliav: The phase of supporting ended. The plans of the bridges and means of access were delivered. Has the topic of the planning moved forward vis-à-vis Ada Karmi-Melamede, since the plans are prior to submission to the District [Planning and Construction] Committee? [I] am aware that Ada Karmi-Melamede worked according to your directives.

Raanan Kislev: There has been no progress vis-à-vis Ada Karmi-Melamede. She cancelled four meetings and was about an hour and a half late to another, and this shortened the time [left] for this meeting. At this stage, we do not delay the approval [of the plan?], according to Dani Rahat, the project's coordinator. In effect, nothing has changed and we didn't receive a new plan beyond the theoretical conceptions presented in the past.

[...] [Discussing conservation]

Jon Seligman: One should treat the growing vegetation, replace the crumbling sacks and also treat stones that crumble.

Rafi Kutschmer: Presently we treat the lining; the question is why the Jerusalem Region stooped the work, which should have lasted only two days.

Yuval Baruch: A completion of the excavation is needed, we passed an estimate, which has not yet been approved.

Chen Canari: We stopped this, since we were worried that the estimate of cost will reach half million shekels.

\section{Following are the decisions of the [IAA] Director:}

1. Raanan Kislev is responsible for submitting a conservation plan based on the assumption of work that we have delivered [to the Western wall Heritage Foundation].

2. An excavation for just one week is approved, at the expense of the IAA.

3. The Western wall Heritage Foundation will supply the workers.

[Rest deals with other sites in the Plaza] 


\section{To Chapter 6: General Planning of the Plaza}

Document 6.1

STATE OF ISRAEL

MINISTRY OF THE INTERIOR - JERUSALEM DISTRICT

ADMINISTRATION

DISTRICT PLANNING OFFICE

February 22, 2009

YT 521-2009

\section{Summary of Meeting Regarding Planning of the Western Wall Plaza of $\underline{15.02 .09}$}

Participated:

Shamay Asif - Director of the Education Administration

Rabbi Rabinowitz, the Western Wall Rabbi

Architect Shlomo Eshkol, Architect Asnat Post - Jerusalem Municipality

Jon Seligman, Shachar Poni - the IAA

Reuven Pinsky - HRLY [The Authority for the Development of Jerusalem]

Architect Eli Elan - Planner

Dalit Zilber - the District Planner

\section{The Course of the Discussion:}

Architect Eli Elan gave a presentation (attached here [not found]).

Jon Seligman - An archaeologist of the IAA - said that excavations are being carried in the Western Wall Plaza and also in the area south of the [City] Wall and the Dung Gate.

Shlomo Eshkol - noted the sensitivity of the planning in the Western Wall Plaza, and that parallel to the advancing of the Strauss Building [plan], a comprehensive planning of the entire Plaza was started. It was clarified that Architect Gobi Kertesz was hired by the Western Wall Heritage Foundation to plan the Plaza under the guidance of Shlomo [Eshkol].

The issue of transportation in the Western Wall Plaza and its surroundings, including the inner system of movement, was raised. An artery for movement that passes from the Jewish Quarter, necessary parking lots near the Western Wall and parking within the Plaza.

The issue of the correct process for advancing the said planning was raised.

\section{Shamay Asif Concluded [the discussion]:}

1. A general plan for the Western Wall Plaza is needed.

2. The statutory tools for advancing the plan will be examined later.

3. One should act for expelling car parking from the plaza. 
4. Excavations - he asks to receive an updated report on the matter of the certainty of excavations of the eastern Cardo and the Herodian Street under the responsibility of Jon Seligman for the next meeting.

5. Shlomo Eshkol is responsible for presenting a general program for the Plaza in the next meeting.

6. The work on a Master Plan for the Old City will be presented - under the responsibility of Reuven Pinski for the next meeting.

7. The projects planned south of the Dung Gate will be presented in one of the following meetings.

Registered by: Dalit Zilber

Copy: to the participants

\section{Document 6.2}

Jerusalem, April 6, 2009

Subject: The Western wall Plaza, Comprehensive Look - Summary of Meeting of $6 / 4 / 09$

Participants: Shuka Dorfman, Uzi Dahari, Raanan Kislev, Jon Seligman, Yuval Baruch, Shachar Poni

Following is the summary:

Shachar Poni presented a detailed status of the Western Wall Plaza area, the Ophel, and the City of David

Raanan Kislev: The question is, what the place of the IAA within this complex process is. We must decide priorities for the entire process. We must reach several operative decisions about movement and parking. We reached a very central junction in the process and we are being drawn in, so we must decide our position. In my view we must be fully involved in the process.

Jon Seligman: Concerning the Mughrabi Ramp, existing plans for [building] permit have not been submitted, only the city building plan is ready. Regarding the IAA's place in the process, it concerns the Old City, and we have a responsibility beyond the archaeology. Therefore, we must be present and manage the heritage of the Old City. We must be at the centre of this process; not to lead it, but to be a central player. There is a problem with the pressures that are placed upon us and therefore, it is important that the process advances quickly. There was harsh public criticism of the pressure system that was activated in order to approve the plan for the Strauss Building. It was determined in the municipal plan of the Mughrabi Bridge that no [building] permit would be approved as long as there is no comprehensive plan; and then it was agreed that any future project would also require a comprehensive plan, 
despite the fact that it has not yet been completed. It is not just the planning issue, but also the public issue. The question is, how to operate the site on the public level. The southern direction [?] requires a separate examination. He is worried from the connection of the Archaeological Park with the Western Wall Plaza [meaning the allocation of a prayer podium to the 'Women of the Wall,' see Chapter 3]; in the past we objected to this. My lack of content is because the discussion is based on the persons who work in the place [?], the powers that act in the Western Wall Plaza against those that act in the Archaeological Park will cause the enlargement of the prayer plaza at the expense of the Archaeological Park. Our duty is to maintain its future as an archaeological garden and not as a prayer plaza.

Yuval Baruch: Indeed, the encroachment of the Western Wall [prayer] Plaza towards the Archaeological Park is a cause for worry. We should keep the present borders of the Plaza. We should avoid religious ceremonies inside the Archaeological Park. A comprehensive plan for the area is like 'tossing dust in the eyes' [Should be zriyat chol, 'sprinkling sand'; but the protocol renders it incorrectly as zrikat chol, 'throwing sand']. We are talking about such an expensive project that it will not materialize. There are a number of projects that are 'happening piecemeal' [mitrachashim baderech] (the Givati parking lot is the prime example of this). We have to set conditions, but should not treat the topic as a comprehensive plan.

Uzi Dahari [Deputy Director for Archaeology]: We must not give up our right to veto according to clause 29 of the Antiquities Law. We need to be involved [in the project/planning] from the basement to the size and shape of the windows. We have to find a mechanism that will allow us to be both partners and overseers. It is important to us to lead the archaeological [and] conservational process from within this building project. We must act through the force of the Antiquities Law and reach decisions accordingly. [I am] in favour of the large project; this is a national project that will necessitate receiving funding from the state. We should work in an orderly fashion, in stages and according to an orderly plan. [...] [The rest is missing]

\section{Document 6.3}

Jerusalem, June 21, 2009

$\mathrm{J}-40033$

Subject: Update on Projects, the Western Wall Plaza - Summary of Meeting of 21/6/09

Participants: Shuka Dorfman, David Gabay, Yuval Baruch, Shachar Poni, Eran Chemo, Jonny Ivanowsky, Amos Goldstein, Alexander Onn, Soli Eliav, Chen Canari, Rafi Kutschmer, Ofer Cohen, Amir Gilead, Eli Elan Following is the summary: 
[Ha-Liba Building - not translated]

\section{The Mughrabi Ramp}

\section{Ofer Cohen presented the engineering planning.}

Soli Eliav: The engineer resigned and the subject was passed to Ofer Cohen. He suggest considering a separation between the tower and the operation of the bridge. In fact, the digging and casting will last about five months. The Municipality does not want to issue the permit [for construction] a long time before the erection of the bridge. According to the demand of the Police, the bridge will be erected in one go.

Yuval Baruch: According to the proposed plan, an extensive archaeological excavation is required. An engineering plan is necessary for making the excavation and he suggests that Ofer Chen will make it. It is a complicated excavation and the question is whether we can create a plan that will not require an archaeological excavation. Supports, grading, and evacuating part of the plaza are called for, and we have to be prepared for that. We have to decide what will be the fate of remains that are discovered. It is already clear now that the excavation will not be complete, and, therefore, I propose that we do not conduct it at all, and find an alternative engineering solution.

Alexander Onn: He sees no problem in that the diameter [of foundation piles?] will be $35 \mathrm{~cm}$.

Shuka Dorfman: Piles for the supporting walls will spare us the excavation, so we should therefore build the wall on piles. We will conduct an orderly archaeological excavation, with the intention of levelling most of the plaza, but decisions will be made according to the remains that are exposed.

Ofer Cohen: We are talking about a gravity wall that goes under the level of the plaza to a depth of a metre and a half. Therefore, there is no sense in constructing piles.

Amos Goldstein: He presented two alternatives for executing the planning. Work will continue for about half a year. The costs of the two alternatives are identical.

Shachar Poni: There are two issues of conservation; one is the 'Mamluk Wall' in the north. The second is the Ottoman parts in the southern zone, whose state of preservation is not good; there is an engineering problem that should be considered.

Eli Elan: Regarding the method of foundation and the location of the pillars, the plan called for overall coordination with Mike Turner. The foundation method is built-in already at the stage of the permit [for building].

Chen Canari: The goal of the project is to expand the women's prayer area and, for that reason, it is impossible not to conduct the excavation. 
[Second page]

\section{Following are the Director's Decisions:}

a) Parallel to the stabilization [perhaps yitzuv; misspelled as yitzur, 'manufacture'] of the [Mughrabi] Bridge we should start the additional works.

b) We should coordinate the alternative with the Police.

c) We should advance the planning by piles.

d) Regardless of the permission [for construction], a detailed plan should be advanced and submitted within three weeks. Then we will issue a bid, order the work, and erect the Bridge.

$[\ldots][$ Rest not translated]

\section{Document 6.4}

Jerusalem, April 27, 2008

J-37195

Subject: Update on Projects in the Western Wall Plaza - Summary of Meeting of $27 / 4 / 08$

Participants: Shuka Dorfman, Uzi Dahari, Jon Seligman, Yuval Baruch, Raanan Kislev, Jonny Ivanowsky, Shachar Poni, Amos Goldstein, Alexander Onn, Hayim Barbé, Soli Eliav, Chen Canari, Rafi Kutschmer, Amir Gilead, Dan Bahat.

Following is the summary:

\section{Ha-Liba Building}

With the participation of: Shlomit Weksler-Bdolah

Shlomit Weksler-Bdolah: The building of the bridge was finished. The excavation will resume on Sunday with 40 workers and will last about three months $[\ldots]$

Jon Seligman: Archaeologically, it is better to enlarge the excavation area eastward [...]

Soli Eliav: The Western Wall Heritage Foundation intends to excavate under the stairs that climb towards the Jewish Quarter [in the northwest corner of the Plaza?]. Also, we intend to expose the continuation of the Cardo to the south, and the aim is not to delay the planning of the Ha-Liba Building. Practically, is it better to extend the excavation to the east or to continue it in the direction of the Cardo [to the south?] The frame of the Ha-Liba Building is fixed and it does not continue east or south. [...] 
Following are the Director's decisions: $[\ldots]$

4. We should coordinate an inner [IAA] discussion concerning making an excavation to the east or to the south, in order to examine the issue on a wider scope. [...]

\section{Document 6.5}

Jerusalem, June 1, 2008

$\mathrm{J}-37487$

Subject: Update on Projects in the Western Wall Plaza - Summary of Meeting of $1 / 6 / 08$

Participants: Shuka Dorfman, Uzi Dahari (in part), Jon Seligman, David Amit, Raanan Kislev, Jonny Ivanowsky, Shachar Poni, Eran Chemo, Amos Goldstein, Alexander Onn, Hayim Barbé (in part), Soli Eliav, Chen Canari, Rafi Kutschmer, Amir Gilead, Dan Bahat, Ofer Cohen, Eli Elan, Gobi Kertesz, Eli Rotberg (in part).

Following is the summary:

\section{Ha-Liba Building}

With the participation of: Shlomit Weksler-Bdolah

[...] [Shlomit Weksler-Bdolah reported that the excavations resumed, but there are problems of too many pillars and lack of storage place for the large balot bags. Her suggested solutions implied, in the view of the Western Wall Heritage Foundation, partial closure of the Plaza.]

Soli Eliav: Last week we received the suggestion of Eli Elan to install wide stairs instead of those that descend [at present] from the Ha-Shalshelet Street to the Western Wall. The plan is to install south of them iron stairs (above the area of the First Temple Period [in the Ha-Liba Building excavations]), and then all the northern past [of the Plaza] will be completely exposed. We will examine [options for] an additional storage area next week. Concerning the timetable, the Western Wall Heritage Foundation will approve making an excavation only between Succot and Easter [roughly, October to April]. The excavation will be done in stages. They will do temporary excavations [?], and above there will be a deck that enables passage of the public, but not of trucks. After the excavations we shall also have to approve passage of trucks for removing the material [earth]. To advance the Ha-Liba Building plan, we were required to advance planning done by Gobi Kertesz, who has studied the needs. After the idea is crystalized, we will focus on detailed planning. We cannot stop the planning [of the various separate projects] until there is a general plan [by Kertesz]. We have reached a point in time, where we can move forward and give the public good access. In Parallel, we will continue to integrate detailed planning. 
Gobi Kertesz presented the comprehensive [kolel] plan of an excavation in the Western Wall Plaza.

Eli Elan: The stairs [in the northwest] will be in a width of six metres. There will be a gap of two metres between them and the existing stairs.

Jon Seligman: Descending deep will require temporary support systems with very high costs. We should consider whether we really need to descend so deep. The paperwork concerning the excavation on the south part will be delivered to the Western Wall Heritage Foundation. We do not speak about an excavation of the stairs, but of all the surrounding buildings (the Hidra area).

$[\ldots]$

Shuka Dorfman: We speak about a large project, which is affected by the start of the excavation of the Ha-Liba Building. [They started years ago; he probably means the on-going excavations in the eastern, covered area - or maybe the new plans to excavate east or south of the Ha-Liba Building.] Now we enter into planning the excavation of the entire Plaza. It was agreed to establish a small team that will lead the thinking and suggest how we will excavate. The intention is to leave the level of life [meaning the active Plaza] at the same height, and create underneath it a complete archaeological level. We speak about a project that will last between five to ten years.

\section{Following are the Director's Decisions:}

$[\ldots]$

3. The Western Wall Heritage Foundation approves in principle the excavation under the southern extent of the Bridge [probably in the eastern, covered area of the Ha-Liba excavations].

4. Decisions about drilling [in this area] will be received later.

5. The Western Wall Heritage Foundation approves the scope of the full conservation work, which includes all the stages.

6. Within a month the planning of the [new wide] stairs will be submitted, after consultation with the participation of: Yosi Gordon, Jon Seligman, and Shlomit Weksler-Bdolah. We should reach a planning that will be convenient to the public and [at the same time also] serve the excavation.

7. After approval [by the Western Wall Heritage Foundation] of the excavation estimate [=budget] in the southern area, the IAA will start the excavation.

8. The Western Wall Heritage Foundation approves the making of the excavation in points 3 and 4 [maybe rectangles 3-4, see map in Chapter 6, Fig. 6.5].

9. The spatial [sic] planning presented by Gobi Kertesz will be examined in detail by the IAA. He suggest checking all the plans of the Municipality. Within two weeks the IAA will submit comments about the presented plan. 


\section{Document 6.6}

Jerusalem, July 6, 2008

$\mathrm{J}-37801$

Subject: Advancing the Strauss Building and the Excavation of the Western Wall Plaza -

\section{Summary of Meeting of 6/7/08}

Participants: Shuka Dorfman, Uzi Dahari (in part), Jon Seligman, Yuval Baruch, Raanan Kislev, Shachar Poni, Alexander Onn, Soli Eliav, Chen Canari, Ofer Cohen, Eli Elan, Dani Rahat.

Following is the summary:

1. The Strauss Building [...] [see Chapter 2, Document 2.1]

2. The Excavation of the Western Wall Plaza

Eli Elan presented the plans

Ofer Cohen: We estimate that the diameter of the pillar will be $70 \mathrm{~cm}$. On the one hand, we will examine the archaeological damage and on the other hand, the demands of safety. The suggested solution will allow movement of vehicles. We will consider more options. We work in the most efficient way. We should take into account the network [ $\mathrm{gril}]$ of the pillars and therefore, the plan of Eli Elan is efficient and [even] necessary.

Uzi Dahari: The question is, do we work in the method of the Ha-Liba Building, or install pillars and only later carry out the excavation. The insertion of micro-piles is very problematic and will lead to severe public criticism. One should discuss this issue and put it to public debate before reaching decisions. In the present case, the exposure of the archaeology is important but is not vital. There is great importance to exhibiting archaeology, but not at all costs. The project is not urgent and one should work slowly.

Chen Canari: Currently, in the excavations of Ha-Liba Building the roof is made of steel and wood [, it is] temporary, in order to stabilize the floor. Such conditions would demand about 70 pillars in each sub-section [of $12 \times 24$ metres?], and it means that practically the excavator will not be able to excavate. The micro-piles' solution is aimed at advancing the timetable.

Soli Eliav: Most of the excavations will take place between Succot and Easter [so from middle of October 2008 to late April 2009]. The question is, do we want to use the present opportunity for excavating the entire Plaza within six years.

Jon Seligman: In the upper part we will discover the foundations of the buildings of the Mughrabi neighbourhood and all the rest is open [=unknown]. We should consider whether there are more engineering solutions for roofing 
the excavation areas. We speak about archaeologic damage on a large scale [nezek archeologi be-hekef gadol]. Presently we miss a lot of data in order to make such a fateful decision. He suggests organizing a public discussion.

Dany Rahat: Today we presented the pillars in a theoretical manner. He suggests making 8 drills, which result in damage by 8 and not 16 pillars.

Yuval Baruch: There must be a complete, single move, in which we integrate the [general] planning of the Western Wall Plaza with the excavation of the Plaza. Therefore, he suggests defining the project of the excavations as a salvage excavation in the frame of planning and restoring the Western Wall Plaza. If we speak about salvage excavations, we can face public criticism. Such a project has not been done in Jerusalem since the excavations of Benyamin Mazar in the Archaeological Park, and therefore, it is a unique opportunity which would be a pity to miss. Although it is a difficult decision, since clearly the drills would destroy antiquities, one has to grasp the opportunity and approve the excavation on a similar scheme to what has been presented to us. In the past we have approved the building of support walls using micro-piles even at the expense of damage to antiquities (for example, at the Mughrabi Bridge and Givati Parking [=Silwan]). The system of work at the Ha-Liba Building and erecting a light steel-beam and wood ceiling does not fit the type of excavation, when we shall dig to a large depth of c. 15-20 metres.

Shachar Poni: The need to coordinate the comprehensive planning of Gobi Kertesz with the planning presented by Eli Elan is noticeable. The location of the pillars is problematic not just in relation to the antiquities, but also on the architectural level.

Raanan Kislev: We should separate technology from planning. At the moment, the discussion is only about making an excavation in one technology or another. The micro-piles will cause archaeological damage. He suggest closing [by construction, i.e., roofing] only part [of the area] and working in three shifts [this means nonstop!]. Both solutions are problematic.

Shuka Dorfman: A detailed planning is required, giving solutions to entry and exit and only later, an engineering planning. Inserting the micro-piles is very problematic.

Alexander Onn: The question is, what is the aim of the project? Is it only an archaeological excavation? Is it exposing the archaeology? Why not excavate in smaller squares?

Soli Eliav: The aim is that through the stones and the exposing of the archaeology we shall teach the next generation, what was here and what will be the future. There are no two sides of the coin here [?]. Everybody is aware of the importance of the archaeology and knows that is must not be destroyed. [Still,] one must receive decisions, sometimes also brave decisions. We should not accept decisions that will lead to an irreversible situation. It is important 
to receive public support. Today we presented the needs, the problems, and a certain direction. Perhaps other solutions exist. He suggest not to work on the basis of the rate of work in the Ha-Liba Building excavations. The project does not have religious needs [en la-proyect tzrachim datiyim] and it is not inevitable that the Orthodox world will oppose its execution.

\section{Shuka Dorfman Summarized the Discussion:}

a) The excavation of Ha-Liba Building is a large excavation, which is done in a very fast rate in relation to other excavations.

b) The [excavation of the Plaza] project is very worthy and the ambitions are legitimate.

c) One should examine the planning [?], which ought to be done correctly. [The word is hitachnut, roughly 'practicability'; but it does not fit the context, so perhaps the intention is 'planning'].

d) Undoubtedly the issue will reach public debate, but only after there is a detailed planning for the entire Western Wall Plaza.

e) One should set professional planning teams with the participation of: engineers, architects, and archaeologists.

f) The planning teams will examine all the relations [between various aspects?], will set orders of priorities, and will present three alternatives within two weeks.

g) In principle, the project is approved, according to conditions that will be decided later.

\section{Document 6.7}

Jerusalem, October 5, 2008

$\mathrm{J}-38563$

\section{Subject: Update on Projects in the Western Wall Plaza - Summary of Meeting of 5/10/08}

Participants: Shuka Dorfman, Uzi Dahari, David Gabay, Jon Seligman, Yuval Baruch, Raanan Kislev, Jonny Ivanowsky, Shachar Poni, Amos Goldstein, Eran Chemo, Soli Eliav, Chen Canari, Rafi Kutschmer, Eli Elan, Amir Gilead, Ofer Cohen.

Following is the summary:

[Not translated: Ha-Liba Building, except the following:]

Soli Eliav: If we divide [read: rate] the finds [and consider what are] the dominant finds, which should point at the site, then undoubtedly the first is the Cardo, which must be stressed. Then [comes] the Iron Age Period and the First Temple [sic, these two are the same period...], and finally, the preservation of 
the Rock escarpment and all that is concerned with it (the shops, etc.). The question is whether within three weeks the work of archaeological dismantling will also be finished [...]

\section{Excavation of the Western Wall Plaza}

Soli Eliav: Alternatives to the engineering aspect have been presented. One alternative was accepted by majority view. An official opinion by the IAA was not yet submitted. The plan is to start the excavation in the zone nearer the divide between the upper [men] Plaza and the lower [women] Plaza. We should use the time [until the excavation?] to perform the drillings. Also we should use the winter time. Concerning the Western Wall Heritage Foundation, the central size [sic, meaning the centre of the Plaza] is less problematic.

Jon Seligman: The Jerusalem Region started to build the excavation system [meaning prepare for it]. Presently we are collecting the material; when this is done, we will bring it to the approval of the Director.

Ofer Cohen: According to the claim of the soil advisor, we can lower the number of pillars and perform a permanent roofing directly, without performing a temporary roofing.

Decision [by Shuka Dorfman]: After Jon Seligman will finish collecting the material, the issue should be summarized in an inner IAA meeting. [Rest not translated]

\section{Document 6.8}

Jerusalem, November 9, 2008

$\mathrm{J}-38782$

\section{Subject: Update on Projects in the Western Wall Plaza - Summary of Meeting of 9/11/08}

Participants: Shuka Dorfman, Uzi Dahari, Jon Seligman, Yuval Baruch, Raanan Kislev, Jonny Ivanowsky, Amos Goldstein, Eran Chemo, Alexander Onn, Hayim Barbé (in part), Soli Eliav, Chen Canari, Rafi Kutschmer, Eli Elan, Avner Gilead, Ofer Cohen (in part)

Following is the summary:

[Not translated: Ha-Liba Building]

Excavation of the Western Wall Plaza

Shuka Dorfman: The IAA can submit an estimate for performing the Western Wall Excavation within a month. 
Chen Canari: We have not yet reached the stage that we can start excavating. We are in the stages of planning and examining. We cannot [yet] give answers to complex issues, especially the issue of canalization. Only in about two months we can submit a plan, which will be brought to the approval of the forum [meaning the IAA status meetings?].

Soli Eliav: The project must be placed within a time table.

Ofer Cohen: Before starting the excavation, one must make preparations and take in account the phase of drilling.

\section{Following are the [IAA] Director's decisions}

1. The Jerusalem Region is responsible for submitting to the Western Wall Heritage Foundation an estimate for the excavation of two rectangles $12 \times 48$ [metres], only for the excavation, excluding supports and additional works.

2. The Western Wall Heritage Foundation is responsible for informing the IAA about the start of the excavation one month in advance.

3. The excavation of the first two squares will be defined as a pilot.

4. The Western Wall Heritage Foundation is responsible for presenting a plan for approval in the next status meeting.

\section{Document 6.9}

Jerusalem, December 14, 2008

$\mathrm{J}-39071$

\section{Subject: Update on Projects in the Western Wall Plaza - Summary of Meeting of 14/12/08}

Participants: Shuka Dorfman, Uzi Dahari, David Gabay, Jon Seligman, Yuval Baruch, Raanan Kislev, Jonny Ivanowsky, Amos Goldstein, Eran Chemo, Shachar Poni, Alexander Onn, Hayim Barbé, Soli Eliav, Chen Canari, Rafi Kutschmer, Eli Elan, Avner Gilead, Ofer Cohen (in part)

Following is the summary:

[Not translated: Ha-Liba Building]

Excavation of the Western Wall Plaza

Eli Elan presented the planning

Chen Canari: We drill, we reach the final phase [mofa], and only then the excavation starts. We should take into account that the pillars' module is unified and orderly, and the Western Wall Plaza remains active throughout the period of the excavation. 
Ofer Cohen: We defined section 3 and 4 as a pilot, [because] to work next to the women's prayer area [ezrat nashim] is not realistic. The removal of material [will be made] from the side through [units] 1 and 2 . We will put beams and re-pave the Plaza. The excavation shall be made from the top down. We will not remove the earth through the centre of the Western Wall Plaza.

Yuval Baruch: Buildings and cellars of the Mughrabi neighbourhood will be exposed. In the past the area was excavated by Benyamin Mazar; earth fill and not refuse appeared already in the first metre [from the surface].

Shuka Dorfman: Can we start working, regarding the engineering planning?

Ofer Cohen: The engineering planning exists on the principal level. It was agreed that we shall make a pilot for a diamond drill to a depth of 15 metres.

Chen Canari: Perhaps we shall make a percussion drill (a regular micro-pile). In the first three metres the excavation will be done by tractor (until we reach an archaeological layer).

Avner Gilead: One should consider that the micro-piles might cause concussions to the work done in the Western wall Tunnels.

Ofer Cohen: There is a reasonable distance which will prevent concussions.

Raanan Kislev: The question is what will happen with the excavations, against the work at the Ha-Liba Building, which is close to the pilot area.

Shuka Dorfman: The question is whether there will be an excavation from east to west, and whether there are open engineering questions?

Ofer Cohen: There is a large weight to the issues of canalization and general planning.

\section{Following are the Director's decisions:}

1. The making of the pilot [in units] 3 and 4 is approved.

2. One should receive decisions prior to the start of building at Ha-Liba Building.

3. The continuation of detailed planning is approved.

4. It is the responsibility of the Director's Office to invite Eli Elan to the meeting of the IAA Board, in order to present the planning [there].

\section{Document 6.10}

Jerusalem, January 18, 2009

\section{Subject: Update on Projects in the Western Wall Plaza - Summary of Meeting of 18/1/09}


Participants: Shuka Dorfman, Uzi Dahari, David Gabay, Raanan Kislev, Jon Seligman, Yuval Baruch, Shacher Poni, Jonny Ivanowsky, Amos Goldstein, Eran Chemo, Alexander Onn, Soli Eliav, Chen Canari, Rafi Kutschmer, Amir Gilead, Ofer Cohen

\section{Following is the summary:}

[Not translated: Ha-Liba Building]

\section{Excavation of the Western Wall Plaza}

Soli Eliav: The Western Wall Heritage Foundation approved the continuation of the planning. He asks to receive an estimate for the pilot, in order to immediately approve it. It was agreed to do the drillings in the first phase. We prefer advancing the engineering part and only later advancing the excavation. $\mathrm{He}$ understands that we cannot set the estimation for the excavation exactly, therefore, we have learned how we can make progress exactly as we did with the Ha-Liba Building. We ask to receive an estimate for the excavation in one square [meaning unit or rectangle] (according to the definition of the pilot).

Yuval Baruch: We cannot make an estimate for the excavation of the pilot, because we do not know what are the depths and finds. At the Ha-Liba Building we worked on the basis of a periodical budget, deducing the sum [of budget] according to the progress. The problem is not the [cost of] the workers, but the issue of treatment of finds [after the excavation]. In the Jerusalem Region we do not know how to calculate [the cost of] the treatment of the finds. He suggests that Uzi Dahari will do the calculation of the days [of work] of the treatment of finds. We have an estimate [of it], but what we have asked [concerning the Ha-Liba excavation?] does not fit the needs, estimate-wise.

Chen Canari: The engineering work is unrelated to the IAA. Our estimates are ready. We speak about sections 3 and 4 . He assumes that the submission of the estimates will take at least two months. It was agreed that Rafi Kutschmer will manage the project on behalf of the Western Wall Heritage Foundation.

Jon Seligman: One should take into account that the rock level is unknown to us and we cannot estimate [how deep] it [is].

Uzi Dahari: We should receive a decision where the rectangles are located, since this has financial consequences.

Shuka Dorfman: One should prepare a [flexible] estimate which will change according to the developments.

\section{Following are the Director's Decisions:}

1. The engineering works are the responsibility of the Western Wall Heritage Foundation. 
2. The Jerusalem Region is responsible for delivering an estimate for [excavation of] two rectangles, which will change according to [future] developments, according to the experience we have gained in the Ha-Liba Building and the depths one assumes to exist in the area, including a time table.

[Rest not translated]

\section{Document 6.11}

[Three pages, undated]

\section{Archaeological excavation of the Western Wall Plaza}

Estimate for performing one unit of excavation in an area of $12 \times 24$ metre Price per square metre, according to 8,000 square metres: 49,100 shekels Price for an excavation of $12 \times 24$ metres: 14,141,000 shekels

The area of the excavation is between 8,000 and 8,400 metres.

\begin{tabular}{|c|c|c|c|c|}
\hline Description of the item & Unit & Quantity & Price per unit & $\begin{array}{l}\text { Price } \\
\text { [shekels] }\end{array}$ \\
\hline $\begin{array}{l}\text { Estimated depth of } \\
\text { excavation } 6.0-12.0 \\
\text { m. Average excavation } \\
\text { depth } 8.0 \mathrm{~m}\end{array}$ & Sm & 67,200 & 1,500 & $100,800,000$ \\
\hline $\begin{array}{l}\text { Cost of the archaeology by } \\
10 \% \text { or } 1 \text { million shekel } \\
\text { per year for ten years }\end{array}$ & Comp & 1 & $10,000,000$ & $10,000,000$ \\
\hline $\begin{array}{l}\text { Temporary construction } \\
\text { for especially high loads, } \\
\text { including adjustments } \\
\text { and changes during } \\
\text { the excavations and } \\
\text { maintenance until } \\
\text { finishing the permanent } \\
\text { roof }\end{array}$ & $\mathrm{Sm}$ & 8,400 & 4,000 & $33,600,000$ \\
\hline $\begin{array}{l}\text { Permanent, reinforced } \\
\text { concrete construction. } \\
\text { Ceiling thickness } 50 \mathrm{~cm} \text {. } \\
\text { Pillar space } 8.0 \times 8.0 \\
\text { m, diameter } 60 \mathrm{~cm} \text {. } \\
\text { Weighted height of } \\
\text { ceiling, including pillars } \\
\text { and heads of piles, } \\
75 \mathrm{~cm}, \text { i.e., } 0.75 \mathrm{cubic} \mathrm{m} / \\
\text { sm. Cost of entire item, } \\
\text { including execution, } \\
\text { moulds, cement and } \\
\text { reinforcement. }\end{array}$ & $\mathrm{Cm}$ & 6,300 & 3,000 & $18,900,000$ \\
\hline
\end{tabular}




\section{Appendix}

\begin{tabular}{|l|l|l|l|l|}
\hline $\begin{array}{c}\text { Description of the item } \\
\text { Unit }\end{array}$ & Quantity & Price per unit & $\begin{array}{l}\text { Price } \\
\text { [shekels] }\end{array}$ \\
\hline $\begin{array}{c}\text { Mini piles' foundations. } \\
\text { 4-5 mini piles per } \\
\text { foundation. Depth 6 m, } \\
\text { diameter 20 cm. The } \\
\text { item includes everything } \\
\text { required for execution } \\
\text { and supply of the } \\
\text { foundations }\end{array}$ & Unit & 600 & 10,000 & $6,000,000$ \\
\hline $\begin{array}{c}\text { Conservation during } \\
\text { the excavation and } \\
\text { conservation of finds for } \\
\text { exhibition }\end{array}$ & Sm & 8,400 & 3,000 & $25,200,000$ \\
\hline $\begin{array}{c}\text { Restoring some } \\
\text { [archaeological] } \\
\text { pavements and building } \\
\text { parts }\end{array}$ & Sm & 8,400 & 1,500 & $12,600,000$ \\
\hline $\begin{array}{c}\text { Upper coating and } \\
\text { arranging the } \\
\text { infrastructure for the } \\
\text { Western Wall Plaza }\end{array}$ & Sm & 8,400 & 1,500 & $12,600,000$ \\
\hline $\begin{array}{l}\text { Ventilation system and } \\
\text { light system }\end{array}$ & Sm & 8,400 & 1,200 & $10,080,000$ \\
\hline $\begin{array}{c}\text { Signs and means of } \\
\text { informing and } \\
\text { demonstration }\end{array}$ & Comp & 1 & $5,000,000$ & $5,000,000$ \\
\hline $\begin{array}{c}\text { Development - boards, } \\
\text { passes, stairs and railings }\end{array}$ & $\mathrm{Sm}$ & 1 & 500 & $5,000,000$ \\
\hline $\begin{array}{c}\text { Arranging access for the } \\
\text { handicapped }\end{array}$ & $\mathrm{Comp}$ & $5,000,000$ & \\
\hline
\end{tabular}

Total 243,980,000

Planning, VIT $40 \% \quad 97,592,000$

Total 341,572,000

BZM $15 \% \quad 51,235,800$

General Total $\quad 392,807,800$

[Page 2: plan; see Chapter 6, Fig 6.5]

[Legend: $\mathrm{BZM}=$ insurance, and various expenses; $\mathrm{cm}=$ centimetre; $\mathrm{Cm}=$ cubic meter; comp = complete $; \mathrm{m}=$ metre; $\mathrm{Sm}=$ square metre $][$ Page 3] Timetable for Executing the Western Wall Plaza Excavations

\begin{tabular}{|l|l|l|}
\hline Unit No. & Start of Work & End of Work \\
\hline 1 & $01 / 11 / 2008$ & $30 / 10 / 2009$ \\
\hline
\end{tabular}




\begin{tabular}{|c|c|c|}
\hline Unit No. & Start of Work & End of Work \\
\hline 2 & $02 / 03 / 2009$ & $30 / 10 / 2009$ \\
\hline 3 & $01 / 11 / 2009$ & $30 / 10 / 2010$ \\
\hline 4 & $02 / 03 / 2010$ & $30 / 10 / 2010$ \\
\hline 5 & $01 / 11 / 2010$ & $30 / 10 / 2011$ \\
\hline 6 & $02 / 03 / 2011$ & $30 / 10 / 2011$ \\
\hline 7 & $01 / 11 / 2011$ & $30 / 10 / 2012$ \\
\hline 8 & $02 / 03 / 2012$ & $30 / 10 / 2012$ \\
\hline 9 & $01 / 11 / 2012$ & $30 / 10 / 2013$ \\
\hline 10 & $02 / 03 / 2013$ & $30 / 10 / 2013$ \\
\hline 11 & $01 / 11 / 2013$ & $30 / 10 / 2014$ \\
\hline 12 & $02 / 03 / 2014$ & $30 / 10 / 2014$ \\
\hline 13 & $01 / 11 / 2014$ & $30 / 10 / 2015$ \\
\hline 14 & $02 / 03 / 2015$ & $30 / 10 / 2015$ \\
\hline 15 & $01 / 11 / 2015$ & $30 / 10 / 2016$ \\
\hline 16 & $02 / 03 / 2016$ & $30 / 10 / 2016$ \\
\hline 17 & $01 / 11 / 2016$ & $30 / 10 / 2017$ \\
\hline 18 & $02 / 03 / 2017$ & $30 / 10 / 2017$ \\
\hline 19 & $01 / 11 / 2017$ & $30 / 10 / 2018$ \\
\hline 20 & $02 / 03 / 2018$ & $30 / 10 / 2018$ \\
\hline 21 & $01 / 11 / 2018$ & $30 / 10 / 2019$ \\
\hline 22 & $02 / 03 / 2019$ & $30 / 10 / 2019$ \\
\hline Wilson's Arch & $01 / 11 / 2019$ & $30 / 10 / 2021$ \\
\hline
\end{tabular}

\section{Document 6.12}

Jerusalem, August 30, 2009

$\mathrm{J}-41170$

Subject: Update on Projects, the Western Wall Plaza - Summary of Meeting of 30/8/09

Participants: Shuka Dorfman, David Gabay (in part), Raanan Kislev, Jon Seligman, Yuval Baruch, Jonny Ivanowsky, Amos Goldstein, Soli Eliav, Chen Canari, Rafi Kutschmer, Ofer Cohen, Dan Bahat, Amir Gilead, Eli Elan

Following is the summary: 
314 Appendix

Ha-Liba Building

[See Chapter 5, Document 5.22]

The Mughrabi Ramp

Ofer Cohen presented the principal engineering planning

Shuka Dorfman: We have reached the final stages. Permit will be received after the Succot [Holiday]. Until then we should settle all the details, so that we can start the work immediately.

\section{Excavation of the Western Wall Plaza}

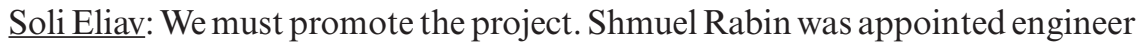
and Eli Elan [an architect who works on different projects for the Foundation] was appointed architect. The goal is to reduce the number of pillars. I request that a representative of the Jerusalem Region [IAA] will participate in the meetings that take place at the Western Wall Heritage Foundation.

Ofer Cohen: We are talking about minor changes to the plan that was presented in the past.

Decision: It is Shmuel Rabin's responsibility to present the plan in the next status meeting.

[...] [Brief item on the Madrassah Al-Ashrafiyah]

\section{Document 6.13}

Jerusalem, October 13, 2009

J-41492

\section{Subject: Continuation, Excavation of the Western Wall Plaza - Summary of} Meeting of 12/10/09

Participants: Shuka Dorfman, Soli Eliav, Raanan Kislev, Jon Seligman, Yuval Baruch, Shachar Poni, Ofer Cohen, Eli Elan, Shemuel Rabin

Following is the summary:

Eli Elan presented the architectural plans.

Shemuel Rabin presented the engineering plans for the continuation of the excavation of the Western Wall Plaza.

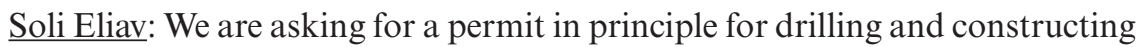
pillars; on the basis of the principle of six pillars for every 12 by 24 [metres] rectangle. 
Shuka Dorfman summarized the discussion:

1. We should undertake a pilot of two rectangles, on the basis of 12 pillars [for the two rectangles], east of the Ha-Liba Building excavation, adjacent to the excavation.

2. Eli Elan is responsible to deliver the presented engineering and architectural plans to the [IAA] Director.

3. After acceptance of the plans, the Director's Office is responsible for setting a date for a discussion about the execution of the pilot, with the participation of Uzi Dahari, Raanan Kislev and Jon Seligman.

\section{Document 6.14}

Jerusalem, December 6, 2009

J-41621

\section{Subject: Update on Projects the Western Wall Plaza - Summary of Meeting of 30/11/09}

Participants: Shuka Dorfman, Uzi Dahari, David Gabay, Raanan Kislev, Jon Seligman, Yuval Baruch, Shachar Poni, Eran Chemo, Jonny Ivanowsky, Alexander Onn, Amos Goldstein, Soli Eliav, Chen Canari, Rafi Kutschmer, Ofer Cohen, Avner Gilead, Eli Elan, Shmuel Rabin, Eitan Kimmel, Udi Armoni

Following is the summary:

[...] [Page 3]

\section{General}

Soli Eliav: The plan is to do in 2010 a pilot in the narrow tunnel [in the Western Wall Tunnels] and a pilot of excavation in the Western Wall Plaza. We have to draw conclusions, which will serve as a basis for a decision by the government towards 2011 about performing the entire project. We speak about a five year budget. He asks to finish the pilot within six months.

Chen Canari: The plan for the narrow tunnel was [already] finished and presented.

Jon Seligman: The new planning by Eitan Kimmel influences the [Ohel Yitzhak] Area $\mathrm{C}$ vaults. The archaeological issue should be considered.

Soli Eliav: You are right, but the engineering [and not the archaeology] is leading here. 


\section{Appendix}

Many works are done by the IAA regarding archaeology and preservation, all over the Western Wall Plaza and its surroundings. We present to the Jewish people delightful treasures. The framework that we have established is the right one and the work teams are working properly. The process of work is proper and should be advanced further. First we should start with the Plaza pilot (before Easter), and then with the narrow tunnel pilot.

$[\ldots]$

\section{Excavation of the Western Wall Plaza}

Soli Eliav: We have presented alternatives, now we wait to the green light from the IAA. Budget was allocated for making the pilot.

Chen Canari: You [IAA] will receive a principal idea, [but] we have not yet reached the actual execution phase.

Raanan Kislev: We asked to receive the plans, in order to hold an inner [IAA] discussion and approve them.

Jon Seligman: One should consider the issue of removal of material [earth].

\section{Following are the Director's Decisions:}

1. The Jerusalem Region and Conservation Administration are responsible for presenting the implications and estimations to the Director, with the aim of getting ready for the start of the pilot after receiving the plans from the planners.

2. The pilot of the Western Wall Plaza will be made in early February 2010, by opening two fields [=units/rectangles] adjacent to Ha-Liba Building.

\section{Document 6.15}

Jerusalem, March 7, 2010

L-18203

\section{Subject: Update on Projects - The Western Wall Plaza - Summary of Meeting of 7/3/10}

Participants: Shuka Dorfman, Uzi Dahari, Raanan Kislev, Jon Seligman, Yuval Baruch, Shachar Poni, Eran Chemo, Yoram Saad, Jonny Ivanowsky, Alexander Onn, Amos Goldstein, Soli Eliav, Chen Canari, Rafi Kutschmer, Ofer Cohen, Avner Gilead, Amir Gilead, Eli Elan

Following is the summary:

[Ha-Liba Building, see Chapter 5, Document 5.5] 
Excavation of the Western Wall Plaza

Soli Eliav: We are waiting for the IAA's comments.

Raanan Kislev: We have not yet received the plans. It is already two months that we are waiting for the file of plans.

Chen Canari: We are talking about two grids, 1 and 2, that were already excavated in the past.

Eli Elan: Shmuel Rabin, the project engineer, and I are discussing the topic. I am not pleased with the solution of the pillars. I am still trying to get a plan that I can be satisfied with, and then I will pass it along to the IAA.

Jon Seligman: When the plan is prepared, we can get ready and begin to work.

Uzi Dahari: We are talking about a mega-project; we have to prepare all the aspects.

Yuval Baruch: This is a smaller project than the Ha-Liba Building.

Decision: A working group should be established and decisions should be made regarding all aspects of the pilot.

[...] [Discussion of lowering the electricity containers from the area of the Esh Ha-Torah Yeshiva; an excavation is needed. Yuval Baruch: 'the area is not your property.' Decision: The Jerusalem Region will prepare an estimate for the excavation.]

\section{Document 6.16}

Jerusalem, April 14, 2010

\section{Subject: Status of Projects - The Western Wall Tunnels -}

\section{Summary of Meeting of 14/4/10}

Participants: Shuka Dorfman, Raanan Kislev, Jon Seligman, Yuval Baruch, Shachar Poni, Jonny Ivanowsky

Following is the summary:

Raanan Kislev: Jonny [Ivanowsky] will present a presentation that analyzes [lit. cuts] all the sub-projects and includes status and order of priorities for execution.

Jonny Ivanowsky presented the projects that are in danger [meaning potential danger]

[Several items not translated]

Shuka Dorfman summarized the discussion: 
1. The status of the main projects:

A. The Western Wall Plaza - we are in principle in agreement [with the Western Wall Heritage Foundation] regarding the plan. We must accept the final plans and approve them. We must prepare an excavation plan, determine who will excavate, and bring it to approval.

B. The Narrow Tunnel - the plan was approved [;] after choosing a contractor we can start working [lit. la-zet la-derech, 'hit the road'].

C. The Model Hall - We should see a plan of the Western Wall Heritage Foundation and examine the implications of the planning, also regarding the overall view [?].

D. Room 9 - The plan was approved [;] after choosing a contractor we can start working.

E. The Ha-Gay Street - we are waiting now for the finish of the work for removal of [potential] danger; [then] we stop the work and enter planning.

F. The Mughrabi Ramp - on wait, we wait for green light for continuation of the works.

G. Ohel Yitzhak A - we should advance the conservation work and check the planned program.

H. Wilson's Arch - we should receive a principal decision, do we approve the project.

2. We should decide the priorities and make work plans for executing the main projects. We should sit with the entrepreneurs [so] that they will settle priorities about entering into the execution of the projects, and enter [to these work palns?] also the archaeological, engineering and architectural works. [We should] prepare a work plan of integration with the implications for the archaeology, preservation, and engineering, and enter everything into a time table.

3. We should define, for projects with potential dangers, the priorities for immediate treatment, and what is the [potential] danger that can be treated within one-two months, so that it will be clear. The Conservation Administration is responsible for receiving a letter from the engineer of the project, which details all the works that must be done at the site, in order that we 'shall be covered' [so, if something happens, nobody can claim that there has been neglect]

4. He sees that there is a large volume of work and this is good, we should maintain the work [volume] over time.

5. The Jerusalem Region is responsible for sending to the Director, within ten days, an engineering report on the [potential] danger at the Mughrabi Ramp, on the bridge and also on the ramp (the status of the excavations).

6. The Director's assistant is responsible to set a separate discussion, as soon as possible, for principal approval of the Wilson Arch plan. 


\section{Document 6.17}

[Partial, missing date; probably written by Yuval Baruch]

\section{Proposal for Managing the Excavation Project of the Western Wall Plaza}

1. Excavation of the entire Western wall Plaza is a huge enterprise that will continue for many years.

2. The main axiom (expect in alternative $\mathrm{C}$ ) should be that the IAA is not interested in performing the excavation alone, therefore, partnership is necessary with a leading academic institute in the field of archaeology.

3. The Institute of Archaeology of the Hebrew University, Jerusalem, is best suited as a partner to the IAA in managing the excavation.

On the basis of experience gathered in recent years in the excavations at the Western wall Plaza and additional areas nearby, the suggested structure for managing the enterprise of the excavations of the Western Wall Plaza is as follows:

[Table - rendered in textual format:]

\section{Alternative A:}

1. Managing and Professional Coordination - under the responsibility of the Head of Excavations and Surveys Department, coordinated with the Jerusalem Region Archaeologist. As in any excavation, the overall responsibility on executing the project rests in the hands of the Region Archaeologist.

2. Managing the Excavation - a team of 3-4 archaeologists with PhDs will be set (two from the IAA and two from the partner institution). They will be responsible for the professional management of the excavation. The team will be chosen so that each member will have a professional field of specialization in one of the periods or features expected to be found in the excavation [,namely]: the Iron Age, the Second Temple days and the Late Roman period, the Medieval period, the array of streets, etc.

A clear division of areas of interests between the team members will be set clearly and in advance, under the responsibility of the Head of Excavations and Surveys Department. The latter will be responsible for the field work and the work on the finds in all stages. The excavation license will be shared by all the directors of the excavation [that is, the team mentioned above].

3. Execution - The excavation will be executed in a modular way according to the needs [rest missing].

\section{Alternative B:}

1. Managing and Professional Coordination - As in alternative A. 
2. Managing the Excavation - The management of the excavation will be shared between an expert $(\mathrm{PhD})$ on behalf of one of the academic institutions [in Israel] and Shlomit Weksler [-Bdolah]; both will be the owners of the license/permit and responsible for the publication.

Shlomit should try to find a person that fits these criteria, with whom she thinks she can cooperate.

3. Execution - Each modular area will be managed by the head of the team [but the team in alternative $\mathrm{B}$ includes two archaeologists with equal status?], with the administration/manager [rest missing].

\section{Alternative C (Without the University):}

1. Managing and Professional Coordination - As in alternative A.

2. Managing the Excavation - One senior scientific manager will be chosen, an employee of the IAA. He will be responsible for all the scientific issues both before the excavation (proper preparations, choosing a fitting professional team, etc.), during the excavation, and at the stage of work on the finds [after the excavation]. At his disposal will be a permanent professional team (subject to him, not to related IAA departments) of a photographer, surveyor, pottery restorer, draftsperson for the finds and a secretary.

There will be a manager of excavation for each major area, at a level of a senior archaeologist from the IAA or the [partner] university, and a team of area supervisors. The [area] manager will be the owner of the license (shared with the chief scientific manager), and he will be responsible for practical management of the excavation [in each area] and for bringing it to publication until [the stage of] submitting the final report. The excavation of each of the major areas will last only about half a year (in the remaining half year the manager of the excavation [area], together with his team, will treat the work on the finds and their preparation for publication.

3. Execution - The excavation in the major areas will be done in parallel or in sequence, [rest missing]

\section{Document 6.18}

[Letter without date/name of author, sent by fax to the IAA on Feb 22, 2010] [Stamp of acceptance 28.2.2010 and a handwritten note:] To pass to Jon [Seligman] for study and reference, [Signature] Shuka Dorfman

\section{Principles of Design for the Meeting of the Work Committee}

\section{At the Western Wall on December 10, 2009}

The utmost principle for the new buildings is making them fit to the buildings around the Plaza, which functioned in the past for dwelling, but have become public through the years: 
1. The design of the buildings with be 'modest' and will fit [the environment], and not function as an attraction of design itself.

2. The scale of the façades on the side of the Western Wall Plaza will have proportions of windows that fit stone construction, for example like the 'Esh Ha-Torah' and the Western Wall Yeshiva [buildings].

3. The new buildings will meet the level of the Plaza/ground in a different way from the existing buildings, thus creating sort of partial of full detachment (floating) from the ground, by this enabling connection to the construction that goes out of the archaeological level. That, following the foundation pillars that rise up from the antiquities, while giving view and access to the antiquities area.

4. The Cardo Street will be exposed in stages along all its length and will serve as a public artery. To its west, the rock escarpment that descends from the Jewish Quarter will be exposed along its entire length, as far as possible.

5. The archaeological levels [this does not mean all the layers, but the 'final' ones in terms of the plans, e.g., the Cardo level at Ha-Liba Building] that have been [already] exposed, and those that will be exposed in the future, near the western edge [of the Plaza], will be public. Access to them will be, in principle, by way of the new buildings.

6. The façades of the buildings that touch the Plaza on the western side will create, as far as possible, a continuous front [lt. façade], unified in its design and as far as possible in its height, thus contributing to stressing the Western Wall.

7. The [horizontal] floor surfaces of the roofs of the new buildings will be adjusted for accepting public groups.

8. The windows of the new buildings will be relatively small, like in traditional stone construction.

[Handwritten at the bottom:] 28.2.2010

To Shuka [Dorfman]

The principles written here were set in the meeting of the Work Committee for the Western Wall Plaza, and they were acceptable to me.

Sincerely,

[Signed] Jon Seligman

\section{Document 6.19}

[Letterhead:] The Jerusalem Development Authority

January 19, 2010

44826

To

[Jerusalem] Mayor Mr. Nir Barakat, Mrs. Naami Zur, Mr. Yair Maayan, Mr. Shlomoh Eshkol

Mr. Moshe Leon, Mr. Yisrael Bargil, Mrs. Anat Zur 
Rabbi Soli Eliav, Rabbi Rabbinowitz

Mrs. Ruth Joseph, Mrs. Dalit Zilber, Mrs. Michal Frank

Mr. Shuka Dorfman, Mr. Shai Wiener, Mr. Yishay Talor, Mr. Gay Alon

Mr. Oded Wiener, Mr. Gilead Bar-Adon, Mr. Avi Royf

Members of the Steering Committee

\section{Subject: Agenda - The Steering Committee for the Western Wall}

Following is the agenda for the committee, which will convene on Thursday, January 22, 2010 at 12:00-13:30

Agenda for the Steering Committee:

1. Approving the former protocol

2. Report- Reuven Pirski:

- Design of the Strauss Building Façades.

- Esh Ha-Torah.

- The Western Wall Lifts.

3. Presenting the plan of the Davidson Centre - invited: the planning team, PAMI [East Jerusalem Development Company].

4. Presenting guidelines for the comprehensive planning - attached [not found].

5. Final approval of the program.

6. Discussion of the entrance compound and the parking lot for licensees [meaning VIP, donors, etc.]

Attached [not found]: Protocol of the Steering Committee of 19.1.2009.

Protocol of the Work committee of 3.1.2010.

Protocol of the Work Committee of 14.1.2010. [...]

Manager of the Development of the Old City Basin

Sincerely, Reuven Pinski [Page 2]

\section{Movement and Transportation:}

There is a severe problem with the progress of the planning and coordination of the transportation issue.

Meeting for planning transportation and movement were not done, due to a technical difficulty of gathering the committees

Agreed: The City Engineer will ascertain the gathering of the committee.

In about a month a meeting of the transportation committee will take place at the Mayor Office.

\section{Planning Presentation:}

Gabriel [Gobi] Kertesz presented the ideas for the planning of the Plaza until and including the part south of the [City] Wall. 
The following issues were raised, among others:

1. The area for absorbing the [arriving] public [will be] south of the [Mughrabi] ramp - in the area of the [City] Wall.

The entrance will be on the lower level of the Umayyad Palace in the Dung Gate area, and from there in two arteries:

Upward to the Plaza (a difference of height of ca. 7 metres), and in parallel toward the Cardo, which will be exposed along its entire length until the Ha-Liba Building.

The aim of the principal planning, of entrance on foot on the archaeological level, including an area for security inspection [ezor biduk] and areas for storage and public functions under the current road, is to treat the considerable friction between [vehicle] transport and pedestrians and to create a meaningful entrance to those who come to the Western wall from the south. This planning will allow proper absorption of the public and enlarge the carrying capacity of the Western Wall area.

2. One should abolish parking places for licensees [VIPs, etc.] in the areas of the Plaza and examine alternative solutions [for parking].

3. One should consider accommodating toilets for the public at the entrance to the lift in the [Jewish] Quarter.

The Western Wall Rabbi clarified that the [new] buildings are vital for the public and there is no option except advancing the plans of building, while giving a possibility for archaeologists to carry out excavations in the future [sic].

Agreed: one should present a principal plan that includes [deciding] stages of execution of the different projects, in a way that will minimize the damage to the [regular] use of the Plaza during the works.

Agreed: [Car] parking should be removed from the Western Wall Plaza.

One should perform a transportation and engineering analysis of the subject of parking outside the Dung Gate.

One should coordinate with PAMI [East Jerusalem Development Company] a future abolishment of the office building [near the Davidson Centre]. (The Jerusalem Development Authority is responsible for receiving a legal opinion about the ways to include this issue in the Davidson Centre [city building] plan [as yet unapproved at the time]).

The plan of the Davidson Centre will be presented in the next meeting until then it will not be deposited.

\section{Document 6.20}

[Copy of email from Shachar Poni to Shuka Dorfman, forwarded by Yuval Baruch]

From: Yuval Baruch

To: Shuka Dorfman 


\section{Appendix}

Sent: Wednesday, October 20, 2010

Subject: Discussion headed by the advisor of the Minister of Education concerning the Western Wall Plan.

Dear Shuka,

The meeting was held in anticipation of the discussion that should take place next week in the District Committee (yesterday I have sent you a memo about it).

Participated: Shai Rinsky (Advisor of the Minister of Education), Soli Eliav, Dani Bareli (UNESCO), Reuven Pinski (Prime Minister's Office) Architect Gobi Kertesz and Architect Eli Elan (The Western wall Heritage Foundation), and Architect Shachar Poni (IAA).

Following are the major decisions accepted by Rinsky:

1. A preparatory meeting shall be convened with the participation of Mike turner, Gobi Kertesz, Eli Elan, and a representative of the IAA (only if we wish to participate), in order to formulate a unified position. The position will be based on the principles of UNESCO. It will be presented to the Minister of Education as 'a tool' in anticipation of the discussion next week in the District Committee.

2. Rinsky requested that the IAA urgently provides a document detailing the IAA's position on the plan.

Shachar [Poni]

\section{Document 6.21}

[Probably the document prepared for Rinsky, cf. 6.11; partial]

October 25, 2010

To

Shai Rinsky

Advisor to the Minister of Education

Dear Sir,

\section{Subject: The Comprehensive Plan for the Western Wall Plaza: the IAA Position}

For hundreds of years, the Western Wall and the Plaza in front of it are one of the concrete symbols [sic] of the Jewish people.

In the area that lies in the shadow of the Temple Mount there are important sites, where remains of various periods have been exposed, since the First Temple period until our days. Some [of the] are exposed for all to see, others are still buried underground. These remains stress the historical variety of 
Jerusalem in general and of the Western Wall compound in particular, as well as the cultural heritage values imbedded within it.

Accordingly, Architect Gobi Kertesz prepared a comprehensive plan that concerns the assemblage of sites that are attached to the Western Wall Plaza, in addition to the area of the [prayer in the] Plaza: the system of the 'Western Wall Tunnels' to the north, and the 'Archaeological Park' to the south.

The IAA demands that there will be a clear reference in Architect Kertesz' plan to the borders of the plan and to the sites that are attached to them.

According to the position of the IAA, all the development and building acts done now in the Western Wall Plaza and in the sites attached to it, and those which will be done in the future, will be done as sustainable [bar kayma] development acts. Also, they will refer to the historical and cultural variety of the place.

\section{Document 6.22}

[Almost certainly another page of Document 6.21] [Letterhead:] IAA 20 years [...]

The IAA expressed its professional opinion at each stage of the making of the comprehensive plan. This opinion was backed up by a thorough documentation file [mismach teud mekif] (attached as an appendix to the documents of the plan). This document details the cultural and archaeological importance of the sites in the area and the components of the cultural heritage in it [=area].

This file, which has been prepared on the basis of the Antiquities Law (1978) forms an integral part of the plan and one should act on its basis.

The comprehensive plan for the Western wall Plaza will enable a rational discussion of the development and building plans that are now being advanced in the Western Wall compound, such as the 'Mughrabi Bridge', the 'Strauss Building', the building of the 'Western Wall Heritage Foundation' [Ha-Liba], the 'Esh Ha-Torah' Yeshiva, and more. A special stress was given to detailed analysis of the movement systems, both by vehicles and on foot, to and from the area.

The IAA sees the comprehensive plan under preparation as a necessary means. Thanks to the plan we can keep the balance between the wish to preserve the archaeological remains and display them to the public, and the necessity of development in the Holy Basin.

We stress that this file does not replaces the stipulations of the Antiquities Law.

Additionally, the said file refers to the comprehensive plan as presented to the IAA by Architect Gobi Kertesz. However, we clarify that each plan for building, preservation, etc., which will be advanced in the frame of the borders of the [Kertesz] plan, necessitates an approval in advance from the IAA according to the conditions of the Antiquities Law.

Sincerely,

Dr. Yuval Baruch

Deputy of the Jerusalem District Archaeologist 


\section{Document 6.23}

[Two pages without author/date. A fax stamp clarifies a date before October 22, 2010. This is not the 'thorough documentation file' (see Document 5.22), but a sort of introduction to it.]

\section{The Western Wall Compound-Principles}

The instructions for applying the [International UNESCO] Convention Concerning the Protection of the World Cultural [and Natural] Heritage (1972) define the ethical rules of conservation, according to which one should act in places that embody international cultural values.

Accordingly, every act of development, conservation and building will be done while stressing the historical, religious, and cultural variety of communities and cultures represented at the site.

In addition, every country that is partner to the convention recognizes its duty to ensure identification, protection, preservation and the legacy of the cultural and natural heritage found in its area.

The Old [City of] Jerusalem including its walls and therefore, the extent of the Western Wall Plaza with its religious and national value to world Jewry is included within the declaration of UNESCO (the site was suggested for declaration by the Kingdom of Jordan in 1981) [.] [It is] based on 3 of the 10 criteria that define the universal value of the site:

Criterion II: expression of joined human values in time or in a cultural area of the world, which is related to developments in architecture or technology, monumental works of art, city planning, or landscape design.

Criterion III: expression of a unique or exceptional testimony of cultural tradition, or a living or extinct culture.

Criterion VI: a site where there is direct or tangible relation to events or traditions, ideas or beliefs, artistic and literary creations with an exceptional, universal significance.

Accordingly, the planning, conservation, development and building acts included in the comprehensive plan for the Western wall Compound are done with identification and conservation of the characteristics mentioned in the lists of criteria, and [lit. 'when'] they are found in the background to the most sacred site for Judaism.

As a basis for defining the conservational value of the elements included in the site, a thorough documentation file is being completed [holech ve-mushlam], which analyzes the components of the tangible and intangible [gashmit ve-al-gashmit] heritage found in the area of the site (IAA, Conservation Administration, 2010), and is attached to this document.

Making the comprehensive plan for the Western Wall Compound is based, beside the identification of the site, on the definitions and instructions of the Convention for World Heritage - and the instructions of ICOMOS (the international body that advises to the Centre for World Heritage of UNESCO) 
concerning exhibition and demonstration of World Heritage sites (document of the general assembly of ICOMOS, Quebec 2008).

[At bottom: line-drawing, view of the Western Wall and the Holy Mount]

[Second page]

The Principles of the Comprehensive Plan:

2.01. The introductory [or preliminary] documentation file is based on a review of the history of the compound and its development from the Ancient Periods until the 19th century, and identifies the built heritage, its significance and its preservation. Thus, [it gives tools for the making of a plan that enables identification and demonstration of every one of the archaeological layers, which form the skeleton for the [Jerusalem] Region's development and preservation plan.

2.02. The general outlines [of the plan] preserve the city plan from the Second Temple period (including a number of locations where finds from the First Temple period were discovered); and are based on the Roman street plan - the period of Aelia Capitolina (135-326 CE).

The entry for the public from the southern introductory areas (The Dung Gate and the Tanners' Gate) is founded on north-south arteries - mainly on the Easter Cardo artery, which has been partially exposed (levels of +724 [metres above sea level] in the south; +726 [metres] in the north-western area of the Plaza]).

The continuation of the exposure of the Cardo and its relation to the rock escarpment on the west will form the lower entrance lobby, which enables access to the archaeological level that is located along the Cardo artery and the building adjusted to it.

The areas for the entry for the public from the south will be established in the complex of the Umayyad palaces nos. 3 and $4-$ [these are] governmental buildings at the foot of the Holy Mount. The conservation of the archaeological finds, and integration of these finds in the route of the visitors to the Plaza and to the Archaeological compound, will be done while stressing the significance of the cultural heritage of the site, by preserving remains that represent the various layers, which lead to the Western Wall Plaza, the site that more than any other site symbolizes the holiness of the place.

2.03. Integrating the finds at the foundation of the Western Wall Heritage Foundation [Ha-Liba] Building, preserving the rock escarpment in the west.

2.04. Preserving the northern side of the Plaza - the Machkameh Building and the Strauss Building.

[Photo of the Western Wall before the creation of the Plaza; a restoration of the Umayyad buildings; and three Old City maps: Second Temple, Roman, and Umayyad periods.] 


\section{Document 6.24}

[A page from a presentation by Shachar Poni]

\section{Defining the Vision}

- Handling the visitor entrance to the Western Wall Plaza from an overall perspective.

- Creating a public space that will allow visitors to experience a world heritage site in a proper and acceptable way, through exposure, understanding, and display of the different archaeological layers.

- Arranging visitor access in a convenient, accessible, clear, and experiential way, and laying the groundwork for an increase in visitors.

- Preserving the spirit of the site, and creating an appropriate planning frame for it.

\section{Document 6.25}

Jerusalem, June 17, 2010

L-18510

\section{Subject: Analysis of the Movement of the Public in the Hall - Summary of Meeting of 14/4/10}

[The 'Hall' is perhaps the Model Hall in the Western Wall Tunnels]

Participants: Shuka Dorfman, Raanan Kislev, Jon Seligman, Yuval Baruch, Shachar Poni

\section{Following is the summary:}

Shachar Poni Presented the issue. [He showed a presentation - Document 5.15 is most likely one page from it.]

Raanan Kislev: There are numerous questions. First, one should examine the borders of our intervention. It is important to create separation and order between the daily level (the level of those who pray and of the operation), and the level of the archaeological-touristic experience. The excavation at the Wilson's Arch was supposed to solve the [problem of] connecting them [the two levels]. Currently, it is impossible to descend into the lower level. The suggested bypass is correct and efficient, but first we have to consider its application from all [the possible] aspects. It is important to check all the [possible] alternatives in order to initiate and not just respond.

Jon Seligman: The ascent toward the Western Wall, according to the plan of Gobi Kertesz, is missing. As a matter of fact he presented the current situation. One should consider the issue of arrival [to the Plaza?] and the connection to the compound, which has been raised in the discussions of the Work Committee of the City Mayor, also at the level of transportation. 
Yuval Baruch: If we create a new plan, we should examine the both the problems and the issue of arriving to the compound. Concerning intensification of the archaeological experience, this is where we should intervene and not in other aspects. We should reach a conclusion about what archaeological experience we wish to deliver to the visitor. We have to refrain from developing [individual] sites, separated [from each other]. For that reason we have to create a logical connection between the sites in terms of content. We should consider the plan [of Kertesz], which was created in a natural way. The separation between the Archaeological Park complex, the City of David, and the Western Wall Tunnels is no less important than regulating visitor movement. He suggests showing the initiative to the team that handles the masterplan for transportation.

\section{Shuka Dorfman summarized the discussion:}

1. The plan of comprehensive view by Gobi Kertesz should be considered.

2. The question is, whether we would like to continue to lead and influence, or [only?] to say 'what not' [to do]. We are the most dominant influential factor. As of today, nothing happens without our involvement.

3. Archaeologically we understand much better today what was exposed in the area of the Old City, thanks to the recent excavations.

4. What has been presented is a random collection of many different small projects. On the national level things should not be conducted in this way, since it [the Plaza/Old City] must be planned from a comprehensive perspective.

5. It is important that we say in advance 'what' needs to be and 'how' it should be.

6. He suggests initiating a cooperation with the Jerusalem Municipality, with the aim of creating several layers; a layer of enterprises, a layer of archaeological excavations, a touristic layer, etc., on the basis of the presentation made by Shachar Poni. It is important that we shall present a planning, even if it materializes only partially.

7. One should present the project to the [Jerusalem] Mayor and even demand that the Jerusalem Municipality advances and finances it.

8. The routes [for visitors] shown in the presentation [of Poni] are in principle only, from the routes that have been presented one should develop touristic routes.

9. It is important to integrate also the [opinions of the local/Jerusalem?] inhabitants in the comprehensive planning and in the connections to the Western Wall compound.

10. The presentation [of Poni] will be shown in the [next] meeting of updates on projects in the Western Wall Plaza.

Registered by: Ashrat Zecharya

Distribution: to the participants. 


\section{Document 6.26}

[Fax stamp October 22, 2010. On the left, The Kertesz plan or some version of it, with construction projects marked by numbers. On the right, the following table:]

\begin{tabular}{|c|c|c|}
\hline Project & Description & Area \\
\hline 1 & 'Strauss Building' & $\begin{array}{l}1716 \mathrm{sm} \text { (new areas } 944 \mathrm{sm} \text {, } \\
\text { existing areas } 772 \mathrm{sm} \text { ) }\end{array}$ \\
\hline 2 & 'Ha-Liba Building' & $2,500 \mathrm{sm}$ \\
\hline 3 & $\begin{array}{l}\text { Underground parking for vehicles of } \\
\text { licensees outside the Western Wall area, } \\
\text { Plaza and restoration of buildings }\end{array}$ & $1,200 \mathrm{sm}$ \\
\hline 4 & Sh.Z.P. ‘Esah ha-Torah’ & Ca. $480 \mathrm{sm}$ \\
\hline 5 & $\begin{array}{l}\text { The plan of PAMI [Development of East } \\
\text { Jerusalem Co.]: enlarging the Davidson } \\
\text { Centre; preparing existing structures }\end{array}$ & $\begin{array}{l}32.5 \text { dunams }[32,500 \mathrm{sm} ; \\
\text { this is the general area of } \\
\text { the garden, not an area of } \\
\text { construction] }\end{array}$ \\
\hline 6 & $\begin{array}{l}\text { Compound for reception of the public } \\
\text { on two levels: [security] checking, } \\
\text { information [booth], toilets }\end{array}$ & $3,460 \mathrm{sm}$ \\
\hline 7 & $\begin{array}{l}\text { The Jewish Quarters lift [lifts to enable } \\
\text { movement to/from the Plaza to the Jewish } \\
\text { Quarter; at present descent/ascent is done } \\
\text { by foot and there are quite many stairs.] }\end{array}$ & $360 \mathrm{sm}$ \\
\hline 8 & Energy centre, toilets & $200 \mathrm{sm}$ \\
\hline 9 & $\begin{array}{l}\text { Rehabilitation of the [Jewish] Quarter } \\
\text { slopes. }\end{array}$ & \\
\hline 10 & The Kedem centre [of El-Ad in Silwan] & $\begin{array}{l}\text { [Officially } 5480 \mathrm{sm} \text {, in fact } \\
\text { ca. } 16,000 \mathrm{sm} \text {, so naturally } \\
\text { the IAA does not disclose } \\
\text { the numbers...] }\end{array}$ \\
\hline & $\begin{array}{l}\text { [Total area, new construction, without } \\
\text { no. 10] }\end{array}$ & [At least 9,144] \\
\hline
\end{tabular}

[Notes: $\mathrm{sm}=$ square metres, written in origin with Hebrew initials. For the area of the Kedem centre in Silwan see Nir Hasson, Haaretz, April 3, 2014; and Guy Nerdi, Globs, March 27, 2017.]

\section{Note}

1 Here the author used square brackets; we changed to round ones to prevent confusion with our comments. 


\section{Bibliography}

Abu el-Haj, N. 2001. Facts on the Ground. Chicago: University of Chicago Press.

Adams, D. 1980. The Restaurant at the End of the Universe. London: Random House.

Aderet, O. 2013. "Prayers, Notes and Controversy: How a Wall Became the Western Wall," Haaretz, May 14, 2013 (Hebrew).

Aharoni 1962. Excavations at Ramat Rahel. Seasons 1959 and 1960. Rome: Universita di Roma, Centro di Studi Semitici.

Aharoni 1973. Beer-Sheba I. Excavations at Tel Beer-Sheba 1969-1971. Tel Aviv: Institute of Archaeology, University of Tel Aviv.

al-Houdaliyeh, S., Bernbeck, R. and Pollock, S. 2017. "Notes on a Disappearing Past. Palestinian looted tombs and their Archaeological Investigation." Journal of Eastern Mediterranean Archaeology \& Heritage Studies 5/2: 198-239.

Amirav, M. 2007. Jerusalem Syndrome. The Palestinian-Israeli Battle for the Holy City (Hebrew).

Antiquities Law 1978. The Antiquities Law, 1978. Reshumot - The Official Government Gazette, Book of Laws 885. Jerusalem, 10.2.1978 (Hebrew).

Antiquities Ordinance 1929. "Antiquities Ordinance No. 51 of 1929." Ordinances, Annual Volume for 1929 (Government of Palestine). Jerusalem: Greek Covenant and Azrieli Presses: 405-414.

Avigad, N. 1991. "It is Indeed a Pomegranate from the 'House of the Lord'." Qadmoniyot 93/94: 60-61 (Hebrew).

Avner, R. and De'adle, T. 2009. "Jerusalem, the Ohel Yizhaq Synagogue." Excavations and Survey in Israel 121. www.hadashot-esi.org.il/Report_Detail_Eng. aspx?id=1134\&mag_id $=115$

Avnery, U. 2014. "The Language of the Israeli Occupation. Semantics of the Israeli Occupiers." Scoop, April 27, 2014. www.scoop.co.nz/stories

Avni, G. 2000. "Should the Antiquity Law be applied to cultural Objects made after Year 1700?" Unpublished Lecture, the Conference of the National Israel Academy of Sciences, November 18, 2000 (Hebrew).

Avni, G. and Seligman, J. 2006. "Between the Temple Mount/Haram el-Sharif and the Holy Sepulchre: Archaeological Involvement in Jerusalem's Holy Places.” Journal of Mediterranean Archaeology 19/2: 259-288.

Bagatz 2016. "Emek Shaveh vs. Israel Antiquities Authority". Verdict, Case 3556/16, Israel Supreme Court of Justice, Jerusalem, 19 July 2016 (Hebrew). www.court. gov.il

Bahat, D. 2007. "On the History of the Sacralisation of the Western Wall." Ariel 180 181: 33-54 (Hebrew). 


\section{Bibliography}

Bahat, S. 2016. "The Neighbourhood that Stood before our Wall." Etmol 250: 1-4 (Hebrew).

Bar, D. 2014. "Between Jewish and Muslim Holiness: The Beginning of the Process of Juification of Muslim Sacred Sites in the State of Israel 1948-1967." Israel 22: 133158 (Hebrew).

Bar, D. and Cohen-Hattab, K. 2017. "Can the Two Go Together? Archaeology and Sanctity at the Western Wall and surrounding Area, 1967-1977." Journal of Modern Jewish Studies 16: 1-21.

Barkay, G. 2013. "Archaeology and Ethics in Jerusalem." Ariel 203: 67-73 (Hebrew).

Bar-Sheshet, O. 2012. "Letter of Objection.” April 15, 2012, Appendix to Planning Committee Plan 11053, Meeting No. 2010013, October 26, 2010, Transcript.

Bar-Yosef, E. 2013. A Villa in the Jungle: Africa in Israeli Culture. Jerusalem: Van Leer institution (Hebrew).

Barbé, H. and Da'adli, T. 2007. "Jerusalem, Ohel Yitzhaq Synagogue.” Excavations and Survey 119. www.hadashot-esi.org.i1/Report_Detail_Eng.aspx?id=486\&mag_ id $=112$

Barbé, H. and Da'adli, T. 2011. "The Southern Bathhouse and the Tankaz Inn Which Came First?” Hidushim Be-Archeologiya shel Yerushalayim ve-Sevivoteiha 5: 142-157 (Hebrew).

Beer, Y. 2009. "Voices from Jerusalem: The City and the Dogs." Huffington Post, August 30, 2009. www.huffingtonpost.com/ir-amim

Behrman, D. 2010. Born Again Landscape. London: Centre for Research Architecture, Goldsmiths College, University of London.

Ben-Ami, D. 2013. Jerusalem: Excavations in the Tyropoeon Valley (Giva'ati Parking Lot). (IAA Reports 52). Jerusalem: Israel Antiquities Authority.

Ben-Dov, M. 1981. The Western Wall. Jerusalem (Hebrew).

Ben-Dov, M. 1982. The Temple Mount Excavations. Jerusalem (Hebrew).

Ben-Dov, M. 2012. "Letter of Objection," appended to the Jerusalem District Planning and Construction Committee, Objections Subcommittee, Meeting No. 2013007, February 26, 2012 (Hebrew).

Bender, E. 2013. "Within Less Than a Year - a Plaza for Joint Prayers," Haaretz, May 7, 2013 (Hebrew).

Benvenisti, M. 1996. City of Stone. The Hidden History of Jerusalem. Berkley: University of California Press.

Benziman, U. 1973. Yerushalayim. Ir lelo Homa (Jerusalem: A City without a Wall). Jerusalem: Schocken (Hebrew).

Berlin, A.M. 2015. "A Once and Future King. Review of: S. Rozenberg and D. Mevorah (eds.), A Herod the Great. The King's Final Journey." Journal of Roman Archaeology 28: 895-901. doi:10.1017/S1047759415003293.

Berman, S. 1987. "Antiquities in Israel in a Maze of Controversy." Journal of International Law 19: 343-360.

Blumenthal, P. 2012. "Irving Moskowitz, Controversial Backer Of Israeli Settlements, Gives \$1 Million To Anti-Obama Super PAC.” Huffington Post, April 12, 2012. www.huffingtonpost.com

Borges, J.L. 1935. Historia universal de la infamia. A Universal History of Infamy (Eng. Trans. N.T. Di Giovanni, 1972). New York: E.P. Dutton.

Borges, J.L. 1999. Collected Fictions. Translated by Andrew Hurley. London: Penguin.

Borschel-Dan, A. 2018. "Culture Ministry Earmarks NIS $60 \mathrm{~m}$ for Jerusalem Archaeology Digs, Preservation." The Times of Israel, May 9, 2018. www. timesofisrael.com 
Chen, N. 2017. "Hidden Gems of Jerusalem." The Times of Israel, November 16, 2017. www.timesofisrael.com

Cheshin, A., et al. 1999. Separate and Unequal. The Inside Story of Israeli Rule in East Jerusalem. Harvard University.

Chesler, P., and Haut, R. (eds.) 2003. Women of the Wall: Claiming Sacred Ground at Judaism's Holy Site. Woodstock, Vermont: Jewish Lights.

Cohen, H. 2007. The Market Square is Empty. The rise and fall of Arab Jerusalem. Jerusalem: Jerusalem Institute for Policy Research (Hebrew).

Cohen, S. 2001. The Beginnings of Jewishness: Boundaries, Varieties, Uncertainties. (Hellenistic Culture and Society 31). Berkeley: University of California Press.

Cohen-Hattab, K. 2010. "Struggles at Holy Sites and Their Outcomes: The Evolution of the Western Wall Plaza in Jerusalem." Journal of Heritage Tourism 5/2: 125-139.

Cohen-Hattab, K. and Bar, D. 2018. "From Wailing to Rebirth: The Development of the Western Wall as an Israeli National Symbol After the Six-Day War." Contemporary Jewry 38: 1-20. https://doi.org/10.1007/s12397-018-9251-z

Corry, L. 1997. The Literary World of Jorge Luis Borges. Israel: Ministry of Defence (Hebrew).

Dahari, U. 2014. In Memoriam Shuka Dorfman. www.antiquities.org.il/Article_heb. aspx?sec_id=65\&subj_id=664\&id=4070 (Hebrew).

Dinstein, Y. 2009. The International Law of Belligerent Occupation. Cambridge: Cambridge University Press.

District Committee 2010. Ministry of the Interior, Jerusalem District Office, Minutes of the Decision from the District Committee, Meeting No. 2010001, March 9, 2010 (Hebrew).

Dorfman, S. 2015. Beneath the Surface. Tel Aviv (Hebrew).

Dumper, M. 1997. The Politics of East Jerusalem. New York: Columbia University Press.

Dumper, M. 2011. "Constructive Ambiguities?" In: S.M. Akram et al. (eds.), International Law and the Israeli-Palestinian Conflict. London: Routledge: 113-143.

Dvar Avar. The Israel Antiquities Authority Newspaper. Jerusalem: IAA (Hebrew).

Dvir, N. 2011. "Elad Architect Appointed to Head of UNESCO Committee," Haaretz, June 19, 2011 (Hebrew).

East Jerusalem 2015. "East Jerusalem 2015: Facts and Figures." Association for Civil Rights in Israel, May 2015. www.acri.org.il

Eisenbud, D.K. 2014. "14th Century Grand Hall Discovered Underneath the Kotel Tunnels," The Jerusalem Post, June 1, 2014. www.jpost.com

Eli, Y. 2013. "Experts: Expanding the Toilets Endangers Antiquities on the Western Wall Plaza," Maariv, May 28, 2013 (Hebrew).

Emek Shaveh 2017a. "Salvage Excavations in the West Bank for Settlers Only." Position Paper, August 2017. www.alt-arch.org

Emek Shaveh 2017b. "Digging the Tunnels in Silwan - Data from the IAA following Request for Freedom of Information.” August 9, 2017 (Hebrew). https://alt-arch. org/he/iaa-2017

Feige, M. 2015. “'Where It All Began.' Archaeology, Nationalism, and Fundamentalism in Silwan." In: F. Markowitz, S. Sharot and M. Shokeid (eds.), Toward an Anthropology of Nation Building and Unbuilding in Israel. Nebraska: UNP: 243-258.

Fischer, N. 2016. "Seeing and Unseeing the Dome of the Rock: Conflict, Memory and Belonging in Jerusalem." In A. Björkdahl and S. Buckley-Zistel (eds.), Spatializing Peace and Conflict. Mapping the Production of Places, Sites and Scales of Violence. Baskingstoke: Palgrave-Macmillan: 242-264. 
Galor, K. 2017. Finding Jerusalem. Archaeology between Science and Ideology. Oakland: University of California Press.

Gendelman, P. and Chalaf, O. 2016. "The Excavations of the Strauss Building at the Western Wall Plaza." In: G. Stiebel et al (eds.), New Studies in the Archaeology of Jerusalem and its Region Vol. 10. Jerusalem: 115-127 (Hebrew).

Getz, Y. 2014. "The Attempt to Find the Temple beneath the Temple Mount, according to the Diaries of Rabbi Getz," speech delivered at the conference: "Discovering the City of David Conference - Ramat Rachel," www.youtube.com/watch? $=\mathrm{QBrFc8ymNyE}$.

Gnecco, C. and Lippert, E. eds. 2014. Ethics and Archaeological Praxis. New York: Springer.

Gorky, M. (ed.) 1935. Belomor: An Account of the Construction of the New Canal between the White Sea and the Baltic Sea. New York: H. Smith.

Grabar O. and Kedar, B.Z. (eds.) 2009. Where Heaven and Earth Meet: Jerusalem's Sacred Esplanade. Austin: University of Texas Press.

Greenberg, R. 2008. “"The Rock of Our Existence': A Parable of Archaeology-State Relations in Israel." In: M. Feige and Z. Shiloni (eds.), Archaeology and Nationalism in Eretz-Israel. Beer Sheba: Ben-Gurion University: 105-120 (Hebrew).

Greenberg, R. 2009a. "Towards an Inclusive Archaeology in Jerusalem: The Case of Silwan/The City of David." Public Archaeology 8/1: 35-50.

Greenberg, R. 2009b. "Extreme Exposure: Archaeology in Jerusalem 1967-2007". Conservation and Management of Archaeological Sites 11: 262-281.

Greenberg, R. 2014. A Privatized Heritage. How the Israel Antiquities Authority Relinquished Jerusalem's Past. Jerusalem: Emek Shaveh Report.

Greenberg, R. 2015. "Ethics in Action: A Viewpoint from Israel/Palestine.” In: A. González-Ruibal and G. Moshenska (eds.), Ethics and the Archaeology of Violence. New York: Springer: 19-32.

Greenberg, R. 2018. "One Hundred and Fifty Years of Archaeology and Controversy in Jerusalem.” In: S. Mourad, N. Koltun-Fromm and B. Der Matossian (eds.), Routledge Handbook on Jerusalem. London: Routledge: 363-376.

Greenberg, R. and Keinan, A. 2009. Israeli Archaeological Activity in the West Bank and East Jerusalem: A Sourcebook. Ostracon Press: Haifa.

Ha-Liba Plan 2006. Directives of Plan No. 11053, Western Wall Heritage Foundation, Western Wall Plaza - Old City (Hebrew). www.tabainfo.co.il

Haber, A. 2014. "Archaeology and Capitalist Development: Lines of Complicity." In: C. Gnecco and D. Lippert (eds.), Ethics and Archaeological Praxis. New York: Springer: 95-114.

Hagbi, M. and Uziel, J. 2015. "Jerusalem, the Old City, the Western Wall Foundations." Excavations and Surveys in Israel 127. www.hadashot-esi.org.il/report_detail_eng. aspx?id=15729\&mag_id=122

Hamilakis, Y. et al. 1997. "Relativism, Objectivity and the Politics of the Past." Archaeological Dialogues 4.2: 164-198.

Hamilakis, Y. 2007. "From Ethics to Politics." In: Hamilakis, Y. and Duke, P. (eds.), Archaeology and Capitalism. From Ethics to Politics. Walnut Creek: Left Coast Press: $15-40$.

Hamilakis, Y. 2012. "Are We Postcolonial Yet? Tales from the Battlefield.” Archaeologies 8: 67-76.

Hanauer, D.I. 2011. "The Discursive Construction of the Separation Wall at Abu Dis: Graffiti as Political Discourse." Journal of Language and Politics 16/6: 782808. DOI: 10.1075/jlp.10.3.01han 
Hasson, N. 2010. "J'lem Considers Tunnel Entry to Western Wall Plaza". Haaretz, October 10, 2010.

Hasson, N. 2011. “Jerusalem's Time Tunnels.” Haaretz, April 24, 2011.

Hasson, N. 2012. "Rare Photograph Reveals Ancient Mosque Destroyed in 1967." Haaretz, June 15, 2012.

Hasson, N. 2013. "Right-Wing NGO Funding Tel Aviv University Dig in East Jerusalem." Haaretz, June 13, 2013.

Hasson, N. 2014a. "Settler Group Elad Edges Closer to Controlling the Western Wall, Despite Protests." Haaretz, March 3, 2014 (Hebrew).

Hasson, N. 2014b. "Appeal Accepted to Reduce Compound Planned for the Western Wall Plaza.” Haaretz, June 12, 2014 (Hebrew).

Hasson, N. 2015a. "Museum and educational Centre at the Western Wall Plaza." Haaretz, December 2, 2015 (Hebrew).

Hasson, N. 2015b. "Archaeologists: Western Wall Stones Result of Earthquake not Roman Destruction." Haaretz, April 1, 2015.

Hasson, N. 2016. "Jerusalem, the Way Downward.” Haaretz, April 21, 2016 (Hebrew).

Hasson, N. 2017a. "The State approved that the Elad Organization will run the Archaeological Park near the Western Wall Plaza." Haaretz, November 21, 2017.

Hasson, N. 2017b. "Jerusalem's 'Landlords' are Digging Away Again." Haaretz, February 21, 2017. www.haaretz.com/opinion/.premium-jerusalem-s-landlords-aredigging-away-again-1.5438996

Hasson, N. 2017c. Urshalim. Israelis and Palestinians in Jerusalem, 1967-2017. Rihson Le-Zion: Miskal Books (Hebrew).

Hasson, N. 2018a. “'You want a Girl? How Many?' Tapes Reveal How Right-Wing Group Tried to Make East Jerusalem Jewish.” Haaretz, January 7, 2018.

Hasson, N. 2018b. "Israel Admits: Jerusalem Land, Home to 700 Palestinians, Given to Settler Group Without Proper Checks." Haaretz, June 11, 2018.

Hasson, N. and Dvir, N. 2011. "Israeli UNESCO Head Ousted for Preserving Heritage Sites." Haaretz, May 25, 2011.

Hasson, S. 2007. "The Struggles Over Jerusalem.” Eretz Israel 16: 389-397 (Hebrew).

Hawker, N. 2013. Palestinian-Israeli Contact and Linguistic Processes. London: Routledge.

Hawkes, A. 2018. "Battle of Belgravia: Oligarchs Who Bought Big in London Have Assets Frozen as Ukraine Chases Them Through Courts." The Mail, January 7, 2018. www.pressreader.com/uk/the-mail-on-sunday/20180107

Heller, M. 2014. "Chief-of-Staff at the Western Wall.” May 19, 2014, www.jdn.co.i1/ news/350867 (Hebrew).

Hever, Sh. 2013. "The Economy of the Occupation. Private Funding of Right-Wing Ideology in Israel." Socioeconomic Bulletin 29-30. The Alternative Information Center. www.alternativenews.org

Holzberg, S. 2012. "Letter of Objection." April 22, 2012, Appendix to Planning Committee (Plan 11053, submitted to Meeting No. 2010013), October 26, 2012. (Hebrew).

Horesh, U. 2016. “L'arabe Palestinien Colonisé par l'hébreu Moderne.” In: F. SaquerSabin and E. Persyn (eds.), Regards sure le proche-orient éclaté-complexe-paradoxal. Lille: Universite Charles de-Gaullee Lillee III: 243-253.

IAA 2000. "The Israel Antiquities Authority - Vision and Goals." Anonymous. www. antiquities.org.il/article_eng.aspx?sec_id=40\&subj_id=226 
ICOMOS 1981. "UNESCO, ICOMOS World Heritage List No. 148" (document 148rev-ICOMOS-165). http://whc.unesco.org/en/documents/152790

ICOMOS 2008. "Charter for the Interpretation and Presentation of Cultural Heritage Sites", 18th General Assembly of ICOMOS, Quebec, October 4, 2008. www. icomos.org/charters/interpretation_e.pdf

Jacobson, M. 2011. "The Western Wall is also Praying, 'Leave Me Alone." YNET online, August 9, 2011.

Jacobson, M. 2015. "Western Wall Plaza is still in Our Hands? The Complete Plans of the Ha-Liba House are exposed." Xnet, August 12, 2015 (Hebrew). https://xnet. ynet.co.il/architecture/articles/0,14710,L-3110182,00.html

Jerusalem 2000. Tochnit Mitar Yerushalayim. Local Outline Plan "Jerusalem 2000" (Hebrew). www.jerusalem.muni.il/Residents/PlanningandBuilding/CityPlanning/ FileOpening/Notebook42066/Pages/Default.aspx

Jobani, Y. and Perez N. 2017. Women of the Wall: Navigating Religion in Sacred Sites. Oxford: Oxford University Press.

Johnson, A. 1992. A United Jerusalem: The Story of Ateret Cohanim. Hoboken, N.J.: Ktav.

Kafka, F. 1961. Parables and Paradoxes. New York: Schocken Books.

Kedar, A. 2003. "On the Legal Geography of Ethnocratic Settler States: Notes towards a Research Agenda." Current Legal Issues 5: 401-441.

Kedar, B.Z. et al. 2012. "The Madrasa Afdaliyya/Maqam Al-Shaykh 'Īd: An Example of Ayyubid Architecture in Jerusalem." Revue Biblique 121: 271-287.

Kersel, M. 2006. "From the Ground to the Buyer: A Market Analysis of the Trade in illegal Antiquities." In: N. Brodie et al. (eds.), Archaeology, Cultural Heritage, and the Antiquities Trade. Gainesville: University Press of Florida: 188-205.

Kersel, M. 2008. “The Trade in Palestinian Antiquities.” Jerusalem Quarterly 33: 21-38.

Kersel, M. and Kletter, R. 2006. "Heritage for Sale? A Case Study from Israel.” Journal of Field Archaeology 31/3: 317-327.

Kimmerling, B. 2008. Clash of Identities. Explorations in Israeli and Palestinian Societies. New York: Columbia University Press.

Kingwell, M. 2011. "The Language of Work.” Harper's Magazine 323: 19-23.

Klemperer, V. 1957. The Language of the Third Reich. LTI - Lingua Tertii Imperii. A Philologist's Notebook. Translated by Martin Brady, 3rd ed. London: Bloomsbury.

Klemperer, V. 1999. To the Bitter End. The Diaries of Victor Klemperer 1942-1945. Translated by M. Chalmers. London: Weidenfeld and Nicholson.

Kletter, R. 2003. "A Very General Archaeologist: Moshe Dayan and Israeli Archaeology, 1951-1981." Journal of Hebrew Scriptures 4. www.jhsonline.org

Kletter, R. 2006. Just Past? The Making of Israeli Archaeology. London: Equinox.

Kletter, R. 2013. "Archaeological Voices from Jerusalem.” In E. Van der Steen, J. Boertien and N. Mulder-Hymans (eds.), Exploring the Narrative. Jerusalem and Jordan Bronze and Iron Ages. London: Bloomsbury: 394-427.

Kletter, R. 2015. Antiquities in the Basement ('Atiqot be-Martefim). Jerusalem: Emek Shaveh (Hebrew). https://alt-arch.org/en/category/publications/the-old-city

Kletter, R and Sulimany, G. 2010. "Archaeology and Professional ethical Codes in Israel in the Mid 1980s: The Case of the Association of Archaeologists in Israel and its Code of Ethics." Journal of Hebrew Scriptures 10.

Kletter, R. and Sulimany, G. 2016. "The Destruction That Can be Studied." In: I. Hjelm and T.L. Thompson, History, Archaeology and the Bible Forty Years after "Historicity.” London: Routledge: 174-204. 
Krampf, A. 2018. The Israeli Path to Neoliberalism. The State, Continuity and Change. London: Routledge.

La Salle, M. and Hutchings, R.M. 2018. "What Could Be More Reasonable?' Collaboration in Colonial Contexts." In: A.M. Labrador and N.S. Silberman (eds.), The Oxford Handbook of Public Heritage Theory and Practice. Oxford: Oxford University Press: 223-237. https://doi.org/10.1093/oxfordhb/ 9780190676315.001.0001

Lapidoth, R. 2011. Jerusalem. Some Legal Issues. Jerusalem: The Jerusalem Institute for Israel Studies.

Levy, G. and Lavac, A. 2017. "What I've Seen in 30 years of Reporting on the Israeli Occupation." Haaretz, June 3, 2017. www.haaretz.com

Levinson, H. 2018. "Under Pressure by the PM Office: The Mixed Podium at the Western Wall Will be Enlarged.” Haaretz, August 27, 2018 (Hebrew).

Lis Y. and Etinger, Y. 2013. "The Women of the Wall Retract." Haaretz, January 5, 2013 (Hebrew).

MacCannell, D. 2011. The Ethics of Sightseeing. Berkeley: University of California Press.

Mack, E. 2016. Selectively Sacred: Holy Sites in Jerusalem and its Environs. Jerusalem: Emek Shaveh. http://alt-arch.org/en

Mackay R. and Palmer S. 2015. "Tourism, World Heritage and Local Communities: An Ethical Framework in Practice at Angkor.” In: T. Ireland and J. Schofield (eds.), The Ethics of Cultural Heritage. New York: Springer: 165-184.

Maeir, A.M. 2016. "Why Not Dig the Whole Site?" In C. Shafer-Elliott (ed.), The 5 Minute Archaeologist in the Southern Levant. Sheffield: Equinox: 32-33.

Margalit, M. 2010. Seizing Control of Space in East Jerusalem. Jerusalem: Aliyat Gag Books.

Marom, M. 2004. The Planning Trap: Policies of Planning, Property Registration, Building Permits and Destruction of Houses in East Jerusalem. Jerusalem: Ir-Shalem and Bimkom (Hebrew).

Mayer, T. 2000. "From Zero to Hero: Masculinity in Jewish Nationalism." In: T. Mayer (ed.), Gender Ironies of Nationalism. Sexing the Nation. London: Routledge: 283-308.

Mazar, E. 2011. The Temple Mount Excavations in Jerusalem 1968-1978 Directed by Benjamin Mazar IV. The Tenth Legion in Aelia Capitolina. Jerusalem: Qedem 52.

Mazar, E. and Ariel, D.T. 2003. The Temple Mount Excavations in Jerusalem 1968 1978 Directed By Benjamin Mazar II. The Byzantine and Early Islamic Periods. Jerusalem: Qedem 43.

Mazar, E. and Mazar, B. 1989. Excavations in the South of the Temple Mount: the Ophel of Biblical Jerusalem. Jerusalem: Qedem 29.

McCoy, T. 2013. "South Florida Millionaire Irving Moskowitz's Millions Thwart Middle East Peace." Broward Palm Beach New Times, March 28, 2013. www. browardpalmbeach.com

McGreal, C. 2009. "Gambling with Peace: How US bingo Dollars are Funding Israeli Settlements." The Guardian, July 19, 2009. www.theguardian.com/world/2009/jul/ 19/us-bingo-funding-israeli-settlements

McGuire, R. 2008. Archaeology as Political Action. Berkeley: University of California Press.

Mizrahi, Y. 2008. "The Story of Two Neighbourhoods That Were Treated by the East Jerusalem Development Company.” Haokets, November 29, 2008. www.haokets.org 
Mizrahi, Y. 2012. From Silwan to the Temple Mount. Archaeological Excavations as a Means of Control in the Village of Silwan and in Jerusalem's Old City. Jerusalem: Emek Shaveh Report. https://alt-arch.org/en

Mizrahi, Y. 2013. Remaking the City: Archaeological Projects of Political Import in Jerusalem's Old City and the Village of Silwan. Jerusalem: Emek Shaveh. https:// alt-arch.org/en

Mizrahi, Y. 2018. The Cable Car to Jerusalem's Old City: Who Gains and Who Loses? January 22, 2018. Jerusalem: Emek Shaveh. https://alt-arch.org/en/jm_ cable_car_en

Mizrahi, Y. and Veeder, A. 2013. Another Future: Conservation of Antiquities Sites - Suggestions towards a Partial Solution of Jerusalem's political Problems. Jerusalem: Emek Shaveh. https://alt-arch.org/en

Moshenska, G. 2010. "Ethics and Ethical Critique in the Archaeology of Modern Conflict." Norwegian Archaeological Review 41/2: 159-175.

Moshenska, G. and González-Ruibal, A. 2015. "Introduction: The Only Way is Ethics." In: A. González-Ruibal and G. Moshenska (eds.), Ethics and the Archaeology of Violence. New York: Springer: 1-19.

Neiman, R. 2015. "Remembering the Man behind the Duck." Israel 21c, February 15, 2015. www.israel21c.org/remembering-the-man-behind-the-duck

Nesher, T. and Hasson, N. 2012. "Tel Aviv University Will Excavate in East Jerusalem with Funding of Right-Wing NGO.” Haaretz, October 25, 2012 (Hebrew).

Nitzan-Shiftan, A. 2011. "Stones with a Human Heart." Theory and Criticism 3839: 65-100 (Hebrew).

Nitzan-Shiftan, A. 2017. Seizing Jerusalem. The Architectures of Unilateral Unification. Minneapolis: University of Minnesota Press.

Omland, A. 2006. "The Ethics of the World Heritage Concept.” In: C. Scarre and G. Scarre (eds.), The Ethics of Archaeology. Philosophical Perspectives on Archaeological Practice. Cambridge: Cambridge University Press: 242-259.

Patrich, Y. 2013. "A Tragedy for Generations to Come." May 28, 2013, NRG site (Hebrew).

Phillips, C. and Ross, A. 2014. "Both Sides of the Ditch: The Ethics of Narrating the Past in the Present." In: C. Gnecco and E. Lippert (eds.), Ethics and Archaeological Praxis. New-York: Springer: 27-40.

Planning Committee 2009a. The Agenda of the Subcommittee - Urban Building Plan, Meeting No. 22/2009, November 26, 2009 (Hebrew).

Planning Committee 2009b. Minutes of the Jerusalem District Planning and Construction Committee, Subcommittee on Objections, meeting number 2009031, December 2009 (Hebrew).

Planning Committee 2009c. Jerusalem Regional Planning and Construction Committee, Meeting No. 2009013, July 21, 2009, Protocol (Hebrew)

Planning Committee 2010. Jerusalem District, Planning and Construction CommitteePlenum, Meeting No. 2010013, October 26, 2010, Transcript and Official Minutes (Hebrew).

Planning Committee 2011. The Jerusalem District, Planning and Construction Committee, Subcommittee on Objections, Meeting No. 2011114, September 27, 2011 (Hebrew).

Planning Committee 2012. Jerusalem Municipality, Planning and Construction Committee, Meeting No. 2012/24, January 21, 2012, Transcript (Hebrew). 
Planning Committee 2013. Jerusalem District, Planning and Construction Committee, Minutes of Decisions of the Subcommittee on Objections, Meeting No. 2013007, 14 February 2013 (Hebrew).

Planning Committee 2014. Sub-Committee for Objections, Jerusalem District Planning and Construction Committee, Meeting number 2014048, December 9, 2014, Transcript, p. 40 (Hebrew).

Poni, Sh. 2010. “Activity Report 2010.”www.iaa-conservation.org.il/article_Item_heb. asp?subject_id=42\&id=136 (Hebrew).

Portugali, A. 2016. "The Hidden Donors of the El-Ad Organization." Haokets, March 12, 2016 (Hebrew). www.haokets.org

Price, J. 2005. "Orphan Heritage: Issues in Managing the Heritage of the Great War in Northern France and Belgium." Journal of Conflict Archaeology 1: 181-196.

Raab, L.M., Klinger, T.C., Schiffer M.B. and Goodyear, A.C. 1980. "Clients, Contracts, and Profits: Conflicts in Public Archaeology." American Anthropologist 82/3: 539-551.

Rapoport, M. 2005a. "The Post that the Police and the Jerusalem Municipality Will Not Like You to Read.” Haaretz, April 2, 2005 (Hebrew).

Rapoport, M. 2005b. "Unearthing Earthy Jerusalem.” Haaretz, September 23, 2005.

Rapoport, M. 2008. "The Most Explosive Place in the City." Haaretz, March 8, 2008 (Hebrew).

Rapoport, M. 2009. Shady Dealings in Silwan. Jerusalem: Ir-Amim Report (www.iramim.org.il/) (Hebrew).

Raz, S. 2003. The Kotel Rabbi: The Life of Rabbi Meir Yehudah Getz. Jerusalem (Hebrew).

Regev, Y. 2016. "Between Samaria and Sebastia, or to Whom Belong the Archaeological Finds in the Rockefeller Museum." Mivzakey Hearot Pesikah 58, August 5, 2016 (Hebrew). http://zola.colman.ac.il

Reich, R. 1995. Invitation to Archaeology. Tel-Aviv: Dvir (Hebrew).

Reich, R. 2007. "The Second Temple Period Road along the Length of the Western Wall." Ariel 180-181 (Hebrew).

Reich, R. 2011. Excavating the City of David: Where Jerusalem's History Began. Jerusalem: Israel Exploration Society (Hebrew).

Ricca, S. 2007. Reinventing Jerusalem. Israel's Reconstruction of the Jewish Quarter after 1967. London: I.B. Tauris.

Rosenblum, K. 2013. "Jerusalem of Dreams." Haaretz, May 15, 2013.

Rubin, Sh. 2005. The Licensing Process for the Exhibition and Simulation Centre Named after Davidson. Report by the Jerusalem Municipality Comptroller, May 2005, pp. 1013-1039. www.jerusalem.muni.il/municipality/mevakert/report/ report2005-6/Pages/default.aspx (Hebrew).

Rubin, Sh. 2007. "Permit Proceedings for the Mughrabi Gate Bridge," in Comptroller's Report, 2007 (Hebrew).

Said, E.W. 1978. Orientalism. London: Routledge.

Sayej, G.J. 2013. "Can Archaeologists Intervene in Public Debate on Urgent Questions of a Social, Cultural or Political Nature?” Archaeological Dialogues 20/1: 47-58.

Scarre, C. and Scarre, G. 2006. The Ethics of Archaeology. Cambridge: Cambridge University Press.

Schuster, R. 2018. "Top Biblical Archaeology Stories of 2018." Haaretz, Deceber 23, 2018. www.haaretz.com/archaeology/MAGAZINE-top-biblical-archaeologystories-of-2018-1.6764751 
Segev, T. 2008. Israel, the War, and the Year That Transformed the Middle East. New York: Metropolitan Books.

Seligman, J. 2011. "The Departments of Antiquities and the Israel Antiquities Authority (1918-2006): The Jerusalem Experience.” In: G. Galor and G. Avni (eds.), Unearthing Jerusalem. Winona lake: Eisenbrauns: 125-146.

Seligman, J. 2013. "The Archaeology of Jerusalem. Between Post-Modernism and Delegitimization." Public Archaeology 12/3: 181-199.

Selimovic J.M. and Strömbom, L. 2015. "Whose Place? Emplaced Narratives and the Politics of Belonging in East Jerusalem's Contested Neighbourhood of Silwan." Space and Policy 19/2: 191-205.

Sfard, M. 2003. "International Legitimation in the Local Court. Between Legal Dilution and Judicial Separatism." Hamishpat 15: 73-83 (Hebrew).

Shragai, N. 1995. The Temple Mount Conflict (Har Ha-Meriva). Jerusalem: Keter Press (Hebrew).

Shragai, N. 2007. "Tunnel to Connect Western Wall with Muslim Quarter." Haaretz, November 2, 2007 (Hebrew).

Shragai, N. 2008. "Underground Connection Completed.” Haaretz, March 5, 2008.

Shragai, N. 2011. "The Mughrabi Gate to the Temple Mount in Jerusalem: The Urgent Need for a Permanent Access Bridge." October 24, 2011. http://jcpa.org

Shragai, N. 2013. "To Whom Does this Western Wall Belong?” Yisrael Hayom, April 19, 2013 (Hebrew).

Shukron, E. and Reich, R. 2012. "Excavations Near the Robinson Arch 2011." New Studies on Jerusalem 17: 219-228.

Slae, B. et al. 2013. "Heritage and Space in the Planning of the Jewish Quarter of Jerusalem and its Restoration, 1967-1975." Cathedra 148: 143-178 (Hebrew).

Smith, C. and Wobst, H.M. 2005. "Decolonizing Archaeological Theory and Practice." In: Indigenous Archaeologists. Decolonizing Theory and Practice (One World Archaeology 47). London: Routledge: 4-14.

State Comptroller 2018. Development and Strengthening the Position of Jerusalem. Special Report 002-2018, May 13, 2018 (Hebrew). www.mevaker.gov.il/he/Reports/ Report.../jerusalem-1.docx

State of Israel v. JQDC 2014. "Civil Suite (Jerusalem) 60379-03-14: The State of Israel v. the Company for the Reconstruction and Development of the Jewish Quarter in the Old City of Jerusalem Ltd." Nevo, August 9, 2014. www.nevo.co.il

Strich, D. 2013. "Contested Archaeologies: Archaeology in Politics and Identity Formation." In: C. Russell, L. Hogan and M. Junker-Kenny (eds.), Ethics for Graduate Researchers. A Cross-Disciplinary Approach. London: Elsevier: 147-165.

Sulimany, G. 2013. "Israeli Archaeology in the Old City of Jerusalem.” In: E. Pfoh and K.W. Whitelam (eds.), The Politics of Israel's Past: The Bible, Archaeology and Nation - Building. Sheffield: Phoenix Press: 120-136.

Sulimany, G. and Kletter, R. 2017. "Bone Considerations: Archaeology, Heritage and Ethics at Mamilla, Jerusalem." International Journal of Cultural Property 24: $321-350$.

Thelle, R.I. 2016. "Contested Antiquities, Contested Histories: The City of David as an Example.” In: K. Chalikias et al. (eds.), The Future of the Past. Archaeological Institute of America: 11-20. http://futureofthepast.wix.com/culturalheritage

Trouw, C.M. 2010. Media and Motivations: A Discourse Analysis of Media Representations of Eilat Mazar's "City of David" Excavations. MA Thesis, University of Melbourne. 
Tsafrir, Y. 2005. "In Memorium Amir Drori." Qadmoniyot 130: 127-128 (Hebrew).

Tsafrir, Y. 2008. "Our Generation's Responsibility for Jerusalem's Future Image." Lecture at the Conference: Jerusalem of the Coming Generations, Beit HaAkademia, 2006 (Hebrew).

UNESCO 1954. "Convention for the Protection of Cultural Property in the Event of Armed Conflict." The Hague, May 14, 1954. http://portal.unesco.org/en/ev.phpURL_ID=13637\&URL_DO=DO_TOPIC\&URL_SECTION=201.html

UNESCO 1972. "Convention Concerning the Protection of the World Cultural and Natural Heritage." General Conference Meeting, Paris, October 17 to November 21, 1972, https://whc.unesco.org/en/conventiontext

UNESCO 1999. "Second Protocol to the Hague Convention of 1954 for the Protection of Cultural Property." The Hague, March 26, 1999. http://portal.unesco.org/en/ ev.php-URL_ID=15207\&URL_DO=DO_TOPIC\&URL_SECTION=201.html

UNESCO 2017. "UNESCO, 41st Session of the World Heritage Committee, Krakow, July 2017." Document WHC/17/41.COM/18. http://whc.unesco.org/en/sessions/ $41 \mathrm{com}$

Van der Haven, A. 2008. "The Holy Fool Still Speaks. The Jerusalem Syndrome as a Religious Subculture.” In: T. Mayer and S.A. Mourad (eds.), Jerusalem. Idea and Reality. London: Routledge: 103-122.

Veracini, L. 2006. Israel and Settler Society. London: Pluto Press.

Warren, C. and Conder, C.R. 1884. Survey of Western Palestine. London: Palestine Exploration Fund.

Weigert, G. 1990. "A Maghribi Religious Endowment in Fourteenth-Century Jerusalem." Cathedra 58: 25-34 (Hebrew).

Weksler-Bdolah, Sh. et al., 2009. "Jerusalem, the Western Wall Plaza Excavations, 2005-2009." Excavations and Surveys in Israel 121. www.hadashot-esi.org.i1/report detail_eng.aspx?id=1219\&mag_id=115

Weksler-Bdolah, S. 2014. "The Foundation of Aelia Capitolina in Light of New Excavations along the Eastern Cardo." Israel Exploration Journal 64: 38-63.

Williams, J.F. 2013. Archaeological Ethics in Armed Conflicts. PhD Thesis, University of Leicester.

Wilson, C. 1865. Ordnance Survey of Jerusalem. London: G.E. Eyre and W. Sopttiswoode.

Wright, G.R.H. 1966. "A Method of Excavation common in Palestine." ZDPV 82: 113-124.

Yadin, Y. 1975. Jerusalem Revealed. Archaeology in the Holy City 1968-1974. Jerusalem: Israel Exploration Society.

Yaniv, Y. 2007. "The Mughrabi Neighbourhood near the Western Wall.” Ariel 180181: 114-120 (Hebrew).

Zandberg, E. 2007. "The Architectural Conspiracy of Silence.” Haaretz, February 14, 2007 (Hebrew).

Zorzin, N. 2014. "Archaeology and Capitalism: Successful Relationship or Economic and Ethical Alienation?" In: C. Gnecco and D. Lippert (eds.), Ethics and Archaeological Praxis. New York: Springer: 115-140. 


\section{Index}

Note: The index includes the text and notes, but not the appendix of documents, figures, and table.

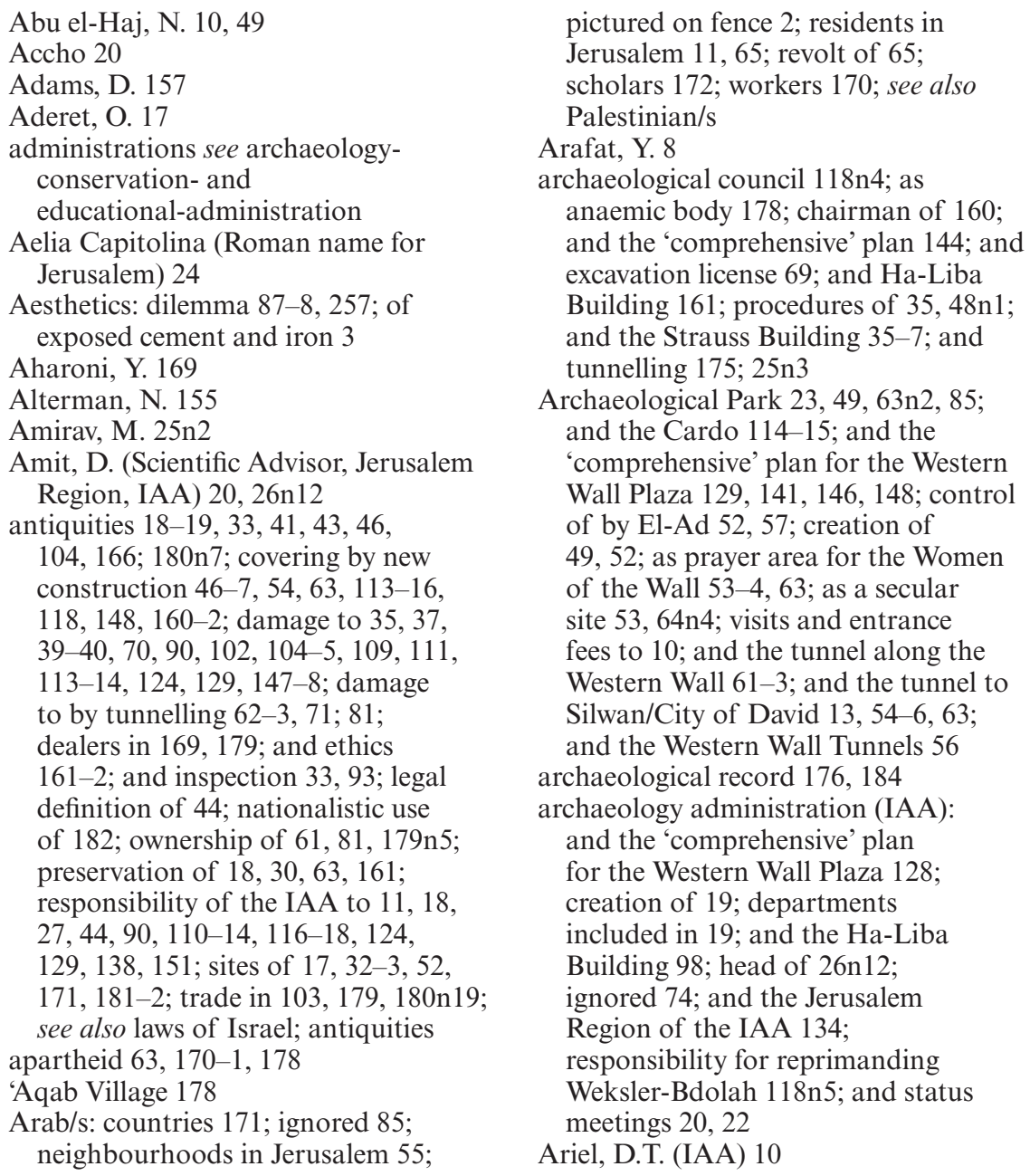


Ariel, U. (Minister of Agriculture and

Rural Development) 52

'Arunah (the Jebusite, II. Sam.) 55

Argentina 25

Ashkelon 180n7

Ateret Cohanim 16, 19, 65-6, 69-70, 182

Avigad, N. (Hebrew University, Jerusalem) 118n2, 119n5, 169

Aviram, J. (Secretary of the Israel Exploration Society, Member of the Archaeological Council) 36

Avneri, U. 149

Avni, G. (Head, Excavations and Surveys Department, IAA) 19, 26n12, 44; criticizes former excavations at the Western Wall Tunnels 11, 169; criticizes excavations in tunnels 167; notices Reich's transgression 175; and status meetings 19

Bab a-Rahma Cemetery 63

Babel 156, 160, 165

Bach, J. (Helsinki University) 25

Badran (family) 178

Bahat, D. (Bar Ilan University and IAA) $11,17,104$

Bahat, S. 9

Bantustan 175

Bar, D. 9, 17

Bar Giora 104

Bar Ilan 161

Bar Sheshet, U. (Municipal Planner), $111,113,122$

Bar Yosef, E. 180n17

Barbé, H. (Excavating Archaeologist, IAA) 65, 89-90, 92, 104

Barakat, N. (Major of Jerusalem) 110, 142, 144, 147

Barkay, G. 167, 170

Barnea, G. (Attorney) 114

Barshad, D. (Head of Northern District, later of Educational Administration, IAA) 155

Baruch, Y. (Jerusalem District Archaeologist, later Jerusalem Region Archaeologist, IAA) 26n12, 124; and the Archaeological Park 54, 56-7; and damage to buildings 90 ; and the Ha-Liba Building 104-5, 107, 112-17, $119 n 5,134$; and inspection instead of excavation 92-3; and the Mughrabi Bridge 125; and Ohel Yitzhak 69-71, $74-5,86-9,91-2$; and scientific truth $117,152,184$; and status meetings 20; and the Strauss Building 28-9,
$31,37-8,44,46$; suggesting to call unnecessary excavations salvage 129 ; supporting entrepreneurs' plans 87 , 105, 107, 112-16, 125, 129; supporting the comprehensive plan for the Plaza 121, 124, 129-30, 133, 137-9, 141, 144, 147; supporting tunnelling 59,167 ; trying to guess the wishes of Dorfman 104

Basilides (of Alexandria) 156

Bat Sheva 55

Bede (the Venerable) 156

bedrock of our existence/mother rock (referring to Natanyahu's expression) $70,76,93,96,169,183$; reached in drilling for foundations $37,39,74-5$, 142; reached in excavations 142

Beer, Y. 2

Beer Sheba 169

Beeri, D. ('Davidleh') (head of El-Ad) 25n6, 56, 74, 180n16

Behrman, D. 91, 183

Belomorkanal 173

Ben Ami, D. (Excavating Archaeologist, IAA) 164,169

Ben Basat, R. 58

Ben Dov, M. 11, 101

Ben Hagai, M. 24

Bender, E. 54

Bennett, N. (Minister of Education) 52

Benvenisti, M. 17

Benziman,U. 9, 49

Berlin, A.M. 182

Berman, S. 179

Bible: book of 11; in Christianity 56 ; historicity of $164,165 n 3$; period of 55,171 ; reading of $64 \mathrm{n} 3$; sealing of 55 ; used as soundtrack 95

Biblical archaeology 179n6

Binyamin Area (part of the West Bank) 58

Binyanei Ha-Uma Convention Centre 119n8

Blumenthal, P. 65

board (var. council) of the IAA 38, 100, 107, 118n4

Boaz, B. 65, 69-70, 73

Bogolyubov, Z. 95

Bonn, J. 25

Borges, H.L. 156

Borscel-Dan, A. 13

Boyd, E. 25

Brazil 5 


\section{Index}

British Mandate period 17, 27, 167, 171, 179n5

budget 44; and beliefs of scientists 153, 184; estimations for excavations $42,101,127$; and excavating archaeologists 23 ; governmental 17-19; of the IAA 17, 23, 117, 124, 131; of the Jewish National Fund 18; and overdevelopment 186n3; and scientific truth 152; of the Western Wall Heritage Foundation 54, 92, 126, 136; see also funds

bulldozers see tractors

burial 39, 100

'burial' of antiquities under new construction: in the Archaeological Park 54; in the Ha-Liba building 113, 115,160 ; in the Western Wall Plaza $125,128,132 ; 119$ n 8

Byzantine period 49, 56, 63, 97

California 17

Canari, C. (Western Wall Heritage Foundation): and the comprehensive plan for the Plaza 128, 132-3, 136-8; and the Mughrabi Bridge 125; and Ohel Yitzhak 92-3; and the Strauss Building toilets 43, 46

capitalism 152-3, 178

Cardo (Eastern) 54, 102, 118n2, 126; and the comprehensive plan for the Plaza 129, 139-40, 142, 144, 146-8, 160; compromised by the Ha-Liba Building 97, 105, 107, 109-10, 114, 146; 'excavated' by the Conservation Department 102-3; placing a container on 110; and removal of 'late' remains $100,102,144$; threatened by modern pillars 104-05, 107; under Esh Ha-Torah 110, 119n7; under Ohel Yitzhak 66, 87; see also Ha-Liba Building

Cardo (Western/Central - in the Jewish Quarter) 117, 118n2

Cathisma Church 169 cemetery, 18, 63, 178, 185; see also tombs Central Highlands (of Israel) 19

Chalaf, O. (IAA) $48 \mathrm{n} 3$

Chapel Hill 25

checkpoint 142, 144-5, 149

Chen, N. 95

Chesin, A. 16, 25n2
Chesler, P. 63n3

Christian/Christianity 56, 169; archaeology 179n6; birthplace of 171; expectations 170; institutions 85; mentioned favourably 56, 180; prayers 86; as scholars 171-2

City of David 1, 8, 20, 62, 141; and conservation reflecting El-Ad propaganda 55; emptied of Palestinian presence 17, 52, 55, 59; and ethics $168,170,172-3,177-8,179$ n8; and the IAA policy 183; and promise to allow building before excavation 99; and Tel Aviv University 162; and the sin of David 186; and the Western Wall Tunnels 120; see also El-Ad Visitor Centre; Givati Parking Lot/ Site, Silwan

Coastal Plain 19

Cohen, H. 25n2

Cohen, L. 25

Cohen, S. 186n2

Cohen, O. (Engineer, IAA) 62, 92, 125; and the plan to excavate the Plaza 127, 132-3, 136

Cohen-Hattab, K. 9, 12

Colonialism: archaeology 178, 185; enterprise 172; essence 180n15; in Israeli research $180 \mathrm{n} 17$

Company for the Development of East Jerusalem (PAMI) 18, 49, 51-2, $63 n 1,144$

Company for the Reconstruction and Development of the Jewish Quarter (JQDC) 18, 51-2

Comptroller: of Israel 18, 39; of Jerusalem municipality 51, 82

Concubine at Gibeah 165

Conder, C.R. 62

conservation $22,47,57,62-3,74,89-90$, $101,124,161$; advisor/consultant of 107, 144; and exhibitions 92; file 37-8; in situ 115; and inspection 93; and jargon/LOH 152; plan for 72-4, 87, 92, 140; pure matter of 23; reports of, in the IAA website 55-6; as substitute for excavation $38,46,102$; and tunnels 57, 62; see also conservation administration; department (of conservation); preservation; restoration

conservation administration (IAA): and the 'comprehensive' 
plan 129,137 ; creation of 19 , $22,150-1$; high status of 22 ; and $\mathrm{LOH} /$ jargon 152; conservation department (IAA) see department in the IAA, conservation

Copenhagen, University of 25

Cotton Market 83

Crusader period 171

Da'adli (var. De'adle), T. (Excavating Archaeologist, IAA, later Hebrew University) 65, 90

Dahari, U. (Head of Archaeological Administration, IAA) 17, 26n12, 134; and conflict of interests 124; and the Ha-Liba Building 98, 124; and status meetings 19-20; supporting the excavation of the Plaza 124, 162; treating El-Ad as landlord 57; warning against the excavation of the Plaza $128,131,137-8$

damage to antiquities: at the Archaeological Park 54; and development 151, 155; at the HaLiba building 101-2, 105, 113; at Ohel Yitzhak 32, 74, 87, 88-9, 91; prevention of 124, 151, 179n3; and the rule of Law 35; at the Strauss Building 31, 35, 37, 39-40; at the Western Wall Plaza 34-5, 121, 127-30

damage to existing buildings by excavations/tunnelling 90

Dan, M. (Head of Ateret Cohanim) 69

David (King of Israel) 1, 55-6, 165, 170,185

Davidleh see Beeri, D.

Davidson, B. 50

Davidson Centre (in the Archaeological Park) 23, 53; and the Cardo 114-15; establishment and history of 10 , 49-53, 57; exhibitions and finds in 49-51, 63; legal status of 51,82 ; and plans to give it to El-Ad 52, 57, 63; as secular site $64 \mathrm{n} 4$; and the tunnel to Silwan/City of David 54

Davidson Museum see Davidson Centre

Dayan, M. 179

De'adle see Da'adli

democracy 8, 24, 175

department of antiquities, Mandate Period 179

department (in the IAA): of administration and security 150 ; of conservation (later

administration) 20, 22-3, 28, 56, 66, 70-1, 89, 101-2, 103; $105,118,120,125,141,151$; of excavations and surveys 19-20, 26n12, 175; of finance 93; of publications 19; of robbery prevention 103; of treasures of the state $19,87-8,252$; of treatment of finds 19

Dinstein, Y. 166

Disneyland 183

donor/s 16; for Davidson Centre 51; for Ohel Yizthak 65-6, 87, 90, 92, 95

Dorfman, S. (Director of IAA 2000-2014) 17-18, 22-3, 26n12, 136, 159n6, 170, 174; approves excavations as inspection 92; and the Archaeological Park 56-7, 59; encourages transgression to the Law and excavations in Palestinian property $174-6,180 \mathrm{n} 14,180 \mathrm{n} 16$; forces high tempo of excavating 118; and the Ha-Liba Building 99, 102, 104, 107, 109-11, 118, 160; and the IAA vision 18, 109, 120; initiates 'salvage' excavations by tunnelling 59, 167; and jargon/LOH 42, 150-2, 154-5, 157-8, 184; and the Mughrabi Bridge 125; and Ohel Yitzhak $69,73-4,86-8,90-1$; opinions about museums 87 ; relations with archaeologists $22-3,39,118 \mathrm{n} 5$, 131, 134, 152; relations with Tel Aviv University 160-2; supports the plan to excavate the Plaza 120, 124, $127,130-4,136,138,141-2$; and status meetings 19-20, 22; and the Strauss Building 28-30, 32-8, 47; and the Strauss Building toilets 43-4, 46, 48; and what scientists must believe in 184

drills: brutality of $38-40$; can be prevented by Law 124; at Ohel Yitzhaq 74-5; at the Strauss Building 27, 29, 32, 35, 37-40; at the Western Wall Plaza 129, 132-4, 136; see also foundation piles

Drori, A. (Director of IAA 1989-1999) 17-18

Dumper, M. 25n2, 166

Dung Gate 55, 107, 109, 114, 146

Dvir, N. 116 
Early Islamic period 49, 63n2, 97, 171-2; see also Islamic periods; Late Islamic period

East Jerusalem 1, 17, 19-20, 55, 103, 165n2; aesthetics of 3; antiquities trade in 179; and the cable car 165; and colonialism 172; Development Company of (PAMI) 49-52, $63 \mathrm{n} 1,144$; and digging in tunnels 49, 63, 160; and ethics 166, 168, 170, 172, 175-8, 179n4, 180n16, 181, 183, 185-6; and excavation methods 119n9; governmental investments in 13 , 18,126 ; illegal construction in 11 ; inequality and Apartheid in 25n2, 170, 175, 178; Jewish settlers in 65, 124,165 ; lack of master plan in 11; and language 184; legal status of 166 , 177, 184; Palestinian neighbourhoods in 16,165 ; residents of 11 ; and rightwing entrepreneurs 80, 182; and Tel Aviv University 162, 164

educational administration (IAA) 155

Einstein, A. 154

Eisenbud, D. 95

El-Ad 17, 25n6; 116, 124, 165n2, 180n8, 182; and the Archaeological Park/Davidson Centre 52, 54-59, 61-3; and the cable car 164-5; close ties with and influence on the IAA 19, 22, 25n6, 55-9, 61, 63, 183; as entrepreneur of tunnels 54-59, 62; as extreme settler organization 1 , $15,18-19,55,63,170$; fence art of 5,8 ; finances of $13,55,183$; and the Givati Parking lot 5, 164; and Ohel Yitzhak 74; and Reich 160, 170, 172-3; and sifting earth from the Temple Mount 170; and silencing heritage 170, 179n1; and Tel Aviv University 162, 164, 165n4, 183

El-Ad visitor centre (in Silwan) 1, 13, 17, 22; see also City of David

Elan, E. (Architect) 105, 126-7; and the excavation of the Plaza 127-8, 130, 136-7

Eliav, S. (Director, Western Wall Heritage Foundation): and aims of excavations 130-1, 137; and the Archaeological Park 56-7; and the Ha-Liba Building 111-12, 118; and Ohel Yitzhak 91-2; and the Strauss
Building 27, 46; and the Western Wall Plaza 126, 128, 131-2, 134, 136-7

Eretz Israel see Israel

Esh Ha-Torah (Yeshiva) 109-10, 119

Eshkol, S. (Jerusalem Municipal Architect) 111, 117, 120

ethics 181, 184-5; code of 178, 185; discourse and principles of 128,172 , 177, 184-5; and the Givati Parking Lot 160; as human 179, 185-6; and Israeli archaeology 168, 178, 185; and the Ha-Liba Building 36; and nationalism 144, 172, 17, 183, 185; and Ohel Yitzhak 88; and power relations 176-7; and professionalism 176-8, 185; and the Strauss Building 36; and stressing/ignoring periods 170-2; and the Western Wall Plaza 128-31, 134, 139-40, 144, 169; and tunnelling 166-7, 175; and UNESCO 140, 166

Etinger, Y. 54

excavation and survey department see department in the IAA

excavating archaeologists (IAA) 19-20, 41, 66, 88, 104, 130, 181; and academic freedom 164; low status of 22-4, 66, 103; as well-trained professionals 24; see also Barbé; Chalaf; Da'adli; Gendelman; Hagbi; Onn; Shukron; Solomon; Sulimany; Uziel; Weksler-Bdolah

excavation license 24, 25n3, 35, 69, $76,84,174$; according to the Law 93,181 ; as acknowledgment of the issuing authority 171; approval by the Archaeological Council 178; authority of issuing 167; as circumvent of building permits $82-3,85,102,181$; as 'professional' process 155 ; and Tel Aviv University 162, 165n4; transgression of 174-5

excavation permit: and the Archaeological Park 58; digging without one $76,85,92-3,181$; and the Ha-Liba Building 102; and Ohel Yitzhaq 69, 76, 83, 85, 92-3; procedures of 25n3, 68; and Tel Aviv University $162,165 \mathrm{n} 4$

excavation report (final) 1, 10, 61; and academic freedom 170, 172; limited readership of 170,183 ; as limited source for history 
of archaeology 168-9; and nationalism 168; not yet published 172,180 n 10 ; writing of 23-4 excavation report (preliminary) 38, 40, $42,48 \mathrm{n} 3,58 ; 65 ; 157$

excavation report (to the entrepreneur) 58, 97

excavation method/s, and budget for excavations $117 ; 119 \mathrm{n} 9$; and excavation along walls 59 ; in the future 144; and inspection 93, 181; in salvage excavations $25 \mathrm{n} 2$; and tunnelling 157, 160, 167, 174; and wet sieving 101

excavation squares $41,130,132,172-3$, 178,181

exhibition/s 1, 33, 158, 183; at Davidson Centre 53, 63; at Ohel Yitzhaq 72-3, $75,81,86-7,89,91-2,94-5,158$; in the Strauss Building toilets 27, 47, 87,182

experience of the visitor $55,113,182$; to the Archaeological Park 54; and the 'comprehensive' plan for the Plaza 141, 147; to the Ha-Liba Building 113-14, 116, 147; to Ohel Yitzhaq 86, 94, 96; to the Temple 51; to the tunnel between the Archaeological Park and Silwan 58; to the Western Wall 9 export license for antiquities 179

Ezrahi, T. 24

Ezrat Yisrael (podium for prayer) 54

Fatimid period 63

Feige, M. (Ben Gurion University) 16

Finkelstein, I. (Tel Aviv University) 160,162

first temple: bringing water to 3 ; destruction of 145; and El-Ad 1; tools of 170; as goal for excavating/ exhibiting 63, 75-6, 79, 83, 102, 140, 144, 182; see also Second temple

foundation piles: of the Ha-Liba Building 97, 107; of the Mughrabi Bridge 125; of the Strauss Building 33-7, 40; of the Western Wall Plaza project 128-30, 133-4; see also pillars

France 186n6

funds: of El-Ad 162, 173, 183; and excavations 129, 138, 170; governmental 164, 183; of Moskowitz 16; and scientific truth 184; and the Strauss Building toilets 182; wasted on research 153 ; see also budget

Gadot, Y. (Tel Aviv University) 164

Galilee 18-19, 20

Galor, K. 157, 167, 183

Gaza Strip 179

Gendelman, P. (Excavating Archaeologist, IAA) 40-2, 48n3

Getz, M.Y. (Western Wall Rabbi 1969-1995) 11

Getz, Y. (son of M.Y. Getz) 11

Geva, D. 158, 159n7

Gibeah (Judges 19) 165n1

Gilboa Mountains 100

Gilead, A. 76, 133

Givat Hamivtar 169

Givati Parking Lot/Site: and the Archaeological Park 57; and the cable car 164-5; and damage to antiquities 129; and excavations of Tel Aviv University 164, 165n4; and fence art $1,5,8,165$; as 'piecemeal' project $121-2,124$; and promise of the IAA before excavation 98-9; and removal of 'late' remains 169, 183; as yawning hole and discomfort to Palestinians 1; see also City of David; El-Ad Visitor Centre; Silwan

Gnecco, C. 166

Gonzáles-Ruibal, A. 176-7, 184-5

Government of Israel: and the Archaeological Council 25n3, 69; bodies of $11,18,39,51,156$; and building permits 82; and El-Ad 61, 63, 164; and the IAA 18-19, 56, 71, 74, 80; investment in East Jerusalem/ Jerusalem 13, 17-18, 126, 136, 164; and the Women of the Wall 52, 54

Grabar, O. 19

Greenberg, R. (Tel Aviv University) 18, 96n1, 157; and archaeological ethics 166, 168, 170, 177-8, 185; and criticism of excavations/tunnelling 10, 166; and excavations in the West Bank 177-8; and Silwan/El-Ad 16-17, 54, 98, 124, 170, 180n7, 183

Ha-Gai Street 65, 71-2

Ha-Liba Building 23, 48n2, 104, 107, 117, 120; 'burial' of antiquities under 54, 63, 147, 162; excavations 
by Weksler-Bdolah at 97, 42, 118, 126-7, 134; fast rate of excavation at 131, 136; figurines from $26 \mathrm{n} 14,118 \mathrm{n} 1$; hinders movement on the Cardo 107, 109; location of 13,97 ; major discoveries in 87; and 'our' remains 102; pillars of threating the Cardo 22, 104-5, 107; and promise of the IAA to allow building before excavation 36, 54, 99-100, 105 , 110-11, 181; and removal of 'late' remains 100-1, 158, 182; and Tel Aviv University 160-2; and scientific truth 117-18; and support of a maximal building plan 112-14, 117, 160-2; and the 'comprehensive' plan for the Plaza 124, 126-31, 133, 136-8, 144, 146-7

Ha-Shalshelet Street 83, 126

Haber, A. 176

Hagbi, M. (IAA) 58

Hague 166, 177

Hamilakis, Y. 168, 177-8, 184

Hanauer, D.I. 25n1

Haram al-Sharif 10, 169; see also Temple Mount

Hasson, N. 9, 25n2, 116, 145, 178-9; and the Archaeological Park 55, 57; and corruption of settlers 16; and the dispute PAMI-JQDC 52; and the Ha-Liba Building 97, 101, 118; and Moskowitz/Ateret Cohanim 17; and Ohel Yitzhak 95; and Silwan/Givati site 183; and Tel Aviv University connections with El-Ad 162; and tunnelling 176; and the Western Wall Plaza 148n5

Hasson, Y. (Director of IAA since 2014) $25 \mathrm{n} 6,26 \mathrm{n} 12$

Haut, R. 63n3

Hawker, N. 149

Hawkes, A. 95

Hebron 179

Heller, M. 95

heritage $23,85,120,185$; and the cable car 164, 166; cultural 158n4; damaged by the entrepreneur 90 ; division of in Jerusalem 165n5; Islamic 179n1; 181; and jargon/ LOH 152, 159n4; management of 183-4; neglected 114; in open areas 115; 'our' 26n10, 159n4, 167, 182, 185; owned by entrepreneurs 183, 185; and toilets 182 ; and tunnels 167; and UNESCO 115, 139-41, 148n4, 184

Herod (King) 115, 182, 186n2

Herodian Street 54, 142, 144-5, 167

Herzl, Theodore 1

Hever, S. 18

Hezekiah's Pool 57

Hjelm, I. 25

Holmes, S. 152

Holy Basin (area) 24, 139

holy site/s: active 17,39 ; declared 17, 169; and drilling 136; to Jews 8, 17; to Muslims 17

Holzberg, E. 111, 114

Horesh, U. 149

Hutchings, R.M. 178

Hulda Gates 63

Iceland $179 \mathrm{n} 6$

ideology 19, 56-8, 168, 183

illegal building 11, 16, 84, 94

illegal excavations $70,79,169-70$

inspection see archaeological inspection

in situ see conservation, in situ

inspection: before excavation $32-3$; 'close' 33, 37-8, 115; and exposure 41; as IAA expertise 19-20, 23, 134;

instead of excavation $83,85,92-3$, 181; not performed 9, 102

inspection facilities 144n4; see also checkpoint

intifada 150,172

Iron Age 1, 63, 172; figurines 118n1; finds for sieving 101; structure 97, 107 Isaiah 44

islamic archaeology 86

islamic heritage 179

islamic periods $1,56,100-1,118,172$

islamic remains 102, 169, 182

islamophobia 172

Israel 11, 22, 24, 37, 53; 96n1, 117, 149, 165n3; Archaeological Council of 35; and archaeological ethics 144, 168, 171-2, 177-8, 179n6; archaeology in $24-5,185,186 \mathrm{n} 5$; becoming fundamentalist 8 ; development in 18, 124, 126; earthquakes in 90; government of 50, 61; and El-Ad's ideology 55-6; heritage in 184; holy sites in 17; and Jerusalem as World Heritage Site 140, 148n4; land tenure in 
18,84 ; legislation of antiquities in $44,81,93,179,179 \mathrm{n} 5,181$; and the Mughrabi Quarter 100; and the Naqba 170; neoliberalism in 152; and occupation of East Jerusalem 26n10, 126, 165-6, 177, 180n18, 181; and orthodox Judaism 12; political changes in 13; salvage excavations in 17,$22 ; 25 \mathrm{n} 3,30,33,48 \mathrm{n} 3$; as secular, western state 1; State Comptroller of 39; and Tel Aviv University 164

Israel/Palestine 171, 180n19

Israeli Department of Antiquities and Museums (preceding the IAA): and the Antiquities Law 17; and the division inspection-excavations 19; and financing salvage excavations 17 ; and the Western Wall Tunnels 11, 17

Jacobson, M. 12, 118

Jaffa 20

Jerusalem 5, 18, 24-5, 52, 98, 101, 119n8, 151; antiquities dealers in 169; antiquities trade in 179; becoming right-wing 15; and the Cardo 110, 161; divided reality of $25 \mathrm{n} 1,55,165$, 178-9, 182; in El-Ad's ideology 55; and ethics 168-9, 173, 177-9, 179n6, 184; foundation of 70; Hebrew University of 35-6, 46; as holy city 23, 94; and the IAA 20, 22, 160; and the IAA region/district of $19,20,22$, 25n7, 26n12, 28, 31-2, 41; 44, 51, 53-4, 69, 89, 93, 120-1, 128, 132, 134, 136-9, 174-5; in Isaiah 44; legal status of 166; master plan for 11, 115; mayor of 142, 144, 147; Minister for 18, 52; Muslim rule in 95; and Ohel Yitzhak 70-1, 75, 86, 89; and 'our' remains 81, 95; as portrayed by El-Ad 5; possible division of heritage in $165 \mathrm{n} 5$; as the rock of our existence 70;

Roman name of 24; skyline of 109; and the Strauss Building 27, 31, 37,43 ; syndrome of 138; and tunnels 71, 160; United Lands of 3, 149, 184; and the Western Wall Plaza 129, 139; as World Heritage Site 140; see also East Jerusalem; Old City

Jesus $55,170-2$

Jewish finds 101

Jewish layers 81
Jewish periods and remains 62-3, 171

Jewish Quarter 55, 85; broad wall in 169; company for reconstruction of (JQDC) 51-2; complaints of residents of 39,114 ; and the comprehensive plan for the Plaza 139; and ethics 169-70, 172; excavation methods in $119 \mathrm{n} 9$; excavation of stairs climbing to 126-7; excavation of the Cardo by Avigad in 117, 118n2; and the Ha-Liba Building 97, 111, 126 Jobani, Y. 63n3

Johnson, A. 17

Jordan 140, 166, 171

Joshua's Altar (site) 178

Josseph (Yossef) (fictional figure) 158

JQDC see Company for the Reconstruction and Development of the Jewish Quarter

Judah (Kingdom of) 63; see also Judea Judaism: conservative 52, 53; orthodox 1, 12, 39, 54, 64n $3,131,186 \mathrm{n} 1$; reform 52-3; and sites 55, 140, 171

Judea 1

\section{Kafka, F. 160}

Karmi-Melamede, A. (Architect): attitude to archaeology 105, 107, 112; and the Ha-Libah Building 22, 99, 105, 107, 110-12; and the Strauss Building 28-9, 36; and the Strauss Building toilets 43

Katzav, M. (former President of Israel) $165 \mathrm{n} 3$

Kedar, A. 175

Kedar, B.Z. 19, 101, 144

Keinan, A. 177

Kersel, M. 180n19

Kertesz, G. (Architect) 142, 144, 146-8; hired by the Western Wall Heritage Foundation 120; planning the Western Wall Plaza 121, 124-8, 130, 132, 139-42

Kimmel, E. (Architect) 87-9, 91

Kimmerling, B. 150

King David see David, King of Israel

King Solomon see Solomon, King of Israel

Kingwell, M. 158n3

Kislev, R. (Head of Conservation Department, IAA) 19, 22, 71; and the Archaeological Park 57; and the 
Ha-Liba Building 105, 112; and the 'inspection mode' of excavating 93; and Ohel Yitzhak 73-4, 91-2; and status meetings 20; and the Strauss Building toilets 44; and the Western Wall Plaza 120, 129-130, 133, 137

Klemperer, V. 149-50

Kletter, R. 23, 35, 180n9; and criticism of tunnelling 167; and the Department of Archaeology 17, 180n7; and ethical codes 178, 185; and Moshe Dayan 179; and salvage archaeology 17; and legal definition of antiquities 44; and the Mamilla Cemetery 18, 22

Kloner, A. (Bar-Ilan University), and objections to the Ha-Liba Building plans 98; and objections to the Strauss Building plans $34-6$

Kollel Shomrei HaChomot (Ohel Yitzhak) 71

Knesset (Parliament) 52

Krampf, A. 152

La Plata, University of 25

La-Salle, M. 178

land, confiscation 17, 96n3; annexation 166

land ownership: and archaeological remains 171; and building permits 11; and El-Ad 57, 63; by Israeli Law 84, 175; by the Jewish National Fund 18; by Moskowitz 69, 72; by Palestinians 72-3, 80, 82-5, 174; by the JQDC 97

Lapidoth, R. 166, 179

'late' remains 81, 168; in the Ha-Liba Building 100-02, 107, 158; in the Strauss Building 32, 42, 44, 182; in the Western Wall Plaza 129, 182

late islamic period/s 101, 171; see also islamic periods

laws: international 25n3, 166, 177, 184-5; Jordanian 179

laws of Israel: antiquities (1978) 17, $22,30,35,44,84-5,93,114,124$, 174-6, 180nn15-16, 181; basic law of human dignity and freedom 175; building and Planning 82-3; freedom of information 23; holy sites 17 ; Jerusalem, the capital of Israel 166; property 84

Le-Corbusier (Jeanneret), C.É. 28
Lev, A. (Project Coordinator) 41

Levinson, H. 54

lingua orientalis hierosolimitane $(\mathrm{LOH})$ 149-51, 153, 155, 157-8, 159n4, 175,184

Lippert, E. 166

Lipschits, O. (Tel Aviv University) 160-2

Lis, Y. 54

MacCannell, D. 183

Machkama Building 90, 96n3

Mack, E. 17

Mackay, R. 184

Madrasah al-Afdaliyya 100, 144; see also Sheikh 'Id Mosque

Maeir, A. (Bar Ilan University) 144,162

Magness, J. 25

Makhouli, N. (Inspector of Antiquities) $180 \mathrm{n} 7$

Mali, Y. 58

Mamilla cemetery 18, 22, 178, 185

Mamilla quarter 172

Mamluk period: at Ohel Yitzhak 65, 70-1, 76, 81, 86-9, 94-6, 182; at the Ha-Liba Building 97, 101

Margalit, M. 16-17

Marom, M. 16

Masada 115

Mayer, T. 149

Mazar, B. (Hebrew University, Jerusalem) 10, 36, 49, 63, 129, 133

Mazar, E. 10, 49, 165n2, 179n4

Mazuz, M. (Attorney General) 79

McCoy, T. 65

McGreal, C. 17

McGuire, R. 177, 185

medieval 33, 63, 101

men: burial of 100; of action 128, 130 , 149, 183; as decision makers 183; of high military rank 130; of letters 149; members of the management $158 \mathrm{n} 1$; pictured 5, 8; of 'pure' science 24, 175; religious $64 \mathrm{n} 3$; section of prayer in the Plaza for 132; toilets of 46; see also women

Messiah (the) 96n4, 161

Middle Ages 32, 75

Middle East 5

Milstein, F. (Architect, IAA Conservation Department) $70-1$, 73, 75-6 
minister/ministry: agriculture and rural development 18, 52; construction and housing 18, 52; development of the Negev and the Galilee 18; education 17,52 ; environmental protection 18, 25n5; finance 186n6; Jerusalem and the diaspora 18,52 ; justice 17 ; national infrastructure, energy and water 18; prime 12,70 ; public security 82 ; religion 9-10, 17, 104; the economy 52 ; the interior 18,36 ; transportation 18, 116-17

Mizrahi, Y. (Head, Emek Shaveh NGO) 24, 55-6, 63, 63n1, 97, 164, 183

Moshenska, G. 166, 176-7, 184-5

Moskowitz, I.: donor for Ateret Cohanim 65; family fund of 16, 65-6, $69,96 \mathrm{n} 1$; financing the excavations at Ohel Yitzhak 69; transferring Ohel Yitzhak to the Western Wall Heritage Foundation 76

mother rock see bedrock, of our existence

Mount of Olives 164-5

Mount Zion 37, 164-5

Movement for the Quality of Government in Israel 37

Mughrabi Bridge 17, 36, 120, 154; collapse of 11; and comprehensive/ piecemeal planning 121, 124-5; and damage to antiquities 129; erasure of remains in 47; excluded from this study 23 ; history of 9 ; lack of building permit for 82; separating the prayer Plaza from the Archaeological Park 10, 49; and tunnelling 56-7

Mughrabi Neighbourhood/Quarter: establishment of 8,134 ; destruction of $8,11,49,100,182$; Jewish settlers in 13; population of 8 ; treatment as 'late'/unimportant 42,44 , 128-9, 133-4, 182

Municipality of Jerusalem 18, 51, 103, 179

museum 89; for archaeology/history of Jerusalem 65-6, 69-76, 85-6, 92; for bar mitzvah children 85, 92; for lost causes 92; for prayer 85-7, 91-2; Rockefeller 169; see also Davidson Centre

Muslim Quarter 65; Jewish settlers in 16; and legal status of its Palestinian residents 63; and opening of exit from the Western Wall Tunnels 85 , 96n; 157; and tunnels underneath it $13,76,80,85,96,186 \mathrm{n} 4$

Na'aman, N. (Tel Aviv University) 162 naqba 169

Negev 18-19

Neiman, R. 159n7

Nesher, T. 162

Netanyahu, B. (Prime Minister of Israel) 70, 96n1

Nitzan-Shiftan, A. (Technion) 9, 12, 120

North Africa 8

North Carolina 25

Ohel Yitzhak 130, 136, 182; and Area C 65, 69-70, 72-3, 75-6, $81,83-4,95,186 \mathrm{n} 4$; and attorney Seidemann 79-80; building plan of 65-6; conservation of 158; and the Cardo 109; damage to antiquities in 32, 89-90, 182; and donor from the Ukraine 95; excavated by inspection 92-3, 181; finding 'our' remains in 66, $70,75,83$; and the IAA $69,74,79,83$; linked by tunnels to the Western Wall Plaza 13, 70, 76, 79-81; location and history of $65,186 \mathrm{n} 4$; and the Mamluk bathhouse (Area A) 71, 81, 89-90, 94-5; ownership of $65,69,76$; plans to establish museums at $66,71,74-5$, 85, 91-2, 94; the Synagogue at 13, 23, $65,71,74$

Old City (of Jerusalem) 80, 83, 141, 160; antiquities trade in 179; as antiquities site $17,30,32,42$, 115, 120; architect of 20; and the cable car 164; and danger of collapse 90-1; and illegal building 84; Jewish settlers in 65 ; lack of master plan in 11, 73, 84; Palestinian residents of 96; planning of 28-9, 31, 120, 151; preservation of 115 ; skyline of 109 ; and tunnels 71, 86, 96; walls of 142, 164; see also Jerusalem; East Jerusalem

Old Testament see Bible

Omland, A. 148n4

Onn, A. (Excavating Archaeologist, IAA) 26n9, 88-9, 104; and criticism of the plans to excavate the entire Plaza 130,132

Ophel 62-3 
Ophel Walls 63

Oslo 13

Ottoman Period 89-90, 96-7

'our', archaeology 180n6; dead 186n1; expectations 170; finds 87, 102; finest youth 172; heritage $26 \mathrm{n} 10,159 \mathrm{n} 4$, $167,182,185$; history 46 ; prayers 86 ; remains $1,62,69,81,88,96,102$, 144n3, 164, 169-70, 172, 182-3; periods $66,171,183$; treasures 83

Palestinian/s 2, 96n1; 172, 181; anonymous labourers 172, 174, 180n12; antiquities dealers 179; archaeologists 171, 177; claims 185; expectations from excavations 170, 185; life above tunnels 5, 71, 96, 167, 174; life under the planned cable car 165; neighbourhoods 16; as poor, temporary residents $16,84,174-5$, $177-8,179 \mathrm{n} 1$; rights of 178,185 ; segregated $55,179 \mathrm{n} 1$

Palmer, S. 184

PAMI see company for the development of East Jerusalem

Patrich, J. (The Hebrew University, Jerusalem) 35, 46

Perez, N. 63n3

Pfoh, E. 25

Philippines 180n 12

Phillips, C. 177

piles see foundation piles

pillars 104, 183; for the cable car 164; for the Ha-Liba Building 22, 104-5, 107, 109, 111; for the Mughrabi Bridge 82; for the Ohel Yitzhak compound 88; for the tunnel along the Western Wall 62; for the Western Wall Plaza $125,127-34,136-8,147-8$

Pirski, S. 25

plan 19, 43-4, 54, 56, 58, 69, 76, 88-9, 91, 102, 110-11, 164-5; building, for the Ha-Liba Building 97-101, 104, 107, 109, 111-14, 116, 126-7, 160-1; building, for the Ohel Yitzhak project 65, 68, 71-2, 81-3, 186n4; building, for the Plaza (comprehensive) 12, 23, 31, 51, 107, 120-2, 124, 126-7, 130, 132, 139-42, 144, 146-8, 152, 181-4; building, for the Strauss Building 27-36, 39-40, $42,47,121$; cancellation of 91 ; conservation 72,87 ; dangerous 96 ; detailed 29, 94, 125; of Eli Elan
128-30, 132, 136-8; excavation 66, 72, 138-9, 151; foundation 28; engineering 33-4; 'Jerusalem 2000' 115; and LOH/jargon 151-2; master 11, 30, 124, 144, 147; museum 69-7, 72, 91; project 75-6, 83; of Safdie 12; of Sharansky 54; and technology 129

Planning and Construction Committee (Planning Committee in short) 20; and the Archaeological Park/Davidson Centre 51; and the 'comprehensive' plan for the Plaza 120, 122, 124, 139, 142, 144-5, 147, 152; and the Ha-Liba Building 98-100, 102, 104-5, 107, 109-10, 112-18, 160; and the Strauss Building 27, 30-6, 39

Plaza see Western Wall Plaza

political aims: of the author 25; 'dirty'/ left wing 24-5, 164, 168, 175, 184; in East Jerusalem 25n2, 26n10, 182, 185; of excavations and tunnels 55,59 , $76,81,83,167,182,185,186 \mathrm{n} 4$; and the IAA $18,22,181$; necessity of acknowledging 176-7, 185

politicians $16,22,26 \mathrm{n} 8,165 \mathrm{n} 3$

Pompeii 115

Poni, S. (Architect of the Old City of Jerusalem, IAA) 23; and construction in the Old City 84; and the HaLiba Building 104-5, 112; and Ohel Yitzhak 86-8; and status meetings 20; and the Strauss Building 28, 30-2, 37-8; and the Strauss Building toilets 43-4; warns against the excavation of the Plaza 129

Portugali, Y. 13

postmodern 168

power 13, 54, 118n4, 150; of the Archaeological Council 178; of archaeologists 177-8; configuration of $26 \mathrm{n} 11$; of the IAA 17,112 , 178, 186n5; of the IAA Director 22,167 ; monument of 146 ; relations of 19, 23, 26n11, 176, 181, 185; of University archaeologists 178, 186n5 preservation $33,35,137$; criteria for 107; economic value of 43; of finds 30; and the IAA vision 18; in situ 30; initial 161; of open areas 115; program/plan of 68 ; of the 'other 144; of the rock escarpment 102; of toilet walls 43-4, 46

Price, J. 182 
principles: as empty jargon/LOH 153 , 158, 176, 184; ethical 128, 144, 169; lack of 76; normative 183; and Ohel Yitzhak 71-4, 96n2; political 76; professional 144; and the Western Wall Plaza 139

Quebec 140, 184

Raab, L.M. 183

Rabin, S. (Engineer) 136-7

Rabinowitz, S. (Rabbi of the Western Wall) 85

Radi, M.I. (Antiquities Guard) 180n7

Rahmimoff, A. (Architect) 57-8

Ramallah 178

Ramat Rahel 169

Rapoport, M. 12, 16, 65, 70, 91, 183

Raz, S. 11

Reem, A. (Jerusalem District Archaeologist) 20, 26n12, 44

Regev, Y. 166

Reich, R. (Haifa University; Advisor to Shuka Dorfman; Chair of the Archaeological Council) 58, 146, 160; blames Greenberg for unemployment in East Jerusalem 172; and ethics 144, 170-2, 183; and excavations in tunnels 58-9, 160, 167, 174-5; and excavation reports 180n10; and fun in East Jerusalem 178; and the Ha-Liba Building 161; and jargon/ LOH 175; offers work to Palestinians 172-3, 180n13; and Palestinian property $174-6$; relations with Shukron 173-4; transgresses the Law of Antiquities 174-6, 180n14, 180n15; and Silwan/City of David 172

report see excavation report

rescue excavations see salvage excavations

restoration: of the Jewish Quarter 18; of the Ohel Yitzhak Synagogue 65, 89, $182,186 n 4$; of pottery 23 ; as source of income 17

Ricca, S. 18

Rockefeller Museum 169-70

Roman period: Cardo 54, 66, 97, 102, 110, 118n2, 140, 144; destruction of Jerusalem 49; early 79, 83; earth for sieving 101; late 97, 199; name of Jerusalem 24; 'our' finds 87, 144; remains of structures 49 ; stairs 95 ; wall 88-9, 182

Rosenblum, K. 12

Ross, A. 177

Rubin, S. (Jerusalem Municipality Comptroller) 50, 82-3

Safdie, M. (Architect) 12

Safrai, Z. (Bar Ilan University) 162

Said, E. $25 \mathrm{n} 11$

St. Nicholas 180n6

salvage excavations $178,186 \mathrm{n} 6$; as condition for building permits 28-30, 32,148 ; executed by 'inspection mode' 92 ; as a highly complex task 23 ; legal aspects and methods of $25 \mathrm{n} 3$; as misnomer for initiated excavations 49 , 58, 61, 66, 68-9, 73, 79, 81, 129, 138; and occupied territories $162,165 \mathrm{n} 4$, $166,177,185$; and promises to support the building plan 97, 98, 100; as sources of income 17, 124; waiving of 33-4, 40, 46-7, 181

Samaria (the northern part of the West Bank) 2; see also Judea

Samuel (biblical) 55, 186

Sayej, G.D. 165n5, 176

Scarre, C. 166

Scarre, G. 166

Schuster, R. 179n6

scientific excavations $30,33,57,63,83$

scientific method/methodology 25, 61, 93, 157, 181

scientific publications and reports 1, 23, $42,81,170,172,183$

scientific truth $117,152,184$

second temple: destruction of 55 ; and El-Ad 1; as focus of Messianic hopes 94; as goal of excavating/ exhibiting 66, 75-6, 83, 102, 140, 144, 182; highlighted in exhibitions 49, $51,63 \mathrm{n} 2$; no longer studied by some scholars 171; and 'our' study 171; steps to 94

Segev, T. 8-9

Seidemann, S. (Attorney, Ir Amim) 79-80, 83

Seligman, J. (Jerusalem Region Archaeologist, later Head of the Excavations and Surveys Department, IAA) 26n12, 179n5; and archaeological ethics 168-70; criticizes excavations in tunnels $167,179 \mathrm{n} 3$; criticizes the former excavations at 


\section{Index}

the Western Wall Tunnels 11, 169; is deceived by Reich 174, 180n14; and the Ha-Liba Building 102, 104-5; keeping the Archaeological Park secular 53; and Ohel Yitzhak 69-73, 80-1, 83, 87, 90, 96n2; and status meetings 20; and the Strauss Building 27-30, 32-4; trying to guess the wishes of Dorfman 104-5; warns against improper development 127-9, 132, 179n3; and the Western Wall Plaza 120-2, 124, 127-128, 132, 136-7

Selimovic, J.M. 183

settlers: and Ateret Cohanim 65; and East Jerusalem 80, 124; and El-Ad 1, 15, 52-3, 63, 116, 176, 180n16; excavations for 177, 185; fanatical 165 ; illegal deals by 16, 186; occupying houses 3

Sfard, M. 166

Shaked, A. (Society for the Protection of Nature in Israel) 117-18

Sharansky, N. (Chairman of the Jewish Agency) 54

Shean, B. 115

Sheikh 'Id Mosque 100; see also Mughrabi Quarter

Shiloh, Y. 173

Shmuelian, E. (Deputy Director, PAMI) 51

Shoham, A. (Conservation Consultant, the Jerusalem Planning Committee) 107, 109, 144

Shragai, N. 9, 54, 65, 85, 89

Shukron, E. (Excavating Archaeologist, IAA): ascending to the Temple 58; excavates in tunnels 58-9, 180n113; excavates with Reich 173-4; termination of work in the IAA 174

Shwartz, J. (Bar Ilan University) 162

Siloam Pool 3, 8

Silwan (Village) 8, 52, 55; and the cable car 164-5; collapses due to excavations at 91; damage to antiquities at 129; and ethics 168-9, 172, 179n8, 183; Jewish settlers in 3,16 ; as a poor Palestinian neighbourhood 1, 16; promise allowing building before excavation at 22, 98-9, 124; and Tel Aviv university 162,164 ; and tunnel to the Archaeological Park 13, 55, 57, 59,
62, 124; visit to 1,3 ; see also City of David; El-Ad Visitor Centre; Givati Parking Lot/Site; Siloam Pool

Slae, B. 12

Smith, C. 178

Solomon, A. (IAA) 93, 104

Solomon (King of Israel) 3, 170

Sparta 8

Sperber, D. (Bar Ilan University) 162

status meetings: establishment and nature of 19-20, 22, 184; male dominance in 130; and the Ha-Liba Building 110, 118n5; and jargon/ LOH 153, 157; and Ohel Yitzhak 86; and the Western Wall Plaza 126, 130, 132, 136

Stern, E. (Hebrew University, Jerusalem; Chairman of the Archaeological Council) 36

Strauss Building 23, 120, 124; history of 27; initial position of the IAA towards $22,27,31$; limited excavation at 40-2; location of 13 , 27,49 ; preserving remains in the toilets of $43,46-8,87,144,182$; promise of the IAA allowing building at $36,47,54,181$; waiving of excavation at $32-3,35-7,39,46-7$, 54,121

Strich, D. 63n2, 177, 182, 184

Strömbom, L. 183

Sulimany, G. (Excavating Archaeologist, IAA; later member of Emek Shaveh NGO) 24, 180n9; and ethical codes 178, 185; and excavations in East Jerusalem 10, 49, 167; and legal definition of antiquities 44; and the Mamilla Cemetery 18, 22

Superman 2

Tacitus, P.C. 156

Tanners' Postern 107, 109

Tel Aviv: antiquities trade in 179; involvement in excavations in East Jerusalem 160-2, 164, 165n4, 183; sand dunes in 155; statue honouring Geva in 159 n 7

Telor, Y. (Representative of the Ministry of Transportation) 116, 118

Temple Mount 37, 51, 55, 172; destruction of 94-5, 145; dreams for resurrection of 94-6; and ethics 169-70; illegal diggings at 169-70; 
period of 171; new tunnel along the face of 59,62; plan to excavate along southern wall of 59; reached by a sewage tunnel 58 ; search for artefacts of 11; sheep taken as sacrifice to 5; southwest corner of 10 ; water supply to 3

Teomi, G. (Architect) 43, 112

Tessler, D. 24

Thailand 180n12

'their' remains see 'late' remains

Thelle, R.I. 167

Thrope, S. 25

toilets: in the Strauss building 27, 43-4, 46-8, 87, 169, 182; in the Western Wall Plaza 142, 148, 183

tomb/s: at Ha-Liba Building 97, 100-1, 118, 169, 182; of House of David 170; of Jesus 170; at Mamilla 22; and religious bodies $186 \mathrm{n} 1$

Tomb of the Sanhedrin 169

tractors/bulldozers 11, 41-2, 133-4, 138,173

Trail of Ritual Bathes 62

treasure/s: ancient 35; delightful 137; Islamic or Byzantine 56; 'our' 83; Solomonic 3; State of Israel, Department of 19, 86-7

Trouw, C.M. 177, 179n4

Tsafrir, Y. (Hebrew University, Jerusalem) 18, 26n12, 36; organizes a tour to the Ha-Liba Building 107; tries to keep the Cardo open 105, 109-10, 113-15, $117,160,161-2$

tunnel/s 5, 86, 91, 165, 178, 179n3; along the western wall 58-9, 61-2, 71, 73; between the Archaeological Park and City of David/Silwan 13, 54-8, 62-3, 174, 180n13; between Ohel Yitzhak and the Western Wall Tunnels 13, 70-1, 76, 79-81, 84-5, 182, 186n4; between the Western Wall Tunnels and Via Dolorosa 96n1; dug by 19th century explorers 62; and gender 183; and jargon/LOH 175; narrow (in the Western Wall Tunnels) 136-7; as political means 55, 58, 71, 167, 184; and R. Reich 160, 170, 174-6, 180n13; and Silwan 3, 5, 167; as unethical and destructive 49, 61-2, $76,81-2,84,90,96,119$ n9, 157,
166-7, 169, 174, 181, 184, 186; see also Western Wall Tunnels

Turner, M. (UNESCO Israel's Committee) 115-16, 142

Tyropoeon Valley (Valley of the Cheese Makers) 37

\section{UK 25}

Umayyad Period 51

UNESCO 115, 139-40, 166

university 101; and academic freedom 178, 185; of Bar Ilan 34, 98, 161; and the 'comprehensive' plan for the Plaza 138; 148n3; and field experience 24; of Jerusalem (Hebrew University) 10, 35-6, 46, 69, 100, 160, 165n2; of La Plata, Argentine 25; of North Carolina 25; scholars affiliated to 24; of Tel Aviv 160, 162, 164

Uziel, J. (Excavating Archaeologist, IAA) 58

Valley of the Cheese Makers see Tyropoeon Valley

Van Der Haven, A. 138

Van Der Ruhe, M. (Architect) 130

Van-Zaiden, A (Conservator, IAA) 103

Veeder, A. 24, 56, 183

Veracini L. 175

Via Dolorosa 85, 96n1

vision: in the 'comprehensive' plan for the Plaza 40,109, 120, 122, 126-7, 141; of El Ad in art 1, 5; of the IAA 18, 57 109, 120, 155; of male power wielders 130; of R. Reich 174; of the Western Wall Heritage Foundation 130,134

Wadi Qadum 103

Warren, C. 62

Watson, J. 152

Weigert, G. 9

Weksler-Bdolah, S. (Excavating Archaeologist, IAA) 26n14; and the Ha-Liba excavations 22, 97, 101, 110,127 ; and lack of funding for sieving 22; and procedures of work 101-4, 110, 118n5, 119n5; and status meetings 22

West, J. 25

West Bank 58, 166, 171, 177-8, 180n18

West Jerusalem 63n1, 166, 168, 178-9, 185 
Western Wall: area of 156, 182; commercialization of 183 ; and the 'comprehensive' plan for the Plaza 136, 144-6; and El-Ad 61-2; and ethics $169,178,185$; history of 9,11 ; as holy Jewish site 17, 54, 115, 186n3; and Messianic dreams 96n3; and Ohel Yitzhak 71, 76, 85; Rabbi of 11, 85; and removal of 'late' remains 100; and the tunnel along it 58-9, 61-2, 71, 73; visitors to 107 ; Western Wall Heritage Foundation: and the Archaeological Park/Davidson Centre 56; establishment and nature of 12 ; finances of 13, 54; and the Ha-Liba Building 54, 97-8, 104, 110, 112-13, 117, 161-2; obtaining documents from 23, 35; and Ohel Yitzhak 76, 79-81, 91-4, 96; political position of 182; and the Strauss Building 27, 35, 47, 54; and the Western Wall Plaza 120, 125-7, 130, 132-4, 136, 138

Western Wall Plaza 12, 15-16, 31, 35, 53,65 ; area of $13,29,49,55,57$, 98, 139; and change of policy of the IAA 18, 183; and the comprehensive plan for the Plaza 23, 31, 35-6, 40, $51,97,107,109,120-1,125,136-42$, 144-5, 147-8, 151, 181-2; creation of 8-9, 41-2; and ethics 169,183 ; governmental allocations to 18; and the Ha-Liba Building 97, 102, 104-5, $110-11$; as heritage site $34,55,115$; as holy site $8-9,17,20,53,169,186 \mathrm{n} 3$; and keeping the Cardo open 115, 199n7, 160-1; and the Mughrabi Bridge 124; piecemeal 'pilot' of 126-33, 137-8; piecemeal mode of work at 86,91 ; preservation of 115 ; Rabbi of 56; religious management of 12,27,39; and tunnels to Ohel Yitzhak 13, 79; and tunnels to Silwan 13, 55-6; unnecessary excavations at 128-9, 138; and the Women of the Wall 54, 64n3

Western Wall Tunnels 44, 49, 81; and Alexander Onn 26n9; and the Archaeological Park 56-7; and the comprehensive plan for the Plaza 133, 141; excavations by inspection at 92-3, 181; expansion of 13,109 , $120,126,136$; management of 27 ; reason for exclusion of from this study 23-4; as religious site $17,64 n 4,186 n 3$; removal of finds from 104; and tunnels to Ohel Yitzhak 70, 76, 79, 84-5, 182; and Via Dolorosa $96 \mathrm{n} 1,157$

Wienner, O. (Architect, Ha-Liba Building) 48n2

Williams J.F. 176, 185

Wilson, C. 62

Winter, K. 25

Wobst, H.M. 178

women: pictured 5; prayer section in the Plaza for $125,132-3$; toilets for 46

Women of the Wall 52-4, 64n3, 186n3

Wright, G.R.H. 179n2

Yadin, Y. 49

Yaniv, Y. 9

Yatziv, A. 25

Zagorin, 168

Zandberg, E. 12

Zilber, D. (Planner, Jerusalem District Planning Committee) 32

Zion 165

Zorzin, N. 153, 176, 185 